STy

5.5

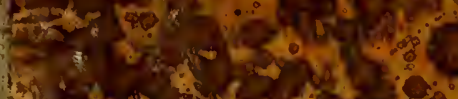

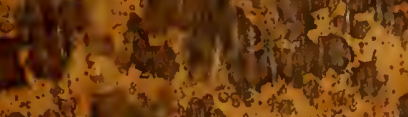

1.20

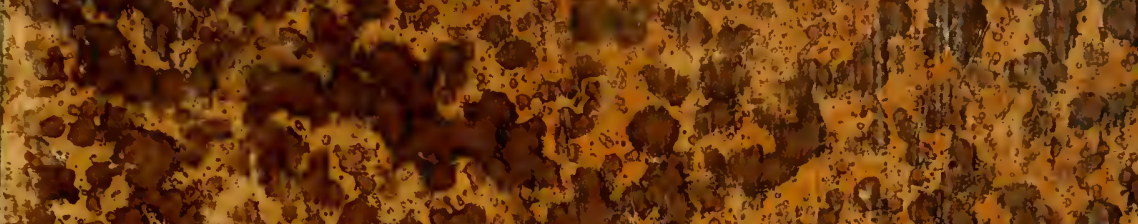

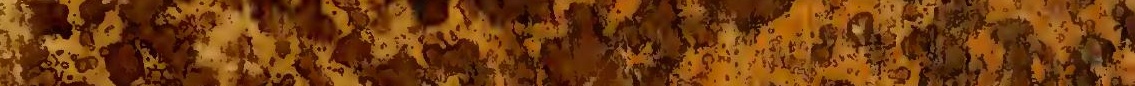

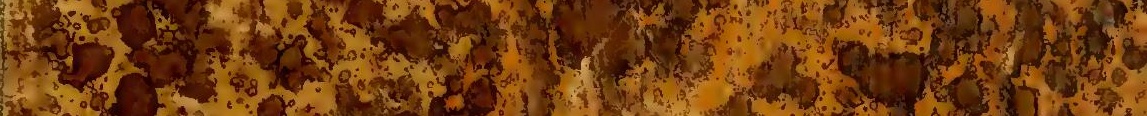

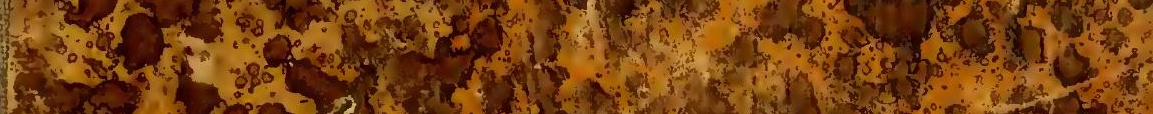

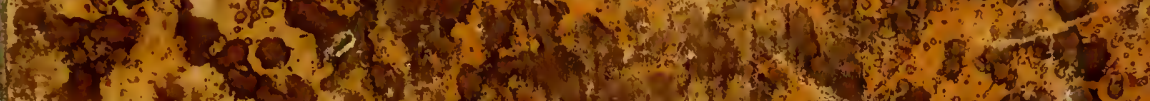

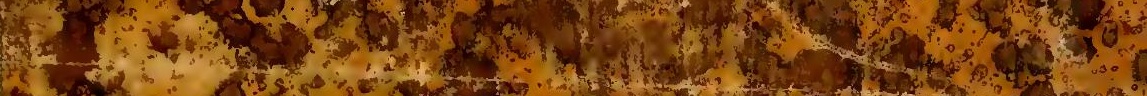

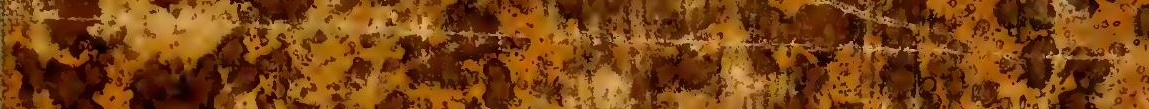
1) 20.70 . D.

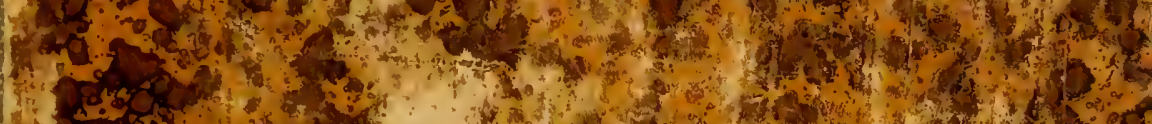
(1)

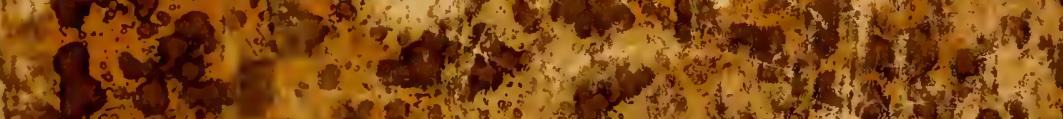

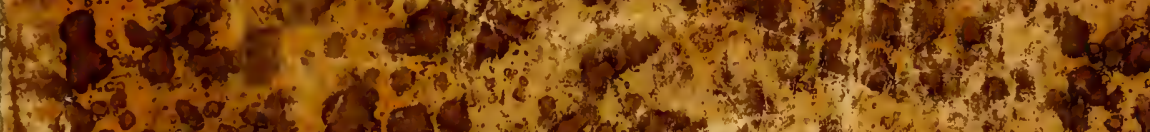

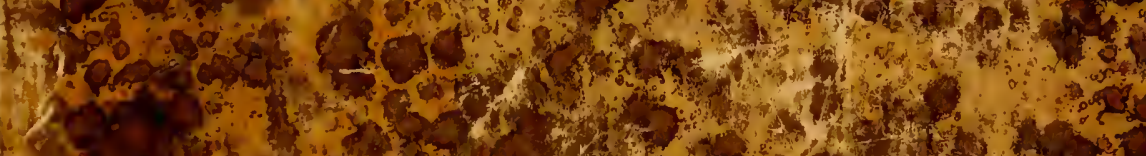

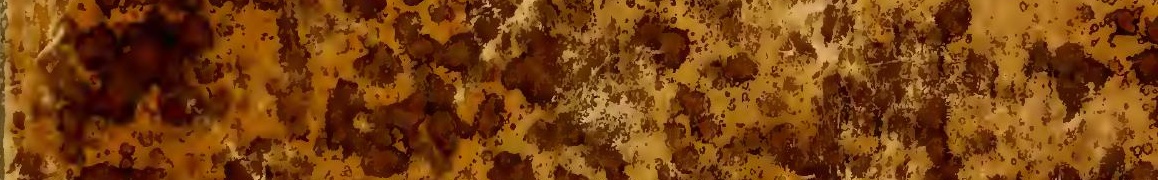

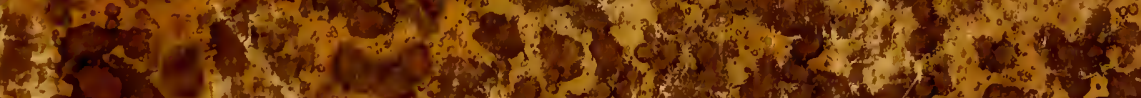

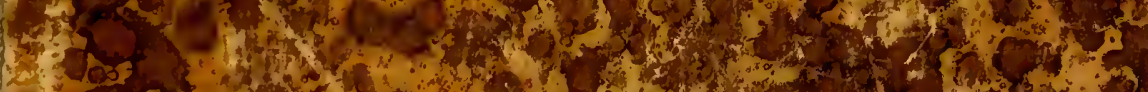

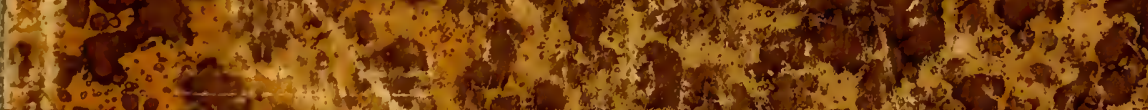
(1)

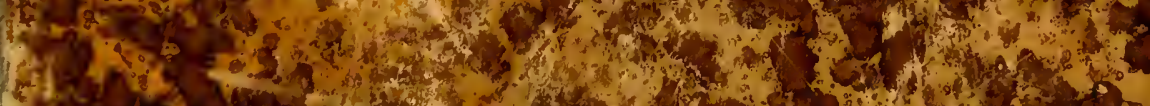

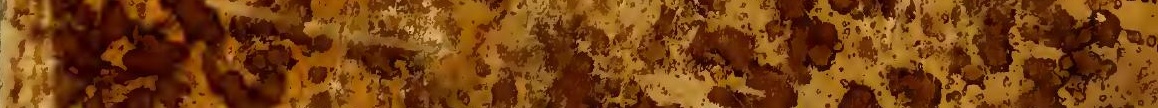

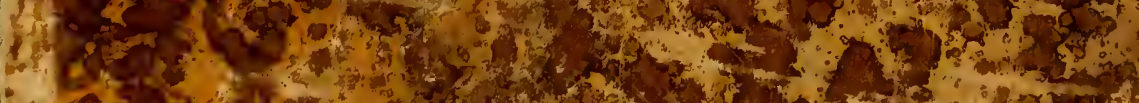

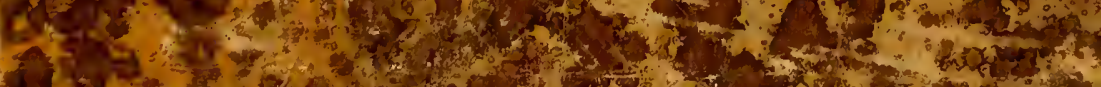

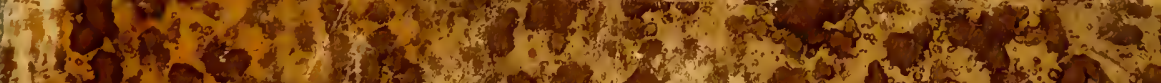

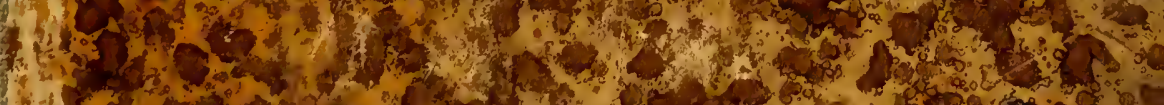
1.5.

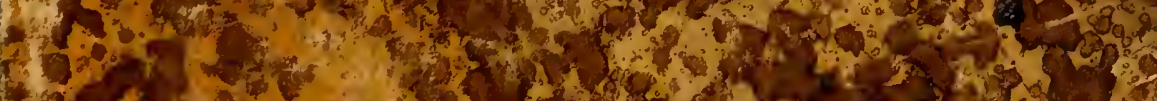

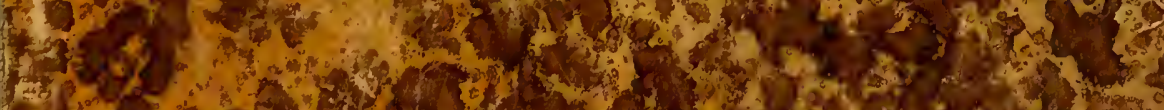
Af

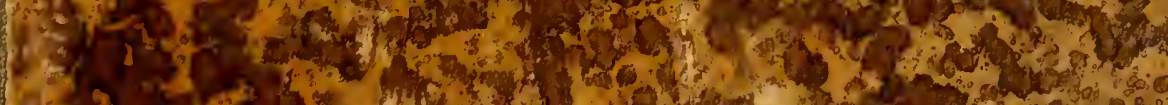

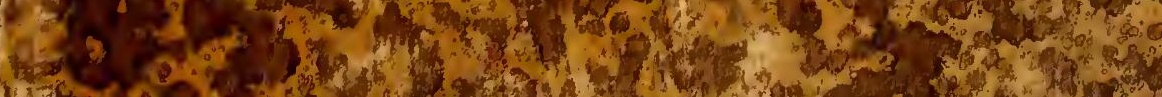

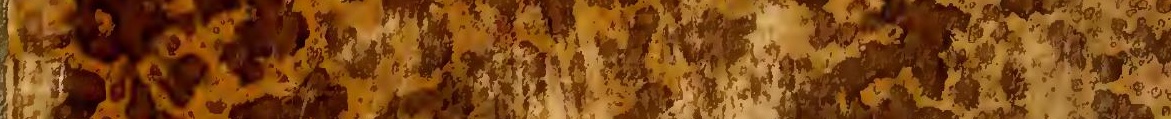

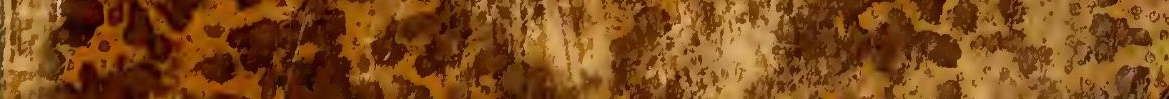





$$
96254 \text { at c44 }
$$






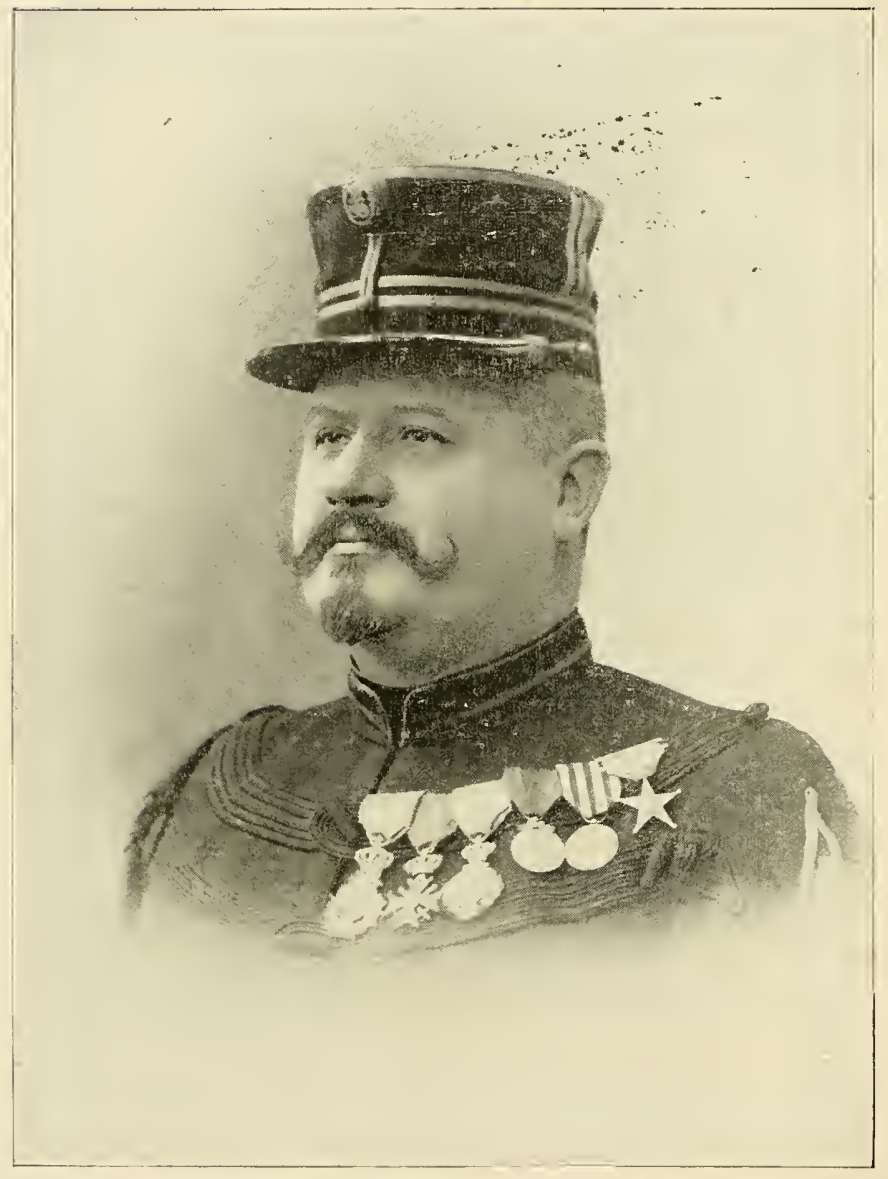

Commaniani Oscar milCHAUX 


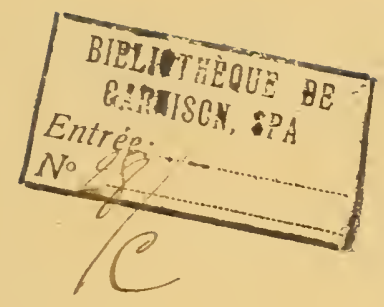





\section{AU CONGO}

\section{Carnet de Campagne}

ÉPISODES \& IMPRESSIONS

DE 1889 à 1897

PAR

\section{le Coinmandant MICHAUX}

Du 1er régiment de lanciers,

Ex-Commissaire de district de 1re classe du Kasä-Lualaba.
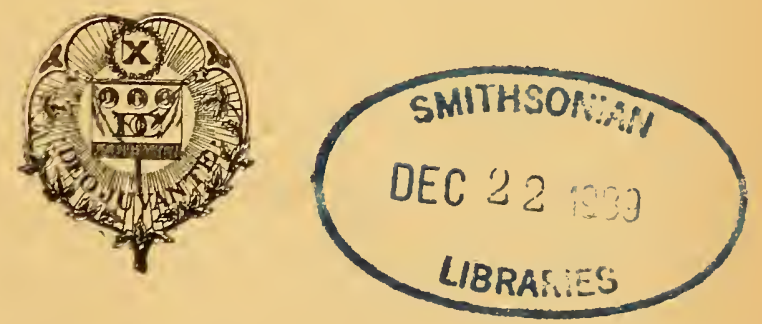

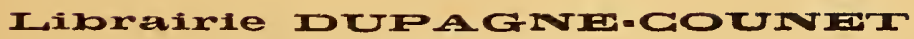

33-35, rue de Bruxelles, 33-35

NAMUR 
NAMUR. - Imp. DUPAGNE-COUNET \& Fils 



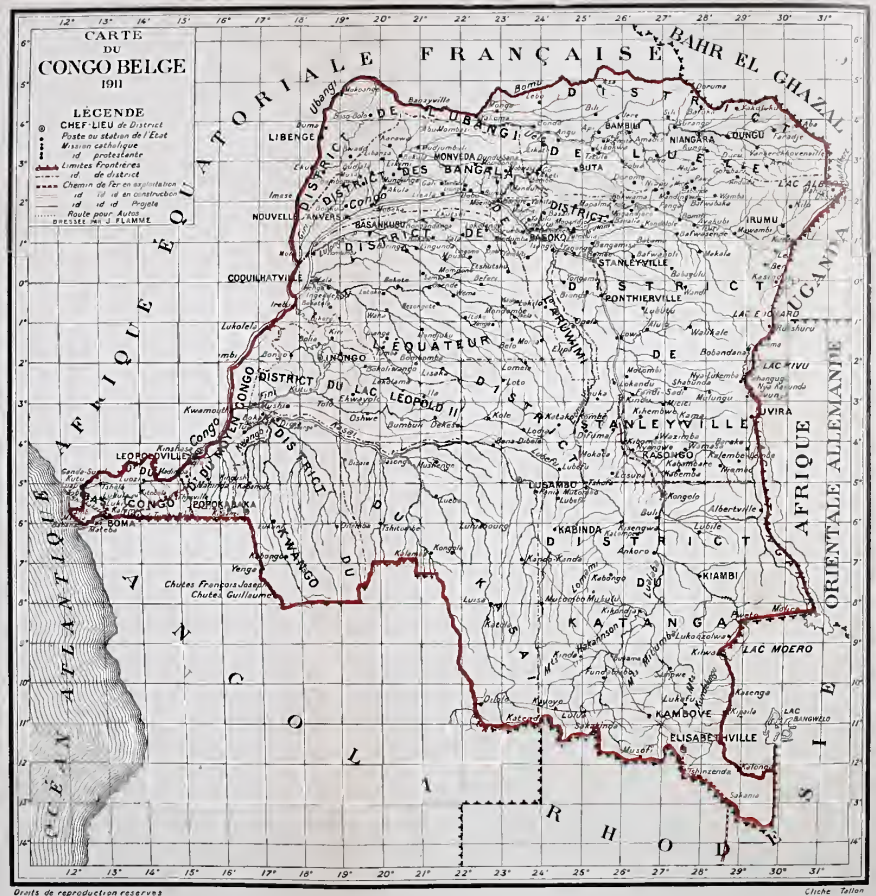





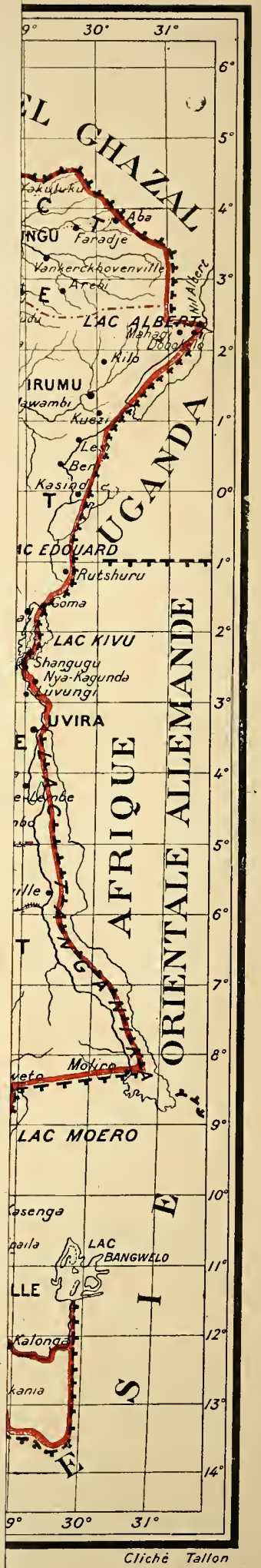




\section{PRÓLOGUV}

A mes anciens camarades d'Afrique.

Ces quelques souvenirs de voyage, je les écris pour vous, sans la moindre prétention.

N'étant pas littérateur, je n'ai qu'un but: vous rappeler à vous, mes vieux camarades, certaines heures passées ensemble, heures heureuses ou malheureuses suivant les circonstances, parfois heures tragiques mème, mais maintenant heures chéries, je dirai heures bénies, puisque nous ne les revoyons plus qu'à travers le prestige qu'apporte le recul du temps.

Nos douleurs, nos souffrances, nos déceptions, les dangers que nous avons courus, ne nous apparaissent maintenant que comme de pittoresques incidents de voyage uniquement destinés à leur donner plus de relief, à leur servir de point de repère.

Aussi, ne nous reste-t-il plus dans l'esprit que l'ensemble de l'œuvre accomplie et, dans le cœur, que le souvenir de ces jours virils, où nous aspirions tous à faire quelque chose, à devenir quelqu'un, où nous n'avions qu'un désir : la réussite de l'œuvre congolaise, qui se dessinait à peine, mais que nous sentions devoir être grande et généreuse. 
Ce sont ces heures que j'évoque, ce sont ces heures que je veux revivre quelques instants avec vous.

Je n'essaierai pas de poétiser les lieux, ni de dramatiser les choses; ce que je veux, c'est ètre vrai et vous reparler familièrement, en camarade, acle ce que nous avons vu, de ce que nous avons fait ensemble.

Ces quelques souvenirs je ne les écris sous l'influence de personne, ni avec l'idée préconçue d'attaquer ou de défendre qui que ce soit. Toutes les réflexions que je ferai me sont absolument personnelles et ne me sont inspirées que par les faits dont je fus témoin. Je me suis surtout astreint à ne cacher aucune des fautes que j’ai commises pendant mon long séjour au Congo; espérant faire œuvre utile en instruisant mes jeunes camarades, qui pourront profiter ainsi d'une expérience que nous, "les anciens ", nous n’avous pu acquérir, hélas! qu’à nos dépens. 


\section{CHAPITRE $I^{\text {er }}$.}

Le départ d'Anvers. - Mes compagnons de route. - où sont mes malles? - L'lle de Wight. - Du champagne en chantant. - Une douche en dormant. - On ferme toutes les écoutilles: C'est la tempête ! !..... - Las-Palmas : Les beautés de l'lle, ses produits.

C'était à Anvers, le 2 décembre 1889, par une des plus froides journées dont je me souvienne; il gelait à pierre fendre et le thermomètre marquait certainement $10^{\circ}$ sous zéro; la bise vous coupait littéralement la figure.

Nous devions partir à 10 heures du matin, mais, des retards s'étant produits, nous ne démarrâmes que vers midi el demi.

Nous étions tous sur le quai, entourés de quelques parents et amis attristés, car à cette époque il n'y avait pas, comme maintenant, de départ officiel ni de musique militaire. Ces départs ressemblaient quelque peu à des enterrements, oì les partants jouaient " les premiers rôles "), car, parmi les ouvriers de la première heure beaucoup déjà, et des plus braves étaient partis, et bien peu, hélas ! étaient revenus. On nous condamnait donc d'a vance, et beaucoup de nos amis venaient plutôt avec l'idée bien arrêtée de nous dire adieu tout en nous criant, mais sans y croire, "Au revoir!".

Tous nous grelottions parmi des sanglots étouffés, parlant à peine, répondant la plupart du temps par un 
triste sourire aux dernières recommandations des êtres chers qui nous entouraient et tous aussi, au fond du cour, nous souhaitions le départ pour mettre fin à celte scène déprimante.

Enfin, ce vieux sabot qui portait le nom d' "Ambriz " se décide à quilter ses amarres. Vite, un dernier baiser, une dernière étreinte, une recommandation suprême, le cri "au revoir !...... " et lentement, comme à regret l' "Ambriz " quitte ses attaches pour nous faire voguer vers ce qui alors était encore l'Inconnu; quelque temps encore les mouchoirs s'agitent: appuyés contre la chaìne qui servait de bastingage, nous regardons avec nos jumelles ces petits carrés de toile qui, pour le commun des mortels, représentent si peu de chose et qui, pour nous, symbolisent le passé et, qui sait, pour certains sont peut-ètre aussi l'espérance.

Enfin, le dernier mouchoir s'est perdu à l'horizon, le bateau vient de tourner le coude d'Austruweel; plus rien, que le sentiment de l'isolement $1 . .$.

Nous descendons dans la boîte que l'on a décorée pompeusement du nom de cabine, et pendant une minute, mais une minute seulement, la nature reprend ses droits; tantòt, en présence des parents, dés amis, il a fallı montrer bonne contenance, faire le fort; maintenant que l'on est seul avec ses pensées, seul arec soi-mème, le cœur se gonfle comme s'il allait éclater. Un nom aussi nous vient naturellement aux 
lèvres et comme au temps de son enfance on se surprend à murmurer. ...... Oh ! maman !!

On pleure un peu ; mais ne souriez pas : cela fait tant de bien. Puis, comme honteux de sa faiblesse, mais soulagé d'un poids immense, ou se sèche les yeux, on se les rafraîchit quelque peu et on remonte sur le pont pour faire la connaissance de ses compagnons de voyage.

Pour nous, ce fut vite fait, nous n'étions que sept passagers de première classe.

Je vais vous les présenter au courant de la plume. Deux officiers, Vanderlinden et Bureau; deux ingénieurs du chemin de fer du Congo, Paulissen et Goffin; un ancien congolais, Poncelet, qui a déjà séjourné trois ans au Congo ; enfin linsch partait comme gérant pour l'hòtel de Boma ; charmants camarades tous!

Bureau, bou garçon ayant toujours la pipe à la bouche et sur les lèvres un sourire un peu ironique.

Vanderlinden, toujours correct, ne craignant qu'une chose : salir ses manchettes ou déranger le noud de sa cravate; au demeurant, un cœur d'or.

Paulissen, boute en train, prenant la vie par son bon côté, s'ćtait donné la mission de relever par de bonnes plaisanteries, le moral de ceux d'entre nous que le spleen guettait.

Goffin, nature fine et contemplative (ce qui ne l'empêchait pas d'être un pince sans rire irrésistible), ne sortait guère de sa rêverie que pour lancer une boutade, qui 
ratait rarement son effet. Peut-être prévoyait-il déjà qu'il aurait un jour l'honmeur de terminer et de mener à bien l'entreprise alors à peine élbauchée du chemin de fer du Congo.

C'était mon compagnon favori et c'est avec lui que j’ai visité les dilléérentes escales.

Poncelet, que nous avions surnommé "Lutété " en souvenir du poste où ill avait passé la plus grande partie de son premier séjour en Afrique, était notre " ancien ", et comme tel, il nous donnait des conseils, qui, disait-il, devaient nous préserver des fièvres bilieuses ou hématuriques ainsi que de la dysenterie, mais, en même temps, il nous en faisait une peur blene, ainsi que des serpents qu'il disait plus gros que notre cuisse et des scorpions, bètes à mille pattes el des tarentules qu'il faisait ressembler anx bètes de l'Apocalypse.

Nous le respections comme notre mentor, tout en nous disant intérieurement qu’il avait exagéré légèrement.

Quant à Finsch, comme il était le seul d'entre nous qui parlàt couramment l'anglais, et que dans tout l'équipage personne ne parlait français, il nous rendait les plus grands services comme interprète, mission qu'il remplissait d'ailleurs avec la meilleure gràce du monde.

J'allais oulblier mon ami Pitch,mon inséparable chien. Pitch était un spits de grande race d'une férocité extrème, mais d'un dévouement et d'une intelligence hors ligne. 
Mes camarades de route rous étant connus,je continue mon récit.

Je vous ai dit qu'il faisait un froid de loup, de plus il rentait à nous démâter; mon chapeau menaçait à chaque instant de me quitter sans permission préalable. Je voulus le remplacer par une coiffure plus commode. Je descends donc dans la cale pour prendre ma toque qui se trourait dans une de mes malles.

Après une demi-heure de recherches vaines, je vais prier Finsch de s'informer auprès d'un des officiers du bord, de l'endroit où l'on avait remisé mes malles.

Celui-ci consulte son bordereau, une fois, deux fois, puis me regardant bien en face, comme pour mieux juger de l'effet qu'il va produire, il me dit : “ Monsieur, il n'y a pas de malles pour vous à bord ! "

$\mathrm{Au}$ premier moment, je suis tellement bouleversé, tellement atterré, que, pendant quelques secondes, j'en perds la parole.

Puis me ressaisissant un peu, je m’écrie : "Comment, pas de malles à bord! c'est impossible "... - " C'est cependant comme cela, Monsieur, voyez plutôt vousmême le bordereau... »

$\mathrm{Oh}$ ! ce bordereau ! je le parcourais dans tous les sens, je l'auscultais en quelque sorte, j'aurais voulu lui faire dire qu'il avait menti !

Nes malles étaient restées sur le quai, il n'y avait plus de doute possible; je partais au Congo avec deux 
chemises, deux paires de bas, six mouchoirs de poche et un pantalon de rechange, le tout contenu dans une valise à main !

Le coup fut terrible,j'en restais atterré.Mais comment, me direz-vous, la chose était-elle possible?

Oh ! c'est très simple : au dernier moment, comme j'avais encore quelques achats à faire en ville, un de mes camarades s'était mis à ma disposition pour faire embarquer mes bagages ; comme j'avais toute confiance en lui, j’avais accepté son offre avec le plus grand plaisir. Malheureusement, mon camarade eut la manvaise idée de charger de la chose un de ses amis, qui probablement, en chargea un troisième, qui, lui ne chargea personne ni ne se chargea de rien du tout.

Bientòt, le bruit de mon aventure, aussi extraordinaire que peu agréable, se répandit parmi mes nouveaux camarades et bientôt aussi, tous furent réunis autour de moi ; un peu, je crois, pour me plaindre et beaucoup par curiosité.

Nous tînmes conseil : que faire? La plupart d'entre nous étaient d'avis qu'il n'y avait qu'à débarquer à Flessingue et reprendre le steamer qui partait le mois suivant.

Je fus premièrement assez de leur avis, mais bientôt me rappelant la scène des adieux, je revis ma chère maman faiblissant une première fois au salon puis au moment du départ, s'élançant sur la portière, comme 
si elle avait voulu marracher de la voiture. Je la revis aussi, tombant par terre comme une masse, pendant que je m'enfuyais au galop.

Puis ce fut la scène d'Anvers! où mon vieux père arait voulu m’accompagner et où sous mes yeux attristés, deux de mes cousins avaient dì le transporter du quai.

Tout cela était donc à recommencer! Non, tout ce qu'on roulait, mais pas cela! Aussi ma résolution futelle vite prise, j'enverrais de Flessingue une dépêche chez moi et une à M. Walford, l'armateur, afin que l'on m'expédiàt mes malles par le prochain bateau et en attendant leur arrivée, comme j'avais eu la précaution de me munir d'une somme relativement assez forte, j'achèterais du linge et des effets à la première escale.

Ainsi fut fait, grâce à l'obligeance de tout le monde, je n'eus pas trop à souffrir de cette...... mésaventure. Elle eut mème ceci de bou : j'en conservai cette moralité que, chaque fois qu'il y a moyen de faire ses affaires soi-même, cela vaut toujours infiniment mieux que de les confier, fùt-ce à ses meilleurs camarades.

Vous parlerai-je du bas Escaut? Non, c'est trop laid et trop triste, il ne faisait qu'augmenter notre propre tristesse!

Je passe donc Flessingue et je quitte l'Escaut pour entrer dans la Nanche.

Ma première nuit à bord fut la plus mauvaise ; il me semblait que je ne pourrais jamais m'habituer à dormir 
dans cette espèce de boîte à cigares ; j'avais anssi un peu de fièvre,mais ce n'était pas étonnant,après les émotions de la veille.

Comme diversion, vers 11 heures du matin, nous apercevons l'île de WVight.

Précisément, à ce moment, plusieurs passagers sont pris du mal de mer.

Ils ont une façon très drôle de saluer cette terre anglaise, mais personne ne rit, chacun s'attendant à y passer; pour mon compte, j'en fus quitte pour la peur.

La côte méridionale de l'île de Wight, est en amphithéâtre, bien abritée contre les vents du Nord, égayée de villas et de châteaux situés au milieu de jolis parcs se distinguant les uns des autres par leur originalité. Nous y remarquons aussi des falaises crayeuses, ainsi que des maisons peintes en couleurs très voyantes, telles que : rouges, vertes, jaunes, bleues, etc.; le tout, grâce à un clair soleil, forme un tableau dont l'ensemble est assez réjouissant à l'oil.

Notre pilote vient de nous quitter ; il emporte avec lui nos lettres, les dernières qui seront datées d'Europe.

La mer est assez forte; il part dans un canot conduit par deux rameurs. Ils sont ballottés d'une façon effroyable et à chaque instant nous croyons les voir chavirer. Pauvres diables !...... quelle existence, mon Dieu !...... 


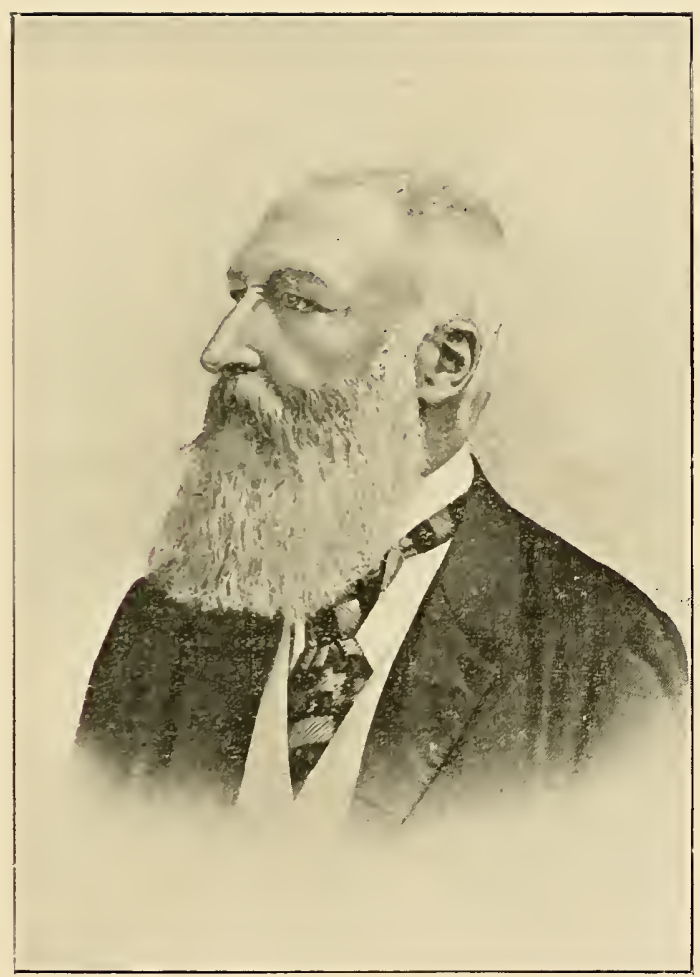

Le Créateur de notre beau Congo! Notre Grand Roi LÉOPOLD II 


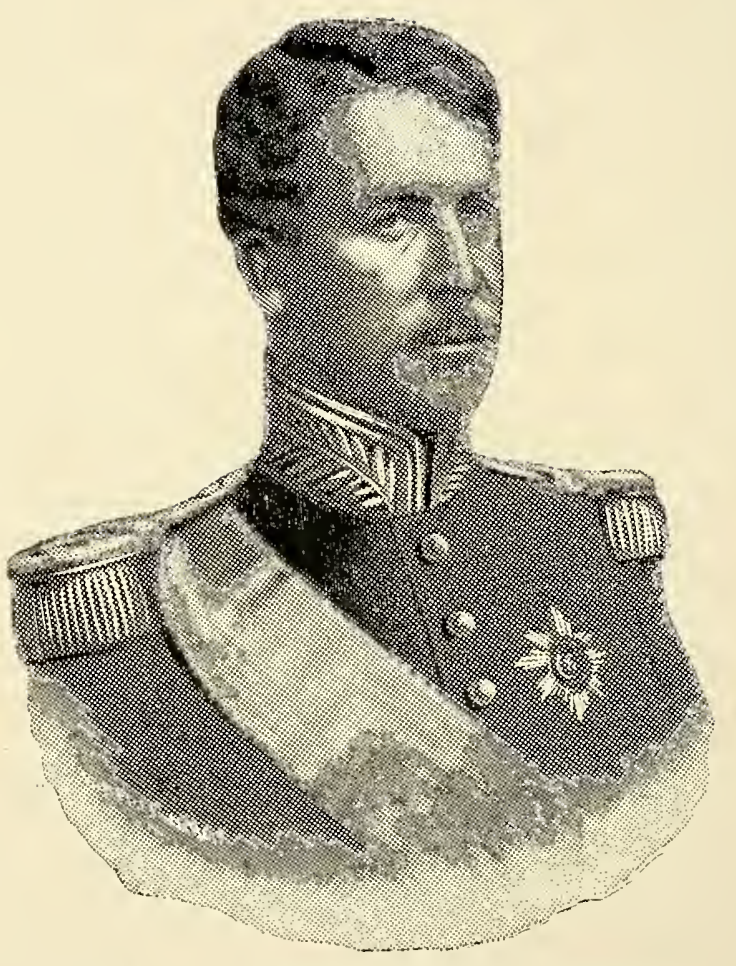

S. M. ALBERT ler, Roi des Belges 
La vie est assez monotone à bord, ef, contrairement au proverbe, on peut dire que " lcs jours sc suivent et se ressemblent ". Aussi le moindrc incident est-il le bienvenu et sert de nrétexte pour se réjouir. C'est ainsi qu'un jour après-dìncr je m’assicds par inadvertance dans le fauteuil du capitaine. Aussitòt, je suis salué d'un hourra formidable et l'on m'apporte la cartc des vins en grande cérémonie. Je commande quelques bouteilles dc champagne, d'autres font de mème, le capitainc trinque avec nous et bientòt chacun y va de son speech puis de sa clianson. Pas fameux, lc champagne du bord, mais enfin, je crois m'apercevoir qu'il grise quand mème.

Bref, lc combat finit fautc dc combattants et chacun s'en va se coucher et pent voir sc réaliscr en rève le secret désir de son cuur. Je parlc pour les autres, car pour moi mon rèvc devait s'interrompre pour mc faire rentrer d'une façon assez brulale dans la réalité.

Nous étions dans le golfe de Gascogne : la mor était quclque pou démontée; la pradence nous faisait un devoir ćlćmentaire de bien fermer nos hublots; mais, comme nos cabines avaicnt la grandcur d'un portefeuillc, le champagnc airlant, je trouvais qu'il manquait totalemcut d'air ct, confiant dans ma bonne éloile, je ine couchai bravement sois mon hublot ouvert. Je dormais du sommcil du justc un peu ćmèché, quand, patatras, je recois la plus belle douche d'eaı de mer que jamais phoque ait rêvée. 
Je pousse un cri, saute de ce que ce jour-là je pus appeler ma baignoire et j'assiste, bien malgré moi il est vrai, à un spectacle inoubliable. Comme la mer était des plus phosphorescentes, chaque goutte d'eau brillait comme un rubis et ma cabine, semblable aux grottes des fées, paraissait tapissée de pierres précieuses. C'était léerique; mais comme j’étais trempé el golé jusque la moelle des os, je dois avoner que j'admirais moins cette féerie que je ne l'aurais fait dans des circonstances normales.

Le lendemain de cette soirée et de cette nuit mémorables nous réservait d’autres surprises; lorsque vers 8 heures du matin nous montons sur le ponl, la mer est complètement démontée.

Le capitaine, ainsi que les olliciers du bord, paraissen I inquiels, on ferme toutes les écontilles, tont est barricadé ; au lieu d'un homme il y en a trois au gouvernail. C'est la tempète qui s'annonce.

Quelques-uns de nous obtiennent du capitaine la permission de rester sur la passerelle, car le pont est inhabitable.

De gros nuages noirs comne de l'encre ont déjà voilé l'horizon; ils semblent se poursuivre daus une course folle et bientòt obscurcissent le pàle soleil qui nous éclaire el qui semble renoncer à lutler contre eux.

Le rent, comme s'il voulait se recueillir et garder toutes ses forces pour l'assaut qu'il va nous livrer, est 
tombé tout-à-coup. Chacun de nous est pàle et ne parle gürè à son voisin. Les ordres du capitaine sont brefs et saccadés; les matelots les exécutent tous au pas gymmasticue et parent le vaisscau comme pour un combat. C'en est un d'ailleurs qu'il va falloir livrer et non pas contre des hommes, mais contre les éléments déchaìnés.

L'attaque ne se fait guère altendre: bienlòt, une trombe apparail sur notre droile; elle arrive sur nous arec une rapidité foudroyante, elle nous rejoint, nous enlace, nous étreint. Un éclair succède à un éclair on plutòt dix éclairs nous aveuglent à la fois; il y en a partout, dans le cicl, à l'horizon, sur les vagues; et pendant ce temps le tomnerre gronde et fait un tel vacarme que e'est à croire que le ciel va s'écrouler sur nos tètes.

Nos mains s'incrustent pour ainsi dire dans le bastingarge de la passerelle, car il s'igit de ne pas nous laisser enlever par les valgues. Toul craque autour de nous; notre grande vergue vienl d'èlre enlevée comme un simple fétu de paille ef les plus gros cordages sont rompus comme de minces lils de soie. Toute l'ossature du vaisscau géénit, se plaint; le vieil " Ambriz » semble nous dire ru’il n'est plus de force à résister à de parcils assauts.

Il se comporte bien cependant; tantòt il est couché sur un flanc, tantðt sur l'autre; tantôt aussi il se cabre 
comme s'il voulait se renverser; d'autre fois suspendu au sommet d'une vague, il pique droit dans l'abìme d'où il ne semble plus devoir sortir, mais toujours il se redresse el comme un vieux cheval de bataille, quoique blessé,il fait face à chaque vague et l'attaque par le front; cent fois vainqueur, cent fois il retourne à l'attaque.

Pauvre vieux "Ambriz ", hier nous ne savions quel mal en dire et maintenant tout notre espoir réside en lui. Cependant, peu à peu, la mer se calme, le vent faiblit; peu à peu également notre sang qui s'était figé dans nos veines circule plus librement et nos figures épouvantées reprennent un peu de sérénité.

Alors, nous regardons autour de nous : tont est cassé, tout est tordu, nous l'avons échappé belle!

Pour nous consoler, le capitaine nous apprend que dans deux jours nous serons à Las Palmas.

C'est égal, maintenant qu'elle est passée, je suis content d'avoir vu cette tempête; mais je vous jure bien que je n’ai pas le moindre désir de la roir recommencer.

Mardi 10 décembre, vers midi, nous nous précipitons tous vers l'avant du navire: on vient de nous dire que l’on apercevait les grandes Canaries. Armé de mes jumelles, je distingue très bien les còtes.C'est splendide! Avant-hier, tout respirait le carnage, la dévastation, l'épouvante et l'horreur. Aujourd'hui, tout est calme, tout est beau, tout nous porte à la joie, tout nous dit d'aimer, l'on se sent heureux de vivre. 
La brise parfumée qui nous vient des bouquets d'orangers, est si faible que c'est à peine si elle ride la surface de la mer qui est entièrement bleue. Quant à l'ìle, c'est merveilleux! Je voudrais vous en faire une description quelque peu ressemblante,mais j’aurais tant de choses à rous dire que je ne sais par où commencer.

Toutes les maisons d'un blane de neige, harmonieusement élagées sur la montagne, sont en style mauresque le plus pur. Les voyant ainsi, je dirai semées an milieu des orangers, des palmiers, bananiers, cocotiers, cactus, etc., on se croirait aisément en Orient et, l'imagination aidant, on se figure à chaque instant voir apparaitre sur ses toits plats, quelque muezzin de Mahomet appelant les fidèles à la prière.

Un canot nous mène à terre et nous allons à Las Palmas, qui se troure à près de deux lieues du port. Les chevaux de l'ile sont de petite taille; ce sont de véritables poneys; mais ils sont très courageux et peuvent parcourir à une allure relativement rapide de très grandes distances.

Nous avons fait les deux lieues qui séparent le débarcadère de la ville, d'une seule traite et au trot allongé.

Sur la route et en ville, j’ai d'abord regardé les femmes qui, enveloppées d'un châle, comme les femmes arabes et l'amphore sur la tête, s'en vont prendre de.l'eau aux fontaines. Jusque maintenant, c'est tout-à-fait biblique. Leur démarche est lente et majestueuse; leur corps 
souple ondule sur des hanches à la ligne opulente; elles glissent plutôt qu'elles ne marchent; la plupart n'ont pas de corset, tout en ayant l'apparence d'en avoir un.

Les femmes sont généralement bien, quelques-unes ravissantes. La figure est d'un ovale parfait, le teint est mat quoiqu’un peu bruni, la lèvre bien dessinée est fine, d'un rouge presque sanglant. Les dents bien plantées sont d'un blanc laiteux, le nez est droit et moyen, l: chevelure portée en nattes sur le dos est aussi longue qu'abondante. Les extrémités, elles, sont presque trop petites; les oreilles, c'est à peine si on les aperçoit ; les mains sont des mains d'enfant; les pieds sont si pelits que l'on est étonné de les voir supporter le poids du corps. Quant aux yeux, je puis vous dire qu'ils sont très noirs, qu’ils sont très grands, qu’ils sont bien lendus, qu'iis ont de longs cils recourbés. Nais ce que je ne puis rous dépeindre, c'est le regard de ces yeux. Ce regard, rapide comme la flèche, s'enfonce comme elle; les eflluves dont il est chargé, vous pénètrenl, vous enveloppent, vous magnétisent en quelque sorte. Et pendant qu'elles passenl, belles et somriantes, vous rous surprenez, restant en place abasourdi, tout entier au ravissement de leur charme et longtemps encore ce regard fascinateur vous poursuit, vous obsède.

Mais ne croyez pas à leur désintéressement.

L'indigène de Las Palmas, ne voit dans tout élrangrer qu'une proie que le ciel lui envoie et qu'il s'agit de 
tondre, de plumer, en un mol d'exploiter par lous les moyens possibles.

Nous allous visiler le Muséc. J’y remarque surlout des momies que l'on me dil provenant des habilants primilifs de lille.

Nous allons aussi voir la Cathédgrale, qui est très belle, flos inposante. Le chorur se troure au milieu de l’église, el, an moment où nous cntrons, nue vinglaine de prèltes el d'enfants de chuml chantent les vèpres à pleine voix, bien qu’il n’y ail que deux personnes daus l’église.

Qnand ou entre dans celle basilique, qui est immense el lriss sombre, on éprouve un semtiment de tristesse el de malaise.

L'alllel, lres Jeau, est en arogent massif el vaut, m’it-l-oll clit, lrois cenls mille franes.

En sorlanl de l'église, nous nous rendons à l'hòlel ponr le dince. Les nels y sont assez bons, l'addition su:tonl esl salće : 187 francs potir sept personnes; c'était Dévin, cela ne nous effraic donc pas trop.

Le lendemain, nous visilons avec Goffin la partie supéricure de la ville; le Resco est d'un pitloresque sale.

Cerlanes maisous sout creusées dans le rocher ou, pour mieux dire, daus la lave. Ce sont de vérilables caverucs sans air el sans hunière.

Les lypes des habilants sont différents de ceux de la ville basse. Il semble gu'ils soient lout à la fois un composé de l'espagnol, du manre et du niggre. Je n’ai plus jamais retrouvé ce type nulle part. 
Goffin a voulu prendre le croquis d'une des femmes et lui a même offert un schelling ; mais elle s'y est refusée absolument et s'est même enfuie. Comme ces peuplades sont très superstilieuses, elle s'est probablement figuré qu'on voulait lui jeter un sort.

Quant à l'ensemble de la ville et de la rade, vues d'en hant et par un beau soleil comme celui qui nous éclaire, c'est superbe.

Redescendus dans la ville basse, nous avons roulu goûter des prodıits de l’ìle : les oranges sont délicieuses, les goyaves un peu fades; quant anx bananes et aux mangues, comme c'est la première fois que j'en mange, je trouve qu'elles ont les premières un goùt de savon et les secondes de iérébenthine.

Le vin n'a pas meilleure grâce devant moi; le muscatel, quoique passable, est trop doux et le vinotinto ne vaut absolument rien.

Vers minuit, le chargement étant complet, nous regagnons l'Ambriz. Nous sommes tous fourbus, éreintés et c'est presque avec bonheur que nous reprenons possession de la maigre couchette qui doit reposer nos membres épuisés. 


\section{GHAPITRE II.}

Un ex-cisailleur de haies improvisé coiffeur. - Entente peu cordiale entre les mules achetẻes à Las Palmas et leurs conduca teurs anglais.- Une bande de marsouins fait escorte au navire. - Coups de feu dans la nuit. - Sierra-Léone à l'heure du marché. - Une distribution des prix chez les petites négresses. - "Est=ce bon, Goffin ?" - Mort tragique de Smith. - A la lueur des éclairs.

Le lendemain de notre départ de Las Palmas, nous nous levons assez tard et le soleil est déjà très haut à l'horizon lorsque nous faisons notre première apparition sur le pont. Il chaufre ferme el, d'un commun accord, nous décidons de nous faire tondre; seulement, comme il u’y a pas de coiffeur à bord, la question est assez embarrassante.

Nous dénichons cependant un matelot qui a déjà ciscillé des haies dans son jeune temps et celui-ci, moyennant un juste tribut, consent à nous débarrasser de notre toison. Armé d'une formidable paire de ciseaux, le brave homme y va de tout cour ; il coupe avec rage, arec. passion et, d'escaliers en escaliers, il arrive triomphalement au sommet de notre occiput.

C'est presqu'aussi pittoresque que le Resco de Las Palmas. Aussi chaque nouveau tondu est-il accueilli par un éclat de rire. 
Hilarité aussi, sur le pont, lorsque les matelots conduisent à l'avant du navire les mules achetées à Las Palmas. Celles-ci, têtues comme toutes leurs consours, refusent d'arancer et ruent avec une conviction remarquable, malgré les remontrances que lenrs conducleurs leur font en anglais. Goffin prétend que le manque d'untente entre eux provieni uniquement de la difiérence de lem nalionalité.

Il y a aujonrlhui lnuil jours, uous débarquions a Las Palnas el e'est encore un de nos sujets de conversalion favori.

Ver's le soir, nous apereevons une bande de marsonius.

lis suivent le navite par loandes el ne l'abaudonnent

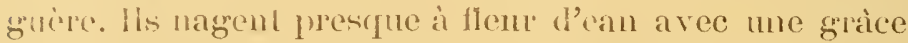
ef une vélocité exfaotdinates ; d̀ cliague instant, ils fonl des bonds de phusicnms mètres hors die l'ean; à ce moment, on he peut mienx les comparer qu’à des chevanx sautant des obstacles, laut leurs bonds sont róguliers et fails arec ensemble.

Mais roici la muil : tout se tail à bord, le ciel est serein ct s'illumine de milliers d'étuiles; la brise est si douce yne cest à peine si clle nons caresse, la mer est aussi calme el anssi unie gu'une glace.

Pour micux jouil de ce grand repos, de ce calme parfait au milieu de l’immensité, je vais m’asseoir seul à l'avant du navire. 
La mer étant précisément ce soir très phosphorescente; les marsouins qui nagent en arant du navire semblent s'y afteler. Ils sont rendus lumineux par le froltement de l'eau et figrurent récllement des poissons de feu, dout les formes soul parfaitement dessinées.

Ils laissent derriere cux un sillage phosphorescent, donuant fïhusion que des serpenls enfammés les pourstivent.

Innginez-rous une vinglaine the marsouins, chacun ponrsuivi de son serpenl, le lonl déerivant des méandres gracieux a rec une ritesse considérable ef se maintenant en avant du navire, el rous anez une idée du spectacle magnilique qu'il m'étail domné d’admirer.

Le bonhear d'ètre, de respirer, de me sentir rivre, de contempler ce spectacle unique, fontes ces schsations si diverses of si neaves étaient si fortes qu'elles m'en. avaient détendu les nerf's.

Je voyais le tout comne daus un rêve délicienx, que l'on craint de voir finir; ma jouissance était lelle que j'en iessentais presque une donleur physirgue.

ban nom extace, je ne tromvis qu'm not pour dépeindre mon aduiration, ponr crier non bonheur; des deux mains me comprimant la poitrine, je ne stmpris à mamurer : "Mon Dien, que e'est beau ! que c'est donc beau !... n

.hais volla le enpilaine el mes camarades qui viennent the retrourer; ils ont disculé la vélocité des masouins 
et mon adresse comme tireur. Un pari s'est même gagé ; on a parié qu'en deux coups de fusil, je ne pourrais pas tuer deux marsouins. Quelle aberration mentale me saisit alors, quelle solte gloriole me tente, je ne sais. Mais le fait est que, saisissant mon fusil, en deux conps de leu je tue deux de ces beaux marsouins.

Les autres s'enfuient dans toutes les directions et l' "Ambriz ", privé de par una faute de son cortège lumincus, vogne maintenant tristement dans le silence de la nuit.

Mes camarades me félicitent vivement de ce beau coup et ils veulent à toute force m'entrainer avec eux, pour aller hoire le champagne que je leur ai fait gagner, mais, furieux contre cux, furieux contre moi-mème surtout, je refuse tout et je vais m'enfermer dans ma cabine, me traitant de sot, de bourreau, regrettant ma vision, mon beau rève, comme un enfant qui a cassé son jonet.

Le lendemain matin, nous étions en vue de SierraLéone.

C'est moins beau que Las Palmas, mais la rade est très pittoresque.

Ce qui attire surtout l'attention de tout Européen, qui n'a jamais vu l'Afrique, c'est la végétation qui est réellement magnifique. Quelques spécimens d’arbres sont tellement hauts, que nos plus beaux peupliers paraîtraient à còté d'eux de simples arbrisseaux. 
Mais revenons à la rade, où beancoup de barques à mat de hambou se balancent indolemment. Dans l'une d'elles, une lady passée au cirage et abritée sous un immense parasol blanc, daigne à peine nous regarder.

Il y a assez bien de navires en rade, entre antres denx garde-còles anglais. Très jolis ces garde-còles blancs a vec leur équipage toul de blanc labillé.

Mais le phus gai va commencer. Nous sommes entourés de barques remplies de moricauds.

En un clin d'eil, lons ces démons noirs escaladent le pout de l' "Ambriz " el nous offrent en vente des hamacs et des fruils. Ils nous offrent également de nous conduire à ferre et tont cela an milieu de cris, de disputes, de rires, de danses el de contorsions invraisemblables ; c'est à se croire au milieu d'une troupe de démons en goguetle. Xous en sommes presque ivres, rien que de les voir, de les entendre.

Enfin, après force coups de poing, nous parrenons à nous caser dans une barque, car tous veulent nous avoir daus la leur : ils nous enlèvent réellement de force.

Nous voilà à lerre, nous risitous rapidement la ville européenne peu intéressante el nous nous enfonçons de sulte daus la ville indigène.

C'est l'heure du marché et il y règue une animation extraordinaire. On y vend là des fruils de foules especes, du tabac, du vin de palme, du poisson, du pain, etc. 
Tous les noils adultes sont habillés; les enfants, enx, sont complitement nus.

Nons examinons el sommes examinés curieusement. Hommes of lemmes chyagent avec nous, en mauvais anglais, des bouts de cosveration oü l'on ne se compread guere el (qui se terminent tonjoan's far des ribes d'mu large, qui ne finil qu'aux oreilles.

Des jelines filles de dix ans, complotement lemmes, du reste, ol vèlues souloment d’ur parne, exéculent devant nous, dans l'espoir de récolter quelques priees, des dances ansisi monolones que fascinanles.

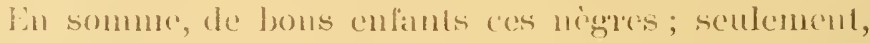
no pas onblier que dans fonte latusation aree eux il

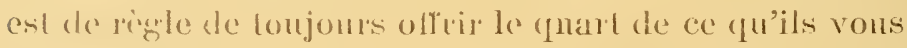
demandent.

finule dim hòlel convenable, nous rentions à hord ares minnil, l'esprit dispos mais le vente creux. La lendenain nublin, noms relommons a terre, chacun

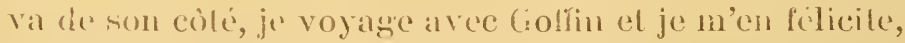
call pendant que les antres fanent dams les calés de l'endroil, nous risilons la ville el les envinoms, voulant loul voir "l gother à lont. Celle manic nous a nome valu me pelile aventure dont nous avons bien ri depuis.

11 lairail tros chand, noms avions soif, el passant devant moc bouligue, nous y remarphons des fruils gros comme des cerises el d'un rouge si beau qu'on les manguait des yeux :" Dis-moi, Gollin, quel fruil cela 
peut-il bien etre? - Je ne le connais pas, main il me parait trèn pafraichissant. - Si nous cntrions? - Je le veux bien. - Ces fruits qui :onl à lat viltine, est-e bon, matame? Eat-ce que celat se mange? - Mais certainenent, monsieur. - Veuillez nous en servir prour six pence, s'il vous plail. n

fivlin en frend nu, le croque. "Eal-ce bon? Délicinux ! molte. ")

J'on prendis un cyalement, mais à peine l'ai-je mis en

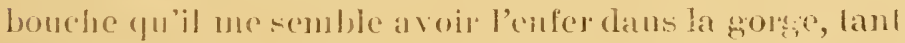
cela nace lurile.

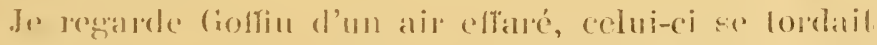

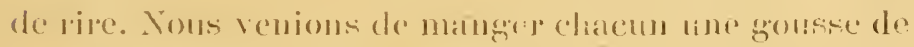
pinsont; senlentent, comme Goffin avait été las premiore viclime de la méprise, il n'avail rien voulu me dire afin que je le fisse à mon tom ; denx hemres aprese, nos bonches l,rilaient encore.

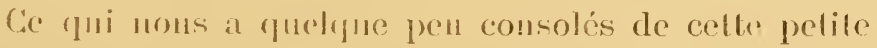

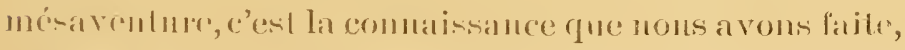
'frelgues instants aprese, du directenr de la mission calliolicyue.

Elanl par lakarde! entrés dans l'égrise, noms y avons rencontre cert exerellent homnue, qui nous a dommé lous les reneigurements que nous désirions.

Eutre autres choses, il nous a dit gu'il y avail seize ans ch'il habitait l'lfrique er, comne il est doné d'une 'xcellente sauté, c’est rassurant pour l'avenis. Il nous al 
dit aussi que primitivement son église n’étail fréquentée que par viogt fidèles, alors que maintenant elle l'est par huit cents.

Il nous conduisit ensuite à la maison dirigée par les Soents. C'était justement la distribution des prix. Là, nous avons été réellement émerveillés. Tous les murs de la salle étaient couverts de difrérents ouvrages de mains exécutés par les petites négresses. C'était maguifique et d'un fini parfait.

C'est égal, il en aura fallu du temps et de la patience aux bonnes soeurs pour arriver à ce résultat.

Nous remarquons parmi les jemnes mulàtresses des types rélloment beaux, entre autres une toute petite fille qui a bien les plus beam yeux que j'aie jamais vus. Ce sont deux réritables diamants noirs.

La sceur supérieure est Française, les autres sont iulaudaises, l'une d'elles est un vrai type de gràce et de beauté.

Nous cansons gaiement arec elles et le Pére supérieur. On se sent tout réconforté par l'amabilité française si diflérente de la politesse froide des Anglais, avec qui nous sommes en contact depuis Auvers. Aussi, est-ce à regret que nous quittons ces bounes sceurs. Ce sont probablement les dernières femmes blanches que nous verrous d’ici trois ans.

Nous allons ensuite visiter les casernes et les forts qui sont en construction. Diable, il chauffe sur la montagne. 


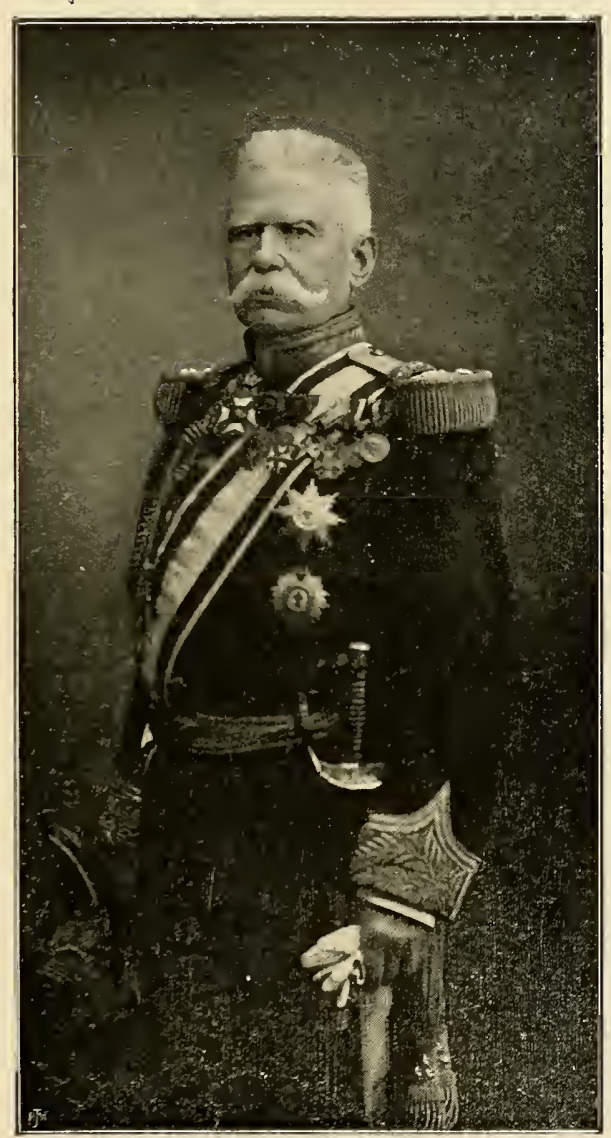

\section{Le Lieutenant Général Baron WAHIS}

Gouserneur Général du Congo

Ine partie des clichés contenus dans cet ouvrage mont été obligeamment prêtés, et je tiens à remercier tout particulièrement :

L'Expansion Belge; le Directeur Général Lepha ; le Commandant adjoint d'Etat-Mlajor René Dubreucq ; le lieutenant Armand Hetereat ; M. Ronigas, du Ministère des Colonies. 


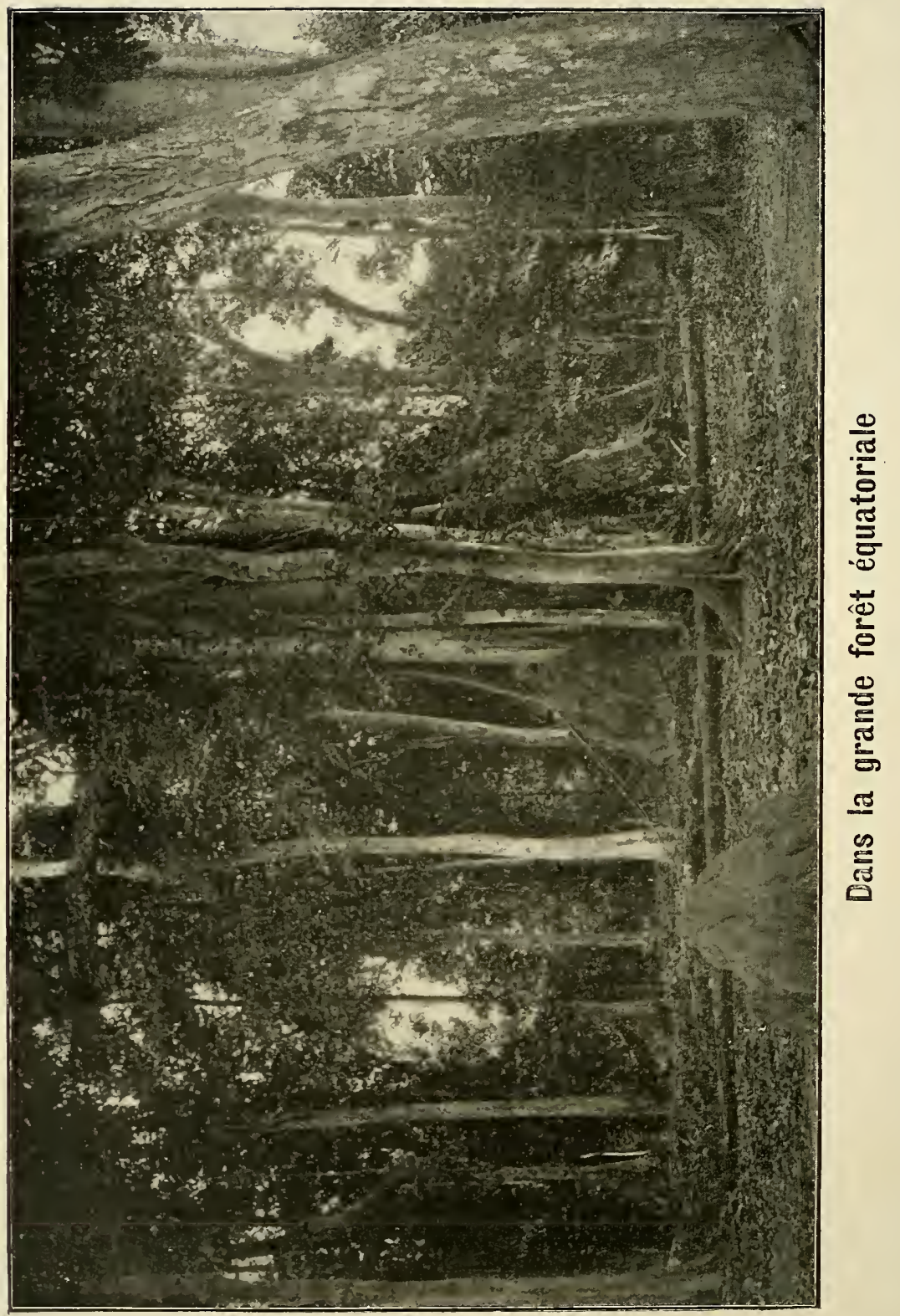


En deseendant, nous voyons le Palais du gouverneur, qui est assez joli, et est entouré d'un très beau pare.

En route, nous reneontrons un officier anglais qui se fait porter en hamae par quatre nègres. Les pauvres diables marchent tout le temps à une espèce de pas gymnastique assez raccourci et, chose eurieuse, au lieu de porter le bois du support sur les épaules, eomme cela se ferait chez nous, ils le portent sur la tète.

Nous rencontrons aussi des nègres et des négresses habillés de la façon la plus originale et l'on ne peut mieux les comparer qu'aux earieatures américaines exposées aux vitrines des magasins de cigares.

Les ladies affeetionnent surtout les chapeaux multieolores et à plumes, ainsi que les tournures gigantesques.

Quant aux gentlemen, j'en ai vu un en pantalon noir, gilet blane, redingote et gibus, mais les pieds nus ; il est vrai qu'il en avait d'énormes et qu'il n'avait peut-être pas trouvé de bottines à sa pointure.

Ce qui est aussi très earactéristique, c'est que tous ont une eanne à la main. Les nègres de Sierra-Léone peuvent au besoin se passer de chemise ou de souliers, mais pour rien au monde ils ne sortiraient sans leur stick, ils se croiraient déshonorés.

Vers le soir, nous rentrons à bord, fatigués, mais très contents de notre excursion.

Maintenant, en route pour Boma, où sauf imprévu, nous serons dans huit ou dix jours. 
Nous avons embarqué à Sierra-Léone trente-cinq nègres pour participer au service du bord, car il fait trop chaud pour faire effectuer ce service par notre équipage européen.

La mer est assez mauvaise et nous roulons et tanguons d'une façon très désagréable.

Deux jours après notre départ de Sierra-Léone, vers $7 \mathrm{~h} .1 / 2$ du soir, nous étions tous assis sur le pont à l'arrière du navire; le steward, un nommé Smith, apporte aux matelots leur seconde ration de rhum.

Brusquement, il revient vers nous en titubant, épanchant le rhum et s'accrochant aux bastingages. On se précipite vers lui et on le descend dans sa cabine, où le docteur lui reconnait les prodromes d'une attaque d'apoplexie. 11 est vrai que Smith est énorme et des plus sanguins; il derait s'attendre à un accident.

Il revient cependant à lui et, le voyant causer avec le docteur, nous remontons sur le pont.

Dix minutes après, le second steward vient parler bas au capitaine, qui, en passant devant nous, nous dit : "The chief steward is dead".

En effet, nous précipitant tous dans la cabine, nous ne trourons plus qu'un cadarre.

La face est un peu blenie, mais l'expression est calme, il n'a donc, probablement, que très peu souffert. Il est étendu sur le dos, le ventre ballonne la chemise, les jambes sont nues. 
Une décomposition rapide étant à craindre, le capitaine décide que l'immersion aura lieu dans la nuit.

L'orage commence à gronder comme si la nature voulait ajouter au tragique de la scène à laquelle nous allons assister.

Ainsi que dans les romans, la cérémonie se fera à minuit, à la lueur des éclairs. Quatre matelots apportent le corps et le déposent sur le pont.

Le bosman lui attache, arec des cordes fortement serrées autour des chevilles dans lesquelles elles tracent de profonds sillons, quatre morceaux de fer, afin qu'il s'enfonce plus vite dans la mer.

Le ventre oscille de bàbord à tribord, sous l'action du roulis, et prend des aspects lamentables sous le blanc de la chemise. Le chef d'équipage coud ensuite le cadavre dans une toile, pendant que les ofliciers du bord, les matelots et les passagers découverts font en commun la triste veillée du mort.

Les figures, insuffisamment éclairées par deux lanternes, sont blafardes. De temps à autre, des éclairs illuminent le navire et le roulement grave et profond du tonnerre, trouble lugubrement le silence de la nuit.

La toile étant cousue, le chef steward est placé sur deux planches mises en travers du pont, les pieds du cadavre sont contre les bastingages, la tête vers l'axe du bâtiment. 
Il suffit de soulever les planches du côté de la tête pour que le corps glisse à la mer.

En attendant, on le recouvre du drapeau anglais avec une lanterne à la tête et une aux pieds. Tout le monde s'éloigne, sauf un matelot qui veille, assis sur l'écoutille.

Nous nous asseyons à l'arrière avec le capitaine, tous, comme cela se comprend, péniblement impressionnés.

L’orage se rapprochant de plus en plus, la cérémonie funèbre, qui devait avoir lieu à minuit, est avancée.

Il est onze heures et demie.

Le navire stoppe et il règne à bord un silence absolu, interrompu seulement par le bruit des vagues, qui viennent battre les flancs du bateau et qui semblent lui réclamer leur proie.

Le capitaine se place devant le corps entouré de ses officiers, du médecin et du commissaire du bord, ce dernier est scandaleusement ivre! En arrière, les hommes de l'équipage et nous. Le capitaine lit lentement les prières des morts à la lueur d'une lanterne qu'un matelot tient au dessus du livre.

A ce moment, tombe une pluie diluvienne; l'orage atteint toute son intensité. Tout le monde se retire sous la tente de l'arrière, laissant le corps seul, inondé, comme foudroyé, par les éclairs qui se succèdent furieusement à de courts intervalles. Tout paraît s'acharner sur ce pauvre cadavre!! 
Le capitaine, reprenant alors sa prière, dit en anglais : "C'est pourquoi je confie ce corps à la mer."

Des matelots s'avancent sous l'averse qui fait rage, retirent le drapeau mortuaire et soulèvent les planches.

Le corps glisse rapidement, presque sans bruit, dans la vague, laissant après lui une trace phosphorescente. Mais tout à coup un cri d'horreur s'échappe de toutes les bouches.

Le corps qui, ai-je dit, est énorme, a été mal lesté et, véritable fantôme, il vient de nous apparaître au sommet d'une rague.

Grandi par l'optique, grandi par notre imagination frappée, il est immense. Tantôt nous le voyons couché sur une vague et comme bercé par elle, tantôt il nous apparait debout sur son sommet; balancé d'arrière en avant, il semble nous faire de profonds et macabres saluts.

Nous voudrions en détourner les yeux, mais la peur nous cloue sur place.Les yeux hagards et démesurément ouverts, les poings crispés, une sueur froide au front, nous le regardons malgré nous, tout en souhaitant de ne plus le voir.

Enfin, il disparaît brusquement. L'un de nous émet l'idée qu'il vient probablement d'être happé par un requin. La prière des morts continue alors dans le recueillement général, interrompue seulement de temps à autre par les hurlements d'une chienne. 
Le 25 décembre, quatre jours après la mort de Smith, nous passons sous l'Equateur, mais nous étions tous encore trop émus pour nous livrer à des manifestations de fête. Il n'y eut donc pas de baptême et la journée s’écoula plutòt tristement.

Le soir au diner, nous arons, suivant l'usage en Angleterre, de l'oie, dı dindon et du plumpudding; mais il n'y a pas d'entrain à lable, car la plupart d'entre nous, traversant l'espace par la pensée, se reportent un an en arrière et se revoient, a pareille date, entre têtes blanches ou tètes blondes, à qui ils distribment des baisers par donzaines; anssi si les ondes sympathiques ou magnétiques existent, plus d'un coeur en Belgique a dì se resserrer en mangeant le gâteau familial. 


\section{CHAPITRE IIÎ.}

En vue de Banane. - Triste impression. - Le brave Docteur Etienne.-Le genièvre au Congo,c'est la mort..... des microbes. - Petit «Boma » deviendra grand. - Merci, Meuleman! De ci, de là, cahin-caha. - Mort du Docteur Petit. - «Vous devez être très fort en artillerie $) !-L a I^{\text {ro }}$ batterie congolaise. - Chasses aux antilopes à coups de canon. - Mon dernier fait d'armes remarquable comme commandant d'artillerie.

Le climanche 30 , après vingt-huit jours de traversée, nous sommes en vue de Banane.

La voilà donc, cette terre du Congo, terre vers laquelle depuis si longtemps ont tendu toutes nos aspirations. Le voilà donc, ce minotaure, comme les journaux de l'époque ont l'habitude de le nommer.

Sera-t-elle pour nous une terre clémente? Sera-t-elle pour nous le monstre impitoyable qui, né sans coeur, fera pleurer nos mères?

Dieu, seul, pourrait nous répondre!

En attendant, nous sommes réduits à nos seules impressions. Elles furent plutôt tristes. Je me trouvais dans ma cabine quand on vint me dire que l'on était en vue de Banane.

Monté de suite sur le pont, j’éprouvai une amère déception. Après Las Palmas, si riant et si pittoresque, après Sierra-Léone, toute débordante de vie et d'animation, la mélancolique Banane, sur sa lagune de sable, 
au bord d'un fleuve boueux! Comme habitations, quelques maisons blanches paraissent jetćes au hasard sur un sol aride! Comme habitants, quelques blancs pâles, à l'air maladif. Comme végétation, quelques palmiers et le funèbre palétuvier.

Un petit frisson me secoue, mais je me garde bien de parler de mon impression aux camarades, redoutant trop de trouver la leur conforme à la mienne.

Enfin, le navire stoppe et un canot nous conduil à terre, oì, ayant quelques marchandises à décharger, nous pourrons rester jusqu'au lendemain. Aussitòt débarqués, nous allons présenter nos respects au commissaire de district, M. Sterpin, qui nous reçoit de la façon la plus aimable.

Mais quel n'est pas mon étonnement et ma joie en reconnaissant dans un promeneur le docteur Etienne, dont j’avais fait la connaissance à Gembloux. Jamais je n'oublierai son accueil si franc et si réconforlant.

Petit, trapu, la barbe longue en éventail, une petite calotte indigène sur le sommet de la tête et, derrière ses lunettes, un regard franc, loyal et bon; tel est le docteur Etienne. A se montrer ainsi, il représente bien l'athlète, le savant et l'apòtre dont la mission est toute de coeur et de dévouement.

A peine m'a-t-il aperçu qu'il s'avance vers moi les deux mains tendues, et me dit toute sa joie de me revoir. 


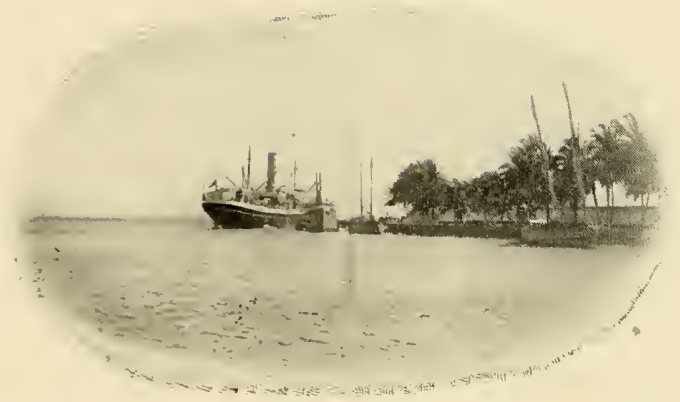

Navire contournant la pointe de Banane

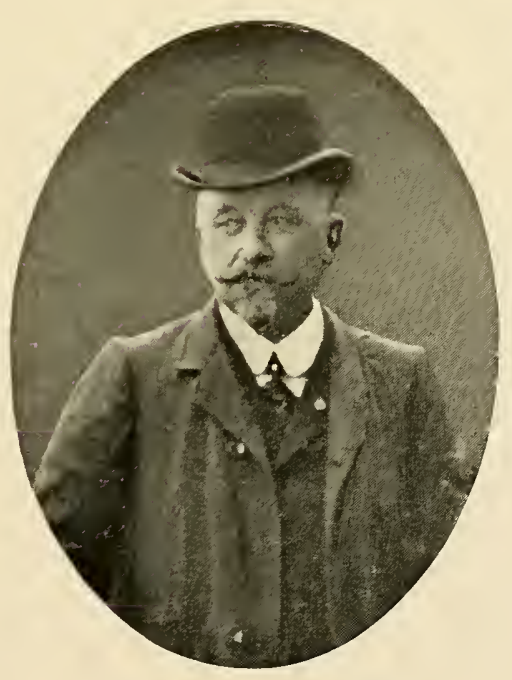

Docteur ETIENNE 


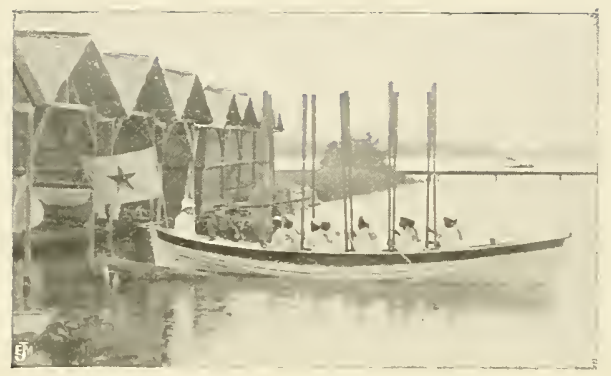

Canot du Commissaire maritime à Banane

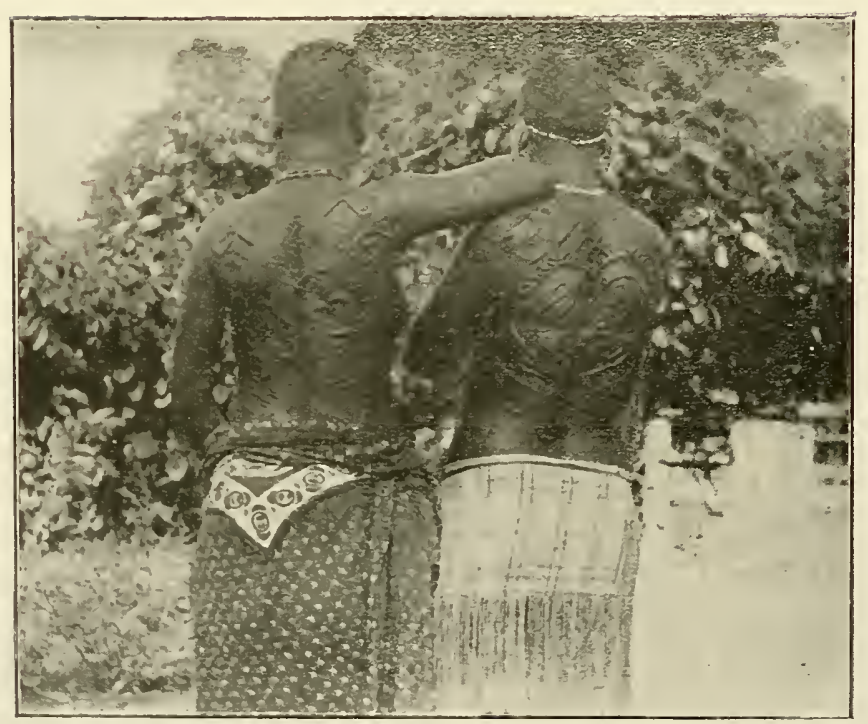

Tatouage des femmes dans le Mayombe 


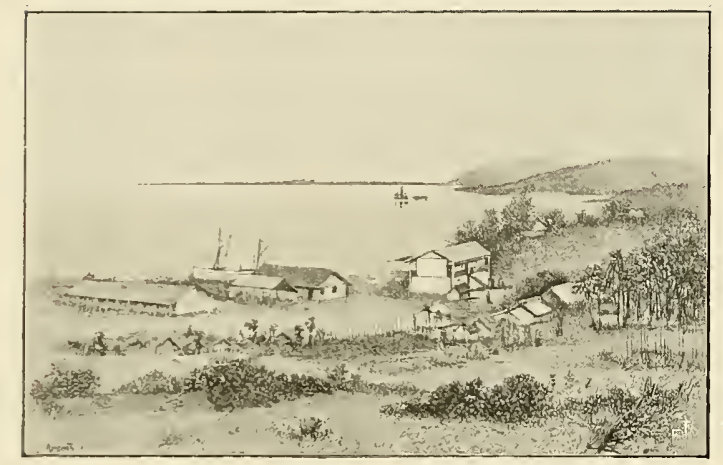

Vue de Boma en 1879

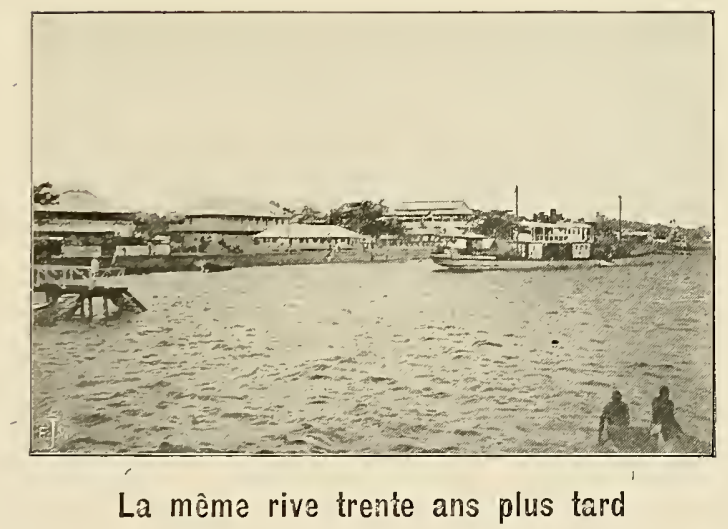




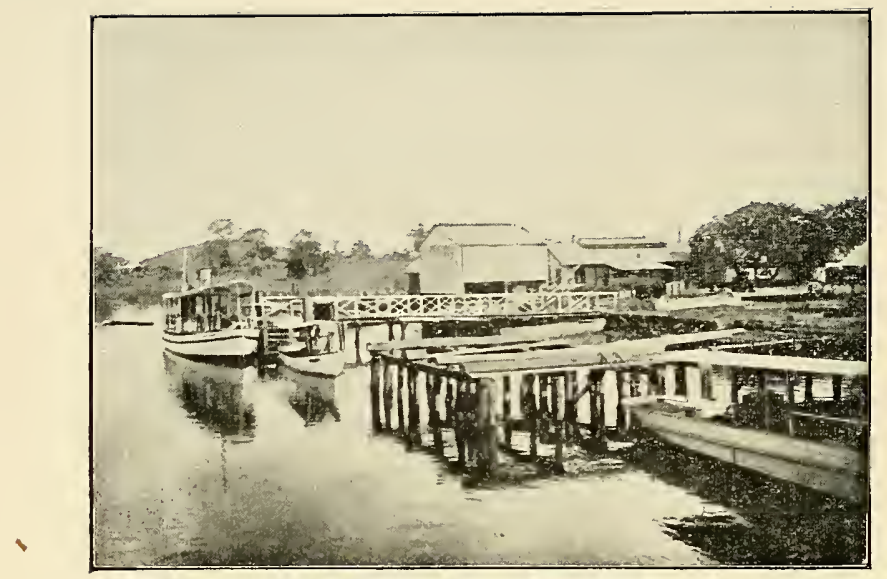

Rive de Boma en 1912

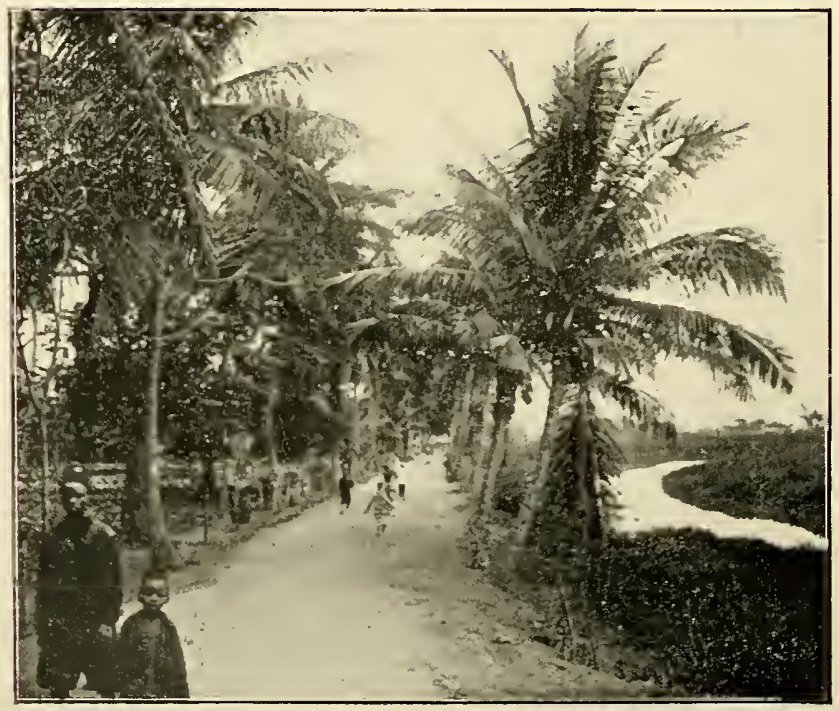

Avenue des cocotiers et rivière des crocodiles à Boma 
Après les premières étreintes, comme je lui parlais de la triste impression que la vue de Banane m'arait produite, il se mit à rire. " $A \mathrm{~h}$ ! oui, me dit-il, les malades ? Je vais t'expliquer. "

- Ici, vois-tu, c'est une station très tranquille, une station de second ordre et qui, maintenant depuis que les navires remontent à Boma et à Matadi, a perdu toute son importance au point de vue commercial; voilà le motif pour lequel cela t’a paru si triste. Seulement, comme il $\mathrm{y}$ fait très sain, à cause du voisinage de la mer, on y envoie tous les malades et tous les convalescents des autres stations, c'est pour cela que tu as vu tant de gens déprimés et amaigris.

Mais, me dit-il en riant, cela ne te concerne pas, c'est bon pour les chétifs, les malingres, ou ceux qui étaient déjà malades en quittant l'Europe : quand on a une constitution comme la tienne, on vit tout aussi bien ici, si ce n'est mieux, qu'en Belgique.

La nuit étant venue, mon brave docleur me réservait une surprise. Rentré avec lui dans ses appartements, il me sert.... un grand verre de Hasselt. Très surpris, je lui fis la remarque qu’à Bruxelles on m'avait dit, avant de partir : "surtout, jamais d'alcool, c'est la mort assurée, le suicide. $)$

- Oui, me dit-il, on dit tant de choses, mais crois-moi, si l'alcool est très dangereux pris pendant la chaleur du jour, ou en trop grande quantité, il est au contraire très 
bienfaisant pris le soir et raisonnablement, et quand tu auras l'occasion d'en prendre dans ces conditions, ne manque jamais de le faire.

J'ai suivi son conseil et m'en suis bien trouvé.

Le Iendemain matin, notre déchargement étant terminé, le coeur bien gros mais l'esprit réconforté, je pris congé de ce bon, de ce hrave docleur Etienne, non sans yn'il m'eut remis me lettre de recommandation pour son confrère el ami le docteur Ruyter, te Boma.

Partis d'assez bonne heure de Banane, nous comptions bien arriver dans l'après-midi à Boma, quand nous vinmes pitensement nous échouer sur le banc de Mateba.

Dans le moment, j’en fus profondément contrarié; aujourd'hui, j'en suis presque heureux, puisque ce petit accident me procura l'occasion de faire la connaissance d'un compatriote qui devint plus tard un bon camarade.

Comme l' "Ambriz " tâchait de se désensabler,j'obtins l'autorisation de me rendre à terre, ò̀ je rencontrai sur la berge un grand garçon, quelque peu efflanqué, vêtu d'un costume en coutil de traite, le bord du pantalon passé dans les chaussettes et chaussé de grandes bottines de chasse.

J'arais devant moi le futur et élégant directeur de la Belgica. Nous étions pays ; la connaissance fut vite faite et, dans la suite, j’ai toujours trouré dans Hallet, car c'était lui, un brave camarade. 
Mais, revenons à l' "Ambriz ). Le capitaine, après avoir constaté l'inutilité de ses tentatives pour se dégager, résolut d'envoyer son steam lunch à Boma pour demander du secours.

Conme mes bagages n'étaient pas encombrants, jobtins l'autorisation de partir sur ce petit bateau et e'est avec lui que je fis mon entrée à Boma.

Il n'y avait à celte époque qu'un bateau postal par mois ; or, nous arrivions avec plusieurs jours de retard et nous étions porteurs de tous les souhaits et de tous les voux du nouvel an. Je vous laisse à penser si l'on nous attendait arec impatience.

Il n'y avail dans le port de Boma que trois petits vapeurs faisant le service du fleuve et, comme tous étaient bien connus de la colonie, vous comprendrez facilement quel remue-ménage et quels potins, tant à Boma-Rive qu'à Boma-Plateau, quand, ayant contourné l'ìle de Mateba,nous apparûmes en face de Fétiche-Rock.

Aussi tous les habitants de Boma étaient-ils sur le pier pour nous recevoir. Aussitôt que nous fûmes à portée de la voix, nous les mimes en deux mots au courant de la situation et, pour calmer leur impatience, nous eûmes soin d'ajouter que nous étions porteurs du courrier.

La réception fut assez cordiale et mon impression première ne fut pas trop mauvaise.

Boma était tout petit, c'est vrai, mais, contrairement à Banane qui périclitait, on voyait que lui, qui venait 
de naître, réclamait sa place au soleil et sur la carte d'Afrique. Les maisons étaient encore peu nombreuses, mais elles élaient neuves, bien construites et disposées d'après un plan d'ensemble parfaitement conçu.

Les allées élaient à peine tracées, mais on voyait qu'on les voulait grandes, larges et ombrenses. Les marais étaient infects, mais on travaillait à les combler. Jardins et plantalions étaient presque nuls, mais autour de chaque maison, on bêchait, on plantait, on arrosait.

Somme toute, on sentait la volonté d'ètre, d'embellir, de parvenir et, dès cette époque, on pouvait déjà prévoir que, quelques années plus tard, l'Etat indépendant pourrait être fier à juste titre de sa jeune et coquette capitale.

Je ne me sonviens évidemment plus de tous ceux qui étaient là pour nous receroir, mais quelques-uns me sont encore très présents à la mémoire, tels que: le major Cambier, qui faisait fonction de gouverneur ; MM. Rezette, Delcommune, Van den Plas, Fievet et mon concitoyen le vétérinaire Neuleman ; celui-ci, haut de six pieds et pas mal de pouces, sortait de maladie et était maigre comme un hareng; en le regardant marcher, je me demandais en le voyant si long, comment il faisait pour garder son équilibre.

Mais assez de plaisanterie, je lui dois trop pour parler de lui autrement qu'au sérieux. Il fut en quelque sorte mon parrain en Afrique. A peine débarqué, il me trouva 
une chambre qu'il fit menbler d'un lit, d'une table et d'une chaise, il me procura un boy et me donna tous les renseignements dont j'avais besoin.

Gràce à lui, j'avais quelqu'un chez qui je pouvais me renseigner, el avec qui, à l'occasion, je pouvais causer du clocher. Il y a dix-sept ans de cela, mais le souvenir de cet accucil est cucore bien vivace dans ma mémoire et c'est encore de tout coeur que je dis: Meuleman, merci de ce que tu as fait pour moi lors de mon arrivée à Boma.

Trop peu, hélas ! initent cet exemple, et l'indilférence avec laquelle sont reçus, la plupart du temps, les nouveaux arrivants a dì causer bien des déceptions et provoquer bien des découragements.

C'est cependant si peu de chose pour ceux qui sont sur les lieux d'accorder quelques attentions, de donner quelques indications, quelques témoignages d'intérêt oll d'amitié à ccux qui arrivent et sont tout à fait dépaysés, parfois malades, démoralisés nıème; car, une bonne parole relève un courage qui chancelle, un peu d'amitié vous réconforte, un bon renseignement peut vous éviter des faules ou des erreurs qui,commises, vous auraient cloné pour des jours, des semaines et peut-ètre pour toujours sur volre lit de douleur, car ne l'oublions pas, ici la liève voils guette et profite de toutes vos imprudences pour vous saisir et vous terrasser. 
Le lendemain de mon arrivée à Bona, mes camarades débarquaient aussi du Héron qui avait été les chercher à bord de l' "Ambriz ", et, tous ensemble, nous nous rendìmes chez le major Cambier, qui, comme je l'ai dit, faisait fonction de gouverneur, ce dernier, M. Janssens, étant en tournée d'inspection dans le haut Congo.

Cette visite termịnée, MM. Golfin, Paulissen, Poncelet et Finsch se rendirent à leur poste respectif, tandis que Vander Linden et Bureau reçurent l'ordre de se mettre à la disposition du commandant de la force publique, le commandant Fiévet, pour servir d'instructeur aux nombreuses recrues qui se trouvaient au camp de Boma.

Quant à moi, on crut ne pouroir mieux utiliser mes aptitudes d'olficier de cavalerie qu'en me donnant le commandement et la haute surveillance de dix-sept mules et baudets qui formaient toute la cavalerie de Boma.

C'était charmant, d'autant plus que cela me laissait de nombreuses heures disponibles dont je profitais pour aller, avec mon brave Pitch, battre la bronsse des environs à la recherche de la faune congolaise.

C'était trop bean et je voyais le Congo d'un trop bon oil, cela ne pourait pas continuer.

Le surlendemain de mon arrivée, je me rendis dès le matin chez le docteur Ruyter afin de lui présenter mes respects et lui remettre la lettre du docteur Etienne. Il me reçut très bien et, ayant appris par moi que je 
pourais disposer de ma matinée, il me proposa de l'accompagner dans ses visites aux malades. J'acceptai de tout cour. Il avait un àne, j'eus vite fait d'en faire seller un et, de-ci de-là, cahin-caha, tels les héros de "Véronique ", nous voilà trottinant dans Boma.

Nos risites étaient à peu près terminées lorsque nous arrivons à l'hòpital militaire des soldats noirs; le docteur s'adressant au sergent-major qui faisait l'office de directeur lui demande :

- Quoi de neuf, major?

- Oh ! rien de bien particulier, docteur, denx soldats sont morts pendant la nuit, et je les ai fail transporter à l’amphithéàtre.

- C'est bien, allons les voir.

A peine suis-je sur le seuil de la porte, que je recule épouvanté. Les deux cadavres sont là ; mais, à la place des yeux, il n'y a plus que deux trous béants et sanguinolents, le nez et les lèvres ont disparu et les dents blanches semblent nons nargner dans un horrible rictus.

Le docteur a aperçu mon mouvement de recul et, assurément, il en a deviné la cause, car, se tournant vers moi le plns tranquillement du monde, il me dit :

- Ce n'eśt rien; ici nous sommes littéralement " mangés par les rats ", et les cadavres aussi, comme til le vois.

Brrr ! j'en ai encore des frissons. Ce diable de docteur, il vous avait une façon si calme de vous parler de ces 
choses, qu'il vous en faisait venir des picotements à la peau.

En sortant de l'hòpital, nous allàmes voir le docteur Petit. Le docteur Petit, arrivé depuis un mois à peine, gardait le lit depuis trois jours; il nous reçut très gentiment, mais nous restàmes très peu pour ne pas le fatigner : ceci se passait ver's 9 heures du matin. A midi, nous étions tous réunis sous la vérauda du mess, où nous prenious l'apéritif en attendant le dìner et l'on me plaisantait un peu sur les rats, quand tout à coup un boy arrive en courant et s'adresse bas au docteur. Celui-ci se lève précipitamment et prend sa course vers la chambre occupée par Petit; poussé par la curiosité, je le suis et, quand nous arrivons dans la chambre, nous ne trouvons plus qu'un cadavre!

Je ne sais pas ce que vous auriez fait à ma place, mais pour mon compte, je vous jure bien que ce jour-là je n'ai pas dìné. Je ne dirai pas que j’ai eu peur, ni que j’ai èté découragé, pas plus que je n’ai pensé à partir, c'enit été me rendre ridicule, mais, ce qui est certain, c'est que si j’avais encore été en Belgique en ce moment-là et sachant ce que je savais, je crois que j’aurais réfléchi à deux fois avant de partir au Congo.

Eufin, tout passe, tout s'oublie et au Congo plus vite que partout ailleurs; deux jours ne s'étaient pas écoulés que j'avais oublié et Petit et les rats ou, du moins, si j'y pensais encore parfois, ce n'était plus que de la façon dont on pense à un mauvais rêve. 


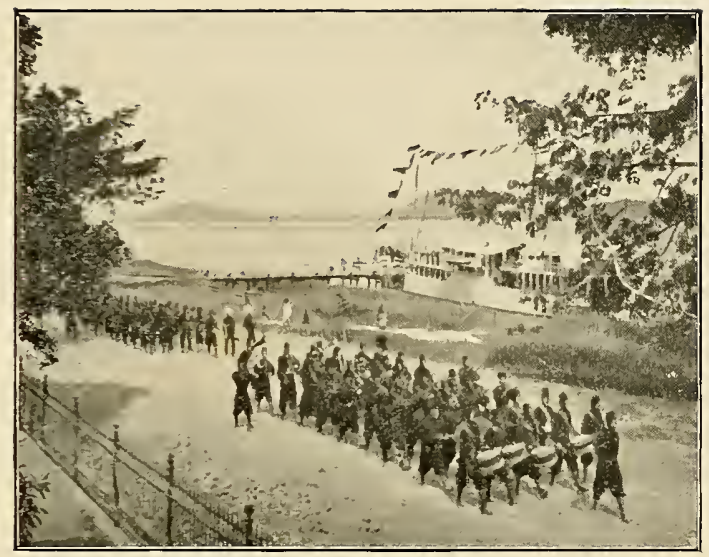

Défilé de la Force publique à Boma

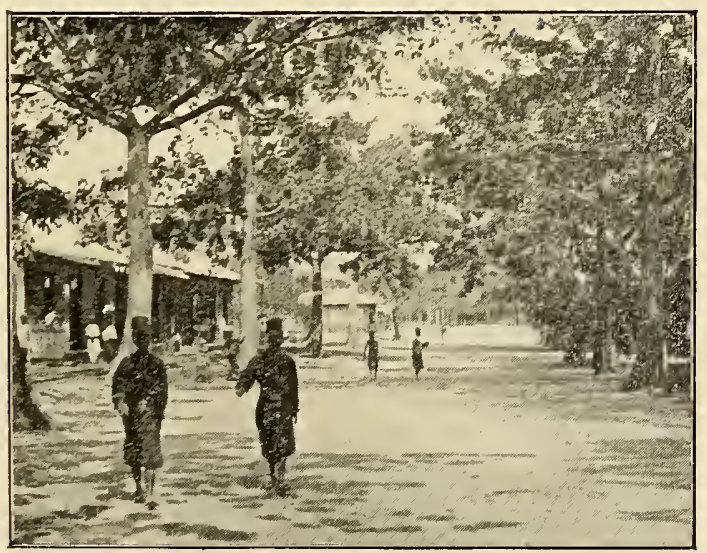

L'avenue Royale à Boma 


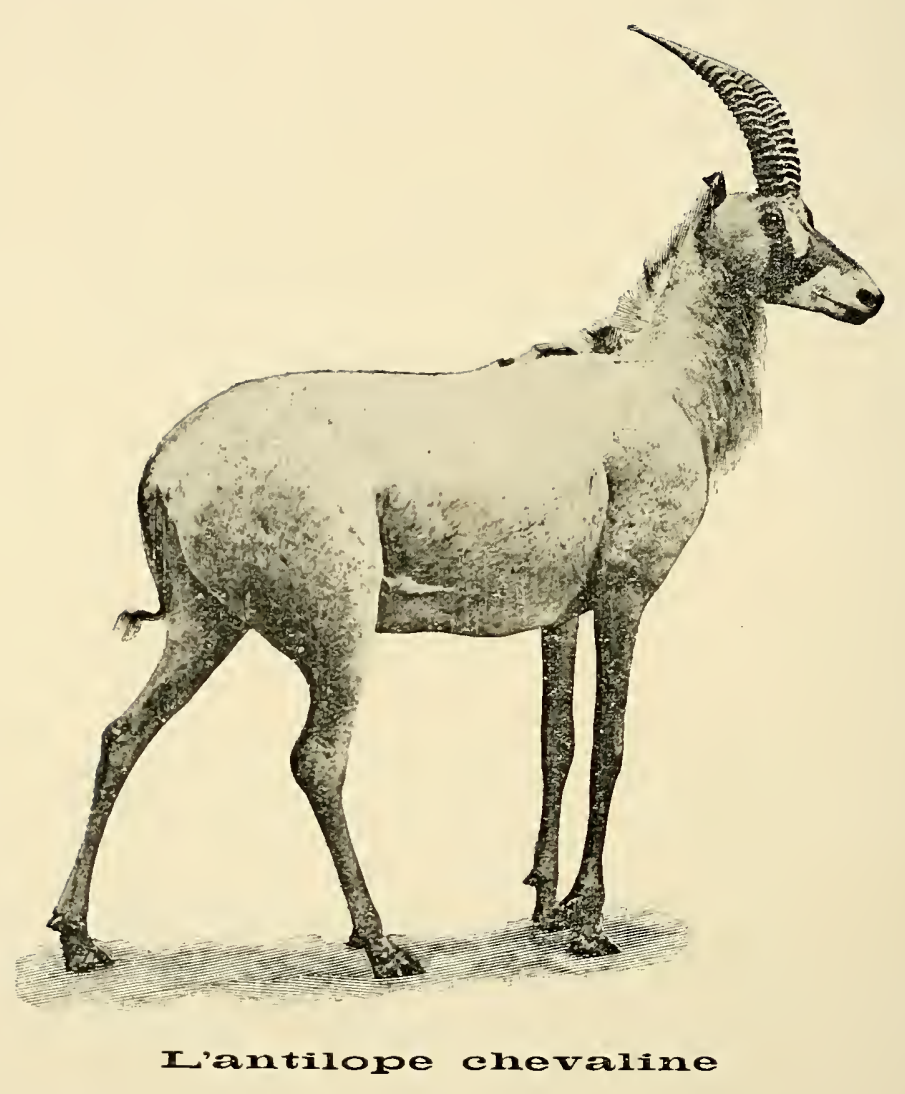


Na préoccupation du jour c'était la chasse et, comme j'avais des loisirs, je m'en donnais tant et plus; je l'ai dit plus haut, je trouvais celte existeuce cliarmante, ne me doutant pas que celte félicité dìt ètre de si courte durée. Je vivais là comme daus un rève, quand, un beau jour, le major Cambier une rappela à la réalité au moyen d'un petit pli caclıeté, me priant de me présenter le lendemain à son rapport.

En m’y rendant, j'avais une vague appréhension. Je pressentais cu'il allait m'arriver quelque chose qui sortait de l'ordinaire.

Le major élait assis à sa table de travail. J'entre, je le salue, il me fait signe de m'asseoir :

- Michaux, me dil-il, je vois dans vos notes que rous avez passé deux ans à l'école d'équitation d'Ypres ; si rous avez bien éludié vos cours, comme je le suppose, vous devez ètre très fort en artillerie. Ici nous avons une batterie de canons krupp, mais nous n'avons pas d'artilleur's. Comme je n'ai pas d'oflicier d'artillerie sous la main, vous allez me faire le plaisir de vous occuper de la chose. Je mets pour ccla à votre disposition le maréchal-des-logis Bakelnan et vous pourrez choisir parmi les soldats de Boma soixante hommes intelligents. Surtout, faites vite et faites bien. C'est tout ce que j'ai à vous dire. Je vous remercie.

Tout cela avait été dit d'un seul trait et sans me donner le temps de placer un mot. De plus, je savais 
le major un excellent homme au fond, mais très tenace lorsqu'il avait décidé quelque chose.

Puis le coup avait été si imprévu que j'en étais encore tout étourdi, aussi l'idée ne me vint même pas de répondre quelque chose; en sortant de chez le major, je me trouvais un peu dans la situation d'un homme? ivre qui recevrait lout-à-coup une douche et qui ne saurait pas bien de quel còté elle lui vient.

Tout ce que je voyais de plus clair, c'est que je devais faire quelque chose et que je ne savais par où commencer ; que j'aurais dù ètre très fort en artillerie, comme me l'avait dit le major et que je ne m'en rappelais pas grand'chose, ayant bien souvent passé moı temps à faire des farces phutòt que d'écouter les leçons.

Enfin, un véritable elfondrement.

Rentré chez moi, les idées me revinrent peu à peu et je me dis que probablement Bakelman pourrait me tirer d'afiaire puisqu'il était maréchal-des-logis d'artillerie. Je le fis done chercher et bientòt il m'apparut. Encore un peu plus graud que Meuleman, mais le double plus gros, Bakelman me parut taillé pour porter toute la batterie à lui seul.

Sa bonne figure et son regard si franc me plurent de suite el, après cinq minutes de conversation, je fus convaincu que je trouverais en lui un aide précieux et un homme de cour. Il avait été instructeur dans son 
régiment; ma besogne devenait donc singulièrement facile et mème agréable.

Cet après-midi mème, nous recrutions nos hommes et dès le lendemain matin nous leur apprenions l'exercice du canon, leur instruclion militaire étant déjà terminée. C'est ainsi que je devins le premier commandant en chef de l'artillerie de l'Elat indépendant du Congo. Nos canons étaient du système lírupp, de 7,5 raccourci. Le canon proprement dit pesait 101 kilogrammes et l'a flùt, sans les roues, 111 kilogrammes.

Gràce à un système de doubles crochets que nous avions trouvé avec Bakclman et que le brave Sneyers, l'homme indispensable de Boma, nous avait fabricué, nous étions arrivés à faire démonter nos canons età les faire charger à dos d'hommes en une minute et demic. Dans le mème laps de temps les canons étaient remontés et placés en batterie.

Pour moi, c'était très intéressant, amusant mème et, en peu de lemps, j'avais pris la chose tellement au sérieux et tellement à coeur que je crois que si celı avait encore duré quelrues mois je me serais persuadé à moi-mème que j'étais réellement un officier d'artillerie des plus distingués.

Ici, je suis obligé d'ouvrir une parenthèse pour vous expliçuer pourquoi le major Cambier avait éprouvé tout-à-coup le besoin d'avoir, une batterie d'artillerie. A cette époque (commencement de janvier 1890), une 
puissance voisine, avec laquelle l'Etat du Congo se trouve maintenant dans les meilleurs termes d'amitié, se croyait lésée par l'Etat, lui faisait grise mine, et, en fin de compte, arait envoyé une canonnière en face de Boma. Or, celle-ci avait poussé le sans-gène jusqu’à siffler presque toute une nuit.

On n'élait pas tranquille à celte époque à Boma. Et voilà pourquoi, à toute éventualité, le major Cambier voulait une batterie coûte que coûte et rapidement.

Ceci dit, je suis naturellement appelé à vous conter denx pelits incidents de ma vie comme commandant de la batterie.

Après six semaines d'exercice, l'inspecteur était venu voir ma batterie an tir et avait bien voulu me féliciter sur les résullats obtenus. Seulement, une chose me chagrinait et me trottait en tète, je n'avais pas de roulcau mobile, donc pas moyeu d'apprendre aux hommes à tirer sur un but mouvant.

J'a vais parlé de la chose à plusieurs de mes camarades et leur avais dit mon ennui à ce sujet, quand, un midi, vers l'heure de l'apéritif, au moment où nous élions tous réunis sur la terrasse du mess, un troupeau d'antilopes vint se promener sur une moulagne en face de nous.

L'occasion était trop belle et la tentation trop forte. J'avais mon but mobile.

- Trompettes, sonnez le rassemblement de la batterie au pas gymnastique. 
Trois ou quatre minutes après, j'eus la satisfaction de voir arriver ma batterie au grand complet arec armes et bagaiges.

En moins de deux minutes, les pièces étaient montées, chargées et pointées et le feu commençait à la plus grande épourante des antilopes, qui furent littéralement coivertes de pierrailles et de terre et, bien entendu, au plus grand plaisir des camarades qui assistaient à cette chasse, d’un genre nouveau et tout à fait inédit.

Mais toul n'étail pas fini : cette camomnade en plein midi avail révolulionné loul Boma, qui n’était pas habitué à se trouver à pareille fète et l'inspecteur, tout comme les autres, s'en lrouvant intrigué, avait envoyé aux reoseignements.

Evidemment, on les lui donna avec beaucoup d'exagération et d'embellissement.

Il me fit donc appeler pour me demander des explications, que je lni fournis d'ailleurs sur le champ, tout en protestant de mes bounes intentions. Il fit semblant de me croire, mais me collseilla, pour mes futurs exercices de tir, de choisir un champ un peu plus éloigné du centre de la ville.

Je fus absolument de son avis "Merci, mon major ".

A quelque temps de là, le commandant Fiévet, le lieutenant de Bergh et deux autres officiers dont les noms m'échappent malheureusement, devaient quitter Boma pour aller avec une centaine d'hommes punir 
quelques villages pour un méfait dont je n'ai plus souvenance.

La veille, le commandant, en donnant ses ordres, avait dit devant moi que l'on partirait à 6 heures du matin et avait également indiqué la route que derrait suivre la colonne.

J'avais une revanche à prendre, car tous les jours le commandant me demandait encore en plaisantant des nouvelles de mes antilopes.

Je vais done trouver Bakelman en lui recommandant le secrel, je l'avertis d'avoir à tenir la batterie prête à partir pour 5 heures du matin. Je lui dis aussi de n'emporter que quatre canons et quatre gargousses, une par pièce.

Le lendemain, à l'heure dite, nous étions en route. J'avais, de plus, emporté deux bouteilles de champagne, six verres et un grand drapeau congolais.

Après une bonne heure de marche, ayant trouvé un emplacement favorable à mes projets, je fais arrêter ma troupe sur la crète d'une colline et après avoir dissimulé soigueusement mes quatre canons tous braqués sur l'étroit sentier venant de Boma et fait concher mes hommes dans les herbes, je me cache moi-même avec Bakelman.

La consigne de mes hommes était celle-ci : après la seconde salve se lever tous, y compris celui qui avait le drapeau, et crier hourra! 
Tontes ces dispositions prises, nous attendons les événements.Bientòt la colonne apparait; quatre clairons sont en tète et jonent de joyeuses fanfares, puis viennent le commandant Fiévet et de Bergh,qui causent ensemble, enfin, la colonne suit. Je les laisse approcher à 70 ou 80 mètres, puis je fais 11 signe à la première section et deux coups de canons partent ensemble.

Du coup, les clairons se taisent, la dernière note mème leur restant dans la gorge et la colonne s'arrête comme pétrifiée. Je fais un autre signe et ma seconde section leur envoie une bordée aussi magistrale que la première.

Les soldats se croient tombés dans une embuscade et filent dans les herbes avec un ensemble admirable.

A ce moment, mon drapeau et mes hommes se lèveut, hurlant leur plus formidable hourra, tandis que, prenant mon sourire le plus ingénu, je m’avance avec Bakelman, chacun une bouteille de champagne à la main, vers le commandant Fieret.

- Commandant, lui dis-je en faisant sauter un bouchon, comme je sarais que vous partiez en expédition, j’ai voulu vous faire une petite surprise, vous faire les homneurs de ma batterie et ètre le dernier à vous souhaiter bon voyage et bon succès tout en vous offrant un verre de champagne.

- Bien oui, fieu, c'est très bien, me dit le commandant d'un air assez maussade, mais regarde-moi un peu ces 
imbéciles-là fuyant dans les herbes, va donc en guerre avec des lapins semblables. Dans tous les cas, je te remercie de ta bonne intention, mais une autre fois, quand tu auras encore l'idée de me faire une surprise de ce genre-ci, préviens-moi quand même la veille.

Le commandant et ses officiers ayant a'ors remis leur colonne en ordre, nous nous quiltimes apros nise bonne poignée de mains.

C'est égal, on était gai à la batterie en retournant à Boma !

Ce fut mon dernier fait d'armes remarquable comme commandant d'artillerie. 


\section{CHAPITRE IV.}

Première chasse à l'hippopotame. - Je joue avec la fièvre, elle me terrasse. - Avocat d'ofiice : acquittement de mon royal client. - Départ̂ pour le Haut-Congo. - Matadi. - Le chemin de fer, cuvre de Titars. - Sur la route des caravanes. Rencontre avec le Gouverneur général à Lukongu. - Une mule anti-protocolaire. - Les boys n'en font jamais d'autres. Prédiction fatale. - Je reçois ma destination définitive pour Lusambo.

Cependant, deux événements marquèrent encore cette période de mon séjour en Afrique. J'eus ma première et ma plus sérieuse fièvre au Congo et je gagnai comme avocat mon premier et probablement dernier procès, au cours duquel je fus assez heureux pour faire acquitter un chef qui arait été condamné à mort.

Pour tranquilliser également ceux de mes amis qui pourraient avoir des inquiétudes sur le sort de mes malles, je dois leur dire qu'elles m'avaient rejoint et au complet.

Je me trouvais donc aussi heureux qu'il est permis de l'être, lorsqu'on est loin des siens.Pendant la semaine, je faisais tirer le canon et le dimanche j'allais tirer le perdreau et la pintade, voire même l'antilope et l'hippopotame. Un samedi soir, j'avais donné l'ordre à trente de mes artilleurs, tous excellents pagayeurs, de se tenir prêts pour le lendemain matin à 4 heures, 
afin d'aller surprendre les hippopotames au petit jour, dans une crique que je connaissais bien.

A l'heure dite, je m'embarcue dans ma pirogue avec mon express et mon inséparable Pitch.

Tous mes hommes sont ì leur poste et me saluent d'un bon : M' Botì m'fumn. Je sens que leur M'Botè est plein de sympathie; il me rend très heureux et bien fier, aussi n'est-ce pas seulement des lévres, mais du coeur, que je leur rends lemr M'Botè.

Je m'assieds à l'avaul sur un banc ad hoc, mon express snl les genoux. Pitch debout devant moi, les deux patles sur le bord de la pirogue semble lui aussi guetler l'hippopolame.

Nous lilous comme un trait dans une demi-obscurité ; c'est charmant dans le mystérieux silence de la muit.

J'élais bicu henreux! et comme toutes mes pensées s'envolent tonjours vers certaine lerme du pays brabançon, je me disais: "Si maman me royait maintenant, seul, la nuit, au milieu de 30 anthropophages (car mes pagnyeurs sont des Bangala) en l'ain de chasser l'hippopolame, elle anrait bien peur." l’un autre colc j’ajoulais: "Si papa pouvait me voir, c'est lui qui serait jaloux, lui qui doit trotter toute une journée et se crotter jusquaux cuisses pour tuer un lièvre ou quelques perdreaux » et je riais de noureau car tout me paraissait charmant ce jour-là, la vie elle-mème me semblait aimable et légère. 
Vers 6 heures, nous étions à la place que j'avais ehoisie ; le jour naissait. Pendant quelques minutes, les pagayes sont levées et le plus profond silence règne à bord de la pirogue, qui semble endormie sur les eaux.

De tous nos yeux, nous serutons l'espaee quand, tout-à-coup, un de mes noirs montre du doigt quelque ehose qu'il eroit ètre des hippopolames; je suis des yeux la direetion indiquée, mais je ne vois rien; eependant je fais un signe pour que la pirogue s'en rapproche lentement. Muni de mes jumelles, je fouille l'horizon dans cetle direetion el,après quelques minutes, je rois apparaitre pendant quelques seeondes, puis disparaître pour reparaître de nouveau de grosses têtes à environ trois eents mètres de nons.

Nous y rolons, mais sans bruil.Chacun de nous retient sa respiration. Quant à moi, j'entends les battements de mon crirtr lant je suis ému. Pensez done, c'est non premier hippopolame : il s'agil de ne pas le manquer!

A dix mètres de nous, une grosse tête hébétée vient de se montrer hors de l'eau. Je vise au milieu du frout; ma balle a porté juste. La bète se cabre comme pour se jeler sur nous, je lui enroie ma seconde balle au eour et celte masse, désormais inerte, s'eflondre pour disparaitre sous les caux.

Mes noirs sont fous! ils rient, ils erient, ils dansent, ils s'embrassent, ils hurlent, enfin il faut avoir vu cela pour s'en faire une idée. 
Les nègres adorent la viande d'hippo, et ils savent que celui que je viens de tirer est pour eux : je le leur ai promis. Seulement, l'hippopotame mort, il faut attendre de quatre à six heures avant qu’il flotte sur l'eau.

Nous santons done sur une petite lle et nous allendons qu’il reparaisse. Nalheurensement, celle île n'élait qu'un marais el te soleil s'élant mis de la partie il s'en dégageail des émanalions les plus putrides et les plus dangerenses. J'étais novice, plein de force, de santé et de vigneur, je ne me méfiais donc de rien. J'ens bientòt l'occasion de m'en repentir.

J'élais à peine depuis denx heures sur l'île, quand je fus pris de maux de tite alroces et de nausées insupportables. J'avais joué avec la fièvre, je m'étais moqué d'elle, je l'avais déliée, narguée; elle prenait sa revanche!

Jappelle immédiatenent mes hommes et je leur dis qu'étant malade je désire, de suite, retourner à Boma.

Pour eux, c'était une grossé perte car, indépendamment d'un bon repas, ils perdaient de beaux bénéfices. Ils n'en firent pas moins voler ma pirogue, et une heure après nous étions rentrés à Boma.

Ceci tne fut donc une première preuve, que le nègre a du cåur, de la reconnaissance el qu'il est capable de tous les déronements lorsqu'il est bien traité.

Aussitòt rentré chez moi je me couchai et je fis appeler le docteur Ruyter. 
Il était temps: peu après, le docteur constata que j’arais 42 degrés de fièrre. 11 me soigna, je dois le reconnaitre, arec un dérouement parfait, venant me roir quatre à cinq fois par jour, el si je suis tonjours debout c'est à lui que je le dois.

Je dus garder le lit pendant quinze jonrs et mon cas fut, parait-il, si grave, que lorsque mes amis rencontraient le doctenr ils ne lui demandaient pas comment j’allais, mais bien si je vivais encore.

Enfin, gràce à la Providence, aux bous soins du docteur et à ma robuste coustitution, j’en échappai.

Mais quels tristes sourenirs! quel horrible cauchemar qu'une pareille maladie, à mille lienes des siens, privé de toutes caresses, de foutes consolations, de tous les soins, des èlres chéris qui vous ont élevé, choyé, dorloté.

Pendant le delire, on n'a conscience de rien et l'on se tronve, si je puis m'exprimer ainsi, dans une siluation pręsque privilégiée. Mais lorsque la raison revient el avec elle les pensées et les souvenirs, rien ne peut rendre Ja désolation de se trouver seul dans une chambre nue, a vec un petit boy noir dont on a peine de se faire comprendre.

La prentière impression est une sensation de stupeur profonde, on ne comprend pas, on se demande comment lon se trouve là. Mais bientôt les souvenirs arrivent en foule et l'on ne se souvient que trop, hélas!

Puis l'on veut faire un mouvement pour prendre un objet quelconque, la force n'y est plus, vos membres 
brisés par la terrible fièvre vous refusent tout service. Oh ! ce moment est terrible et en a dù tuer beaucoup. qui n’ont pas eu la foree de réağirir ; car malgré soi on pense à l'homme fort que l'on élait, et se voyant si récluit et si sent, il fant beaneoup de volonté pour avoir le courage de vivre.

Quant à moi, j’éprouvais, je l'avoue, m véritable sentiment de désespoir,mais bientòl reprenant le dessus, j'eusse volouliers crié : "Mais je ne veux pas mourir, moi! " Oui, ce qui ne paraissait surlont impossible, c'élait de nonrir, comme cela, (n arrivant, sans avoir rien vu, rien fait ! C'élail trop idiol, je ne le voulais pas. Je erois que celle volonté ferme de guérir fut, en efret, pour quelque chose dans mon rélablissentent, ear trois ou fualre jours apres avoir quille le lit, j'entrais en pleine convalescence el bientòl je ne conservais plus de ma lièrre que le jusle souvenir qu’il fallait pour mon défier et prendre mes préeaulions pour l'avenir.

Ma maladie finie, le gonvernenr ayant remarqué que j’arais peul-c̀lre des disposilions pour la chicane et le bavardage résolut d'essayer mes lalents oratoires et sans plus me demander mon aris que dans l'aflaire des canons, il me fit nommer avoeat d'offiee d'un pauve diable de roi nègre nommé "Nefukn " qui avait été eondammé à morl, pour avoir fail prendre la caze (1) à deux de ses sujels, el qui était venu en appel à Boma.

(1) Poison violent que les rois nègres font prendre à ceux de leurs sujets qu'ils soupsonnent d'un crime. 
Non nouveau titre d'arocal faisait beaucoup rire mes camarades, qui me disaient en plaisantant, que je ponrrais pérorer tant que je voudrais, que je ne saurais quand mème pas empècher mon client d’occasion d'ètre pendu.

Anssi, un peu, j'aime à le croire, par compassion el beaucoup, je dois l'avouer, à cause des plaisanteries des camarades je pris la chose au sérieux et je me mis à bloquer et le fait et le droit.

Aussi, le jour où celte alfaire devail se plaider, y a vait-il foule au Palais de Justice, on peut dire que tout Boma s'y trouvait; mes cama rades étaient intrigués de savoir ee que je pourrais bien dire pour défendre mon royal client, d'antant plus que j'avais refinsé obstinément de leur donner le moindre renseignement à cet égard.

Tout ce que l'on savait, e'est que, usant de mon pouvoir de défenseur, j’avais éxigé du gonvernement qu’il convoruàt tous les chefs du bas Congo.

Mon plaidoyer ue fut pas l,ien long: m’arlressant aux membres dłu jury, je leur demandai si, en àme et conscience, ils croyaient que lorsque le législatemr a vait écrit : "Nul n'est censé ignorer la loi " il s'adressait alors aux peuples civilisés ou à de pauvres sauvages qui, en fáil de lois, connaissaient les us et coutumes de leur pays. Je leur demandai done s'ils croyaient que' mème en y mettant de la bonne volouté, il étail possible 
à mon client de connaître toutes les lois qui nous régissent.

M'adressant ensuite au procureur d'Etat, je le priai de m’indiquer les mesures qui avaient été prises dans le district, pour faire connaître les lois aux indigènes.

Enfin, je leur demandai à tous s'ils estimaient que dans une contrée absolument sauvage on pouvait en quelques années implanter une civilisation de dix siècles et y détruire par 111 simple arrèté les superstitions et le pouvoir des félicheurs, alors que chez nons, après nille ans de civilisation, nous a vons encore des paysans qui croient aux sorciers el au mauvais oeil.

Je leur prouvai que dans toute cette histoire, le féticheur seul était compable, que c'était lni qui avait conseillé de faire prendre et avait préparé la caze.

Je demandai que l'on questionnàt séparément tons les chefs que j'arais couvoqués, pour savoir si "Néfuku " avait agi suivant les coutumes du pays et si enx connaissaient les lois dı blanc sur cette matière.

Tous furent unanimes à répondre qu'ils auraient fait comme "Néfuku ", ne connaissant pas d'autres lois.

La bonne foi de mon client était donc évidnute et je réclanai son acpuittement el sa uise en liberté immédiale avec tous les frais à charge de l'Etat. Je fus assez heureux pour faire adopter loules mes conclusions et c'est encore avec une réelle satisfaclion que je donne ci-joint la copie du jugement : 


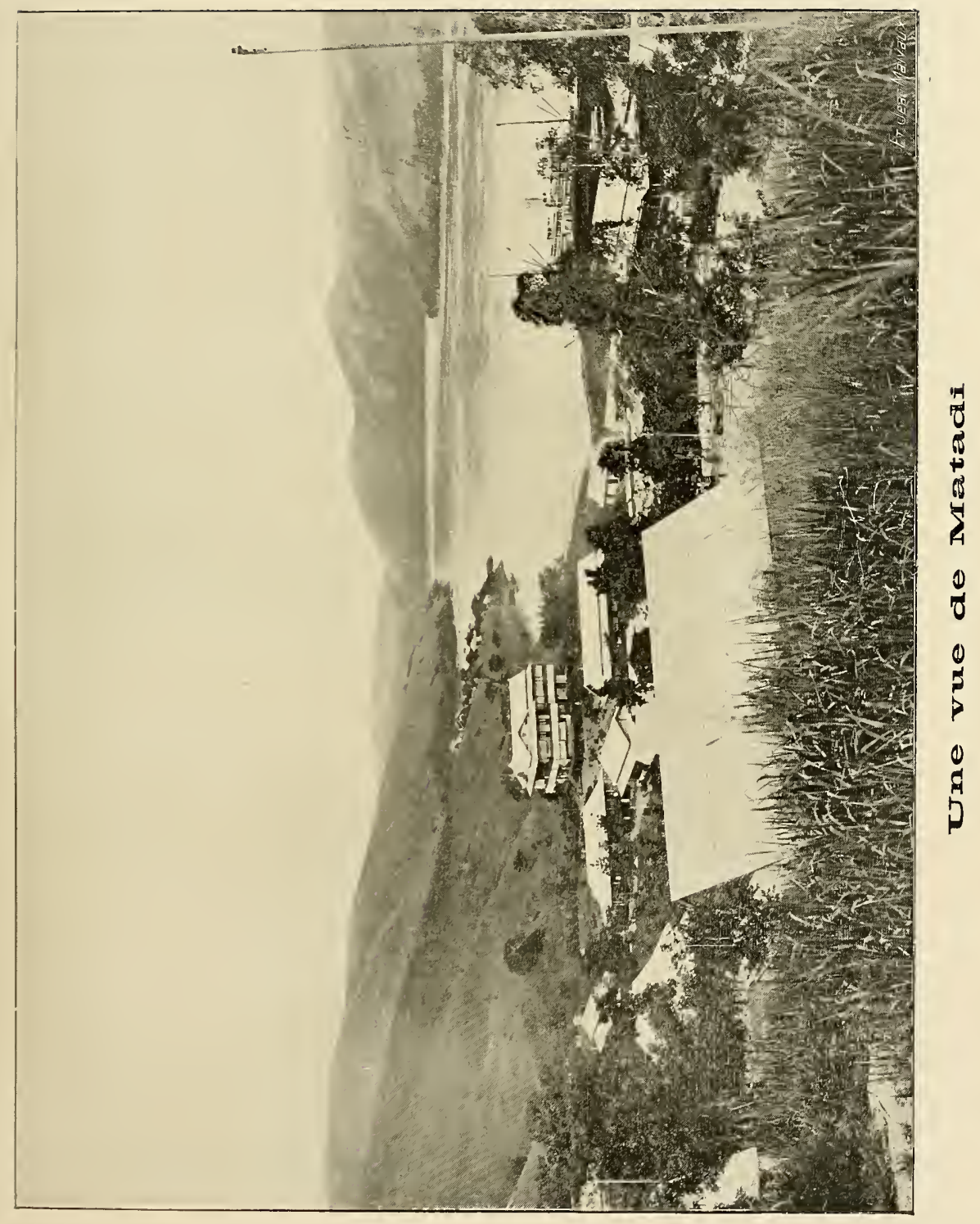




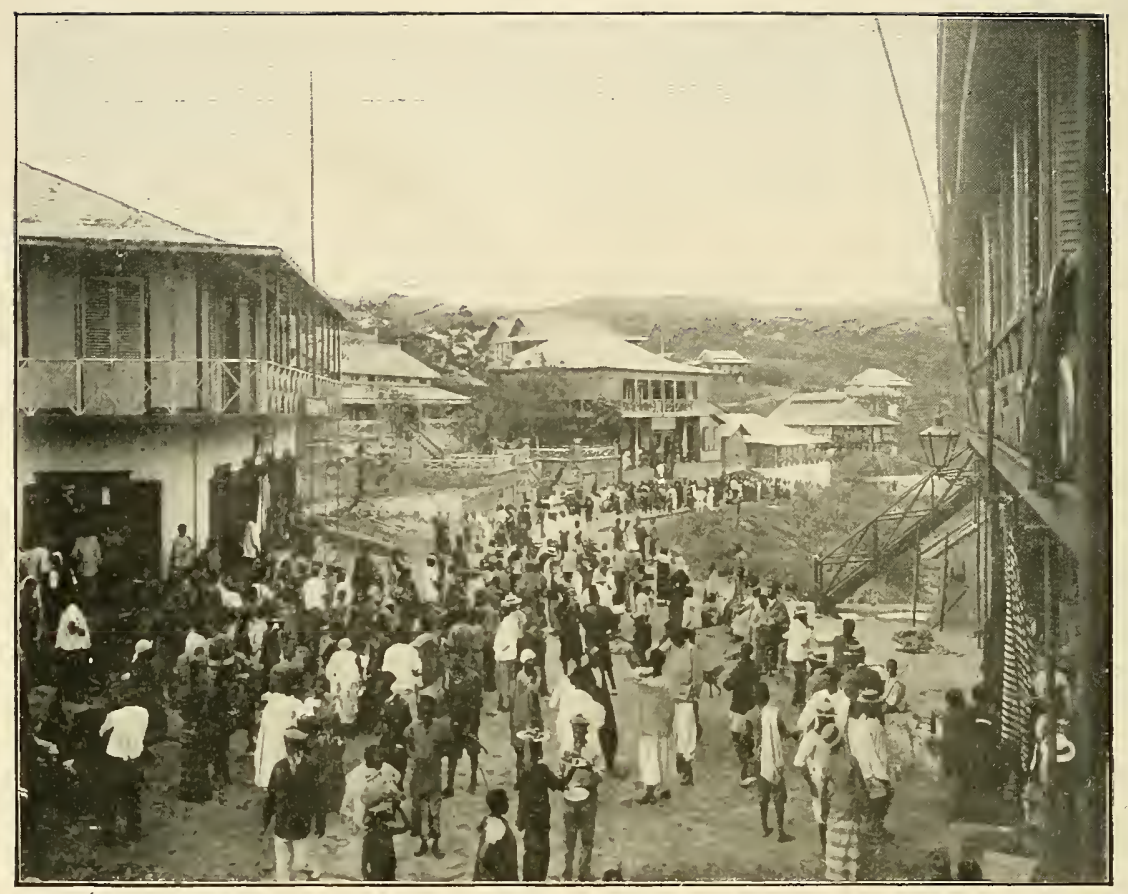

Une rue de Matadi un jour cie marché

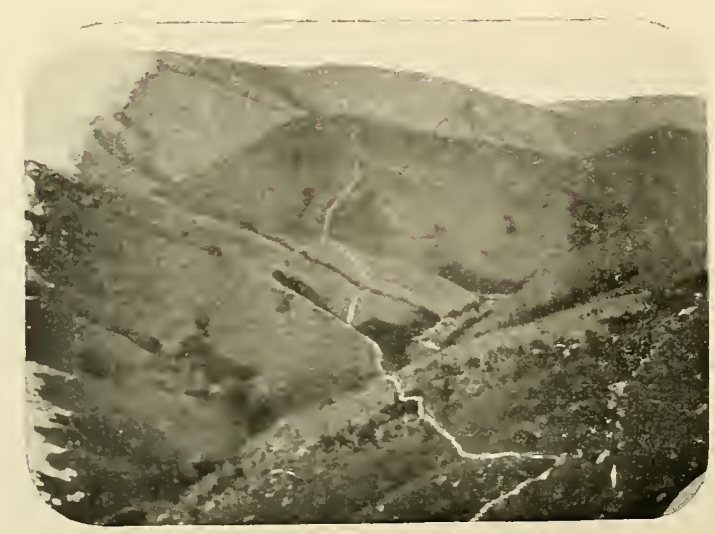

Aspect de la route des caravanes 
LÉOPOLD II, Roi des Belges,

Souverain de l'Etat indépendant du Congo.

A tous présents et à venir faisons savoir :

Le tribunal d'appel,

composé de Messieurs Fuschs, juge, Monet, Rezette, De Keyzer et Detail, assesseur's, Baerts, procureur d'Etat, et Fischer, greffier;

Vu lappel interjeté le trois janvier 1880 dix par le Procureur d'Ftat d'un jugement prononcé par le tribunal répulsif de première instance du Bas Congo à charge du nommé « Nefuku », condamnant l'intéressé à la peine de mort du clıef d'empoisonnement;

Vu les pièces de procédure et de jugement;

Ouï le Ministère public et ses réquisitions ;

Entenhu l'intèressé dans ses moyens de défense, presentés tant par lui-méme que par son defenseur Honsieur Michaux;

Attendu que l'appel est rẻgulier dans la forme!

Attench qu'il n'est pas itabli que l'intéressé s'est rendu conpable du crime d'empoisonnement tel qu'il est défini par larticle 6 bis du Code pénal;

Le tribunal :

Reçoit l'appel et $y$ faisant droit ;

Renvoie l'intéressé des fins de l'accusation;

Yet à nèant le jugement du 6 décenbre 1889 ;

Het tous les frais tant de $1^{\text {to }}$ instance que d'appel à charge de l'Erat;

Ordonne la mise en liberté inmédiate.

Ainsi fait, jugré et prononcé en audience publique, à Boma, le huit février 1880-dix.

Dunt coùt pour expédition : Un rôle quatre francs.

Le greffier du tribunal d'appel, (Signè) G. Fisgher.

Le jugrement rendu, je fus immédiatement félicité et complimenté par tous mes camarades. Nous fêtâmes même tant et si bien ce succès judiciaire, qu'en faisant acquitter " Néfuku » j’eus pu être la cause involontaire de la mort d'une demi-douzaine de mes amis. 
Enfin, tout est bien qui finit bien, et nous en fùmes quittes pour un mal de tète général le lendemain matin.

Peu de temps après ces différentes aventures, je reçus l'ordre de me tenir prêt à partir pour le haut Congo.

Enfin, mon vou le plus ardent allait s'accomplir, et moi aussi j’allais tâter du continent mystérieux ; j’allais éprouver les sensations que rous donne la marche en avant vers l'inconnu et, après a voir contemplé l'immensité des mers, sous ses aspects les plus calmes, les plus enchanteurs ou les plus terribles, j'allais pouvoir me rassasier, m'enivrer de l'immensité des plaines herbeuses, des déserts arides et des forêts vierges.

Mon imagination vagabonde les peuplait à plaisir des êtres les plus fantastiques et mes instincts de chasseur me faisaient rêver des tableaux à faire pålir d'envie Nemrod lui-mème. Aussi mes apprèts furent-ils vile terminés. J'étais bien fier et je me sentais fort.

Jamais en Belgique, lorsque j'endossais mon habit pour assister à un bal ou à une soirée de gala, je ne m'étais senti aussi heureux, aussi content de moi-mème, que ce jour, lorsque, ma toilette de voyage terminée et mon bàton à la main, je me contemplai dans la glace.

Il me semblait que j'étais grandi, je me souris à moi-mème et pendant l'espace d'une minute je me crus presque beau.

Le 28 février, donc deux mois après mon arrivée à Boma, je fis mes adieux aux camarades et, après avoir 
pris congé du major Cambier, je m'embarquai à bord du "Héron " qui devait me conduire à Matadi. De là, je devais gagner Léopoldville par la route des caravanes.

On m’arait prévenu que, chemin faisant, je rencontrerais le Gouverneur général Janssens et que celui-ci me désignerait le poste que je devais aller occuper.

Juscru'alors, je ne savais qu'une chose : c'est que j'étais destiné à une station du haut, j'ignorais laquelle.

Queldues heures de bateau nous conduisirent à Matadi. Ici, autres scènes, autres décors, autres acteurs.

Matadi n'étail qu'une pierre, un roc, mais nne pierre immense, quelque chose de non rèvé qui vous stupéfie. Sentinelle avancée du continent mystérieux, Matadi semblait ètre un défi jelé par la barbarie à la civilisation.

Maintenant Matadi est une ville comme toutes les autres villes, avec sa gare, ses entrepôts, ses rues, śes maisons, ses jardins mème (car on y a apporté de la terre à dos d'hommes et créé des jardins), avec en plus son originalité, son cachet spécial. En 1890, il n'y avait encore presque rien de fait.

Quatre ou cinc maisons et les ateliers du chemin de fer qui s'essayait à peine. Deux ou trois kilomètres de voies étaient terminés, il est vrai, et cela à force de patience, d'énergie et d'elïorts surhumains. Mais à quel prix, ô mon Dieu!

Le travail était si ardu, le climat si malsain, la mortalité telle, que l'on pouvait dire avec raison que 
chaque traverse, chaque bille de la voie que l'on parvenait à placer avait coûté la vie à un homme, recouvrait un cadavre. Qui a vu à ces débuts, ce travail de Titans, a dù, à moins d'être doué d'une seconde vue, douter de la fin.

Véritable miracle de conception et de savoir-faire, le chemin de fer du Congo, que j'ai parcouru lorsqu'il élait presque terminé, a droit à toutes les admirations et c'est le coeur bien pénétré que je lui apporte le laible tribut de mon enthousiaste hommage.

Le commissaire dı district de Matadi élait à cette époque un oflicier autrichien nommé Danffelt.

C'élait déjà un ancien qui a vait eu l'honneur de servir sous Stanley. Lorsque je me présentai chez lui, il était malade et relerait à peine, si j'ai bonne mémoire, de sa dix-septième fièvre hématurique. II était maigre à faire peur el jaune comme un citron.

Il me reçut très bien. Il n'avait pas grand'chose à m'ollirir, car la station était pauvre en ce moment, mais il donnait de bon coeur. Comme il n'avait pas de chambre libre, il fit dresser mon lit dans la sienne.

Je ne l'ai connu que quelques hemres, mais c'est encore avec reconnaissance et bonheur que j'en voie ce souvenir ému à cet ami d'un jour.

Le lendemain, nos porteurs étant réunis, je pris le senticr de la route des caravanes. Je ne vous décrirai pas ce royage pédestre de dix-huit jours par monts et 
par raux; il l'a été trop sourent par des plumes plus autorisées que la mienne.Pour mon compte, je n’ai guère souvenance que des sonllirances que j’y ai endurées.

Il s'y trouve, il est rrai, des points de vue admirables et, si l'on était moins fatigué et moins abruti par la chaleur épourantable qui y règne, on trouverait que c'est bien beau.

Mais allez donc admirer une montagne, quand vous devez la gravir en plein soleil, alors qu'il y a $38^{\circ}$ ou $40^{\circ}$ à l'ombre, ou encore par une pluie lorrentielle qui, rendant le sentier glissant, vous fait reculer d'un pas chaque fois que vous en avancez deux, comme à la procession d'Echternach.

Idmirez-rous davanlage le cours rapide et impétueux d'un torrent, si vous devez le traverser à gué avec de l'eau jusqu'au ventre? Il vous reste, il est vrai, les orages qui sont splendides, réellement impressionnants; mais comme alors, vous et ros gens, vous avez toutes les peines du monde à empècher votre tente de s'envoler, ce plaisir mème n'est pas de ceux dont on soubaite le relour.

Pour ma part, au risque de passer pour un profane et de manquer de poésie, je vous arouerai franchement que je n’ai ressenti que les désagréments du voyage sans apprécier les beautés et le pittoresque des sites.

Enfin, tout a un terme, mème la route des caravanes ; neuf jours après mon départ de Matadi, j’arrivais à 
Lukongu, donc à mi-chemin. Le commandant Van Dorpe y était, à cetle époque, commissaire de district, et le Gouverneur général, M. Janssens, de qui je devais receroir ma destination défnitive, y arrivait le lendemain matin. Aussi, à peine le jonr a-l-il lui, qu'il y a branle-bas de combal dans toute la slation.

Partout on lave, on brosse, on astique. Il faut ètre "beau ", se montrer sons son aspect le phus a vanlagenx.

Des vedelles ont été placées pour annoncer l'illustre visileur.

V'ers 9 heures, il est en rue du poste d'aris, on somne le rappel, les troupes s'alignent, les blancs jettent un conp d'ouil à leur miroir, tout est en ordre, attendons!

Bientòt 11 paraìt. Très imposant sur sa mule avec sa belle barbe blanche en érentail.

- Ciarde à vous! Apprètez. Armes!

Tons les blancs se portent en avant, s'arrêtent et saluent militairement. Le Gouverneur veut rendre le salut, mais en ce moment la salve éclate presque dans les jambes de la mule et celle-ci,prise d'une terreur folle, fait un si brusque demi-tour, que M. le Gouverneur nous montre autre chose que sa belle et imposante figure.

Le protocole, en cette occasion, perdit quelque peu de son prestige, mais je rous assure que la plus franche gaìté ne fit qu'y gagner.

Bientòt, cependant, M. le Gouvemeur reprend son équilibre et nous, notre physionomie la plus officielle : 
la cérémonie put se continuer sans autre incident remarquable.

Le soir, un banquet nous rémnit tous; le petit incident du matin nous avait mis en gaîté et le plus bel entrain ne cessa de régner pendant la fète ; nous étions encouragés d'ailleurs par la bonne humeur du Gouverneur, qui était le premier à rire de sa petite mésaventure.

A la fin du dìner, il eut mème l'occasion de prendre une petite revanche, et il ne la rata pas.

L'officier qui faisait les fonctions de majordome, peu habitué à héberger aussi illustre et aussi nombreuse compagnie, ne savait où donner de la tète, surtout qu'il n'avait pour le seconder dans ses honorables et difficiles fonctions que des cuisiniers et des serviteurs noirs.

Tout s'était cependant bien passé et monsieur X... commençait à respirer. L'on avait doublé le cap dangereux du potage et des sauces, sans tacher aucun habit. On allait donc servir le café.

Fùt-ce un oubli, une distraction, je n'en sais rien, mais le fait est que monsieur X..., avait négligé de se rendre à la cuisine afin de donner ses ordres pour ce dernier service; il y avait donc une gaffe à faire; les boys ne manquèrent pas l'occasion.

Bientôt ils apparaissent avec un service tout dépareillé et tout ébréché.

A cette vue, le pauvre X... se trouble, bredouille et finit par déclarer au Gouverneur que la station possède 
un service tout neuf qui n'a même jamais servi. Il se lève et veut se précipiter pour aller le chercher, mais le Gourerueur, prenant son air le plus bonhomme, lui dit : “ Laissez,monsieur, il faut le conserver,afin de l'étrenner dans une plus belle occasion. ”

Paurre X..., je ne sais pas si dans son désespoir il eut un instant l'intention de faire comme Vatel, mais ce que je sais fort bien, c'est que le lendemain matin il avait cncore l'air tout penaud et qu'il racoutait à toul le monde qu’il n’y avait que lui pour avoir une guigne semblable.

Ce soir ígalement, je fns bien innocenment un prophèle de mauvais augure.

Le Gouvernem m'avait appris incidemment que j’étais dénigné avec le lieutenant Vial pour rejoindre M. Le Marinel au camp de Lusambo; un peu lancé, je pris immédiatement Vial à partie et je répondis en riaut à M. le Gouverneur que moi j'arriverais certainement au camp, mais que Vial resterait en route.

Et comme iutrigué, on me demandait sur quoi je basais mes présages, je leur dis que j’avais remarqué que Vial ne riait jamais et ne trinquait jamais avec les camarades; qu’à mon avis, cela dénolait un esprit chagrin et un manque de ressort dans l'organisme et que par conséquent j'estimais que V'ial n'était pas fait pour vive au Congo.

Tous, Vial le premier, rirent bien de ma boutade, ne 


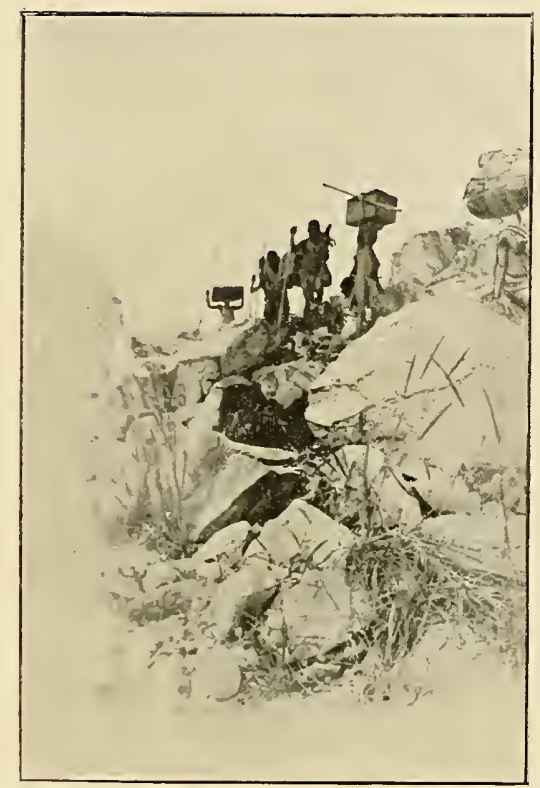

Passage d'une caravane dans les rochers

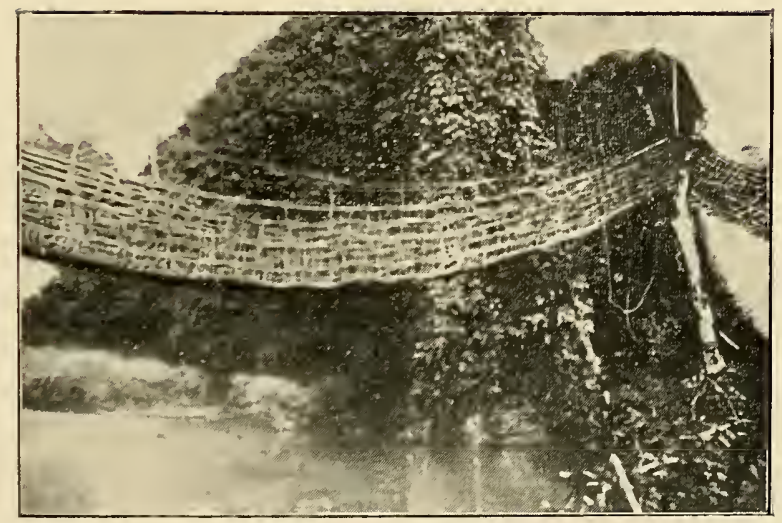

Pont suspendu en lianes dans la région des cataractes 


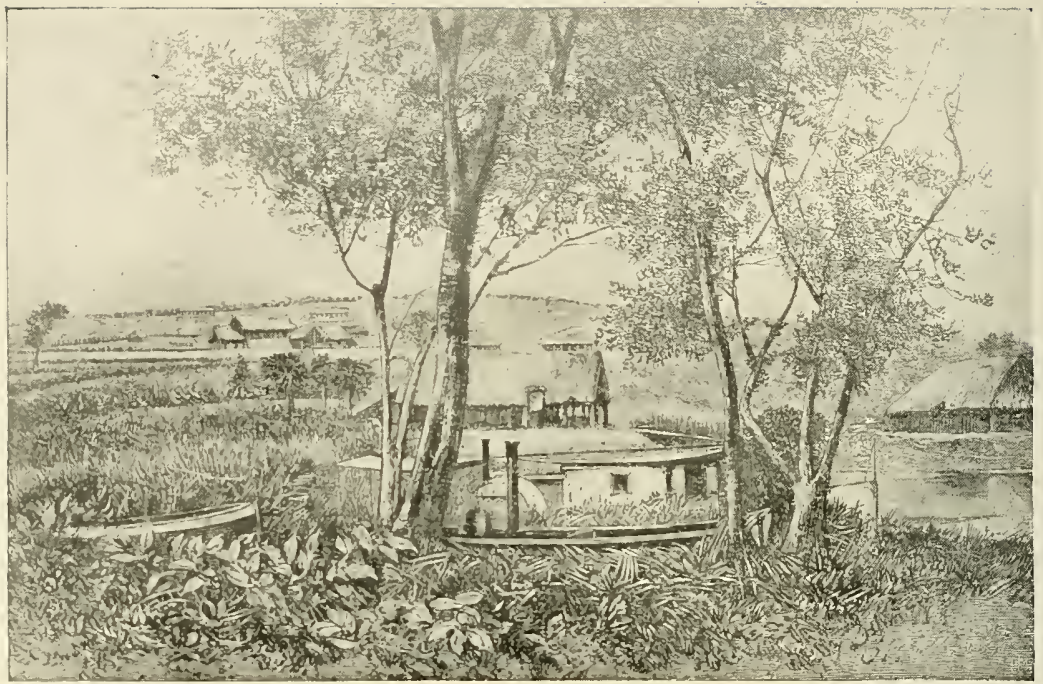

Iéopolaville en $18 B 2$

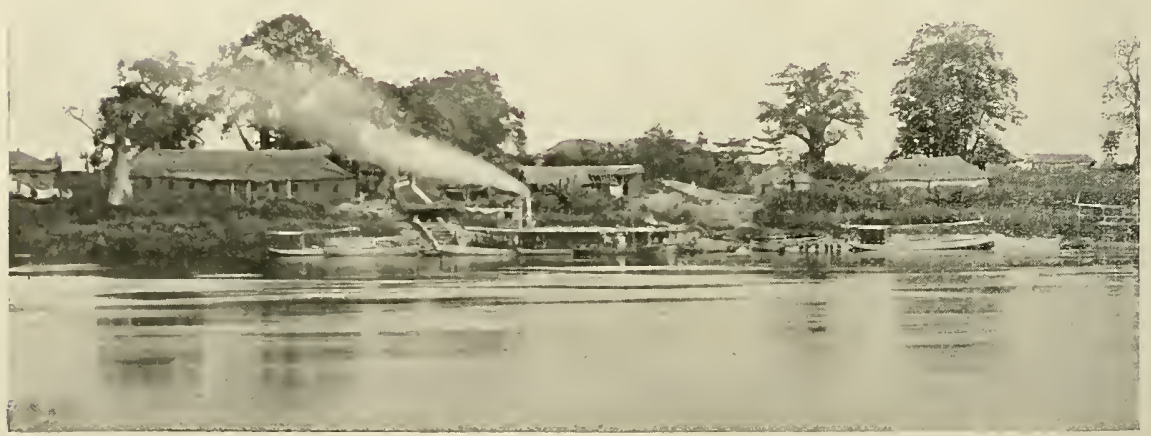

Vue du Port de Léopoldville en 1890 


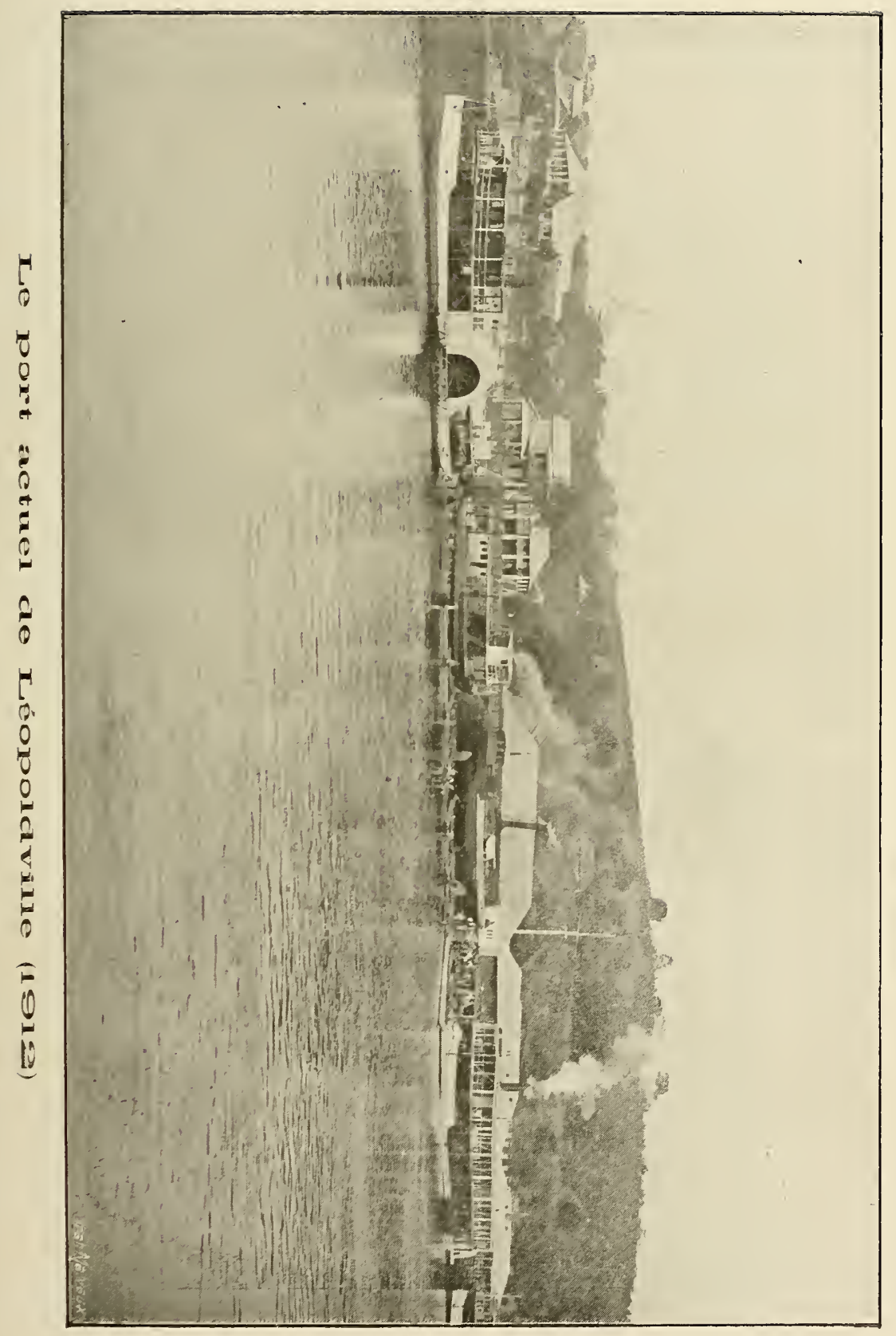




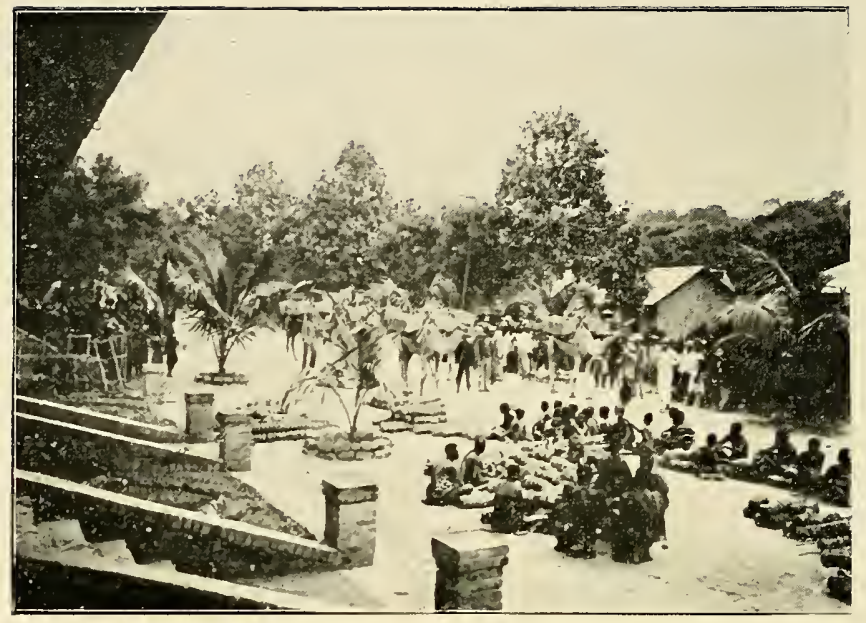

Le portage par chameaux à Léopoldville

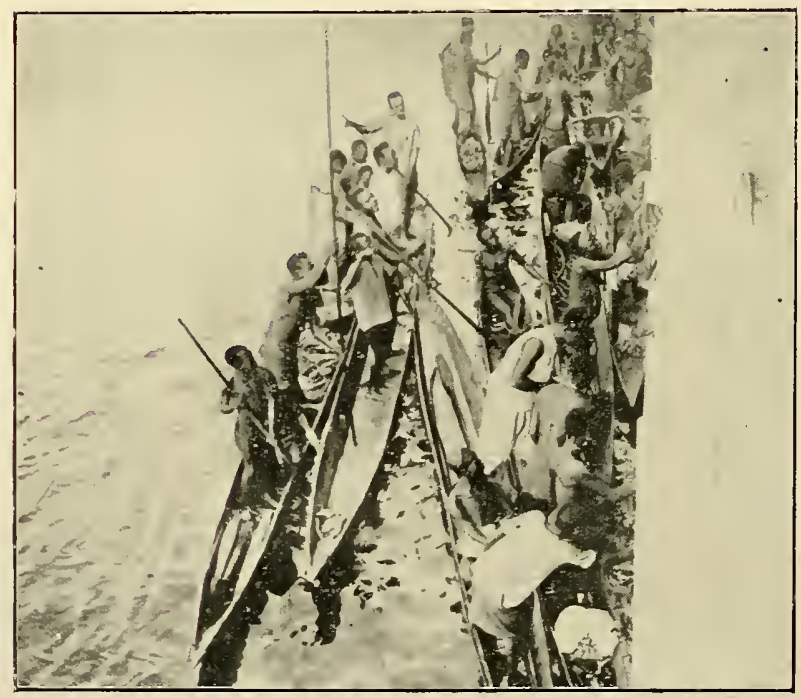

Indigènes faisant le kissalo (marché) avec un bateau en marche 
se doutant guère que la prédiction qu'elle contenait devait se réaliser à courte échéance.

Le lendemain matin, ma caravane étant prête à partir, j’allai présenter mes respects au Gouverneur et prendre ses derniers ordres.

Il me tint ce laugage :

- "Je vous ai désigné pour le haut Congo, c'est vous " dire qu'à partir de cc moment va commencer pour ") vous la véritable vie d'Africain. Ce que vous en avez " v'u jusque maintenant dans le bas Congo n'est qu'une " mauvaise copie. Dans cette vie, il y a deux espèces ") de gens : ceux qui ont de la chance et ceux qui n'en " ont pas. Si vous êtes de ceux qui ont de la chance, " rous serez bieu portant et ros trois ans terminés, ") vous retournerez en Europe. Si, au contraire, vous ") ètes de ceux qui n'en ont pas, si vous êtes marqué " par le sceau de la fatalité, faites ce que vous voulez, " vous ètes condamné d'a vance et, comme tant d'autres, ") vous tomberez victime de la barbarie, martyr de la " civilication. En tout cas, je vous souhaite de la chance " et même beaucoup. "

Sur ce, je pris congé. Il n'était pas très encourageant, M. Ie Gouverneur, avec ses gens qui ont de la chance et d'autres qui n'eu ont pas. Nais enfin, ses vœux m'ont porté bonhcur, puisque, après sept années d'Afrique, ma santé est restée si exuhérante qu'elle fait même tout mon désespoir et celui de ma pauvrc bête de cheval, 
qui, lui, n'a vraiment pas de chance, puisqu'il continue à être condamné à me porter.

Je ne vous parlerai pas de mes nouvelles étapes, c'est toujours la même chose pour changer : des montagnes qu'il faut escalader, des vallées qu'il faut descendre, des torrents qu'il faut traverser, puis remonter pour redescendre encore et ainsi de suite jusque Léopold ville, où j'arrivai au bout de neuf́ nouveaux jours de marche.

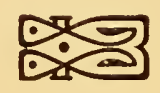




\section{CHAPITRE Y.}

Arrivée à Léopoldville. - Mort tragique de Vial. - En route pour Lusambo. - Impossible de franchir la barre. - Hospitalité charmante des Pères de Bergh $\mathrm{S}^{\prime \circ}$-Marie. - Mon ami le Père ( $U$ ). - Plus fort que le diable! - Les distractions du Père Ferdinand. - Le Congo et le Kassaî. - Nous servons de festin aux moustiques. - (Baron, où est la lune »?

Je précédais Vial de quelques heures, ou du moins je le supposais. J'annonçai mème son arrivée imminente et l'on retarda le diner d'une demi-heure à son intention.

Paurre Vial, il ne devait pas le partager avec nous, et à ce moment mème il se mourait seul, sans secours, sans une parole d'amitié, sans la pression d'une main affectueuse au milieu de nègres curieux ou indifférents, qu'il ne pouvait comprendre et dont il ne pouvait se faire comprendre.

Nous l'attendìmes en vain toute la soirée et le lendemain matin nous nous apprêtions à aller à sa recherche, quand ses porteurs arrivèrent à la station avec son cadarre, qu'ils transportaient dans une couverture transformée à cet effet en hamac. Je ne pouvais en croire mes yeux.

Etait-ce bien lui que j'avais quitté la vẹille plein de force et de șanté ? Toute la station fut bien vite en émoi. Tout le monde courait, tout le monde questionnait et les pauvres diables de nègres, tout interloqués, ne 
savaient à quel fétiche se vouer. Enfin, le calme s'étant quelque peu rétabli, nous sîmes que notre ami avait commis l'imprudence de voyager sans son casque en plein soleil et qu’il était tombé comme foudroyé, mort d'insolation.

11 était déjà tout noir et la décomposition ayant commencé son curre, on dut l'enterrer ce jour même. C'est à peine si l'on eut le temps de lui confectionner une boile resscmblant à un cercueil.

Un enterrentent est foujours triste. Mais celui-ci fut lugubre.

Non seulement le paure élail mort seul, sans consolation, nais de tous ceux qui l'accompagnèrent à sa dernière deneme, j’élais le seul qui le connut un peu. Il élail, je crois, de famille catholique, el ce fut un pasteur protestant qui récila les dernières prières sur sa tombe.

Celle mort nous pesa à lous, à moi surtout, comme un horrible cauchemar, et maintenant encore,après dix-sept ans, je ne puis y songer sans un frisson d'elfroi.

Je passai près d'un mois à Léopoldville en atteudant le steamer qui devait me conduire à Lusambo et, contrairement aux autres stations où j'arais partout reçu l'accueil le plus flatteur, le plus empressé, je n’eus pas à me louer de mon séjour dans celle-ci.

Le monsieur qui y commandait alors n'avait rien trouvé de mieux, afin d'humilier les officiers, que de 
créer deix tables. A la première. qu'il présidait; les officiers ayant raug de capitaine étaient seuls admis. Quant aux lieutenants et sous-lieutenants, ils devaient manger à la seconde, où se trouraieut également tous les ouvriers de la station, dont quelques-uns peu éduqués et peu recommandables.

Je refusai net de me plier à un ordre que je considérais comme préjudiciable à ma dignité ef je déclarai que l'on avait à me servir chez moi ou à me donner les moyens de regagner la còte. De plus, j’informai qui de droit en très haut lien de ce qui se passait et j'eus la satisfaetion d'apprendre trois mois après que des ordres formels avaient été donnés pour que pareils abus de pouvoir ne se reproduisissent plus.

Il y avait cependant de braves coenr's à Léopoldville comme partout ailleurs et les charmautes causeries que j'arais arec le commandant Nankin, qui commandait la force publirue, et le eapitaine du génie Carton, qui avait la direction du port, me distrayaient de mes ennuis et me faisaient prendre mon mal en patience.

Enfin le bateau fut prèt et nous pùmes embarquer.

Je devais faire le voyage à bord du "Stanley " en compagnie d'un sous-officier appelé Verdick. Le capitaine du hord était un Danois, nommé Matsen, et le mécanicien s'appelait Deman. Nous avious aussi à hord environ 15f) soldats, 2 canons et de nombreuses charges en destination de Luébo et de Lusambo. 
De plus, un petit steamer, la " Ville de Verviers " devait navigner avec nous, ou tout an moins, nous retrouver pour la couchée. Doorme, un camarade des chasseur's à cheval, en était le seul passager et, comme il était destiné au district du Kassaï, il devait nous quitter à Luébo.

Le tout alla bien jusqu'à l'embouchure du Kassaï,mais là, les eaux élaient si fortes el notre clargement était si complet, que nous ne pumes jamais franchir la barre.

Le capitaine Matsen pril donc le parti de nous débarquer à la mission de Bergh-Sainte-Marie et de relourner a Léopoldville à bord de la "Ville de Verviers " pour chercher de nonveaux ordres. C'est ainsi que pendant hnit jour's nous devinmes, Doorme, Verdick el moi, les hòtes de la mission.

Le supérieur élait le père de Bac, mais mon camarade étail le père IIuberlan, le père $T$, comme nous l'appelions familièrement, le mème qui devint plus tard provicaire apostolique à Boma et y mourul.

Nous fùmes reçus on ne peut mieux et ces bons pères firent toul ce qui était en leur pouvoir pour nons faire passer le plus agréablement possible ces quclques jours d'altente.

Le jour et quelquefois la nuit, j'allais à la chasse ou à l'aflìt avec le père $U$, et le soir nous chantions ou encore nous tournions une manivelle; un aristophon nous jouait ses plus belles polkas et ses valses les plus entrainantes. 
Je me souviens mème qu'un soir, ayant pris le père U à bras le corps et le portant dans mes bras, je fis tout une valse arec lui.

La ralse finie, le paurre père $U$ tomba tout étourdi sur un fautenil. Nous nous tordions de rire; le père $\mathbf{U}$ prétendit que ce jour-là j’avais été plus fort que le diable, puisque ce dernier n'arait jamais pu le faire dauser.

Un autre jour je me récriai de ce que les pères que je savais très pauvres nous servaient du vin à table tous les jours ar diner.

- Tais-toi, me dit le père $\mathrm{L}$ en me poussaut du geuou et en me montrant le père supérieur du coin de l'oeil. Il ne nous en donne jamais que lorsqu'il y a des invités.

Enfin ils furent charmants et leur hospitalité aussi large que leurs moyens le leur permetlaient.

Ce ful là, et bien entendu avec le père U, que je fis ma première chasse au buffle. Celle-ci est très dangereuse et le coeur me battait un peu le jour où, à 4 heures du matin, nous allâmes nous poster sur un de leurs sentiers qui mènent au fleuve et par lesquels ils ont l'habitude de passer au petit jour lorsqu'ils vont se désaltérer.

Nous étions là depuis une heure environ et je commençais à sommeiller, quand tout à coup j'entendis un bruit de diable et, un buffle qui nous a vait probablement éventés, passa près de nous à fond de train. Il passa mème si près, qu'il faillit renverser le père $U$. 
Jè u’ai jamais été aussi saisi et je me demande encore comment cela se fit, mais aucun de nous deux ne songea à làcher son coup de fusil. Il faut croire que je n'étais pas encore bien aguerri à la vie d'Afrique.

Fatigués! de mauvaise humeur! nous regagnàmes la mission, où, pour nous consoler, on ne nous épargna pas les plaisanteries sur nos exploils cyuégétiques.

Il nous fallait une revanche; le lendemain matin le père U et moi décidons de passer le Kassaï pour aller chasser du còté où se trouvait l'ancieu poste de Kiwamouth. Doorme se joint à nous et le père Ferdinand demande aussi à nous accompagner.

Ce dernier, excellent homme du reste, convenait beaucoup mieux pour faire un moine cloitré qu'un missionnaire. Toujours en conversation avec le ciel, c'est à peine s'il s'apercerait de ce qui se passait sur la terre.

A l'heure dite, donc, nous sommes tous les quatre sur la berge prèts à nous embarquer en pirogiue pour faire la traversée, qui est très difficile et même dangereuse, à cause de la rapidité du courant.

Nous avions déjà fait un bon bout de chemiu quand nous uous apercevons que le père Ferdinand a vait oublié ses cartouches. Il fallut donc faire demi-tour et cela ne contribua pas à nous mettre de très bonne humeur.

Nous nous mettous en chasse et après marche fatigante, nous nous décidons au retour, presque 


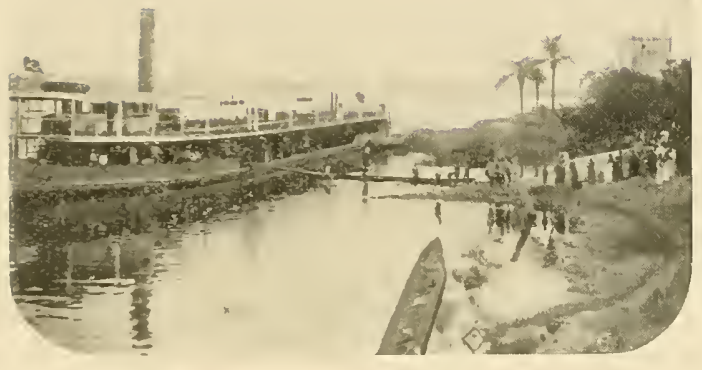

Un vapeur accostant à la rive

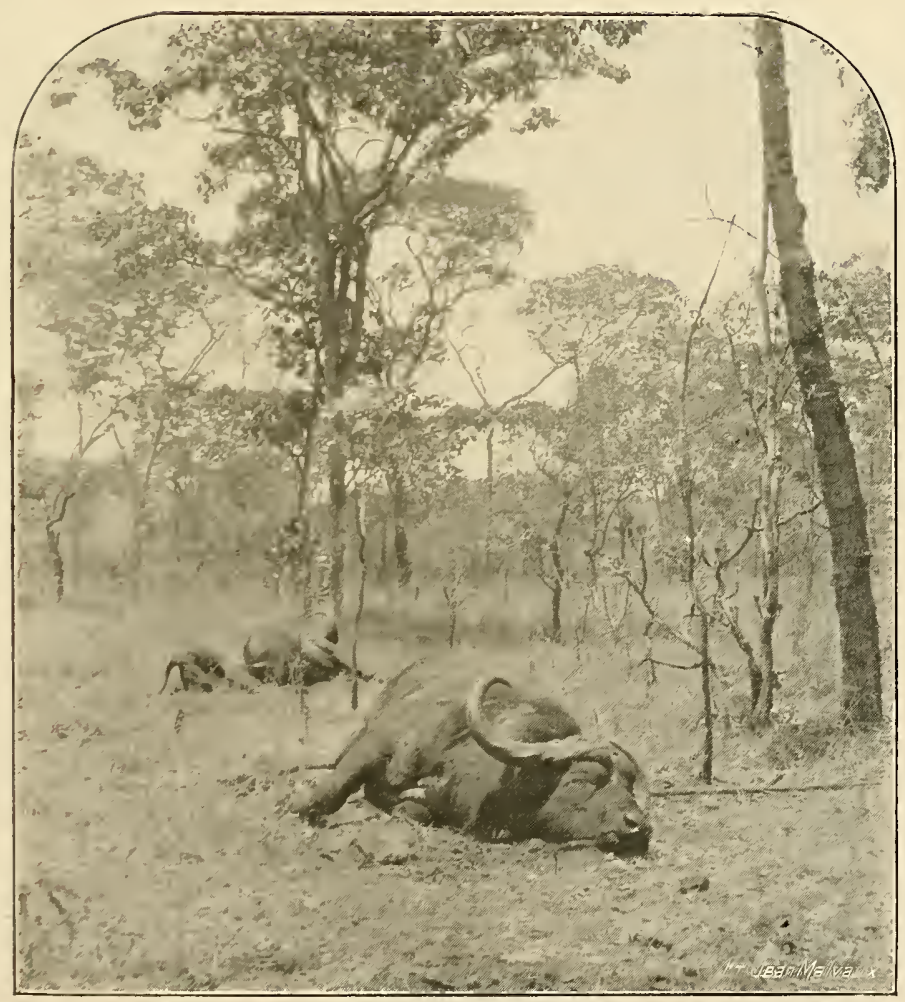

\section{Buffles tués dans la Savane}




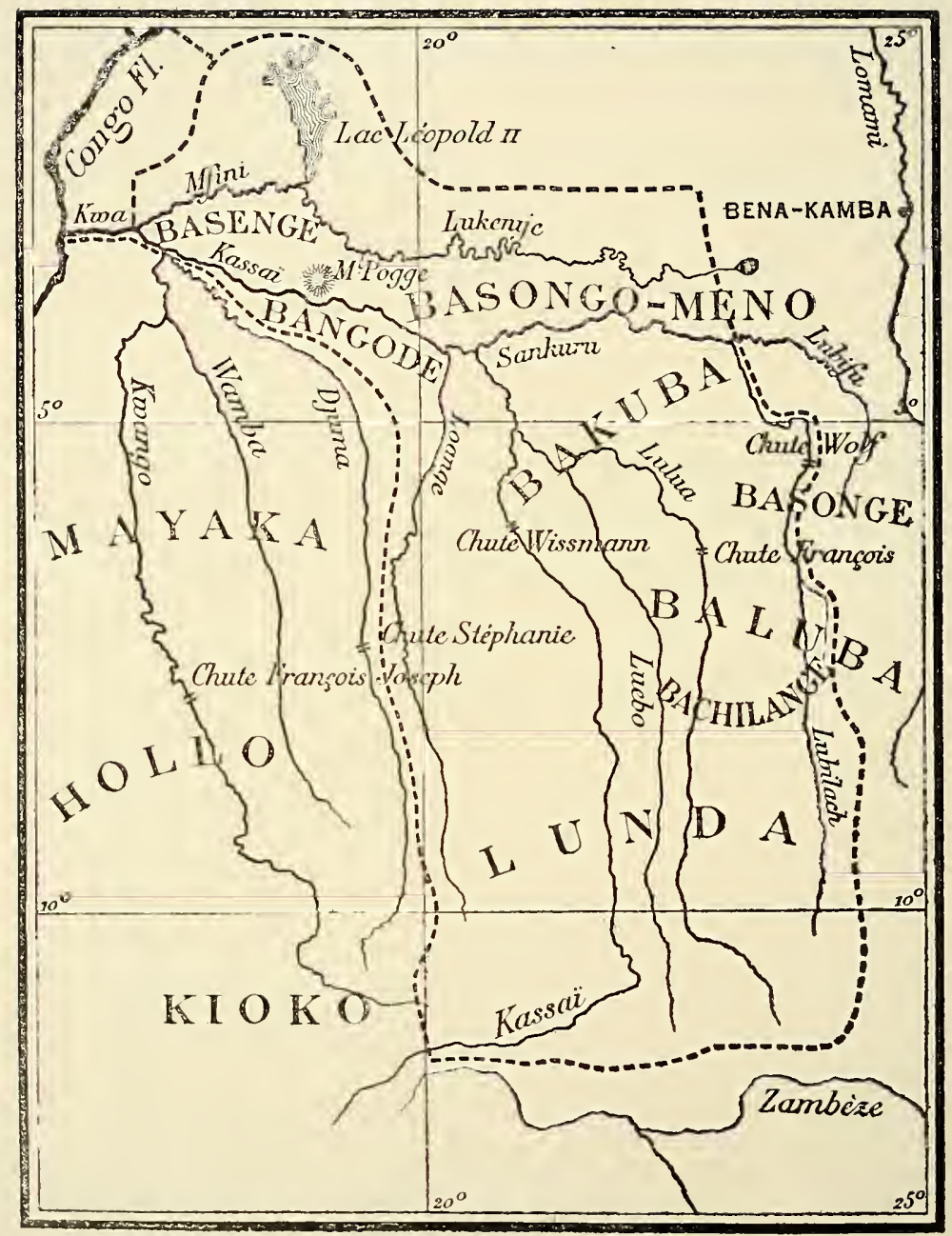

District du Kassaï en 1889 
bredouille : une pintade et deux perdreaux pour nous quatre!

Avant de partir, nous nous asseyons sous un arbre et mangeons quelques papayes pour nous rafraichir, puis nous nous embarquons sous un soleil de plomb.

Nous avions fait presque la moitié du trajet lorsque le père Ferdinand s'aperçoit qu'il a oublié son fusil contre l'arbre où nous nous étions reposés. Il fallut donc de nouveau faire demi-tour. Je vous laisse à penser si nous étions heureux et satisfaits. Enfin, tout bien en place, et après a voir constaté dùment que le père Ferdinand n'avait plus rien oublié, nous nous embarquons.

Mais quelle n'est pas notre surprise et notre joie de voir que pendant notre retour à terre une immense bande de canards est venue s'abattre sur le banc de sable qui se trouve au milieu du fleuve. Il y en avait bien mille.

Nous allons donc pouvoir, en peu d'instants, faire une chasse magnifique. Nous convenons de nous approcher le plus près possible des canards, puis tous ensemble de tirer nos deux coups dans la bande.

Le père U est en avant dans le canot (c'est lui qui doit donner le signal), puis vient le père $F$, puis moi et ensuite Doorme.

Nous nous félicitons déjà de notre manœuvre, quand à environ 80 mètres des canards un coup de feu éclate. 
C'est le père $\mathrm{F}$, qui vient de tirer et son coup de fusil est parti si près de la tête du père $U$, qu'il fait tomber son chapeau.Le père U se retourne furieux et s'adressant au gaffeur :

- Cette fois-ci, dit-il, je dirais bien imbécile!

Quant à moi, je n'ai rien dit, mais j'étais dans une rage telle qu'il me semblait que cela m'aurait fait un sensible plaisir de jeter cet incorrigible distrait par dessus bord.

Quant à lui, il était réellement malheureux des mésaventures dont il était cause, et je suis certain que, rentré dans sa cellule, il s'est donné la discipline pour se punir des péchés de colère qu'il nous avait fait commettre involontairement. On m'a dit depuis qu'il était mort. Il aura probablement oublié quelque jour de respirer. C'était d'ailleurs un saint homme, et nous lui avons pardonné ses distractions.

Eufin, des ordres nous arrivèrent de Léopoldville et après nous ètre délestés d'une partie de notre chargrement et l'avoir confié aux pères de la mission, nous prìmes congé de ceux-ci et pûmes continuer notre voyage.

Nais avant de partir, qu'il me soit permis d'ouvrir ici une petite parenthèse pour rendre hommage à ces braves gens et les remercier de nouveau de tout ce qu'ils ont fait pour nous. Jamais hospitalité ne fut plus large, plus franche, plus sympathique et ils en avaient 
double mérite puisque je l'ai dit plus haut, ils n'étaient pas riches.

La plupart d'entre eux, si ce n'est pas tous, hélas ! ne sont plus.

Ils sont partis pour un autre monde. Puissent-ils avoir trouvé la récompense qu’ils ont si bien méritée! Ce deroir de reconnaissance accompli, en route pour Lusambo.

Que vous dire du voyage, si ce u'est vous parler du fleuve, de ses aflluents, le Kassaï, la Lulua et le Sankuru, ainsi que de leurs riverains?

Les deux rives du Congo sont des plus accidentées et vraiment superbes. On dirait qu'un grand architecte, roulant attacher son nom à une ouvre impérissable, s'est complu à en faire un chef-d'œuvre inimitable.

A droite et à gauche, d'immenses collines affectent à plaisir les formes les plus bizarres et les plus fautastirques.

Tantòt, elles sont très hautes et arides, formées de rochers superposés de diflérentes couleurs (j'eu ai vu qui étaient rouges, blanches el noires), ou eucore parfois de teintes uniformes. Elles sont, du moins le plus grand nombre, taillées à pic et baignent fièrement leur pied dans le lil du fleuve, qu'elles semblent vouloir défier.

D'autres fois, elles se font mignonnes, sont couvertes d'une végétation des plus variées et affectent toutes les formes d'un parc immense et féerique. 
Quant au fleuve, on dirait qu'il a honte de se laisser vaincre, de se sentir emprisonné ; dans sa colère impuissante, il veut remplir tous les espaces que les collines lui ont laissés.

Si elles ne lui marchandent pas trop la place, son cours est calme et majestueux, de ce calme profond qui sied si bien aux forts. Mais se resserrent-elles, il devient ragenr, et on le voit anx tourbillons profonds qu’il forme dans sa course. Les collines empiètent-elles sur son domaine en jetant d'énormes rochers dans son lit, sa rage alors ne se contient plus et il devient terrible. On l'entend mugir à plusieurs lieues de distance et les siècles eux-mêmes n'ont pu apaiser sa rage impnissante.

Quant an Kassaï, il est certainement moins imposant que le Congo, quoique son rolume d'eau soit aussi considérable, mais, s'il n’a pas la majesté imposante du premier, il n’en a pas non plus les fureurs.

Son conrs est calme, ses rives peu montueuses et il ronle ses eanx sur un lit de sable. Comme un bon bonrgeois, il a peu de prétention à l'esthétique, il paraît cossu, sage et tranquille. C'est un patriarche qui a le sonci et la fierté de sa nombrense famille et il nous la présente, sous forme de canaux enserrant d'innombrables îles, de tontes formes et de toutes couleurs.

Ses rives hospitalières sont pemplées de toute la faune congolaise. 
Mais l'animal que, entre tous, l'on rencontre le plus, celui qui semble le plus s'y complaire, qui parait le mieux s'y trouver dans ses domaines privés, c'est incontestablement l'hippopotame, car le Kassaï, avec ses nombreuses iles herbeuses et ses rives basses, semble avoir été créé expressément pour lui. Anssi, en a-t-il fait son séjour de prédilection et est-ce par centaines que l'on peut en compter les familles. Il y en avait tellement à cette époque, qu'ils constituaient même des obstacles pour les petits steamers, auxquels ils faisaient parfois courir un véritable danger.

Amateur de chasse comme je le suis, je vous laisse à penser si je m'en donnais à coeur joie dans ce véritable Eden pour le chasseur.

Tous les jours, lorsque le steamer stoppait pour faire du bois, je partais en pirogue pour la chasse et, amourpropre de chasseur à part, je juis aflirmer que je ne suis jamais rentré bredouille.

Je pourrais mème ciler quelques tableaux réellement merveilleux, mais je craindrais que certains confrères ne les prennent trop pour des histoires... de chasse.

Cetle belle passion me joua, un jour, ou pour mieux dire un soir, un assez mauvais tour: Suivant mon habitude, j'étais parti vers 4 heures en pirogue; or, à cet endroit, le Kassaï forme des centaines de petites ìles. Tout au plaisir de la chasse, j'avais oublié l'heure et, lorsque le soleil se coucha brusquement à l'horizon, 
vers 6 heures, et que je voulus regagner le steamer, nous nous égarâmes dans les nombreux chenaux formés par toutes ces îles.

Continuer notre route, c'était risquer de nous éloigner davantage du steamer; de plus la uavigation devenait très périlleuse, car des hippopolames s'y tronvaicut par cenlaines et, comme il faisait très noir, nous ne les voyions pas; mais rien n'élail plus impressionnant que de les entendre émerger à quelques pas de nous et respirer bruyamment.

L'un d'eux vint même heurter le bord de la pirogue et faillit la faire chavirer. J'en avais réellement la chair de poule et je donnai immédiatement l'ordre d'aborder.

Nous débarquàmes sur une petite île herbeuse, absolument dépourrue de bois et où nous n'eûmes par conséquent pas même le triste privilège d'allumer du feu pour réchanffer nos membres engourdis par l'humidité de la nuit et nous préserver plus ou moins de la visite des moustiques et des hippopotames.

Tous les malheurs semblaient s'acharner sur nous : il y avait un brouillard des plus intenses et des plus froids; tous les moustiques du Kassaï semblaient s'y ètre donné rendez-vous et s'acharnèrent si bien sur nos malheureuses personnes, que, le lendemaiu matin, nos figures étaient gonflées au point que c'est à peine si on apercerait encore les yeux. 
Les hippopotames nous régalèrent d'un concert infernal qui ne prit fin qu'a vec la nuit : à chaque instant, nous les entendions sortir de l'eau ou s'y replonger, ce qui nous tenait dans des transes continuelles par la peur que nous avions d'ètre écrasés.

Enfin,le jour parut et avec lui finirent nos souffrances. Au steamer, on s'était bien douté de notre mésaventure et, dès le petit jour, le capitaine fit siffler le navire et tirer des coups de fusil pour nous indiquer la route; nous n'eùmes donc aucune peine à le retrouver.

Longtemps encore je me souviendrai de cette nuit sans sommeil, où j’ai été gelẻ, mangé par les moustiques et où j'ai risqué d'ètre noyé d'abord, puis piétiné par les hippopotames.

A mon arrivée à bord, mes camarades me plaignirent beaucoup de mes mésaventures de la nuit, mais au fond, je crois qu'ils araient surtout une furieuse envie de rire, en voyant mon air déconfit et ma figure bouffie par les piqùres des moustiques. Ils auront dủ s'en donner à cœur joie lorsque, retiré dans ma cabine, je fus me reposer des fatigues et des émotions de la nuit.

Je leur pardonne d'ailleurs bien volontiers et j'avoue qu'à leur place j'aurais fait comme eux.

Mais continuons notre voyage jusque Luébo où nous devions laisser notre ami Doorme.

Nous fimes un crochet, ce qui me permit de visiter la Lulua et la station de Luébo. 
Sans avoir la prétention de faire grand et d'en imposer par le volume de ses eaux, comme le Congo ou le Kassaï, la Lulua est cependant très jolie, coquette surtout, car elle change de parure à chaque instant; mais toujours gracieuse, tanl dans son cours que dans ses courbes, elle semble n'avoir d'autre préoccupation que de vous plaire. Luébo, lui, n’est plus qu'une simple station commerciale que l'Etat a cédée à une Compagnie.

Cette station est toute petite, mais, située dans l'angle formé par la Lulua et le Luébo, elle se présente très bien ; entourée de ses beaux caféiers et citronniers, elle a son cachet spécial et tout à fait original.

Nous y sćjournâmes 24 heures et y fùmes très bien reçus; je pus constater que la station était parfaitement tenue et qu'elle faisait un chiffre d'afraires énorme,grạ̀ce à son gérant d'alors qui était très aimé des indigènes et dont je regrette de ne pouvoir citer le nom, celui-ci m'échappant complètement.

Notre déchargement terminé, je fis mes adieux à mon vieux camarade Doorme et en route pour Lusambo. Cependaut, avant de le quitter, il faut que je vous conte une mésaventure qui lui était arrivée en cours de route.

Il faisait, conme je vous ai dit, le voyage à bord de "La Ville de Verviers ", petit steamer de 12 tonnes ayant pour pilote un Acra du nom de Danky.

Un jour donc que Doorme, la pipe à la bouche et debout à l'arant du navire contemple les berges $d u$ 
Congo, il reçoit tout-à-coup un choc formidable; le steamer est presque soulevé de l'eau et tout l'équipage, y compris Doorme et Danky, roule pèle-mèle au fond du steamer.

Comme Doorme, efrrayé à juste titre, demande ce qui se passe, Danky lui répond de son air le plus naturel :

- “Ce n'est rien, master, n'ayez pas peur, je sais bien ce que c'est. C'est un rocher qui se trouve sous l'eau, je le connais bien, allez ! c'est la troisième fois que je rais dessus. "

Enfin, puisque nous en sommes aux historiettes, je ne puis m'empècher de vous en conter encore une qui nous advint en cours de route.

Comme nous n'avions pas de cuisinier à bord du "Stanley ", j’avais déniché parmi mes Haoussas un individu qui parlait uu peu de français, et comme il m'a vait affirmé qu'il avait dẻjà fait cuire des moambes, préparé des chikuangues et rôti des chiens dans son pays, je lui arais donné le titre et les fonctions de cuisinier en chef de l'expédition.

C'était bien le plus grand voleur que j'aic jamais connu et je crois qu'il eût rendu des points à n'importe quelle cuisinière pour faire danser l'anse du panier.

Lorsque je le fis appeler pour lui confier ses délicates fonctions, il se présenta à nous avec une vieille buse et en redingote, mais bien entendu pieds nus et sans pantalon. 
En vertu de son chic, nous lui donnâmes le nom de baron, nom qui lui resta dans la suite et dont il était d'ailleurs très fier.

Un soir donc, nous étions réunis sur le pont et, comme la lune n'était pas encore levée, nous discutions l'end roit probable où elle allait nous apparaître.

Comme nous ne parvenions pas à nous mettre d'accord, je dis aux camarades que le plus simple était de nous adresser à un nègre, vu que ces enfants de la nature sont habituellement très experts sur ces sortes de choses.

J'appelle donc baron.

- Baron, lui dis-je, où est la lune maintenant?

Il se trouble, bredouille, et comme il avait probablement quelque nouveau larcin à se reprocher, il finit. par me dire :

- Je n'en sais rien, monsieur. Je vous jure que ce n'est pas moi qui y ai touché et si vous ne la retrouvez pas, c'est qu'il y aura encore un des boys qui l'aura mangée. 


\section{CHAPITRE VI.}

A Lusambo. - Fermier, boutiquier et cuisinier. - Cris de guerre! - Gongo Lutété et Descamps. - Ma première bataille. - Ai-je eu peur. - La critique est si facile ! - Retour de Le Marinel et de Gillain. - Le noir habille très bien. Pauvres cochons! - Leçon de modestie donnée par une tornade. - Qui a eu le plus peur : l'éléphant ou moi ? - J'ai la variole : échaudé d'abord.... Je suis pelé ensuite. - Six mois sans nouvalles ‘..... Sélôo !...... ! Sélóo! — En expédition. - "Si vous en mourez, c'est vous quil'aurez voulu ! »...... - Je le vise avec soin et..... je le manque.

Entrons donc dans le Sankuru.

Ici encore la scène change, ce sont d'autres décors, d'autres acteurs et d'autres mœurs. Pour rester dans le vrai, je devrais dire que c'est encore plus beau que tout le reste, mais je craindrais d'ètre taxé d'exagération.

Quelle différence avec le bas Congo! Autant celui-ci nous est apparu pauvre et triste, autant le haut vous apparaît riche, riant et prospère. Les habitants euxmèmes ne se ressemblent pas.

Dans le bas Congo, on voit de suite que la race est dégénérée et a vachie par l'abus des boissons alcooliques, tandis qu'ici on voit une race forte saine, intelligente, presque belle.

Ici, l'indigène n'a pas peur du blanc, on voit qu'il a été bien traité, il le recherche même.

Tous les jours, du haut de ma cabine, je puis jouir d'un spectacle inoubliable, d'un coup d'œil merveilleux. 
Une cinquantaine de pirognes évoluent autour du bateau.

Tous les noirs nous offrent en vente les marchandises les plus invraisemblables, voire même... des membres de leur famille.

Les habitants du Sankuru sont très habiles aux ourrages de mains. Ils confectionnent, entre autres choses, des nattes et des étoffes indigènes qui sont réellement superbes; ainsi que des haches, des lances, des couteaux el des gobelets en bois qui sont de véritables petits chefs-d'wuvre et dénotent, par leur originalité et leur lini, beaucoup de goùt et d'art chez ces artistes, enfants de la nature.

lls sont aussi très commerçants el, je crois, un peu moins voleurs que les autres. Pour me résumer, je dois dire que c'est nne très belle race, qui est aussi intelligente que sympathique et qui, je n'en doute pas, bien conduite, arrivera en très peu de temps à un degré relativement élevé dans la civilisation.

Mais c'est assez parler du nègre pour le moment; nous voilà à Lusambo, mon port d'attache, là où je dois plus ou moins passer mes trois années d'Afrique.

Lusambo vient à peine de naitre, il n'y a pas trois mois qu'il est fondé. C'est Le Marinel qui y commande ; il a arec lui pour le seconder les lieutenants Gillain, Descamps, Legat et Puissant, l'armurier Lovinfosse, le magasinier Piette, enfin le sergent Verdick et moi qui venons d'arriver. 
Lorsque nous débarquâmes, Le Marinel et Gillain étaient en expédition, ils étaient allés faire une reconnaissance destinée à relier le poste de Bena Kamba à Lusambo.

C'était le lieutenant Descamps qui commandait en l'absence de Le Marinel. Il me reçnt très bien et, en peu de jours, nous devinmes bons camarades ainsi d'ailleurs qu'avec les autres habitants de la station, tons de charmants garçons.

La besogne élait répartie comme suit : Legat et Piette les constructions, Puissant le magasin, Lovinlosse était à la lois armurier, forgeron, menuisier et charpentier. Verdick instruisait les recrues. Moi, j'avais l'achat des petits vivres et la ferme, ainsi que la cuisine.

J'étais enchanté.

L'achat des petits vivres me procurait l'occasion de faire la connaissance de tous les nègres des environs, me donnait la facilité d'apprendre la langue du pays et me permettait de faire des études de mours très intéressantes. De plus, mes visites aux plantations ét mon titre de fournisseur de la table me domnaient l'occasion de in'adonner à mon plaisir favori : la chasse.

J'étais parfaitement heureux, celte vie me plaisait beancoup. Je passais mon temps à visiter mes plantations et mon jardin, j'allais voir mes vaches et mes chèvres, je caressais de l'œeil le dos dodı de mes cochons ou je comptais les neufs que m’avaient donnés mes poules et mes canards. 
Entretemps,je faisais du commerce a vec les indigènes, j'allais goûter la soupe ou la sauce, je m'assurais que le cuisinier ne nous volait pas trop ou qu'il ne se lavait pas les pieds dans notre marmite à soupe; le reste du temps, je le passais avec mon brave Pitch à battre les environs.

C'était tout-à-fait charmant et je commençais à trouver que la vie au Congo était sensiblement la mème qu'en Belgique, avec un peu de chaleur en plus; quand, un jour, un bruit de guerre vint jusqu'à nous et me rappela que je n'étais pas seulement fermier et cuisinier, mais officier avant tout.

Le fameux Gongo Lutété avait quitté son repaire de brigands et déchainé ses bandes sanguinaires sur la contrée; l'on nous affirmait mème qu'il n’était plus qu'à trois jours de marche de Lusambo.

Dans cette circonstance, Descamps envoya Legat en reconnaissance et ayant appris que la nouvelle était certaine, il résolut de marcher à sa rencontre.

Gongo Luteté, avec toute sa bande, campait auprès du village de Gongo des Batempas, à près de trois jours de marche de Lusambo.

Les mesures prises par Descamps furent celles-ci : Verdick garderait Lusambo avec quelques honmes, tandis que Descamps marcherait contre Gongo avec deux cent trente soldats noirs commandés par Legat, Puissant, Lovinfosse, Piette et moi. 
Nous fìmes une marche forcée et le lendemain matin nous nous trouvions campés à environ trois mille mètres de l'endroit où le redouté chef arabe avait établi son camp.

Les quelques villages que nous avions rencontrés étaient tous déserts, leurs malheureux habitants s'étant enfuis dans la brousse pour échapper si possible à la mort ou tout au moins à la captivité.

Nous avions également rencontré quelques gens de Gongo qui apportaient de menuś présents à la station et qui nous assuraient des bonnes intentions de Gongo à notre égard. Aussitòt arrivé, Descamps après avoir pris ses premières dispositions en cas d'alerte, envoya un zanzibarite de nos soldats vers Gongo pour lui demander une entrevue.

Celui-ci fit répondre qu'il viendrait lui-mème nous visiter dans notre camp. En effet, environ une beure après, Gongo s'amena avec tout son appareil guerrier auquel il avait donné l'air le plıs imposant qu'il avait pu. Sa venue nous fut annoncée par une batterie de tambours et de tam-tams de toutes formes et de toutes grandeurs; d'autres artistes frappaient sur des gongs où soufflaient dans des trompes en ivoire. Cela faisait bien la plus infernale cacophonie qui se puisse rèver et un tapage à crever tous les tympans.

Le cortège était composé de la façon suivante : un groupe de tambours, puis venant à la file indienne 
983 de ses soldats portant tous le fusil sur l'épaule droite, mais à la mode arabe, c'est-à-dire la crosse en arrière, l'arme étant maintenue dans cette position par la main droite, qui tient le canon à pleine main.

Venaient ensuite les chanteurs et la musique de Gongo que je vous ai décrite tautôt, puis ses amazones et ses porteurs de fusils, enfin Ciongo entouré de ses Nyamparas les plus fidèles et les plus dévoués.

Tout ce monde défilait dans l'ordıe le plus parfait, et, en arrivant devant nous, se groupait rapidement de façon à former un demi-cercle dont leur chef devait occuper le centre.

C'était la première fois, depuis mon arrivée au Congo, que je voyais un pareil développement de force militaire uègre en mème temps qu’une cérémonie que je qualifierai presque de grandiose et certainement de très impressionnante. Je crois que nous étions tous plus ou moins émus. Le souvenir m'en est resté si vivace, qu’il me semble que la scène s'est passée il y a quelques jours à peine.

En arrivant, Gongo marche droit vers nous et nous donne la main à la mode enropéenne, tout en nous souhaitant le bonjour.

Il u'y a pas l'ombre d'une hésitation dans sa marche, et tout, dans sa façon d'ètre, dénote au premier abord un homme sùr de lui-mème et qui a l'habitude d'être obéi. 


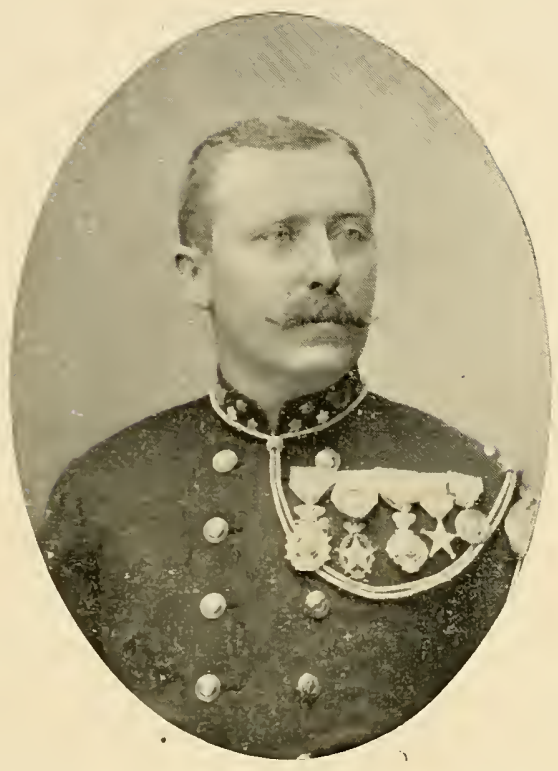

Le Commandant Paul LE MARINEL

Fondateur de la Station de Lusambo et 1er Commissaire de district du Kassaï-Lualaba

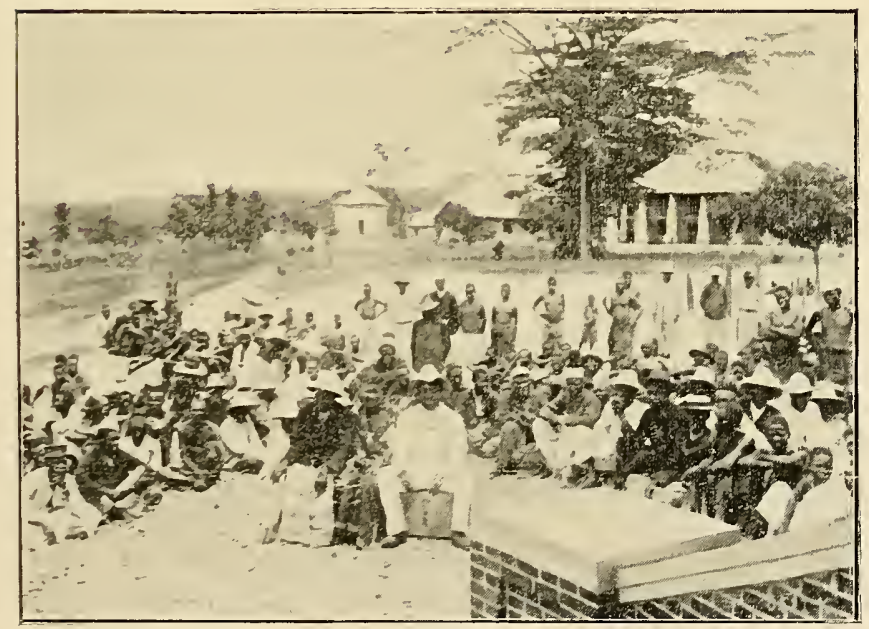

Lusambo: Cheís indigènes attendant l'heure du rapport pour être reçus par le Commissaire de district 

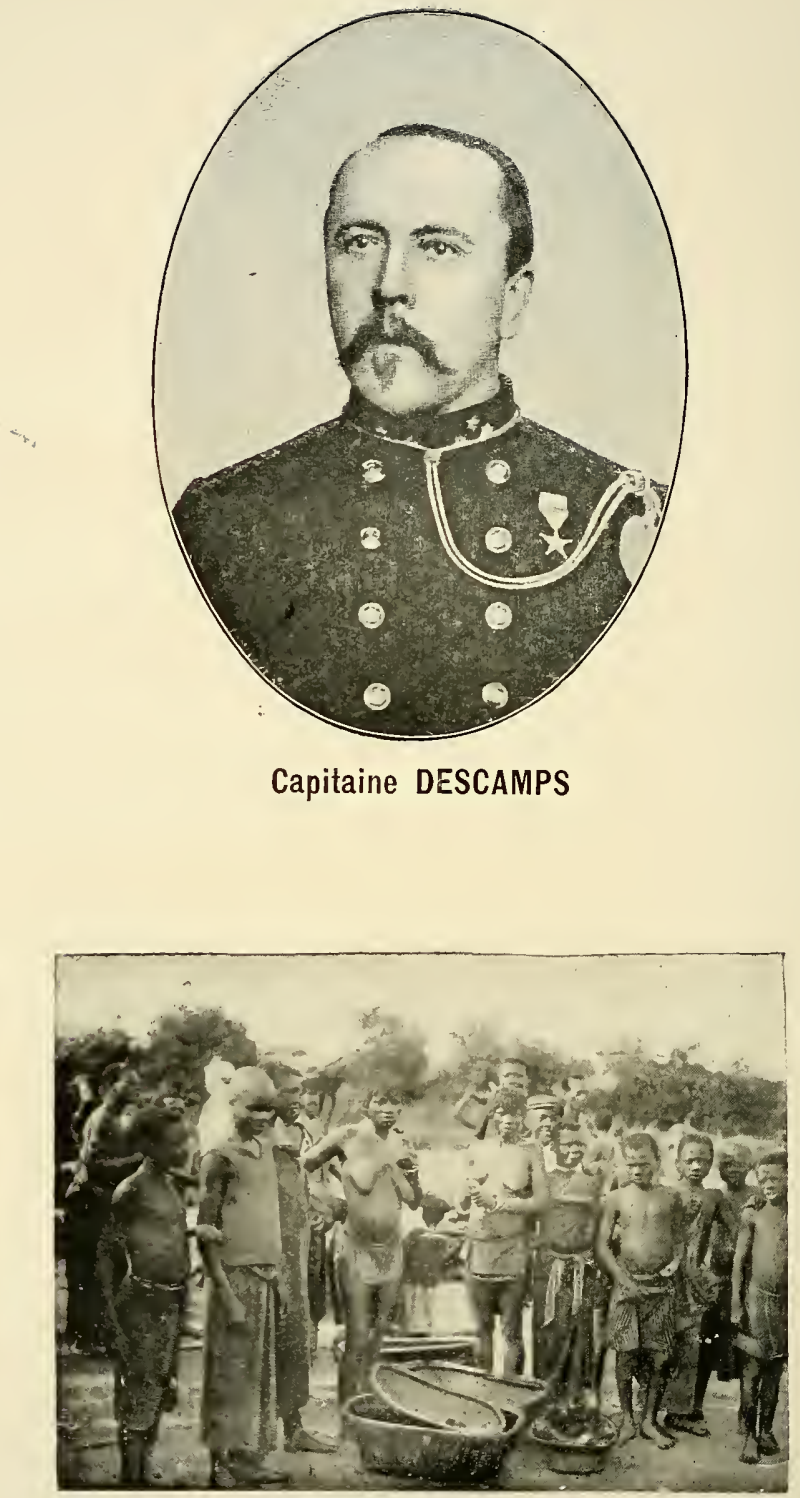

au marché de Lusamba. 
Il pouvait avoir environ 40 ans, d'une taille moyenne et bien prise ; il était plutòt bien de sa personne et rien, ni dans son maintien pondéré, ni dans son oil grand et intelligent, plutòl doux, ne dénotait l'eselavagiste sanguninaire qui terrorisait toute une eontrée.

L'entrerue fut des plus cordiales, mais on ne parla pas d'affaires et il fut eonvenu que Descamps rendrait la visite dans l'après-midi. Ainsi fut fait : Descamps, Legat et Puissant, avee une einquantaine de soldats d'escorte, se rendirent ehez lui pendant que je restais au eamp avee Piette et Lovinfosse prèts à tout événement.

Ce jour, les ehoses en restèrent là, et ce ful seulement le lendemain matin que l'on entama la grande palabre au moyen d'interprètes que l'on s'envoyait réeiproquement. Descamps fit remarquer à Gongo que la zone d'influence eonvenue entre les Arabes et l'Etat avait le Lomani pour frontière, qu'il se trouvait en ee moment sur notre territoire et qu'il avait à le quitter et à retourner ehez lui.

Je n'entrerai pas dans tous les détails des pourparlers; il me suffira de dire que les prétentions de Gongo allèrent jusrqu’à vouloir venir nous rendre visite à Lusambo avee tout son monde. La réponse de notre ehef n'était done pas douteuse. Il lui donna, pour quitter son eantonnement et retoumer chez lui, un certain laps de temps, l'avertissant que, eelui-ci éeoulé, si Gongo n'était pas parti, nous l'attaquerions. 
Aussitôt notre réponse connue, Gongo résolut de nous prévenir : il rassembla ses bandes en toute hâte et marcha contre nous. Prévenus à temps, nous nous portàmes à sa rencontre. Lovinfosse gardait le camp avec 30 hommes. Nous en avions donc 200 à opposer aux 1,000 de Gongo.

Lorsque nous fùmes en présence, nos dispositions étaient celles-ci : Descamps et Legat se trouvaient au centre avec 80 soldats, Puissant commandait l'aile droite composée de 60 hommes; je commandais la gauche ayant sous mes ordres Piette et 60 hommes.

C'était ma première bataille et elle s'annonçait comme devant ètre très sérieuse. Ce que j’ai ressenti est assez difficile à dire. Ai-je eu peur? Je n'en sais rien, mais je ne le crois pas!

Aussitòt que nous fûmes déployés, je remarquai en face de moi un mur en terre qui pouvait a voir un mètre dix à un mètre vingt de haut et qui était formé de gazons enlevés à un champ. Je portai immédiatement mes hommes derrière ce mur et je les fis agenouiller, leur recommandant de bien viser, de tirer avec calme et de n'ouvrir le feu que lorsque j'aurais donné le signal.

Notre attente ne fut pas longue, cinq minutes à peine, car l'ennemi s'avançait en masse profonde et l'on voyait parfaitement se dessiner le mouvement qu'il faisait pour nous envelopper. 
Cinq minutes sont vite passées, me direz-vous, oh! non. Cinq minutes sont bien longues lorsque l'on attend sa première bataille! J'étais donc avec mes hommes, agenouillé derrière mon mur, j'avais pris mon fusil de chasse des mains de mon boy et je l'avais chargé de deux cartouches à ballettes.

Je contemplais cette masse grouillante, cette mer montante qui essayait de nous envelopper et qui, par son nombre, voulait nous engloutir, nous submerger. Je sentais tous mes nerfs tendus d'une façon extraordinaire, j'avais la tète en feu et cependant je suis certain que j'étais très pàle; j'avais des crispations dans tous les membres et je ne souhaitais qu'une chose,commencer le plus tòt possible pour avoir le plus vite fini.

Une chose aussi m'exaspérait au plus haut point : je u'avais jamais vu le feu et cependant, si j'allais perdre la tète, que diraient de moi mes camarades de régiment? Ohı ! ce doute était terrible et me mit réellement la rage au coeur.

Mais bientòt l'ennemi est à portée et Puissant entame l'attaque, suivi de près par Descamps et Legat.

Le voilà également en face de moi ; un grand diable conduit l'attaque; il marche en tète, un drapeau arabe daus la main gauche et sautant, criant, gesticulant et jetant son fusil en l'air suivant la mode arabe. Epauler et faire feu fut l'affaire d'une seconde et j'eus la satisfaction de voir mon homme s'abattre comme une masse. 
C'était ma première victime de ce genre, et, en le voyant tomber, je fus tout saisi de voir comme c'était facile de tuer un de ses semblables. Ensuite, pendant une demi-heure, je ne me souviens plus très bien de ce qui s'est passé.

Je sais qu'à mon signal mes hommes tirèrent, que les Arabes ripostèrent, enfin que je portai mes hommes en avant, que les Arabes s'enfuirent, et que, dans la poursuite, j'ètais comme euragé, fou de colère et enivré de carnage.

Dans la poursuite et sans l'avoir aperçu, nous nous trouvons à un moment donné ell face du boma où Gongo Lutété avait enfermé toutes ses femmes. Sans une seconde d'hésitation, je me lance à l'attaque avec mon peloton et j'y trouve 243 jeunes et jolies négresses que je fais prisonnières.

Cette prise du boma de Gongo avec quelques hommes et sans une seconde d'hésitation m'a fait faire dans la suite bien des réflexions sur le courage et les actions d'éclat.

Pour moi, il y a trois espèces de courage : Il y a le courage froid, qui vous fait faire une action d'éclat et exposer votre vie avec calme et sang-froid parce que c'est votre devoir. C'est le plus rare, le seul vrai et le seul méritoire.

Il y a ensuite le courage que vous donne l'odeur de la poudre, l'enivrement de la bataille et qui fait de vous 
un être qui tue parce que l'ordre est de tuer, et que ses nerfs surexcités le portent à exécuter cet ordre, autant pour satisfaire sa passion propre que par obéissance.

C'est le courage bestial, c'est le plus commun et il est heureux qu'il existe, car sans lui il nous serait bien difficile, je crois, d'entraîner nos hommes à la bataille.

Enfin, il y a le courage des jeunes, des novices, qui ne savent pas, et qui, bravement, follement, se lancent avec quelques hommes à l'assaut d'un boma, parce qu'ils ne se rendent pas compte du danger qu'ils courent et qui, après, sont eux-mêmes tout étonnés d'avoir accompli une action d'éclat dont ils ne se doutaient mème pas. Ce fut mon cas.

Plus tard peut-être livreront-ils encore des combats et prendront-ils encore des bomas, mais alors ils auront conscience du danger qu'ils courent et ils ne le feront plus que par devoir ou par orgueil en songeant que des camarades comptent sur eux, que des jaloux les observent et que succès ainsi que noblesse oblige.

Une chose aussi que j'ai constatée, c'est que tel homme n'est pas le même tous les jours, surtout lorsqu'il commande en chef. Certain jour, ses conceptions toucheront au génie, tandis que d'autres fois elles seront plutôt médiocres. J'attribue la chose aux dispositions du corps et de l'esprit du moment et je suis fermement convaincu que bien des batailles ont été gagnées ou perdues parce que ce jour-là le général en 
chef avait plus ou moins reposé ou plus ou moins mal digéré. Et voilà cependant à quoi tient la destinée du monde!!!

Mais revenons à mes prisonnières que j'ai quittées pour cette petite digression.

Aussitòt que je les eus rassemblées, je les formai en colonne pour les reconduire au camp et, enveloppées par les hommes de mon peloton, nous nous dirigeons vers le cantonnement.

Mais Descamps, qni est déjà rentré avec ses hommes, nous a aperçus et royant line colonne serrée de trois cents personnes se diriger rers lui croit à un retonr oll'ensif de Gongo el s'apprête à nous recevoir de belle façon.

Heureusement, à ce moment, un de ses soldats me reconnnt;sans cela on me faisait une réception à laquelle je ne m'attendais guère et qui m'aurail été d'autant plus désagréable que je ne pouvais pas riposter.

Le combal élait terminé; nous étions victorieux et le lendemain matin nous pûmes reprendre le chemin de Lusambo.

Ce fut certainement une des plus belles victoires remportées par les troupes de l'Etat. Non pas tant par le nombre des combattants ni des morts qui restèrent sur le champ de bataille, mais surtout par son effet moral. Jusqu’à ce jour, en effet, la prise des Falls par les Arabes et la mort de Deane n'avaient pas été vengées, 
et l'Etat avait dù, en quelque sorte, baisser pavillon devant Tippo-Tip et ses bandes sauvages.

Or, Descamps, sans ordre du gouvernement et prenant toute la responsabilité sur lui, avait, avec une audace inouïe, attaqué avec quelques recrues le chef le plus redouté et le plus sanguinaire des Arabes.

Gongo Lutété était vaincu, en fuite et désormais les terribles A rabes n'étaient plus à nos yeux qu'une troupe indisciplinée pour Iaquelle nous n'avions que du mépris.

Est-ce à dire que tout fut parfait dans ce combat et qu'aucune faute ne fut commise? Bien loin de là, nous fìmes mème tous des fautes, puisque nous étions presque tous des novices, et si je me plais à le constater, c'est qu'il est si facile de critiquer après coup les fautes des autres, mème quand on n'a rien fait soi-même et que, le cas échéant, on se serait probablement trouvé bien embarrassé pour se maintenir à la hauteur de ceux que l'on critique de son cabinet. Je dis donc que des fautes furent commises.

Descamps Iui-même, que j'admire sans restriction pour son coup d'audace, commit la faute de ne faire distribuer que 40 cartouches par homme, alors qu'il allait s'engager dans un combat sérieux et se privait ainsi, faute de munitions, des avantages qu'il pouvait retirer d'une poursuite vigoureuse.

Quant à moi, sachant le peu de munitions que mes hommes possédaient, j'en commis une plus grande 
encore en n'épargnant pas mes munitions : le combat fini, certains de mes hommes n'avaient plus de cartouches; aux autres, il en restait très peu.

Les autres pelotons se trouvaient dans le mème cas. Ce fut une rude leçon pour moi et je vous affirme bien que dans mes autres combats ma préoccupation dominante fut invariablement, depuis ce jour, la discipline du feu et le ravitaillement en munitions.

Mais, je le répète, c'est si facile de conslater une erreur, lorscu'elle a été commise. Tout autre chose est de la prévoir ; aussi ma conviction est-elle qu'en fait de bataille, in bon combat vous en apprend sonvent plns que loute me année passée à piocher des traités de tactique ou étudier les batailles des autres.

Je ne venx pas dire par là que l'étude sur le papier ne soit pas très nécessaire, indispensable même, surtout maintenant que la guerre est devenue une chose savante, mais j'estime qne pour être bien sûr de soi-mème, il faut et la théorie et la pratique. Et encore el toujours des fautes se commeltront; toute la question est de saroir celui qui en commettra le moins.

En retournant à Lusambo, nous rencontrâmes Le Marinel qui, rentré à la station de son voyage d'exploration avec Gillain et apprenant notre départ, n'avait fait que toucher barre et accomait avec les cent hommes qui lui araient servi d'escorte, pour nous aider le cas échéant. 
Encore un brave que ce Le Marinel, un des vrais de la première heure, ne regardant que l'œuvre sans en escompter les profits, un homme de cour autant qu'un homme de tète.

Personne mieux que lui,dans le chaos où nous vivions alors, ne s'entendait à résoudre une question difficile, à percer à jour les astuces d'un chef nègre, ou de déduction en déduction à connaître une contrée qu'il n'avait pas parcourue. Avec Dhanis et Gillain, il fut mon professe ur, je dirai mon initiateur des choses nègres, si je puis m'exprimer ainsi, et si plus tard j'eus quelques succès au Congo, c'est en grande partie à leurs bonnes leçons que je les dus.

Rentrés à Lusambo, nous eûmes à nous occuper de loger mes nombreuses prisonnières, puis notre vie de station reprit son cours accoutumé jusqu'au départ de Le Marinel, Descamps, Legat et Verdick pour le Katanga.

Lorsque Le Marinel m'apprit que je ne pouvais pas l'accompagner au Katanga, qu'il jugeait que je pouvais rendre plus de services à Lusambo, ce fut un véritable crève-cœur pour moi, mais comme enfin tout le monde ne pouvait pas partir, il fallut bien me résigner.

Ce fut également à cette époque que je m’aperçus pour la première fois depuis mon arrivée au Congo, qu'un blanc pouvait trouver qu'une négresse était jolie. J'ai dit jolie. Sans doute, ce mot fera sourire quelques 
personnes, mais seulement celles qui n'ont pas été an Congo ou qui n'en ont habité que la côte. Quant aux camarades qui ont habité à l'intérieur, demandez-leur leur avis et ils vous diront qu'après un certain temps de résidence, le noir habille très bien, est très bien porté et qu'après trois ou quatre années de séjour, au moment où l'on est tout à la joie de revoir les siens, son terme en Afrique étant expiré, nne petite frimousse noire vous laisse un charmant souvenir.

Mais assez parler de sentiments. Puisque je suis fermier, revenons à nos moutons. J'étais novice, je ne savais rien des choses du Congo, par conséquent je me croyais beaucoup plus fort que les anciens. Aussi, ayant renarqué une terre d'allnvions à proximité de la station, je me dis qu'elle devait ètre d'une fertilité merveilleuse, et, sans tenir compte de l'observation de Le Marinel qui m'avait fait remarquer qu'il y avait beaucoup de chance ponr que ce terrain fût inondé à la saison des pluies, j'établis une digue, je défrichai et semai un jardin, qui, semblant me donner raison, faisait toute ma gloire et mon orgueil, tellement tout y poussait à souhait.

Voulant éviter à nos sens olfactifs l'odeur sui generis des por'es, je leur avais bâti un palais dans les environs. Le tout allait pour le mieux, et lorsque je contemplais mon jardin en plein rapport ct que de l'œil je caressais mes futurs jambons que je faisais fumer par la pensée, 
je traitais de chimériques, les craintes de Le Marinel et je souriais sous cape, me trouvant infiniment plus fort que lui.

Hélas ! en Afrique, surtout, la roche Tarpéienne est bien près du Capitole.

Une nuit donc, où je rêvais de radis rose, de jeune salade, de sancisse et de boudin, je fus réveillé au milieu de mon festin de Balthazar par une tornade épouvantable. Le tonnerre faisait rage et toutes les vannes du ciel étant ouvertes, c'était absolument comme si des millions de gouttières s'étaient mises à couler sur nos têtes.

Tout le monde comprendra mon anxiété... Vers le matin, la pluie ayant diminué d'intensité, je profite des premières lueurs du jour pour sauter dans mes bottes et courir à mon jardin.

Je renonce à vous dépeindre ma consternation. Là, où la veille encore je m'étais promené au milieu des parterres en fleurs ou portant déjà des fruits, il n'y avait plus qu'un lac immense, lac sur lequel flottaient dans un chaos indescriptible des radis, des melons, des choux, des navets, des ananas, enfin tous les fruits et les légumes de mon jardin.

Ma déception, je dirai presque mon désespoir fut sans borne, surtout lorsque m'étant rendu à la maison de mes cochons, je les vis tous gonflés démesurément et flottant au plafond de leur habitation. 
Ce fut encore une leçon pour moi, mais une leçon de modestie cettc fois, qui m'apprit, pour l'avenir, à faire un peu plus attention aux avis de ceux qui ont déjà acquis de l'expérience.

Quant à Le Marinel, il eut le bon sens, le bon esprit et le bon cour de ne pas se réjouir et de ne pas me reprocher ma mésaventure. Je récoltai ce que je pus de mes légumes, je repiquai ceux qui étaient susceptibles de l'être, je salai ce qui me restait de mes cochons, après que l'on eut fait une ample distribution de viande à nos soldats, pour qui cette noyade fut une véritable aubaine, tant il est vrai que le malheur de l'un fait le bonheur de l'autre et on ne parla plus de la chose que de temps en temps, pour me lancer une " pique " amicale ou encore pour me rappeler à la modestie, lorsque j'essayais d'épater les camarades au récit de mes exploits cynégétiques.

Ici tout n'était pas toujours rose et parfois le gibier prenait une revanche dont mon amour-propre avait quelque peu à souffrir.

C'est ainsi qu'un jour ayant été envoyé par Le Marinel au village de Kassakamibanga pour un motif que je ne me rappelle plus, j'eus une aventure peut-être très amusante pour les autres, mais qui me fut profondément désagréable.

C'était vers le soir; il pouvait être cinq heures. Ma palabre terminée, comme je savais qu'il y avait 
beaucoup de pintades et de perdreaux dans les environs, j'étais parti avec mon chien et mon fusil de chasse à la recherche de mon déjeuner du lendemain. Ne comptant pas m'éloigner du village, je ıe m'étais pas fait accompagner et j'étais tout au plaisir de mon sport favori, quand, m’étant quelque peu éloigué saus le savoir et me trouvant dans une petite clairière à environ une demi-heure de marche du village, j'entends tout-à-coup un grand bruit sur ma droite, des branches écrasées, d'autres cassées, enfin un brouhaha de tous les diables. Pitch, mon féroce Pitch lui-mème en est tout effrayé et il vient peureusement se réfugier dans mes jambes.

Je n'ai encore rien compris à la chose et je reste sur place tout interloqué quand, à moı grand ahurissement, un éléphant énorme m’apparaît à cinquante pas !

Qui a été le plus saisi de la bète ou de moi, je n'en sais rien. Toujours est-il que pendant qu'elle disparaissait au galop, je restais ébahi, contemplant alternativement mon fusil de chasse, sur lequel j'avais du petit plomb, et mon énorme bête qui s'enfuyait.

Franchement, j'ai eu pendant quelques minutes conscience de ma faiblesse en présence de ce monstre ; aussi, depuis lors, je n'ai plus jamais fait un pas sous bois sans être accompagné du porteur de mon express. Ai-je eu peur? je crois bien que oui. Dans tous les cas, j'ai été ce que l'on peut appeler ahuri, car je me rendais parfaitement compte que mon fusil de chasse n'était, 
dans cette occasion, qu'un vrai jouet et que mes plombs n'auraient pas seulement chatouillé l'épiderme de ce géant. Aussi, dans ma colère impuissante et dans ma rancune de la frousse qu'il m'avait donnée, ai-je juré dès ce jour de me venger sur sa race entière.

Un midi, en rentrant des plantations, je fus pris de maux de tête terribles, toute ma figure se boursouflait. Au premier abord, je me crus empoisonné et ce fut seulement le lendemain que l'on constatait que j'avais la terrible variole du Congo qui pardonne si rarement.

Nous n'avions ni médecin, ni médicaments; c'était donc inutile et dangereux d'exposer d'autres blancs à la contagion; aussi ma maison fut-elle sévèrement défendue à toute autre personne qu'à mes serviteurs noirs.

Je vous ferai gràce de mon supplice moral et physique pendant ce mois de douleur, où les plus terribles menaces étaient suspendues sur ma tète, pour ne vous parler que de ma guérison et du remède qui probablement la provoqua.

Mes serviteurs noirs, qui m'aimaient beaucoup, voyant les blancs impuissants à me guérir ou mème à me soulager, tinrent conseil et, après avoir consulté le féticheur de l'endroit, attendirent le jour où toutes les pustules (et il y en avait par centaines) fussent bien sorties; puis sans me demander mon avis, au moyen de longues aiguilles en fer, ils me les percèrent toutes, 
Quant à moi, j’étais si faible que je n'avais la force de m’opposer à rien. Cette première opération terminée, ils me prirent par les pieds et par la tète et me couchèrent dans un canot transformé en baignoire pour la circonstance, et qu'ils avaient rempli d'eau presque bouillante. Enfin, les plus solides de la bande s'emparèrent de moi et, au moyen de torchons de grosse toile, me frictionnèrent de toute leur force, ils me "pelèrent " réellement.

Je crois inutile de vous dire que pendant cette dernière opération je m'étais évanoui consciencieusement.

Echaudé d'abord, écorché ensuite, je crois qu’il y avait de quoi.

Mais le plus curieux de l'histoire, c'est que lorsque je revins à moi, je me trouvai couché daus un lit bien propre, que la fièvre avait disparu et que, sauf les picotements de l'épiderme et une courbature générale, je me sentais réellement guéri.

Est-ce leur remède? Est-ce ma constitution? Est-ce un prodige? Je n'en sais rien; la seule chose qui soit certaine, c'est que je guéris si bien qu'il ne m'en resta mème aucune trace et que, semblable aux anguilles et aux serpents, j'en suis à ma seconde peau.

Six mois sans nouvelles !!!!!

Il y a six mois que je suis à Lusambo et, depuis six mois, nous sommes sans nouvelles d'Europe, aucun steamer n'etant venu nous ravitailler. Aussi je vous 
laisse à penser avec quelle impatience il est attendu. Tous les jours et à chaque heure du jour, lorsqu'on a un moment de loisir, les jumelles sont braquées vers le coude du fleuve, afin de voir si un panache de fumée ne nous annonce pas la présence du courrier. Mais non, rien! toujours rien! C'est à croire que l'on nous a oubliés. Si, par habitude, on scrute encore l'horizon, c'est toujours sans espoir, avec lassitude et découragement.

Mais, qu’entend s-je?... Sélòo !... sélòo! !... et presque aussitòt un coup de sifflet strident traverse l'espace

Je n'ose en croire mes oreilles et, me précipitant hors de ma maison, j'ose à peine en croire mes yeux. Le steamer est là!... Je tremble, je sens que je suis très pâle.

Je voudrais rire, crier, sauter et cependant j'ai une forte envie de pleurer et, malgré moi, de grosses larmes me mouillent les yeux.

C'est que, dans ce moment, tous ceux qui me sont chers viennent de passer devant moi. Oh! qu'elle est terrible, cette seconde pendant laquelle on se demande : " Comment se portent-ils? sont-ils encore tous en vie!" Enfin, le bateau stoppe et, après les saluts d'usage, le capitaine, qui connaît notre impatience, s'empresse de nous remettre nos lettres. Vite, on regarde les timbres. Voici la dernière en date. L'enveloppe saute et l'on court à la fin. 


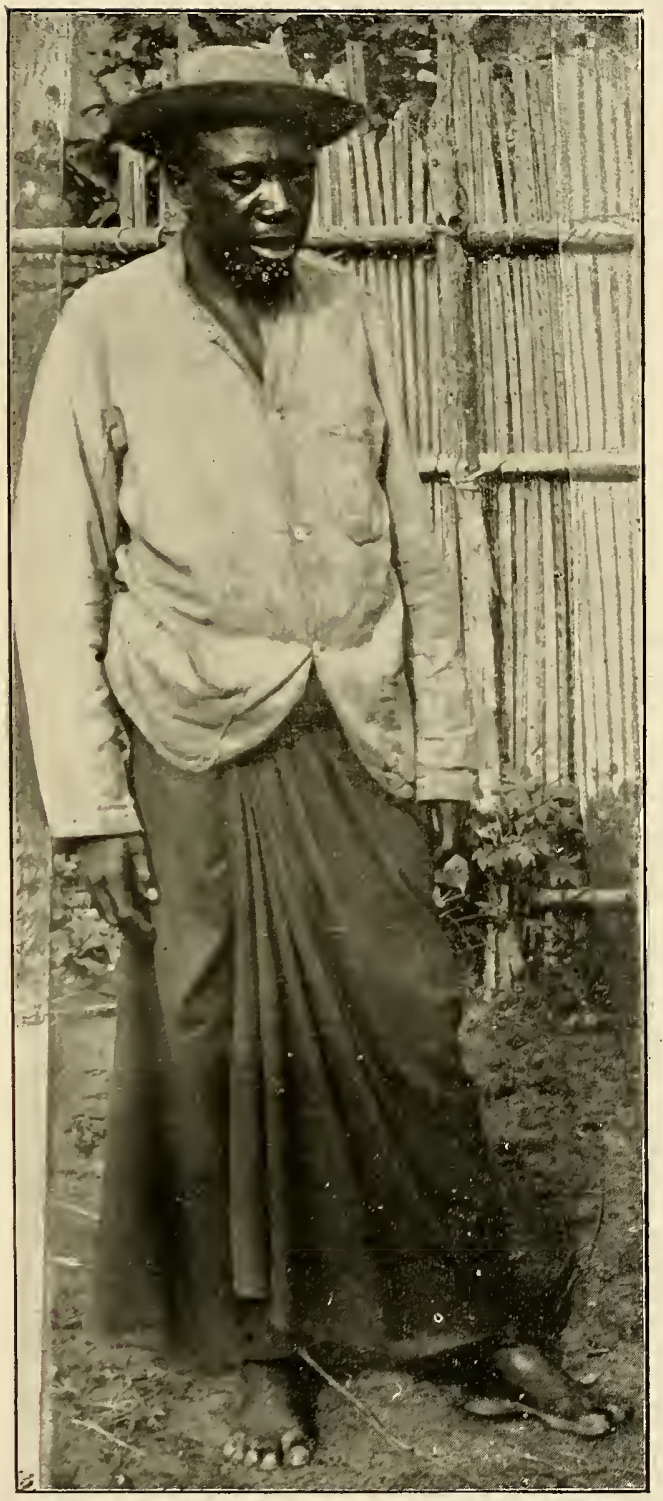

ELONGA, chef des Bakuba de Lusambo et environs 


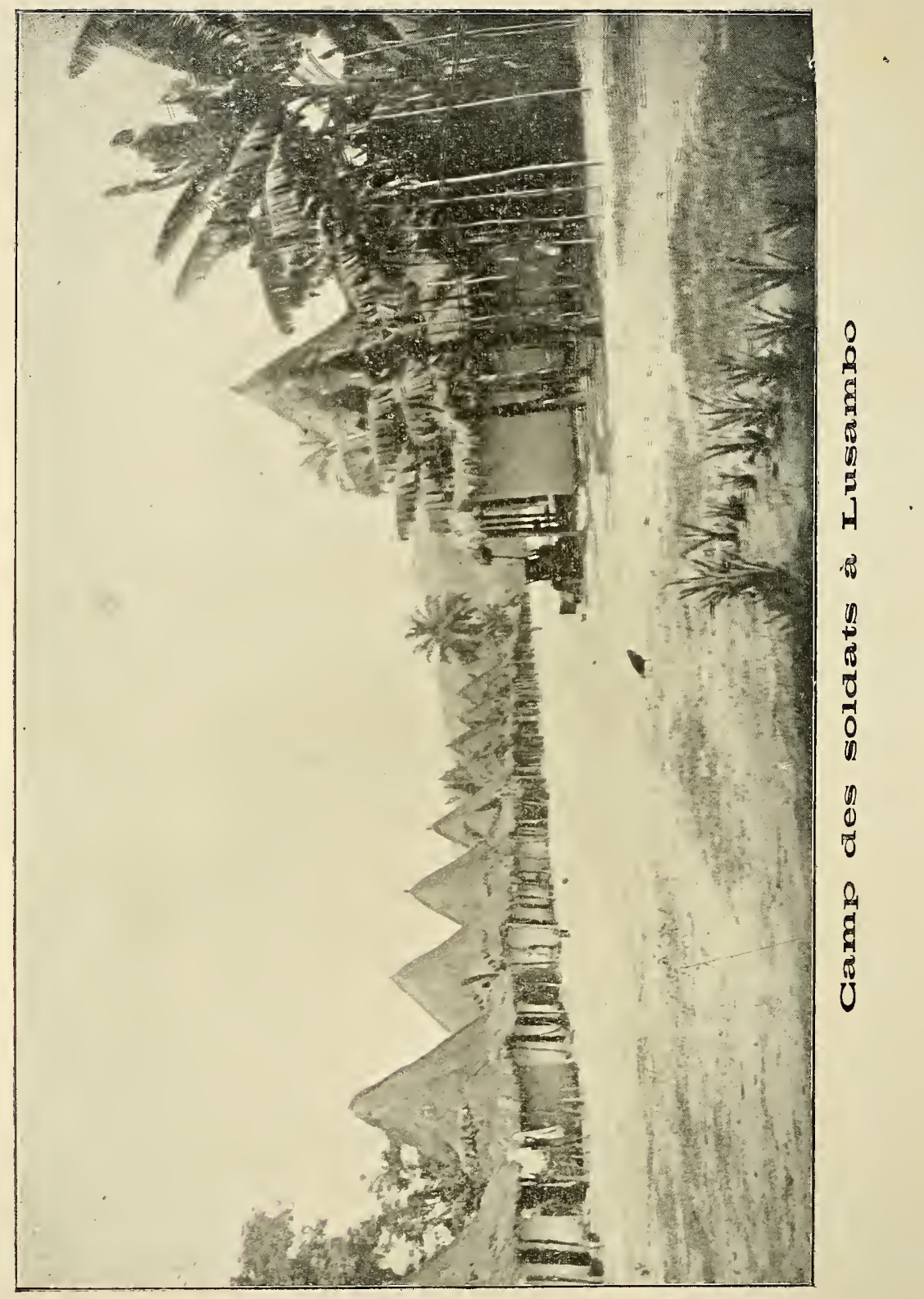


Tout le monde porte bien! On respire enfin! On met ses lettres en poche et l'on a un mot aimable pour les arrivants.

Quant à ses lettres, c'est chez soi qu'on les lira, les relira, que l'on vivra en quelque sorte avec elles et avec les ètres chéris qu'elles nous rappellent.

Lorsque l'on se trouve auprès de ceux que l'on aime, et que chaque jour on les voit heureux et en bonne santé, on fait sans doute des vœux pour qu'ils se conservent dans cet heureux état, mais on s'habitue si vite au bonheur qu'il semble impossible qu'il en soit autrement. Mais quand on se trouve à des milliers de lieues les uns des autres et que l'on n'a des nouvelles qu'après de longs mois d'attente, la confiance s'affaiblit et les voux que l'on forme pour les siens sont d'autant plus ardents que l'on a plus tremblé pour eux.

Alors, au milieu des baisers que l'on reçoit, et que l'on rend par la pensée, le cœur faiblit encore, mais, cette fois, ce sont de bonnes larmes, qui fortifient et qui font vivre, puisqu'elles ne sont dues qu'à d'heureux souvenirs.

Une prière d'actions de grâces monte d'elle-même aussi vers le Dieu tout Puissant et, involontairement, sans le savoir, presque, on lui crie : merci, mon Dieu !

Après le départ du steamer pour Léopoldville, le commandant Le Marinel, désirant laisser une situation aussi nette que possible à Lusambo, avant de partir 
pour le Katanga, organisa une expédition qui devait se rendre chez les Bakuas Kassasus et chez les Bakuas Mulédis.

Ces deux peuplades se trouvaient sur la seule route que nous connaissions alors pour aller de Lusambo à Luluabourg; or, à deux reprises, elles avaient tué nos courriers, interceptant ainsi toutes nos communications par la voie de terre avec cette dernière station.

Une expédition fut résolue contre elles et le major Descamps (à cette époque lieutenant) en eut le commandement; je lui servais de second.

Le $1^{\text {er }}$ novembre 1890 , nous nous mîmes en marche avec 150 bons soldats, bien décidés à obtenir à tout prix la soumission des deux peuplades.

Le troisième jour, nous arrivons au premier village des Bakuas Mulédis. Celui-ci est désert et a été brûlé par ses habitants. Le dolite n'est donc plus possible; loin de se soumettre, c'est la guerre qu'ils veulent et ils doivent s'apprèter à nous attaquer.

A peine installé, et sans que rien m'eùt fait présager la chose, j’ai un assez violent accès de fièvre.

Descamps me fait mettre au lit et s'installe à mon chevet, il me fait prendre force quinine et force thé et me dit que nous resterons le lendemain en place, afin que je sois tout à fait guéri de mon indisposition avant de nous remettre en route. (Ceci se passait vers 3 heures de l'après-midi.) 
Vers 8 heures du soir, un mieux s'était produit et j'étais en pleine transpiration, quand tout à coup la fusillade éclate autour du camp.

Descamps me crie aussilòt de rester dans mon lit et court organiser la défense. Mais à peine est-il sorti de chez moi que, pieds uns, en chemise, enveloppé seulement d'une couverture, je sors de ma tente pour me rendre compte de ce qui se passe.

Ce n'était qu'une petite alerte : deux de nos hommes seuls furent légèrement blessés.

Quant à Descamps, furieux de l'imprudence que j'avais commise, il me força à me recoucher immédiatement, me déclarant que si, par la suite, j'en mourais, c'est moi qui l'aurais voulı.

Je me recouchai assez penaud, je passai une excellente nuit et, le Iendemain matin.... j'étais complètement guéri. Toutefois, c'est un remède que je ne conseille à personue.

Dès 5 heures du matin, chacun de nous est sur pied; un sergent noir garde le camp avec trente hommes. Quant à Descamps et moi, nous partons chacun dans une direction différente et décrivons un grand quart de cercle au bout duquel nous devons nous rencontrer.

Nous voilà, nous faufilant sous bois, chacun de notre còté, et cela dans le plus profond silence, car la grande question est de cacher sa marche à l'ennemi. 
Dans ces sortes d'expéditions, on entendrait voler une mouche et le grand serpent humain que forme la colonne déroule lentement ses anneaux.

Une marche de guerre, exécutée dans ces conditions, a tout à la fois quelque chose de triste, de solenuel et d'effrayant; la nature elle-mème semble vouloir s'associer à nos tristes pensées, et le paysage, devenu tout à coup silencieux, semble se recueillir et méditer sur le drame auquel il va assister.

Nolls marchions dans cet ordre depuis mne heure environ, quand tout à coup la fusillade éclate sur notre droite.

Descamps est aux prises avec l'ennemi.

Peu d'instants après, nous apercevons deux villages qui se touchent et dont toute la population en armes fait face à Descamps.

lls ne nous avaient pas vus ! Je donne aussitôt l'ordre à mes hommes de se ranger en bataille dans le plus grand silence et de ramper jusqu'à la lisière du bois, leur recommandant bien de ne tirer qu'à mon signal. Toutes ces mesures prises, je vois un grand diable qui, monté sur une case d'où il semble donner des ordres, observe les environs. Il n'est pas à plus de cent pas de moi. Je le vise avec soin, je presse la détente et... je le manque!!

Mille diables! !... Comment ai-je pu le manquer, je n’y comprends encore rien et je ne puis m'expliquer 
la chose qu'en la mettant sur le compte de ma fièvre de la veille.

A ce signal, mes hommes font un fell de salve et, ne voulant pas laisser à l'ennemi le temps de se reconnaitre, je fais sonner la charge, mais déjà tout fuit derant nous; quelques instants après, nous nous rencontrons avec Descamps.

Nous n'arons pas de tué, seulement deux soldats blessés, l'un assez légèrement à l'épaule et l'autre le bras traversé d'une flèche.

L'ennemi s'étant retiré chez ses alliés, nous continuons notre marche en avant. Après cinq jours, nous arrivons chez les Bakuas-Eudus. Ceux-ci et leurs alliés sont rangés en bataille sur la lisière du bois et semblent nous attendre de pied ferme.

Descamps, à qui il répugne aussi bien qu’à moi, de répandre un sang inutile, et qui est bien l'homme le plus pacifique que je connaisse (nous l'appelions à Lusambo le papa Descamps), fait tout son possible pour empêcher un nouveau massacre. A cet effet, il envoie un parlementaire aux Bakuas-Endus pour leur dire que maintenant ils devaient bien connaître la puissance de nos fusils et que la lutte étant inégale, il leur conseillait de se soumettre à l'Etat; que s'ils voulaient payer une amende pour les courriers qu'ils avaient assassinés et promettre de ne plus recommencer, il consentirait à leur pardonner. Mais ils firent fièrement 
répondre qu’ils étaient là pour combattre et non pour parlementer, que, d'ailleurs, ils ne nous craignaient pas.

Pauvres diables! leur présomption devait leur coûter cher.

Tout en nous tenant hors de la portée de leurs fusils à piston et de leurs flèches, nous donnons un petit repos à nos hommes afin qu'ils soient plus frais pour l'attaque, et vite nous mangeons un morccau sur le pouce.

Vers onze heures, Descamps me dit :

- Eh bien, Michaux, êtes-rous prêt?...

- Quand vous roulez !...

- Allons !

Notre dernière recommandation à nos hommes est de ne pas gaspiller leurs munitions, de tirer avec calme et de viser avec soin. Ces recommandations faites, nous nous déployons en tirailleurs.

Dans le camp indigène, ce sont des cris, des battements de tambours, des appels sur les cornes de guerre, des hurlements et des contorsions épouvantables.

Chez nous, pas un mot, nous avançons en silence, le doigt sur la gachette du fusil.

Arrivés à environ cent mètres de l'ennemi, une grêle de flèches tombent à nos pieds et leurs monsquets nous envoient une rolée de balles.

Deux de nos hommes tombent mortellement frappés, l'un d'une balle à la tempe, l'autre d'une flèche en pleine poitrine. 
C'est le moment.

Feu à volonté de cinq cartouches! Un feu terrible éclate sur notre ligne et, en moins de cinq minutes, l'ennemi affolé se saure dans toutes les directions. Leur folle présomption leur a coìté au bas mot de 60 à 80 hommes.

Après être restés cinq jours sur place, pour bien montrer que nous étions les maitres de la situation, nous rentràmes à Tchibango, village d'un de nos chefs alliés. Nous nous y reposons quelques jours, puis je reçus l'ordre de rentrer à Lusambo.

Quant à Descamps, il attendit une caravane venant de Luluabourg, afin de l'escorter et de la défendre au besoin.

A mon arrivée à Lusambo, grande nonvelie: un steamer était venu pendant notre absence, et il apportait des ordres de Bruxelles, prescrivant à Le Marinel de partir avec une forte caravane pour le Katanga et cela sans retard. 



\section{CHAPITRE VII.}

Départ de Le Marinel pour le Katanga. - Une Suisse préhis. torique. - La belle Tumba. - " Je te servirai, comme si tu étais mon père. ) - Nouvelle révolte des Bakuas Endus. - Je suis consacré féticheur. - Cinquante contre plus de deux mille. Toréadors malgré nous. - Foudroyées 1 1..... - Chirurglen et même dentiste.

Trois semaines après mon retour, Le Marinel, Descamps, Legat et Verdick se mettaient en route. C'était le 19 décembre 1890.

Cinq cent hommes bien aguerris et bien disciplinés leur servaient d'escorte. Jamais plus belle ni plus brave caravane n'aura traversé l'Afrique. Amis, au revoir et que Dieu vous protège!

L'expédition partie, nous restions encore cinq blancs à Lusambo, mais nous étions presque sans troupes, tout ce qu'il y avait de mieux étant parti pour le Katanga.

Cependant, l'expédition était à peine partie depuis quinze jours, que des rumeurs étranges parvinrent à Lusambo. Les Arabes, disait-on, étaient en mouvement et tout le pays des Batempas était dans le plus grand émoi.

Le major Gillain (à cette époque également lieutenant) commandait le district du Lualaba en l'absence de Le Marinel. 
Voulant savoir au juste ce qui se passait dans ces parages, il me donna l'ordre de partir pour cette contrée avec 30 soldats d'escorte, de voir le plus de chefs possible et de tàcher de me renseigner le plus exactement que je pourrais sur tous les racontars en circulation.

Je partis donc et je fis un des plus beaux voyages qu'il était possible de faire à cette époque au Congo. Pour vous en donner une idée, il faudrait ètre peintre et poète et, malheureusement, je ne suis ni l'un ni l'autre.

Toute la coutrée des Batempas est à la fois montagneuse et boisée. C'est une espèce de Suisse préhistorique.

Toutes les montagnes affectent les formes les plus tourmentées et s'habillent de toutes les coulenrs que le sol et la végétation peuvent mettre à leur disposition.

Quant aux forêts, elles datent assurément du commencement du monde et elles vous en imposent tant par leur immensité que par les dòmes incomparables de tous leurs vétérans.

C'est là qu'il fait bon aller rèver le soir dans la vallée profonde, près du torrent fougueux.

Car les pensées qui vous viennent se ressentent $d u$ milieu où vous vous trouvez, elles sont à lo fois d'une envolée qui vous surprend, tout en vous rappelant à la modestie, car on se trouve bien petit devant ces arbres géants qui, depuis des siècles, défendent même au soleil de les pénétrer de ses rayons. 
Les habitants de la contrée sont aussi des plus intéressants à étudier : ils sont grands, bien faits et intelligents.

Ce fut chez eux que j'eus la première fois l'occasion de constater qu'au moyen de la télégraphie acoustique, ils peuvent en très peude temps se communiquer toutes nouvelles les intéressant. C'est ainsi que plusieurs jours avant mon arrivée dans les villages, ma venue était annoncée par les gongs qui conviaient le ban et l'arrièreban de la population à venir contempler cet être étrange, qui avait la peau blanche sur la figure et les mains, et de diverses couleurs sur les autres parties du corps. (Les pauvres diables ne portaient pas de vêtement et, n'ayant jamais vu de blanc, se figuraient que mes habits faisaient partie de ma personme.) Aussi, partout quelle foule! quels rires! quelles contorsions !

Aussitòt que j'approchais d'un village, tous les tambours battaient et tous les hommes en armes venaient à ma rencontre, pendant que les femmes se sauvaient dans les bois.

Mais, comme bientôt elles apprenaient que je n'avais mangé personne, ni fait personne prisonnier et que j'avais, au contraire, fait quelques cadeaux, bientôt dis-je, elles revenaient et alors j'étais littéralement assiégé.

Si je mangeais ou si je buvais, si j’ouvrais la bouche, leur premier mouvement était de prendre la fuite, mais 
bientôt elles revenaient et se déboîtaient les mâchoires tant elles ouvraient la bouche en mème temps que les yeux, afin de pouvoir mieux me voir.

Au moindre de mes mollvements, c'étaient des rires, des contorsions à se croire au milieu d'une troupe de singes s'exerçant à faire des grimaces.

Enfin, lorsque le lendemain, leur curiosité était un peu apaisée, je faisais rassembler les différents chefs et la grande palabre commençait.

Je m'asseyais sous un abri improvisé et tous les chefs se rangeaient autour de moi, suivant le rang que leur attribuait le protocole indigène; c'est en présence de centaines et même de milliers de moricauds que la palabre se déroulait.

Cela ne se faisait évidemment pas toujours avec tout le calme désirable,certains chefs profitant de la présence du blane pour se plaindre de l'un ou de l'autre de leurs roisins. Alors notre palabre ressemblait, hélas ! à certain de nos Parlements européens.

Vous le dirai-je, à ma honte, je ne détestais pas les assemblées tumultueuses. Il me semblait que, seul au milieu de cette fonle hurlante, je me sentais grandir, j'avais le sentiment que je la dominais, j'avais pleine confiance en moi et, pour la première fois de ma vie, je sentais germer en moi un peu de ce sentiment d'orgueil que nous cachons si souvent et si précieusement sous le pseudonyme mieux porté, d'une juste fierté. 
Un jour,pendant une de ees réunions, j’avais beaucoup admiré, mais sans rien en dire à personne, une jeune et splendide négresse, dont les formes aeeomplies faisaient d'elle une véritable petite merveille en son genre. Aussi, quel ne fut pas mon étonnement lorsque, quelques instants après la palabre, je vis arriver un des chefs avee la belle enfant.

- Maìtre, me dit-il, elle est à toi, j'ai vu tantôt à ton regard que tu la trouvais belle.

Et eomme je lui faisais remarquer que les blanes n'avaient pas d'eselave, il me répondit :

- Je le sais, mais les Arabes, dans leurs razzias, mont déjà pris sa mère et ses trois sœurs, elle seule me reste, si tu ne la prends pas, un jour ou l'autre ils viendront eneore me l'enlever; avee toi, je sais qu'elle sera bien, je pourrai la revoir de temps en temps, tandis qu'avee eux, elle sera probablement malheureuse et eertainement perdue pour moi, pour toujours. "

La jeune fille levant alors sur moi ses yeux immenses et me regardant bien en faee me dit à son tour : " Tu me parais bon, prends-moi avee toi, je te servirai eomme si tu étais mon père. "

Pauvres gens, qui, pour sauver leurs enfants de l'eselavage, étaient obligés, à cette époque, de les confier à des inconnus.

Trois ans après, lors de la prise de Nyangwé, je fus assez heureux pour retrouver, parmi les eselaves des 
Arabes, la mère et une des soeurs de la belle Tumba, et, rentré à Lusambo, je convoquai le vieux chef qui faillit devenir fou de joie, lorsque je lui remis les trois femmes; car alors, nous étions les maitres de la situation et les razziss des Arabes n'existaient plus qu'à l'état de cauchemar pour les malheureuses populations autrefois traquées par eux.

Mais n'anticipons pas sur les événements.

Deux jours après la petite scèue que je viens de vous conter, j’appris qu'un certain arabisé nommé Fuamba, terrorisait la contrée et que si l'on ne m'en avait pas parlé plus tòt, c'était dans la crainte qu'une fois que je serais parti, Fuamba ne vint attaquer les villages pour les punir de l'avoir dénoncé au blanc, et que, d'ailleurs il avait déjà fait couper la tête de plusicurs chefs pour les punir de s'ètre mis en rapport avec nous.

Cette situation ne pouvait pas continuer et bien que n'ayaut que trente hommes, je résolus d'attaquer le forban sans plus tarder, afin de bien nontrer aux différents chefs de la contrée que nous étious fermement disposés à mettre un terme aux exactions et aux crimes des Arabes.

Je passai une inspection minutieuse des armes et des munitions de ma petite troupe et je me disposais à me mettre en marche, quand je reçus une lettre de Gillain me rappelaut en toute hàte à Lusambo. A mon retour au camp, Gillain m'apprit que les Bakuas Endus s'étaient 
de nouveau réroltés, qu'ils avaieut coupé la tète à un de nos courriers, qu'alliés à la puissante tribu des Bakuas Tumbolos, ils menaçaient de détruire nos postes de Tchiniama et de Tchibango, et qu'ils avaient déjà pillé et brùlé trois petits villages, qui s'étaient placés sous notre protection.

Gillain était très malade, et comme il était urgent d'agir de suite, sous peine de voir la révolte s'étendre, il me donna l'ordre de partir le plus tòt possible et d'agir énergiquement.

Il m'adjoignit un sous-officier nouvellement arrivé appelé Sandrart qui était du mème pays que moi.

Nous passàmes ensemble l'inspection de tout ce qui restait d'hommes à Lusambo et, à grande peine, nous parvìnmes à en réunir 50 en étal de partir.

Le lendemain matin, nous étions en route.

Quant à Gillain, il restait à Lusambo sans un homme valide $!$ !......

Jamais, je crois, un blanc ne s'était trouvé au Congo dans une situation semblable à la sienne. Aussi je vous laisse à penser, s'il m'était recommandé de ne pas perdre de temps.

En arrivant à Tchiniama,j'appris que les deux peuples s'étaient réunis chez les Bakuas Endus, et qu'ils avaient caché leurs femmes dans les bois.

Les attaquer dans ces conditions était une folie, c'était courir à un désastre certain, 
Me sachant espionné, je fis semblant d'ètre très irrésolı et discrètement je laissai sous-entendre que j'avais trop peu d'hommes pour les attaquer, 'que je reviendrais plus tard, mais que j'allais profiter de ce que les Bakuias Tumbolos n'étaient pas chez eux pour aller piller leur village.

Dès le lendemain, je prends la route qui conduit chez eux. Prévenus par leurs espions, ils quittent en toute hâte leur's alliés et volent à la défense de leur village. C'est ce que j'attendais.

Je fais aussitòt demi-tour et par nue marche forcée de nuit j'arrive le lendemain matin à neuf heures en face du village principal des Bakuas Endus.

Ne nous attendant plus, ceux-ci étaient rentrés tranquillement chez eux et nous n'étions pas à plus de cinq cents mètres de leur village, quand l'alarme fut donnée.

Ils ne s'en précipitèrent pas moins et très bravement à notre rencontre, mais surpris, sans ancune organisation, et balayés par nos balles, ils furent vite forcés de prendre la fuite et de nous abandonner leur village, oì nous trouvâmes une dizaine de fusils, un taureau, 64 chèvres et des poules en quantité.

Désirant profiter de la dépression morale que ma victoire a certainement causée à l'ennemi, ainsi que de l'enthousiasme de mes hommes, je ne leur donne qu'une nuit de repos et je repars pour Tchiniama, où je laisse mes prises de guerre à la garde du poste, puis sans rien 


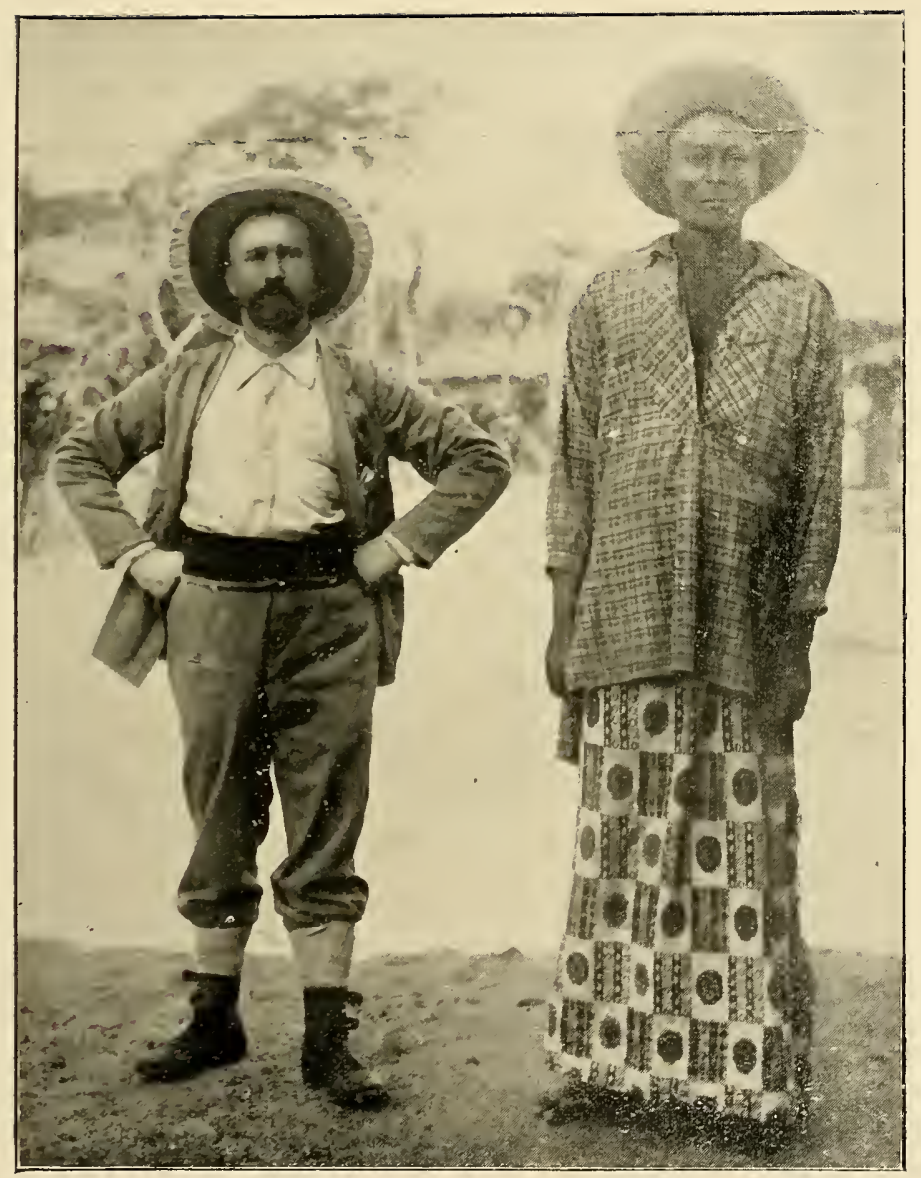

DUFOUR et le chef des pagaysurz de Lusambo 


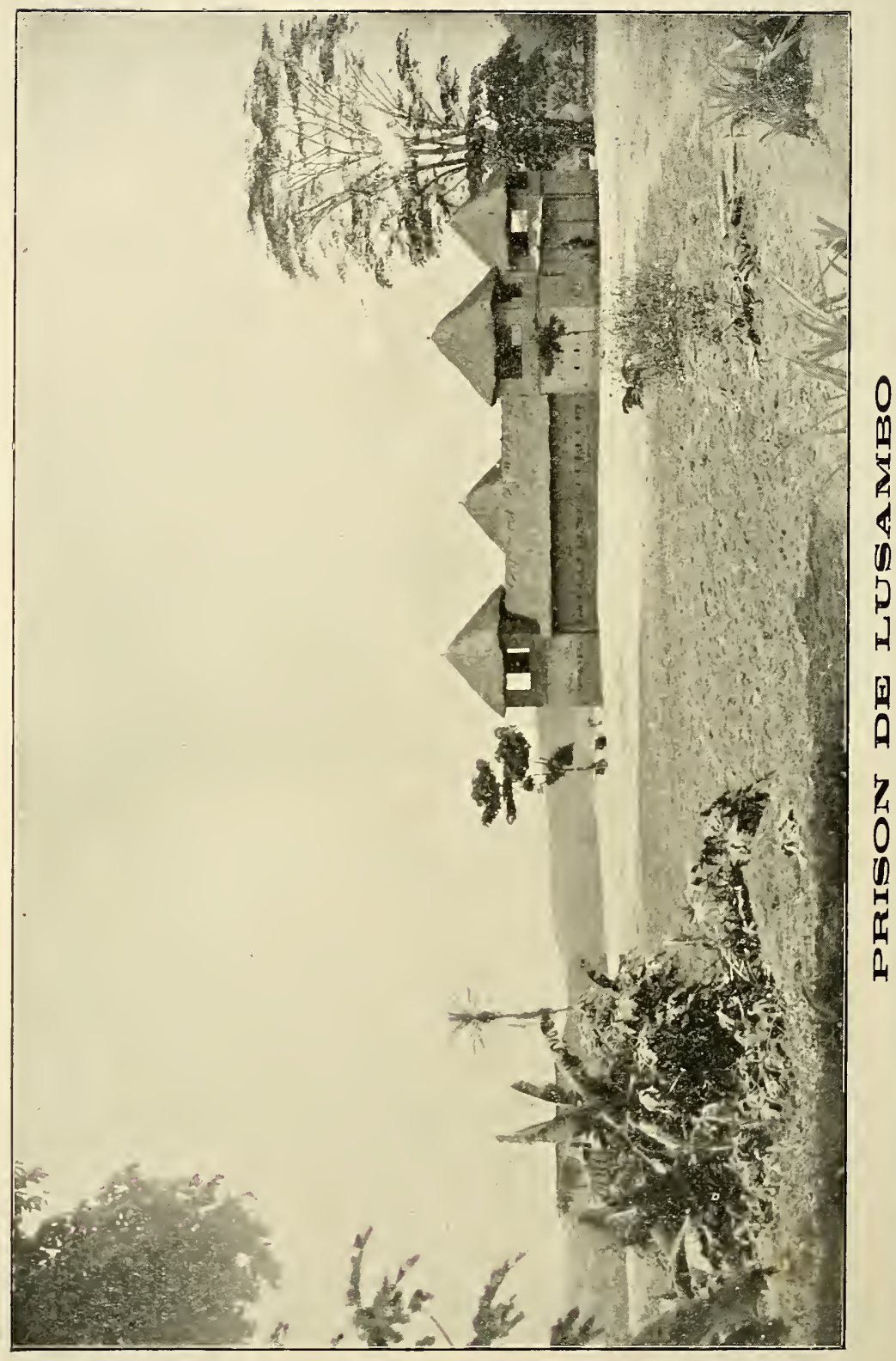


dire à personne de mes nouveaux projets, je fais un immense détour sous bois et, trois jours après, j’arrive en vue des Bakuas Tumbolos.

Ici se passe un fait qui eut une grande importance sur ma vie future en Afrique.

Je fus consacré félichetir ! !.....

Nos ennemis étant très nombreux, très braves et possédant beaucoup de fusils, dont ils savaient parfaitement se servir, je n'étais pas sans appréhension sur les résultats de notre attaque, vu notre petit nombre.

Voulant donc mettre le plus d'atouts possible dans mon jeu, je réunis mes hommes et leur recommandai bien de ne faire ni bruit, ni feux et de ne pas s'éloigner du camp, mon intention étant de faire une attaque de nuit et par surprise. "A moins, leur dis-je en riant et sans ajouter aucune arrière-penséc à mes paroles, qu'il ne pleuve, car, alors, ils ne sauraient pas tirer parti de leurs fusils et toutes les chances seraient pour nous. $)$

Or, il faisait un temps splendide, quoique très chaud, et il pouvait ètre midi; vers une heure, j'étais assis dans ma chaise longue, quand, tout à coup, je ressens comme une décharge électrique dans tout le corps. (Chez moi, c'est un sigue certain d'orage qui ne me trompe jamais.) Je fus assez surpris de la chose, car le ciel était d'une limpidité et d'un bleu parfait. Voulant 
mieux me rendre compte de l'état de l'atmosphère, je monte sur une haute termitière et je scrute l'horizon. Il me semble alors voir dans le lointain un petit point noir qui grossit à vue d'œil.

Bientòt le doute n'est plus possible, nous allons avoir un orage et il s'annonce comme sérieux.

Connaissant mes hommes et les sachant très superstitieux et très curieux, je me mis alors à faire des signes cabalistiques arec les bras vers l'horizon.

Ce que j’avais prévu ne tarda guère à se réaliser. Mes hommes, intrigués de ma mimique, se rassemblèrent autour de moi et me dépèchèrent un des leurs pour me demander respectueusement ce que j'étais en train de faire.

- Chut !... leur répondis-je en prenant mon air le plus solennel, je viens de faire ma grande médecine et je vais faire pleuvoir!!! De plus, mon fétiche vient de m'assurer que de tous ceux d'entre vous qui iront franchement de l'avant et qui n'auront pas peur, aucun ne sera tué !...

Ayant ainsi électrisé ma petite troupe, je la portai rapidement mais silencieusement en avant.

Le ciel était devenu tout noir et l'orage s'annonçait comme devant ètre d'une violence extrème.

Mes prévisions ne furent pas trompées et nous étions encore à environ un kilomètre du village, quand l'orage creva sur nos tètes avec une violence inouïe. 
Ce fut d'un tragique sans nom.

J'avais recommandé à mes hommes de ne pas tirer avant d'ètre au centre du village.

Armé d'une petite hache,je prends la lète de la colonne et bientòt nous débouchons dans le village.

J'avais à peine fait quelques pas clu'un homme armé de son fusil, entendant probablement du bruil, sort de la case auprès de laquelle je me trouvais.

Il veut me mettre en jone, mais je ne lui en donne pas le temps; écartant son fusil de la main gauche, je lui assène $11 n$ coup de hache sur la lète et l'élends mort à mes pieds.

Pendant ce temps, mes hommes se sont dispersés an pas de course dans le village et chacun fail de son mieux, afin d'ètre protégé par mon fétiche.

Surpris par notre brusque atlaque et dans l'impossibilité de se servir de leurs fusils, les indigènes se sauvent affolés dans toutes les directions, pendant que mes hommes les fusillent à bout portant.

Nous sommes cinquante, ils sont plus de deux mille! Mais que fait le nombre en ces circonstances?

Leurs pertes durent ètre énormes el le butin fut considérable, mais comme, à aucun prix, je ne voulais détruire leur villagre qui élail magnifique el que, d’un autre còlé, je ne pouvais le garder avec une poignée d'hommes, je fus bien lorcé, dès le lendemain, de relourner à Tchiniama. 
Les résultats étaient acquis et nul doute que, tôt ou tard, ils viendraient faire leur soumission.

J'obtins, en arrivant à Tchiniama, un premier résultat: je reçus une députation des Bakuas Muledis qui venaient faire leur soumission complète et cette fois définitive.

Je repris alors rapidement le chemin de Lusambo, où Gillain fut d'autant plus heureux de nous revoir que je n'avais pas perdu un seul homme!

A partir de cette époque, ma réputation de faiseur de pluie fut bien établie chez les indigènes.

Quelque temps après ma rentrée à Lusambo, Gillain, étant à peu près guéri, se mit à son tour en route et, pendant plus de deux mois, il travailla sans relâche à la carte des environs du camp.

Quant à moi, j’avais repris mes travaux agricoles, mais, outre la culture, je m'occupais aussi, comme je l'ai déjà dit, d'élevage.

Parmi mes élèves, j'avais deux jeunes taureaux de deux ans, à qui il était grand temps de percer le nez afin d'y placer l'anneau traditionnel.

Un matin, je fais rester mes deux animaux dans l'enclos, qui porte ici le nom de coral. (C'est un endroit clos par de gros bois, ayant environ $1 \mathrm{~m}$. 50 de haut et placés l'un à côté de l'autre, dans le genre des clôtures faites en billes de chemin de fer, comme l'on voit parfois près des gares.) 
Aidé de six nègres robustes et résolus, j’entreprends la petite opération.

Nous commençons par le moins fort; en moins de cinq minutes, nous l'avons par terre et l'opération est terminée. C'est parfait !

A l'autre maintenant. Mais ici la scène change; notre animal, furieux des entraves que nous essayons de lui mettre, se précipite sur nous et nous charge successivement avec une fougue inouïe.

Toréadors improvisés, bien malgré nous il est vrai, nous n'avons pour toute ressource que de franchir la palissade a plus vite.C'est miracle qu'il n'y ait personne de tué. Enfin, après plus de deux heures de travail, nous parvenons à lui passer une première entrave et bientôt après nous en sommes les maîtres.

J'en suis arrivé maintenant à l'aventure qui m'a le plus impressionné de toutes celles qui me sont survenues au Congo.

C'était le premier mardi de mai en 1891.

Je m'étais rendu aux plantations, où je surveillais une centaine de femmes qui y étaient employées.

Le soleil était épouvantable, le thermomètre marquait certainement 40 à 42 degrés à l'ombre.

Je venais justement de donner une demi-heure de repos et toutes les femmes s'étaient groupées autour de moi, sous un arbre énorme, le seul qui se trouvât aux environs. 
Je leur dis qu'il faisait réellement trop chaud pour travailler, mais, que si elles voulaient se dépêcher, en une demi-heure elles pourraient nettoyer le petit morceau de terrain où nous étions occupés, et que ce serait fini pour la journée.

Toutes s'étaient donc remises courageusement et joyeusement à la besogne et, ne voulant pas rester à l'ombre quand elles travaillaient au soleil, je m’étais avancé de quelques pas. Ce fut mon salut! Au mème moment, un coup de vent, un éclair, un coup de tonncrre,... et, avec une force irrésistible je suis jeté violemment sur le sol, où je reste anéanti l'espace de quelques secondes, mais qui m’ont paru un siècle.

Je me demandais si je vivais encore, ou si je me trouvais dans cet état intermédiaire où notre âme a cléjà quitté notre corps, mais n'est pas encore partie pour d'autres régions.

Enfin, par un efrort de volonté surhumaine, je me relevai! Que vis-je?... j’en frémis encore. Toutes mes femmes étaient par terre... foudroyées, ne donnant plus le moindre signe de vie ! !...

Ce qui s'est alors passé en moi est impossible à dire. U'ne peine immense, folle, indescriptible, s'est emparée de moi. J'ai eu peur !... J'ai souvent entendu siffler des balles à mes oreilles et j'en ai ri. J'ai vu tomber des flèches empoisonnées à mes pieds, et j’ai haussé les épaules. J'ai ru des lances dirigées contre ma poitrine et elles m'ont laissé indifférent. 
Mais, me trouver seul vivant au milieu de tous ces morts qui, une minute auparavant se trouvaient encore pleins de vie à mes còtćs et conversaient avec moi et qui, sans transition aucune, venaient passer de vie à trépas !...

Non, c'était trop épouvantable, je ne comprenais plus, je me sentais derenir fou, et certainement un poltron se trouvant subitement au milieu de fantòmes n'aurait pas eu plus de peur que je n'ai eu.

Enfin, au bout d'une longue minute, une,... deux,... dix,... nonante femmes se lèvent.

Je me précipite vers les autres; trois étaicnt mortes, précisément celles qui se trouvaient à la place que je venais de quitter. Quant aux sept autres, gràce à nos soins, elles se sont entièrement rétablies.

Mais Gillain, qui était rentré depuis la veille à Lusambo, a, comme tout le monde, entendu le coup de tonnerre; de plus, il entend des cris et des gémissements. Pris d'un pressentiment sinistre, il se précipite à ma rencontre et, lorsqu'il me voit pâle, blème, me soutenant à peine, il me demande avec angoisse ce qui se passe. Impossible de lui répondre. Je ne puis que porter les mains à ma gorge, en lui faisant signe que je ne sais plus parler.

Il a certainement, à ce momcnt, dù penser que j'étais devenu fou. Enfin les femmes le mirent au courant de ce qui s'était passé, mais la parole ne me revint que 
petit à petit et certainement plus de deux heures après l'accident, les cordes vocales ayant été paralysées par un effet de la foudre.

Depuis cctte époque et deux autres mésarentures que la foudre me causa encore dans la suite, j’ai gardé de l'orage une crainte irraisonnée et que rien nc peut vaincre.

Ce fut également vers cette époque que, par la force des choses et les nécessités du moment, je devins chirurgien et même dentiste.

Pendant que je guerroyais chez les Bakuas Tumbolos, un de mes soldats avait eu un doigt complètement broyé par une ballc. Le laisser dans ect état, c'était la gangrène certainc, donc la mort; or, pour lui couper le doigl, je ne savais comment m'y prendre.

Voici ce que je résolus :

Je fis apportcr dans une case trois Bakuas Tumbolos tués et, aidé dc Sandrart, je leur cnlevai à chacun le doigt correspondant à celui qui était broyé chez mon Haoussa; puis, quand jc fus certain que l'opération marchcrait assez rondement, je fis venir mon homme et l'opérai à son tour. J'eus la chance de réussir et quinze jours après il était complètcment guéri.

- Ccla m'encouragea et m'enhardit évidemment beaucoup ; dans la suite, je continuai à procéder de la même façon : quand j'avais une opération à faire, n'étant pas très ferré sur l'anatomie, je commençais toujours par 
exécuter ce que l'on pourrait appeler une répétition générale sur un cadavre.

Les sujets ne me manquaient d'ailleurs jamais, puisque je n'avais guère l'occasion d'exercer mes talents chirurgicaux qu'après une bataille.

Mais, me direz-vous, à ce jeu-là vous deviez en tuer beaucoup? Ma foi non, pas trop.

Je réussissais assez bien et beaucoup de mes anciens camarades d'Afrique diront encore que j’avais gagné un véritable tour de main, et qu'ils avaient grande confiance en moi.

Et puis, n'étant pas patenté, je devais évidemment mettre des formes pour expédier mes clients d'occasion dans l'autre monde.

Il en est anssi qui se demanderont comment je faisais pour avoir toujours du chloroforme pour endormir ceux que leur malheureux sort m'envoyait.

Mais c'est très simple, je ne les endormais pas!

Alors, me direz-vous, vous les opériez tout éveillés !... Parfaitement. Valait-il mieux les laisser mourir? Ils criaient parfois bien un peu, mais, à la fin, je ne les entendais plus. J'avais même un avantage sur mes confrères les docteurs : tant qu'ils criaient j'étais au moins certain qu'ils n'étaient pas morts.

Il me reste maintenant à vous expliquer comment je devins dentiste.

Un jour, à Lusambo, nous faisions la visite des 
malades avec Gillain et plus de vingt individus étaient là souffrant de la rage de dents et nous n'avions rien pour les soulager!

Nous les contemplions donc d'un air navré, mais impuissant, quand tout à coup Gillain me dit :

- Mais, Michaux, tu as une poigne de fer, toi, si tu voulais, tnl leur arracherais bien leurs chicots?

Je me récriai, disant que je n'avais jamais fait ce métier-là et que je ne sanrais comment m'y prendre.

- Cela ne fait rien, me dit-il, essaie, tu verras que cela ira tout seul.

Et étant allé chercher une boîte à outils, nous choisimes ensemble le davier correspondant à la dent malade de celui qui avait été désigné pour être mon premier patient.

Ce choix du davier n'était d'ailleurs pas difficile; sur le couvercle de la boite se trouvait un dessin représentant deux deni-màchoires et sur chaque dent un numéro correspondant à un numéro du davier.

Gillain tenait la tète du patient et m'encourageait en me répétant que cela irait bien.

Quant à moi, j'étais un tantinet nerveux, je crois mème que je tremblais un peu, me figurant qu'il fallait faire un ellort extraordinaire.

J'introduisis donc la pince dans la bouche, je l'ajustai de mon mieux sur la dent, puis serrant de toutes mes forces, je tirai violemment vers moi. 
A ma grande stupéfaction, cela vint tout seul, mon effort ayant été dix fois trop considérable. Ce n'est pas tout, dans le mouvement que je fis, mon instrument a vait glissé, s'était mis entre deux dents, et je les avais arrachées toutes deux! Une bonne et une mauvaise!!! Mais le comble, c'est que le moricaud était encore très content, estimant qu'il ne payait pas trop d'une bonne dent la salisfaction d'ètre débarrassé d'une mauvaise.

- Tu vois, me dit Gillain, cela va très bien et puis ils ne sont pas difficiles, tu feras bien sans moi, j'ai de la besogne ailleurs.

Et voilà comment je devins dentiste.

Depuis lors, j’ai arraché des dents par centaines et j'opère avec une rapidité à faire envie à un professionnel. Si, d'ailleurs, un de mes lecteurs metlait en doute mon savoir-faire, j’ai toujours conservé ma bonne poigne et il peut venir se faire opérer, je ne réclame pas d'honoraires.

Vers cette mème époque, Gillain partit pour dresser la carte des environs de Lusambo, et, pendant quatre mois, je vécus de la paisible vie des stations du Haut Congo en temps normal; je passais mon temps à surveiller les différents travaux de la station, à palabrer avec les chefs qui venaient me rendre visite et à chasser aux environs.

Je me portais à merveille, je me laissais vivre sans inquiétude, c'était tout à fait charmant. 



\section{CHAPITRE VIII.}

Retour de l'expédition du Katanga. - La danse chez les Bakuas N'Gombés. - Le vertige. - Encore Gongo Lutété. Chez Kichimbi. - La bête était domptée, elle avait trouvé son maître. - Rentrant à Lusambo, j'y trouve l'expédition Bia. Tempête sur le Sankuru. - Pauvres diables ! - Grand combat contre les Kiokos. - (Clairons, sonnez la charge !) - Mise à l'ordre du jour.-Départ de Le Marinel et Gillain pour l'Europe. - Arrivée de Dhanis.

Brusquement, sans crier gare, Le Marinel et Descamps rentrent du Katanga. Nous étions le 19 août 1891. Le lendemain, Gillain rentrait également de son voyage et, pour comble de bonheur, un steamer arrivait nous apportant notre courrier d'Europe et notre ravitaillement.

C'était presque trop de bonheur à la fois, la joie et le matabiche aidant, nous eùmes tous beaucoup de chance de ne pas en faire une maladie.

Enfin, deux jours après, nos esprits et nos estomacs étant à peu près remis daus leur état normal,Le Marinel, a vec ce tact parfait qui le caractérise si bien, m’annonça que les Bakuas Tumbolos et les Bakuas Endus demandant la paix, il n'était que juste, puisque je les avais vaincus, que ce fût moi qui reçût leur soumission; je devais, par la mème occasion, fonder deux nouveaux 
postes sur la rive droite du Lubi, l'un à six, l'autre a treize jours de marche de Lusambo. De là, je devais me rendre à Luluabourg afin d'acheter du bétail. Enfin, revenir par chez les Bakuas Endus et les Bakuas Tumbolos. Ce fut un voyage magnifique.

Cent bons soldats m'accompagnaient.

Pendant les trois premiers jours, rien de bien saillant. J'arrive alors chez les Bakuas N'Gombés (traduisez Enfants de la vache), et malgré les faligues de la marche, je visite immédiatement le village, non pas pour le village lui-mème, qui ressemble à tous les villages indigènes, mais pour ses dignes habitants.

A cette époque, ees gens élaient encore tout à fait sauvages el leurs dehors accusaient la barbarie. Regard déliaul, gestes exubérants, aussi peu vètus que possible, loujours sur la défensive, s'amusant de rien et passant les trois quarts de leur temps à s'arranger la chevelure, dont ils ont le plus grand soin. Ils en font des monuments qui atteignent des proportions phénoménales. Pour eux, c'est le comble de l'élégance; j'en ai vu qui, comme dimension, pouvaient être comparés aux bonnets à poils de nos gendarmes.

Chose curieuse à constater, ce sont les hommes et non les femmes qui sont parés de ces coiffures extraordinaires.

Le soir de mon arrivée, le chef du village, à qui j'avais

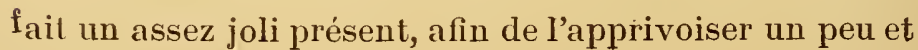


de le décider à se rendre à Lusambo, voulut me faire fète. Pour cela, il fit réunir un quadrille de seize filletles de 10 à 12 ans (IS à 20 ans en Belgique), qui exécutèrent derant moi une des danses les plus sauvages et en mème temps des plus gracieuses que j'aie jamais vues. Il est vrai que les ballerines étaient toutes ravissantes.

Les Baknas N'Gombés sont connues pour leur's formes sculpturales; aussi arant notre domination la contrée était-elle régulièrcment mise en coupe par les Arabes qui y recueillaient les plus belles femmes de leur harem.

Leurs dauses, qu'elles exécutèrent le soir à la lucur des feux de bois de senteur, avaient quelque chose de féerique, que je u'ai pas retrouvé ailleurs, bien que d'autres chefs plus puissants, tel que Kichimbi, aient fait danser jusque cinq cents fenmes à mon intention. Mais ici, elles étaient toutes du mème âge, toutes de la mème taille, toutes fraìches et jolies et dansaient avec un rythme et une cadence admirables.

Mon plaisir fut d'abord sans mélange, j’éprouvais presque de l'extase à contempler ces nymphes aux formes harmonieuses et accomplies. Mais bientòt une immense mélancolie me saisit, car en les voyant si belles et si gracieuses, je ne pouvais m'empècher de songer qu'elles élaient esclaves, et que cette joiє qu'elles montraient étaient une joie de commande, que cette danse, où elles semblaient prendre tant de plaisir, n’était exécutée que pour le plaisir du maître, que leurs 
sourires avaient été réglés, que leur regard même avait reçu sa direction. Aussi, tout en les contemplant, tout en les admirant, je souffrais plutôt que je ne jouissais du spectacle inoubliable qu'il m'était donné d'admirer et malgré moi je me disais en les voyant: pauvres enfants ! !..... pauvres esclaves !!... mais, en mème temps, je pensais à la rédemption, au salut que nous leur apportions et volontiers je leur aurais crié : l'heure de la délivrance est proche, et bientôt vous ne danserez plus que pour votre plaisir, vous ne chanterez plus que pour témoigner votre joie, et vos sourires, ainsi que vos regards heureux u'auront plus pour guide que votre cour.

Trois jours après mon départ des Bakuas N'Gombés, j'arrivais aı village de Moina N'Gachi où j'établis un poste de dix hommes, ainsi que j'en avais reçu l'ordre.

Je partis ensuite pour Kalalakafumba. Tout ce pays avait été ravagé par les Arabes et partout on ne rencontrait que le désert et la ruine.

Pendant la route, j'eus encore une aventure de chasse assez désagréable.

Une après-midi que nous étions campés, on vint me dire qu'une magnifique antilope se trouvait à cinq ou six cents mètres du camp.

Sauter sur mon fusil et me mettre en route fut pour moi l'affaire d'une minute. En arrivant à l'endroit indiqué, je vis en effet une magnifique antilope, qui, 


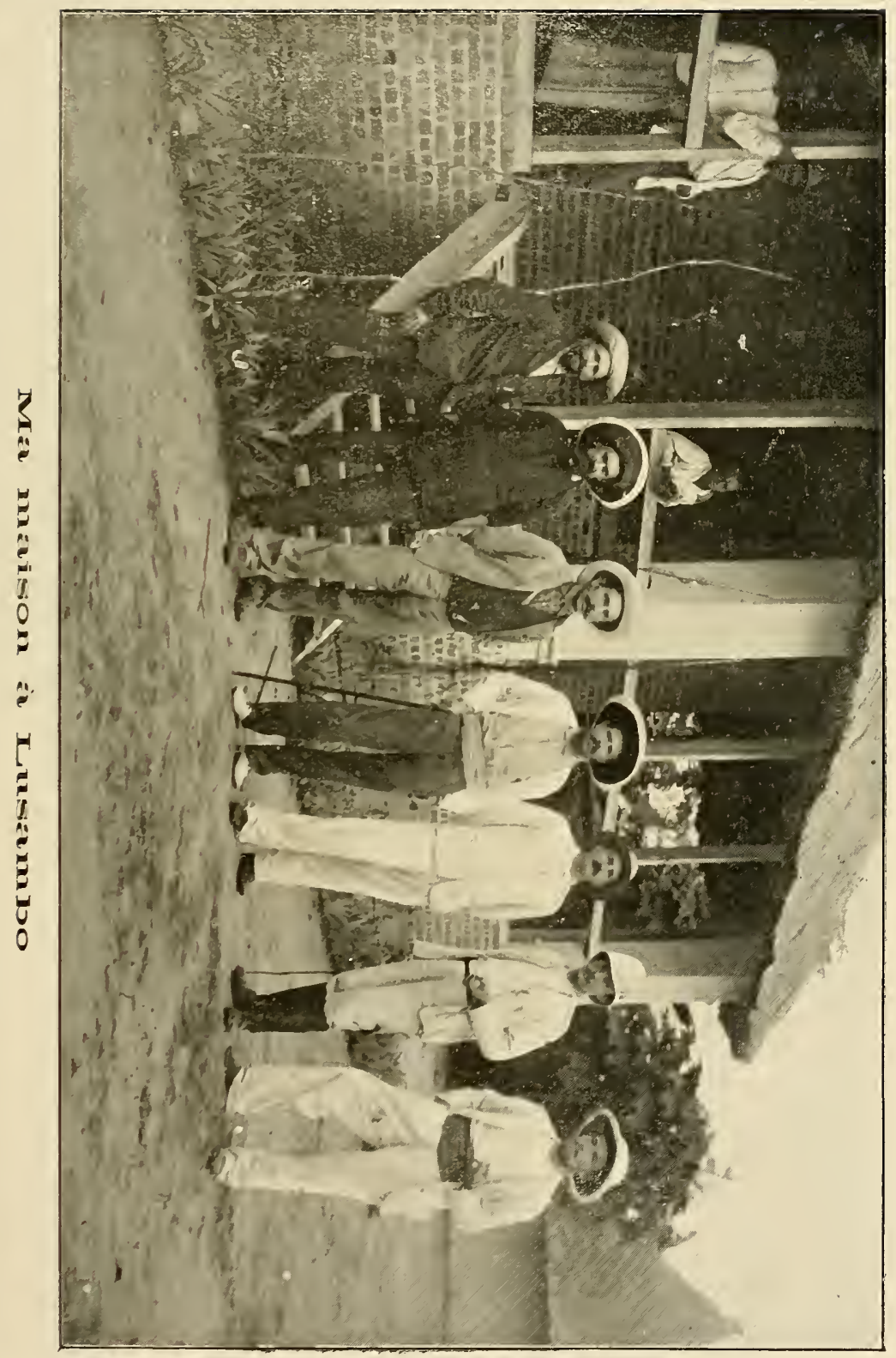




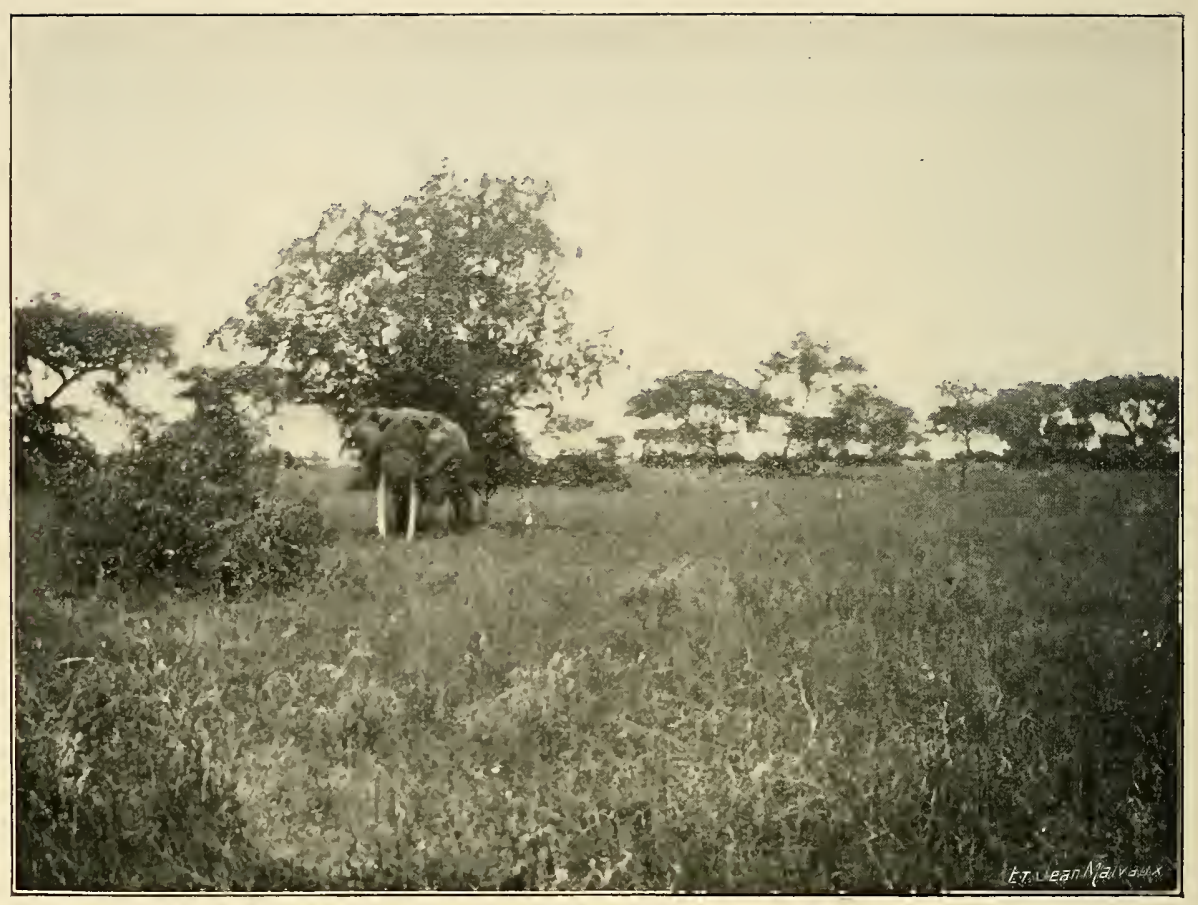

Eléphant se promenant dans la Savane

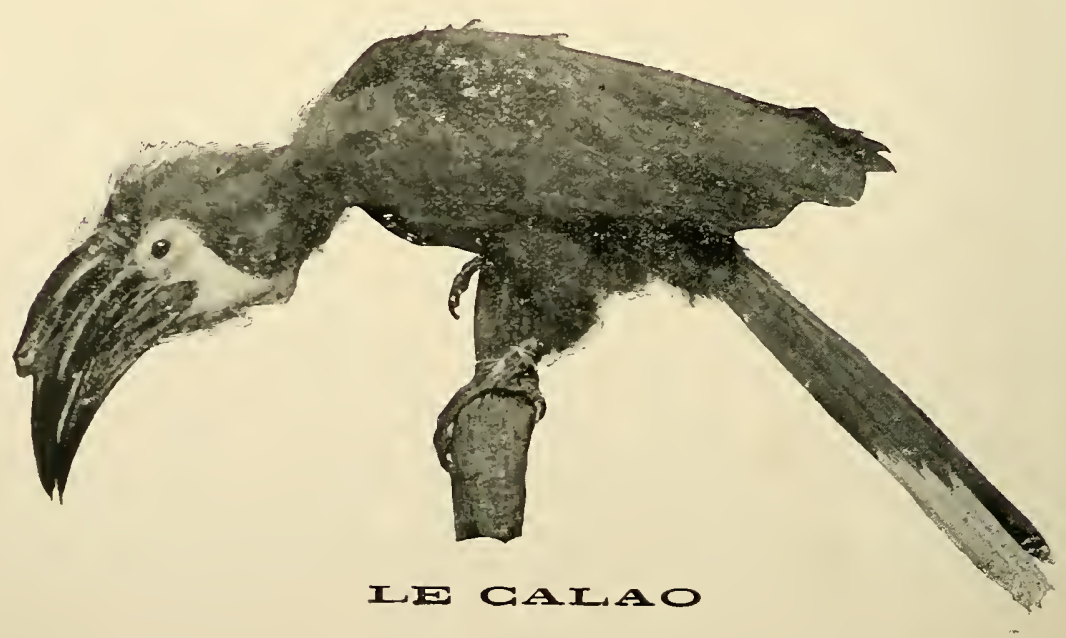


malheureusement, m’avait probablement éventé, car elle disparaissait justement derrière des rochers.

Je me mis immédiatement à sa poursuite; seulement elle avait pris un chemin qui formait une espèce de balcon naturel au rocher. Celui-ci, très étendu pour commencer, allait en se rétrécissant jusqu'au moment où il n'avait plus qu'un mètre de large. D'un còté le rocher, de l'autre le précipice.

Dans l'ardeur de la poursuite, je ne m'étais pas bien rendu comple de la chose et quand je m'en aperçus je me trouvais justement à l'endroit le plus étroit. Du coup, le vertige une prend, je me mets à trembler, la tète me tourne et je suis obligé de refaire une partie dı trajet que je venais de faire, en marchant sur les genoux et sur les mains. Inutile je crois de vous dire qu'en ce moment l'antilope était la moindre de mes préoccupations.

En arrivant à Kalalakafumba, j’appris la nouvelle la plus inattendue qui pouvait m'arriver.

Le fameux Gongo Lutété, que nous croyions à N'Gandu, venait de ravager tous les Bakuas Kaloges et le grand chef Kichimbi, chez qui je devais absolument passer pour me rendre à Luluabourg, lui avait fait sa soumission et s'étail déclaré son vassal.

Or, à ce moment, j’avais laissé vingt hommes en poste et dix escortaient le courrier que j'avais envoyé à Lusambo. Septante hommes me restaient pour faire 
face à Kichimbi et aux bandes nombreuses qu'il pouvait m'opposer. La situation pouvait donc devenir assez grave.

Confiant dans ma bonne étoile, je n'en persistai pas moins à marcher de l'avant et, quatre jours après, j'entrais dans l'immense village qui lui servait de résidence.

Ayant remarqué à la sortie du village une petite éminence qui dominait celui-ci, je m’y rendis avec mes hommes et y établis mon campement, afin d'avoir, le cas échéant, une bonne position de combat.

Mon camp était établi depuis une heure environ, quand un tintamarre infernal m'apprit que le chef venait me visiter.

Comme il fallait tout prévoir, j'avais donné l'ordre à mes hommes de vaquer à leurs travaux, comme si rien n'était à craindre, mais d'avoir leur fusil chargé à portée de la main, leur recommandant que, si je donnais un coup de sifflet, ils avaient à se précipiter à mes còtés. Je fis aussi placer deux sentinelles à ma tente.

Sur ces entrefaites, j’avais appris que deux émissaires de Gongo Lutété se trouvaient dans le village afin sans doute de surveiller les agissements de Kichimbi.

Je résolus sur-lc-champ d'agir avec énergie.

Quand le chef vint donc me saluer et avant de répondre à son salut, je lui demandai à brûle-pourpoint 
de quel droit il recevait des ennemis des blancs chez lui et les hospitalisait ; j'exigeai aussi qu'il me les livrât immédiatement.

Cette audace lui parut tellement extraordinaire qu'il en fut tout abasourdi, mais bientòt, comparant le peuple immense qui l'entourait à ma faible escorte, il reprit contenance, se mit à rire et me répondit qu'il recevait chez lui qui bon lui semblait et que ces gens étant ses amis, il ne les livrerait pas.

- Réfléchissez bien, lui dis-je. Est-ce votre dernier mot?

- Oui, me dit-il, je ne vous les livrerai pas.

En ce moment, je donnai un violent coup de sifflet et, lui mettant le canon de mon revolver sur la poitrine, je lui déclarai qu’il était mon prisonnier.

En quelques secondes, mes soldats, le fusil chargé et armé, nous ont entourés. Mon homme comprend que toute résistance lui est impossible el il passe sans transition de la plus grande arrogance à la peur la plus méprisable.

Il se roule à terre, se couvre la têle de poussière en forme de soumission et me jure que j'aurai tout ce que je voudrai, pourvu qu’il ait la vie sauve.

Je lui déclare alors qu'il est mon prisonnier et qu'il a à me livrer immédiatement les deux hommes que Gongo a laissés dans son village et que, de plus, il me payera deux boeufs comme amende pour avoir fait alliance 
àvec nos ennemis. Une demi-heure après, le tout était chez moi.

Comme je ne voulais pas nous faire un ennemi du chef, mais un allié, je le fis remettre de suite en liberté et lui fis un très beau présent, lui recommandant pour l'avenir d'être toujours fidèle et loyal, s'il ne voulait pas s'exposer à ètre déchu de sa chefferie.

Une fois libre et ses cadeaux reçus, il pouvait à peine en croire ses yeux : il se tâtait pour être certain que c'était bien lui et, dans son enthousiasme, il me proclamait le meilleur des hommes. Il ordonna de suite les plus grandes fètes en mon honneur.

La bêle élait domptée, elle avait trouvé son maìtre et doréna vant, elle n'était plus à craindre.

En me rendant à Luluabourg, je rencontrai un parti de Kiokos, à qui je repris quatre hommes, une petite fille et deux barils de poudre.

Au passage de la Lulua, je fus assez heureux pour tuer un très grand crocodile ainsi qu'un hippopotame. Je vous laisse à penser si mes hommes étaient enchantés de cette aubaine qui leur procurait de la viande à discrétion.

A Luluabourg, je ne fis que passer, le chef, le commandant Liénart, étant précisément absent.

Quant aux Bakuas Endus et aux Bakuas Tumbolos, après les avoil vaincus par les armes, je mis une certaine coquetterie à les vaincre par de bons procédés. 
Cette politique me réussit si bien que leurs voisins les Bakuas N’Daies vinrent spontanémeut me faire leur soumission à l'Etal et mème m'accompagnèrent à Lusambo.

En rentrant à la station, je ne fus pas peu étommé d'y roir plusieurs blancs que je ne connaissais pas.

C'était l'expédition du liatanga, commandée par Bia et Franqui, qui arait choisi Lusambo comme tête de ligne et y était débarquée pendant mon absence.

Le lendemain de mon arrivée, M. Wauters, agent de la S. A. B., mourait dans nos bras, à Descamps et à moi, et, quelques jours plus tard, Sandrart et un nommé Spellier, de la Compagnie du Katanga, étaient obligés de prendre le bateau afin de rentrer en Europe, tant leur état de santé était précaire.

Quelques jours après ces tristes événements, Le Marinel ayant fourni à Bia tous les porteurs dont il avait besoin, je fus chargé de conduire la caravane par voie de terre jusque M'Pania Motombo, tandis que ces Messieurs s'y rendaient par la voie du fleuve.

Ia mission terminée, je rentrai à Lusambo, mais j'y étais à peine arrivé qu'un courrier de Bia annonçait à Le Marinel que M'Pania Notombo Jui mettait des bètons dans les roues et demandait qu'on voulût bien l'aider à se mettre en route. Une heure après, sur l'ordre de Le Marinel, j'étais de nonveau parti, mais en pirogue cette fois, afin d'arriver plus vite. 
Le voyage, à l'aller surtont, fut charmant. J'élais à moitié couché dans ma chaise longue, ayant à mes pieds deux jeunes moricauds teuant chacun un de mes fusils, tandis que Pitch se tenait tout an bout du canot et semblait être en faction.

Comme paga yeurs, j'a vais vingl-quatre beaux, grands et forts nègres, qui faisaient récllement voler ma pirogue sur les flots du Sankuru.

$\Lambda$ vant d'artiver à M'Pania, je fus assez heurenx pour tuer deux énormes hippopolames, qui furent les bienvenus à l'expédilion Bia, où les vivres étaient assez rares.

J'arrangeai rapidement les questions pendantes avec M'Pania el, le surlendemain de mon arrivée, l'expédilion s'étant mise en route, je relournai à Lusambo.

Pendant le relour, je fins témoin de tout un drame.

Nous revenions gaiement, voguant avec une rapidité extraordinaire daus la descente du fleuve, quand tout à coup le ciel se conrre comme par enchantement. Cinq minutes après, un orage éponvantable se déchaine sur nous el le Sankurtu, loujours si tranquille et si calme, devient furieux el semble vouloir nous englontir.

Par un malheur étrange, nous étions justement au - milieu de hautes falaises où il ne fallait pas penser à aborder et notre canot, petit à petit, et malgré fous nos efforts, se remplissail d'eau. Quant à la tempête, elle semblait redoubler d'efiorts et notre position devenait de plus en plus critique. 
A moitié aveuglés par la pluie et les éclairs, nous apercerons tout à coup, à cinquante mètres à peine de nous, denx paurres diables montés sur une véritable coquille de noix qu'ils s'évertuent à tenir en équilibre. Nous étions presque à leur hauteur et allions pouvoir les secourir, quand un coup de vent plus violent que les autres fait chavirer leur frèle embarcation et les fait disparaitre pour ne plus revenir. C'était d'autant plus terrifiant qu'il ne pouvait ètre question pour nous d'essayer de leur porter' secours ; c'eùt été nous perdre nous-mèmes.

En rentrant à Lısambo, j'eus l'agréable surprise d'y trouver un compatriote. Duchène, de Jodoigne, y était arrivé pendant mon absence.

Dès lors, j’arais un copain avec qui je pouvais parler du clocher.

Le 5 janvier 1892, Le Marinel recevait une lettre de de Croy, qui avait remplacé Liénart à Luluabourg, lui demandant de bien vouloir se rendre le plus tôt possible avec-un fort détachement chez M. Saturnino, négociant portugais, afin d'aider les troupes du Kassaï à réprimer une révolte des Bakuas Pikas, qui menaçait de se généraliser daus le district et aussi de repousser une forte bande de Kíiokos et de Bihénos qui pillaient et rançonnaient toutes les malheureuses populations du district.

Au reçu de cette lettre, Le Marinel nous donne l'ordre, à Lekeu et à moi, de nous tenir prêts à partir afin de l'accompagner. 
Le lendemain matin, nous nous mettions en route, ayant avec nons septante bons soldats et quarante auxiliaires Bakubas.

En route, nons apprenons que le comte d'Ursel est mort à Luluabourg.

Après treize jours de marche, nous arrivons chez Saturuino et y trouvons Doorme avec quarante soldats de Luluabourg.

Quant ì de Croy, il priait Le Marinel de bien vouloir l'excuser, étant malade en ce moment. Il lui demandait aussi d'avoir l'obligeance, la palabre terminée, de passer' par Luluabonrg afin d'avoir ses conseils sur plusieurs points en litige.

Notre expédition chez les Bakuas Pikas fut vite termince : nous eùmes bien tòt fait de les mettre à la raison.

Le tout étant rentré dans l'ordre, Le Marinel partit avec Doorme pour Luluabourg.

Il me donna ses instructions sur les différentes choses qui restaient à arranger et rendez-rous fut pris au village de Tchiniama.

A près mon départ, tout alla bien au début; seulement, il ne se passait pas un jour sans que je reçusse de nouvelles plaintes sur les forfaits commis par les Kiokos: Ici, ils avaient volé des femmes, là e'étaient des chèvres, ailleurs de l'ivoire ou du caoutchouc, partout ils avaient commis quelques méfaits et même ils avaient entièrement pillé, puis brûlé plusieur's villages. 
Le 7 février au matin, me trouvant au village de Kissangha, j'appris qu'ils campaient à environ deux heures de marche de nous et que, se fiant à leur grand nombre (environ 600 guerriers, tous armés de fusils), ils a vaient dit aux indigènes qu'ils ne nous craignaient pas. Je résolus de les attaquer immédiatement.

Je confiai la garde du campement à notre interprète, Kachaballa, ainsi qu'aux douze hommes les moins valides de notre petite troupe et, accompagné de Leken, de 43 bons soldats et de 35 auxiliaires Bakubas, je me mis en route.

C'était peu de monde pour affronter une telle masse, mais les circonstances étaient telles qu'il n'y avait pas à hésiter.

Désirant que l'ennemi fùt prévenu le plus tard possible de notre arrivée, je fis òter la veste et le fez de nos hommes et leur donnai l'ordre de cacher leur fusil le plus possible. Bien m'en prit.

Nous avions à peine marché pendant une heure que nous rencontrons trois de leurs sentinelles qui, nous prenant pour une paisible caravane Bachilange, furent saisis, désarmés et ligotés sans a voir pu donner l'alarme à leurs compagnons. Quelque temps après, nous rencontrâmes deux indigènes à qui les kiokos avaient pris leurs fusils et qui nous donnèrent des renseignements précieux sur le campement ennemi. Celui-ci, admirablement situé au point de vue de la défense, était assis 
sur le sommet d'une colline en pente assez raide et dénudée de tout abri. Sur son flanc gauche, un ravin profond et très escarpé ; sur son flanc droit et en arrière, la forèt qui devait donner une retraite assurée à l'ennemi en cas de de défaite.

Notre présence fut signalée à environ 600 mètres. Un roulement de tambour suivi de plusieurs autres, quelques cris, puis plus rien, le silence le plus absolu; e’était à faire croire qu'il avait abandonné son camp sans combal.

A deux cents mètres, je déploie ma petite troupe en tirailleurs, laissant Lekeu, à qui j’avais donné le commandement des Bakubas, en réserve, ceux-ci n'étaut pas aptes à l'attaque el ne devant servir que dans la poursuite.

Sentant bien que ce silence étail menteur, nous u'avançons qu'avec la plus grande prudence et en rampant dans les herbes qui, heureusement, nous couvent assez bien. A cent mètres, toujours rien. Enfin, à environ septante mètres, un premier coup de fusil part et aussitòt tout le camp et la lisière de la forèt s'illumineut de centaines de coups de feu. Je fais répondre par quelques salves el en avant!

Mais, à ce moment, un nouveau contirigent étant probablement renu renforcer nos adversaires, leur feu redouble. Six cents fusils font pleuvoir sur nous une véritable pluie de balles. 
Mes hommes, étonnés d'une pareille résistance, hésitent d'abord et, quoi que je fasse pour les maintenir en place, reculent petit à petil.

Quelques secondes encore, ils allaient làcher pied et nous étions perdus. La baïonnette seule pouvait encore nous sauver; mais comment amener mes hommes a oser entreprendre une attaque de ce genre ? Je résolus pourtanl de l'essayer.

Ils se sauvent !... criai-je à mes hommes. Ils sont à nous !... Clairon sonnez la charge !... et je m’élançai en avanl. Ce que j'espérais se réalise : mes Haoussas, qui m'aiment beaucoup, me voyant en danger, poussent leur légendaire "Oh Koko ! » et comme un seul homme se précipilent sur mes pas.

A vingl mètres, un grand diable me barre la route et veut me mettre en joue; plus rapide que lui, je lui envole un coup de six balletles en pleine poitrine et nous entrons en ouragan dans le camp. Ici, un très court combat s'engage, car les Kiokos ne se servent pas d'armes blanches et, surpris par notre brusque allaque, ils ne font qu'un semblant de résistance et se sauvent dans toutes les directions.

Trois sur quatre de lenrs principaux chefs furent tués et un drapeau fut pris pendant le combat et je suis certain que les survivants n'ont jamais compris conment ils avaient été vaincus, au moment où ils se croyaient vainqueurs. 
Le camp pris, nous y avous trouvé treize barils ainsi que deux grands sacs de poudre, une quantité de fusils, quatre hamacs qui servaient à transporter les chefs et une foule d'objets divers. Quant aux femmes et à leurs prisonniers, nous n'en àvons pas trouvé.

Comme ils s'attendaient à notre atlaque, ils les avaien t déjà mis en sùreté ; leurs guerriers seuls étaient restés au camp.

Le lendemain, j’écrivis à Le Marinel, qui avait déjà quilté Luluabourg el qui dare dare écrivit à son tour à de Croy que c'était le moment pour lui de se débarrasser des autres bandes de Kiokos qui pourraient encore se trouver dans le district, ceux-ci devant ètre profondément alterrés de la délaite de leur bande principale.

En mème temps qu'il recerait la lettre de Le Marinel, de Croy apprenait qu'un marchand d'esclaves du Bihet, nommé Antonio, était campé à quatre heures de marche de Luluabourg, au village Kanioka.

Rassemblant rapidement ses soldats, il partit pendant la nuit accompagné de Doorme et emmenant comme auxiliaire la puissante tribu des Zapo-Zapes.

A 3 heures du matin, il eut la chance de tomber sur le camp endormi qui s'enfuit sans résistance, laissant aux mains des soldats de l'Etat trois cents esclaves qu'il avail volés dans ses razzias.

Cette victoire, véritab̧le corollaire de la mienne, débarrassa les environs de Luluabourg de la présence des Kiokos. 
Le Gouverneur fut si heurenx de nos deux victoires, que tons deux, de Croy et moi, nons eûmes l'honneur d'ètre portés à l'ordre du jour de l'armée. Voici en quels termes :

"Sont mis à l'ordre du jour :

" Le prince de Croy, pour l'énergie qu'il a montrée en faisant, arec quarante soldats, une attaque de nuit qui a réussi, sur un canp de chasseurs d'esclaves disposant de plnsienrs centaines d'hommes armés de fusils.

" Le lieutenant Michaux, pour l'andace dont it a fait preuve en attaquant arec quarante-trois soldats el trente-cinq auxiliaires, un antre camp de chasceurs d'esclares, des mèmes régions du sud de l'Etat, et la bravoure personnelle qu'il a montrée et qui a seule déterminé le succès du combat.

") Boma, le 8 mai 1892.

$$
\begin{aligned}
& \text { "Le Vrice-Gouverneur général, } \\
& \text { fr. de Gouverneur général, } \\
& \text { " (Signé) WAHIS. " }
\end{aligned}
$$

Rentrés à Lusambo, nous y reprìmes nolre genre de vie habituel, mais pour bien pen de temps, car les événements s'y succédaient a vec rapidité.

En l'espace de denx mois, de Croy rentre malade en Europe et Descamps va le remplacer.

Le Marinel et Gillain retournent en Belgique, leur terme en Afrique étant expiré, et Dhanis vient prendre le commandement du district, 



\section{CHAPITRE IX.}

Vingt mille kgs. de gibier. - Un bain forcé. - Attaques pen. dant la nuit. - Bè!è ! Bèlè ! Bèlè ! - Aurdessus de l'abîme. A cache=cache avec Fuamba. - Nouvelle expédition pour le Katanga. - Gongo Lutété demande la paix. - Les Arabes entrent en ligne. - Une tribu de Nains. - Chez Gongo. - Sanglante et tragique bataille du Lomami, à Chigé. - Le sergent Debruyn. - Répugnant festin. - Cadavres dans la mare. Revolver à la main. - Prise de Lusuna.

Ce fut à cette époque, un peu arant le départ de Le Marinel, que je fis ma plus belle chasse en Afrique.

La station étant momentanément à court de vivres, je reçus l'ordre de me rendre en canot à un endroit que nous connaissions comme très giboyeux afin d'essayer de me procurer quelques grosses pièces de gibier que nous pourrions distribuer à nos hommes.

Il n'était pas possible de me donner une mission plus agréable, puisqu’elle caressait ma passion favorite.

Aussi, je vous assure que je fus vite prêt; une heure après l'ordre reç,j’étais embarqué,car je voulais arriver le soir mème à destination, afin de pouvoir commencer la chasse dès le jour naissant.

Je ne vous en conterai pas toutes les péripéties; ce serait un peu long; je vous dirai seulement que, le lendemain, soir, j'avais tué sept hippopotames, trois 
buffles et quantité de menus fretins, tels que pintades, canards, etc.... Enfin, je rentrai à Lusambo avec sept grandes barques que j’avais réquisitionnées et qui, toutes, étaient remplies de viande. J'avais certainement de 18 à $20,000 \mathrm{kgs}$ de viande à faire distribuer en rentrant à Lusambo.

Je vous laisse à penser si nos noirs étaient dans la jubilation et si j'étais fier de mes exploits cynégétiques. C'est à peine si je me serais incliné devant Nemrod lui-mème. Je considérais ces chasses comme étant mes vacances. Mais elles furent de conrte durée car, dès le 27 mars, mon nouveau chef, le commandant Dhanis, me donnait l'ordre de me tenir prèt à partir avec un détachement de soixante hommes pour aller mettre à la raison quatre tribus qui venaient de se révolter.

Dès le lendemain, 28 mars, j'étais en route.

Cing jours plus tard, donc le 2 avril, je faillis ètre noyé. J'avais dù passer le Lubi dans une mauvaise petite pirogue pour aller arranger une palabre avec un chef de l'autre rive; à mon retour, le canot chavira et je fus jeté à l'eau. Précisément, à cet endroit, le courant est d'une violence inouïe. C'est ce qui me sauva, car je ne sais pas nager. Enlevé par le courant, je passai sous uu arbre couché fortement sur l'eau et je m'accrochai aux branches avec une énergie que vous comprendrez sans peine. 


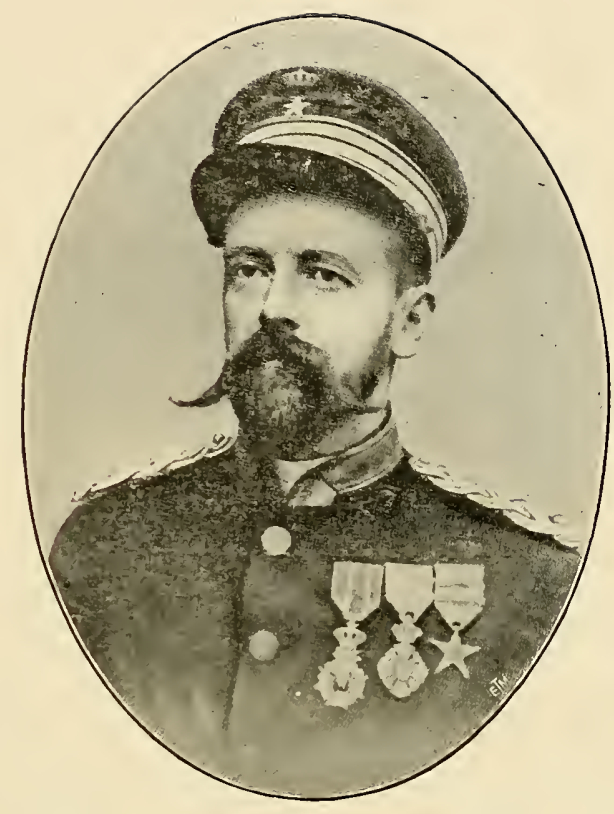

Le Capitaine Commandant Baron DHANIS

Commandant en chef les tronjes de l'Etat eontre les Arabes ct les Arabisís du Manyéma

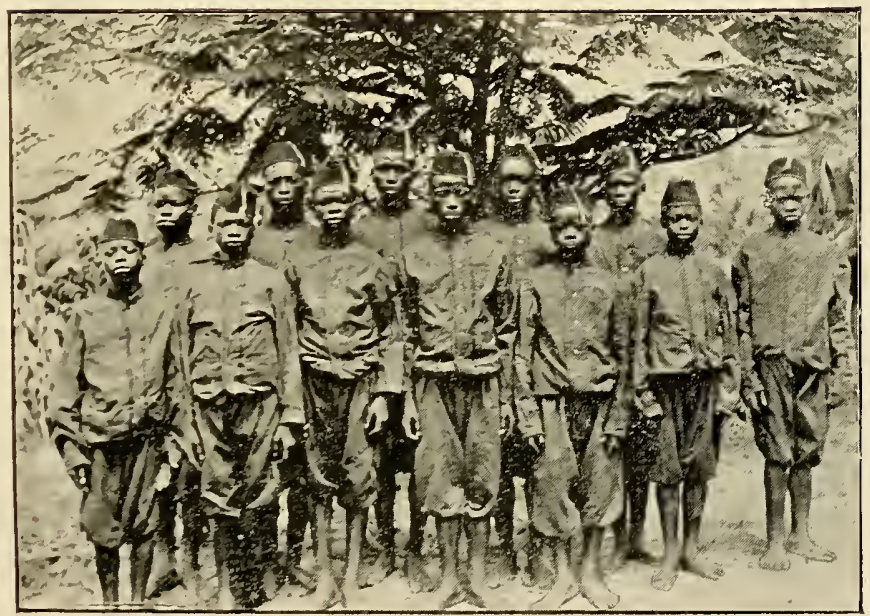

Groupe de soldats Congolais 


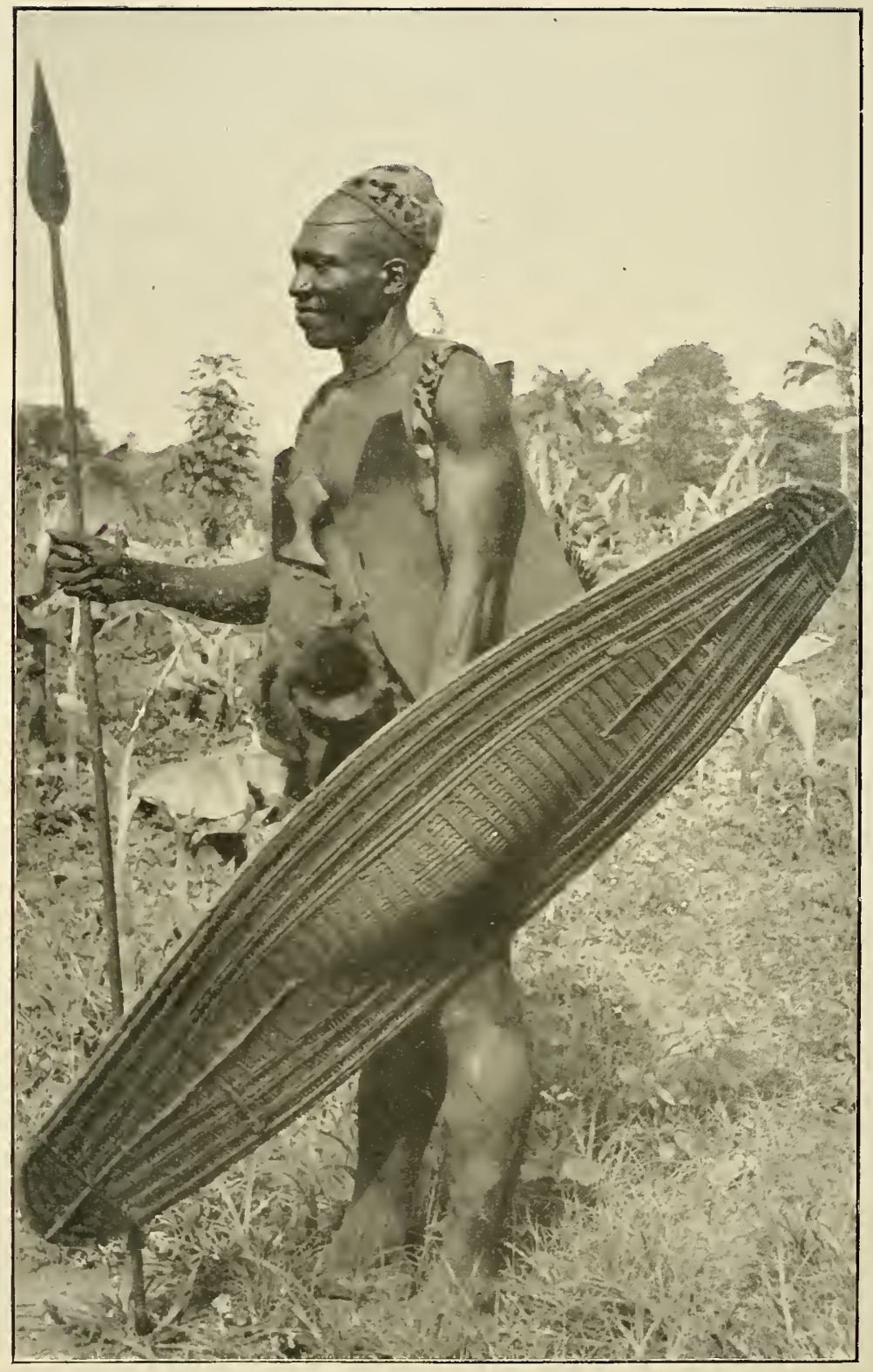

Guerrier indigène armé de la lance et du bouclier 
Cinq minutes après, mes hommes parvinrent à me hisser sur l'arbre et j'en fus quitte pour un bain qui n'avait pas été pris sans émotion.

Nous arrivons le 7 chez les Baknas Lukokas et le 8 chez les Bakuas I'Bélés et les Babindjis, mais pas plus chez les uns que chez les autres nous ne rencontrons un seul indigène; ils nous a vaient cédé la place.

Ne me liant pas aux apparences, je pris cependant la précaution de faire fortifier mon camp. Bien m'en prit, car la nuit du 8 au 9 je subis la plus formidable attaque qui se puisse rèrer.

Toutes ces populations ne possédaient, à cette époque, aucun fusil et ne se servaient, dans leurs attaques,que de lances et de couteaux, mais elles étaient d'une bravoure sans pareille.

Pendant la nuit, on vint me prévenir que les sentinelles avaient entendu du bruit, comme celui d'une foule (fui se rassemble. Je fis immédiatement lever mes hommes et je leur fis prendre leur poste de combat. Il était temps! Nous étions à peine postés qu'une immense claneur se fait entendre et des milliers d'indigènes lancent en mème temps leur cri de guerre : Bèlè! bèlè ! bèlè ! hou! hou ! hou !..... la terre tremble, car tous ensemble, la lance en arrèt, se précipitent sur nos retranchements. Il faisait heureusement un splendide clair de lune et, dans ces masses profondes, nul doute que chaque balle ne dût faire plusieurs victimes. 
Ils n'en arrivèrent pas moins à quelques mètres de nos retranchements et, à cinq reprises, ils renouvelèrent leurs attaques, toutes plus furieuses les unes que les autres ; ils ne s'en allèrent qu'après avoir constaté leurs pertes énormes et l'inutilité de leurs efforts.

Quels braves gens !... quels bons soldats !......

Lorsque, plus tard, ils nous seront complètement soumis, quelles pépinières de héros l'Etat aura à sa disposition!

J'ai livré pas mal de batailles en ma vie et je crois m'y connaitre un peu en fait de bravoure ; or, je déclare rque nulle part je n'ai vu une énergie, une bravoure, un dédain de la mort comparable à ce que j’ai vu chez les Bakuas M’Bélés.

Bien armés et bien commandés, ils feraient les premiers soldats du monde.

Des Bakuas I'Bélés, je me rendis à M'Pania Motombo, où Dhanis m'avait donné rendez-vous et où j'arrivais le 18 avril.

Là, nous apprìmes d'assez graves nouvelles. Gongo Lutété s'était de nouveau mis en marche pour ravager le pays des Balubas, tandis qu'un de ses principaux lieutenants, nommé Fuamba, ravageait toute la contrée des Batempas et les rives de la Luidi.

Dhanis résolut de frapper un grand coup.

Aidé de M'Pania Motombo,il attaquerait Gongo Lutété, tandis qu'a vec mon détachement j'irais attaquer Fuamba. 
Ainsi fut fait et, dès le lendemain 19, nous nous mettions en route, chacun pour remplir notre mission.

Un chef appelé Mukundji m'accompagnait et devait me servir de guide.

Le 27, nous arrivons au village de Fuamba, mais celui-ci, en apprenant notre arrivée, s'est envolé.

Il'étant mis à sa poursuite, j'arrive le 30 à un campement qu'il renait de quitter. Le 3 mai, j'arrive de noureau juste à point pour constater qu'il venait de passer la Luidi et en arait naturellement détruit le pont. Yous comprendrez dans quel état de fureur je me trouvais. Je me rendais parfaitement compte que le scélérat était instruit par ses espions de tous nos mouvements et qu'il se disposait à me faire traverser l'Afrique sur' ses talons.

Il fallait en finir; je réunis tont mon monde et je déclarai que j'en avais assez, que je retournais à Lusambo, que je reviendrais dans trois lunes el qu'alors, coutte que coùte, je parriendrais bien à joindre Fuamba.

Sur ce, je donnai des ordres pour la retraite et je repris le chemin de Lusambo. Le lendenain, je continue ma roule, mais je fais une très petite étape.

Le surlendemain, 5 mai, je fais un brusque crochet et après une longue marche nous arrivons à la Luidi ; je donne immédiatement l'ordre de construire un pont de lianes auquel mes hommes travaillèrent toute la nuit. 
Précisément, à cet endroit, la rivière avait au moins 40 mètres de large et le courant était d'une rapidité effrayante. Malgré les difficultés de la chose, au matin, un pont était construit tant bien que mal, c'est-à-dire que quatre ou cinq grosses lianes liées ensemble, formaient le tablier du pont et que deux autres lianes servaient de garde-fou.

Au moment de m'y engager, j'eus un mouvement de recul, mais pensant que Fuamba devait se moquer de moi, je résolus de passer quand même.

Au commencement, cela alla assez bien et, avançant centimètre par centimètre, j’étais presque au milieu du pont, quand, ayant eu la mauvaise idée de regarder l'eau, le vertige me prit à un tel point que je me mis à trembler et qu'il me fut impossible de faire encore un pas. Mes hommes, s'étant aperçus de la chose, vinrent heureusement à mon secours. Un me précédait et je me tenais à ses épaules, pendant qu'un autre me tenait par les flancs. Je parvins ainsi à gagner la rive opposée, mais ce n'est pas pour un million que j'aurais recommencé le passage ; je serais certainement tombé à l'eau.

Lorsque ma petite troupe fut passée, nous nous mîmes rapidement en route pour le campement de Fuamba.

Ce que j’arais espéré, se réalisa alors : Fuamba, me croyant parti pour Lusambo, ne s'était pas fait garder. Surpris comme il le fut, sa résistance fut presque nulle; ce ne fut pas tant un combat qu'une chasse 
à l'homme. Toutefois, ses pertes ne furent pas ce qu'elles auraient dù être, car mes soldats, qui étaient des Haoussas, étaient si mauvais tireurs qu'ils auraient manqué un homme à vingt pas. Nous fîmes cependant environ deux cents prisonniers.

Le 28 mai, je rentrai à Lusambo et Dhanis y rentrait le 29. Le 9, il avait rencontré et battu Gongo, à Batibingué, et lui avait fait plus de cinq cents prisonniers.

C'étaient deux belles victoires que nous venions de remporter et elles eurent une grande répercussion dans les événements qui se succédèrent dans la suite.

Coïncidant avec notre rentrée à Lusambo, un steamer était arrivé à la station, nous apportant le courrier d'Europe.

Parmi ses nombreux plis, il y en avait un qui prescrivait à Dhanis de former le plus tòt possible une nombreuse caravane, afin d'aller occuper effectivement le Katanga.

Pendant tout un mois, on ne s'occupa donc que de pousser l'instruction militaire de nos hommes, de trier nos magasins et de confectionner les nombreuses charges que l'expédition devait emporter avec elle.

Pendant tous ces préparatifs, un bien douloureux accident vint nous frapper tous de douleur et de consternation : un de nos sous-officiers blancs des plus vaillants et des plus énergiques, un nommé Smith, mourut presque subitement. 
Pendant quelques jours, les travaux furent suspendus, puis reprirent avec plus d'ardeur et l'on était prèt à partir, lorsque, le 19 juillet, nous reçumes, par l'entremise de M'Pania Notombo, la nouvelle que Gongo Lulélé, fatigué de ses défailes successives, désiıait la paix et demandait à vivre en bonne intelligence avec nous.

La proposition était trop belle ponr ne pas l'accepter, d'aulant plus que Dhanis partant pour le Katanga avec tout ce yui se trouvait de plus valide à la station, je n'aurais eu, comme commandant du camp de Lusambo, que des invalides el des recrues à opposer à Gougo en cas de nouvean contlit.

1)hanis dépècha donc Hinde ef de Wouters an-devant des envoyés de Gońgo jusque M'Pania Motombo et, lorsque cenx-ci furent arrivés à Lusambo, il les recut très bien el put leur faire voir des forces respectables, puisque la caravane élail précisément prête à se mettre en route.

Désirant me laissel une situation bien netle avant de quitter le district, il promit mème anx agents de Gongo d'aller rendre visite à ce dernier.

Il comptail faire un détour avec sa caravane, passer par N'Gandu avec tout son monde, afin d'en imposer aux Arabes et continuer ensuite sa route sur le Katanga.

Les événements ne lui permirent que de réaliser la première partie de son programme. 
Il se mit donc en route le 18 aoùt, accompagné de de Wouters, du docleur Hinde, Scheerlinck, de Heusch, Duchène et l'armurier Prigaldien, passa par Pania Motombo, Moina Kiolo, et arriva chez Gongo Lutété le 12 septembre, où il séjourna pendant tout un mois.

Pendant le temps qu'il resta à N'Gandu, Dhanis profita de l'occasion pour endoctriner Gongo et lui prouver qu'il a vait tout intérèt à se détacher des Arabes pour faire cause commune arec nous.

Il fit si bien qu'il convainquit Gongo et que celui-ci, ell signe de soumission à l'Etat, remit à Dhanis un présent considérable en pointes d'iroire.

Il fut convenu entre enx que Gongo pourrait rester à N'Gandu, quoique se trourant sur la rive gauche du Lomami ; que Duchène et Prigaldien, avec 40 soldats, resteraient en poste chez lui et qu'ils le défendraient s'il était attaqué par les Arabes.

Ces mesures prises, Dhanis partit pour Kabinda, afin de visiter le grand chef Baluba Lupongu; de là, il comptait gagner le Katanga.

Il fut également très bien reçu par ce chef, chez qui il fonda un nouveau poste, dont il donna le commandement à de Heusch.

Comme Kabinda était le dernier poste d'où il pouvait correspondre avec Lusambo, il en profita pour faire rapidement le voyage, ayant encore quelques mesures à prendre avant son départ définitif pour le Katanga. 
Il ne fit que toucher barre à Lusambo et se trouvait sur la route du retour à Kabinda, quand il croisa un courrier lui apportant la nouvelle que Séfu, à la tête de plus de 10,000 hommes, s'apprètait à se mettre en route pour nolis faire la guerre et détruire tous nos établissements.

Dhanis m'envoya de suite un courrier extra-rapide, me donnant l'ordre de le rejoindre avec tout ce que je: pouvais encore trouver d'hommes valides à Lusambo, el d'emporter avec moi un canon kírupp 7,5 racconrci que nous avions au camp. Je reçus la lettre le 29 octobre et le 30 je partais avec 80 soldats el le canon.

J'arrivai le 2 novembre à M'Pania, où Dhanis m'altendail pour me donner ses ordres, mais il se remit en route immédiatement pour Kabinda et Goie Moyassa, tandis que je devais, des le lendemain, ne diriger avec mes soldats sur N'Gandu.

Le canon, piloté par Cerckel, était destiné aux troupes qui se trouvaient à Goie Moyassa.

Me voilà donc, par la force des circonstances, le prolecteur en titre de ce mème Gongo Lutété que j’ai ballu arec Descamps il y a quelques mois, et à qui j'ai enleré toutes les femmes de son harem.

Dans une conversation avec Duchène, Gongo, à qui l'on in'a probablement dépeint sous des aspects peu avantageux, lui a dit qu'il aimait bien tous les blancs, sauf Chibalauga, qu'il n'aimerait pas à voir chez lui. 
Quant au chef qui me sert de guide, c'est précisément ce mème Fuamba, à qui j'ai donné une si bonne leçon sur la manière de surprendre les bomas, six mois auparavant ! !...

Depuis lors, j’ai trouvé en Fuamba un aide intelligent et sùr; quant à Gongo, j'en avais fait presque un ami et, en tout cas, un allié de tout repos et je n'ai jamais eu qu'à me loner de ses procédés.

Je reprends ma marche rers N'Gandu.

Parti de M'Pania le 3 novembre, j'arrivai le 5 et je logeai dans un village de nains, les Batuas.

Ces Batuas sont bien les êtres les plus extraordinaires qu'il soit possible de rêver.

Lenr taille rarie de $1 \mathrm{~m} .20$ à $1 \mathrm{~m}$. 30 ; ils ont de petits pieds et de petites mains, mais une grosse tête et ils sont franchement laids. Quoique très petits, ils sont d'une jolie force, d'une agilité surprenante et d'une adresse au tir à l'arc tout à fait extraordinaire et comme ils ont une connaissance parfaite de la forêt et de tous les poisons qu'elle renferme, ils peuvent à l'occasion, être des ennemis redoutables, même pour les blancs.

Quant aux Arabes, chaque fois que ceux-ci les ont attaqués, ils ont eu à le regretter ; aussi maintenant les laissent-ils bien tranquilles.

Le 5 novembre, j'arrivais donc dans un de leurs villages, que je trouvais désert; mais mes hommes, en furetant aux alentours, découvrirent une vieille femme qu'ils m’amenèrent. 
Désirant beaucoup faire leur connaissance et, si possible nous les attacher, je fis présent à cette vieille femme de quelques perles et d'un pagne et je donnai l'ordre de la laisser aller.

Ma tactique réussit pleinement, car elle revint peu après avec un nain et une antre vieille femme.

Les deux nouveaux venus avaient une frayeur atroce, mais je les rassurai de mon mieux et leur remis également quelques petits présents.

P’onr le soir, un à un, tous étaient rentrés, y compris le chef et, gràce à mes largesses, ils n'avaient plus peur du lout; ils me déclurèrent infiniment supérienr aux Arabes et me promirent leur amitié pour moi et mes frères blancs.

Voulant me faire fète, le chef ordonna le soir des danses en mon honneur ef, comme nous manquions de tlambeaux, il fit mettre le feu à un vieux chimbeck atin de mienx éclairer la scène.

Si l'on veut avoir une idée de la danse des Batuas, que l'on s'innagine, à la lueur du chimbeck qui brûle dans le fond et qui nous donne un éclairage tout à fait fantasticne, denx cents poupées à grosses têtes, ressemblint à des guomes se trémoussant aux sons du tambour et poussant des oh! oh! oh! sur le ton que l'on pourrait prendre, si l'on tàchait de se rendre aimable, au moment oì l'on vous frapperait sur le ventre. 
Le 9, nous passons le Lubéfu à gué, au village de Kitenghé. Il est partout le mème ce Lubéfu. Bien qu’ici il n'ait que 10 à 12 mètres de large et à peine nu mètre de profondeur, il est déjà dangereux tant son courant est rapide, et pour le traverser, on est obligé de se placer en file indienne, en se tenant par les épaules, afin de pouvoir se soutenir mutuellemeut en cas de chute.

Le 12, j’arrive à Kolomoni, dont le chef vient à ma rencontre avec son ami Machipula.

Le village de Kolomoni est composé d'une façon très curieuse : le chef Kolomoni et ses sujets sont de très bons guerriers, mais pas du tout cultivateurs. le chef Machipula et ses hommes sont, au contraire, très bons cultivatenrs, mais pas du tout guerriers. Les deux. chefs, amis d'enfance, ont alors uni leurs deux peuples et si Kolomoni se charge de défendre Machipula, • Machipula se charge d'entretenir Kolomoni et ses gens. Ils s'entendent admirablement et leur village. est un des plus beaux et des plus prospères que j’aie rencontrés au Congo.

La ronte de Kolomoni à N'Gandu doit être assez bonne durant la saison sèche, mais, pendant la saison des pluies, elle est presque impraticable, tant à cause de ses rivières débordantes et d'un passage difficile, que de ses marais, qui sont infects, innombrables et sans fin. Cette route, toujours plate et sans village, est d'une monotonie désespérante : des herbes, encore des herbes, 
toujours des herbes et des marais, sans qu'un peu d'ombrage vienne vous rafraîchir et vous protéger quelques instants contre les rayons de soleil qui ont surchauffé la terre au point de rous donner la sensation d'une brûlure à la poitrine.

Enfin, lè 18, j'arrive à N'Gandu, où je trouve Duchène relevant d'une hématurie et Prigaldien à peine guéri de la dysenterie.

lls ont tous denx bien manvaise mine. En revanche, ils me trouvent une nine superbe! comparée à la leur surtout...

Quelques instants après mon arrivée, Gongo vient me visiter ; il paraìt un peu gèné en ma présence, mais Fuamba aura dù lui dire que je valais nieux que la réputation que l'on m'avait faite et nous ne tardons guère ì devenir de bons amis.

Le 19, repos complet. Le 20 , je vais rendre visite à Gongo.

Le 21 , vers 6 heures du soir, on vint me prévenir en toute hàte de la part de Gongo Lutété que Séfu, accompagné de la plupart des chel's arabes, passait le Lomami à deux jour's de marche environ, en amont de N'Gandu.

Bien qu'il n'y eùt pas de lıne, Gongo se décida à partir de suite arec tous ses hommes armés, afin de contrarier si possible le passage du lleuve par les hommes de Séfu. Je me décidai, de mon còté, à organiser immédiatement une colonne volante et à partir le lendemain matin dès le point du jour. 
Duchène et Prigaldien, quoique très faibles tous deux, insistent pour m’accompagner.

Je choisis dans les deux détachements une centaine de bons soldats noirs qui ont déjà fait leurs preuves sous mes ordres et sur lesquels je suis certain de pouroir compter.

Après douze heures d'une marche des plus pénibles, je rencontre Gongo ainsi qu'un détachement de quarante soldats sous les ordres du sergent morovien Albert Frees et du caporal Benga qui avaient été envoyés en reconnaissance par Dhanis, de mème Lupongu et Kolomoni avec leurs bandes armées.

Tous ensemble, ils avaicnt essayé de s'opposer au passage de la rivière par les troupes de Séfu, mais ils avaient éprouvé de telles pertes qu'ils avaient été obligés de battre en retraite.

Il était trop tard pour rien entreprendre ce jour, et d'ailleurs mes hommes étaient trop fatigués. Je fis donc arrèter ma colonne et campai dans une bonne position.

Les soldats d'Albert Frees, qui ne venaient que de Goie Moyassa, étant beaucoup moins fatigués que les miens, je lui donnai l'ordre de rester aux avant-postes, afin de prévenir toute surprise des Arabes.

La nuit fut épouvantable; ma tente et mes effets restés en arrière n'arrivèrent que très tard et il plut à torrents toute la nuit. De ma tente ouverte, où nous nous étions réfugiés à trois,je vois mes pauvres hommes 
sans le moindre abri, se groupant le plus possible autour de moi et grelottant sous l'averse qui fait rage. J'en étais navié, mais que faire? ?

Inutile, je crois, de dire que je ne fermai pas l'œil de toute la nuit, attendant le jour avec impatience.

Enfin, il se lève et la pluie cesse de tomber vers 6 heures.

Je fais aussitôt prévenir Gongo que je vais attaquer et lui envoie l'ordre de m'amener son monde pour concourir au mouvement, mais il me fait répondre que la presque tolalité de ses fusils étaut des fusils à piston el ceux-ci étant mouillés, il est impossible à ses hommes d'attaquer en ce moment, qu'il n'aurait que des ratés, d'autant plus qu'une petite pluie fine s'était remise à tomber.

Ce fut pour moi un trait de lumière; car je me dis qu'évidemment cenx de Séfu devaient se trouver dans le mème ètat. Je résolus donc de profiter de cette heureuse circonstance en attaquant immédiatement.

Les ordres que je donnai furent ceux-ci : Lupongu avec tous ses hommes devait garder les bois en amont du boma jusqu'au fleuve et empècher les Arabes de fuir de ce còté. Gongo, avec ses gens, reçut la même mission pour les bois qui se trouvaient en aval. Mes deux llancs élant gardés, j’attayuai les Arabes de front. Albert Frees, et ses quarante soldats, formaient une première ligne; je l'avais fait renforcer par l'élite des hommes 
de Goïe Moyassa que je savais très braves. Ce chef m’avait demandé de lui faire l'honneur de pouvoir participer à l'attaque a rec les blancs. Les cent hommes qui me restaient furent formés en trois colonnes d'assaut : celle de droite sous les ordres de Duchène, celle de gauche sous les ordres de Prigatdien, celle du centre sous mes ordres, nos effectifs étant trop faibles pour me constituer une réserve. Ces dispositions prises, je donnai le signal du départ.

J'étais très calme, très sùr de moi-même et bien persuadé que j'allais remporter la victoire, mais malgré moi, en royant ces masses profondes, sombres et silencieuses, en pensant à mon immense responsabilité, ainsi qu'au massacre effroyable qui allait avoir lieu, je me sentis envahi par une invincible tristesse et ce fut presque religieusement que je donnai le signat du combat.

$\downarrow$ ce moment, Gongo vint vivement â moi : “ Chibalanga, me dit-il, restez avec moi et dites à vos hommes d'aller se battre, car il y aura beaucoup de morts aıjourd'hui! " " Non, Gongo, lui répondis-je, mes hommes sont habitués à me voir au milieu d'eux. et s'its ne m'y royaient pas, ils croiraient que j’ai peur et ne se battraient pas bien. " " Ah !... » me dit Gongo, et il s'en alla tout rèveur.

Mes derniers ordres étaient ceux-ci : Albert Frees et les hommes de Goïe Moyassa devaient, en se défilant le plus possible, arriver à 150 mètres des palissades, se 
coucher ct, dans cette position, ouvrir un feu rapide sur les homas arabes. Cachées par le rideau de fumée, mes trois colonnes d'assaut rejoindraicnt rapidement la ligne des tirailleurs, d'où elles tireraient elles-mèmes le plus rapidement possible cinc cartouches, puis, tous ensemble, la baïonnetle au canon et la machette dans les dents, nous nous précipiterions à l'assaut. Ainsi fut fait.

Bientòt, la fusillade éclate de toutes parts, rageuse, épouvantable, dèsespérée! car', d'un còté comme de l'aulre, on sait que e'est me question de vie ou de mort que le vainqueur sera impitoyable el que, le voulùt-il, il ne pourra faire graice au vaincu.

lls ont pour eux le nombre et les palissades derric̀re lescuiclles ils se cachent; nous avons pour nous la supériorité des armes, de la discipline et la confiance illimilée que j’ai su inspirer à mes hommes.

Je fais pousser l'allaque le plus vigoureusement possible el, quelques instants après mon arrivée sur la ligne des tirailleurs, je fais sonner la charge et j'enlève mes hommes dans un élan irrésistible; nous profitons du rideau de fumće qui se tronve en avant de nous et arrivons aux palissades avant que nos ennemis soient remis de leur stupeur.

On se fusille à bout portant; mes hommes aftaquent les palissades à la machelte et bientòt Albert Frees, aidé de Benga, qui est un hercule, fait une brèche par laquelle nous entrons en ouragan. 


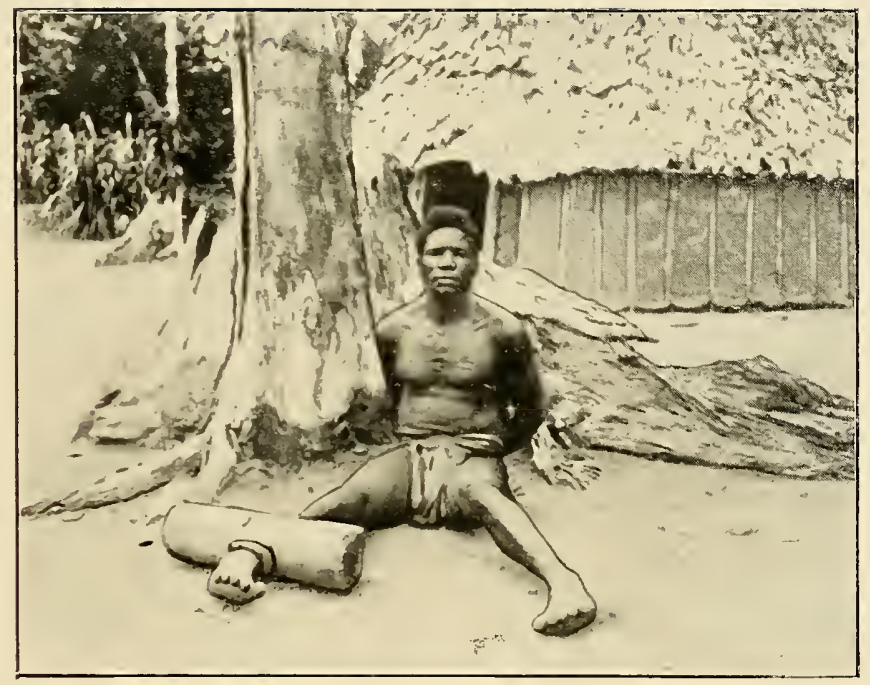

Un des supplices infligés par les Arabes à leurs esclaves fugitifs

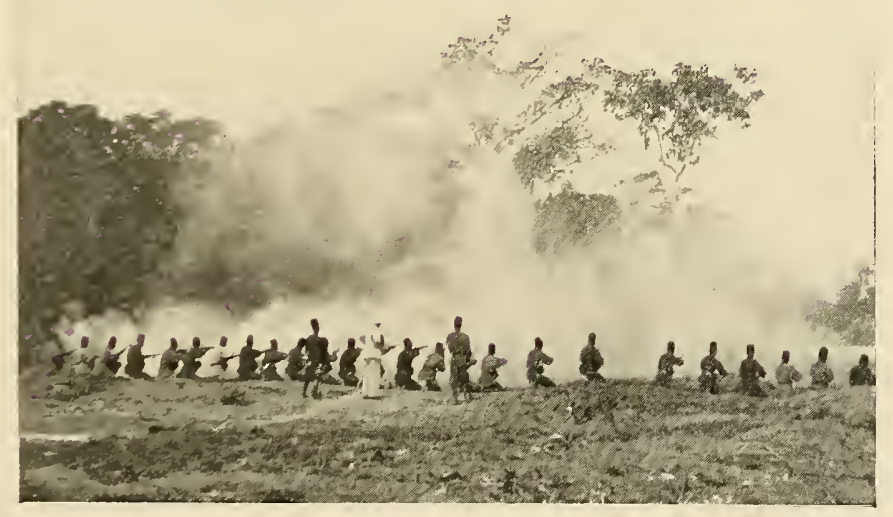

En tirailleurs ! 


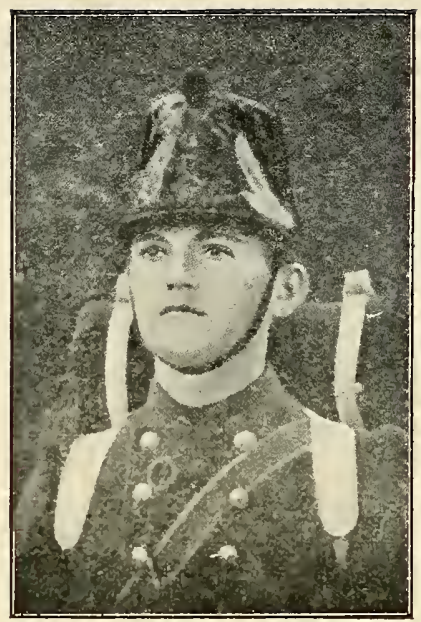

UN HÉROS!

IE Sergent DE BRUYINE

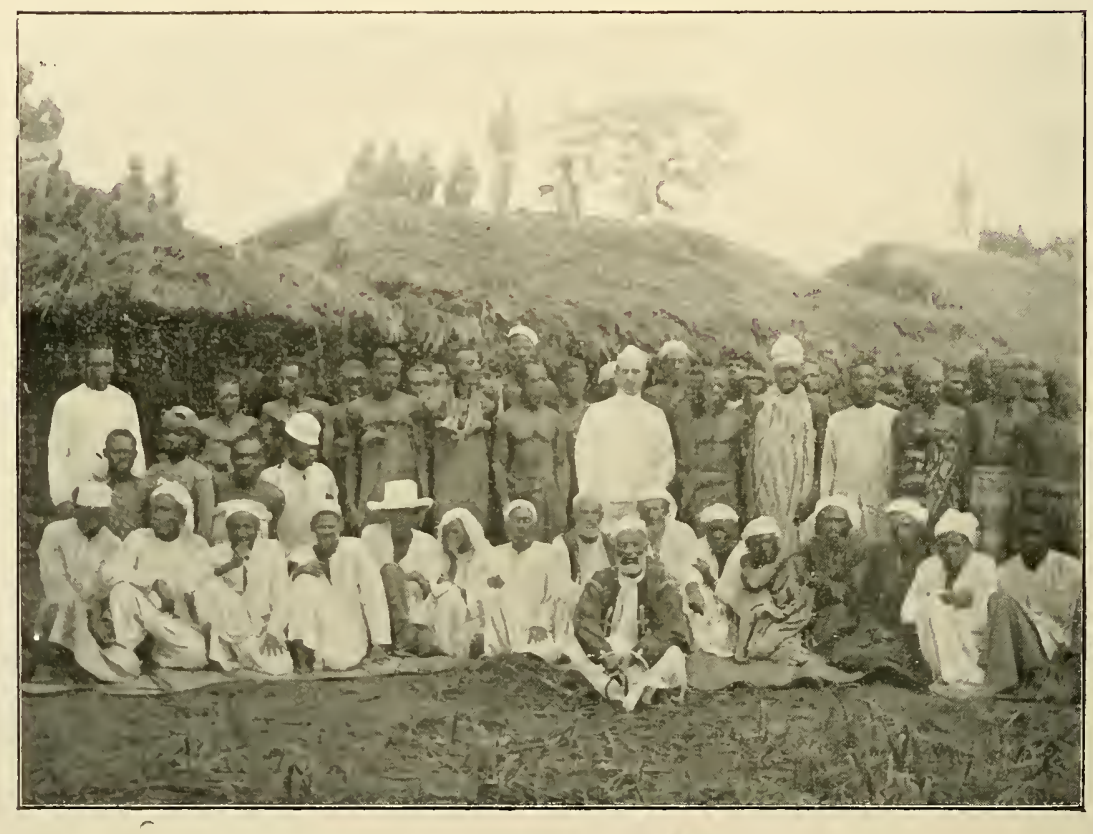

Groupe d'Arabisés du Manyéma 
Soudain, la place est libre, les Arabes fuient éperdus, nos pieds baignent daus le sang; et, comme si le destin eùt enfin voulu punir les Arabes de tous leurs crimes passés, tout s'acharne contre eux.

Déjà, le Lomami gronde et à peine ont-ils fait deux cents mètres, qu'il leur barre le passage et leur rend toute retraite impossible. On dirait que lui aussi, las d'assister à loutes leurs infamies, il a résolu de se venger et qu'il veut prendre sa part du carnage.

Le rugissement de ses rapides, placés à quelques centaines de mètres en aval, semble prédire à nos ennemis aflolés que ceux d'entre eux qui échapperont à nos balles n'échapperont pas à sa colère.

Voyant la place vide, je crie à mes hommes : "Vite au Lomami!"»

Mais dans la fusillade, j’ai peine à me faire comprendre et quinze homnes seulement me suivent. A peine avons-nous fait quelques pas et avons-nous dépassé les quelques arbres qui séparent le camp d'une petite plaine qui se trouve au bord du Lomami, que nous voyons une foule immense qui hésite encore entre nos balles el les eaux furieuses du fleuve. Joute !..... feu !...... Quinze coups de fusil partent et toute cette multitude, en vrai troupeau de Panurge, saute dans le Lomami. Mes hommes ont entendu notre salve, et bientòt tous sont autour de moi. 
Ici, ma plume s'arrète impuissante et renonce à décrire ce qu'aucun pinceau ne saurait rendre et nous assistons à la scène la plus grandiose, la plus démoniaque que jamais imagination de poète ait pu rèver.

Le Lomami en rage entraine vers ses rapides des milliers d'hommes enchevètrés en grappes fantastiques; la terreur les affole, paralyse leurs mouvements; leur masse les empèche de nager et, dans les spasmes du désespoir, ils tàchent en vain de se soustraire à l'étreinte mortelle de leurs compagnons.

Pendant ce temps, 140 fusils à tir rapide ne cessent de leur envoyer une grèle de balles. Partout de l'eau! du fer! du feu !

Ce fut d'un tragique sans nom; Satan lui-mème dut en être épouvanté, car je doute que jamais sabbat de démons ait approché de cette vengeance de chrétiens. Quant aux pertes subies par les Arabes, elles furent efrrayantes. Tous leurs principaux chefs furent tués; trois drapeaux dont celui de Séfu restèrent entre nos mains et eux-mèmes avouèrent plus de trois mille morts et parmi ces derniers se trouvait le fils de Séfu.

Un trait qui montrera l'héroïsme des noirs et mème des enfants, lorsqu'ils sont sous les yeux du blanc, trouvera ici son application.

Pendant le combat, un petit boy à qui j'avais confié mes cartouches me dit tout-à-coup, en me montrant son pied : "Regarde maître ". Préoccupé de ma bataille et ne voyant qu'un léger filet de sang, je lui répondis : 
" Ce n'est rien, passe-moi mes cartouches !... " Et le brave enfant resta à mes còtés jusqu'à la fin du combat. Ce fut seulement lorsque le tout fut terminé qu'il se mit à pleurer, me demandant de ne pas l'abandonner. L'examinant alors plus attentivement, je constatai, avec l'émotion que vous comprendrez, que le pauvre enfant avait le pied broyé par une balle; or, pendant tout le combat, il n'avait pas fait entendre une seule plainte et avait continué son service auprès de moi. Je l'emmenai et le soignai, comme bien vous pensez.

Cette bataille fut, de toutes celles qui se livrèrent au Congo, la plus sanglante et probablement celle aussi dont l'efret moral fut le plus grand.

Avant de terminer ce chapitre, je tiens à rendre hommage à la mémoire de Duchène et de Prigaldien ; tous deux sont morts, aujourd'hui, mais leurs familles peuvent et doivent ètre fières d'enx, car ils se sont comportés en braves et bien qu'assistant tous les deux à leur première bataille, ils se sont montrés admirables de sang-froid et d'entrain.

A la stite de cette victoire, à ma rentrée en Belgique, je reçus la plus belle récompense qu'un oflicier puisse ambitionner. Sa Majesté le Roi Souverain daigua me remettre un sabre d'lonneur portant son chiffre.

Qnelque temps avant les événements que je viens de relater, un autre drame tout aussi poignant se déroulait également sur les rives du Lomami. 
Le 22 octobre, Scheerlinck et Hinde, qui se trouvaient à Goië Moyassa en attendant Dhanis, reçurent une première lettre de De Bruyne, dans laquelle celui-ci leur disait qu’il était, ainsi que Lippens, prisonnier des Arabes à Kassongo et que le chef de ceux-ci, Séfu, avait réuni plus de dix mille hommes armés de fusils, et qu'il s'apprêtait à nous attaquer et à détruire toutes nos stations jusqu’à Léopoldville. Le seul moyen, disait De Bruyne, de calmer la colère de Séfu, c'était de lui livrer Gongo, afin de le punir de sa trahison envers les Arabes.

Le 29 octobre, nouvelle lettre de De Bruyne dans laquelle il proposait à Scheerlinck et à Hinde, de la part de Séfu, une entrevue sur la rive droite du Lomami.

Ces deux officiers n'acceptèrent évidemment pas de s'y rendre. S'ils s'y étaient rendus, ils se seraient fait massacrer infailliblement.

Quelques jours après, le 15 novembre, Séfu envoya De Bruyne au Lomami, sous bonne escorte, tonjours dans l'espoir qu'il finirait par persuader les blancs de trarerser le fleure.

L'entrerue fut tragique. Prévenus de l'arrivée de De Bruyne, Scheerlinck et Hinde avaient fait cacher leurs meilleurs tireurs dans les hantes herbes qui se trouvent au bord de l'eau et leur avaient recommandé de viser chacun un Arabe avec soin, mais de ne pas tirer sans leurs ordres. 
En arrivant sur la rive, De Bruyne leur conta qu'il était traité plus mal qu'un esclave, qu'on le faisait mareher toute la journée en plein soleil et que, le soir, on l'enchainait afin qu'il ne pùt pas fuir. Il leur dit aussi qu'il était dépourvu de tout article d'échange et leur demanda de bien vouloir lui envoyer quelques perles et des mouchoirs pour pouvoir se procurer de la nourriture. Scheerlinck lui denıuda alor's s'il savait uager et, sur sa réponse affirmative, lui dit que plutòt d'endurer tous les tourments qu'on lui faisait subir, il vilait mieux essayer de fuir. Il le mil alors au courant des mesures qu'ils avaient prises.

" - En ee moment, lui dit-il, les trente meilleurs tireurs de nos troupes sont cachés dans les herbes et tiennent ehaeun un Arabe au bout de leur fusil. Je vais envoyer une barque aree des marehandises et, aussitòt qu'elle aura fait quelques mètres pour revenir à notre rive, jetez-vous résolument à l'eau, les hommes de la barque rous aideront et d'ici nous tirerons sur les Arabes pour les empèeher de tirer sur vous.

Mais De Bruyne refusa, disant qu'il savait bien que c'était sa seule ehanee de salut, mais qu'il ne pouvait pas abandonner son chef, le eommandant Lippens, auquel il avait donné sa parole de ne pas partir sans lui; il ne voulait pas manquer à la parole jurée!

Quelques jours après, Séfu les faisait lâchement assassiner tous les deux pour se venger de la défaite que je lui avais infligée à Chigé. 
Mais revenons à ce combat. La bataille étant terminée, il ne pouvait ètre question pour nous d'essayer de poursuivre, car nous n'avions aucune barque à notre disposition.

Le jour même, je fis donc lever le camp et repris la route de N'Gandu, afin d'échapper à l'infection et à l'horreur du champ de bataille.

A peine étions-nous installés que Gongo vint me rejoindre avec tout son monde et établit son campement à proximité du mien. Ces gens, comme vous le savez, élaient à cetle époque les plus endurcis cannibales de la terre, mais j’avais perdu la chose de vue on plutôt je n'y pensais pas, lorsque vers le soir, je proposai à Duchène et à Prigaldien d'aller en nous promenant et en fumant notre pipe, dire un petit bonjour à Gongo ef faire un bout de causette avec lui. Tous deux acceptèrent bien rolontiers et nous étions déjà assez loin dans le camp, oì nous avions remarqué qu'il réguait une forte odeur de viande ròtie, sans y altacher d'importance. Quand tout-à-comp, Prigaldien, fraîchement débarqué d'Europe et peu au courant des mœurs du pays, me saisit le bras el me serrant de toutes ses forces, s'écrie d'mn air épouvanté : " Oh ! les mâssis pourgais! " Et du doigt il me montrait une jambe entière en train de cuire sur un feu de bois; la pointe du pied tout recroquevillé était venue rejoindre le tibia. 
J'entrainai rapidement Prigaldien vers notre campement, lui expliquant de mon mieux que je savais que c'était horrible, mais qu'enfin, pour le moment, nous devions feindre de ne rien voir, afin de nc pas ètre obligés d’intervenir; la guerre arabc étant finie, nous y mettrions le holà.

Mais lui ne m'écoutait pas, on s'il m’écoutait, ne me comprenait certainement pas, car toute sa route il continuait à dire : "Pouah !... oh ! les màssis rowes !... les màssis pourçais, ni fàt-i nin qui l'dialc les arcdje!!! "

Il cn cut certaincment la fièvre pendant la nuit et, longtemps après, il suffisait encorc de lui rappeler la chose pour lui donner le mal de mer.

Quant à moi, j’étais déjà blasé, je ne dirai pas que je voyais la chose avec indifférence, mais enfin jc la regardais comme une plaie horrible, longue à guérir et contre laquelle nous étions désarmés. Nos soldats ne se lirraient plus à ces répugnants festins.

Quant aux hommes de Gongo, vouloir les punir et les cmpêcher en ce moment de fesloyer avec les restes de leurs cnncmis, c'eùt ćté de la folic : ils se scraient retournés contre nous et, indépcndamment des milliers de vies humaincs que nous aurions dû sacrifier pour protégcr quelques cadavres, nous aurions risqué de compromettre tout le succès de la campagne, et peutêtre retarder d'un siècle les bienfaits de la civilisation que nous apportions dans les plis dc notre beau drapeau bleu étoilé d'or. 
A la suite de cette bataille, je reçus de Dhanis la lettre suivante que je publie avec fierté :

Camp de Goie Moyassa, le 27 novembre 1892.

Mon cher Michaux,

J'ai le plaisir de vous accuser réception de votre lettre concernant le combat du Lomami du 21-22 novembre.

Votre marche forcée vous a permis d'arriver à temps, pour empècher l'envahissement complet du pays, silué à la rive gauche du Lomami, par toutes les forces arabes ef vutre altaque énergique et rapide de la position déjà fortifiée de Séfu a eu pour résultat d'inlliger aux Arabes des pertes des plus sérieuses.

Presque toutes les forces de Sélu sont ancianties, les autres forces arabes doivent être dénoralisées; nous devons en profiter.

Je vous félicite personnellement de ce brillant snceès, dû surtout à volre initiative, el qui amènera, j'espère, la solution de la question arabe et la prise de Nyangwé.

Soyez assuré que je signalerai au Gumerneur l'importance capitale de ce combat el des conséquences qu'il pent avoir.

Bien à vous,

(S.) DHANIS,

Commissaire de district du Lualaba.

De retour le 24 à N'Gandı, le 27 je recois de Dhanis l'antorisation de passer le Lomami.

Heureux de l'avoir obtenue, le 28, accompagné de 90 soldats, de Gongo et ses baudes, je passe le fleuve. Duchène et Prigaldien, toujours malades, restent à N'Crandu, oì ils nous sont d'ailleurs des plus utiles pour assurer nos communications avec Lusambo.

Trois jours après, nous sommes au grand village de Dibué, mais il est abandonné et nous pouvons nous installer sans nouveau combat. 
Le chef, sur ma promesse qu'il ne lui sera fait aucun mal, ne tarde d'ailleurs pas à venir me faire sa soumission.

C'est un grand bel homme dans la force de l'àge, il me parait très a fiaissé et s'excuse de ne m'apporter aucun tribut, mais il n'a plus rien, ayant tout perdu au combat de Chigé, où il a été entraince de force par les Arabes. Presque tous ses gunerriers ont élé lués ou noyés et les débris des bandes arabes, en se sauvant, ont repassé par chez lui et l'ont complètement pillé.

Je lui donne l'ordre de réintégrer son village avec ce qui lui reste de monde, lui prometlant qu’il ne sera plus inquiété dans l'avenir, si lui, de son còté, se montre loyal et fidèle.

De Dibué, toujours accompagné de mon ami Gongo (car nous étions devenus de bons amis), nous marchons sur Lusuna.

Pendant la route, le deıxième ou troisième jour, nous étions restés toute la journée sans rencontrer le moindre ruisseau où nos hommes pussent se désaltérer, aussi étaient-ils à moitié morts de soif,lorsque nous arrivâmes à l'étape ; ici, il ne se trouvait qu'une seule mare d'eau et les Arabes, dans leur fuite, a vaient tué trois esclaves, dont ils avaient précipité les cadavres dans la mare.

Ces cadavres étaient complètement en putréfaction, gonflés comme des outres et tout couverts de pustules purulentes et de grosses mouches vertes; ils étaient 
horribles à voir. Quant à l'eau, elle répandait une odeur infecte et était également verte.

Malgré le danger, malgré la mort certaine qui les attendait, mes hommes étaient si désespérément altérés, qu'ils voulaient quand mème boire de cette eau et je dus mettre le revolver à la main et menacer de tuer le prenier qui cnfreindrait ma défense pour les empècher de s'empoisonner à coup sùr.

Après avoir fait enlever les cadavres, je fis remplir d'eau toutes les marmites que l'on put trouver, on . alluma des feux et je fis bouillir l'eau en ma présence.

La soif de ces pauvres diables était si terrible que, pendant que l'eau bouillait, ils y trempaient les doigts sans s'oceuper des brutures qu’ils se faisaient, afin de pouvoir se rafraichir les levres.

Nous parvinmes à Jusuna le 8 décembre, sans que notre approche eùt élé signalée ; aussi, ce fut plulòt une tuerie qu'un combat. Nous fimes des prisonniers par centaines et les habilants n'ayant eu le temps de rien cacher, mes hommes et ceux de Gongo furent largement et pour longtemps réapprovisionnés en tontes choses. 


\section{CHAPITRE X.}

Réunion avec Dhanis à Lusuna - Revue des troupes de nos aliiés. - La ménagerie Michaux. - Combat dans un marais. Un réveillon. le revolver à la ceinture. - Le fétiche de Dhanis. - Le brave Cassart! - Mort de Mohara. - Mes cheveux se dressèrent sur la tête..... - Attaque inopportune.

Dhanis, ayant pris une antre route, me rejoignil à Lusuna quatre jours après mon arrivée. 11 élait accompagnıé de Scheerlinck, de Wouters, Hinde, de Heusch et Cerckel, ainsi que de 350 soldats noirs. Il avait également notre canon.

A leur arrivée, je dus les ravilailler tous en café, sucre, tabac et sel; il y a vait déjà longtemps qu'ils en étaient privés; aussi firent-ils lète à mes largesses.

Nous restàmes trois semaines à Lusuna où, comme je l'ai dit plus hant, nous avions des vivres en abondance.

Cependant, aucune contrée, eût-elle mème été dix fois plus riche que Lusuna, u’aurait pu nourrir longtemps des masses comme celles que nous traînions à notre suite.

Nous étions six blanes et nous avions environ avec nous 400 soldats. Quant aux bandes de Gongo, Lupongu, Kolomoni, etc..., elles se chiffraient par plus de 25,000 personnes. 
Afin d'éviter la famine, Dhanis résolut donc de renvoyer Lupongu et Kolomoni ainsi que les autres chefs chez eux, ne gardant que Gongo et ses gens.

Mais, avant de les renvoyer, il voulut les dénombrer, afin de savoir exactement ce que chacun d'eux possédait de fusils. Pour le faire, il employa la mode arabe.

Lorsque nous fìmes assis, une peau de chèrre fut apportíe et fixée en terre, an moyen de petits piquets en bois, puis chaque chef fit défiler ses hommes armés de fusils, tous devant passer sur la peau.

Nous croyions de prime abord que Gongo avait beaucoup plus de fusils que Lupongu; à notre grand étonnement ce fut le contraire: Gongo avait environ 2,000 fusils et Lupongu en arait plus de 3,000.

Les premiers jours de notre séjour à Lusuna furent charmants et, après nos grandes fatigues et toutes nos privations, nous nous sentions heureux de vivre et de nous reposer dans notre Capoue noire.

Mais, habitués à une vie très active, nous n’y étions pas de huit jours, que le spleen nous gagnait et que nous souhaitions courir à de nourelles fatigues, à de nouveaux combats.

Tous les jours donc, Dhanis s'informait auprès de Gongo de l'emplacement actuel des Arabes et tous les jours aussi Gongo Ini donnait des nouvelles plus ou moins fantaisistes, qui étaient vite reconnues inexactes par nos patrouilles de reconnaissance. 
Il y arait trois semaines que nous nous morfondions dans l'inaction, quand Congo vint nous donner des nouvelles de l'ennemi avec une assurance telle qu'il proposa mème à Dhanis de parier que cette fois elles étaient exactes.

Celui-ci accepta le pari avec d'autant plus de plaisir qu'il ne demandait pas mienx que de le perdre. L'enjeu était, du còté de Dhanis, dix pièces d'étoffe, de la part de Gongo dix bœufs.

Les dispositions de Dhanis étaient celles-ci : A l'avenir j'arais arec mes 90 hommes le commandement de l'avant-garde et Gongo arec ses gens m'étaient adjoints, Dhanis suivait arec le grros de ses forces.

Ces dispositions me comblaient sous tous rapports: $\left.1^{\circ}\right)$ j’étais mon maitre, considération qui passait avant toutes les autres ; $2^{\circ}$ ) j'étais au moins certain que l'on ne pourrait pas livrer une bataille sans moi; $3^{\circ}$ ) j'a vais avec moi Gongo Lutété, dont je m’étais fait un véritable camarade et en compagnie duquel j'étais très heureux de voyager; $4^{\circ}$ ) il y avait la question de mes animaux. Aimant beaucoup les bètes, j’a vais un buffle de selle qui me rendait les plus grands services, que j'affectionnais beaıcoup, mais qui était passablement méchant avec les autres personnes; j’avais aussi un âne de Mascale, qui, comme caractère, ne valait guère mieux que son compagnon de selle; ensuite j’avais un léopard que j'avais apprivoisé, puis mon chien, mon brave Pitch, 
qui, comme fidélité, n'avait pas son pareil, mais qui aurait infailliblement sauté à la gorge de celui qui, par inadvertance ou dans la conversation, m'aurait touché ne fùt-ce que du bout du doigt. Toutes mes bètes m'étaient sacrées et je les aimais beaucoup ; malheureusemenl, il n'en était pas de mème de mes camarades, qui avaient pris en horreur ce qu'ils appelaient la ménagerie Nichaux, car, disaient-ils, il était presque impossible de se rendre chez moi sans risquer de se faire mettre en pièces. Evidemment, ils exagéraient beaucoup. Enfin, chose très rare, la décision de Dhanis satisfit tout le monde.

Le 30 décembre, dès 5 heures du matin, nous nous élions done mis en route. Gongo, avec ses fusiliers, batlait l'estrade et formait, si je puis m'exprimer ainsi, notre cavalerie d'exploration ; je suivais à environ trois kilomètres, puis venait Dhanis marclıant en tète du gros de nos forces.

Vers midi, en pleine chaleur du jour, j'entends touta-conp tune fusillade enragée en avant de nous, je fais presser le pas à mes hommes et j’arrive sur les bords d'un narais énorme, au moment oì Gongo et lont son monde étaient en pleine déroute, presqu'en fuite devant des forces arabes considérables, qu’il avait follement attaquées, sans attendre mon arrivée.

Une minute d'hésitation et mon brave ami Gongo pouvait ètre perdu. J'entrai donc résolument dans le 
marais arec tous mes hommes et ce fut arec de l'eau jusqn'anx épaules que nous ouvrìmes le feu sur les Arabes.

Dhanis de son còté, entendant la fusillade, arrive au pas grmmastique arec une compagnie, afin de me soutenir et rent entrer dans le marais derrière moi, mais arant remarqué que les Arabes roulaient nous tourner sur le flanc droit, je lui criai : " A droite, commandant, à droite !... "

Bien que de l'endroit où il se trouvait il ne pùt voir le mourement des Arabes, il comprit que la situation devait ètre pressante et, lıi aussi sans hésiter, se jeta dans le marais avec ses hommes, sur mon flanc droit; il arriva juste à temps pour empècher leur mouvement enveloppant.

Pendant ce temps, le docteur Hinde avait recu l'ordre de rester avec ses hommes pour garder les femmes et les bagages, ainsi que pour presser l'arrivée des autres troupes.

Du haut d'une termitière, il vit donc tout le combat d'une facon idéale et il nous dit dans la suite qu'il était impossible de rêver un plus beau spectacle que cette bataille arfuatique.

I)'abord les masses de Gongo en retraite poursuivies par les masses arabes, puis nos hommes, à Dhanis et à moi, entrant dans l'eau et cette ligne de têtes s'avançant vers les Arabes, car on ne voyait rien du restant du. 
corps, puis tout-à-coup cette mème ligne semblant cracher du feu, enfin les Arahes, se mettant eux-mèmes en retraite, poursuivis à leur tour par nos hommes et les forces de Gongo.

Mais, pendant que Hinde, tout an spectacle qu'il admirait, oubliait un peu ses hommes, ceux-ci lui jouèrent un tour qui aurait pu lui coùter cher.

Tous les hommes de Hinde étaient des Haoussas; environ une moitié des miens l'étaient aussi ; or, lorsqu'ils devaient prendre une position d'assaut, ils avaient conservé l'habitude d'entommer leur chant national. Le chanteur de la troupe s'écrie, sur un ton plutôt plaintif : "è dièbè ko è malèla " et, tous ensemble, ils reprennent "oh! ko! ko! " et cela dix, quinze, vingt fois de suite, pendant la marche en avant; lorsqu'ils sont prèts à aboutir, le chanteur s'écrie " koriko! " et tous ensemble : "Oh ! Koriko !.. " Oh ! !..."

Mlors, ils sont partis, c'est la masse, c'est la brute qui se rue en avant et plus rien ne les arrète.

Mes Haoussas ayant donc entonné leur chant de guerre, ceux de Hinde ne purent tenir en place et pendant que leur chef se délectail à la vue de la scène fantastique qu'il avait devant lui, ils étaient tous vemus se ranger près des miens et prendre leur part au combat.

Mais si ce renfort inopiné m’agréait heaucoup, il n'en était pas de mème de Hinde qui s'aperçut précisément de leur départ au moment où il remarquait sur sa 


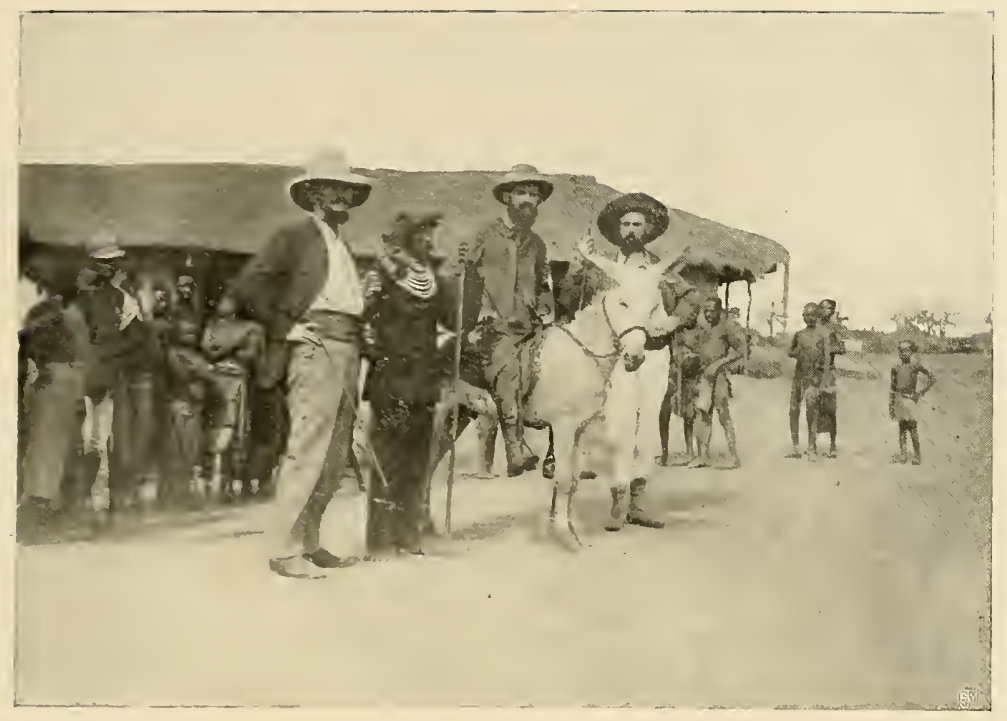

De gauche à droite

GILLAIN, PANIA MOTOMBO, DHANIS, HINDE

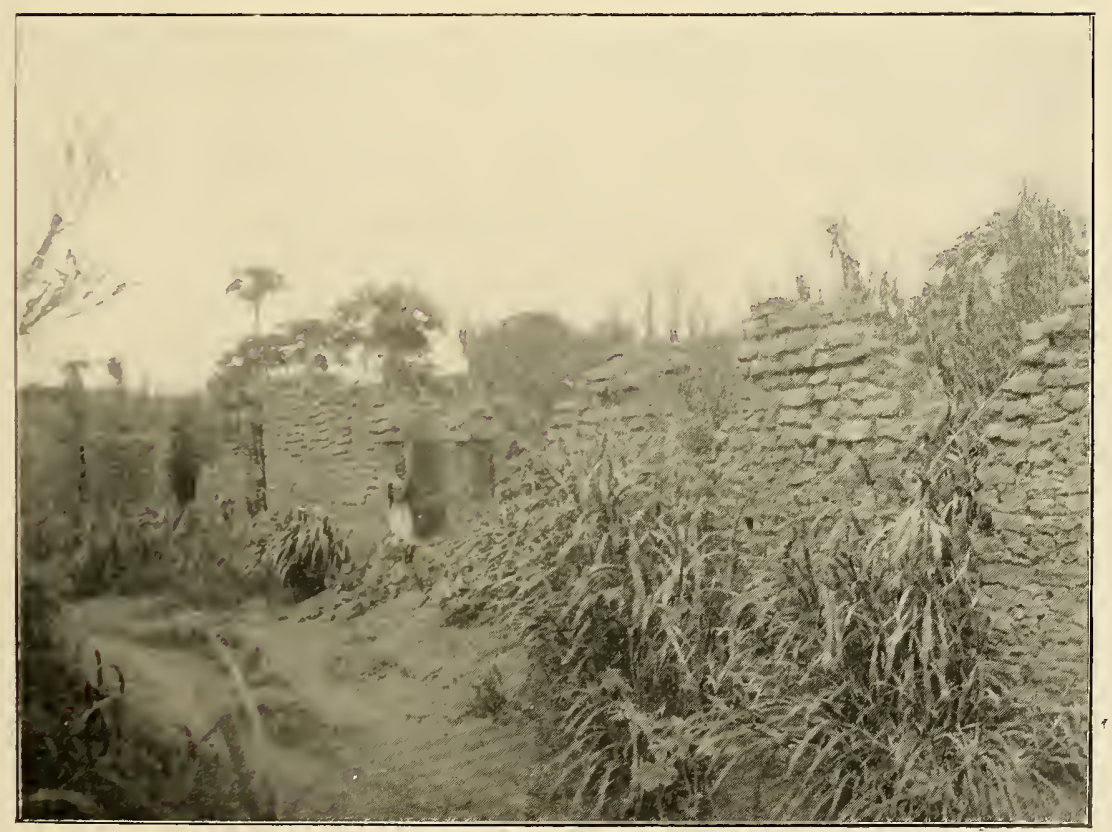

RUINES D'UN BOMA ARABE A KASSONGO 


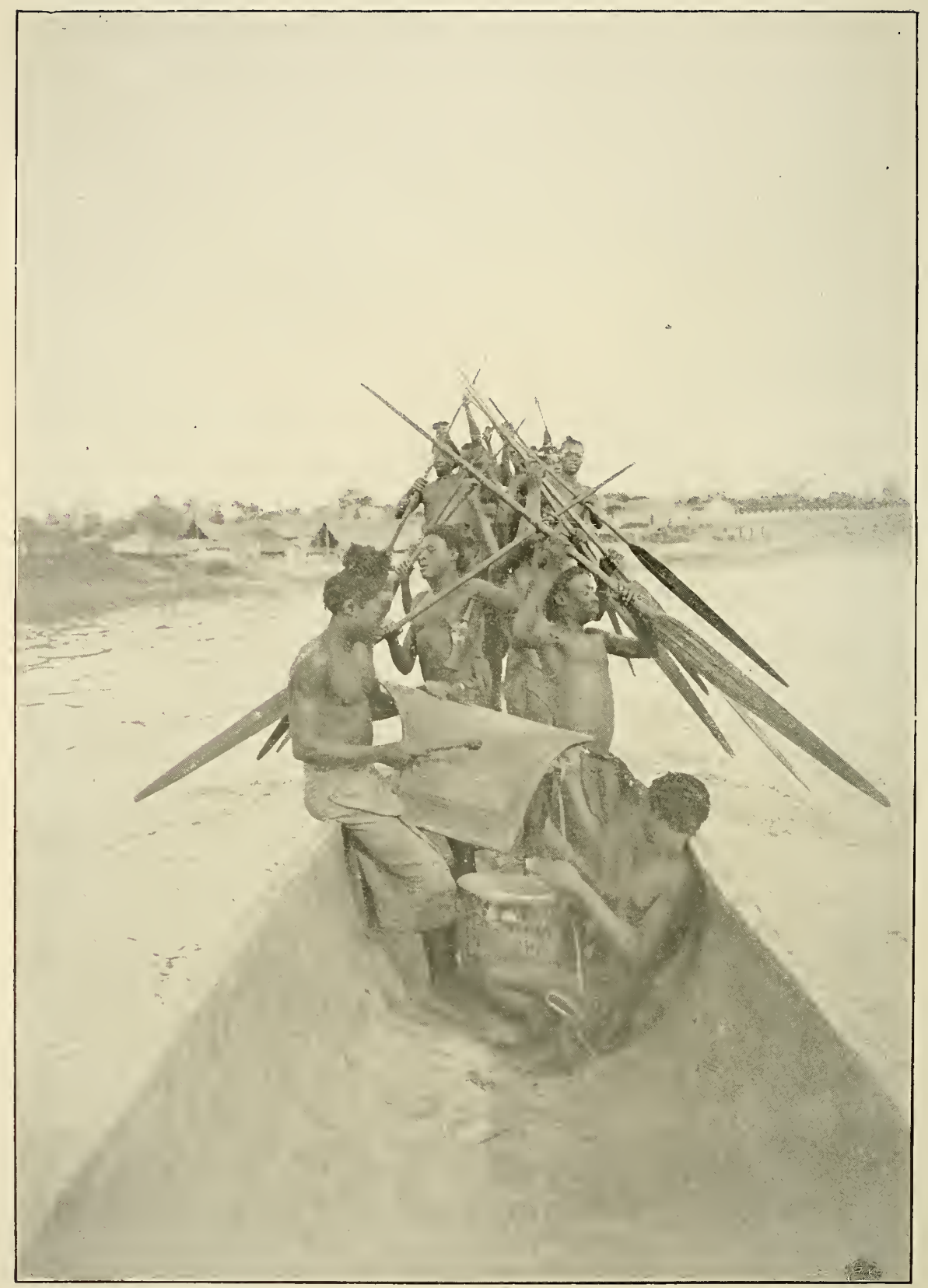

PAGAYEURS WASSONGOLA SUR LE LUALABA 
gauche un gros de $t$ à 500 Arabes. Heureusement, ceux-ci prirent sans doute pour des soldats les femmes et les porteurs qui se trouvaient près de Hinde el ne les attaquèrent pas.

Il eut ce jour-là une chance peu ordinaire.

Enfin, successivement, Scheerlinck el de Wouters le rejoignirent et, dès lors, il put se considérer comme sanvé, mais il aura dù se faire de singulières réllexions pendant les ringt ou vingt-cinc minutes durant lesquelles il est resté seul sur son perchoir.

Le marais passé, nous nous mimes à la poursuite des Arabes, mais conme le thernomètre marquait ce jour-là certainement 40 degrés à l'ombre, Dhanis et moi nous fiunes asscz vite complètement épuisés par cette marche rapide en plein soleil.

IIenreusement, vers denx heures, uous rencontrimes à un croisement de sentiers, quatre piquets soutenant un petit toit de chaume à environ un mètre de terre et abritant un fétiche. Nous eùmes vite fait de jeter le fétiche dans les herbes et de nous coucher còte à côte à sa place.

II était temps, j’avais la tète en fen, mes jambes flagrolaient, ma gorge brullait, mes tempes battaient et je sentais mon cerveau en ébullition. La congestion avail déjà commencé son ceuvre el si j’avais encore dû faire cent mètres, c'était la mort certaine. Dhanis me dit après qu'il se trouvait dans le même élat. 
Pendant un certain temps, qu'il m'est impossible d'apprécier, nous restâmes couchés dans un véritable état de prostration, quand tout-à-coup, Dhanis se souvint qu'un de ses boys était porteur d'une demibouteille de champagne. Quel que fût le danger de la chose, dans l'état ò̀ nous nous trouvions, notre soif était si terrible que Dhanis ouvrit la bouteille et, tour à tour, buvant au goulot, nous la vidàmes avec un bonheur ineffable.

Notre heure dernière n'était pas encore sonnée, car ce qui aurait dù nous tuer, nous rendit des forces et nous ne fûmes mème pas malades.

Vers le soir, nous arrivons au camp arabe qui se trouvait à Kassongo Luakila ; celui-ci était désert, mais nous y trouvàmes assez bien de poudre, de cartouches et d'objets divers que les Arabes, dans leur fuite, n'avaient pas eu le temps d'emporter.

Comme la position était très forte, nous nous y installàmes.

Nous avons su plus tard par des prisonniers, que c'était Muéni-Pembé, fils de Muéni-Mohara, qui commandait les Arabes que nous venions de vaincre.

Leurs pertes dans cette rencontre furent évaluées à environ 300 morts. Les nòtres, en y comprenant les gens de Gongo, furent d'environ cent hommes.

Arrivés le 30 au soir, nous sommes restés à Kassongo Luakila jusqu'au $1^{\mathrm{er}}$ janvier. 
Le 31 décembre all soir, Gongo me prévint que les Arabes ròdaient aux envirous et comme l'idée de nous altaquer pendant la nuit pouvait très bien leur ètre venue, alin de tacher le provoruer une panique parmi nos soldals, je résolus de passer la unit tont habillé, dann ma chaise longue,alin d'ètre prèt à tout évènement.

Ce ful donc le revolver à la ceinture el le fusil en travers sur les genoux que je vis ma montre marquer minuit. Je me levai a alors je me découvris el par la flensée, jenroyai mes souluits el mes haisers aux ètres chers qui, eux aussi, j’en étais certain, je le sentais, pensaicnt à moi et faisaient des veux d'autant plus ardents pour l'exilé gu’ils le savaient engagé dans une lulte sans merei.

C'est dans ces circonstances que les comes battent le micux à l'unisison : les varux les plus sincères n'ont nullement liesoin de phrases ni d’intermédiaires pour arriver surrement à leur adresse.

Lo L $^{\text {ar }}$ janvier, uos hommes manrfuant absolument de nourrilure, nous fümes obligrés de uous remeltre en roule, afin de trouver un campenent plus riche en vivres.

Nons ne fiumes heureusement pas obligés d'aller très loin : apress aroir traveré le Muadi sur un pont que nos hommes furent forcés de construire, mous arrivànes au village de Goïe Kapopa, qui se trouve sur une hauteur situce dans l'angle formé par la réunion du Muadi et du Lufubu. 
La position était superbe et nous permettait de résister à toutes les forces que les Arabes étaient capables de coaliser contre nous.

Nous restâmes dans cette position une vingtaine de jours.

Pendant que nous y campions, nos soldats vinrent un jour dire à Dhanis que les Arabes avaient mandé dans leur camp un célèbre sorcier afin de " faire une médecine $)$ contre nous, qui leur permit de nous battre et de nous exterminer.

Dhanis, qui savait mienx que tout autre comment il faut compter avec les préjugés et les superstitions des noirs, leur répondit avec un admirable à-propos que, lui aussi, il allait " faire son fétiche » et que l'on verrait bien laquelle des deux médecines, de celle des Arabes ou de la sienne, serait la plus forte.

Comme il savait que tout ce qui se passait dans notre camp était immédiatement rapporté aux Arabes, il eut soin de faire publier dans tout le camp que le lendemain soir il consulterait son fétiche et que, si celui-ci était trois fois blanc, les Arabes seraient vainqueurs; s'il était trois fois vert, le combat serait incertain ; trois fois rouge, annonçait notre victoire, mais une fois blanc, une fois vert et une fois rouge,prédisait l'anéan tissement des Arabes.

Le lendemain, dès la tombée de la nuit, tous nos hommes. et certainement tous: les Arabes avaient le 
nez en l'air pour voir ce que le fétiche allait leur annoncer.

Aussi, lorsque vers 8 heures du soir, la première fusée à feu blanc monta dans le ciel, ce fut de la terreur chez nos hommes et du délire chez les Arabes, mais bientòt une seconde du plus beau vert monta à son tour et, dans un camp comme dans l'autre, ce fut de la stupeur et tous les cours, je crois, cessèrent de battre, tant on était anxieux de voir le troisième feu. Enfin, après un long instant plein d’angoisse, une superbe fusée rouge monta, monta..... et finit par éclater couvrant et éclairant tout notre camp, de ses lueurs fantastiques.

Les dernières étincelles n'avaient pas touché le sol, (qu'une clameur immense s'élevait de notre camp soulignée par de nombreux coups de fusil au moyen desquels les gens de Gongo fètaient la bonne nouvelle.

Chez les Arabes, au contraire, c'était le silence; l'on sentait la terreur planer sur leurs têtes.

Nul doute que,si vingt hommes déterminés les a vaient attaqués cette nuit, ils se seraient sauvés épouvantés tant leur frayeur fut extrème.

Quelque temps avant les événements que je viens de conter, Dhanis avait appris que les deux expéditions de Delcommune et de Bia-Franqui etaient de retour du Katanga et il avait écrit aux deux chefs pour leur demander de bien vouloir se joindre à nous pour repousser les Arabes. Ces messieurs, leur mission et 
leur long voyage étant terminés, aspiraient évidemment à rentrer en Europe et ne crurent par conséquent pas devoir se rendre aux instances de Dhanis.

Tons ne furent cependant pas de cet aris, un cie leurs adjoints, un pelit sergent des chasseurs, alors $\mathbf{n}$ inconnu, s'ofírit à venir nous rejoindre.

C'était le brave pelit Cassart; il nous amenait 27 hons soldats de renfort de l'expédition Delcommune et nous apportait 25,000 cartouches et 43 chassepols de l'expédition Franqui, ainsi que de nombreuses caisses et ballols contenant notre ravilaillenient de Lusambo.

Cassart avait donc avec lui 27 soldats ainsi que les hommes de Gongo, dont quelques-uns seulement armés de l'usils à piston, les autres simplement de lances.

Pendant que uous campions à Goïe Kapopa, nous sarions qu'il y avait un nombreux camp arabe sur la rive droite du Lufubu; c'élail le camp de Séfu, qui, ayant réorganisé ses forces, était venu s'élablir en cet cudroit. Nous savions aussi que Muéni Pentbé campait sur la rive ganche du Muadi, mais, ce que nous ignorions, c'es/ que Mnéni Mohara, faisant un immense détour, essayait de nous lourner, afin de nous attaquer de tous les còlés à la fois.

Cette ignorance de la présence de Muéni Mohara sur nos derrières faillit ètre la cause de la perte de notre brave camarade Cassart. 
Le 8 janvier 1893 au soir, ses porteurs étant fatigués, il campa à quelques lieues de nous; le 9 au matin, vers 5 heures, désirant partir de bonne heure, il fait rentrer ses sentinelles; à peine celles-ci sont-elles renlrées qu'il est attaqué avec fureur par les Arabes de Muéni Mohara.

Arec un courage et une présence d'esprit extraordinaires, en quelques minutes il rassemble ses hommes, fait face à l'ennemi, qu'il fait reculer par un feu enragé et a la bonne idée de faire ouvir ses caisses de cartouches et de distribuer anx gens de Gongo les fusils qu'il nous apportait; de cette façon, il avait plus que doublé ses forces. Après un combat de cing heures, gràce à son sang-froid et aux bonnes dispositions qu'il avail prises, il put se dégager et amener sa caravane à Dhanis, sans avoir perdu une seule charge. C'est certainement un des plus beaux tours de force qui ait été accompli en ce genre.

En arrivant au camp, il eut un mot typique.

- Commandant, dit-il, j’ai été tout, excepté pris, mais j’ai brùlé une terrible quantité de cartouches.

- Cela ne fait rien, lui dit Dhanis, le principal, c'est que vous soyez vivant; quant aux bagages et aux munitions que vous nous apportiez, je suppose que vous les avez perdus?

- Pardon, commandant, dit Cassart, sauf les cartouches que j'ai brùlées, je crois que le tout est au complet. 
Et c'était parfaitement exact; il n'avait pas perdu une seule charge!

Le matin du mème jour, nous avions entendu une vive fusillade et, sur l'ordre de Dhanis, de Wouters et moi élions partis en reconnaissonce; après enriron une heure de marche, nous n'avions plus rien entendu, croyant à une fausse alerte causée par les gens de Gongo, qui se querellaient parfois avec les indigènes, nous étions rentrés au camp.

$\Lambda$ peine étions-nous de retour qu'un noir arriva au camp hors d'haleine, disant que l'Homme blanc était allaqué et qu'il demandait du secours, puis il tomba en syncope.

Nous repartîmes aussitòt avec de Wouters el Schecrlinck, mais n'ayant pour nous diriger que les comps de feu entendus le matin, nous prìmes une autre route que celle de Cassart et, de celte façon, nous ne le rencontràmes pas.

Après environ trois heures de marche, nous arrivons en face du camp arabe qui se trouvait dans un grand village situé sur une colline avançant en éperon.

Nos dispositions sont bientòt prises; de Wouters et Scheerlinck attaqueront de front, done sur la plus grande largeur du camp, tandis qu'avec mes hommes je ferai un rapide crochet de façon à attaquer par le côté oì la colline s'arance le plus. 
Notre mouvement réussit à merveille, gràce à un champ de manioc qui entourait le village : les Arabes, quoicue nous ayant vus renir d'assez loin,nous laissent, à notre grand étonuement, approcher à cinquante pás avant d'ouvir le feu.

Ils attendaient des renforts venant de Séfu et ils nous avaient pris pour eux !

Le combat fut d'ailleurs très court; pendant que de Wouters et Scheerlinck les attaquaient de front, je les prenais de llane et en enfilade avec mes hommes; en pen de temps, ce fut une fuite désordonnée.

En entrant dans le village avec de Wouters, nous vimes un beau vieillard qui agonisait soutenu par deux femmes; je lui demandai : "Qui ètes-vous?" Il nous jeta un long regard et me répondit: "Mo... ha... ra." Et il expira.

Nous apprìmes ainsi par lui-mème que nous venions de tuer le chef le plus redoutable des Arabes.

Nous apprìmes aussi dans la suite qu’il avait été blessé à la jambe, le matin, dans le combat qu'il avait livré à Cassart ; c'était alors que le combat avait cessé et c'était là le motif pour lequel, à un moment donné, nous n'avions plus entendu la fusillade.

Dans le camp de Muéni Mohara, nous trouvâmes une quantité d'objets les plus disparates, tels que fusils, pourlre, capsules, ânes, chèvres, etc., mais ce qui nous frappa surtout, c'est que nous y trouvâmes une tente et un lit. 
En ce moment, il n'y avait plus de doute possible, notre pauvre ami Cassart avait été tué par Mohara et c'élail sa tente et son lit que nous venions de retrouver.

Malgré notre victoire, ce fut donc plutòt tristement que nous reprìmes la route du camp.

Le matin, pendant la marche, je m'étais assez fortement écorché le pied et comme j’avais beaucoup de peine à marcher, j’avais moi-mème conseillé à mes camarades de prendre les devants, je les suivrais comme je pourrais; ils pouvaient ètre tranquilles sur mon comple, puisque tous mes hommes me restaient.

Quelque temps après, j’avais rencontré un indigène qui me dit que pendant que nous nous battions avec Muéni Mohara, Séfu avait profité de notre départ pour allaquer le camp et s'en emparer.

Au début, je n’avais accordé aucune créance à ce raconlar, mais au moment ou de WVouters et Scheerlinck arrivent au camp une vive fusillade y éclate.

Les paroles de l'indigène me revenant aussitòt à la mémoire, je me dis que la chose doit ètre vraie et que Séfu attaque maintenant de Wouters et Scheerlinck, auxputels il a probablement tendu une embuscade.

En ce moment, j'a voue que mes cheveux se dressèrent sur la tète, car je me disais que nous étions perdus puisque les Arabes pourraient ainsi nous battre séparément. L'instant u'était pas aux réflexions, mais à l'action ; il fallait qu'elle fût prompte afin d'ètre efficace. 
Je réunis rapidement mes hommes et, oubliant mon pied malade, je pris arec eux le pas gymmastique.

Mais quelles ne son! pas ma surprise et ma joie lorsulen arrivant an camp, j'y retrouve non seulement tous les cantarades, mais encore le brave petit Cassart, qui, après aroir fail sa trouée, élail arrivé sain el sauf at camp).

Quant aux nombrenx coups de fusil que j'avais entendus lor's de l'arrivée de de Wouters, c’était notre allic Ciongro qui, pour nous faire fète, avail célébré notre vicloire suivant la mole arabe.

Nons emmen anssi plus tard l'explication de la tente ef du lil que nons avions trouvés dans le camp de Muéni Mohara : c'étaient les objets de campement qui avaieut appartenu au malheureux Hodister, massacré arec lous ses compagnons quelque temps auparavant.

La défaile el la mort de Muéni Mohara enrent énormóment de relenlissement parmi les Arabes, car les tronpes du vieux chef élaieul comuses pour lenr bravoure ch lui-mème jouissait, parni ses congéncres, de la répulation d'un stratioge de prentier ordre. Il disait d'aillours volonliers qu'il u'avait jamais perdu une lataille livrée sous ses ordres el qu'il ainterail micux monrir que d'ètre vaincu.

Il tiut parole : il ne voulut pas survivre à sa défaite.

Deux jours aprís la mort de Muéni Mohara, Dhanis résolut de profiter de l'émoi dans lequel devaient être 
les Arabes pour attaquer Séfu, mais le Lufubu, rivière large et profonde, se trouvait sur notre chemin ; il fut convenu que Congo et ses gens feraient un pont, tandis qu'avec mes hommes je protégerais les travailleurs en cas d'attaque.

Commencé de bonne heure, le pont fut terminé vers midi.

Quel diable alors me tenta? je ne sais; mais les gens de Gongo m'ayant dit que le camp de Séfu se tronvait sur une hauteur à environ deux heures de marche de l'endroit où nous étions, il me prit une envie folle d'aller le reconnaître.

Outrepassant alors mes droits et sans m’inquiéter des intentions de mon chef, je partis arec mes hommes à la recherche du camp de Séfu.

Les gens de Gongo ne m’avaient pas trompé : après deux heures de marche, nous vimes le camp de Séfu, installé sur une hauteur à environ un kilomètre d'une rivière pas très large, mais très profonde et au courant rapide, appelée Kipango.

Si uous voyions leur camp, les Arabes de leur côté nous avaient aperçus : constatant notre petit nombre, ils descendirent en masse pour nous attaquer.

Malheurensement pour les Arabes et heureusement pour nous, le seul passage sur la rivière consistait en un tronc d'arbre jeté d'une rive à l'autre.

Leur grand nombre, daus cette circonstance, ne leur 
fut d'aucun secours et je n'eus aucune peine à battre et à rejeter à l'eau ceux qui avaient traversé avant notre arrivée.

Deux chefs importants furent aussi trés, ainsi que la femme de Séfu, qui se trouvait assise près de lui et fut atteinte d'une balle perdue à plus d'un kilomètre de l'endroit où l'on se battait.

Ces trois morts ainsi que l'annonce de la défaite et de la mort de Muéni Mohara impressionnèrent tellement Séfu que, la nuit mème, il leva son camp et retourna à Kassongo : Jorsque, le lendemain, Dhanis vint avec toutes ses forces pour attaquer le camp, il était vide.

Yis en éveil par mon attaque inopportune, l'ennemi s'était envolé.

En cette occasion, Dhanis pècha par excès d'indulgrence; si j’avais été à sa place, j'aurais certainement envoyé mon ami Michaux anx arrèts dans sa tente pour lui apprendre à outrepasser ses ordres.

Ia seule excuse, et elle est bien mauvaise, c'est que nous avions à celte époque un tel dédain des Arabes qu'il nous semblait que toutes les bravades nons étaient permises. Nous ne souhaitions qu'une chose : livrer de nouveanx combats, afin d'angmenter le nombre de nos victoires. 



\section{CHAPITRE XI.}

Le Lualaba. - Nyangwé ! - On n-u : prend pour des Arabes. - Affût et contre affût. - Invasion de femmes. - Retour offensif des Arabes. - All right, sir ! - Méprise qui eût pu être fatale. - Deux lettres disant : l'une oui et l'autre non. Une flottille de canots à l'assaut.

Le camp de Séfu étant une position de tout premier ordre, nous y restàmes jusqu'au 20 janvier. Comme nous prenions le the avec Dhanis, on vint à dire que nous ne croyions pas au débul de la campagne arriver aussi près du Lualaba, puisque uous n'en étions plus qu’à deux jours de marche. Unn de nous dit mème en plaisantant :

- "Commandant, vous devriez nous conduire jusque là, ne fuit-ce que pour pouvoir dire que nous avons vu le Lualaba!!! et Nyangwé; puisque les Arabes sont venus chez nous, nous pouvons bien nous permettre une petite promenade chez eux. "

- "Vous y tenez? demanda Dhanis."

- "Beaucoup, lui répondìmes-nous en chœur."

-- Eh bien! soit, nous partirons demain matin : aprèsdemain, vous verrez le Lualaba el même Nyangwé.

Le lendemain matin, nous étions en route et le surlendemain, nous arrivions en vue de la capitale des Arabes, 
Je marchais en tète de mes hommes, lorsque le 21 janvier, vers 11 1/2 heures, au sortir de la forèt, Nyangwé m'apparut tout à coup. J'étais déjà, à cette époque, un vieux soldat et j’avais livré pas mal de hatailles et cependant j'avoucrai sans fausse modestie, qu'à la vue de Nyangwé je me sentis pâlir et qu’il n’y eut pas une fibre de mon ètre qui ne vibràt d'un légitime orgueil en pensant qu'à six Belges et un Irlandais, nous avions vaincu ces horribles handes dévastatrices et sanguninaires, terreur du continent noir el qu'après en avoir purgé toute une immense contrée, nous venions maintenaut les provoquer, el qui sail? les chasser peut-èlre de leur repaire.

$\Lambda$ près a voir marché environ une demi-heure, au sortir de la forèt, nous établìmes notre camp sur une espèce de tertre qui se trouvail au milieu d'un immense marais, nous séparaut des eaux du fleuve.

De l'endroit où nous nous trouvions, iỉ y avait encore environ deux kilomètres el demi avant d'arriver au Lualaba.

Pendant que nous étions occupés à installer notre camp, on vint nous dire que toute une troupe venant du Lualaba se diligeait vers uous en se dissimulant dans les herbes. Montés sur une termitière, nous vîmes en effet une troupe assez nombreuse s'a vancer vers nous.

Je reçus immédiatement l'ordre de Dhanis d'aller avec mes hommes reconnaître l'ennemi et le repousser au 


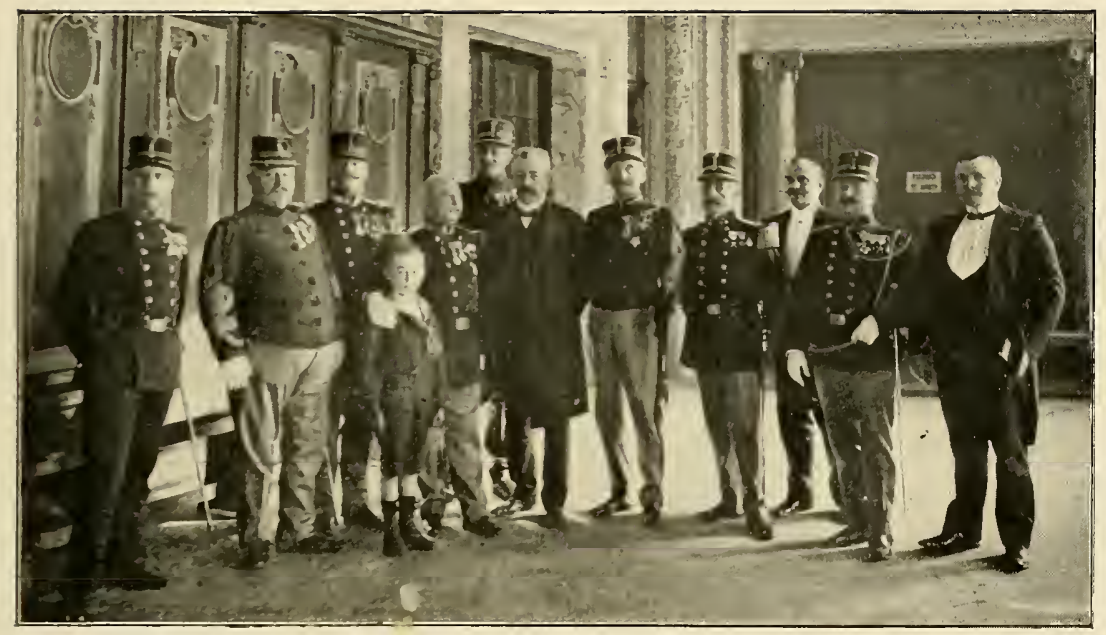

Groupe de qútelques survivants de la campagne arabe De gauche à droite

D D DUPONT, MICHAUX, JACQUES, DAENEN, SILLYE, LOTHAIRE, GILLAIN, SCHERLINCK, RUE, CASSART, VAN RIEL. 


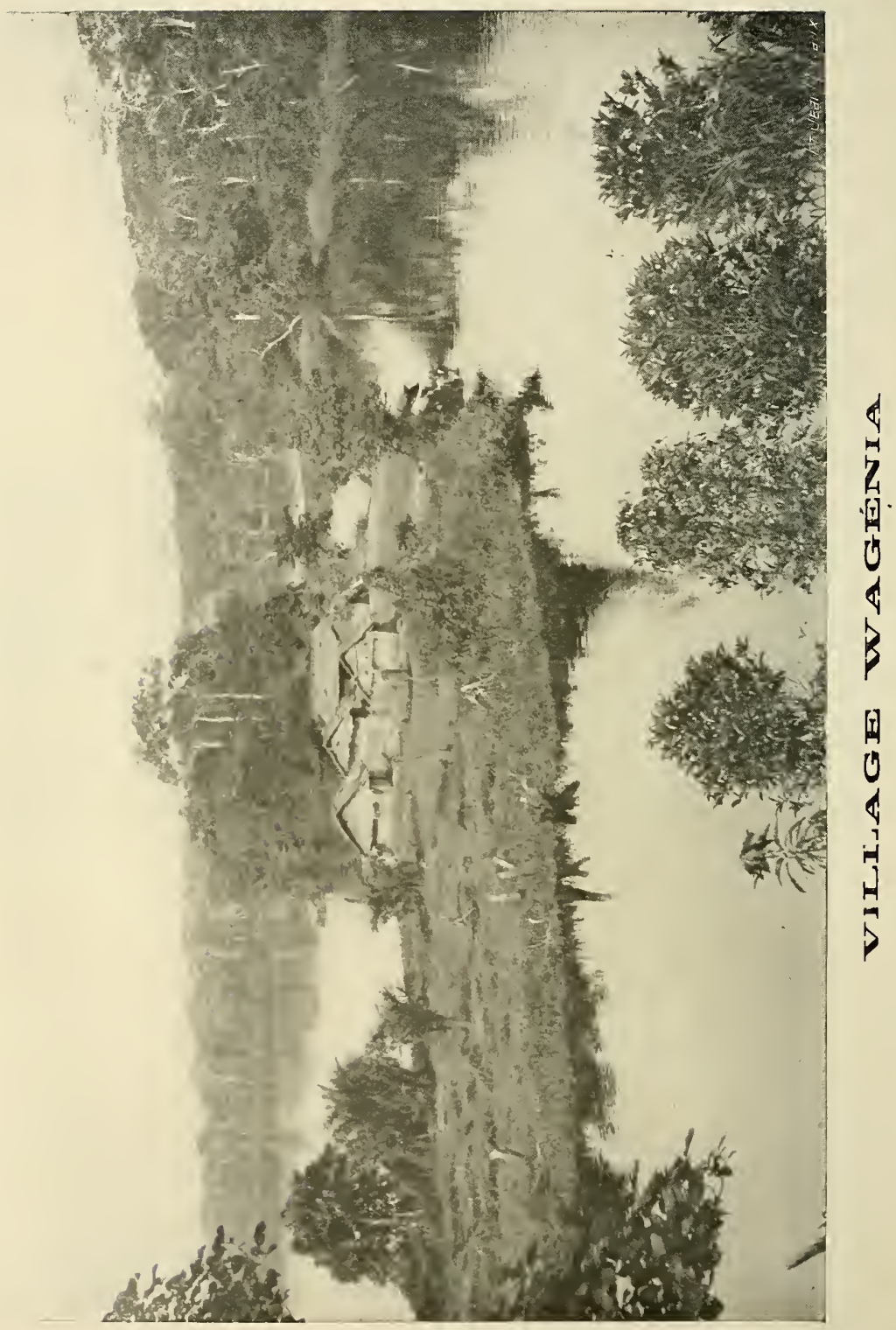


besoin. A cet efret, il m'adjoignit mème une compagnie, mais je ne me rappelle plus lacuelle.

Aussitòt parti, et afin d'ètre moins vite reconnu des Arabes, je fis òter le fez à mes hommes.

Cela faillit nous conter cher. Nons étions à environ 1,500 mètres du camp et nous renions de nous aperceroir que nos soi-disant Arabes étaienl des gens de Gongo Lutété, qui, trop pressés d'arriver an Lualaba, y araient été reçus à coups de fusil et avaient pris la fuite dans notre direction. Nos denx troupes rémnies formaient nne masse assez considérable et les gens de Gongo étaient oceupés à me conter lenr mésaventure, (quand tout à coup un obus passe en sifflant au-dessus de nos tètes et ra s'enfoncer à cincuuante mètres plus loin dans la vase, sans henreusement éclater; deux minutes après, un second obus prenait la mème direction que le premier.

Je fis immédiatement remettre les fez à mes hommes, lever mon drapeau bien haut et sonner mes clairons le plus fort qu'ils pouvaient et le feu cessa.

Comme rous l'avez tous deviné, c'était Dhanis qui, nous prenant pour des Arabes, avait fait tirer sur nous, afin, croyait-il, de nous venir en aide!

Notre campement étant établi,nous restàmes an mème endroit pendant environ cing semaines.

Comme seule distraction, nous partions tous les jours Hinde et moi, avec une escorte composée des vingt 
meilleurs tireurs de l'expédition, et après avoir traversé avec de l'eau jusqu'à la ceinture et plus tard jusqu'aux aisselles, un marais infect de plus de deux kilomètres, nous allions nous cacher dans les hautes herbes qui bordaient le fleuve et faisions un véritable affùt à l'Arabe.

Nous avions repéré toute la rive au fusil et, couchés sur le ventre, la hansse mise à la distance exacte, le canon du fusil reposant sur une petite fourche qui nous servait en quelque sorte de chevalet, nous attendions patiemment qu'un Arabe se montrât sur le bord du fleuve.

Dans les premiers jours, nous en avions descendu de la sorte assez bien, mais au bout de quelque temps ils étaient devenus excessivement prudents et l'afrùt ne donnait presque plus de résultat. Quand ils avaient absolument besoin d'eau pendant la journée, rien n'était dròle comme de roir arec nos jumelles une tête effarée sortir prudemment des roseaux pour explorer les environs puis tout à coup se précipiter vers l'eau avec un récipient quelconque, pour s'enfuir ensuite avec la rapidité d'un chevreuil.

Mais bientôt, les Arabes organisèrent ce que l'on pourrait appeler un contre affùt.

A environ 400 mètres de notre rive, il y avait une assez grande île, dont les berges soulevées dominaient notre rive de deux à trois mètres. Les Arabes ayant eu 
soin d'enlever toutes les pirogues du flenve, se rendirent done dans l’ile et, pendant la nuit, creusèrent des tranchées profondes dans la berge nous faisant face; certain jour, où nous venions précisément de tirer sur un des leur's et par conséquent de révéler, par la fumée de nos fusils, l'endroil où nous étions cachés, ils répondirent par une véritable grèle de balles, qui vinrent s'abattre autour de nous. Ce fut réellement miracle (fu'aucun de nous ne fùl touché.

Dans ces conditions, la partic n'était plus égale, car ils avaient, eux aussi, de très bons tireurs. Je mesouviens entr'autres d'm jour où, deboul sur la rive, j'explorais les envirous avec mes jumelles; une balle vint se loger en terre juste sous mes pieds et à quelques centimètres; comme je regardais d'où était venu le coup de fusil, une seconde me rasa la lète de si près que je sentis sur ma joute le vent occasionné par le déplacement de l'air.

Pour parer aux avantages que l'ennemi avait sur nous avec leur ile, Dhanis dit douc construire pendant la nuit par les hommes de Gongo une espèce de tour carrée en bois, du sommet de laquelle nous dominions à notre tour les tireurs de l'ìle; uous eûnes bientòt fait do les déloger de leur abri. Malheureusement, le soir, comme uous avions omis de faire garder la lour, les Arabes vinrent l’incendier pendant la nuit. Il fallut donc en reconstruire une seconde que, cette fois, nous prîmes soin de faire garder. 
A partir de ce moment, les Arabes durent abandonner leur île devenue intenable pour eux.

Un jour aussi que la chasse n'avait rien donné, il nous vint à l'idée de tirer sur un troupeau de vaches et de taureaux à demi sauvages qui se promenaient dans les rues de Nyangwé ; nous assistàmes alors à un speclacle inénarrable! Les bètes deveńues furieuses par les blesşres reçues se figuraient que c'étaient les Arabes qui les leur causaient; elles se mirent à charger ceux-ci dans leurs retranchements. Ce fut une course folle et une poursuite enragée dans toules les rues de Nyangwé.

Nos malheureux ennemis purent penser, ce jonr-là, que leur cause ćtait bien malade, puisque leurs animaux mèmes se liguaient contre eux !

Pendant que nous campions dans notre île du marais, Gongo demanda à Dhanis l'autorisation d'aller razzier quelques tribus, qui s'élaient déclarées contre nous; celte antorisation lui ayant été accordée, il partit avec la presque totalité de ses hommes, ne laissant que quelques malades et quelques éclopés pour garder toutes ses femmes. Sou campement était établi à sept ou huit cents mètres de celui de Dhanis, mon petit camp à moi entre les deux et à cinquante ou soixante mètres du grand.

Or, nos espions vinrent nous dire que les Arabes, voulant profiter du départ de Gongo, avaient passé le flenve en aval de Nyangwé et que nous serions altaqués incessamment. 
Ayant été souvent trompés par les racontars des indigènes, nous attachions assez peu d'importance à leur dire, tout en prenant néanmoins nos précautions.

Dans la nuit du 25 au 26 février, une panique se mit tout-à-coup parmi les femmes du camp de Gongo; toutes à la fois envahireut mon camp. Je m'en débarrassai très dinicilement; une heure après, un coup de fen étant parti par mégarde, je subis de nouveau leur invasion.

Si une attaque s'était prodnite en ce moment, nous aurions été certainement dans me fàcheuse position.

Ne sachant comment me débarrasser de cette invasion féminine, je domnai l'ordre à loutes ces femmes de se coucher par terre, menaçant de faire tirer sur celles qui se relèveraient. Je les fis garder par quelques sentinelles et le restant de la nuit se passa plus tranquillement, sous les armes bien enteudu; mais aucune attaque ne se prodnisit.

Comme celte situation était très énervante, Dhanis, qui avait d'abord décidé d'attendre l'attaque des Arabes, changea d'avis et résolut d'aller les attaquer chez eux.

Il donna ses ordres en conséquence.

Deux routes conduisaient aux bomas arabes; il fut premièrement décidé que de Wouters, Hinde et Cerckel, a vec le canon, suivraient la route la plus longue, tandis que Dhanis et moi partirions un per plus tard par la route la plus courte de façon à arriver en mème temps aux bomas. 
Scheerlinck et Cassart, avec une centaine de soldats, devaient garder le camp.

Toutes ces mesures étant prises, de Woulers, Hinde et Cerckel se mirent en route. Dhanis et moi, nous ne devions partir qu'une demi-heure plus tard.

Cependaut, vingt minutes après le départ de la première colonne, Dhanis se ravisa. Craignant que celle-ci ne fùt trop en l'air et que les Arabes n'eussent le temps de la détruire avant notre arrivée, il me donna l'ordre de partir immédiatement el de faire diligence pour la rejoindre.

Je partis aussitòt. Guidé par un homme de Gongo Lutété, je pris un sentier qui formait la corde de l'arc de cercle décril par la colonne sous les ordres de de V'outers.

Cela me permit d'entrer en ligne presque en même temps que lui.

Nous étions partis depuis environ 45 minutes, quand, tout-à-coup, la fusillade éclate sur notre gauche.

D'après le bruit des détonations, car étant dans les hautes herbes nous ne voyons rien, j'estime que l'on se bat à environ trois à quatre cents mètres de moi.

Je fais immédiatement précipiter la marche afin de prolonger la droite de de Wouters et si possible me rabattre sur le flanc gauche de l'ennemi.

Quelques minutes après nous entrons en ligne et je suis rejoint par le doctenr Hinde qui, avec quelques 
hommes seulement, avait, dans la bataille, été séparé des forces de de Wouters.

En ce moment, j'ai en face de moi un gros d'Arabes qui a exécuté la mème manœurre que moi et qui s'apprète à attaquer de Wouters en flanc.

Par la force des choses, de flanc offensif que je croyais ètre, je deviens flanc défensif.

Toujours accompagné de Hinde, nous venons de repousser les Arabes qui nous font face et nous nous mettons vigoureusement à leur poursuite, quand tout-àcoup nous rencontrons une résistance à laquelle les Arabes ne nous ont pas habitués. Les balles s'abattent par rafales autour de nous.

En ce moment, Hinde vint me trouver et me demande si je ne trouve pas qu’il serait préférable de nous rabattre sur de Wouters et Cerckel, afin d'unir nos forces pour vaincre cette résistance acharnée. "Non, docteur, lui répondis-je, la baïonnette seule peut nous tirer de ce guèpier. Si nous faisons un pas en arrière, nous sommes perdus! - All riøght, sir! " Et sans la moindre émotion, quoique n'étant pas de mon avis, ce brave Irlandais n'hésite pas une seconde, glisse flegmatiquement cinq cartouches dans son Mauser et vient se ranger à mes còtés. Je salue en lui un brave dans toute l'acception du mot.

Réunissant alors rapidement mes hommes, je fais sonner la charge! Ceci nous sauve. Je ne suis pas peu 
étonnélorsqu'au moment d'aborder l'ennemi, je découvre en face de moi Dhan is et ses hommes!

Voici ce qui s'élait produit : Pendant que nous altaquions une colonne arabe et la refoulions, Dhan is altaquait ef en repoussait une seconde; or, ces deux colonnes, en se retirant, avaicut choisi deux chemins qui se croisaient à angle droit el c'est ainsi qu'cn les poursuivanl, nous nous étions pris mutucllement, Dhanis et moi, pour des Arabes et en étions arrivés à tirer l'un sur l'autre. Heureusemenl que j'a rais eu l'idée de fairc charger à la baïonuctte; sans cela nous nous serions occasionné l'un à l'autre des pertes terribles dont les conséquences auraient pu ètre désastreuses pour l'cxpédition tout entiére.

Une fois rémnis à Dhanis, nous reprenons la route des bomas el ceux-ci tombent assez rapidement en notre pouvoir, car les Arabes ayant négrligé d'y laisser nne garnison permanente, les fuyards n'ont pas le temps de s'y organiscr sérieusement et ne font qu'un scmblant de résistance.

Ce qu'il y a de curieux dans ce combat, c'cst que les Arabes quiltent leur camp à la mème heure cl adoptent les mèmes dispositions que nous.

Dans des conventions conclues précédcmment entre l’Etat du Congo et les Arabes, il avait été stipulé que le Lomami servirait de frontic̀re et de zone d'influence aux deux partis. 
Les Arabes ayant franchi le fleuve et nous ayant attaqués sur la rive gauche, avaient donc eux-mèmes rompu les conventions; aussi Dhanis n'avait-il pas lıésilé à les poursuivre sur la rive droite du Lomami.

Mais lorsque, de victoires en victoires, nous arrivons au bord du .Lualaba, en face de Nyangwé, un doute terrible le prend : il se demande si sa conduite sera approuvée du Gouvernement, et puis il hésile à passer ce lleuve immense el à se mettre au dos cet obstacle infranchissable qui, en cas de défaite, doit transformer celle-ci en calastrophe irréparable.

Il se trouve done dans une siluation des plus embarrassantes, surlout que les ordres qu'il a réclamés de Boma n'arrivent pas.

Enfin, un courrier renant de Lusambo lui apporte deux leltres. Il nous réunit le soir, uous les lit et nous demande notre avis.

La premicre est du faisant fonclion de Gouverneur général; elle nous intime l'ordre de nous maintenir sur la défensive sur la rive gauche du Lomami. La seconde est de l'inspecteur d'Etat Fivé qui, lui, écrit de Lusambo; de sa lettre, je copie le passage suivant : "J'apprends à mon arrivée au camp de Lusambo les défaites que rous avez infligées aux Arabes; nous avons pour devoir de proliter de ces victoires. Maintenez vos positions avec objectif immédiat de vous emparer de Nyangwé. » 
Nous sommes unanimes à dire à Dhanis que, puisque les ordres sont contradictoires, c'est à lui de choisir celui qui s'adapte le mieux aux circonstances; que, dans le cas présent, il n'y a pas de doute que nous devons profiter de nos victoires pour nous emparer de Nyangwé; chasser à tout jamais les Arabes de leur antre redouté et substituer enfin les bienfaits de la civilisation aux horreurs de l'esclavage et du camnibalisme.

Dhanis ne demande pas mienx que de se laisser convaincre et, à dater de ce jour, la prise de Nyangwé est résolue.

Mais ce n’est pas lout de décréter la prise de Nyangwé; encore faut-il le prendre.

Un fleuve immense et profond au courant rapide, qui, d'une rive à l'autre ne mesure pas moins de 900 à 1,000 mètres, nous sépare ef nous n’avons pas même une pirogue à notre disposition.

Toutes les pirogues du fleuve appartiennent à une tribu que l'on appelle les Wagénias.

Ces IVagénias sont des espèces d'amphibies, qui vivent sur l'eau et de l'eau. Ils n'ont pas de villages permanents et habitent de simples huttes avec des herbes et quelques piquets.

Toute leur industrie consiste en la pêche et en transports thuvianx, qu'ils entreprennent pour le compte des riverains. Lorsque la pêche donne mal en un endroit, ils ront s’établir dans un autre. 
Chose également remarquable chez les Wagénias, leurs barques ne sont pas la propriété de tel ou tel individı ; elles appartiennent à la tribu et celui d'entre enx qui a besoin d'une barque la prend sans avertir personne et sans en demander la permission à qui que ce soit.

Ces Wagénias servaient d'espions aux deux camps; après ètre renus nous conter ce qu'ils savaient des Arabes et avoir été payés pour leurs renseignements, ils s'en allaient rapporter aux Arabes les différentes nouvelles qu'ils avaient pu surprendre daus notre camp et se créaient ainsi de doubles bénéfices.

Yous étions parfaitement au courant de leur conduite, phus productive que loyale, mais, n'ayant pas le choix pour nos espions, nous étions bien forcés de nous en contenter.

Nons les avions śouvent plaisantés sur leur commerce en partie double, mais nos plaisanteries les laissaient parfaitement indilférents ef ils n'en continuaient pas moins leur petit trafic.

Qunant à leurs canols, aussitôt qu'une guerre éclate entre riverains, ils les détachent de la rive et vont les mettre en sùreté à des distances considérables du terrain . de l'action.

Dhanis avait, en plusieurs occasions, essayé de leur acheter quelques barques, au taux le plus élevé, toujours sans succès; car, ils voulaient absolument 
rester neutres, se disant que si, par la suite, nous étions vaincus par les Arabes, ceux-ci leur feraient payer cher leur trahison.

Cependant, après le combat du 26 février, ils se rendirent compte que le règne des Arabes était bien fini, que le moment était venu de se déclarer pour celui qui élait éridemment le plus fort, et sur de nonvelles inslances qui lenr furent faites, ils consentirent enfin à nons procurer les canols tant désirés. Ceux-ci se tronvaienl en aval de Nyangwé. Scheerlinck et Cerckel fmrent chargés, avec un délachement de soldats, de les escorter ot de nous les ramener.

Les canols, an nombre d'me bonne centaine, nous arrivèrent le 4 mars an matin.

De suite now soldats sont rassemblés sur la rive et, en quelques instants, ils sont embarqués.

An signal convenn tous les canols s'élancent et font force de rames, atin de rester le moins longlemps possible exposés au feu des Arabes.

Ce ful certainement un des spectacles les plus impressiommants de tonte la guerre arabe, que celui de cette llottille s'ólançant à l’assant d'un camp retranché !

Il faut croire que les Arabes enx-mèmes en furent fortement impressionnés, car, après une première décharge tirće de trop loin, leur résistance mollit. Ce fut presque une désillnsion pour nous; nous trouvions que nous avions pris trop facilement la ville. 
Pour mon compte, j’avoue que j’aurais préléré une résistanee plus aeharnée, ear le plaisir de vainere est toujours en raison directe des difficultés que l'on a eues à surmonter. Or, ici nous étions à peine débarqués qu’ils fuyaient tous épouvantés, résistant à peine et nous donnant plutòt l'illusion d'une chasse à l'homme que les émotions fortes d'une belle bataille.

La ville prise, les canots retournèrent à l'autre rive, a fin de passer les femmes, les boys et les alliés; eomme la ville élait très grande, nous nous installàmes seulement dans la partie la plus haute: premièrement parce que e’était la partie la plus saine, secondement afin de ne pas nous éparpiller el de rester bien groupés de facon, le eas échéant,à pouvoir faire faee à tous les événements.

Le lendemain de la prise de Nyangwé, nons apprîmes (qu'un camp arabe se trouvait à quelques lieues de la ville. Il fut résolu que l’on essayerait de le surprendre pendant la nuit et, eomme il eut été dangereux d'exposer des blancs dans une entreprise de ee genre, ee fut Albert l'rees, accompagné de 60 soldats et d'un détaehement d'hommes de Gongo Lutété qui fut ehargé de eette mission.

Il réussit très lien, surprit les Arabes à la pointe du jour et ramena au camp un butin eonsidérable.

Il fut anssi assez heureux pour retrouver et nous ramener les denx enfants d'Hodister, que les Arabes retenaient prisonniers dans leur eamp. 
Pendant les quelques jours qui suivirent notre prise de possession de Nyangwé,une grande quantité de chefs et de simples indigènes vinreut faire leur soumission ; tous prétendaient n'avoir servi les Arabes que parce qu’ils y avaient été forcés; tous aussi se disaient heureux de la défaite de nos ennemis et nous faisaient les plus grandes promesses de fidélité et de dévouement.

Le tout alla pour le mieux jusqu'au 9 mars. Ce jour-là, je faisais tranquillement la sieste dans la maison que j’avais choisie pour résidence, quand, tout-à-coup, uu boy se précipite vers moi, avec mou fusil en s'écriant que les Arabes étaient maitres de la ville et que l'ou tuait les blancs.

Je ne ne rappelle pas avoir jamais eu un réveil aussi désagréable, ni avoir été aussi vite sur pied, d'autant plus que j'entendais une vive fusillade dans toute la ville, ce qui semblait confirmer les dires dı boy.

J'étais en manches de chemises, je ne pris pas le temps de remettre mon veston et, saisissant mon fusil des mains du boy, je me précipitai hors de ma maison.

C'était très imprudent de ma part, car je formais ainsi un admirable point de visée.

Heureusement mon clairon était à son poste et, en moins d'une minute, j'ens réuni une poignée d'hommes autour de moi, les autres étant dispersés dans toutes les directions, puisqu’ils ne s'attendaient pas à un appel. 
Mais l'essentiel n’était pas d’avoir rémni quelques hommes, la question était surtout de savoir à quoi je pourrais les employer, car l'atlaque avait été si soudaine que nous n'avions pas eu le temps de prendre aucune mesure.

Il n'y arait pas de chefs ; on ne donnait pas d'ordres, chacun combattait là où il se trouvait et pour son propre compte. Je crois que l'on n'a jamais vu m gâchis senblable ; personnellement, j'estimai que le plus sage était de garder la position que j'occupais, qui élait dominante et qui me permettait de battre une bonne partie de la ville par mon feu; lorsque je voyais des soldats à la poursuite de quelques indigènes, je les rappelais près de moi, afin de grossir le noyau que j’étais parvenu à constituer.

La bataille dura bien deux heures et nos pertes furent assez considérables; quant à celles des iudigènes, elles furent effrayantes, je n'ose pas risquer un chiffre, car je suis certain que je serais au-dessous de la vérité et cependant je serais encore taxé d'exagération.

Ce fut la dernière bataille à laquelle j'assistai peudant mon premier terme au Congo et, contrairement aux autres batailles, je ne me la rappelle qu'avec tristesse, car je n'ai pas encore tous mes apaisements à son sujet.

Mes hommes et ceux de Gongo, que j’ai questionnés dans la snite, mont toujours el tous affirmé qu'ils avaient été attaqués les premiers ; j’aime à pouvoir les 
croire, car le contraire serait trop horrible; mais un doute terrible a toujours subsisté en moi et je me suis souvent demandé s'il était bien possible à l'ennemi, après les défaites écrasantes que nous lui avions infligées, de penser encore à se révolter et à vẹnir nous attaquer chez nous. Je me suis aussi demandé si ce n’étaient pas les gens de Gongo qui avaient imaginé et machiné cette révolte afin de se procurer de la viande pour leurs horribles festins.

J'aime à croire qu'elle fut réelle, et je voudrais bien me persuader la chose à moi-mème, mais, malgré tout, le donte, le terrible doute subsiste tonjours.

Lorsque le tout ful rentré dans le calme, on fit brùler toute la partie basse de la ville, afin d'assainir celle-ci, éviter le relour de scènes semblables à celles anxquelles nous renions d'assister et rendre notre position plus facile à défendre.

Le lendemain du combal, lorsqu'on envoya des patrouilles pour recueillir les morts, on ne troura plus un seul cadarre; les vautours de Gongo avaient précédé nos hommes et déjà ils avaient accompli leur horrible el dégoùtante besogne.

Instruit par' mon areuture arec Prigaldien et Duchène au champ de Chigé, je n'eus garde de me rendre chez lui peudaut plusieurs jours; car les tourbillons de fumée noire qui s'élevaient de son camp, ainsi que les bouffẻes d'odeurs àcres et nauséabondes qui nous en arrivaient 
Eérage pour ta captuie du poisson sur le Lualaboz - KATANGA
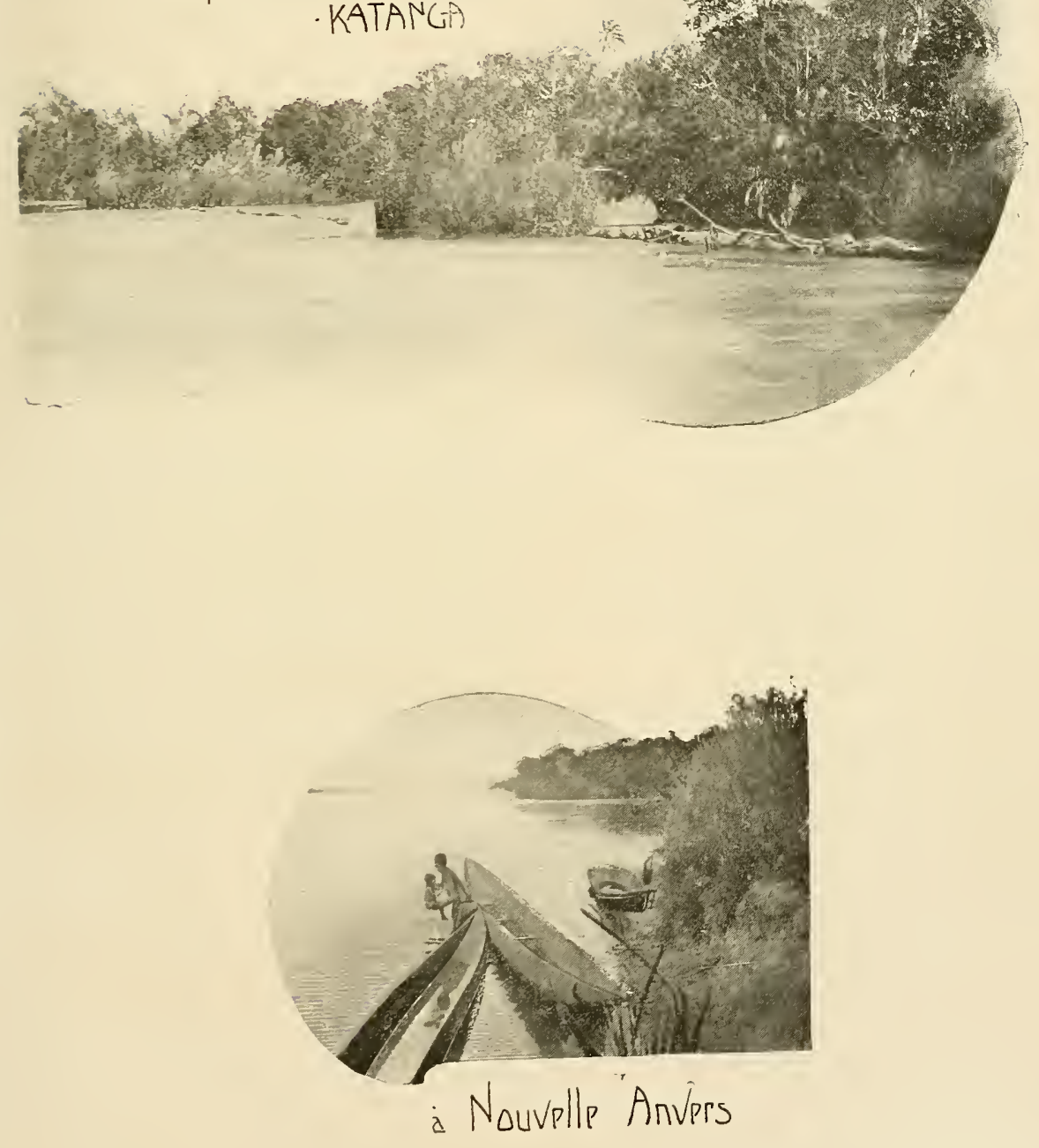

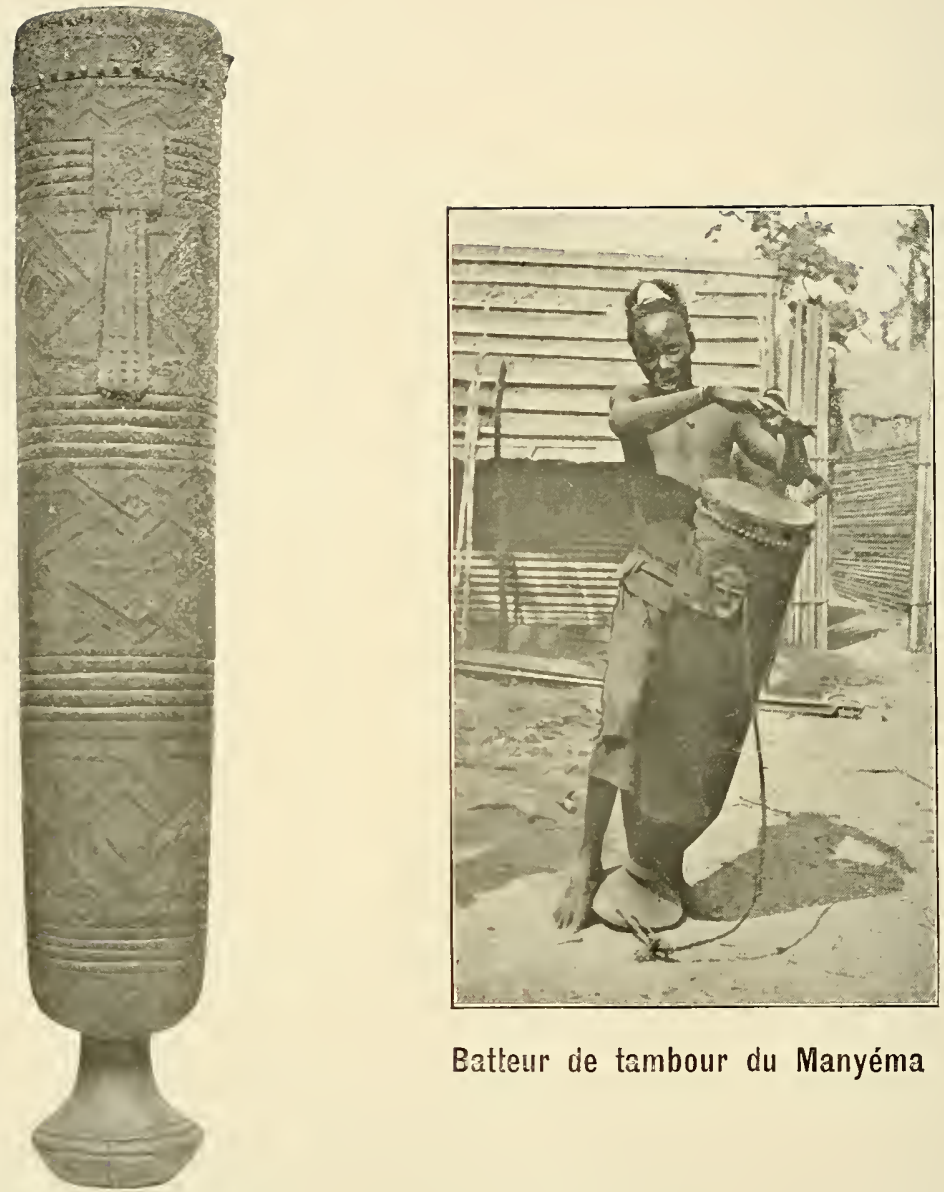

Batteur de tambour du Manyéma

Tambour du Mianyéma 
étaient, par elles-mèmes, assez significatives pour me prouver que mes craintes n'étaient pas chimériques.

Le 5 arril, le commandant Gillain, Doorme et cent cinquante bons soldats venaient de Lusambo renforcer l'expédition et, en mème temps, Dhanis apprenait que de nombreux renforts allaient encore lui arriver, amenés tant par Chaltin que par Lothaire et Ponthier.

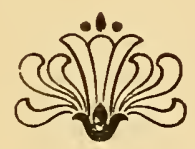




\section{CHAPITRE XII.}

Cassart et moi quittons Nyangwé pour rentrer en Europe. Une chasse à l'hippo en compagnie du Père De Decken. - Une situation difficile à décrire !.... - Dibué prend dans ses griffes une des jambes du juge Desagher. - Quelqu'un qui essaie de nous épater! - Brackmaıl mystificateur !..... - Brackman mystifié ! - Le salut de Pétillon. - Arrivée de ma ménagerie à Anvers. - Dibué, après avoir été offert au Roi, devient pensionnaire du Jardin zoologique d'Anvers.

Notre terme de serrice, à Cassart et à moi, était fini depuis longtemps; Dhanis nous fit appeler tous deux, nous remercia des services que nous lui avions rendus ; il nous dit qu'en ce moment il avait assez d'officiers, pour pouvoir se passer de notre aide, et il nous engagea lui-mème à venir prendre en Belgique un repos que nous avions bien gagné.

Nous partimes donc, Cassart et moi, et comme le bateau m'arait apporté assez bien de matabiches de M'Puttu, toute la route du retour se fit gaiment, je dirai presque luxueusement.

Je n'ai jamais fait un voyage plus agréable au Congo, d'autant plus que je n'avais à m'occuper ni de politique, ni de palabres,et que Cassart s'était chargé des porteurs, de ses bagages et..... des miens.

Grâce à lui et pour la première fois au Congo, je pouvais jouir, mon étape terminée, des douceurs du " farniente ), 
En arrivant à Lusambo, nous eùmes la chance et la joie d'y rencontrer Paul Le Narinel qui était revenı en Afrique, avec le grade d'inspecteur d'Etat, le bon, le brave Père De Decken et le juge Desagher : Nous fîmes route avec eux jusque Léopoldville.

Ce voyage en steamer fut charmant. Avant de nous embarquer, nous avions passé une huitaine de jours à Lusambo, ce qui m'avait permis de faire la connaissance du Père De Decken ; lorsque nous nous embarquâmes, nous étions déjà une bonne paire d'amis.

Un jour, cependant, nous faillìmes nous brouiller, et j'avoue qu'arec tout autre moins idéalement bon que lui, la chose serait arrivée infailliblement. Voici en quelle circonstance :

Notre bois de chauflage pour le steamer étant épuisé, le capilaine avait relàché assez tôt dans l'après-midi, afin que ses hommes pussent faire assez bien de bois pour le lendemain. Or, il se faisait que l'endroit où nous venions d'aborder était précisément l'un de ceux du Kassaï où les hippopotames se trouvaient en très grand nombre.

Dans la conversation, le Père De Decken, ayant dit qu'il n'arait jamais eu l'occasion de tuer un hippopotame, l'inspecteur lui répondit : "Cela s'arrange très bien; comme Michaux est un spécialiste dans l'espèce, je ne doute pas qu'il veuille vous piloter dans votre petite expédition; d'ailleurs, ajouta-t-il, cela me fera 
plaisir de faire une distribution de viande à nos hommes; ils l’ont bien gagnée. "

Je ratifiai immédiatement la proposition de Le Narinel; bientòt une pirogue fut armée et nous fümes prèts à partir.

Comme nous roulions faire les honneurs de la chasse au Père De Decken, nous l'avions placé à l'avant, j'étais derrière lui, enfin Cassart était derrière moi.

Il avait été convenu que le Père De Decken tirerait le premier, mais, comme je dirigeais la chasse, c'était moi qui devais lui dire quand il devrait faire feu.

Bientòt, nous sommes en rue d'un troupeau. J'a vais l'habitude, lorsque je chassais seul l'hippopotame, de laisser approcher ma barque sans bruit et au fil de l'eau jusque 20 à 2.5 mètres de l'hippo, que j'a vais choisi pour ma victime, puis je lui mettais ma balle au milieu du front, s’il était de face; entre les oreilles, s’il était vu de derrière, ou à la naissance de l'oreille, s'il se présentait de profil, et neuf fois sur dix le coup était mortel à ma prenière balle.

A peine avons-nous aperçu les hippopotames que le Père De Decken me demande déjà s'il faut tirer, et nous en étions encore au moins à 300 mètres. Je me mets à rire et lui réponds qu'il a encore tout le temps de réciter un chapelet. A 80 mètres, mème question de sa part. Croyant alors m'apercevoir que le Père De Decken est légèrement ému, je me propose de lui jouer, ce que je 
pense être un bon tour, sans réfléchir aux conséquences qu'il peut avoir pour nous tous, et je fais amener la barque à dix mètres de l'hippopotame avant de lui donner le signal convenu.

Probablement trop surexcité, le Père De Decken vise mal et blesse seulement l'hippopotame, qui était un vieux màle, vétéran du fleuve. L’hippo, rendu furieux, plonge et essaye de renverser la barquette, qu'il soulève hors de l'eau.

Le Père De Decken, perdant la tête, veut se sauver par l'arrière en s'écriant qu'il ne sait pas nager. Juste à ce moment notre ennemi revient à la surface et, empoignant l'avant de la barquette dans ses terribles michoires, essaie de la faire chavirer. Qnelques secondes d'hésitation el nous sommes perdus. Aussi n'hésitai-je pas un instant; empoignant le Père De Decken par le con, d'une brusque seconse je l'envoie rouler au fond du canot, puis, d'un coup d'express tiré à bout portant, je tue le monstre.

Lorsque le Père De Decken se releva un peu meurtri et passablement confus, j'avone qu'il n'était pas content et vraiment, il n'y avait pas de quoi l'ètre; je crois mème qu'il parvint à me bouder pendant près d'une heure. Mais cet homme était si idéalement bon, qu'avant le soir il m’avait déjà pardonné, et je suis persuadé que, si dans la suite quelqu'un avait critiqué en sa présence ma sotte plaisanterie, il eùt été le premier 
à me défendre et à prétendre que les torts étaient de son cỏté.

C'était un homme admirable, possédant toutes les qualités du cœur et de l'esprit et paraissant ignorer tous les petits còtés de la vie, sachant toujours s'effacer, afin de mettre les autres mieux en vue; sa charité n'avait de borne que la mesure de ses moyens.

Je sais que ma plume est bien peu autorisée pour célébrer de pareilles vertus; aussi n'est-ce pas son panégyrique que je veux faire, c'est une simple dette de reconnaissance affectueuse que je paie à sa mémoire.

Le 3 juillet, nous abordions à Léopoldville et je mis encore la bonté du brave Père à une rude épreuve.

M'étant rendu à terre, je constatai avec beaucoup de satisfaction que deux caisses de champagne et une caisse de liqueurs fines s'y trouvaient encore à notre adresse. Ces trois caisses m'auraient embarrassé pour faire la route des caravanes; une me suffisait largement; à cet effet je décidai, séance tenante, d'en vider deux à Léopoldville et de faire profiter mes camarades de la station de cette manne inespérée qui leur arrivait sous forme de champagne. Tous applaudirent à mon idée qu'ils appelèrent géniale et, comme il ne faut jamais remettre au lendemain les bonnes résolutions, nous convînmes de mettre la mienne en pratique sur le champ. 
Aussi, lorsque, vers 2 heures du matin, je regagnai la cabine que je partageais à bord a vec le Père De Decken, me trouvais-je dans une situation assez difficile à décrire, surtout lorsqu'on parle de soi.

Un Anglais dirait, par exemple, qu'ayant bu trop de thé, il s'en trouvait dérangé. Pour moi, qui suis Belge et ne renie nullement mon origine gauloise, j’avoue franchement que je m'étais quelque peu piqué le nez.

Je me trouvais précisément dans cet état de béatitude exlrême qui arrive quelquefois après un bon dîner et qui nous fait, sans effort, aimer notre prochain comme nous-mème, trouver tout le monde charmant et tous nos amis sans défaut.

En me rendant au bateau, je pensai tout à coup à mon ami le Père De Decken et je me reprochai amèrement de l'avoir négligé pendant toute la journée.

Il me vint alors une idée qui me parut lumineuse; "Pourquoi ne prendrions-nous pas un bon et dernier verre ensemble avant de nous coucher? " Car, dans mon idée, le Père De Decken ne pouvait pas encore se reposer à pareille heure !... En arrivant à bord, j'eus une déception ; le Père dormait ou faisait semblant de dormir. Je ne me décourageai pas pour si peu.

Je commençai par l'éveiller, afin de lui présenter toutes mes excuses sur ce que j'appelais mon manque de camaraderie à son égard et comme il m'affirmait (et je suis certain qu’il élait sincère) qu’il ne regrettait 
absolument pas de ne pas m'avoir accompagné à terre, je lui dis que, afiu de bien me prouver qu'il ne m'en voulait pas, il devait se lever pour boire une dernière bouteille avec moi.

Ce fut en vain qu’il protesta, m'affirmant qu'il ne m'en roulait nullement et que nous pourrions, sans inconvénient, remettre la chose au matin ; je ne voulus rien entendre, le pauvre homme dut se lever et boire avec moi. Je le proclamai alors le meilleur des amis et, après avoir trinqué ensemble au Roi, à l'œuvre du Congo, etc.... notre bouteille étant vide, je permis à ma victime d'aller se reposer, et me couchai content des autres et de moi-même, bien persuadé que je venais de combler une lacune et que j’avais dignement réparé mes torts.

Quelques jours plus tard, nous étions sur la route des caravanes et il me souvient de certain soir où nous faisions la causctte après le dìner non loin de l'endroit où mon léopard, l'ami Dibué, était attaché. Tout à coup, Desagher pousse un cri terrible : je m'aperçois non sans émotion que Dibué tenait une des jambes du juge entre ses pattes. Làchez ! !... criai-je, en bondissant vers mon léopard. Mais déjà Dibué avait fait un saut de plusieurs mètres en arrière et riait à sa façon, en nous montrant un admirable casse-noisettes, du bon tour qu'il avait joué au juge. Celui-ci n’avait pas reçu la moindre égratignure et bien que je lui eusse fait observer qu'il n'était 
pas convenable de parler mal d'un absent, il n'en continua pas moins dans la suite à soutenir mordicus que, ce jour-là, mon léopard avait voulu lui enlever un mollet.

En venant d'Europe, j'avais fait la route par Lukongu; en rentrant je désirais beaucoup suivre celle de Manyanga et descendre en pirogue les rapides du fleuve, afin d'éprouver des sensations tout à fait neuves.

Costermans, alors commissaire de district à Léopoldville, nous accorda sans aucune difficulté, à Cassart et à moi, l'autorisation que nous sollicitions, ajoutant toutefois qu'il était des plus heureux de nous obliger, mais que les sensations dont uous nous montrions si avides nous paraitraient peut-ètre un peu fortes.

Il avait parfaitement raison et je puis vous assurer que ni Cassart ni moi, nous n'entmes plus, dans l'arenir, le moindre désir de recommencer l'expérience, d'autant plus que le blanc qui commandait alors la station de Manyanga arait probablement peu de notion de sa responsabilité : il avait chargé notre barque au point que nos rameurs indigènes ne voulaient pas partir.

Si nous n'avions pris la sage mesure de faire débarquer en cours de route les vingt soldats qui nous servaient d'escorte et leur faire suivre la voie de terre, nous aurions certainement tous péri en route. La descente telle qu'elle se produisit mème avec notre canot allégé n'en fut pas moins très périlleuse et je 
n'hésite pas à reconnaître qu'en plusicurs occasions, j’ai été réellement ému.

Pendant la route de Isanghila à Matadi, nous fìmes arec Cassart une petite rencontre qui nous divertit beaucoup. Suivant notre habitude, lorsque nous étions en route, nous étions tous les deux vêtus, des pieds à la tète, de toile bleue, telle qu'en portent nos chauffeurs et nos mécaniciens pendant l'été : c'est ce qu'il y a de plus commode pour voyager et puis,.. c'était tout ce qui nous restait de costume.

Au croisement de deux routes, nous rencontràmes un jeune officier tout flambant neuf et dont le costume d'un blanc immaculé faisait valoir sa belle prestance. A première rue, on reconnaissait l'homme heureux de virre et qui se sent au dessus du commun des mortels. A notre mise plus que modeste, il nous prit sans doute pour des ouvriers du chemin de fer et, lorsque nous le saluàmes, il nous rendit notre salut d'un petit air protecteur et bon enfant.

Au commencement,nous cheminâmes silencieusement et l'un derrière l'autre, comme c'est l'habitude au Congo. Mais bientòt notre jeune coq, dont le cœur débordait d'allégresse et qui eût volontiers chanté sa gloire naissante aux échos d'alentour, n'y tint plus et, s'adressant à Cassart, il se mit à lui conter dans ses moindres détails qu'il venait, avec un peloton, de faire une reconnaissance des plus dangereuses aux environs, 
qu'il était resté dix jours en route! Qu'un jour mème, il avait dû faire arrêter le chef du village et, qu'à la suite de cet acte de vigueur nécessaire, il avait été attaqué et avait dû faire la guerre! Et il aurait fallu entendre comme il prononçait ce mot : "la guerre "; il le faisait sonner comme une fanfare.

Cassart, qui est un farceur de premier ordre, avait pris sa mine la plus ahurie et ne cessait de faire entendre des exclamations plus admiratives les unes que les autres aux récits des hauts faits de notre jeune ami, qui, grandi d'une condée el se rengorgeant dans son triomphe, ne doutait nullement nous avoir épatés. Quant à moi, je ne disais rien, m'abstenant le plus possible de regarder Cassart de crainte d'ètre pris d'un fon rire, que je sentais toujours près d'éclater.

Eu arrivant en face de Matadi, un canot vint nous prendre pour nous faire passer le fleuve. Aussitòt que nous sommes en vue, le clairon sonne et environ cent cinquante soldats se rassemblent et s'alignent sur: la berge pour nous recevoir. A cette vue, notre sous-lieulenant pàlit. Non, c'est trop ! il ne s'attendait pas à tant d'homneur. Nous sommes prèts à aborder, un commandement retentit et toute la troupe salue juste au moment où nous débarquons.

Notre officier rend le salut, mais en ce moment, il dut certainement se demander si le sergent noir qui commandait le détachement était devenu fou, puisque, 
passant près de lui, sans s'en oecuper, il vint se eamper devant moi et, après m'avoir présenté l'arme et rendu l'appel, me demanda si je désil'ais passer l'inspeetion du détaehement. Je remerciai et fis rompre les rangs.

Ce détachement avait fini son terme; j’avais été ehargé de le rapatrier et, étant arrivé avant moi à Matadi, il y attendait évidemment mes ordres.

Quant à notre homme, je n'ai jamais vu quelqu'un d'aussi penaud de ma vie, surtout lorsqu'après s'être présenté, nous lui déelinâmes, à notre tour, nos noms et qualités et que Cassart, toujours sérieux, lui eut dit presque eonfidentiellement que, nous aussi, nous avions eu quelques petites aventures.

En arrivant à Boma, nous rencontràmes, parmi les passagers, le commandant Tobbae qui descendait des Falls, le eommandant Nilis et le doeteur Brackman qui venaient d'Europe.

Ce dernier était bien le plus grand fumiste que l'on puisse rèver et toute la ville de Gand se rappelle eertes eneore deux de ses farces pendant qu'il y était étudiant. Raecntons-les comme il nous les raeonta.

Un jour, le bruit se répandit à Gand que le ministre de l'instruetion publique devait venir visiter l'Université ; on eitait même le jour et l'heure de son arrivée. Mais si tout le monde eonnaissait ces données, personne, en revanche, ne savait de qui venait la nouvelle. Enfin tant de personnes affirmaient la chose avec conviction 
qu'au jour dit il y avait foule à la gare, où l'on avait dû organiser un service d'ordre spécial; plusieurs professeurs de l'Université s'étaient même, dit-on, rendus à la gare pour recevoir Monsieur le Ministre.

A l'heure dite, le train de Bruxelles entre en gare, salué d'une immense acclamation...et l'on voit descendre d'un compartiment de $3^{\text {e }}$ classe naître Brackman, habillé des vieilles défroqnes de ministre, qu'il avait achetées chez in brocanteur.

Il parait que la gare se vida avec une rapidité étonnante, personue évidemment ne tenant à ètre classé parmi les dupes.

Un autre jour, ses amis reçurent une lettre de fairepart annongant sa mort, ainsi que son inhumation pour tel jour, à telle heure.

Au jour dit, comme il était très aimé et avait beaucoup d'amis, la rue était pleine de monde qui s'étonnait bien un peu de voir que la porte, toute tendne de noir d'ailleurs, ne s'ouvrait pas pour leur permettre d'aller déposer leur carte.

A un moment donné, au lieu de la porte d'entrée, ce fut la fenètre du balcon qui s'ouvrit et Brackman y apparut en manches de chemise.

Après avoir remercié ses camarades d'ètre venus si nombreux à ses obsèques, il leur dit qu'il avait tenu à constater par lui-mème quels étaient ceux d'entre eux qui se seraient réellement dérangés, le cas échéant, 
pour lui donner cette dernière preuve d'amitié ; maintenant que l'expérience était faite, il les priait tous de ne plus se déranger, lorsqu'il serait réellement mort.

Notre ami Brackman vous étant connu, je ne puis m'empècher de vous conter une petite aventure qui lui arriva de par mon fait à Boma et vous narrer comment le roi des mystificateurs fut à son tour mystifié.

A mon arrivée à Boma, on m'avait logé au premier dans une maison neuve qui venait d'ètre achevée et est maintenant habitée par les sœurs, mais qui, à cette époque, était encore inoccupée. Dans une grande chambre, à côté de la mienne, on avait logé Nilis et Brackman.

J'avais remarqué, au bout de la cour, une grande annexe et j'y avais enfermé mon léopard. Ayant ensuite fait tenir avec un cadenàs, le bout de sa chaîne, longue de dix à douze mètres, à un poteau en fonte qui se trouvait au milieu de la place et constaté qu'il se trouvait des grillages en fil de fer devant les fenètres, j'étais parti complètement rassuré.

Le premier jour, tout se passa en effet le mieux du monde et, le lendemain après-midi, lorsque sur l'invitation du major Pétillon, je me rendis à Chinkakassa, pour visiter le fort,j'étais bien tranquille sur les frasques de mon ami Dibué. Mais si l'homme propose, ce fut cette fois le léopard qui disposa. 
Contre l'annexe où j'avais logé Dibué, on avait accolé un petit bàtiment sur la porte duquel les Anglais ont l'habilude de marquer un IV qu'ils font suivre d'un C.

Or, il se fit que Brackman eut la malencontreuse idée de se rendre au susdit petit endroit, précisément au moment où Dibué, s'ennuyant dans une solitude à laquelle il n'était pas habitué, avail résolu de prendre un peu l'air et de s'informer de ce qui se passait aux environs.

Il avait son premier prix de voltige, ce fut donc un jeu pour lui de sauter sur la fenètre; comme il n'y a que le premier pas qui coìte, il eut vite fait, d'un léger coup de griffe, de partager le grillage en deux et de sauter dans la cour.

Sa chaìne étant assez longue, il se mit donc à se promener en tous sens, quand tout à coup, intrigué par une porte derrière laquelle il devait se passer quelque chose, il introduisit une grifle dans l'interstice et, tirant à lui la porte, l'ouvrit toute large. A la vue de Dibué, Brackman pousse un cri! (et voilez-vous la face,pudique Albion!!) sans s'occuper de son indispensable, qui, le traitre, abandonnant son maître, s'est écroulé sur ses talons, il se hisse un étage plus haut, où, par ses cris, il cut vite fait d'ameuter la moitié de Boma. Tous se tordaient, se déclarant impuissants à venir en aide à ce nouveau révolutionnaire de 1789 . 


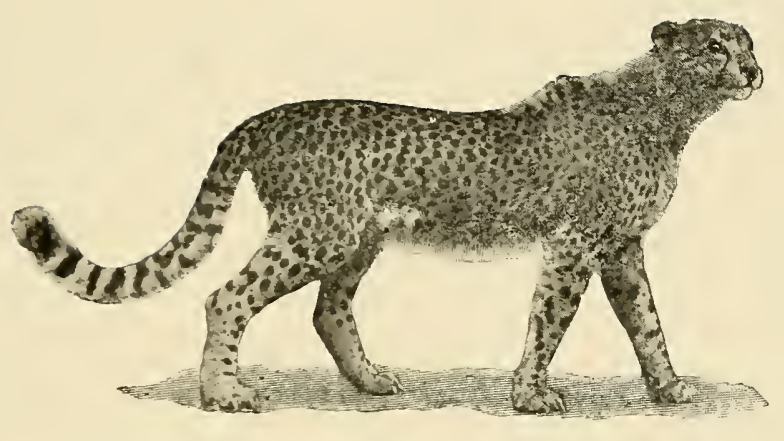

Un petit cousin de mon ami Dibué

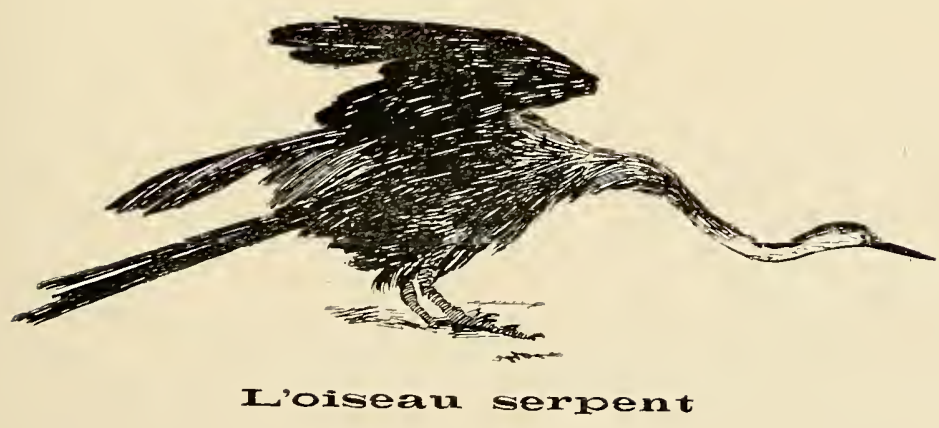



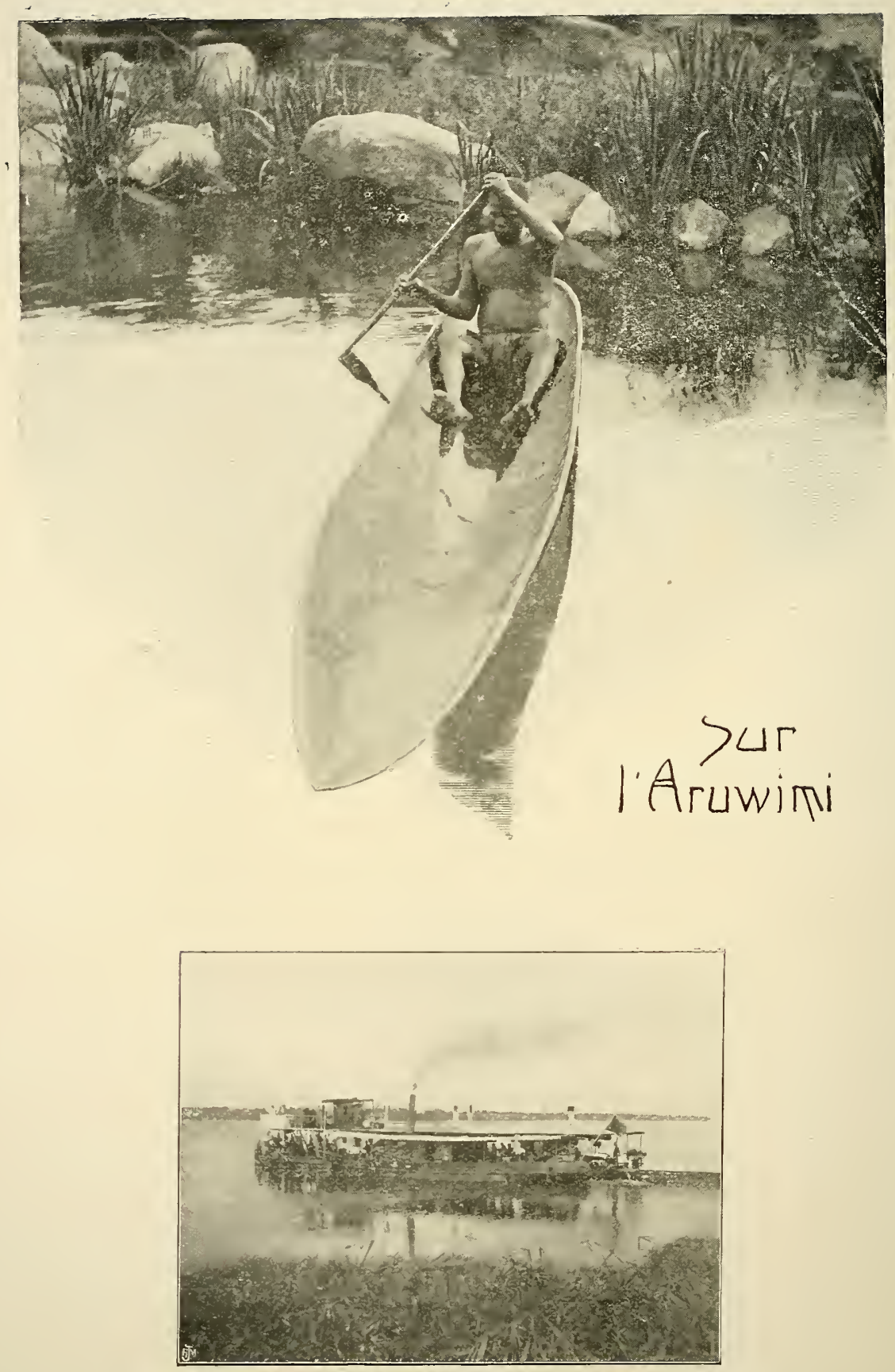

Une barge et son remorqueur 
Quant à Brackman, il faillit devenir fou, lorsqu'on lui dit que j'étais parti pour Chinka et que, en envoyant mème un courrier rapide, je ne serais pas de retour avant deux heures!

Heureusement pour lui, la chaîne de Dibué lui permettait d'arriver avec sa patte juste au seuil de la retraite de Brackman, mais il lui était impossible de faire un pas de plus.

La position du docteur, tout en n'étant pas très agréable, je l'avoue, n'était donc nullement dangereuse.

Après un certain temps, Dibué s'était couché et mettant sa bonné tête sur ses grosses pattes, avait fermé les yeux et semblait s'ètre endormi dans un bienheureux sommeil.

Brackman crut pouvoir en profiter, sinon pour s'en aller, du moins pour mettre un peu d'ordre à sa toilette. Nais à peine était-il descendu que Dibué ouvrait un neil et faisait une risette qui eut le don de faire bondir Brackman sur son perchoir.

Enfin, des camarades ayant prévenu Cassart de ce qui se passait, celui-ci accourut. Dibué le connaissait très bien, puisque depuis des mois nous vivions ensemble; sur son injonction, il daigna regagner ses pénates et Brackman put regagner sa chambre.

Mais la comédie n'était pas finie, elle ne faisait que commencer. 
Vers le soir, étant rentré à Boma, les camarades m'eurent vite mis au courant de ce qui s'était passé le matin; Tobbac, "Deus ex machina " de la comédie qui se préparait, vint m'avertir en grand secret que Brackman se trouvait à l'hôtel, où il ne cessait de déclamer contre moi et ma sale bête de léopard, disant que le lendemain matin il irait se plaindre au gouverneur.

Il me dit aussi qu'une cabale était montée contre ce roi des farceurs; on lui avait fait croire que j'étais un alcoolique et que, lorsque j'avais bu, j'étais très dangereux, très méchant, capable de tout, que si, par conséquent, je revenais pris de boisson, comme c'était malheureusement probable, de mon excursion à Chinka, le mieux était de ne pas m'exciter; sans cela, les plus grands malheurs étaient à craindre.

Mis ainsi au courant du ròle que j'avais à jouer, un quart d'heure plus tard je me rendis à l'hôtel d'où, du pied de l'escalier je m'écriais : Où est Brackman! je veux voir Brackman !...... du coup, les camarades paraissent atterrés et disent à Brackman : “ Cela y est !... Il est saoûl !... Nous allons en voir de grises !... »

A ce moment, je fais mon entrée dans la salle et, marchant droit à Brackman, tout en ayant soin de faire tomber une chaise sur mon passage, je lui demande : " Est-il rrai, Brackman, que tu as calomnié Dibué et que tu l'as traité de sale bête? ") 
Saus lui domner le temps de répondre, je continue :

- Brackman, tu as tort! Dibué est un agneau, la plus douce des bètes, et si vous avez eu une palabre ensemble, e’est que tu lui anras manqué d'égards. Dailleurs, je veux remeltre les aflaires, nous allous prendre quelques bouteilles de champagne avec les camal'ades, puis je te présenlerai à Dibué, et comme il le doit une réparation, je le forcerai à se coucher comme 111 chien sur la descente de lit, el à te servir de gardien pendant toule la nuit! »

Brackman s'écric qu’il ne veut ni excuses, ni présentation avec Dibuc, que c'est inutile..... que l'aflaire est oubliée !...... que sais-je enfiı.

Mais je ne veux rien entendre.

- Garcon, n’écriai-je, apportez ruatre bouteilles de champagne.

Tous ceux (fui sont présents paraissent désespérés et, derrière moi, levent les bras d'une facon tragique.

Brackman essaic de me raisonner, mais je ne lui réponds que par un : Buvous, Brackman! In verras Lantòt comme tu arais nual jugé cet amonr de léopard ! "

Enfin des camamdes m'altirent dans un coin, pendant que d'autres conseillen' à IBackman de s'esquiver, lui promettant de mettre tout en ceuvre pour me faire renoncer à mes projels.

Le docteur parti, nous faillîmes tous devenir malades de rire. Mais ses tourments n'étaient pas encore finis : 
Environ une heure après son départ, on était allé me chercher une chaîne d'une couple de mètres de long et tous les camarades s'étant cachés dans les fourrés aux alentours de la ınaison pour être témoins du dernier acte,je commençai à monter l'escalier en laissant traîner la chaîne derrière moi tout en criant : “Viens, Dibué, je veux te raccommoder avec Brackman!"

Mais aussitòt nous entendons des cris : " Au secoụs ! à l'assassin ! » et des bruits de meubles que l'on déplace.

C'était Brackman qui déménageait tous les meubles de sa chambre, afin de se barricader!

Après avoir été frapper à sa porte et l'avoir fait languir pendant une dizaine de minutes, je red escendis avec ma chaîne, tout en disant : "Viens,Dibué,Brackman a un trop mauvais caractère ce soir, nous reviendrons demain! »

Le lendemain matin, Brackman se trouvait à sa fenêtre et pérorait devant une vingtaine de personnes à qui il contait les divers incidents de sa nuit tragique, quand le Gouverneur qui faisait sa promenade quotidienne passa précisément par là. Voyant un rassemblement, il s'approcha et demanda au docteur ce qui paraissait exciter sa colère.

Sans se faire prier, celui-ci recommença tout le récit de sa triste odyssée; à son grand dam, le Gouverneur, au lieu de s'indigner, riait de bon cœur, car il connaissait déjà toute la farce de la nuit; et lorsqu'il lui demanda, 
avant de s'en aller, s'il était bien certain d'avoir couru tous les dangers qu'il disait, Brackman dut penser, à part lui, que le Gouverneur a vait une singulière façon de veiller sur la vie de ses administrés.

Je ne sais si, par la suite, on lui a appris qu'il arait été mystifié, mais, en tont cas, celui qui se sera chargé de la chose aura, je crois, eu fort à faire pour le persuader que les dangers qu'il avait courus n'étaient que chimériques.

Quelques jours plus tard,en compagnie de l'Inspecteur d'Etat Fivé, du juge Desagher et du commandant Daenen, je rentrais par le bateau qui fait relâche à Lisbonne.

Quant à Cassart, il avait consenti à convoyer ma ménagerie et il rentrait par le bateau ordinaire.

Pendant que j'étais à Boma, Pétillon avait appris que j'avais été le premier commandant d'artillerie de Boma et, la veille à table, il a vait dit que lorsque je passerais devant le fort, celui-ci me saluerait d'une façon tout à fait spéciale; comme il n'en avait pas voulu dire davantage, nous étions tous assez intrigués, puisque le protocole lui interdisait de faire tirer le canon.

Le lendemain donc, au moment où nous passions en face du fort, il salua du drapeau et fit éclater treize fortes mines qu'il avait fait préparer à cet effet.

Je ne connais que lui pour avoir de ces attentions si délicates, pour faire de ces trouvailles charmantes. 
Ce sont de ces riens qui vont droit au cœur et dont le temps lui-même n'efface jamais le souvenir. De nouveau et de tout cœur : merci, Major.

Je n'ai rien à dire de la traversée, si ce n'est que sur le navire se troivait avec nous un négociant portugais, qui élait resté vingt-trois ans factorien à St-Paul de Loanda el y arait gagné une fortune de 350,000 franes.

Se trouvant récemment veuf, il avait réalisé ses fonds et, accompagné de ses trois charmantes jeunes filles, qui avaient de dix-sepl à vingl ans, s'en retournait à Lishonne afin de jouir d'un repos qu'il avait bien gagné.

Or, il advint qu'il se mil à jouer sur le bateau et, en arrivant à Lisbonte, il ne lui reslait plus un centine?

Mon voyage de retour s'accomplit alor's sans autre péripélie.

A peine élais-je rentré en Belgique de quelques jours que le batean ordinaire dı Congo, par lequel revenait Cassart, élail annoncé; je dus partir en toute hâte, afin de ne trouver à Anvers lors de son arrivée. Non senlement it m'amenait un de mes boys, mais encore toule ma pelite ménagerie, composée de mon chien Pilch, d'un léopard, d'un singe et de cinq perroquets.

Aussilòl que le bateau accoste, je monte à bord et, après a voir renercié Cassarl, qui a pris soin de toutes mes bètes pendant la traversée, je me mets en devoir de les débarquer. 
J'étais accompagné de mon père, d'un de mes cousins, de sa femme et de ses deux petites filles.

Midi étant sonné depuis longtemps, nous avions tous faim et primes la résolution de nous restaurer au plus près. L'hòtel du Rhin, si j’ai bonne souvenance, se trouvant en face du débarcadère, nous nous y rendìmes.

Pour nous rendre à l'hôtel nous derions quelque peu ressembler à Robinson Suisse, ou tout au moins à des gitanos : j'ouvrais la marche avec Dibué, que je tenais en laisse, mon père et mon cousin suivaient portant entre eux une grande cage d'oi mes cinq perroquets faisaient entendre leurs cris harmonieux; enfin, fermant la marche, ma cousine portait le singe et mes deux cousinettes, toutes blanches, avaient entre elles mon petit boy tout noir.

Je ne vous étonnerai guère en vous disant que notre entrée à l'hòtel fit sensation.

Pendant le dìner, ne sachant que faire de Dibué, je l'avais attaché au pied de l'escalier.

Nous venions à peine de manger notre potage, que le propriélaire de l'hỏtel, entrant en coup de vent dans la salle à manger, s'écrie : "Partez, monsieur! Partez vite avec votre léopard, car, depuis que mes locataires savent que cette bête se trouve dans la maison, c'est une fuite générale. Partez, si vous ne partez pas immédiatement, dans une demi-heure mon hôtel est vide! » 
Quoique cela ne me sourît guère de m'en aller avec un potage pour tout dîner, il fallut bien me rendre aux instances de l'hôtelier et, après avoir donné rendez-vous à ma petite caravane, j'allai détacher Dibué afin de le conduire an Jardin zoologique.

Malheureusement, j’avais compté sans la police : celle-ci, ayant vu un nombreux rassemblement devant l'hòtel, s'était informée du motif qui l'arait provoqué et, Jorsque escorté de Dibué je voulus sortir, je trouvai devant moi un commissaire de police et cinq ou six agents qui s'opposèrent formellement à notre sortie, sous prétexte que l'on ne pouvait pas promener des animaux dangereux en rue.

- Alors, leur demandai-je, que voulez-vous que je fasse? L'hòtelier ne vent pas me laisser rentrer, vous ne voulez pas me laisser sortir, je ne puis cependant pas m’éterniser'sur le seuil de l'hòtel ! Et puis, ajoutai-je traitreusement, mon léopard a très faim et, si je ne puis pas lui donner de suite à manger, il pourrait tantôt devenir dangereux.

Du coup, mon cercle d'investissement s'élargit d'un cran et, comme ces messieurs, par charité bien entendu, ne voulaient pas laisser avoir faim à Dibué, ils me dirent que cela n'était pas très réglementaire, mais qu'enfin, pour sortir de cette situation, si je voulais monter avec mon léopard dans un fiacre qui nous conduirait au Jardin zoologique, ils m’autoriseraient à partir. 
J'acceptai évidemment leur proposition avec enthousiasme et un agent ayant été chercher une voiture, je convins avec le cocher que je lui donnerais dix francs pour sa course; après m'ètre installé avec Dibué, je demandai aimablement au commissaire, s'il ne tenaît peut-ètre pas à m'accompagner; mais il me remercia de mon offre, m'affirmant qu'il avait toute confiance en ma parole.

Pendant la route, le cocher s'était assis sur le bord de son siège, le corps penché le plus possible en avant et, de temps en temps, il jetait un coup d'œil peu rassuré sur ses deux clients.

A un moment donné, il me vint à l'idée que, puisque je ne pouvais pas diner, un cigare m'aiderait à prendre patience; mais, n'en ayant plus en poche et comme nous passions précisément en face d'un magasin, je frappai avec le doigt sur la vitre afin que le cocher put m'en aller chercher.

Mais, du coup, celui-ci abandonne et son cheval et ses rênes, saute de la voiture et se sauve au moins à dix mètres.

Voyant alors que rien de particulier ne se passe dans son véhicule, il revient vers nous et je lui transmets poliment ma requête. Mais lui, tout à fait furieux cette fois, s'écrie pour toute réponse : "Tu sais Môssieu, tu vas pas tenir le fou avec moi et te payer mon tête, zelle! Si tu recommences encore une fois ton sale blague, 
hé bien, toi et ton sale bête ira te promener oùsque tu veux ! ”

Je me le tins pour dit et comme je n'arais pas l'envie de recommencer à palabrer avec la police, je mis tous mes soins à empècher mon compagnon de route de gratter dans la direction de notre irascible et poltron cocher.

Quelque temps après, nous faisions notre entrée au Jardin zoologique, où nous fûmes admirablement reçus. Je prévins le directeur que je désirais faire cadeau de mon léopard au Roi et je lui demandai l'autorisation de le laisser quelques jours chez lui ; il accueillit ma requète le plus gentiment du monde. Aussi, dans la suite, ce fut arec plaisir que je lui fis présent de mon léopard ; voici en quelle circonstance: Ayant été appelé chez le Roi, je lui offris Dibué. Sa Majesté me remercia beaucoup de mon cadeau, qu'Elle voulut bien qualifier de peu ordinaire, mais Elle me dit que, ne poss édant pas ma poigne, il Lui serait peut-être difficile de se faire obéir. Sa Majesté ajouta que cela pourrait occasion ner des désagréments aux personnes qui iraient lui faire visite au palais et qu'enfin, puisque le léopard se trouvait au Jardin zoologique d'Anvers, le mieux encore était de l'y laisser.

Après réflexion, je dus convenir que le Roi avait raison, mais, en ce moment, j'aimais tellement mon cher Dibué,qu'il me paraissait impossible que quelqu'un 
ne l'aimàt pas ou que l'on pùt faire un plus beau cadeau à qui que ce frìt.

C'est le motif qui m'avait déterminé à l'ofrrir à Sa Majesté.

Après avoir mis Dibué en sùreté, j’allai retrouver ma famille qui, ayant fini de se restaurer, était venue à ma relicontre.

En route, mes parents estimèrent que, malgré son beau pagne, mon boy serait cependant plus présentable vèlu à l'européenne; voulant me faire une surprise, ils eurent vite fait de l'habiller des pieds à la tète.

Je les remerciai et les félicitai de leur heureuse inspiration. Au moment où nous arrivons a venue de Kayser, qui était pleine de monde, mon gamin se met à remplir les mèmes fonctions que le plus ancien ciloyen de Bruxelles. J'a vais oublié de lui dire qu'en Europe il y avait des endroits spécialement réservés à cet exercice.

Malheureusement, sa petite opération terminée, mon bonhomme ne s'y retrouve plus pour remettre son ajustement en ordre; royant qne la foule, qui s'était quelque peu amassée autour de lui, riait de sa mésaveuture, il se mit à pleurer. Quant à moi, je riais de trop bon cosur pour pouvoir lui porter secours; ce fut ma cousine qui, en bonne mère de famille, ne put se résoudre à laisser plus longtemps l'enfant dans l'enluarras et remit enfin de l'ordre dans sa toilette. 



\section{CHAPITRE XIII.}

Second départ pour le Congo._L'lle de San Thomé : ses sites enchanteurs,ses roças somptueuses. - En route pour Lusambo. - Deux chasses des plus accidentées. - En route pour Lulua. bourg. - Lapière et le poste de Makabua. - Campagne contre Kalamba et les Kiokos. - Combats acharné3. - Une chefesse prisonnière fait appel à son peuple dans la nuit.-Douze heures de combat sous bois. - Grande fête précédant la plus terrible des catastrophes.

J'étais à peine de retour au pays natal que la fièvre des royages me reprenait et, dès le mois de juin 1894, je repartais en qualité de commissaire de district de $1^{\text {re }}$ classe, pour le district du Kassaï Lualaba, où je devais succéder au commandant Gillain.

Dans ce nouveau voyage au Congo, j'étais accompagné de M. Comblé, car nous devions, sur ma demande, aller étudier à San Thomé le système employé pour les plantations de café et de cacao, afin de faire de grandes plantations dans le district.

Je ne parlerai pas de la traversée de Lisbonne à San Thomé, car toutes les traversées se ressemblent.

Parmi les passagers qui se trouvaient avec nous, je dois cependant citer le fameux chasseur suédois Harisson, qui se rendait à Mlossamédès et qui, à cette époque, avait déjà plus de trois mille tètes de gros gibiers à son actif, tels que éléphants, lions, etc. 
En arrivant à San Thomé, je fus présenté au Gouverneur, qui était, à cette époque, M. Serpa Pinto, un des plus illustres explorateurs portugais. Il me reçut de la façon la plus charmante et fil tout ce qui était en son pouvoir pour me faciliter ma mission.

L’ile de San Thomé étant située sous l'Equateur, je crois inutile de vous dire qu’il y fait très chaud.

Quant à la ville en elle-mème, elle est très peu intéressante; deux ou trois cents marchands en tous genres, surtout des facloriens, voilà tout. Pas de luxe. Les gens qui s'y établissent ne cherchent qu'une chose, qu'ils trouvent d'ailleurs presque toujours : gagner rapidement beaucoup de contos de reis et puis s'en retourner vivre en Porlugal.

Mais ce qu'il y a de beau, ce qu'il y a d'intéressant, re qui est splendide, inoubliable enfin, c'est l'intérieur de l'île. Son sol, formé d'irruptions volcaniques, prend à chaque instanl les formes les plus bizarres, les contours les plus fantastirpues.

Partout, dans ces montagnes, une eau claire et limpide qui, jouant à ravir son ròle providenticl, serpente de toutes parts, arrose et fait fructifier la terre dont elle sort et, après mille tours et létours, se laisse choir en cascades merveilleuses, tels que le Blou-Blou, la Guêgue et cent autres. Tout cela au milieu d'une débauche de végétation, car tolit ici, grâce à l'eau et à la chaleur, prend des formes énormes, atteint des proportions 
gigantesques. Aussi, dans les premiers moments, l’àme ravie et les yeux éblouis, a-t-on peine à comprendre qu'il puisse se trouver sur un mème coin de terre tant de richesses unies à tant de poésie.

Mais, jusqu’ici, je ne vous ai parlé que de la nature sauvage, de la nature primitive, de celle que Dieu a faite, et que la plupart des propriétaires, moins féroces que nos architectes et nos ind ustriels d'Europe, ont respectée dans bien des endroits comme une relique, à laquelle ils ont laissé toute sa saurage beauté, tout son aspect quelque peu mystérieux.

Il me reste à vous parler des roças et des splendides propriétés qui les entourent.

Je ne vous en citerai qu'une, où je reçus une hospitalité quasi royale : le Rio d'Or appartenant à Madame la comtesse de Val Flore.

Les bàtiments de cette roça couvrent plusieurs hectares et abritent des centaines de travailleurs noirs.

Aussi, est-ce par millions que se chiffre l'exportation d'une seule année.

Outre le café et le cacao, on y cultive aussi la canne à sıcre, le maìs, la vanille, la cannelle, le quinquina et le tabac.

Tous ces produits sont manufacturés sur place.

Quant aux fruits, gràce au pic San Thomé, qui se trou ve dans la propriété, on peut dire que l'on y trouve tous ceux de la création, tels que la pomme, la poire 
et les nèfles, les autres dont j'ai conservé les noms, sont : la banane, papaie, ananas, maracuja, mangue, cajamanga, sapu-sapu ou cœur de bœuf, nona, saputi, abiu, carambola, pitanga, grou me chamos, grou m'appelle, jabu ticabo, caja, arbre à pain, gaigue, coco, citron, mandarine, figue, raisin, pèche, goïave, araça, noix de cola, abakats, safu, pépinelle.

J'écris tous ces noms comme je les ai entendu prononcer, mais sans aucune garantie au point de vue de l'orthographe du nom.

Eu quittant San Thomé, nous nous rendimes à Cabinda, d'où l' " Hirondelle ", vaisseau appartenant à l'Etat du Congo, vint nous prendre pour nous conduire à Boma.

Quelque temps après mon arrivée, Dhanis et le docteur Hinde, qui rentraient en Europe, descendirent à leur tour à Boma, où j'eus le plaisir de passer quelques jours avec eux. Ils ctaient accompagnés de Rachid, l'ancien vali des Falls.

Lorsque jarrivai à Léopoldville, M. le Gouverneur génèral baron Wahis s'y trouvait également; comme toujours, d'ailleurs, il fut charmant pour moi.

Je devais me rendre à Lusambo et y conduire une troupe de 150 hommes, deux canons et trois officiers.

Il me donna comme mission d'installer Rachid en poste, dans l'endroit qui me paraittrait le plus propice, aux environs de l'embouchure dụ M'Fini, Je devaiø 


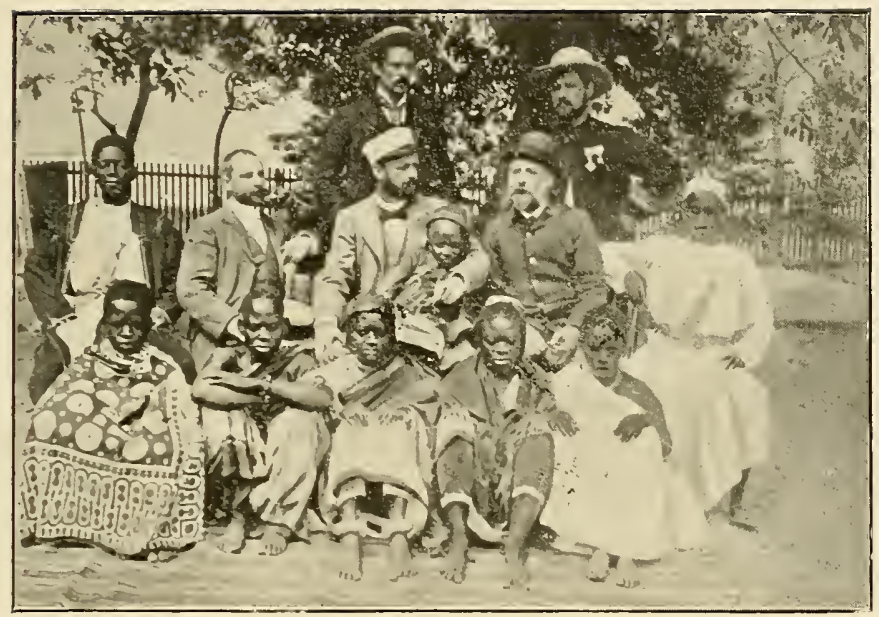

ler plan

Femmes de RACHID

2e plan de gauche à droite

RACHID, DE KEYSER, DHANIS, VANDEN PLAS, BWANA=N'ZIGHÉ

3e plan

Docteur HINDE, Commandant MICHAUX

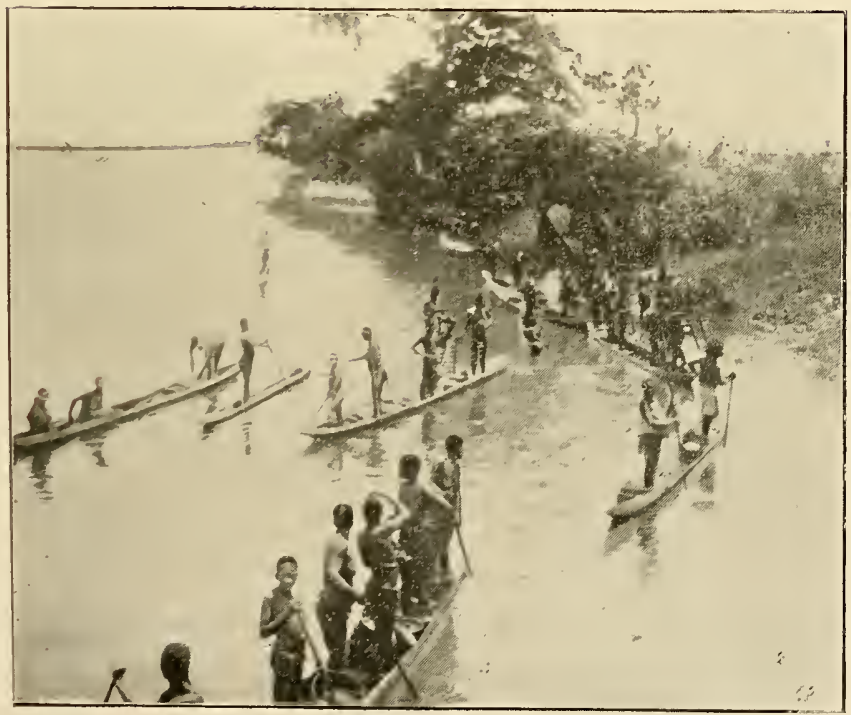

Riverains du Kassaï attendant_le passage du bateau 


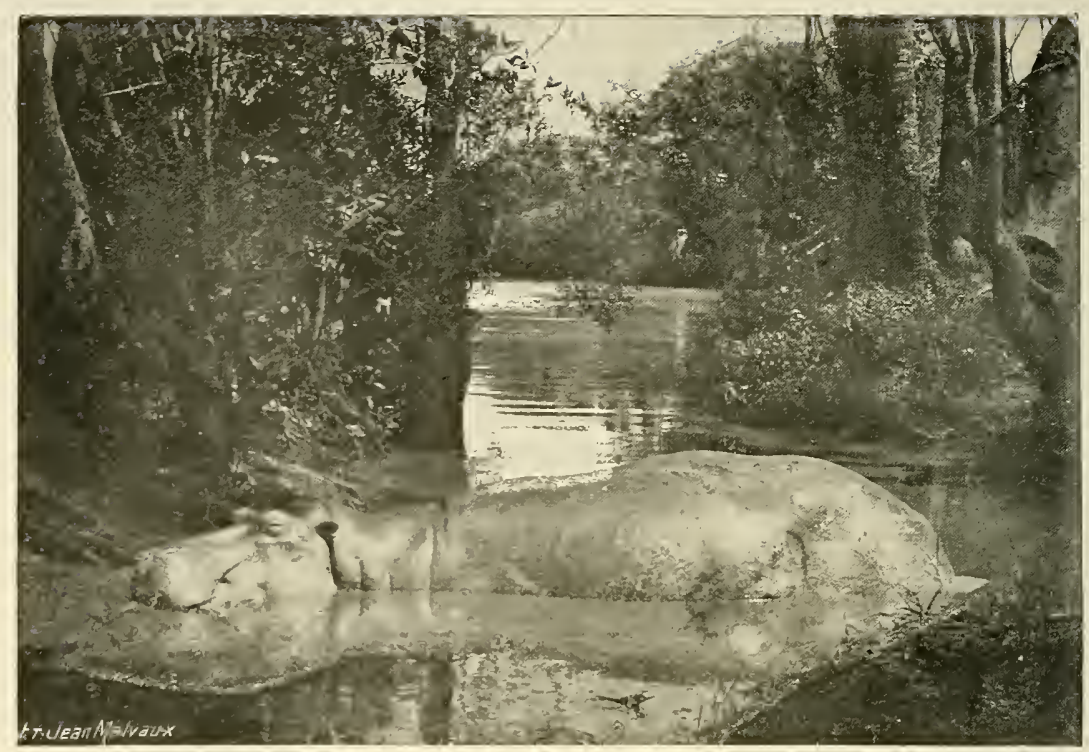

Un hilploo faisant la sieste

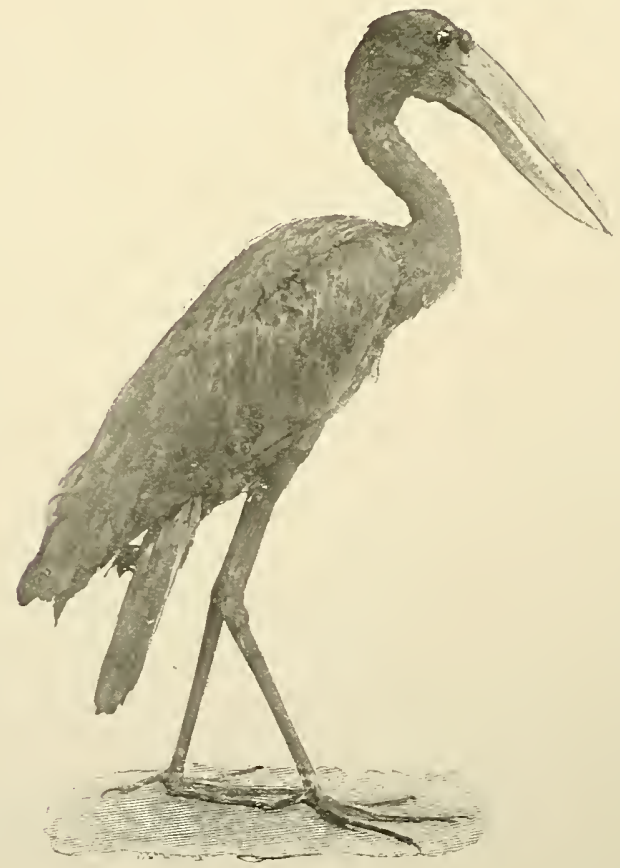

Anastaurus appelé vuigairement Bec ouvert 
ensuite inspecter les deux postes qui se trouvaient sur l'Ikata, fonder un camp provisoire à Lubué, inspecter le poste de Wisman Falls et fonder dans le Sankuru un poste que j’établis à Ienga.

Afin de me faciliter la besogne, M. le Gouverneur eut soin de mettre sous mes ordres le steamer qui nous emportait.

Je ne vous parlerai pas de mes différentes missions, cela serait un peu monotone, je préfère vous narrer deux des chasses que je fis en cours de route.

A près avoir installé Rachid au village de Bokaka et lui avoir construit un boma magnifique, je me suis rendu au lac Léopold II par le M’Fini. Ensuite, j’ai remonté l'Ikata jusque Tallo. C'est un des voyages les plus intéressants que j'aie faits. Partout, des populations immenses; un pays plat comme la main, d'une richesse incroyable.

A chaque pas, des bandes de canards, d'oies, de pélicans, de sarcelles et d'oiseaux aquatiques de toutes espèces et de toutes grandeurs. J'en ai tiré un qui avait deux mètres quarante d'envergure et c'était un des petits!!!

Il y en avait par milliers. J'étais dans une joie folle. Je n’ai jamais tant tiré. A la fin, je ne tirais plus, il $y$ en avait trop. Je les admirais et les laissais passer. C'était trop facile, puis le plaisir de l'imprévu n'y était plus. 
Cela devait durer peu, car quelques jours plus tard, nous entrions dans le Kassaï et là, les grandes chasses ou si vous lé préférez, les chasses au gros gibier recommençaient et avec elles, les émotions fortes qui nous font vivre, en quelques instants, l'espace de plusieurs années.

Ma première belle partie fut une chasse à l'hippopolame... J'en ai tué 18 pendant le voyage.

C'était par une jolie après-midi, où le soleil, ayant daigné meltre son voile, ne nous envoyait que des rayons indirects, juste assez pour animer le paysage et nous en faire valoir la beauté des décors, que la nature, en artiste inimitable, a accumulés en ces lieux.

Le Kassaï, formant lac, prenait des proportions énormes ; partout des îlots minuscules semblaient avoir été mis là pour reposer l'œil, qui, sans eux, se serait perdu dans l'immensité des eaux. Enfin, dans le lointain, bien loin, bien loin, des forêts préhistoriques couronnaient le sommet des collines placées là comme à souhait, pour donner plus de relief à ce divin tableau. Ajoutez à cela quatre ou cinq troupeaux d'hippopotames, prenant leur bain au soleil, avec la quiétude du juste et du fort, car, depuis toujours, ne sont-ils pas les maîtres, je dirai les rois de ces eaux que jamais personne ne leur a disputées et dont les blancs seuls, toujours insatiables, ont pu rèver la conquète? 
Ayant besoin de viande pour mes hommes, je donnai l'ordre au steamer de stopper et je partis aussitòt en canot.

Bientòt, nous sommes en face d'un des troupeaux; vingt mètres nous en séparent; le plus proche de nous est un vieux grand-père qui a dù assister au déluge; sa tète énorme émerge de l'eau. Il me regarde approcher de son œil tout à la fois doux et bète; d'une balle au front, je l'envoie se baigner dans le paradis des hippos.

Au même instant, effrayé du bruit produit par la détonation de mon arme, un jeune hippo, encore à la mamelle, bondit hors de l'eau. Quoique connaissant le danger, la tentation est trop forte. Rapide comme la pensée, je presse la détente et l'innocent, transpercé d'une balle de mon express, retombe inerte à côté de sa mère. Mais, rendue furieuse par la perte de son petit, la mère s'élance vers le canot et, du choc, je suis renversé a vec tous mes pagayeurs, en compagnie desquels je roule pêle-mêle au fond du canot.

Heureusement je ne perds pas mon sang-froid; mon express étant déchargé de ses deux coups, je saisis mon Mauser et veux mettre la bête en joue, mais d'une seconde attaque plus impérieuse encore que la première, la mère me fait de nouveau rouler au fond du canot.

Le moment est critique, car, à chaque instant, l'embarcation peut chavirer et alors nous serions tous infailliblement perdus. Je parviens enfin à reprendre plus ou 
moins mon équilibre et juste au moment oǹ le monstre se précipite sur nous pour la troisième fois, je l'arrête net dans son élan : d'une balle, je mets fin à ses peines..... et à notre frousse, qui n'était pas banale.

Une autre histoire et paș beaucoup moins tragique et comique, je vous assure : Quclques jours après la chasse que je viens de décrire, j’avais tué un buffle très facilement. A huit ou dix jours de là, les noirs nous crient tout à coup : N'Gombés! N'Gombés. Comme le premier nous avait paru succulent et avait fait une heureuse diversion aux meuns du bord, nous eûmes vite fait, le capilaine du steamer et moi, d'aborder et de sauter à terre; nous voilà dans la brousse.

Devant nous, dans une espèce d'immense prairie, un troupeau d'environ cinquante bêtes paissent le plus tranquillement du monde, ne se doutant guère de nos desseins criminels.

Quant à nous, nous sommes également bien tranquilles, car il est un fait connu de tous les chasseurs et que j’avais expérimenté moi-même en plusieurs occasions, e'est que le buffle seul attaque toujours, tandis que le buffle en troupeau se sauve à la première alerte.

Tout en rampant, nous nous approchous donc à cuviron 75 mètres, puis au commandement de trois, nos deux coups partent et deux bêtes roulent par terre. Mais ce à quoi nous ne nous attendions pas, c'est que 
le troupeau affolé prend notre direction et arrive sur nous comme une trombe. Résister n'est pas possible, fuir ne l'est guère. Il nous reste une planche de salut : grimper sur un arbre! Heureusement, il s'en trouve à proximité ! En moins de temps qu’il ne faut pour le dire, après aroir jeté notre fusil en bandoulière, nous empoignons chacun notre arbre et bien que personnellement je n’aie jamais été très fort pour ce geure de sport, en deux secondes nous sommes dans les branches! Comment ai-je fait? je n'en sais rien. La seule chose que je sais, c'est que pour rien au monde, je ne voudrais recommencer.

Décidément, il n’y a que le danger imminent pour nous donner de la souplesse et de l'agilité!......

Notre royage s'accomplit sans antres incidents remarquables.

En arrivant à Lusambo, comme le commissaire du district, M. Gillain, n'avait pas encore fini entièrement son terme, il fut convenu entre nous qu'en attendant son départ, j’irais inspecter les différents postes du district.

J'étais à Lusambo depuis un peu plus d'un mois, lorsque, le 10 février 1895, nous apprìmes par un courrier rapide venu de Luluabourg que Lapière, qui se trouvait au poste de Mukabua, allait être attaqué par toutes les forces du grand chef Bachilange Kalamba et qu'à cette fiu celui-ci s’était allié aux Kiokos. 
Dès le 11 au matin, j'étais en route et le 18 j'arrivais à Luluabourg.

J'appris alors que l'on avait reçu des nouvelles de Lapière ; tout était rentré dans le calme.

J'avoue que je n'étais pas très satisfait.

Je passai un jour à Luluabourg, puis je me dirigeai sur Mukabua, afin de me rendre compte par moi-même de ce qui s’y passait.

Mon impression première ne fut pas du tout favorable à Lapière, qui devint cependant par la suite un de mes bons officiers et un de mes meilleurs camarades.

Son poste était admirablement situé sur une petite colline découverte pouvant donner des feux dans toutes les directions; seulement il s'élait construit un boma tel que pour le garder décemment, il aurait fallu avoir deux cents hommes à sa disposition et il n'en avait que quarante.

Enfin, ayant repris une situation difficile, je l'avoue, au lieu de l'améliorer, il l'avait plutòt empirée.

Toutes les populations des environs avaient fui ; il se défiait de tout le monde, et tout le monde se défiait de lui.

Etait-ce sa faute au moins? Pas du tout; à peine débarqué, on l'avait bombardé chef de poste. Il ne connaissait rien, ni les mœurs, ni la langue, ni l'historique du pays, mais, tant pis; il n'avait qu'à se débrouiller !

Et l'on s'étonne alors qu'il y ait eu parfois des maladresses commises ! 
Je restai plus de trois semaines à Mukabua, pendant lescquelles je m'employai à raccommoder Lapière avec le plus de voisins possible; comme j'avais pu conslater qu’il ne demandait qu’à bien faire, nous nous quittàmes bons amis.

Je retournai à Luluabourg, dont le chef de zone, le capitaine Pelzer, était précisément en expédition; je m'établis alors pour quelque temps dans la station, afin de pouvoir étudier sur place les besoins et les ressources de la contrée, que je ne connaissais que peu à ce moment.

J'étais depuis cing semaines à Luluabourg et je m’apprètais à retourner à Lusambo, car Gillain, ayant fini son terme, devait reprendre le baleau pour l'Europe, quand, le 28 avril au soir, je reçus un courrier rapide de Lapière, me disant que Kalamba uni aux Kiokos était à un jour de marche de son poste.

Le lendemain matin, je partais avec une centaine de soldats ainsi que le chef Zapo-Zape et trois cents de ses hommes armés de fusils à piston.

J'arrivai le 2 mai à Mfukabua, vers 10 heures du matin.

Celte fois, la nouvelle était réelle : Kalamba et les Kiokos s'apprètaient à nous attaquer.

Aussitôt arrivé, je mis Lapière au courant de mes projets, qui étaient de donner quelques heures de repos à mes hommes, puis de faire une marche de nuit, afin de tomber au petit jour sur nos ennemis eadormis. 
Après avoir recommandé à Lapière le secret le plus absolu, je le chargeai, puisqu'il élait frais et dispos, de distribuer de la poudre et des capsules aux Zapo-Zapes, de confectionner nos charges, enfin de prendre toutes les mesures pour notre départ pendant la nuit.

A minuit il vint me réveiller. Je fis aussitòt prévenir mes deux sergents noirs ainsi que Zapo-Zape de venir me parler.

Dès qu'ils sont arrivés, je les mets en quelques mots au conrant de mes intentions et leur donne l'ordre d'aller réveiller leurs hommes, mais en faisant le moins de bruit possible.

Une demi-heure après, tout le monde était prêt et une longue caravane d'ombres prenait le chemin du camp de Kalamba. Zapo-Zape et ses gens marchaient en avant-garde. V'enaient ensuite Lapière avec un peloton de Wabudjas, puis moi arec les Batétélas, ensuite le sergent Djuma avec un peloton de Haoussas, enfin les bagages, escortés par l'interprète Humba avec une trentaille de ses hommes, armés pour la circonstance de fusils Albini.

Une marche de guerre, entreprise dans ces conditions, a quelque chose d'impressionnant, qui fait que l'on se recueille malgré soi.

C'est tout à la fois grandiose, mystérieux et lugubre. Il n'y avait pas le moindre clair de lune et la nuit élait très obscure. Toutefois, comme le terrain était très plat, 


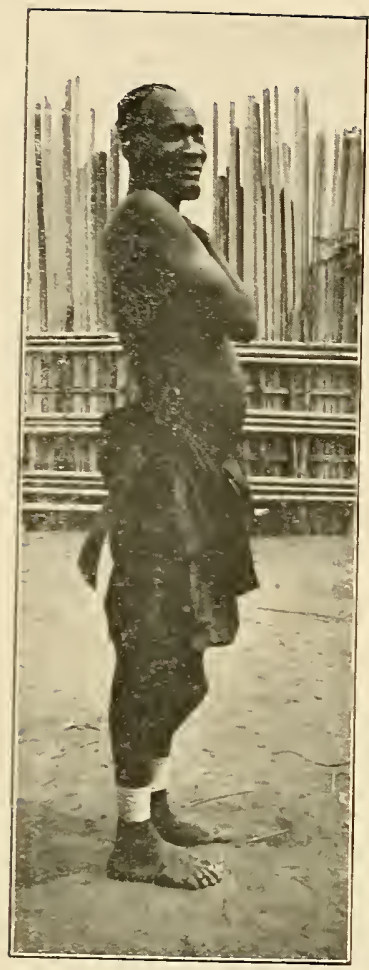

Indigène du Kassaï

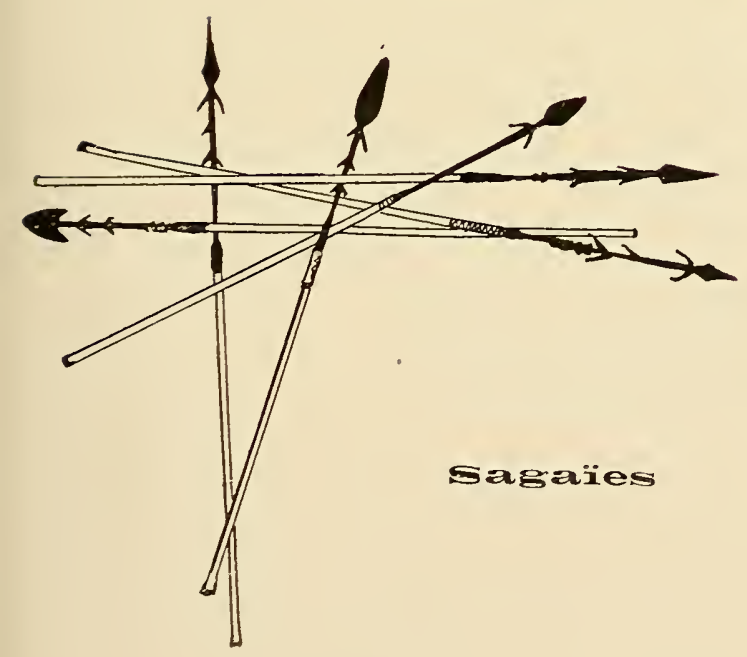

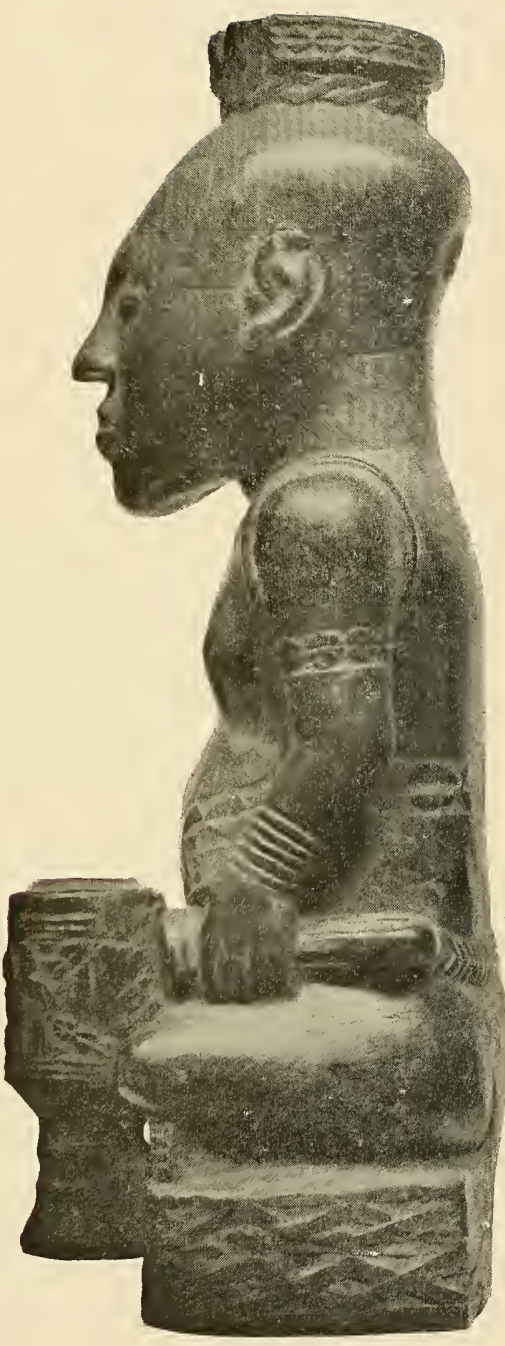

FETICHE 


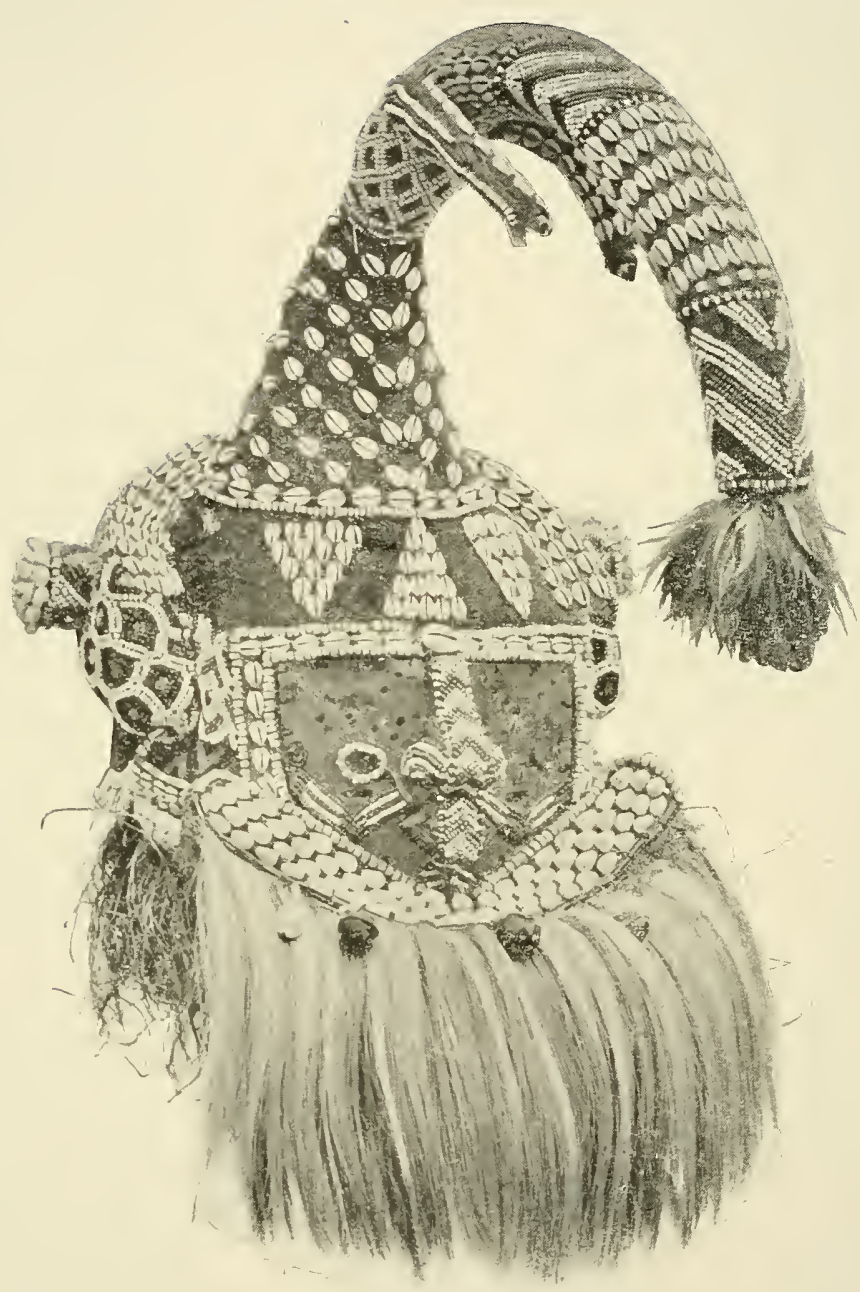

Tn masque de fóticheur 


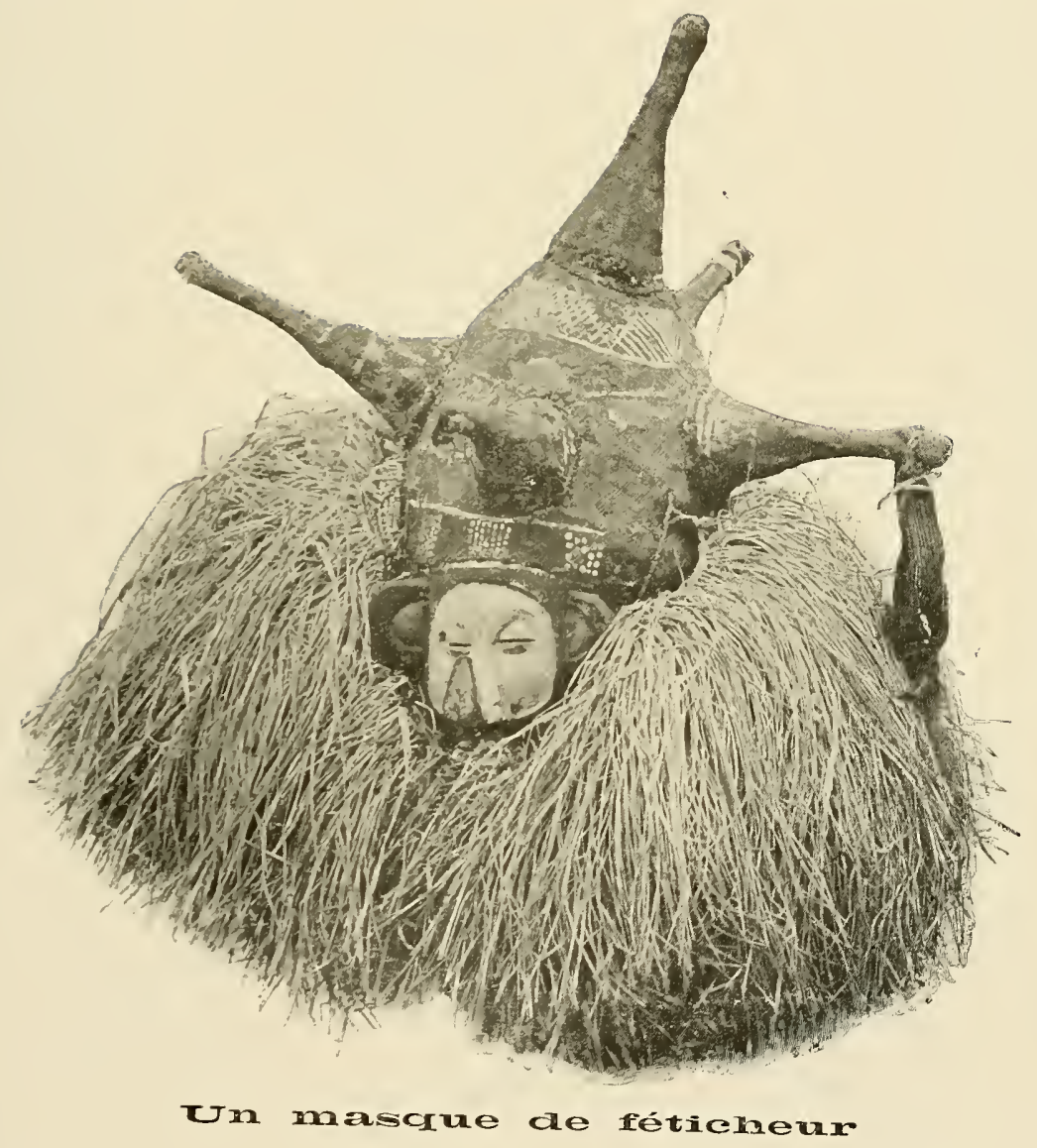



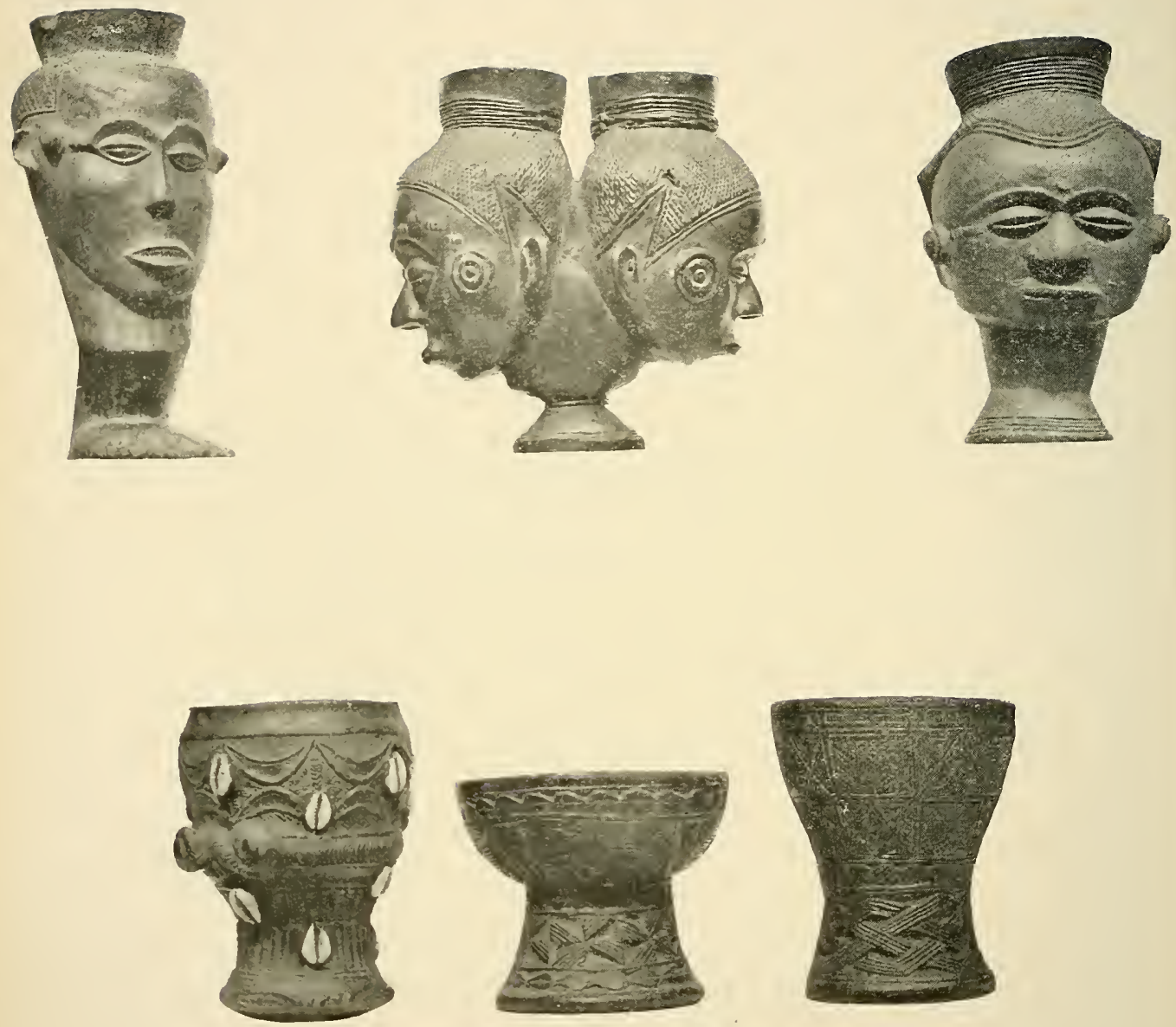

Gobelets en bois sculpté de la région du Kassaï et du Sankuru 
nous franchissons la première partie de la route assez facilement. Malheureusement, vers 3 heures du matin, nous rencontrons une vallée boisée que nous devons traverser et qui nous fait perdre un temps précieux.

Enfin, vers 6 heures, nous essuyons le feu des sentinelles ennemies. Il n'y a donc plus de surprise; le retard du petit bois nous a fait perdre une bonne partie du bénéfice de notre marche de nuit.

Nous aurons toutefois toute la journée à notre disposition pour le combat et la poursuite.

En arrivant sur le sommet du plateau, nous apercevons̄ l'immense camp occupé par Kalamba et ses gens. Une seconde rallée nous en sépare, mais celle-ci est complètement dénudée et la pente du côté de l'ennemi est assez raide à gravir. Sa position est donc bien choisic et le combat s'annonce comme devant ètre sérieux.

Je lance aussitôl les Zapo-'Zapes en avant afin d'occuper l'ennemi et je déploie mes hommes en tirailleurs. Je suis au centre, Lapière à ma droite et Djuma à ma gauche.

Nous arançons d'un pas calme, car j’ai défendu de se presser; sans cela tantôt, lorsque les poitrines seront haletantes, mes hommes ne sauront plus viser.

Ils avancent comme à la parade, rectifiant même leur alignement sous les balles qui pleuvent autour de nous! Braves gens! comme je sens que je les aime! 
Aussitôt que les gens de Zapo-Zape se trouvent à portée, ils sont reçus par des salves, il n'y a donc plus de donte que les Kiokos se soient joints à Kalamba, car je les connais : c'est bien là leur manière de combattre.

Aussitòt que nous sommes parvenus à prendre pied sur le bord du plateau, les Zapo-Zapes se retirent, ainsi qu'il avait été convenu, sur nos deux flanes, afin de dégager notre champ de tir, car, jusque-là, nous n'avons pas encore brùlé une seule cartouche. A notre tour, nous envoyons salve sur' salve et bientòt l'ennemi est obligé de se retirer devant l'eflicacité de notre feu.

Aussitòt que nous l'avons refoulé dans la forêt, je donne l'ordre à Lapière et à Djuma de rassembler leurs hommes afin de parer à un retour oflensif et je lance mes Batétélas et les Zapo-Zapes à la poursuite.

Pendant le combat, une colonne ennemie essaye de s'emparer de nos bagages, mais les gens de Humba, qui sont cachés derrière les caisses, la reçoivent si bien qu'elle ne taide pas à prendre la fuite.

Le combat m'a cependant coùté assez cher ; j'ai deux de mes meilleurs soldats tués et une vingtaine de blessés dont six grièvement.

Dans l'après-midi, les hommes envoyés à la poursuite rentrent avec assez bien de poules et de chèvres, que l'ennemi nous a abandonnées en route; pas de prisonniers. 
Vers la soirée, nos sentinelles remetlent aux mains d'un petit poste, qui me les amène, deux femmes Balubas, qui étaient venues se rendre volontairement. Elles me dirent qu'elles avaient appartenu à un chef Zapo-Zape, qui les avait vendues à un chef de Kalamba et qu'elles avaient profité du désarroi de la défaite pour venir se rendre aux blancs, qu'elles connaissent pour les avoir fréquentés à Luluabourg, étant bien certaines qu'il ne leur sera fait aucun mal.

Elles me donnent aussi quelques renseignements intéressants. C'est ainsi que je sais par elles que Kalamba a donné quatre énormes pointes d'ivoire aux Kiokos pour les intéresser à sa cause, mais que ceux-ci ont perdu dans la bataille sept de leurs chefs et une foule de guerriers, qu'ils ont reproché amèrement à Kalamba de les avoir entrainés dans une mauvaise affaire et ont encore exigé cinquante femmes. Elles m'apprennent enfin que, tous, ils se sont réfugiés chez les Bena-Kalembas, à deux jours du Kassaï. Je les y suivrai! Mais avant je veux attendre les renforts que je sais en route, pour me rejoindre, sous les ordres de Dufour, ainsi que mon ravitaillement en vivres et en munitions.

Dès le lendemain matin,je retourne à Mukabua et deux jours après la caravane de ravitaillement m'y rejoint.

Voulant ménager les plantations du poste, le 15 au matin nous quittons Mukabua afin de nous installer 
dans l'ancien village de Bakua-Chilamba, qui est maintenant abandonné et où il se trouve des plantations énormes.

Le 19, Dufour nous arrive avec quarante bons soldats et, le 21, mes hommes ayant eu tout le temps de s'approvisionner largement de vivres de toutes espèces, nous levons le camp et : En avant!

Bien que ce soit un grand détour, je désire m'assurer si le chef Kassongo Moina N'Zila, qui m'a fait de magnifiques promesses, mais à qui je ne me fie pas beaucoup, ne m'a pas trompé; je me dirige douc sur son village. Heureusement nos hommes sont chargés de vivres lors de leur départ, car, pendant huit jours, nous voyageons dans un véritable désert.

Le $1^{\text {er }}$ juin, vers midi, nous arrivons devant le village de Kassongo Moina N’Zila. Le village vient d'ètre incendié. Je sais donc à quoi m'en tenir sur le compte du chef.

S’ils ont incendié le village, ils n'ont heureusement pas touché aux plantations; celles-ci sont inmenses et de toutes espèces et nous arrivons juste au moment de la récolte. Il y a de tout : du manioc, du maïs, du millet, du sorgho, des arachides, des bananes, des patates douces et mème des ignames et des ananas.

Pour nous, e'est la terre promise des Hébreux.

Mes hommes sont fous de joie et je ne le suis guère moins qu'eux. Enfin, vers le soir, on me ramène un 
troupeau de chèrres que les indigènes ont cachées dans les bois; en mème temps, un courrier de Palate, venant de Luluabourg, nous apporte de l'eau de vie, du tabac et des citrons. Nous n'avons jamais été aussi riches!

Voulant permettre à nos hommes de se refaire un peu de leurs privations el leur donner le temps de se préparer de nonvelles provisions pour notre marche en avant, je décide de resiler au village juscu'au 4 au matin.

Pendant trois jours, nous traversons une contrée dont les sites les plus enchanteurs alternent avec les plantations les plus riches. Aussi, si les blancs ne cessent d'admirer les paysages, l'admiration de nos hommes n'est-elle pas moindre à la vue des riches moissons.

Le 7 , vers midi, nolls arrivons à la Luébo.

Après quelques recherches, un de mes hommes trouve un arbre tombé en travers de la rivière, j'en fais abattre un second à còté; bientòt un pont est fait et nous pouvons passer.

Dans l'après-midi, nos lıommes s'emparèrent de quelques femmes, dont l'une est précisément la femme principale du chef de la contrée.

Voulant à tout prix empêcher des tueries inutiles, je résolus de mettre à profit la bonne aubaine qui avait fait tomber cette femme entre mes mains.

Ayant remarqué qu'elle était très inlelligente et sachant que chez les Bachilanges, le pouvoir de la 
femme principale du chef est toujours au moins égal à celui du mari, j'entrepris immédiatement de la raisonner et lui fis tout l'historique de la campagne que j'avais été amené à entreprendre par l'entêtement du vieux Kalamba et les déprédations des Kiokos. Je finis enfin en lui déclarant que mon plus vif désir était de vivre en paix avec les autres populations et que si parfois j’étais forcé de faire la guerre, c'était à mon corps défendant, que jamais je n'attaquais le premier.

Finalement, je lui fis comprendre que si son mari nous faisait la guerre, c'était certainement pour lui la défaite et la ruine; qu’il valait donc bien mieux pour lui et pour elle qu'il vint faire sa soumission à l'Etat, puisqu'alors non seulement je la rendrais à la liberté, mais qu'encore son mari et son peuple seraient, à partir de ce jour, sous notre protection.

Elle parut parfaitement comprendre mes arguments et se rendit à mes bonnes raisons ; aussi m’affirma-t-elle que la nuit venue, elle parlerait à son peuple et que la paix ne tarderait guère à ètre conclue.

Dès le soir, la consigne fut donnée dans le camp d'observer le plus profond silence, car dans ce pays il est de règle en temps de guerre, lorsqu'on a une communication à se faire pour entamer des pourparlers de paix, d'attirer l'attention de l'adversaire par un roulement de tambour, puis de lui faire ses propositions, auxquelles il répond toujours. 
Nous étions done certains oll que les indigènes nous parleraient, ou bien qu'ils étaient aux aguets pour enteudre nos propositions.

Vers 8 heures, la femme m'ayant dit que le moment était propiee, je fis exécuter un long roulement de tambour.

La ehefesse monta de suite sur une haute termitière qui se trouvait dans le camp et fit entendre un retentissant : Moyo ! à la roude, anquel les indigènes, cachés dans les herbes, répontirent en ehœur.

Pendant plus d'une heure, elle ne cessa de parler en gestieulant, eomme si ses auditeurs araient pul la roir, parfois aussi, elle ponctuait sa narmation de cris perçants et suraigus.

Cette grande femme noire, presque nue, gestieulant et parlant avee foree et autorité à des ètres que nolls ne voyions pas, mais que nous savions ètre présents, toute cette scène enfin qui se passait dans le silenee absolu de la nuit el était seulement éelairée des lueurs indécises d'un feu de bois, avait quelque chose d'impressionnant et me fil songer malgré moi aux histoires de sorcières, encore si fort en vogue dans les fermes du pays wallon.

Lorsqu'elle eut fini de parler, les indigènes lıi répondirent et la palabre se termina par un Moyo! final de part et d'autre.

Comme mon interprète me tenait au courant de tout 
ce qui se disait, je savais déjà, lorsçu'elle revint près de moi, que la paix était conclue.

En descendant de son tertre, elle me parut grandie et, franchement, lorsqu'elle revint vers moi, la palabre terminée, elle avait grand air ; sans la moindre hésitation, elle vint s'asseoir à mes côtés et me dit : " La paix est faite entre toi et mon peuple et désormais nous vivrons en frères. Mon mari est trop vieux pour venir dans ton camp; ce sera son frère qui viendra demain sceller la paix entre nous. ")

En effet, le lendemain, vers 11 heures, mon interprète vient me prévenir que Tambo, le frère du chef, se trouve sur la route et me fait demander l'autorisation de pouvoir se présenter. J'envoie aussitôt à Monsieur l'. Imbassadeur une carolte de manioc en signe de paix ct, voulant respecter les lois du pays jusqu'au bout, je fais donner l'ordre à mes sentinelles de mettre leur f:ısil la crosse en l'air et la baïonnette en terre, afin de bien !nontrer que la guerre est enterrée entre nous.

Tambo me remit quelques chèvres de la part de son frère, je lui remis également un présent pour lui et un pour son frère, ainsi cu'un magnifique pagne pour la chefesse.

Nous nous (quittàmes alors en hons amis et Tambo me promit de venir me prendre le lendemain afin de me servir de guide pendant tout le temps que je resterais sur le territoire de son frère. 


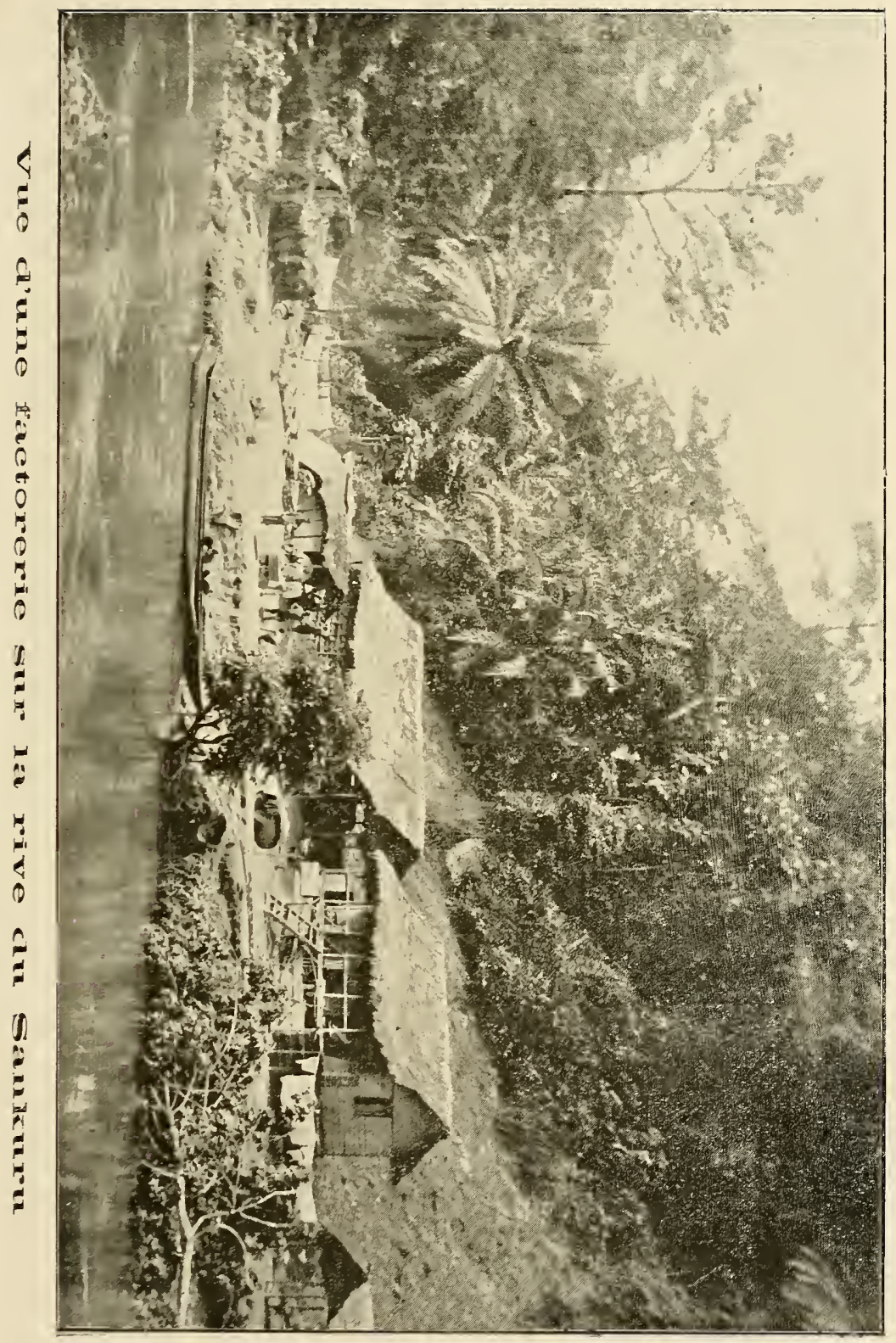



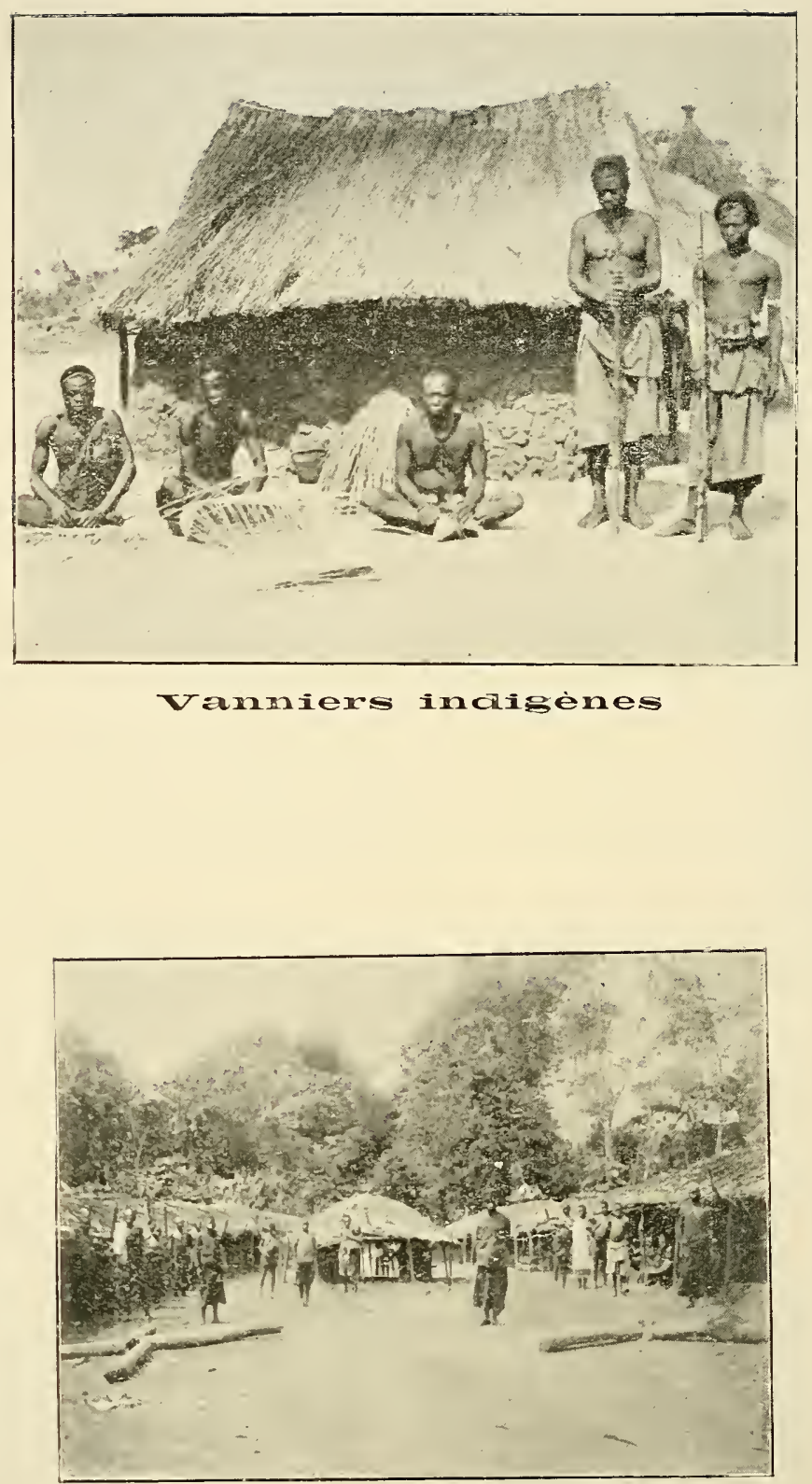

Cases recouvertes de papyrus 
Il tint parole et le lendemain matin il vint se mettre à ma disposition. Pendant les quatre jours que nous sommes restés sur le territoire de son frère, nous avons été reçus partout avec la plus grande cordialité.

Le quatrième jour, vers midi, nous arrivons au village des Béna-Kalengas et Tambo me prévient qu'à partir de ce moment nous ne sommes plus sur le territoire de son frère et que, par conséquent, il ne peut plus répondre des évènements.

Le village est abandonné et nous nous y installons. Dans l'après-midi, nous entendons une assez vive fusillade du côté du ruisseau qui approvisionne d'eau le village. J'envoie vite aux nouvelles et bientòt on vient me dire qu'un Haoussa et quatre femmes viennent d'ètre tués par les Bachilanges. Mes hommes sont furieux; j'ai toutes les peines du monde à les empècher de se porter en avant.

Vers 5 heures du soir, le camp est attaqué de tous les côtés à la fois; nous repoussons cependant assez facilement nos agresseurs.

La nuit se passe alors relativement de façon assez tranquille; on nous tire encore quelques coups de fusil, mais sans nous occasionner de nouvelles pertes. Au matin, désirant me renseigner pour savoir exactement à qui j'ai affaire et ne voulant pas exposer la vie d'un de mes officiers dans une reconnaissance sous 
bois, je donne quarante bons soldats à Djuma et je le charge d'éclairer la route.

Pendant ce temps, je fais cacher mes hommes dais le village, afin de domner une leçon à ceux qui essaieraient d'attaquer nos bagages.

Notre ruse allait réussir, lorsque l'un de mes hommes fut pris d'un éternuement intempestif qui suffit pour donner l'éveil à l'ennemi et faire rater ainsi notre combinaison.

Quant à la reconnaissance que j’avais envoyée, elle était à peine sous bois qu'elle était attaquée avec rage. Elle se défendit de son mieux, mais comme l'ennemi avait fait tomber de gros arbres en travers de la route et qu'il s'en servait comme abri, elle fut obligée de battre en retraite ayant assez bien d'hommes blessés grièvement.

La situation devenait critique et un mouvement énergique pouvait seul nous sauver.

Ma patrouille étant rentrée, je rassemble mes chefs de pelotons et leur déclare qu'il faut que nous passions, coùte que coùte, et à l'instant.

La forèt, nous dit-on, est bondée d'indigènes et de Kíokos, tant pis! Il faut les en déloger et nous les délogerons!

Mes ordres sont rapidement donnés et non moins rapidement exécutés.

Puisque la route est barrée, que l'on me fasse un sentier à còté du premier et en avant! 
Les Zapo-Zapes sont, pour commencer, en avant, mais bientòt ils ont brùlé toutes leurs cartouches et ils sont remplacés par Lapière et ses hommes.

Mon seul cri est " En avant! En avant ! " car j'ai hâte d'ètre hors de cette maudite forèt.

A un moment donné, nous sommes attaqués de toutes parts. Je fais alors numéroter nos hommes et je donne l'ordre aux numéros pairs de tirer vers la droite et aux numéros impairs de faire feu vers la gauche.

Le feu crépite partout, la pétarade est assourdissante ; à chaque instant, des balles viennent couper des branches au-dessus de nos têtes, ou s'enfoncent dans les arbres à quelques centimètres de nous.

A un moment donné, la queue de la colonne étant attaquée, les femmes, prises d'une terreur folle, se jettent au milieu des soldats et causent un tel désordre que c'est miracle que nous en soyons sortis.

Enfin, au moment où nous traversons une petite clairière, mon sergent Battétéla, un nommé Kondolo, me repousse brusquement et se jette devant moi; au mème instant il reçoit une balle dans l'épaule d'un Bachilange que je n’avais pas vu et qui, à genoux, me visait à son aise.

C'est ce même sergent qui venait de me sauver la vie aux dépens de la sienne, qui, quelques jours plus tard, avec un autre sergent de même race, nommé Kimpoké, 
devait se mettre à la tête des rèvoltés et eauser la mort de tant d'offieiers blancs.

Dans ce même combat, Lapière fut également sauvé par son elairon, qui envoya une balle dans la tête à un autre indigène, qui visait notre ami à quelques mètres de dislanee également.

Vers 5 heures de l'après-midi, nous sortons enfin de la forèt. Cette fois, nous sommes sauvés!

Eu faee de nous, se trouve un immense village, e'est eelui de Kalamba.

Il n'est pas défendu, les Kiokos et les indigènes en ont assez eelle fois. Nous n'avons done qu'à nous installer. Mes pauvres hommes l'ont bien gagné, il y en a qui se battent depuis 5 heures du matin!

Quant à moi, loin de pouvoir me reposer, je dus même passer une bonne partie de la nuit à soigner el à opérer de nombreux blessés.

Le lendemain, après une forte marehe, nous arrivons à un village abandonné. Voulant me rendre compte du nombre de eartouehes qui avaient été brûlées dans le eombat de la forêt, je passai une inspeetion des munitions.

Je eonstatai alors que mes hommes avaient brûlé neuf mille cartouehes ! J'étais réellement eonsterné, ear lorsque j'eus rendu des eartouches à tous eeux à qui il en manquait, il ne m'en restait plus une seule de réserve. 
Ne roulant pas, dans ces conditions, risquer de nouveaux combats dans la forèt et ayant marqué notre victoire par notre marche en avant, je décidai de regagner Mukabua, mais par une route plus courte que Tambo uous avait indiquée et gràce à laquelle, le 18, nous étions à la Luebo et le 20 à Mukabua. Nous Y restàmes jusqu'au 22.

Le 21, au soir, nous donnàmes une fète et fìmes de larges distributions à nos soldats; le lendemain, après avoir largement pourvu aux besoins du poste, où je laissai 80 soldats el 13,000 cartouches, je repris avec Dufour le chemin de Luluabourg.

Le 24, nous logeons chez le père Cambier, qui nous reçoit d'une façon chamante.

Le 25, nous arrivons à Luluabourg, et les Pères de la mission qui sont venus nous rendre nolre visite nous font le plaisir de diner avec nous.

Le lendemain, nous recerons un courrier du capitaine Pelzer, qui nous annonce son arrivée pour le 27. Nous passons deux jours ensemble; toute la slation est en liesse, fêtant l'heureux retour de deux expéditions menées à bonne fin.

Nous ne nous doutions guère en ce moment que nous festoyions sur un volean et que quelques jours à peine nous séparaient de la plus sombre des tragédies congolaises, que ces soldats, enfin, qui nous fètaient avec tant d'entrain, étaient les mêmes qui allaient 
trahir leurs officiers et les massacrer dans quelques jours!

Le 29 juin, nous partons de Luluabourg.

Le 5 juillet, nous nous trouvions chez le chef Mocadi, lorsque le chef Matadi vint se plaindre que les Bakuas M'Putt lui enlevaient de ses gens.

Voulant régler la chose de suite, je décidai que Dufour se rendrait le lendemain 6 chez le chef, afin d'y faire une enquête sur place.

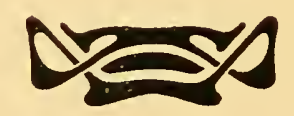




\section{CHAPITRE XIV.}

La révolte des soldats Batétélas. - Un billet de Lassaux. Triste retour à Lusambo.-Les causes principales de la révolte. - A la poursuite des révoltés. - Je perds un temps précieux à Luluabourg. - Le récit des événements par Cassart et Lapière. - Désastres de Kayéyé et de N'Gandu.-Une page douloureuse à écrlre. - J'opère Lapière malgré lui. - Combats du 18 octobre et du 6 novembre.

Dufour était parti avec soixante soldats depuis le matin, lorsque, ver's 2 heures de l'après-midi, je reçus un courrier de Luluabourg.

C'étaient quatre lignes écrites au crayon, au moyen desquelles Lassaux me prévenait que les soldats de la station s'étaient révoltés, qu'ils avaient tué Pelzer et Cassart et que lui, enfin, était parvenu à se sauver chez les Zapo-Zapes !

Après un premier moment de stupeur profonde, j'envoyai un courrier rapide, afin de rappeler Dufour, qui fut heureusement rejoint et rentra au campement à 2 heures du matin.

Je fis immédiatement désarmer et mettre dans l'impossibilité de nuire les Batétélas qui se trouvaient dans le détachement et, dès le lendemain matin, j'envoyai Dufour, avec 40 Haoussas, à Luluabourg, afin qu'il pùt porter aide aux blancs qui seraient encore en vic. 
Quant à moi, je rentrai le plus rapidement possible à Lusambo, afin de prendre toutes les mesures que comportaient les circonstances.

Ma présence dans cette dernière station était d'autant plus impérieusement nécessaire, que dans l'après-midi mème, j'avais reçu un billet de Gillain me disant qu'il partait pour le Lubéfu. Sa lettre m'arrivait deux heures après le billet de Lassaux.

En ce moment, je me trouvais presque seul, et sans cartouche,ayant laissé la plus grande partie des miennes à Lapière et donné celles qui me restaient à Dufour. Ma situation était terrible, car, dans le cas où les révoltés auraient voulu marcher sur Lusambo,je n'avais absolument rien à leur opposer.

Mais, avant de parler de cette triste page de notre histoire du Congo, il est, je crois, indispensable de parler des causes qui ont amené cette révolte.

Elles sont multiples, mais il y en a trois capitales :

La première et la seule dont je m'occuperai fut la mort de Gongo Lutété;

La seconde fut la faute que l'on commit de laisser tous les anciens hommes de ses bandes réunis et formant des compaguies parfaitement homogènes ;

La troisième fut que la solde des soldats indigènes était très mal réglée à cette époque.

Mais la grande faute fut la mort de Gongo. 
Je ne veux incriminer personne, il a été régulièrement jugé et condamné et, certes, les officiers qui ont rendu ce jugement étaient tous de bonne foi et ont élé trompés par de faux témoignages. Je les connais tous les trois et, en agissant comme ils l'ont fait, ils ont certainement cru rendre service à l'Etat et faire un acte de justice.

Nalheureusement, ils ont été circonvenus et nul doute que c'est cette erreur qui a couvert le Congo de ruines et de cadarres pendant plus de dix ans.

Gongo Lutété, que j’ai connu peut-ètre mieux que personne, car après avoir battu ses bandes je m'étais fait de lui un ami et avais vécu plusieurs mois presque constamment à ses còtés, Gongo, dis-je, était un homme tout à fait remarquable : doné d'une sagacité extraordinaire, il avait pu s'élever du rang le plus infime à une quasi-royauté, à un ponvoir sans limite sur les bandes les plus sauvages, mais aussi les plus braves du Congo. Dans sa main de fer,elles s'étaient assouplies et n'a vaient plus d'autre volonté que la sienne.

Son énergie égalait son courage, et sa perspicacité était telle que les Arabes étaient encore à leur apogée lorsqu'il s'est aperçu que leur règne était bien près de finir et devait faire place à la domination des blancs.

Pour moi, il n'y a pas l'ombre d'un doute : sa bonne foi a toujours été parfaite ; lorscu'il s'est allié à nous, il l'a probablement fait parce que les circonstances l'y obligeaient, mais il l'a certes fait sans arrière-pensće de 
trahison. Si, dans la suite, sa conduite a été incriminée et ses actes dénaturés, cela n'a pu qu'être l'œuvre d'ennemis intéressés à le perdre ou de sous-ordres, funèbres vautours qui convoitaient ses dépouilles.

Personne ne nie, personne n'a jamais nié sa grande intelligence ; ses plus mortels ennemis, eux-mèmes, ont été obligés de reconnaître son génie sauvage.

Ceci admis, la conclusion s'impose d'elle-même : pourquoi voulez-rous que cet homme, à l'esprit vaste et lucide, eût attendu pour nous trahir que les Arabes fussent vaincus, écrasés et que leur cause fût irrémédiablement perdue; pourquoi aurait-il choisi le moment où nos forces,faibles au début,étaient plus que doublées, où, en un mot, nous étions les maitres de la situation?

S'il avait voulu faillir à ses serments, pourquoi ne m'avait-il pas attaqué au moment où je livrais bataille à Séfu, au Lomami ? Car il est évident que s'il l'avait fait alors, j'aurais été pris entre deux feux et ma position eût été des plus difficiles, pour ne pas dire désespérée!

Mais non, au lieu de cela, il nous aide de toutes ses forces, de tout son pouvoir, ses meilleurs guerriers se sacrifient mème pour notre cause!

J'aurais voulu faire le silence sur cette triste affaire, mais cela m'était d'autant moins possible que c'est un épisode appartenant désormais à l'histoire et que, après douze ans, nous en subissons encore les tristes effets. 
Le Marinel et Dhanis, par leur politique d'apaisement, étaient parvenus à se concilier les chefs indigènes au détriment des Arabes. Le pays conquis, pacifié, nous était attaché, autant à cause de nos bons procédés et notre esprit de suite et de justice qu’à cause dı succès de nos armes, quand, tout à coup, une clameur immense, un cri d'épouvante, de rage, de malédiction et d'horreur, monta de cette terre sanglante et, en quelques jours, se répandit sur tout le territoire.

Ce fut une stupeur pour tous.

"Les blancs, disait-on, n'ayant plus besoin de Gongo Lutété, ont tué leur allié ! leur ami ! leur frère ! !...”

Quelle confiance, après cette mort, voulait-on que les nègres pussent encore avoir en nous?

A leurs yeux à tous, nous n'étions plus que des forbans, des parjures: la fusillade de Luluabourg n'a été que la répercussion ou l'écho lointain du feu de peloton qui a exécuté Gongo Lutété.

Voyons maintenant la suite des événements.

Dufour étant donc parti pour Luluabourg avec 40 Haoussas et tout ce qui me restait de cartouches, je repris en hâte la route de Lusambo, où j'arrivai le 9 juillet.

Aussitôt que j'avais reçu le billet de Lassaux, j'avais envoyé un courrier rapide à Lusambo afin que l'on prévînt le Commissaire du district, ainsi que tous les chefs de postes, des terribles nouvelles que je venais de recevoir. 
Le lendemain soir de mon arrivée, donc le 10, Gillain rentra à son tour à Lusambo.

Nous eûmes aussitôt un long entretien sur les mesures qu'il convenait de prendre.

Nons ne fùmes pas du même avis.

J'aurais voulu marcher sur Kabinda avec les soldats qui nous reslaient, joindre mes forces à celles de ce poste et à celles de Lupongu, appeler à moi le capitaine Augustin, qui se trouvait à N'Gandu avec une centaine de " braves " soldats, et réquisitionner d'urgence deux cents soldats à la zone arabe; ensuite, avec tout mon monde, me porter à la rencontre des révoltés et les anéantir d'un seul coup.

Je crois qu'au point de vue militaire, mon plan était le seul bon. Mais mon chef, qui était non seulement militaire, mais avant tout Commissaire de district responsable, ne fut pas de mon avis. Il m'objecta que l'on n'avait aucune nouvelle des révoltés, donc que l'on ne savait pas s'ils se trouvaient encore à Luluabourg et que, en tout cas, nous devions protéger les missions de Luluabourg et de Kalala-Kafumba. Il ajouta toutefois que si j'apprenais en cours de route leur départ de Luluabourg, il m'autorisait à me rabattre sur Kabinda. Il n'avait peut-être pas tort, mais je crois que j'avais raison, puisque, le 5 août, Bolhen se faisait battre et tuer à Kayéyé, avec une centaine de soldats et que, le 17 du mème mois, Augustin, avec quatre officiers sous ses 
ordres, 280 bons soldats et 3 à 400 auxiliaires, subissait le mème sort.

Or, en partant de Lusambo, j'avais exactement avec moi : 27 Babouilles, 19 Dahoméens et 55 Balubas. Aı total, 101 soldats et une bonne centaiue d'auxiliaires dont 30 armés de fusils Albini.

Mais n'anticipons pas sur les événements.

J'arrivai le 19 au soir à Luluabourg, j’y restai jusqu'au 31 à batailler contre les chefs dles environs, qui avaient profité de nos désastres pour se révolter et menacer la mission.

Ce fut peut-être une faute, car si le 17, lorsque j’appris que les révoltés avaient quitté Luluabourg, je m'étais rabattu à marches forcées sur Kabinda, au lieu de passer mon temps à batailler à Luluabourg, peut-ètre serais-je encore arrivé à temps pour prendre le commandement des deux détachements de Kabinda et de N'Gandu et éviter ainsi de terribles désastres, mais peut-être aussi aurais-je rencontré les révoltés sur ma route et alors je me serais certainement fait massacrer avec tous mes hommes, sans aucun profit pour personne.

Et puis, pensez donc dans quel état d'esprit je me trouvais depuis le $6 !$ !

Le 17, j'apprenais tout à la fois que Cassart n'était pas tué, ainsi que je l'avais cru, et que les révoltés avaient quitté Luluabourg. 
Mais, en même temps, il me revenait aussi que tout le pays était en révolte et que les missions que j’avais précisément ordre de secourir étaient attaquées de toutes parts.

Le 18, Lapière me faisait parvenir un billet de Cassart, afin de me meltre au courant des événements et, dès mon arrivée à Luluabourg, je recevais un autre billet du Père Cambier. Je crois ne pouvoir mieux faire que de les transcrire, afin de bien montrer quelle était la situation :

Mon cher Lapière,

On est aux prises; Dufour et moi étions partis chez Sagasch, cela a été chaud, Dufour a pris le village d'assaut. Pendant ce temps, une autre colonne de Grongo mettait le feu chez Umba, mais on est à leur poursuite. Cela va bien, mais cela n'est pas fini. In Zapo-Zape et un homme d'Umba sont blessés. - Que Zapo-Zape envoie 25 hommes ici de suite. De suite, de suite une lettre chez le Commandant Michaux; dites-hui que nous sommes aux prises et qu'il nous faut des cartouches aujourd'hui, aujourd'hui. Dites qu'il ne s'efrare pas, je me tirerai d'affaire, mais des cartouches. Quant à vous, soyez sur vos gardes. Si Décola vient, ayez vos hommes armés à côté de vous. Prenez ce qu'il apporte et remballez-le. Non, n'envoyez pas de ZapoZapes, tenez-les au contraire chez vous à la station 25 . Je ne pourrai revenir, mais demain natin je serai là. Gongo a beaucoup de tués.

Les cartouches aujourd'hui, n'est-ce pas? Employez comme courriers les homnes de Simon et de Matheyus. Les hommes venus avec le courrier de hier recevront une pièce d'américani.

C'est marché aujourd'hui, achetez du manioc et du madimba; s`il y a du nouveau je vous écrirai.

Bien à vous.

(S.) CASSART.

P.S. Envoyez-moi également de la poudre. 
Mission, 7 h. 45.

Mon cher Monsieur Michaux,

Un homme de Umba vient d'arriver pour nous anuoncer que les chefs Kipinda, Luadina, Kizassu, Mukenge Nkula, Mukidiba et Tchikango, répondant à l'appel de Gongo, doivent arriver cette nuit et attaquer la mission du côté de Tchitendé pendant que Gongo nous attaquerait du cỏté de Sagache.

Les chefs Kiemvu, Kanomaï, C'hamatenga, Tchikanana ont refusé de répondre à l'appel de Gongo. Ne serait-il pas bon d'envoyer dès maintenant les hommes que vous comptez en voyer demain ?... à votre entière disposition naturellement.

Umba sera demain à Mlukabua.

Son envoyé dit que, d'après les renseignements des indigènes, des caisses se trouveraient encore au poste.

Respectueuses amitiés.

(S.) P. GaMmer.

P. S. Nons veillerons toute la nuit. Amiliés à tous.

Dans ces conditions, devais-je partir à la suite des réroltés, ou rester à Luluabourg, jusqu'à ce que j’aie conjuré le danger?

Maintenant que je vois la chose avec sang-froid et surtout que je connais les résultats, je pense que j’aurais dù ravitailler Cassart en munitions et partir au plus vite sur Kabinda. En ce moment, j'estimai qu'il y aurait de la lâcheté de ma part d'abandonner des missions en danger; je craignais que, si elles étaient détruites, l'on me reprochàt un manque d'énergie et que l'on fît retomber la responsabilité des faits sur moi, d'autant plus qu'il s'y trouvait des religieuses, donc des femmes blanches. Dans ces conditions, que valait-il mieux faire? 
Avant de continuer mon récit, voyons ce qui s'est passé à Luluabourg et à Mukabua lors de la révolte. Pour cela, je crois ne pouvoir mieux faire que de céder la plume à deux des témoins oculaires; à Cassart pour Luluabourg, et à Lapière pour Mukabua.

\section{Récit de la révolte de Lualabourg par Cassart}

Quelques Batétélas de Luluabourg ayant décidé de se révolter ouvrirent, le 4 juillet 1895, à l'appel du matin, le feu sur les Européens : le capitaine Pelzer, le commis de $I^{\text {re }}$ classe Lassaux et moi. Nous nous trouvions à 25 pas de la troupe. Lassaux eut d'abord le côté éraflé par une balle; une seconde balle traversa son veston; quant à moi, j'eus le flanc droit traversé.

Malleureusement, les Batétélas étaient bien pourvus de cartouches; 8 hommes qui devaient partir en poste le mème jour possédaient chacun 100 cartouches. Il ne nous restait donc qu'une chose à faire : nous mettre à l'abri. Pelzer et Lassaux partirent du còté du village des Zapo-Zapes ; quant à moi, au bout de quelques pas, je dus m'arrèter, déjà affaibli par la perte de sang; des fuyards me dirent que les Batétélas étaient à la recherche des blancs pour les tuer. Je faiblissais de plus en plus et j'eus toutes les peines du monde à me traîner jusqu'à un petit ruisseau se trouvant au fond du ravin près de la station. Pour y arriver, je dus traverser un petit marais, en rampant sur le ventre; ma soif était 


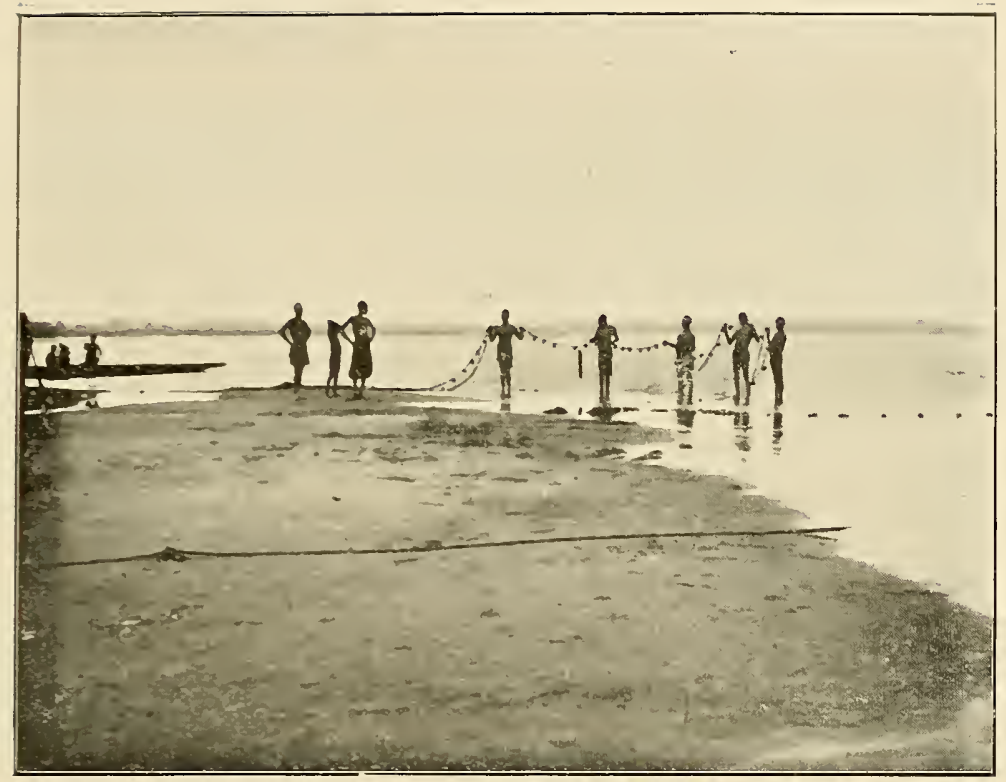

Pêcheurs indigenes instailant leurs filets

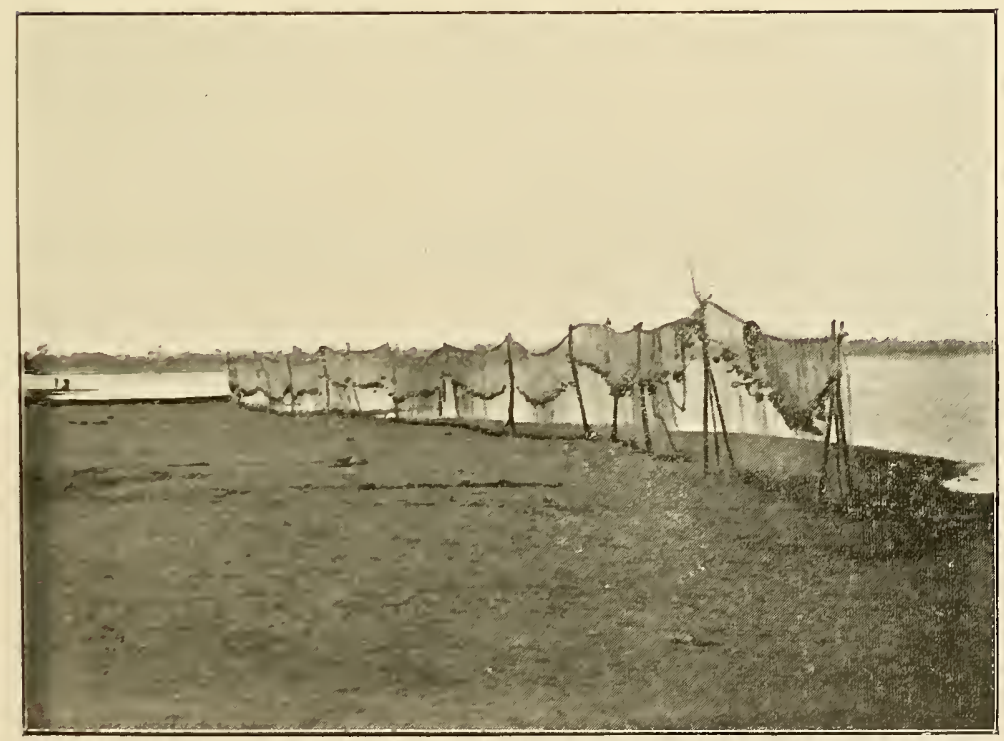

Filet de pêche séchant au soleil 


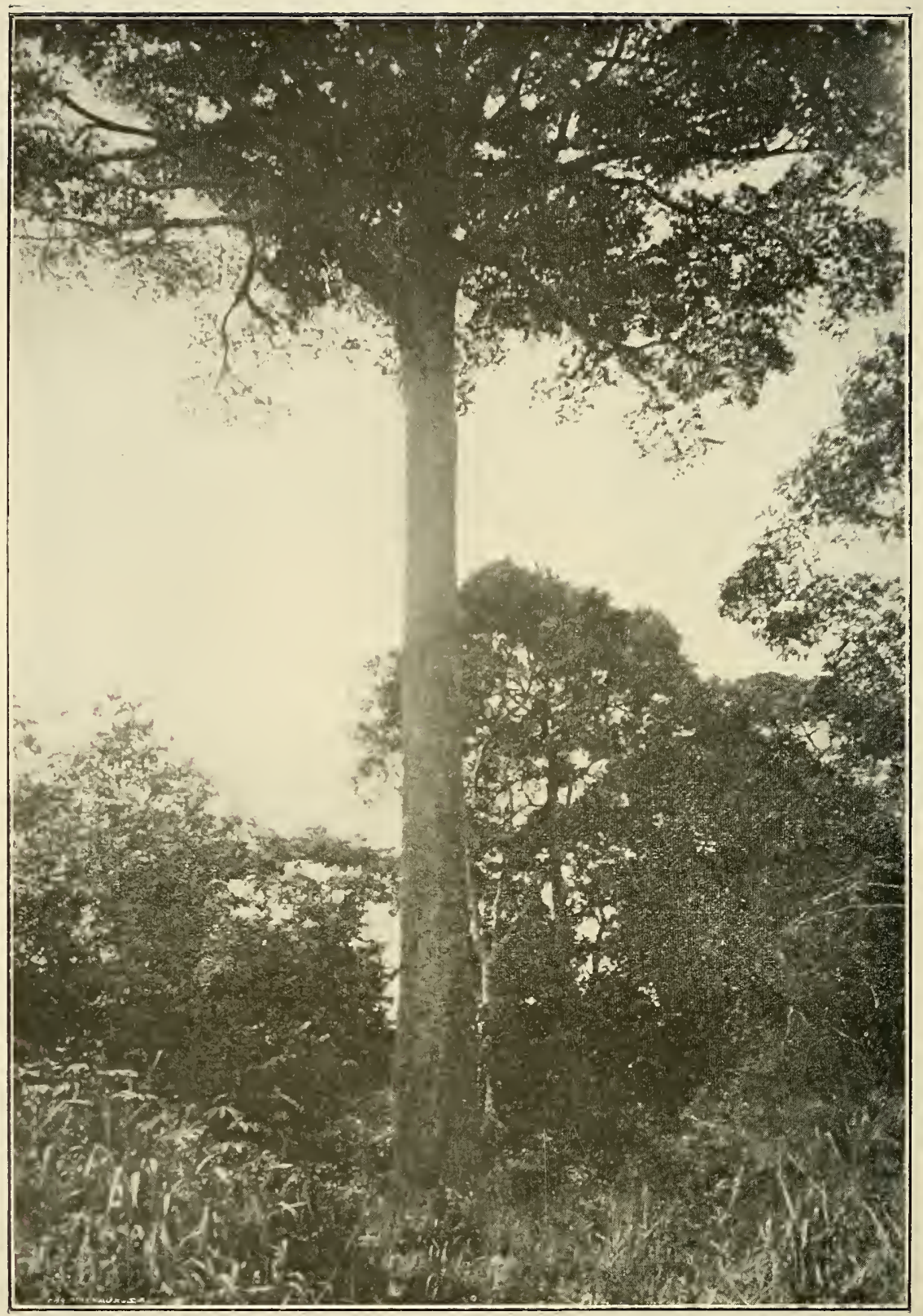

DANS LA FORET DU MAYOMBE 
tellement violente que je me mis à boire de cette eau stagnante. Arrivé au ruisseau, je pus panser enfin ma blessure et me rafraichir : il était grand temps, car je sentais la fièvre arriver; à sa sortie, la balle d'Albini avait fait un trou de la grandeur d'une pièce de 5 franes.

Après beaucoup d'efforts, je pus sortir du ravin et arriver près de la station; des femmes me rapportèrent aussitòt, mensongèrement, que tout était rentré dans l'ordre à la station et que les blanes s'y trouvaient sains et saufs. Heureusement pour moi, je n'avais plus la foree de mareher jusque là.

Des soldats Balubas, ayant appris ma présence, vinrent me prendre; je voulais me faire conduire à la station, mais ils refusèrent; deux soldats s'y rendirent pendant que j'étais transporté, au village de Mampnya.

Les deux soldats Balubas me mirent au eourant de ee qui s'était réellement passé à la station :

Pendant que quelques soldats étaient à la recherehe des blanes, les autres pillaient les magasins. Quand les soldats apercurent le capitaine Pelzer, eelui-ei voulut parlementer, mais ils refusèrent de rien entendre et tirèrent sur lui ; il fut tué, ainsi que l'interprète Soudrai, à la première salve. Les mutins passèrent ensuite près de Lassaux sans le voir; il ne fut aperçu que lorsqu'il fut arrivé près du village des Zapo-Zapes. Les Batétélas ouvrirent le feu, mais ils ne purent l'atteindre; ils envoyèrent alors une pointe d'ivoire et des étoffes au 
chef Zapo-Zape pour qu'il leur livrât Lassaux, mais Zapo-Zape répondit qu’il préférait la guerre.Les Balubas ajoutèrent que Lassaux était mort en arrivant chez Zapo-Zape ; heureusement, il n’en était rien.

La nouvelle de la révolte fut vite connue dans les environs, et plusieurs chefs des alentours, craignant les Batétélas, voulurent se joindre à eux. Les gens de Kanioka eurent six hommes tués par les Zapo-Zapes, en arrivant près de la station.

Le chef Mukengé vint me dire, sur ces entrefaites, que son oncle Mampuya faisait cause commune avec les Batétélas, que ceux-ci allaient venir, puis se rendre à la mission St-Joseph, chez le Père Cambier.

Je croyais toujours pouvoir parlementer arec les Batétélas, me fiant encore au dévouement de plusieurs d'entre eux, mais personne ne voulait me seconder; chacun disait que les Batétélas étaient comme frappés de folie subite, qu'ils ne roudraient rien entendre, qu'ils n'oseraient d'ailleurs plus rester à la station, après a voir tué deux blancs.

Mukengé me demanda de me confier à lui et je fus littéralement porté de l'autre côté de la Lulua, car je n'aurais plus su faire un pas. L'interprète Umba et trente Zapo-Zapes venus à ma recherche ne purent même savoir où j'étais, tellement Mukengé se méfiait de son oncle; j'étais loin de partager ses craintes. Le clairon Katembo put me rejoindre et m'apporter du 
papier et un crayon; j'envoyai tout de suite uu billet au Père Cambier et un courrier à Lusambo.L'après-midi, Úmba était près de moi : Les Batétélas savent que vous ètes ici ; Mampuya vous trompe, dit-il, la seule route libre est celle de la mission !"

Dans mon billet au Père Cambier, je lui demandais de prévenir Lapière, qui était en poste avec 70 soldats. Lapière devait venir me rejoindre de suite; je demandais de la quinine au Père, car ma blessure me faisait atrocement souffrir et je ne voulais pas me rendre à la mission, craignant d'y attirer les Batétélas.

Mais le Père Gambier ne l'entendait pas ainsi.

Le soir, j’arrivai donc chez le Père Cambier, qui, appréhendant l'arrivée des révoltés, avait déjà fait partir le Père De Clereq avec les Soeurs. Les Batétélas devant venir prendre la mission le soir et comme nous n'avions que quelques soldats, nous nous décidâmes, a vec le Père Cambier, à aller rejoindre le Père De Clercq et les Sœurs.

Le lendemain, nous revenions vers la mission; les révoltés avaient pris une autre route la veille; j'avais été éloigné des Pères, qui avaient appris que Gongo, chef des Bena-Luluas, voulait ma tête. Ce ne fut qu’à minuit que nous fûmes à nouveau réunis.

Donc, en retournant vers la mission, nous courions un autre danger, puisque Gongo nous barrait la route, mais il eut affaire à plus malin que lui ; le Père Cambier 
lui dit des " moyos " et, grâce à sa diplomatie, Gongo me promit de marcher contre les révoltés; mais je m'empresse d'ajouter que dès que nous fûmes passés, sa colère fut toute pour ses hommes, parce qu'ils n'avaient pas tiré sur nous.

A peine avions-nous dépassé le village de Sagasch, où se trouvait Gongo, que nous rencontràmes des soldats Balubas; un billet de Lapière nous apprenait son arrivée de Mukabua avec 60 soldats, mais j’hésitais à croire à cette nouvelle, me disant que, puisque les Batétélas de Luluabourg m’araient quillé, les autres ne resteraient pas a rec Lapière.

Mes prévisions ne furent pas trompées; un second billet de Lapière nous apprenait bientòl qu'il arrivait seul, tout son monde ayant déserté.

Enfin, nous voilà à la mission. Les Batétélas sont partis, mais tonte la contrée est en révolte; un chef a envoyé une oreille de Pelzer au chef Kalamba pour lui prourer que nons avons été battus et que c'est le moment de venir prendre la slation et la mission.

Le chef Gongo eutoure la mission. Nous possédons 10 fusils Albini, 14 chassepots, 26 fusils à piston; le Père Cambier a son express, mais, malheureusement, quelques cartouches seulement. Nous espérons néanmoins tenir tète, en attendant du renfort. Le Père Cambier craint pour les soeurs, car pour lui c'est un homme de fer, né soldat; ce bon missionnaire aurait 
fait un rude général. Quant aux søurs, loin d'ètre effrạeées, elles considéraient la situation avec calme, el ce calme me les montrait plus braves que nous, car elles n'auraient pu se défendre et ne pouraient compter que sur nous.

La station de Luluahourg arait subi un vrai pillage : tout était arraché; lettres, papiers de comptabilité, livres, tout était déchiré et éparpillé.

Je fus assez étonné, en arrivaut dans ma chambre, de retrouver ma malle bain, une autre petite malle et toute ma correspondance.

22 breufs, qui s'étaient échappés lors de la fusillade, étaient rentrés à la station; mon bouf de monte, mon brave Jules, élait là aussi. Mais je ne voyais pas mon chien : je ne pus retenir mes larmes; pourquoi l'avais-je attaché ce jour-là ?

Lassaux avait procédé à l’inhumation de Pelzer el, malgré notre peu de cartouches, je voulus que les honneurs militaires lui fussent rendus.

Lassaux m’apprit que le courrier que j’avais expédié à Lusambo avait été arrèté, mais que le sien devait ètre parvenu à destination; or, il annonçait ma mort ainsi que celle de Pelzer ; je m'empressai done d'expédier un courrier rapide.

J'avais, d'autre part, expédié un courrier à Konings, qui se trouvail au Kussaï : lui aussi avait des Batétélas ; je le priai de venir me rejoindre le plus tòt possible. 
Le 8 , je reçus un billet de Lassanx, qui se trouvait à la mission ; celle-ci allait être attaquée, je m'y rendis immédiatement ; c'était une fausse alerte. Là, je reçus un billet m'ammonçant l'arrivée du $1^{\text {er }}$ sergent Dufour avec 38 Haoussas; c'était le premier renfort qui m'arrivait.

Le 9 , je me rendis à sa rencontre, il arriva le soir à la station. Quel fut son étonnement en me voyant! Il me croyait mort ; le courrier de Lassaux avait produit son effet, la nouvelle de ma mort était partie pour l'Europe!

Dufour arrivait après une forte étape, aussi ses hommes étaient-ils exténués. Nous n'avions encore pu nous parler qu'un nouveau billet arrivait de la mission : les Béna-Luluas vont attaquer!

Je confie les Haoussas à mon brave ami, le sergent noir Moulonda M'Bougi, que les Batétélas auraient tant voulu avoir avec eux et qui reçurent des coups de feu pour réponse à leurs invitations.

Il fait vite tuer un bouf pour que les soldats puissent manger de suite; ceux-ci arrivent peu après nous à la mission.

Les Béna-Luluas ralentissent leur élan, ayant appris l'arrivée des soldats, lesquels n'ont malheureusement que 25 cartouches chacun, trop peu pour que j'attaque, car sans cela et malgré mon petit nombre d'hommes, je n’aurais pas hésité à me porter en avant. 
Le 11, je m'installai à la station avec Lapière, en laissant Lassaux, Dufour avè ses Haoussas et Umba a vec ses hommes à la mission.

Le 12, j'avais à la chaine le chef qui avait fait couper l'oreille à Pelzer, Mampuya et son compagnon.

Arec Lapière, nous travaillions ferme à faire disparaitre les traces de la rérolte, mais l'on dut continuellement veiller.

Le 17, je reçus un courrier du commandant Michaux qui arrivait avec 130 fusils! Enfin, j'allais pouvoir me reposer ; il élait temps, car depuis le 4 , je n'avais pas dormi, toujours en route, porté en hamac, et ma blessure continuait à me faire souffrir. Le soir, pour la première fois, j'osai me mettre "hardiment " au lit.

A 10 heures, un billet de la mission m’annonçait que l'ennemi était à une heure de la mission et allait l'attaquer. Bah! je connais l'ennemi ; je sais cu'il ne se risquera pas à une attaque de nuit, aussi je me repose encore une couple d'heures; je parviens à la mission à 4 heures du matin.

Le commandant Michaux arrivant avec des cartouches, je ne crains plus cette fois de brûler les miennes; aussi je décide d'attaquer; je marche au devant de l'ennemi avec Dufour; Umba, parti en reconnaissance, est déjà attaqué ; je laisse Lassaux et dix Haoussas au Père Cambier. Pour Umba, nous intervenions à temps : il était aux prises avec l'ennemi ; 
les balles nous arrivaient de tous côtés, quand, tout à coup, je vois une colonne de fumée du côté de la mission : c'est le village d'Úmba qui commence à brûler. L'emnemi avait formé deux colonnes ; celle qui attaquait la mission devait être très forte pour oser attaquer le P'ère Cambier, car les indigènes connaissaient sa bravoure.

Moi, toujours en hamac, je dus faire prendre le village de Sagasch d'assaut par Dufour; heureusement, Dufour n'avait pas froid aux yeux : en moins de temps qu'il ne faut pour l'écrire, il élait dans le village et l'ennemi prenait la fuite.

Nous nous rendîmes immédiatement à la mission, où la défeuse était des mieux organisées : Lassaux avec les llaoussas d'un côté, le Père Cambier, bien armé, a vec quelques hommes à l'autre aile, et le Père Declercq avee les hommes de la mission, tous armés de longs bàtons pointus, entouraient les sœeurs. L'ennemi avait déjà perdu beaucoup d'hommes quand nous arrivèrent encore 100 Zapo-Zapes. Les Bena-Luluas durent battre en relraite. Lassaux continua une savante poursuite; jusque midi, nous n'eûmes que quelques blessés, malgré les grandes pertes qu'éprouva l'ennemi.

Le 19 , je rentrai à la station, où le commandant Michanx était déjà arrivé avec mon ami Palate; eus aussi m’avaient cru mort; quelle fête de revoir le commandant Michaux avec qui j'avais fait la guerre 
arabe, qui était rentré en Europe avec moi, et qui n’avait jamais cessé de me témoigner la plus grande amitié! Quelle joie aussi de revoir Palate, mon vieux camarade de régiment!

A 9 heures dı soir, nous entendions des roulements de tambours; c'élait Konings qui arrivait de WismanFalls; il avait voulu arriver arec ses Batétélas, mais, en cours de ronte, cenx-ci avaient voulu se révolter. Prérenu par le caporal Monkédé, Batétéla également, Konings avait pris ses précantions ef, au moment où les Batétélas a vaient voulu tirer, six d'entre eux avaient été tués; les autres avaient pris la fuite.

J'aurais encore pu receroir du secours de Luébo, car le Directenr de la Sociélé des Produits Végétaux, M. Marius Baudour, ancieu sergent-major et vieil africain, m’avait écrit pour se mettre à ma disposition ; allerau feu aurail été un plaisir pour lui; mais, Baudour pouvait aussi empêcher un soulèvement du còté de Luébo, où il avait la plus grande influence; lui à Luébo, c’était la tranquillité assurée de ce còté.

(S.) GASSART, F.

\section{Récit de la révolte des soldats de Mukabua par Lapière.}

Le 2 juillet, je quitte Mukabua avec 20 soldats pour me rendre chez le chef Chamatinga, en désaccord avec un de ses parents. Il y a quatre jours de marche. 
Le 4 au soir, je reçois une lettre du Père Declercq de la mission Saint-Joseph me disant qu'une révolte de soldats vient d'éclater à Luluabourg. Le capitaine Pelzer est tué et les deux autres blancs sont en fuite, de plus les révoltés se sont emparés des magasins d'étoffes et ont pris possession des armes et des munitions. Le billet disait également que c'étaient les soldats Batétélas qui s'étaient révoltés, que la mission allait ètre atlaquée d'un moment à l'autre ; le Père m'appelait à son secours.

Singulière situation que la mienne...... Ma force publique se compose de 28 Batétélas, de 17 Manyémas et de 35 Balubas. J'arais avec moi, en ce moment, 12 Batétélas, 4 Manyémas et 4 Balubas et je me trouvais au village de Kalono, à cinq heures de marche de la mission; je ne pouvais donc porter aucun secours aux Pères. Aussi la uuit mème, je reprends la route pour retourner à Mukabua, il y a dix heures de marche de là.

Vers 2 heures du matin, j'arrive au village de Kiéfu, sur la rive droite de la Lutchacha; je suis obligé de m’arrèter ici, le passage de la rivière n'étant pas praticable la nuit. Le 5 au matin, j'envoie deux Manyémas au poste avec l'ordre de rappeler tous mes hommes, bien entendu en $y$ laissant les hommes de mon interprète pour garder la station.

Ici, j'ouvre une parenthèse : les soldats Batétélas sont, pour la plupart, des anciens guerriers de Gongo Lutété ; 
bons et courageux, armés d'armes rayées, ils en font de la besogne ; il y avait des Batétélas dans tous les postes, souvent en majorité; d'ailleurs, c'étaient les soldats préférés par tous les blancs. Grands et vigoureux, aussi intelligents que braves, on les portait aux nues naturellement. C'étaient les Batétélas que je prenais de préférence pour aller en palabre, car j'étais sùr qu'ils ne me làcheraient pas; je suis certain qu'ils se seraient fait tuer à mes còtés.

Durant le restant de la nuit, je suis resté plongé dans d'amères réflexions; il y avait deux résolutions à prendre : désarmer mes Batétélas pour me porter avec les autres soldats au secours de la mission; ou bien les laisser armés et marcher avec eux. La question, je dois l'avouer, m'a donné la fièvre. Les désarmer n'était certes pas chose facile à faire avec les autres soldats, dans lesquels j'avais peu de confiance et puis, en définitive, étaient-ils responsables de ce qui s'était passé à Luluabourg? Je résolus de jouer gros jeu, ne pas les désarmer; d'ailleurs, je n'avais que 12 Batétélas avec moi ; leurs camarades qui se trouvaient encore au poste se seraient certainement révoltés en apprenant ma façon d'agir.

La journée du 5 se passe dans des transes du reste faciles à comprendre, je n'avais aucune notion exacte de ce qui s'était passé à Luluabourg et les indigènes ne savaient rien ou plutòt ne voulaient rien me dire 
Notez bien que j'étais en pays ennemi, où j'ayais fait la guerre depuis.novembre 1894. Enfin, je prends mon courage à deux mains et je rends compte de la situation à mes soldats; ceux-ci étaient aussi bien et peut-ètre micux renseignés que moi. lls me répondent qu’ils ne sont nullement responsables, ni complices des actes commis à Luluabourg et qu'ils ne me quitteront pas, quoi qu'il arrive. Que pouvais-je exiger da vantage?

Le 6 au matin, je rois arriver tout le personnel de mon poste, les femmes de soldats en tète. Naturellement, je fais aussilòt sonner le rassemblement, criant aux soldats de se ranger à ma droite, les femmes à ma ganche. Inutile, on ne m'écoute plus, on ne m'obéit plus, on ne me connaît mème plus !...... Moment terrible et pénible à la fois. J'étais habitué à ètre obéi d'un geste, mes gens me respectaient et m'aimaient beaucoup.

Je cherchais vai:rement à comprendre la cause de ce désordre, quand les trois caporaux vinrent me rappeler à la situation, me donnant comme explication que les soldats ont peur et u'osent plus retourner à Luluabourg.

Je m'efrorce en vain de leur faire comprendre qu'en restant arec moi ils n'ont rien à craindre et tout à g'agner; qu'au contraire, en m'abandonnant,ils se rendent complices des révoltés de Luluabourg. Rien n'y fait, ils ne reulent rien entendre et je vois, à mon grand désespoir, les soldats et leurs femmes prendre hâtivement la route de la mission. 
Le caporal Batétéla me force pour ainsi dire à les suirre, c'est d'ailleurs ce qui me reste de mieux à faire.

Je me mets donc en route avec eux et, à un moment donné, je longe la colonne pour me mettre en tète comme d'habitude; on me laisse marcher et c'est pendant ce temps-là que tous mes effets ont été pillés.

Enfin, vers 10 heures, nous traversons le village de Kalomo (où j'avais recu la fatale nouvelle l'avant-veille) et une demi-heure plus tard nous arrivons devant la Miauw (rivière de 10 à 15 mètres de large).

A ce moment-là, les Manyémas, qui se trouvent en tète, font des difficultés pour me laisser passer le premier, prétextant qu'il y a des indigènes sur l'autre rive qui se tiennent cachés dans les broussailles, qu'il est plus prudent de laisser aborder quelques soldats d'abord.

Je me rends à cette raison qui me parait logique et je fais partir la première pirogue portant une dizcine de soldats; je passe ensuite à l'autre rive avec mes boys. Pensif, je m’assieds, livré à de tristes pensées, attendant que tous mes gens aient fini de passer. Il était décidé que je partirais ell avant avec quelques hommes jusqu'au village de Tshikadama. Je quilte donc la rive accompagné de 4 Batétélas, de 3 Balubas et de mes boys.

A peine ai-je fait 100 mètres que les autres soldats que j'avais laissés à la rive, me voyant suivi de quelques hommes et craignant sans doute une trahison de leur 
part, leur crient de s'arrêter s'ils ne veulent pas recevoir des coups de feu, de me laisser partir seul, accompagné de mes boys, sans me faire le moindre mal. Il se produit aussitòt une certaine hésitation chez mes soldats; inquiets,ils s'arrètent, je me retourne en leur demandant ce qui les retient, s'ils ont peur de me suivre? s'ils ne connaissent plus leur chef? s'ils vont l'abandonner sur la route en pays ennemi? Ils avaient les larmes aux yeux et je vous avoue que, de mon côté, j'étais on ne peut plus éniu ; c'étaient précisément mes sept soldats préférés que j'arais eus à mes còtés à chaque combat. Quelques-uns d'entre eux avaient même été assez grièvement blessés ; enfin, ils me répondent que j’avais toujours été bon pour eux, un véritable père, seulement qu'ils ne pouvaient pas abandomner non plus leurs frères. Là-dessus, ils sont partis sans mème tourner la tète. J'étais à ce moment à l'entrée de la forêt, je suis allé m'asseoir près du petit ruisseau et là je suis resté bien longtemps indécis, ne sachant plus que faire.

De mes 80 soldats, il ne m'en restait plus un seul, tous m’avaient abandonné jusqu'au dernier.

Mon poste allait, d'un moment à l'autre, retomber entre les mains de Kalamba.

Une femme appartenant à mon interprète vient me prévenir que le caporal de mon poste (un Manyéma) excitait les soldats à venir me tuer, sous prétexte qu'un blanc tué serait un ennemi de moins plus tard; 
seulement, les Batétélas s'y étaient opposés énergiquement, menaçant le caporal de l'amarrer s'il donnait suite à son projet.

Je poursuis alors ma route, une vingtaine de minutes me séparent du village qui se trouve sur la hauteur.

Ii me fallait quitter le sentier et marcher avec précaution, car un indigène caché derrière un arbre pouvait me làcher un coup de fusil en traitre et j'avais pour toute arme un fusil de chasse, que mes anciens soldats avaient bien voulu me laisser, mais dont ils avaient eu soin d'emporter les cartouches. Ensuite, une autre difficulté à surmonter : au village où je devais passer, comment les gens allaient-ils me recevoir? Je leur avais fait la guerre dans le temps, leur chef a vait mème fait plusieurs mois de chalne au poste; s'ils allaient se venger maintenant et me livrer à Kalamba, ce qui leur serait facile, puisque me voilà sans défense?

Il n'y avait pourtant pas de temps à perdre ; rcculer, c'était la captivité et les atroces supplices des Bachilanges ; marcher en avant, n'avais-je pas les mèmes dangers à craindre? Machinalement, je suis la direction du village à travers broussailles et marais et j'arrive bientòt en vue des premières cases. De là, je découvre une colonne en marche, suivant la route de Kanova; c'était tout le personnel de mon poste; nos deux directions forment un angle droit. J'entre ensuite dans le village, le cour me battant bien fort; il fallait 
cependant payer d'audace. Le chef du village vient à ma rencontre, me demandant ironiquement où sont mes soldats. Je lui réponds qu'ils sont partis pour faire la guerre et que je viens m'installer dans son village en attendant leur retour. Il me répond en souriant qu'il connait toute l'affaire et qu'il sait parfaitement bien tout ce qui s'est passé à Luluabourg. D’ailleurs, ajoutet-il, je n'ai rien à craindre chez lui. Il me conduit comme d'habitude sous l'abri que j'avais fait faire et me fait apporter à boire et à manger; je mourais de faim; je n'avais plus rien pris depuis la veille; ces nouvelles m'avaient coupé l'appétit. Le chef vient ensuite gravement s'asseoir à mes còtés; je lis dans ses yeux qu'il a de mauvaises nouvelles à m'apprendre. Il me demande aussitòt si je sais ce qui est arrivé à la mission.

lnquiet, pressentant de nouveaux malheurs, je le presse de questions, lui demandant de me raconter rapidement tout ce qu'il sait. Il me dit que quatre de ses hommes viennent de revenir de Luluabourg et qu'ils ont vu la mission en feu ; les révoltés ont mis les cinq søeurs à la chaìne et ont coupé la tète aux Pères; ils se sont ensuite jetés sur les étoffes, après avoir mutilé tous les enfants de la mission. Cela me paraît invraisemblable; je fais appeler les quatre hommes, qui m'affirment avec force gestes que c'est bien ainsi. Donc, plus de doute possible, que vais-je faire maintenant? 


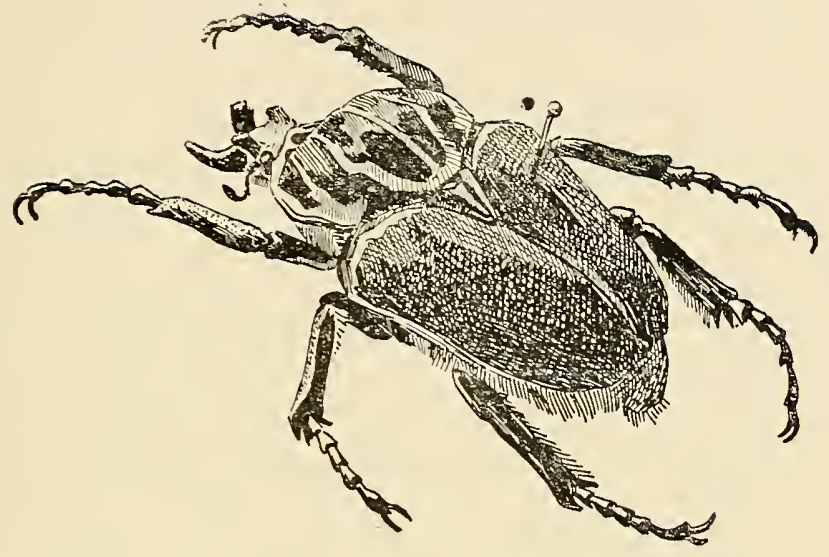

Ie Goliath Royal

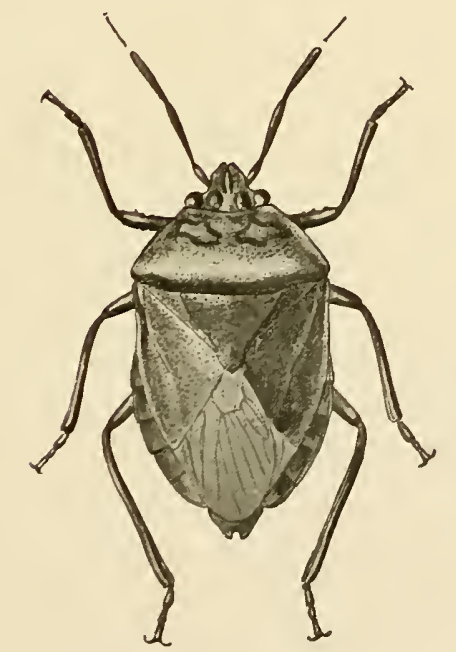

punaise cles looís 


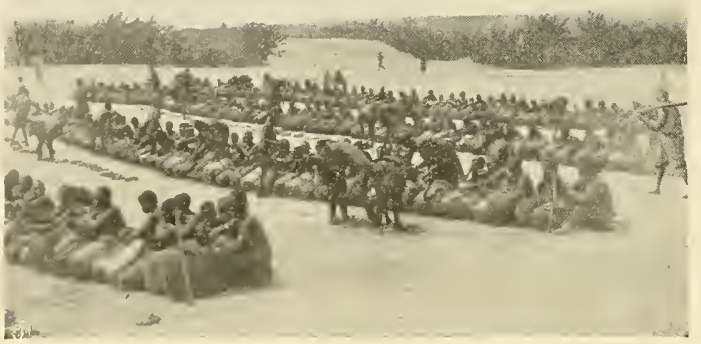

Femmes indigènes atłendant l'ouverture du marché à Nyangwé

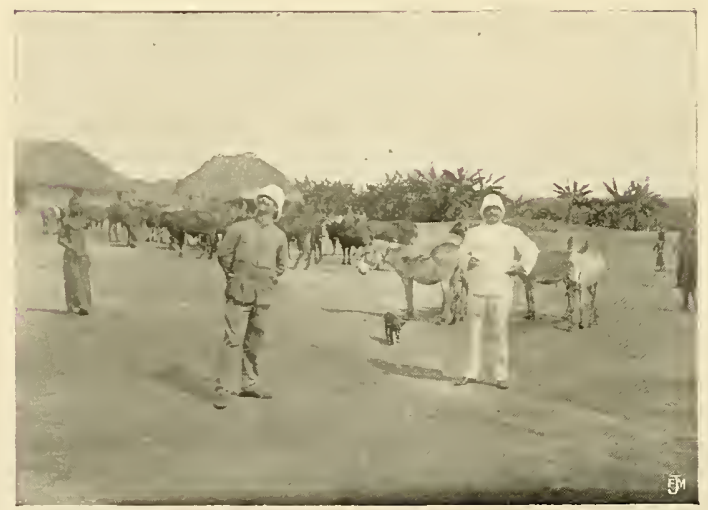

LA FERME DE LUSAMBO 
Luluabourg détruit, la mission également, je restais donc seul blanc, ne sachant plus à qui me fier.

J'enroie tout de mème un courrier à la mission pour annoncer mon arrivée avec quatre boys; peut-ètre les gens de Tshikadama ont-ils exagéré, peut-ètre aussi ont-ils menti.

Vers 2 heures et demie, je reprends la route, il me reste encore cinq heures de marche à faire pour arriver à la mission.

En arrivant près de la mission, j'enverrai un de mes boys en avaut pour voir ce qui se passe; si ce qu'on m'a raconté est vrai, je pourrai toujours me cacher dans la brousse en attendant les érénements.

Je continue ma route, songeant à la situation qui m’était faite, puis je pensais à tout ce qui était arrivé à Luluabourg, à la mission Saint-Joseph, les sœurs à la chaine et à la merci de ces misérables.

A 6 heures, j'arrive au villago de Tshikudi qui, en m'apercevant, vient à ma rencontre porteur 'd'un billet.... Je le Iui arrache des mains et je lis, à ma grande joie, que tout est tranquille à la mission, que les révoltés ne donnent plus signe de vie et enfin que le Père Cambier m'attend avec impatience.

J'étais on ne peut plus content et j'aurais bien embrassé le chef Tskikudi. Je me remets de suite en route, entièrement réconforté cette fois. Vers 7 heures et demie, j’arrive à la mission, exténué, n'en pouvant 
plus. Là, je retrouve Cassart et Lassaux, les deıx blancs de Luluabourg; nous voici donc.tous réunis, à l'exception de notre malheureux chef, le capitaine Pelzer.Je conte les différentes péripéties de mon voyage. Le Père Cambier conte également tout ce qui s'est passé; quant à Cassart, il a passé aussi de bien mauvais moments.

Nous reillons toute la nuit, car nous craignons que les soldats de mon poste ne viennent attaquer la mission au chant du coq et, pour toute défense à leur opposer, nous n'avons que six soldats Balubas de Luluabourg qui nous sont restés fidèles.

Le jour de la révolte, les Pères, craignant pour la mission, étaient partis pour mettre les soeurs en lieu sùr; les indigènes se montrant méfiants, ils avaient jugé prudent de regagner la mission d'autant plus vite qu’ils venaient d'apprendre que les révoltés n'étaient plus à Luluabourg. Il s'en est fallu de peu que les Soeurs et les Pères ne tombassent entre les mains du chef Gongo Tshitengé; ils sont donc revenus à la mission le 6 et, détail curieux, ils ont retrouvé tout dans l'état où ils l'avaient quitté; rien n’avait été dérangé, mème la table qu'ils avaient abandonnée au déjeuner; personne n’avait touché à quelque chose.

Enfin, le 7 au matin, quand le jour a paru, nous avons tous éprouvé un grand soulagement; les espions envoyés par le Père Cambier sont venus nous dire que 
les révoltés avaient tous passé la Lulua et prenaient le chemin de Kalala-Kafumba. Là se trouve également une mission, celle du Père Garmyn ; heureusement, un courrier est déjà parti pour l'avertir. Le lendemain, je pars pour Luluabourg, qui se trouve à deux heures et demie de marche de la mission. La vue de la station, que j'avais quittée au mois de novembre, m'a fait mal au cœur. Toutes les maisons des blanes, dévastées, saccagées, étaient dans un triste état; il y avait des paperasses dans tous les coins de la station. J'ai été voir la place où est tombé le capitaine Pelzer, frappé de plusieurs balles; la terre élait encore humide du sang qui avait coulé..... Une lettre de son frère, qu'il venait de recevoir au dernier courrier, élait tachée de sang et tombée de sa poche sans doute pendant le meurtre.

Voici les faits qui se sont passés à Luluabourg :

Le 4 juillet, au matin, les soldats se trouvaient à l'appel en armes, les trois blanes étaient présents. A un moment donné,les soldats Batétélas ont commencé a tirer sur les blancs, ont blessé Cassart à la hanche et Lassaux au còté ; ceux-ci sont parvenus à s'échapper; (quant au capitaine Pelzer, les soldats l'ont poursuivi a vec acharnement. Alors, il s'est arrèté, leur demandant ce qu'ils voulaient. Les révoltés l'ont écoulé quelques instants et lui ont répondu qu'ils n'avaient plus d'ordre à recevoir, qu'ils étaient maîtres de la station; alors ils 
l'ont blessé à la tête; le capitaine Pelzer est tombé ensuite, atteint en pleine poitrine, et les Batétélas l'ont achevé à coups de crosse. Immédiatement après, les révol tés ont abattu le mât de pavillon,ont pris possession du magasin de poudre et des munitions, ensuite ont pillé les magasins de marchandises et se sont partagé les effets des blancs; une grande partie des bœufs, les moutons, les chèvres, les poules, tout a été massacré à coups de fusil. Quant aux femmes, qui n'étaient pas de leur nationalité, elles ont été mises à la chaîne.

La nuit s'est passée en danses et en orgies et, le 5 au matin, les révoltés ont passé la Lulua, chargés de butin ; tout ce qui était lourd et encombrant a été jeté dans la rivière : ivoire, argent, croisettes en cuivre, malles.

Ils ont quitté Luluabourg aussi précipitamment parce qu'ils craignaient que du renfort ne vìnt de Lusambo, malgré les sentinelles qu'ils avaient postées sur toutes les routes pour intercepter les billets, puis ils avaient hâte de se joindre à mes soldats. Ils se sont rejoints au village de Kalala-Kafumba. Mais ce qui est in explicable, c'est qu'ils n'ont pas incendié une seule case de la station et n'ont pas détruit un seul arbre fruitier, ni caféier, ni citronnier, rien.

Ce qui paraît également incom préhensible, c'est qu'ils n'ont pas été piller la mission, si proche, et où ils savaient bien qu'il $y$ avait beaucoup d'étoffes et de marchandises. 
Dans tous les cas, le jour de la révolte, la plus grande partie d'entre eux se sont mis en route dans le dessein de piller la mission, tandis que les autres Batétélas gardaient le butin et les femmes.

Ils sont mème arrivés jusqu’au Mikalaïe (petit ruisseau à une heure de marche des Pères). Là, ils ont rebroussé chemin et sont revenus aussitòt à Luluabourg. Voilà ce qui est étrange. Ils n'a vaient pas de défense à craindre de la mission et puis ce n'est pas cela qui les aurait retenus.

Le 8 au soir, je suis revenu à la mission, où je suis encore resté deux jours; ensuite je suis revenu à la station pour la défendre en cas d'attaque; j'étais à la tète de 5 fusils rayés et de quelques Zapo-Zapes. (Leur chef est un de ceux qui n'ont pas abandonné le blanc au moment critique).

Le 12, M. Dufour nous arrive de la route de Lusambo avec 40 Haoussas munis de 30 cartouches et va camper à la mission, une attaque des indigèues devenant de jour en jour plus imminente.

Le 4, j'étais seul à Luluabourg, lorsque la mission se trouve attaquée par le chef Gongo Tshitengé. Après un combat acharné, nos soldats ont repoussé les Bachilanges et les ont poursuivis à deux heures de là en leur causant des pertes sérienses.

Le 19, le commandant Michaux nous arrive de Lusambo avec une centaine de fusils et des auxiliaires : 
il laisse quelques soldats à Luluabourg et va s'installer avec tout son monde à la mission.

(S.) A. LAPIÈRE.

Les faits qui se sont passés à Luluabourg et à Mukabua étant connus, je continue mon récit.

Parti le $1^{\text {er }}$ aoùt de Luluabourg, j'arrive le 8 à KalalaKafumba. Le chef nous étant très dévoné,j'essaie d'aroir par lui des nouvelles des révoltés, mais il ne sait rien de précis, si ce n'est que la mission a été complètement détruite ainsi que le poste de Kaiéié où le sergent Dehaese a été tué par ses soldats. Il croit aussi que les révoltés se sont dirigés sur Kabinda.

Je pars donc pour Kabinda, où j’arrive le 16.

Le village est rasé. Shaw, le chef de poste et le chef Lupongu, venus à ma rencontre, m’apprennent que, le 5, Bolhen, Shaw et Fromont, aidé des chefis Lupongu et Pania Motombo, ont livré un combat aux révoltés à Kaiéié, mais qu’ils ont été écrasés et que Bolhen a élé tué.

Les Batétélas après avoir pris le poste militaire y ont trouvé tout ce qui leur était nécessaire et entre autres choses, le ravitaillement destiné au Katanga, soit 70 ballots d'étolfes, 30 caisses de perles, des chobox de vivres et 50.000 cartouches. C'est avant d'arriver à Kabinda qu'ils ont livré leur premier combat aux blanes ; combat dont l'issue était d'ailleurs à prévoir. 
Quelques porteurs Angolais armés de la veille ne pouvaient pas tenir tète aux Batétélas, tous vieux soldats aguerris. Il est vrai que ces porteurs étaient soi-disant soutenus par un millier d'auxiliaires du chef Lupungu, mais ces derniers aux premiers coups de feu ont làché pied arec un ensemble vraiment touchant, laissant les malheureux blancs aux prises avec l'ennemi. Aussi le désastre fut-il complet; le lieutenant Bolhen fut tué et horriblement mutilé, Fromont parvint à échapper au massacre; quant au lieutenant Shaw, chef de poste de liabinda, il réussit non sans peine à gagner la forèt poursuivi par les révoltés.

Heureusement ceux-ci perdirent ses traces, gràce à une traince de sang, d'un soldat blessé qui s'était également réfugié dans le bois; ils cessèrent leur poursuite se disant que le blanc avait son compte el était allé mourir sous bois.

Shaw passa une nuit terrible au fond d'un ravin, dans un infect marais, n'osant faire le moindre mouvement de crainte d'ètre découvert, car le combat terminé, les Batétélas avaient établi leur campement sur la lisière même de la forêt à proximité de la place où il se tenait.

De temps en temps, les sentinelles placées sur le hord du ravin déchargeaient leurs fusils dans le fond et les balles venaient lui siffler sinistrement aux oreilles. 
Le lendemain, je repartais pour N'Gandu, espérant que Augustin, aidé des forces de la zone arabe, avait pu tenir les mutins en respect; mais le 21 , en arrivant à Koolomoni, j'appris que dans la journée du 17, Augustin avec 5 blancs, 280 soldats et 3 à 400 auxiliaires, avait livré bataille près de N'Gandu et qu'il avait été battu et tué, ainsi que de Franken et Langeroi.

Dans ces conditions attaquer les révoltés avec mes seules forces élait pure folie puisqu'ils disposaient de plus de 600 fusils Albini. Il ne me restait donc plus qu'une chose à faire, me rabattre sur Lusambo afin de protéger cettestation contre un coup de main de leur part et y attendre des renforts.

C'est ce que je fis. J'arrivai le 2 septembre à Lusambo.

Quatre jours avant notre rentrée, un steamer avait amené 250 soldats de renfort, conduits par le lieutenant Swenson.

Le 5, Gillain, Swenson, de Bèche et 250 soldats quittaient Lusambo. Le 7, mes hommes étant un peu reposés et mes pelotons étant reformés, je partis à mon tour et je rejoignis Gillain, le 12, à Mukundji ; nous arrivâmes le 17, tous ensemble au Lomami, à l'ancien poste de N'Gandu.

Les révoltés étaient établis sur l'autre rive et ils y avaient dressé trois tentes prises aux blancs, comme pour nous narguer. Ayant bien repéré le but, j’envoyai 
avec mon Mauser une dizaine de balles dans les tentes.

Le procédé dut ètre trouvé pen courtois par ces messienrs, car, quelques minutes après, les tentes avaient disparm.

Le lendemain et les jours suivants, j’envoyai également quelques obus dans leur campement. Cette manière de faire dut leur déplaire souverainement, car quelques jours après notre arrivée, ils levèrent le camp et allèrent s'élablir à Lukoléka, qui se trouve à trois heures de marche de leur ancien campement.

Jusqu’au 8 septembre, nous restàmes les uns et les autres dans l'expectative. A cette date, il fut convenu que nous irions les attaquer.

Gillain, étant très malade, me remit le commandement des troupes et je m'occupai aussitòt de leur faire passer le Lomami.

Le passage nous prit toute la matinée et une partie de l'après-midi ; comme il était trop tard pour nous mettre en route, nous campàmes à une heure de marche de la rive, remettant le combat au lendemain matin.

J'en arrive à la page qui, pour moi, est la plus doulourense de mon récit. Vingt fois j'ai pris la plume et vingt fois aussi je l'ai rejetée, découragé. Aussi, est-ce la rage an cour et des larmes pleins les yeux que je vous crie, ne voulant plus reculer : "J'ai été vaincu et ce fut ma faute!!" 
C'est si facile d'écrire une victoire! Votre plume court...... court d'elle-même sur le papier et vous fait, tont en courant, escalader fossés, tranchées et parapets, comme si,elle aussi,elle avait hàte d'arriver au " hourra ) final!

Tout autre chose est d'écrire une défaite! Votre petite vauité vous fournit toujours des excuses pour chacune de vos fautes, vous suggère des mots qui sont presque des synonymes de cenx que vous devez employer et vous avez besoin de loute votre conscience pour ne pas dénaturer la vérité.

Quant à mói, j’ai promis de tout dire, et quoi qu'il m'en coùte, je dirai tout :

Ma nuil du $S$ au 9 ful atroce; j’eus la fièvre tout le temps et, lorsque je me levai, un peu avant la pointe dı jour, j’élais moulı, éreinté, découragé ; j’avais la perception très nette que, ne me trouvant pas en possession de la plénilude de mes moyens, je serais ballu. Aussitòt que nous fimmes tous sur pied, je fis ce que je n'avais jamais fait.

Moi, l'homme autoritaire, qui n'avais jamais pris conseil de personne, et qui, en toute autre circonstance, n'aurais pas mème admis que l'on pùt m'en donner un, je réunis mes blancs pour avoir leur avis sur la facon dont nous allions a ttaquer!

La plupart furent d'avis que, pour en finir, il fallait euvelopper l'ennemi, que le mieux était donc de nous 
partager en deux colonnes, afin de l'anéantir en le prenant entre deux feux.

Bien que je fusse d'un avis tout à fait opposé, désirant garder toutes mes forces dans ma main,j'eus la faiblesse, je dirai mème la folie, de céder.

Il fut décidé que Swenson et de Bèche,a vec 230 soldats et le canon. Krupp, prendraient une route, tandis qu'arec Lapière, Dufour, Palate, Droven et le Nordenfeld ainsi (que 191 soldats et 25 auxiliaires, je prendrais l'autre route.

Il fut également convenu que la première colonne qui arriverait en face de l'ennemi tirerait un coup de canon el que la seconde répondrait immédiatement par un autre coup de canon, afin de faire connaître l'endroit où elle se trouvait.

Ces dispositions prises, nous nous mìmes en route.

D’après les renseignements que nos guides nous avaient donnés, nous nous trouvions à environ trois heures de marche de l'ennemi.

Partis de notre campement a 5 heures et demie, nous devions donc ètre en présence vers 8 heures el demie. Or, à 10 heures et demie, nous n'avions encore rien vu.

Mon appréhension était terrible, car je me disais que Swenson élait peut-être déjà aux prises a vec l'ennemi et que peut-être aussi, il serait écrasé avant que je parvinsse à lui porter secours. Toutefois, comme ni 
mes hommes ni moi n'avions entendu aucun coup de fusil, je finis par me rassurer, me disant qu'il s'était probablement caché aux environs, attendant mon signal pour attaquer.

Vers 11 heures, nous arrivons sur le bord d'un plateau, d'où nous distinguons le village des révoltés, qui se trouve en contre-bas à environ 800 mètres de nous et à la lisière de la forêt.

La vallée qui nous en sépare est traversée par un ruisseau aux rives marécageuses. Je fais aussitòt déployer deux pelotons en tirailleurs sur la crète du plateaı el, après avoir pointé soigneusement le canon, moi-mème j'cnvoie un obus dans le village des révoltés, afin de donner le signal convenu à Swenson.

J'altends pendant dix minutes,..... pas de réponse!

J'envoie un second obus, suivi d'un troisième..... toujours mème silence de la part de ma deuxième colonne.

Persuadé alors que nous avous été trahis et voyant qu'un mouvement tournant se dessine sur ma droite, de plus étant bien persuadé que toute retraite est impossible, la mort dans l'âme je donne le signal du combat.

Dufour et Lapière, le premier avec 31 hommes, le second avec 44 , devaient attaquer de front.

Palate, avec deux pelotons, formant un ensemble de 70 hommes, devait s'opposer au mouvement tournant. 
J'avais remis le canon à Droven, avec une garde de 2.5 fusils appartenant à des auxiliaires.

Enfin, j'avais avec moi 46 vieux soldats, formant réserve et destinés à parer à toutes les érentualités.

Bientòt, les deux pelotons de Dufour et de Lapière sont anx prises avec l'ennemi, qu'ils refoulent mème jusquaux premières maisons des révoltés; mais, à ce moment, un second contingent élant entré en ligne, je sens qu'ils ront faiblir, s'ils ne sont promplement secourus.

Je commis ici ma seconde grande faute de la journée : Au lieu d'envoyer Palate avec ses hommes au secours de Dufour et de Lapière, je le laisse en réserve et, voulant ranimer mes hommes par ma présence sur la ligne des tirailleurs, je m'y précipite avec mes vieux soldals, persuadé que je l'emporterai de haute lutte, puisque, jusqu'à ce jour, il m'a suffi de vouloir pour que mes hommes, électrisés par ma voix, se jellent a vec rage sur nos ennemis aftolés !

Il n'en fut rien, hélas! Au bout de 25 minutes, sur un ensemble de 131 hommes engagés, 42 étaient tués et 38 blessés : plus de la moilié étaient donc hors de combat. De plus, Palate venait d'ètre tué d'une balle au front, Lapière et Dufour étaient blessés tous les denx ; ma réserve, privée de son chef, s'était évanouie sans avoir été engagée et mon canon, sur leçnel je comptais beaucoup, ne tirait pas, Droven ayant perdu sa corde tire-feu! 
A ce moment, mes hommes furent tout à coup pris d'une panique épouvantable; ni prières, ni menaces ne purent les retenir : ils làchèrent pied de toutes parts. J'espérais les rallier au ruisseau, derrière la réserve; mais, comme je l'ai dit plus haut,celle-ci s'était dispersée sans mème avoir été engagée.

Désespéré, voyant qu'il u'y avait plus rien à faire, puisque je n'avais plus quinze hommes autour de moi, je leur donnai l'ordre de se porter au plus vile au Lomami, afin d'y arriver si possible avant les révoltés, protéger la retraite et le passage de ma malheureuse colonne.

Sur la route du retour, nous fùmes assez étonnés de voir que l'on ne nous poursuivait pas.

Nous eumes plus tard la clef de l'énigme: Swenson était arrivé sur ces entrefailes, avait pris l'emnenti à revers, et celui-ci, surpris, n'avait fait qu'une faible résistance, puisque Swenson n’eut qu'un seul blessé dans son détachement.

Done, en somme, la vicloire nous restail, va que Swenson avail pris l'ennemi en déroute et en fuite. Mais, si les troupes de l'Etat étaient viclorieuses, je n'en avais pas moins, moi personnellement, subi un échec.

Cette jonrnée fatale me pèse encore comme un horrible cauchemar et me gàte souvent le plaisir que j'ai à me reporter aux jours heureux que j’ai passés au Congo. 
Aussi je vous jure que je dommerais dix ans de ma vie pour recommencer celle balaille, dans les mèmes circonstances, avec les mèmes éléments..... mais en prenant d’autres dispositions.

Le lendenain de ce jour néfaste, comme nous n'avions pas de médecin, je fus obligé de soigner moi-mème nos nombreux blessés; or, je l'ai déjà dit, parmi eux se trouvaient Dufour et Lapière.

Ce dernier avait un biceps prescfue entièrement enlevé; la blessure était hidense el tout autour pendaient des morceaux de chair morte.

Je me rends donc chez lui, arec ma boìte à outils, suivi d'un soldat portant les médicaments.

Mon ami Lapière était dans sa chaise longue, le bras en écharpe. En me voyant entrer, il se lère d'un bond et, sans répoudre à mon salut, s’écrie :

"- Qu'allez-vous faire, commandant?"

"-Albert, lui dis-je, tu le vois bien, je viens te soignel."

" - Oni, seulement je vois aussi (que vous avez tout votre altirail de couteaux el de ciscaux, mais je vous jure bien que vous ne une couperez rien du tout. "

Ce fut en vain que, pendant plus d'une demi-heure, j'essayai de lui faire comprendre que, si l'on ne coupait pas toutes ces chairs mortes, la gangrène se meltrait dans la plaie, c'est-à-dire qu'il était perdu sans rémission. 
Dans son entètement de malade, il ne voulait rien entendre et ne cessait de répéter : « Vous ne me couperez rien du tout ! »

Voyant qu'il était impossible de le convaincre, je résolus d'employer les grands moyens :

" - Albert, lui dis-je, puisque tu ne veux pas ètre raisonnable, je vais faire appeler quatre soldats et te faire ficeler, après quoi je t'opérerai. "

- "Vous ferez cela? me dit-il. "

- "Mais certainement, je le ferai, puisqu’il n'y a que ce moyen là pour te sauver. "

- Et s'il ne me convient pas à moi d'ètre sauvé?

- Je te sauverai malgré toi.

- Alors, dlans ce sale pays, on n'est plus mème maitre de sa peau?

- Cerlainement non, tu appartiens entièrement à l'œuvre que tu sers, et tu sais aussi bien que moi qu'en ce moment surtoul, la vie d'un blanc est trop précieuse pour qu’il lui soit permis de se sacrifier bètement.

- El bien, finit-il par me dire, puisque c'est comme cela, et puisque vous avez la rage de couper, coupez donc, mais surtout faites vite et ne me faites tenir par personne. "

Un quart d'heure après, le pansement était terminé. Au bout d'un mois, mon ami Albert était guéri.

Depuis cette époque, je me suis souvent amusé à lui rappeler qu'il me doit la vie. Mais chaque fois aussi il 


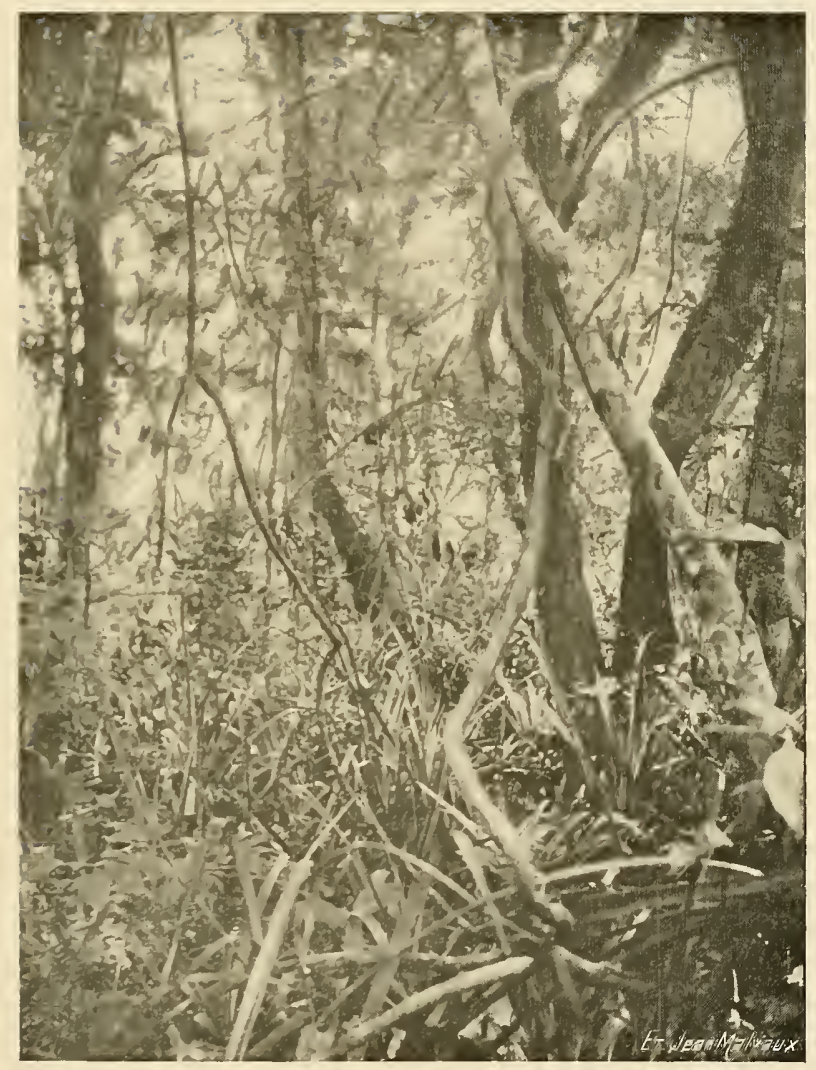

Aspect cle la forêt vierse 


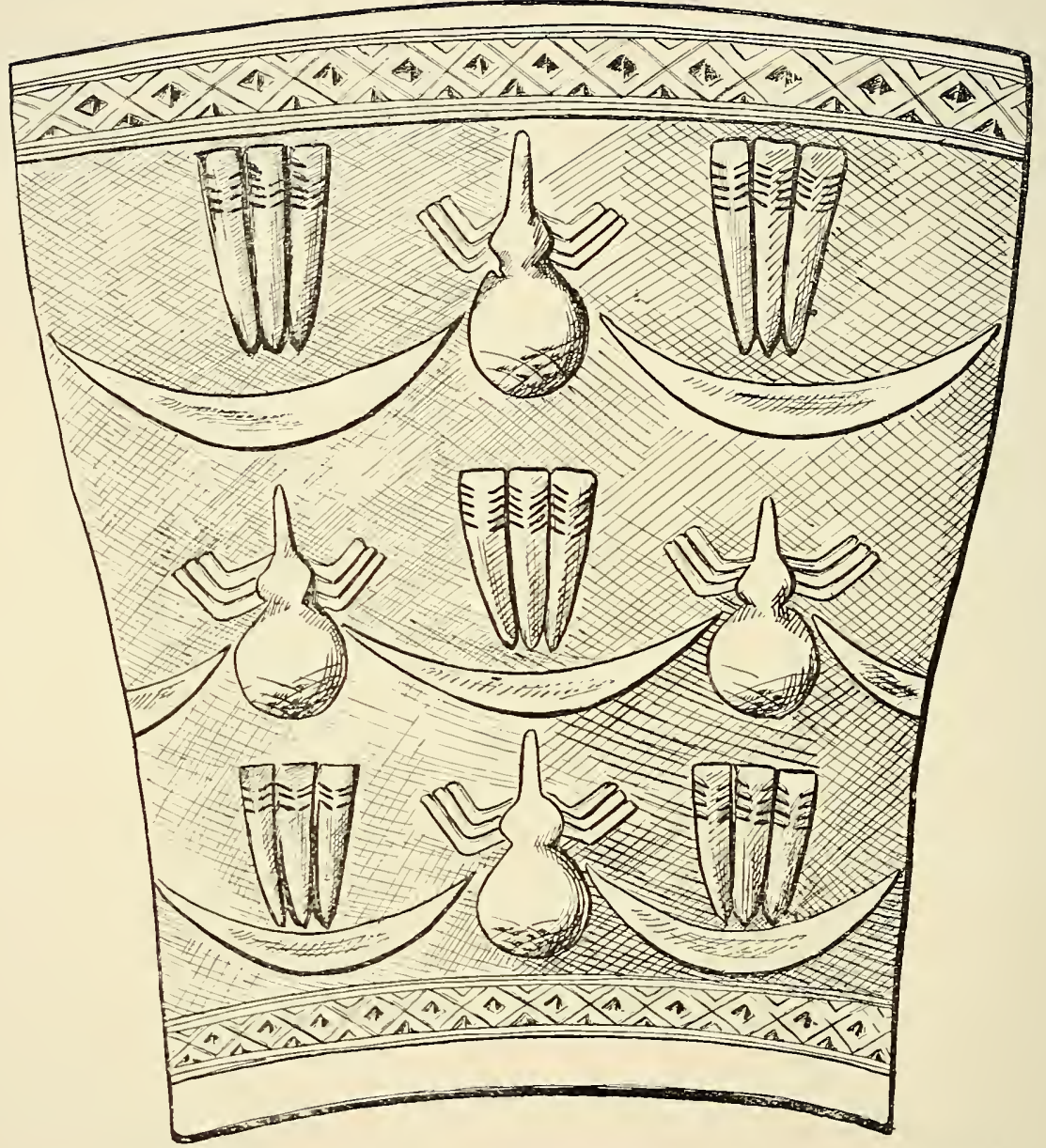

Gobelet en bois sculpté du Kassaï servant à boire le malafu 
ne manque jamais de répondre : "Cela se peut, mais rous ne m'òterez jamais de la tète que vous n'aviez pas le droit de m’opérer malgré moi !...... n

Mais rerenons aux révoltés. Huit jours après notre combat livré aux Batétélas, donc le 16 septembre, Lothaire arrivait de la zone arabe avec 700 soldats, 8 blancs et 150,000 cartouches; réunis, nous avions donc plus de 1,000 fusils à opposer à l'ennemi.

Les réroltés s'étaient réfugiés dans une forèt dont la route formait une succession de clairières. Il fut décidé que nous irions les y attaquer.Toutes nos forces réunies, nous nous mìmes en marche dès le 18.

Toutes les clairières furent défendues, jusqu’au campement, mais la véritable bataille se livra à la première. L'ordre de marche était celıi-ci : Doorme, avec les troupes de Kassongo; puis moi avec les troupes du Kassaï-Lualaba, enfin Lothaire avec les autres troupes de la zone arabe.

Dans cette journée, c'est Doorme qui eut à soutenir le plus fort de l'attaque et il le fit avec un courage et un brio dont on ne peut trop le féliciter. Les autres pelotons qui furent engagés par la suite ne l'ont été que successivement et lorsque les munitions de Doorme étant presque épuisées, on dut retirer petit à petit ses hommes de la mêlée pour les remplacer par des troupes fraîches et bien pourvues de cartouches. C'est donc à Doorme, en grande partie, que revient le succès de cette journée. 
Les révoltés s'étaient enfin dispersés; nous perdìmes pendant quelque temps leurs traces.

Un nouveau coup d'audace de leur part nous domna bien tòt de leurs nouvelles ; nous apprenous en effet que, réunis aux gens de Dibué el de Kolomoni, ils ont attaqué el détruit une earavane de la zone arabe, eommandée par quatre blancs qui nons apportaient, entre autres ehoses, vingt-trois eaisses de eartonehes.

Il fut décidé que nous irions les altaquer sans relard; dès le 6 novembre, nous étions en présenee.

liordre de marche restait le mème qu'au eombat précćden l,mais, lorsque nous fumes en contact,Swenson fut envoyé sur notre droile arec 130 hommes et de Bèche sul notre flane gauche avee 70, afin d'empècher tout mouvement tournant de la part de l'ennemi.

Ceei fait, nous uous reportames en avant; Doorme commandait l'avant-garde; je le snivais aree 150 hommes, enfin venait Lothaire, avee le gros des forces de la zone arabe.

Bientòt, nous entendimes une fusillade endiablée sur notre flane droit; Swenson élait done cerlainement aux prises arec l'ennemi; mais quelle étail la foree numérique de eelui-ci?

A tout hasard, Lothaire envoya à Swenson le sergent Spilliart a vee 70 soldats afiu de le renforcer, et la marehe se continua en avant. En arrivant sur le plateau qui se trouvait devant nous, ne voyant pas d'ennemis et 
entendant que la fusillade sur notre droite ne ralentissait pas, je fis arrèter la marche en avant, et, après nous ètre consultés arec Lothaire, il fut décidé que celui-ci et Doorme continueraient leur marche en avant, tandis que moi, arec les 150 soldats qui me restaient, j'irais me rendre compte par moi-mème de ce qui se passait chez Swenson. Il était temps : J'arrivai juste à point pour recueillir Spilliart et ses hommes en pleine retraite et près d'ètre enveloppés, au moment mème oì Swenson, qui arait a flaire à presque toutes les forces des révoltés, allait à son tour ètre débordé et certainement massacré avec la plus grande partie de son monde.

Nos forces réunies eurent assez vite fait de rétablir le combat; l'ennemi fut culbuté et la poursuite se continna juscu'au soir.

Quant à Lothaire et à Doorme, ils ne trouvèrent devant eux, que les bandes de Dibné et de Kolomoni.

Si donc l'honneur dì combat du 16 oclobre revient à Doorme sans conteste, ce furent Swenson et Spilliart qui assurèrent la victoire du 6 novembre, car, sans leur résistance opiniàtre et énergiđque, je ne serais jamais arrivé à temps pour les dégager.

Dès le lendemain de ce combat, Lothaire et moi formaines une colonne de 300 hommes pris parmi les officiers et les soldats les plus valides des deux détachements et la lançâmes, sous les ordres de Swenson, à la poursuite des fuyards. Ce fut sans résultat, car 
ceux-ci parvinrent à nous faire perdre leurs traces; ce ne fut que plusieurs mois après ces derniers évènements que j'appris d'une façon certaine qu'ils s'étaient réfugiés et reformés au Nord-Est de Kassongo-Niembo.

Le 17 novembre, je quittai Lothaire. Tandis qu'il regagnait la zone arabe, je rentrai à Lusambo, où j'avais à reprendre le commandement du district; Gillain repartait pour l'Europe, son terme étant expiré depuis longlemps. 


\section{CHAPITRE XV.}

Rentrée à Lusambo. - Départ de Gillain pour l'Europe. Grande expédition vers le Sud. - Réception émouvante à Kabinda. - Le tribut volontaire de Lupongu. - Chez Kaiéié. - Trop de gibier. - Singuliers effets de la foudre. - Un éléphant monstrueux. - Les chutes et les grottes de Bena-Kaya. - Un marché original. - Invasion de fourmis. - La mort de John. - Arrivée à Muséa. - Départ de la caravane du Katanga. - Un Haoussa de Delcommune. - Mon cuisinier met le feu au campement. - Le dévouement du soldat congolais. - Beaux spécimens de la race dans les deux sexes : Un soldat. Un boy. - Mademoiselle Coco.

Aussitòt rentré à Lusambo, je m’oeeupai de réunir et d'organiser une grande expédition, à la tète de laquelle je me proposais d'accomplir diverses missions d'ordres assez différents.

Ce que je voulais d'abord, c'était faire partir une caravane de ravitaillement pour lo Katanga, ear ee poste n'avait plus été ravitaillé depuis plus d'un an. La caravane devant passer aux environs de l'endroit où les révoltés s'étaient réfugiés, je voulais l'escorter moi-mème, afin de la mettre à l'abri d'un eoup de main de la part de ceux-ci.

Ce que je voulais aussi, c'étail punir les chels qui a vaient fait cause eommune avee les soldats révoltés, réeompenser eeux qui nous étaient restés fidèles aux heures dilliciles, rétablir notre prestige par une exhibition de forces relativement considérables ; visiter tous 
les grands ehefs de ee vaste pays, afin de nous les attacher; faire la eonquête des Bakuas-Kassassus qui n'avaient jamais voulu se soumettre à l'Etat; enfin battre Kalamba et réoccuper Mukabua et la eontrée a voisinante.

Deux mois après ma rentrée, c'est-à-dire le $1^{\text {er }}$ février 1895, je quitlais Lusambo, aceompagné d'Albert Lapière et de trois cents bons soldats; nous avions également avee nous plus de quatre cents charges destinées tant au poste du Kalanga qu'aux besoins de l'expédition. J'avais également donné des ordres à Strenson, qui devait me rejoindre au poste de Kabinda, avec de Bèche et Geyssens, ainsi que deux eents soldats.

Je profitai de ce qu'un grand steamer, "La Ville de Bruges "), se trouvait à Lusambo pour faire transporter mes eharges à M'Pania Motombo. Ayant reçu de ee chef les nombreux porteurs qui m’étaient nécessaires, dès le 3 je le quiltai pour entreprendre mon long voyage.

Après quatorze jours d'une marehe des plus fatigante, par monts et par vaux, nous arrivons en face de Kabinda, l'immense agglomération qui forme le village du grand chef Lupongu.

Ce dernier était pour moi une vieille eonnaissanee, je dirai presque un ami.

Pendant la guerre arabe, il m'avait servi d'auxiliaire aı grand eombat de Chigé, s'était opposé de toutes ses forces au passage des révoltés et son village, avait été 
brùlé par eux; enfin, en toutes les occasions, il s'élait toujours montré l'allié le plus fidèle de l'Elat.

Aussilòt qn’il apprit mon arrivée, il fit tout son possible pour me receroir le mieux qu'il put. Des courriers furent envoyés dans foutes les directions, afin de convoquer ses principanx chefs, ainsi que tous ses ghteriers. Lorstue, le 16 février, je lis mon entrée dans ce village que j’a vais vu brùlé et en ruines quelques mois auparavant, je fus réellement ému.

Sirenson el de Bèche, arrivés la voille avec deux cents soldals, rangèrent leur frompe en balaille en face du poste, a crité des 120 de Sla w, qui formaient la garnison de Kabinda. Quant à lupongur, il se porla à ma rencontre, culouré de ses plus grands chefs el escorté de plus dr trois mille guncriers armés de fusils, ainsi que d'un peuple innombrable. Iussi lorsque, clairons sonnanl, tambonls hallanl el diapean déployé, nous finurs nolve culdre dans le village, ce fut mne scène incinarrable: I'ne clamenr immense, prodigieuse, insensic nous accueillit, landis que des centaines de lambours ballaient el quéclataient des milliers de coups de fusil.

Linsi escortés, nous arrivons en face du poste. All moment précis où les trois ceuts hommes sous les ordies de Siwenson présentent les armes et que les clairons sonneut aux champs pour saluer notre élendard, à ce moment, dis-je, un vent se lève sous 
ce ciel sans nuage et déploie notre beau drapeau qui flotte maintenant joyeusement et fièrement comme un heureux présage.

Pendant tout ce temps, le canon du poste gronde sur sa butte et nous salue martialement lui aussi de sa voix grave et profonde.

Une larme heureuse me mouilla la paupière ; les yeux fixés sur le drapean, je me sentis frémir dans tout mon être d'une juste et patriotique fierté, car pour moi ce lambeau d'étolle représentait à la fois la patrie absente, agrandie par notre fait, le triomphe et la glorification de l'œuvre grandiose et généreuse de notre "Roi ", l'oeuvre à la réussite de laquelle je m’élais consacré corps et âme.

Avant de quitter Kabinda, où je séjournai arec toute l'expédition pendant six jours, je crois intéressant de vous dénombrer les cadeaux que je recus de Lupongu le jour de mon arrivée. Il me donna :

1 boeuf,

5 pointes d'ivoire,

10 charges de cannes à sucre,

10 charges de haricots,

16 charges de sel,

16 charges d'arachides,

37 grands pots d'huile de palme,

100 croix de cuivre,

50 moutons, 


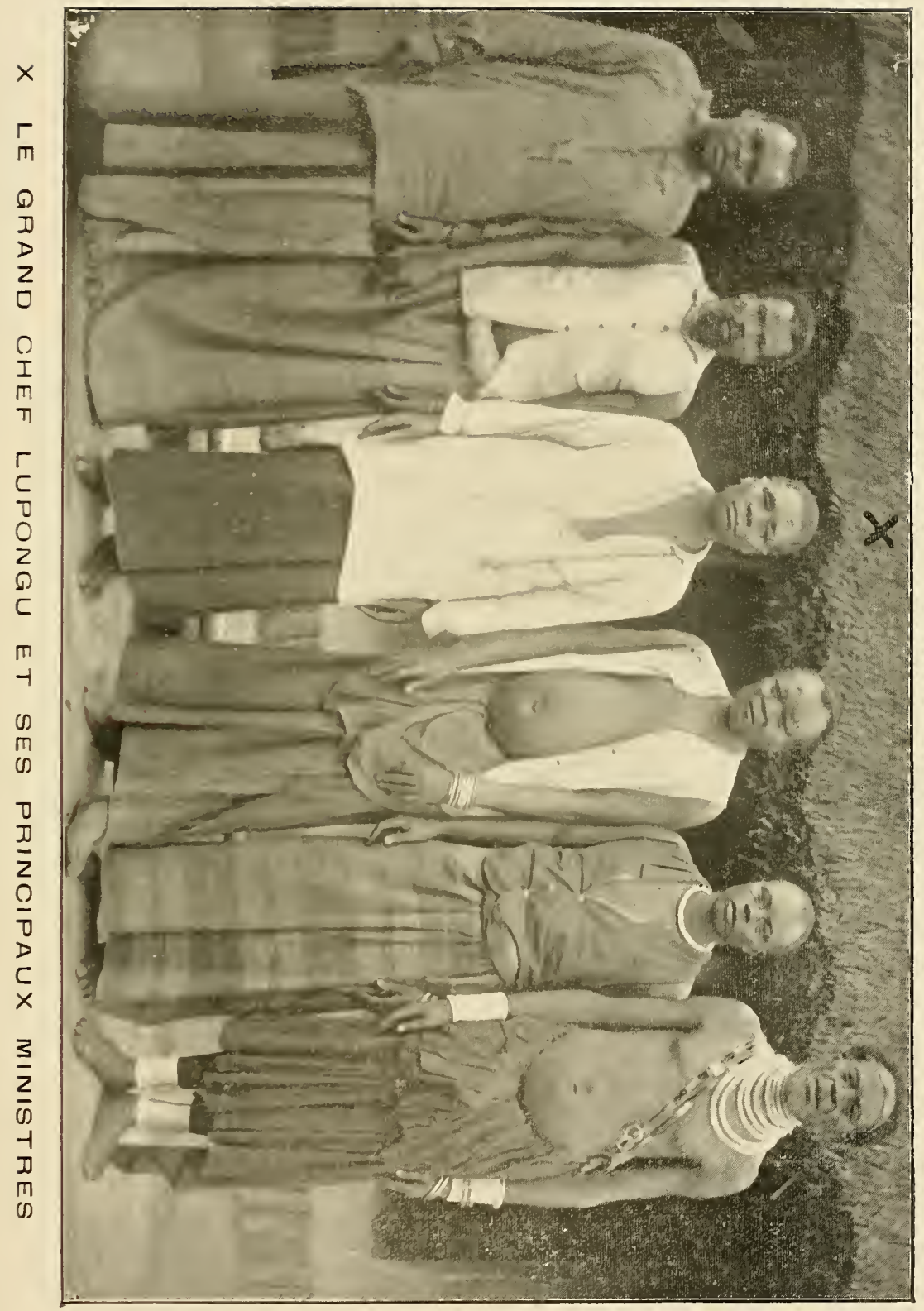




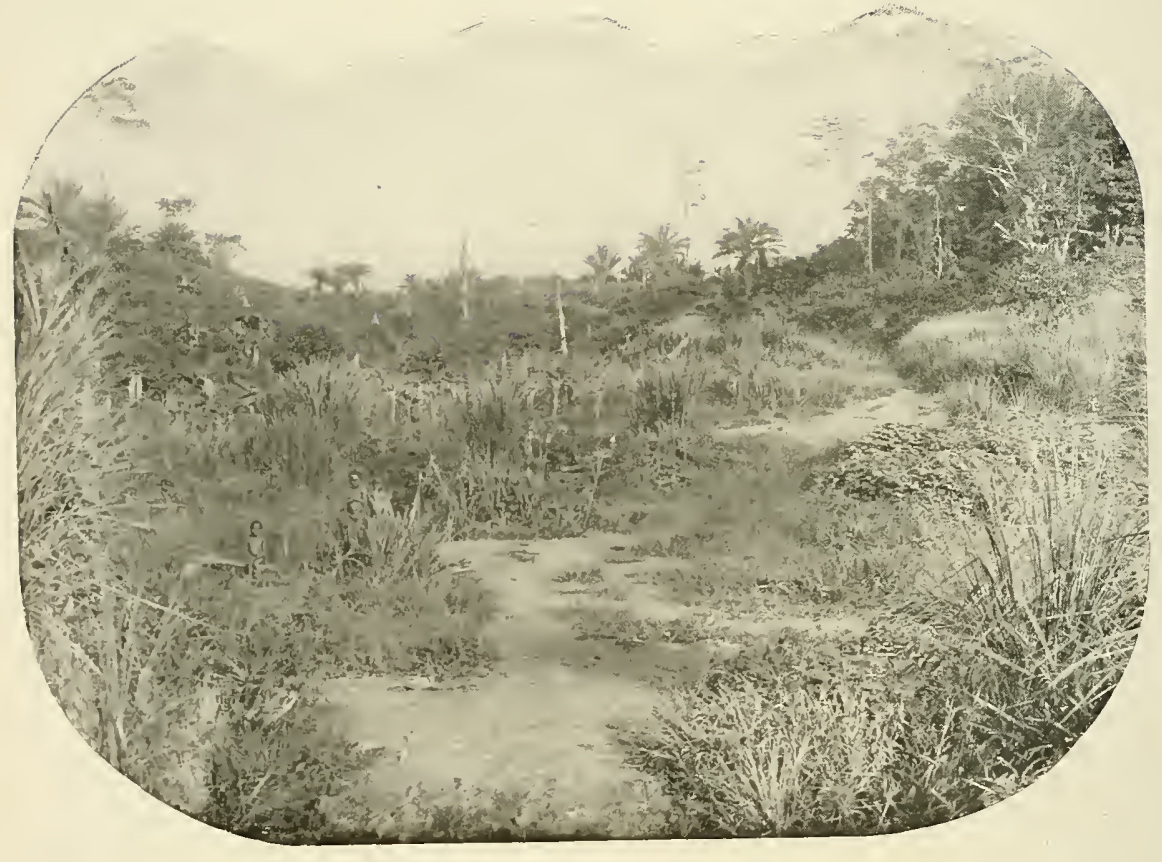

ASPECT DE LA SAVANE 


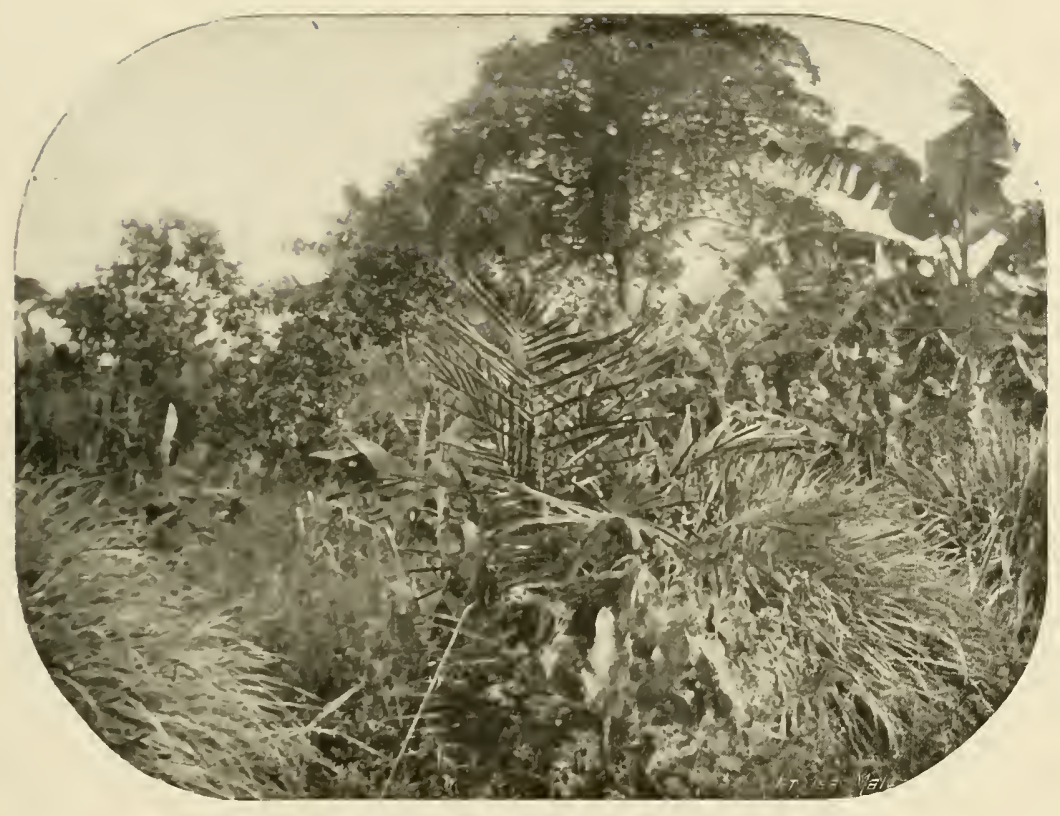

ASPECT DE LA BROUSSE 


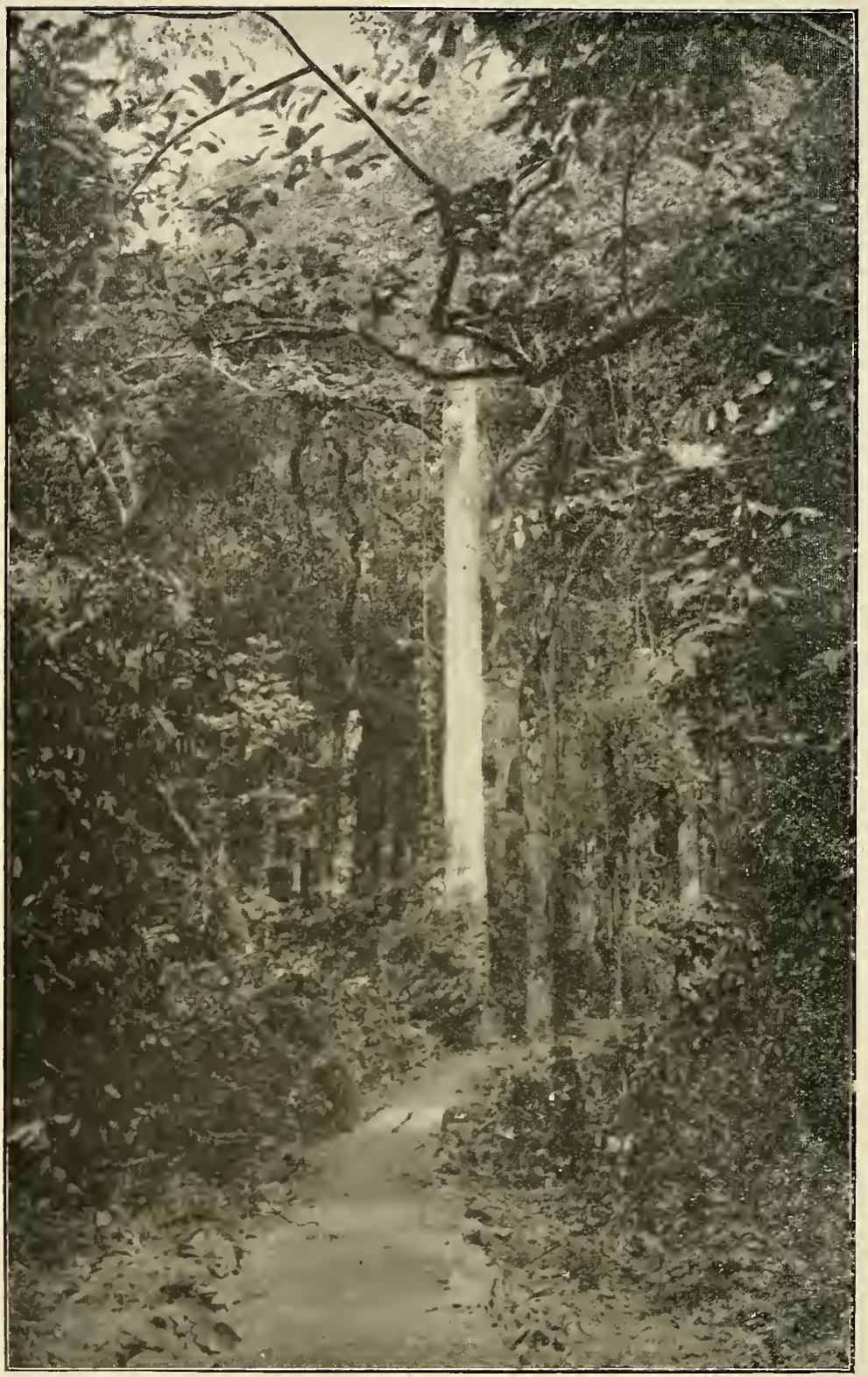

Sentier sous bois dans la grande forêt 
90 chèrres,

700 charges de maïs,

S00 charges de manioc,

910 poules.

Les six jours que je passai à Kabinda furent employés à organiser définitivement l'expédition, à rendre la justice, ainsi qu’à receroir les nombreux chefs des environs, qui tous étaient venus me faire visite.

Le 22, nous quittons définitivement Kabinda, mais en deux colonnes, car nous sommes trop nombreux pour royager ensemble: notre ravitaillement serait trop diflicile.

Nous nous réunirons de noureau à M'Pafu, afin de traverser avec toutes nos forces la régrion dangerense.

I.e 2-t, j'arrivai avec ma colonne clıez le grand chef Kaicié. C'est le seul chef de cette contrée qui, avec Lupongu, nous soit resté réellement fidèle pendant les jours douloureux de la révolte de nos soldats.

Lors du combat qui s'est livré le 5 décembre 1895, près de son village, il a fait enterrer le plus décemment qu'il a pu notre mallieureux camarade le lieutenaut Bolhen, et, lorsque les autres chefs de la " contrée " lụi disaient qu'il avait tort de se ranger du côté des blanes, puisque ceux-ci u'avaient plus de soldats et que leur règne devait ètre considéré comme fini il leur répondit arec conviction (qu'évidemment les blanes traversaient une crise épouvantable, mais que certainement aussi, 
ils reviendraient un jour en nombre et qu'alors ils puniraient ceux qui se seraient révoltés.

Je passai 48 heures chez lni; après avoir fait son éloge, en présence d'un peuple immense, je hıi remis un très riche présent, afin de bien montrer à tous cule, si nous savions punir nos ennemis, nous savions aussi récompenser dignement ceux qui nous étaient déroués.

En quillant Kaićié, nous abandonnons les montagnes pour entrer dans le pays des grandes plaines, aux marais profonds et perfides, mais aussi dans le pays de la chasse. Pendant plus de trois mois, il ne se passa pas un jour sans que j'abattisse an moins une belle pièce de gibier. I la fin, je ne tirais plus que ce qui élait nécessaire à notre table, ou encore quelques très grosses pieces que je distribuais à mes hommes.

11 y avait trop de gibier, c'étail trop facile à tirer et l'on u'avait plus le plaisir de la surprise.

Le 2 mars, il m’arriva une singulirre arenture :

Dans la matinée, nous avions rencontré une rivière nommée Lubimbi, large en cel endroit de 12 mètres environ, très profonde, el dont les eaux grossies par la pluie roulaient arec une violence extrème.

Nons avions mis plus de trois heures pour construire un pont et ma cararane étant passée, j’avais élabli mon camp sur l'autre rive.

Vers 5 hieures du soir, un orage épouvantable se déchaìna au-dessus du camp. J'élais assis dans ma 
tente, sur ma malle-bain, quand, soudain, un coup de tonnerre éclate et je suis jeté à terre hors de ma tente. La fondre était tombée sur un arbre à environ vingt métres de l'endroit oì je me trouvais et avait produit les effets les plus singulicrs : deux femmes qui pilaient du manioc en dessous de l'arbre avaient été renversées sans ressentir aucune espèce de douleur, tandis qu'unc douzaine de poules qui se trouvaient au mème endroit avaient été tuées sur le coup.

Deux fusils appuyés contre l'arbre avaient eu leur crosse fendue d'une façon idenlique, landis ru'aueune partic en for n’était dérangée. Enfin Lapière, qui avait sa tente beancoup plus près de l'arbre que la mienne, ne ressentit pas la moindre secousse.

(Quant à moi, j'éprouvais une douleur assez vive dans la jambe ganche et je boilai même assez fort pendaut deux jours.

Le 4, nous aperçumes de l'autre còté de la Luembé, à environ 500 mètres de nous, un éléphant énorme. Je n'ai jamais v'l un monstre semblable; chacune de ses défenses pesail cerlainement plus de 70 kilogs. Je lui ài envoyé quelques coups de fusil, mais sans résultat apparent. La distance était trop grande.

Le 8 mars, nous arrivons an village de BenaKaya, qui se trouve à cheval sur la Luembé, el le lendemain, la caravane de Swenson vieut nous rejoindre. 
C'est dans ce village que j'ai pu admirer, tout à la fois, les plus belles chutes et les plus belles grottes que j’aie jamais vues. Nous sommes allés les visiter dans l'après-midi du 9.

Pour arriver aux chutes, nous sommes obligés de dégringoler la montagne en nous accrochant à des lianes, tant la descente est raide et difficile, mais, en arrivant au pied des chutes, nous sommes largement payés de nos peines par le spectacle terrifiant et grandiose qu'il nous est permis d'admirer.

La Luembé qui, en cet endroit, a environ 40 mètres de large, se laisse choir tout d'une venue et avec fracas d'une hauleur d'environ vingl-cinq mètres dans un vaste entonnoir rocheux.

l'eau tombe arec une telle violence qu'il se forme au-dessus de la chute un nuage permanent que l'on aperçoit à une très grande distance.

Au sortir de cet entonnoir, les parois des rochers formant ses rives se resserrent en un long couloir, n'ayant pas plus de dix mètres de large, où la rivière se précipite arec une force irrésistible. C'est effrayant, verligineux.

Voulant me rendre compte de la force du courant, j'ai fail jeter par mes hommes plusieurs gros arbres dans la rivière. Lorsque ceux-ci se maintenaient dans le fil du comrant, ils passaient devant nous avec la rapidité de l'éclair et en décrivant des embardées 
fantastiques, mais lorsqu'ils se présentaient en travers à l'orifice du coułoir, en moins d'un dixième de seconde ils étaient réduits en miettes, on peut dire pulvérisés.

Nous allimes ensuite visiter les groltes sous la direction du chef du village. Nous avous commencé par descendre pendant plus de dix minutes, puis nous avons parcouru un grand nombre de couloirs el de salles sur lesquels venaient se greffer un nombre incalculable d'autres. Enfin, après plus de deux heures de promenade souterraine, nous sommes revenus à la surface. Notre guide nous a affirmé que nous n'avions pas parcouru la dixiènı partie des grottes.

Nul doute que, dans un temps plus ou moins rapproché, lorsqu'elles seront mieux conmues, l'on se reudra en excursion aux grolles et aux clutes de la Luembé, de la mème façon que l'on se rend aux chutes du Niagara. Ici, l'on aura deux attractions extraordinaires au lieu d'une.

C'est également à Béna-Kaya que j’assistai au plus curieux marché que j’aie jamais vu.

Lors de notre arrivée, tous les gens du village s'étaient retirés dans leurs grottes. Comme notre campement dominait celles-ci de plus de vingt mètres et que le bruit des chutes rendait toute conversation impossible, voici ce que nos hommes avaient imaginé : au moyen de longues et flexibles lianes, ils laissaient descendre des mitakos, des perles ou des étolles jusque près des 
indigènes, ceux-ci remplaçaient ces marchandises par des poules ou des poissons fumés. Si le soldat était satisfait de l'envoi, le marché était conclu ; dans le cas contraire, le soldat laissait redescendre les ponles ou les poissons en y ajontant autant de petits bàtonnets (qu'il désirait d'mnités en plus; si l’indigène consentait, il ajoutait à son envoi ce qu'on lui réclamait et l'afiaire était faite; dans le cas contraire, il retournait au soldat son envoi et le marché en restait là. Le comble, e'est que ni le chef du village ni moi n'eûmes à intervenir une seule fois ; loutes ces relations commerciales furent clablies avec une entière bonue foi de part et d'autre.

Le village de Béna-Kaya est également très curieux. Les cases se trouvant sur la rive droite servent d'habitalioins exclusivement aux esclaves; quant aux chimbeks de l'intre rive, c'est le quartier des nobles, des guerriers et des hommes libres.

Charfue partie dı village est entourée d'une double el formidable enceinte formée de jeunes palmiers, de ronces el d'épines s'enchevètrant les unes dans les autres et présentant un mur de feuillage impénétrable. Un couloir fortifié relie les deux bomas et cache le senl passage à ğné qu'il y ait.

Done si les assiégés faiblissent d'un côté, il leur reste tout le temps voulu pour passer daus l'autre boma, taudis que l'ennemi serait obligé de passer la rivière pour aller de nouveau les assiéger, ce qui est quasi- 
impossible, la Luembé formant des rapides des deux còtés. Et dans le cas où ils seraient vaincus, soit par la ruse, soit par le nombre il leur resterait toujours les grottes inaecessibles, qui sont leur plus certaine planche de salut.

La coilfure des indigènes de celte contrée est aussi bizarre que variće. Ces guerriers out les cheveux légèrement ondulés sur le dessus de la tète et portent la tresse derriere exactement comme les perruques des anciens seignemrs de chez nous. Celle tresse est garnie de cauris ; c'est la plns élégaute de leurs coilfures el la plus propre, car toutes les autres sont enduites à l'huile de palme et répandent une odeur peu agréable.

D'autres ont la lète converte d'une centaine de petites tresses qui parfoir se réunissent vers le sommet de la lìte, et $y$ sont maintenues par quelques perles ou retombent à droite el à gauche.

J'autres aussi onl les chereux artistement tressés en une dizaine de mèches raides qui lorment une couronne vers le sommet du crine. (Ce rout surlout les hommes libres). Enfin il y en a d'antres encore qui ont tous les cheveux ramenés derrière la tête, où ils forment un gros bourlet et sont rémis par un anneau de cuivre. Quant aux femmes, elles ont tous les ehevenx en longues tresses bouclées entremêlées de cauris; ees tresses retombent des deux còtés; le lout est fortement enduit d'huile de palme mélangée à de la terre rouge. 
Quant à leurs costumes, les hommes portent un petit pagne en madiba (fibres de palmier) qui leur vient au-dessus du genou. Les femmes portent par devant un tout petit pagne qui est attaché à la corde qui leur serre les reins; derrière, elles ont également un pagne long et étroit qui leur tombe sur les talons, ce qui fait qu'en marchant le vètement flotte de droite à gauche. C'est d'un effet tout à fait bizarre.

Dans cette contrée il se trouve de nombreux pièges au gibier. Ce sont des fossés larges d'un mètre sur trois de longueur. Ces fossćs ont environ trois mètres de profondeur et ront en se rétrécissant vers le fond. Dans le fond il se trouve des pieux apointés vers le sommet; le tout est recouvert de broussailles, ce qui fait que la bète qui tombe dans ces trous s'empale le plus souvent et dans tous les cas s'enfonce de plus en plus en raison des efrorts qu'elle fait pour en sortir.

On rencontre de ces traquenards dans les plantations et mème souvent dans le sentier. Nos soldats eurent la chance d'y découvrir plusieurs belles antilopes capturées de cette façon.

En quittant les chutes et jusqu'au village de Muséa, où nous arrivàmes vingt jours plus tard, rien de bien intéressant à signaler, si ce n'est une aventure assez désagréable qui advint à mon ami Lapière.

Une nuit donc, mon camarade se reposait tranquillement des fatigues de la journée, quand, tout à coup, il 


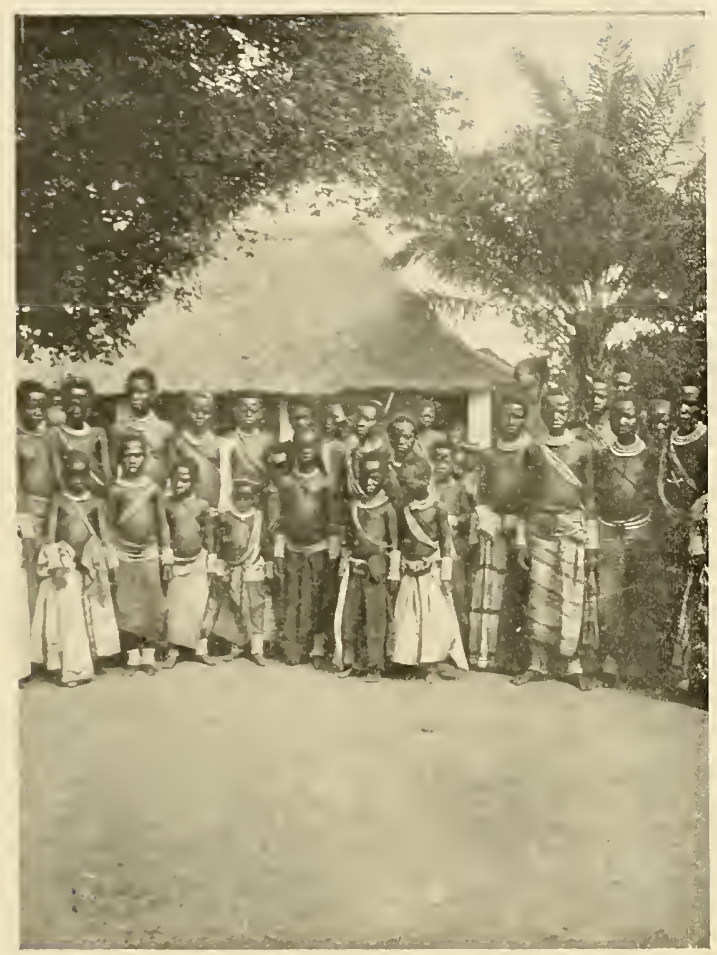

UNE JOLIE FAMILLE!

Ies enfants de ZAPO-ZAPE

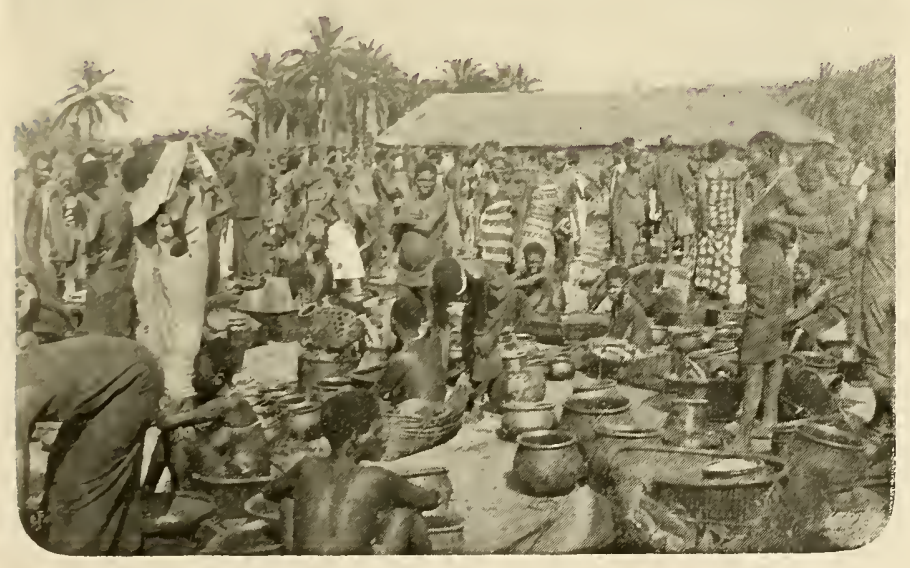

Un marché inclisène 


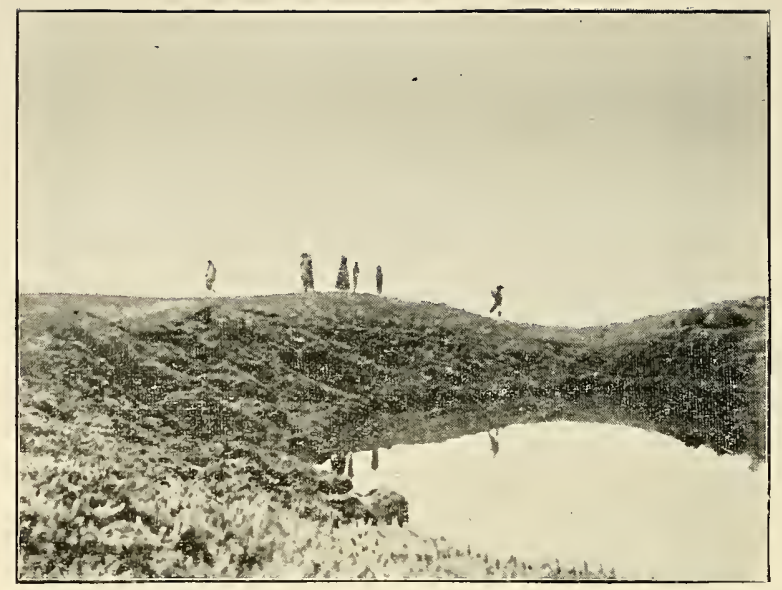

Cratère d'un ancien volcan du Kivu transfcrmé en lac

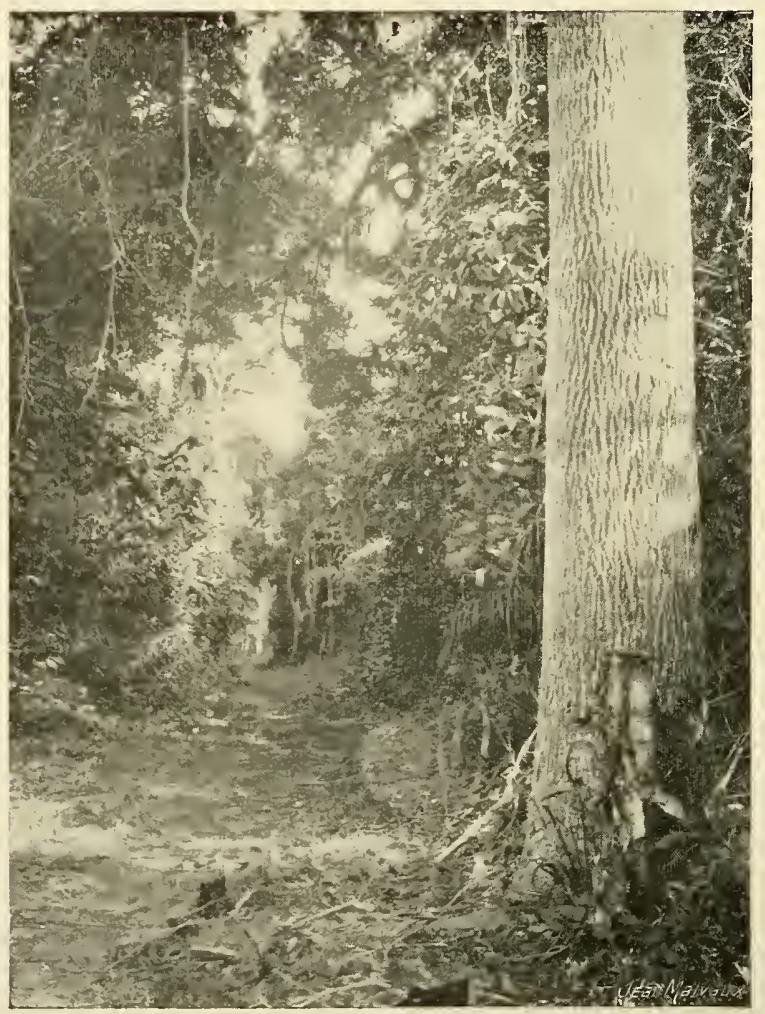

Un séant de la forêt 
est réveillé en sursaut par son chien, qui sautait comme un fou d'un bout de la tente à l'autre.

Il l'appelle, mais le chien n'entend rien et saute de plus belle. Croyant à la présence d'un serpent, Lapière se lève en hàte et fouille partout sans rien voir. Tout à coup, il se sent des piqùres par tout le corps; regardant plus attentivement, il s'aperçoit enfin que sa tente est envahie par une légion de fourmis, il y en avait partout! Il dut travailler avec ses soldats pendant plus de deux heures pour s'en débarrasser et si une pluie des plus opportune ne s'était mise à tomber, je ne sais comment il s'y serait pris pour mettre en fuite ces hôtes incommodes.

Détail assez curieux : j'avais ma tente à quelques mètres de la sienne et, non seulement je ne fus pas dérangé par les fourmis, mais je n'entendis mème rien ; ce fut seulement le matin que j'appris la mésaventure de mon ami.

$\Lambda$ quelques jours de là, j'eus un gros chagrin : mon pauvre John, mon brave chien de chasse, avait vu tant de gibier depuis quelques jours qu'il en avait gagné la fièvre; il en mourut. Ce fut certainement une des plus grandes peines que j’aie ressenties en Afrique. C'était mon compagnon inséparable. Il était doué d'une intelligence hors ligne et d'un dévonement sans pareil. Aussi était-il aimé et cajolé par toute l'expédition. Je l'aimais comme un ami et je l'ai pleuré comme tel. 
Le 26, la route est fort longue; nous n'arrivons au village de Lulu que vers deux heures de l'après-midi. Sur la route il ne se trouve pas le plus petit ruisseau ; on n'y rencontre pas la moindre goutte d'eau. Heureusement qu'on nous a prévenus et que nous avons pu prendre nos précautions.

Il fait une chaleur suffocante; nous traversons d'immenses plaines formant de légers mamelons; le terrain est argilo-ferrugineux et pierreux, les herbes sont peu élevées et la réverbération est très forte; grâce aux provisions d'eau que nous avons eu la précaution d'emporter, nos porteurs et nos gens ne souffrent cependant pas trop.

Vers une heure,nous voyons dans le lointain de hautes montagnes; il y a certainement un village dans les environs, car nous marchons dans de belles plantations; aussi nos hommes reprennent-ils courage. En effet, le village ne se trouve plus loin et nous y arrivons une demi-heure plus tard. Après avoir traversé une forêt très épaisse, où nous découvrons de nombreux pièges et où nos hommes prennent plusieurs bêtes dans les fossés, le sentier descend très raide et nous voyons le village à nos pieds. Il n'est pas très grand; il s'y trouve environ deux cents cases. Il n'y a pas non plus de boma, mais il est défeudu de trois côtés par une brousse impénétrable tandis que le quatrième côté l'est par un vaste marais. A l'entrée du village, le chef fait mine de vouloir susciter des difficultés pour nous laisser entrer, 
donnant comme prétexte que les cases sont très petites et trop peu nombreuses, pour abriter notre immense caravane; il dit aussi qu'on est occupé à préparer le tribut, en deux mots, il nous invite à camper à la porte.

Je lui réponds que mes hommes sont trop fatigués pour établir un campement et passant outre, je prends possession du village, l'assurant que lui et ses gens n'avaient rien à craindre, ni pour eux ni pour leurs biens. Quelques heures après il était tout à fait rassuré.

C'est dans ce village que j'ai vu les plus nombreux et les plus beaux fétiches, une immense tête creuse avec deux grandes cornes servant au féticheur qui se l'adaptait sur les épaules; il y avait encore plusieurs fétiches ayant au moins un mètre de hauteur, et représentant l'un un homme et l'autre une femme avec un pot, battant le manioc, ainsi que plusieurs autres sujets très originaux et tous fort bien sculptés. La canne du chef était formée de cercles en cuivre allant en spirales de bas en haut; elle était aussi surmontée d'une tète de femme très finement sculptée; il y avait également une massue dans le même genre, ainsi qu'une superbe pagaie, véritable merveille. Cette contrée est d'ailleurs très riche en objets de collection.

En arrivant à Muséa,j'eus une assez grande déception : je croyais bien y rencontrer le grand chef de la contrée Kassongo-Niembo, d'autant plus qu'il devait, me semblait-il, nous garder une grande reconnaissance, puisque 
c'était grâce à l'appui que lui avait donné Gillain qu'il avait pu régner.

Je tenais beaucoup à le voir, ayant plusieurs questions importantes à traiter avec lui. Malheureusement, à mon arrivée,je trou vai son village complètement abandonné.

Voulant avoir l'explication d'un fait que rien ne me faisait prévoir, je donnai l'ordre à mes soldats de tâcher de s'emparer, sans lui faire aucun mal, d'un des indigènes de la contrée.

Je fus servi à souhait ; dans l'après-midi, on m'amena, plus mort que vif, tant il avait peur, un indigène qui ródait aux environs du camp; c’était précisément un des petits chefs de Kassongo.

Après avoir réconforté mon lıomme et lui avoir fait quelques petits cadeaux afin de le mettre à son aise, je le " cuisinai " de mon mieux et bientòt j’appris toute la vérité.

Kassongo, après le départ de Gillain, loin de nous être reconnaissant de l'immense service qui lui avait été rendu, n'avait rien trouvé de mieux que de faire alliance arec les Kiokos, ces terribles esclavagistes du Sud, qui, par leur profession, étaient nos ennemis naturels.

Lorsque la nouvelle de mon arrivée parvint à Muséa, il s'y tronvait précisément une caravane immense de Kiokos ; ceur-ci avaient déterminé Kassongo à se retirer avec eux daus un boma formidable, qu'il possédait à quelques jours de marche de sa capitale. 
Je résolus d'aller l'y retrouver, afin de le forcer à se déclarer avec nous ou contre nous.

A Muséa, je donnai un jour de repos à mes hommes. Les porteurs de l'expédition de ravitaillement du Katanga en araient surtout grand besoin.

Comme, de cet endroit il n'y avait plus rien à craindre de la part des révoltés, il fut aussi convenu que le lendemain, $1^{\text {er }}$ avril, MM. de Bèche et Ghyssens termineraieut leur voyage avec leurs propres forces, tandis qu'avec Lapière, je continuerais ma reconnaissance du pays et mes visites aux grands chefs de la contrée.

Le soir, un petit banquel nous réunit; le lendemain matin, après aroir fait nos adieux aux camarades et leur avoir souhaité bon voyage, je fis ranger les deux troupes en face l'une de l'autre. On rendit d'abord les honneurs au drapeau, puis, sur un signe, la caravane de Bèche s'ébranla, pendaut qūe ma musique jouait ses marches les plus entraînantes et que mes soldats saluaient les partants de leurs plus formidables hourras!

De Bèche marchait en tête avec quelques soldats; venaient ensuite 400 porteurs avec un soldat intercalé de temps à autre; enfin Ghyssens, avec quelques hommes, formaient l'arrière-garde.

Cette caravane avait vraiment belle allure; nous formions le vœu que le destin lui fût propice...

Le 2, nous quittâmes également Muséa ; nous étions obligés de revenir sur nos pas pendant plusieurs jours, car nous n'avions pas de route directe pour nous 
rendre au boma de Kassongo-Niembo et à Motombo Mukulı.

Au moment où je m'apprêtais à quitter le village, on m’annonce qu'un ancien soldat Haoussa, qui s'était échappé des mains des indigènes, vient d'entrer dans le camp.

En effet, peu de temps après, on m'amèné un grand et fort gaillard, portant une barbe énorme, les cheveux retombant en longues boucles frisées de chaque côté de la tête et ayant pour tout costume un petit pagne indigène.

Sans soll tatouage, il eût été impossible de le reconnaître. Ainsi accoutré. il avait l'air vraiment comique ; aussi fuit-ce par un immense éclat de rire que nous l'accueillìmes, Lapière et moi.

Nous le fimes asseoir et il nous conta son histoire : Il était venu dans cette contrée avec Delcommune, en 1892; il tomba malade et, comme il ne pouvait plus suivre la colonne, son chef l'avait confié à un chef du village près de Muséa, qui l'avait toujours très bien traité. Seulement, depuis quatre ans, il n'avait plus entendu parler des blancs. Il nous dit aussi qu'il avait appris notre arrivée lors de la fuite de Kassongo, et qu'il s'était esquivé à son tour, afln de venir nous rejoindre.

Chose assez curieuse : il était toujours porteur de sa médaille avec son numéro de matricule; inutile, je crois, d'ajouter qu'il fut reçu arec enthousiasme par les autres Haoussas, qui le croyaient mort depuis longtemps. 
Nous arrivons, le 4, au grand boma de KassongoNiembo, mais celui-ci est également vide.

Pendant quatre jours, jc suis resté sur place, espérant toujours que Kassongo m'enverrait un émissaire quelconque, vain espoir : ce chef est une espèce de fou dont il n'y a rien à attendre.

Du boma de Kassongo au village de MotomboMukulu, il y a dix-sept jours de marche assez ennuyeuse à cause de nombreux marais.

Pendant cette longue marche, il ne nous arriva qu'une seule aventure, qui mérite d'ètre rapportée.

C'était lors du passage de la Luembé : la rivière est très large et très profonde en cet endroit (exactement 48 mètres de large). N'étant établi dans un village à proximité de la rivière, j’avais envoyé Lapière avec tous les hommes ralides pour faire un pont, et j'étais resté au campenent avec les malades et les éclopés.

Mes hommes n'étaient pas partis depuis une heure, que notre cuisinier met par maladresse le feu à la case, où il est établi. En un rien de temps, le feu prend des proportions énormes et menace de détruire le village ainsi que nos marchandises et nos munitions; le moment étant critique, je fais sonner l'alarme ; quelques minutes plus tard, j'ai la satisfaction de voir arriver mes lıommes, qui avaient réellement volé à notre secours et parriennent, après un travail acharné et parfois dangereux, à se rendre maîtres de l'incendie. 
C'est dans des circonstances comme celle-ci, lorsqu'il est livré à sa seule initiative et que tout dépend de son bon vouloir, que l'on peut le mieux apprécier tout ce qu'il y a d'admirable dévouement et d'abnégation absolue dans le soldat congolais.

Le soldat congolais est un être primitif,admirablement doué, capable des actes les plus follement braves et des dévouements les plus complets.

Toute la question est de le traiter en homme et non en brute; de savoir lui parler, de lui expliquer ce que l'on attend de lui, en un mot, de lui témoigner de l'amitié et de la confiance, de le rehausser à ses propres yeux. Quand on le conduit de cette façon, on peut tout lui demander, car il n'est aucun sacrifice qui soit au-dessus de son courage discipliné. C'est le bon chien qui n'a d'autre volonté que celle de son maìtre et qui, au besoin, se fait tuer pour lui.

Quelques exemples que j'ai pu constater de visu viendront je crois, avec à propos, soutenir la justesse de ma thèse.

Le premier se rapporte à un de mes soldats que j'avais dù faire punir; le suivant a trait au dévouement d'un petit boy; enfin le troisième montre l'intelligence, la charité d'une petite négresse.

Un matin j’avais dù faire appliquer la peine du fouet (appelée chicote au Congo), à un de mes soldats nommé Amissi, pour une faute grave concernant la discipline. 
Or, dans le courant de la journée, nous avions précisément à traverser une rivière large et profonde, au courant rapide.

Mes hommes avaient de l'eau juscu'à la poitrine, et craignant une chute de celui qui me porterait, je m'apprètais à entrer dans l'eau, quand mon homme puni le matin vint m’offrir de monter sur ses épaules afin de me faire traverser la rivière.

J'avolte que j'eus une seconde d'hésitation, car je me dis que rien n'élait plus facile pour lui, que de simuler un faux pas et de me faire boire une tasse de mauvais bouillon.

Je résolus cependant de tenter l'aventure, et sans rien montrer de mon appréhension,je montai sur ses épaules.

Il prit des précautions inouïes pendant tout le passage afin de ne pas tomber, et me déposa indemne sur la berge opposée.

Le soir, au campement, je le fis chercher et lui demandai comment il se faisait que c'était précisément lui, qui s’était présenté pour me faire passer l'eau.

" Ma punition de ce matin, me dit-il, je l'avais méritée et lorsque vous rous êtes trouvé au bord de l'eau, j'étais le seul présent qui fût assez fort pour vous faire traverser la rivière sans accident. »

" C'est bien, lui dis-je, je vois qu'il y a en toi de l'étoffe pour faire un bon soldat, prends cette chèvre et tu la partageras avec tes eamarades. ") 
Dans la suite, il ne se fit plus jamais punir, et il devint même un des meilleurs, parmi la troupe d'élite qui composait mon escorte particulière.

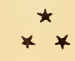

L'autre trait se rapporte à un pauvre enfant appelé Arthur N'tété, que j'avais trouvé sur un champ de bataille et qui depuis ce jour ne voulut plus jamais me quilter.

L'ayant ramené avec moi en Europe, je résolus d'en faire un lomme, et loin de l'exhiber comme un singe savant, je l'envoyai au caléchisme ainsi qu'à l'école.

Il était impossible de trouver un meilleur élève et un meilleur coeur.

Bien que Namur, ma ville de garnison, soit séparée de 27 kilomètres du village où il habitait avec mes Parents, sa plus grande récompense était de venir en bicyclette le dimanche matin, afin de me montrer son builetin de la semaine.

Ce brave enfant faisait donc 54 kilomètres pour recevoir une caresse et un encouragement, et me montrer qu’il était digne de l'intérèt que je lui portais.

Le fait suivant le dépeindra d'ailleurs mieux que tous les discour's.

En 1901, lorsque s'organisa l'expédition qui devait partir en Chine, j'avais eu l'honneur d'être choisi pour commander la colonne montée. 
Arthur avait entendu parler vaguement de la chose.

Quelques jours plus tard, j'avais obtenu l'autorisation d'aller passer quelques henres avec mes vieux Parents.

Il vint me trouver.

"Cela est-il vrai, Commandant, que tu vas partir pour la Chine. "

" Je le crois, Arthur; une expédition s'organise à cet effet et j'en fais partie. '"

"Alors, je pars avec toi ?"

"Cela n'est pas possible mon ami ; l'expédition ne se compose que de soldats, et comme tu es trop jeune pour t'engager, tu ne recerrais ni solde, ni ration de vivres. Et puis peut-ètre faudra-l-il faire la guerre; il y aura donc beaucoup de dangers à courir. "

"Commandant, me répondit-il, je veux aller avec toi. Les dangers ne sont pas plus grands ponr moi que pour toi et tu as besoin de quelqu'un qui t'aime bien, pour te soigner. De soldle, je n'en ai pas besoin, et pour ma nourriture, tu me donneras du pain et les restes de ta table, cela me suffira!"

Enfin, il me reste à vous parler de Mademoiselle Coco.

Coco tout comme Arthur N'tété était un pauvre mioche trouvé dans les herbes après une bataille et que mes soldats m'avaient rapporté.

Elle avait la plus curieuse petite frimousse de singe que l'on puisse imaginer; mais on oubliait vite qu'elle 
était laide,lorsque ses yeux immenses vous regardaient, tant ils reflètaient d'intelligence et de bonté.

Lorsqu'on me l'apporta, elle n'avait guère que 7 à 8 ans. (*)

De suite elle sut se rendre utile, peu après nécessaire et bientòt indispensable.

La brave petite Coco me rendait plus de services à elle seule que tous mes boys ensemble.

Dans les commencements que je l'avais chez moi, aussitôt qu'elle m'entendait appeler un boy, elle accourait, écoutait ce que je disais au boy, puis allait voir où le boy allait prendre l'objet demandé.

Bientòt ce fut elle qui montra aux boys les objets qu'ils ne trouvaient pas assez vite.

Plus tard elle ne se donnait plus la peine de le leur montrer el à moins que le poids ne fût trop lourd pour ses petits bras, elle me l'apportail elle-même.

Enfin elle n'était pas chez moi depuis un an que je lui avais confié toutes mes clefs.

Mais où Coco était incomparable, c'était lorsque nous étions en expédition.Outre mes effets personnels, j’avais alors arec moi parfois 60 ou 80 caisses contenant toutes espèces de marchandises ou de vivres, devant servir soit à faire des présents aux chefs, soit à alimenter notre cuisine. Et bien, comment Coco s'y prenait-elle? je n'en sais rien, mais le fail est que bien qu'elle ve sût évidemment ni lire ni écrire, je ne l'ai jamais vue se

(*) 7 à 8 ans au Congo représentent 10 à 12 ans en Belgique. 
tromper de caisse, ni de clef pour ouvrir le cadenas! c'était réellement prodigieux.

Quant à son bon cceur il égalait au moins son intelligence. Vu les immenses services qu'elle me rendait, j’étais amené à lui faire assez souvent de petits cadeaux tels que un pagne, quelques perles etc....

Or malgré mes largesses il n’y avait pas une femme, pas une fille d'un de mes soldals, qui fùt anssi pauvre que Coco.

Une femme était-elle, ou se disait-elle malade, Coco lui faisait cadeau de son nouveau pagne, soit pour la consoler, soit pour qu'elle ent plus chaud. Une autre avait-elle un gosse, Coco lui donnait ses perles pour faire un collier an moutard.

Un jour que je Iui reprochais assez vertement ses largesses, lui disant qu'après mon départ elle serait elle-mème très pauvre, et qu'elle était folle de donner ainsi tout ce qu'elle possédait, elle me répondit simplement :

"Oh maitre,si tu voyais comme ils sont heureux !!....) Brave petile Coco !...... toi aussi et saus le savoir, par pur instinct, tu avais une àme d'élite, une âme toute pétrie de bonté, de dévouement et de charité!

Qu'es-tu devenue depuis mon départ ?.......

Puisses-tu avoir trouvé un peu de ce bonheur que tu prodiguais si volontiers aux autres et que tu méritais si bien pour toi-même !........... 



\section{CHAPITRE XVI.}

Chez Motombo Mukulu. - Coutumes bizarres. - Le grand chef Mata Yamvo. - Conduite héroüque d'Albert Lapière. Filles d'Eve !... - Chez Kayéyé. - Une cérémonie pénible et impressionnante. - Un homme pris au piège. - Succession de combats acharnés. - Mort de N'Gongo. - Capture de M'Pogna. - Fuite de Kalamba. - Prise d'un drapeau Kiokos. - Meurs et croyances Bachilanges. - Réception du Père Cambier. Une messe militaire.-Retour à Lusambo.-Cruelle déception

A plusieurs jours de marche de son village, Motombo avait fait nettoyer la route, afin de faciliter notre marche. Nous élions encore à plus de trois heures du village que nous recevions déjà une députation de ses principaux chefs, envoyés à notle rencontre pour nous soulıailer la bienvenue.

Quoique très vieux, il vient nous recevoir en personne, porté sur les épaules d'un grand et fort gaillard. Sitôt arrivé près de nous, il met pied à terre et nous salue, nous disant que nous pouvons, ainsi que nos hommes, nous considérer comme étant chez nous. " Demandezmoi tout ce que vous voulez, me dit-il, et je vous le donnerai. )"

Il me prie aussi de rester deux ou trois jours chez lui, afin de me présenter ses sous-chefs, qu'il avait fait appeler. 
C'est avec plaisir que je fais droit à sa requête, car mes hommes ont besoin d'un peu de repos.

Pendant les trois jours passés dans son village, l'amabilité du vieux chef ne se démentit pas une seule fois; aussi est-ce avec regret que nous avons quitté notre amphitryon.

Avant de nous séparer et afin de lui faire honneur, j'ai passé avec lui en revue les 400 soldats de l'expédition, puis je les ai fait défiler. Inutile, je crois, d'ajouter qu'il a été aussi enthousiasmé qu'ahuri.

Le pauvre vieux n’avait jamais rêvé machine guerrière aussi formidable; à chaque instant, il me prenait les mains et se déclarait mon meilleur ami.

En quittant le village de Notombo, je me rendis chez le Mata Yamvo, où j’arrivai après cinq jours de marche.

Le nouveau Mata Yamvo a établi son village sur la rive gauche du Koïla.

Avant de décrire mon entrevue avec ce chef, je crois nécessaire de dire quelques mots de sa personne.

Le chef actuel est le quatrième du même nom, mais si son prestige est toujours immense sur son peuple qui l'adore, ses territoires sont beaucoup diminués en comparaison de ceux de son arrière-grand-père, le grand Mala Yamvo, qui, fondateur de la dynastie et empereur du Lunda, régnait sur un territoire trois ou quatre fois grand comme la Belgique. 


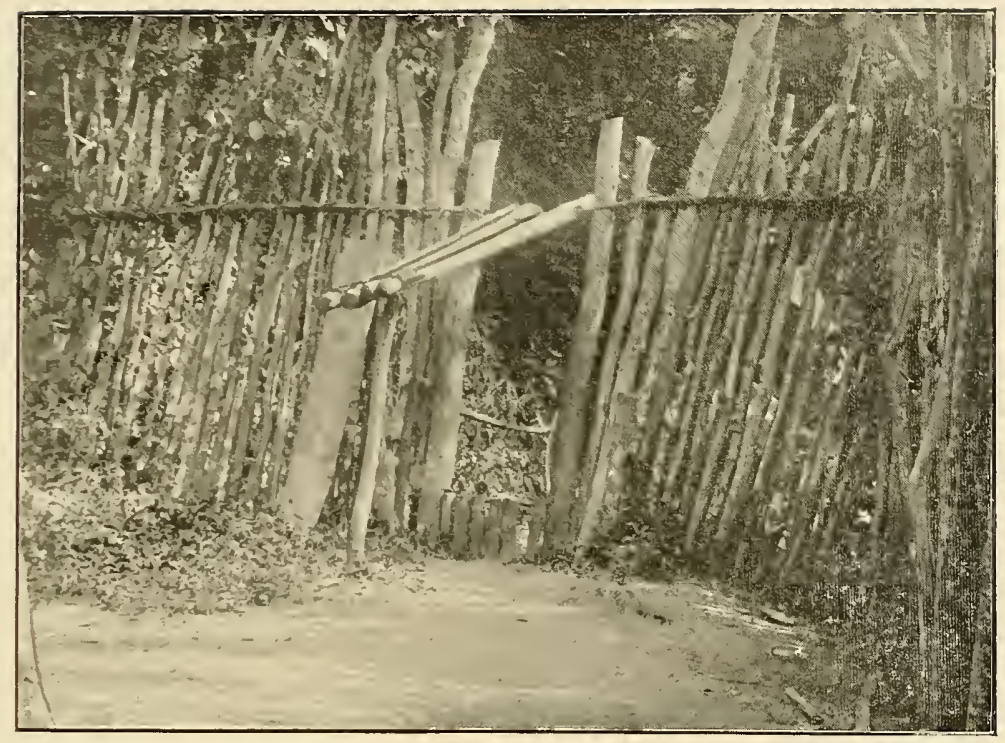

Porte d'entrée d'un village fortifié

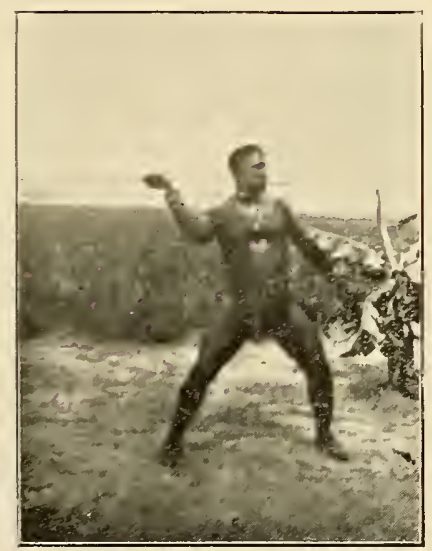

Inciigène lançant la sagaïe

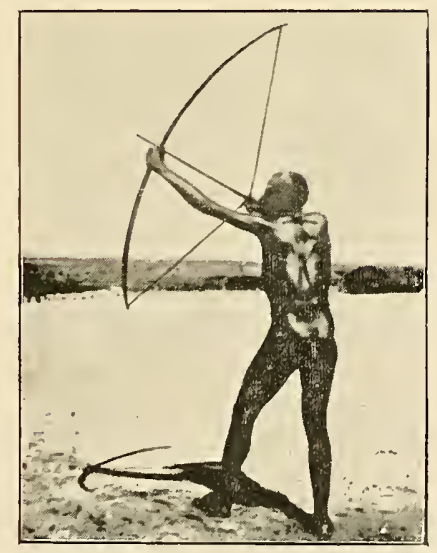

Indigène tirant à l'arc 


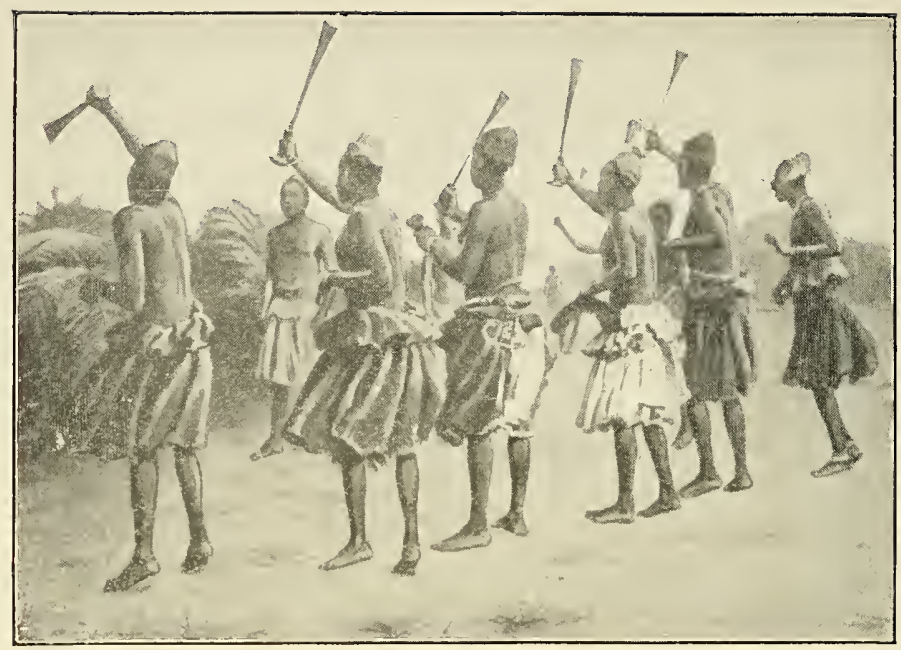

Figure d'une des nombreuses danses indigènes

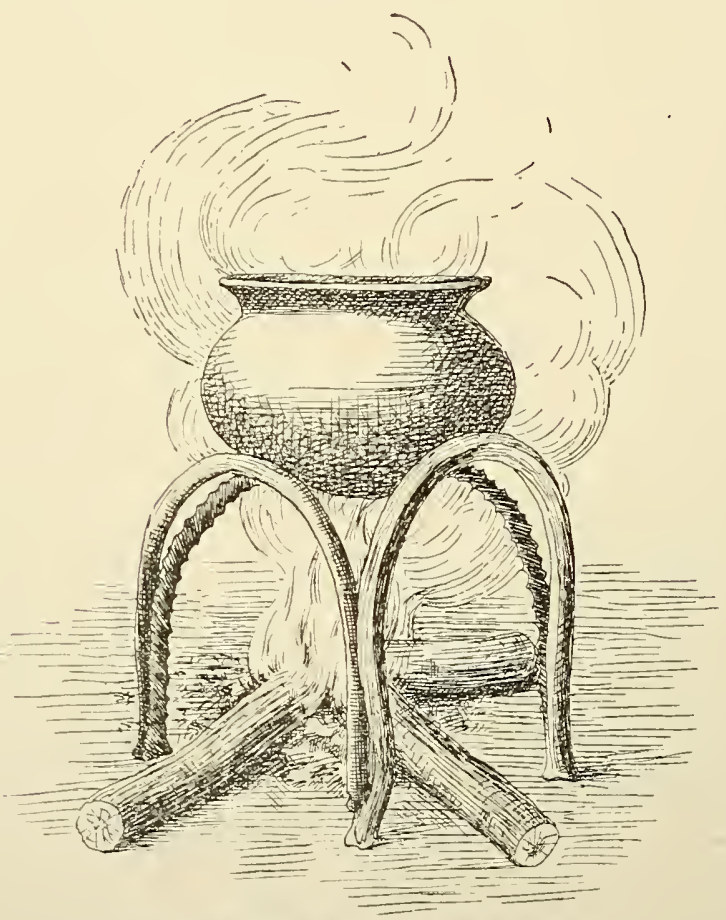

Guisine incigène 
Ce chef avait plus de cent mille hommes armés de fusils à pierre; il n'a pas été, comme beaucoup l'ont cru, battu par les Kiokos, mais lâchement assassiné par eux.

Voici en quelles circonstances :

Depuis toujours, le Mata Yamvo était en relations commerciales avec les Kiokos, auxquels il achetait sa poudre et ses fusils.

Comme bien l'on pense, ces derniers, qui sont bien les plus affreux esclavagistes et les pires forbans $d u$ monde, enviaient ses immenses richesses, son stock considérable d'ivoire et ses nombreux esclaves.

Un jour donc, ils se rendirent chez lui en très grand nombre et, comme le Mata Yamvo avait donné une fête magnifique en l'honneur de leur chef, ils l'assassinèrent traitreusement et se mirent à tirer sur tous ses sujets, qui, surpris sans défense, furent en grand nombre massacrés ou faits prisonniers.

Les deux premiers successeurs du grand Mata Yamvo furent des princes sans énergie et la plupart de leurs grands feudataires se rendirent indépendants.

Celui que je vis est beaucoup plus énergique; il est déjà parvenu à grouper à nouveau tout un peuple autour de lui.

Comme c'est un ennemi héréditaire des Kiokos et que moi-même je hais de toute mon âme, de toutes mes forces, ces bandits qui ont tant fait souffrir toutes nos 
malheureuses populations du Sud de l'Etat, je tenais énormément à me mettre en rapport avec lui, afin de nous liguer ensemble contre ces hordes dévastatrices.

Sachant qu'il n'avait jamais vu de blanc, ni eu de rapport avec aucun d'eux, je fis tout ce que je pus afin de ne pas l'alarmer par une visite inattendue.

Je lui enroyai donc un émissaire avec un présent, afin de le prévenir de ma visite et de l'assurer de nos bonnes intentions à son égard.

La veille de notre arrivée, nous rencontrâmes le soldat que j'avais envoyé en ambassade; il nous dit que le Mata Yamvo était très bien disposé pour nous, mais que, n'ayant jamais vu de blanc, il en avait peur.

Je campai sur une espèce de tertre qui se trouvait à environ trois kilomètres du village et j'envoyai mon interprète en chef afin d'aviser le Mata Yamvo de mon arrivée très prochaine. Les pourparlers furent interminables; enfin, mon interprète vint me dire que les gens du Mata Yamvo, craignant une trahison de notre part dans le genre de celle des Kiokos, ne consentaient ni à laisser venir leur chef, ni à nous recevoir dans leur village.

J'avoue que j'étais très embarrassé ; ce fut Lapière qui me tira d'embarras par un geste d'une bravoure antique daus son héroïque simplicité.

- " Commandant, me dit-il, vous n'obtiendrez rien de ces gens-là, ils sont trop craintifs. Laissez-moi partir 
arec quelques hommes et j'irai leur dire que je me remets comme otage parmi eux pendant que leur chef viendra vous faire visite. De cette façon, ma tète répondant de la sienne, peut-ètre bien aura-t-il confiance et pourrez-vous vous mettre en relations avec lui. "

J'hésitai beaucoup à accepter l'offre généreuse de mon ami ; mais, comme il insistait et que des intérêts absolument majeurs étaient en cause, je le laissai partir.

Sa mission réussit parfaitement. Déjà le chef et son frère ètaient en route vers notre bivac lorsque des gens de leur escorte ayant entendu un appel de clairon, furent repris de nouveau par leur peur et forcèrent le chef et son frère à faire demi-tour.

Albert dut donc revenir au camp, sans avoir réussi ; le pauvre garçon en était réellement malheureux. Désirant, coùte que coùte, entrer en relations avec le grand chef, je résolus alors d'aller le visiter moi-même le lendemain matin.

Dés le point du jour, je me mis en marche avec 20 soldats d'élite; quand je dis : " mis en marche ", c'est une façon de parler, car Lapière m'ayant prévenu que j'en avais pour une bonne demi-heure à patauger dans les marais avec de l'eau jusqu'à mi-jambe, je m'étais muni d'un hamac, afin de ne pas me présenter devant le Mata Yamvo crotté comme un barbet.

Le marais passé, nous arrivons en face du boma, qui est réellement formidable : un fossé très large et très 
profond nous en sépare et, pour arriver à la porte d'entrée, on doit franchir une passerelle formée d'un tronc d'arbre équarri.

L’intéricur du boma est également des plus remarquable: il s'y trouve d'immenses allées très droites, plantées de palmiers et bordées de milliers de jolies cases, soigneusement entretenues.

C'est certainement le plus beau et le plus soigné des villages que j'aic vus au Congo.

Les cases sont très différentes de celles des autres contrées : elles sont rondes, peu élevées et faites de fine paille très bien tressée. Le toit a la forme d'un parapluie et est lui aussi très bien travaillé.

Bien qu'il n'ait que deux doigts d'épaisseur, il est absolument impénétrable et semble pouvoir défier de très nombreuses saisons.

La route que je suis est très large et bordée des deux còtés par plusicur's rangées de cases.

Les femmes que je rencontre sont occupées à battre le manioc dans de jolis mortiers en bois. Elles ne paraissent nullement effrayées en me voyant passer. Elles arrètent simplement leur travail, s'avancent nonchalamment jusqu'au bord de la route où elles se campent et les poings sur les hanches se mettent à bavarder avec leurs voisines tout comme les commères de chez nous; il ne leur manque réellement qu'un tablier et un balai. 
Après aroir marché environ un kilomètre, nous arrivons à une place immense, couverte d'un peuple innombrable et au bout de laquelle se trouve un abri colossal, ayant la forme d'un champignon.

C'est là que m'attend le Mata Yamvo.

A mon approche, toute cette foule s'est levée comme un seul homme et s'est tue respectueusement. Un large couloir est ouvert au milieu et bientòt le chef vient à ma rencontre.

C'est un homme magnifique qui marque environ 40 ans ; sa taille moyenne est bien prise, la physionomie est des plus attrayante; elle fait songer à l'ancien type syrien. On roit de suite que l'on a afraire à un homme intelligent : je ne doute pas un instant que j'aurai vite fait de le convertir complètement à mes vues.

En arrivant sous l'abri, il me conduit à un siége, préparé pour moi et recouvert d'une magnifique peau de lion; lui-mème s'assied sur un siége plus bas, recouvert d'une mème peau, tandis que son frère et une foule d'autres chefs prennent place en demi-cercle sur des peaux de léopard; la foule s'installe, comme elle le peut.

Mais tout cela se fait avec un ordre parfait et dans le silence le plus absolu.

Après que le Mata Yamvo m’a souhaité la bienvenue et que je lui ai répondu de mon mieux, l'assurant de mes bonnes intentions à son égard, lorsqu'enfin tous 
les salamalecs officiels sont finis, je lui fais dire par mon interprète que j’ai un autre sujet plus important à traiter avec lui, mais que je désire lui parler en particulier, son frère et mon interprète devant être seuls témoins de l'entretien.

Il me fait alors entrer dans son lupongo particulier et, pendant plus de deux heures, je lui expose ce que je veux faire et ce que j’attends de lui.

Il me comprend très bien, entre complètement dans mes vues et nous devenons bientôt une bonne paire d'amis.

La palabre terminée, il me fait visiter tous ses appartements, qui dénotent, par leurs ornements et le fini de tous les objets qui s'y trouvent, une civilisation et un goût rare chez leur propriétaire.

Après quoi, nous dînons ensemble et je passe toute l'après-midi avec mon nouvel ami.

Mais comment vous parler du Mata Yamvo sans vous parler de ses filles, de ces êtres étranges qui m'ont ébloui et charmé ?

Leur teint vieil or et leur galbe de statue antique en faisaient réellement, à cette époque, une troupe de nymphes égarées au Continent noir.

Loin d'avoir le nez épaté, d'être lippues et d'avoir les cheveux crépelés comme presque tous les spécimens de la race nègre, elles avaient au contraire le nez aquilin; la bouche et les lèvres étaient d'un contour admirable, 
leur chevelure opulente et oudulée s'épandait librement sur leurs reins fièrement cambrés, leur démarche était souple et gracieuse, et leurs yeux immenses, semblables à des diamants noirs, nous fascinaient par leur éclat.

Leur costume lui-mème s'harmonisait admirablement avec leur beauté sauvage ; il se composait d'une espèce de longue chemise blanche sans manche, tombant tout d'une venue, ainsi que d'une longue pièce d'étoffe, dans laquelle elles se drapaient avec une suprème élégance et qui laissait à découvert le bras droit et le bas des jambes.

Filles d'Eve, elles avaient de leur mère toutes les curiosités. Elles voulaient tout voir, toucher à tout, et, par leur familiarité ingénue, ne laissaient pas d'embarrasser parfois ceux auxquels leur intérêt s'attachait.

Mais laissons ces séductrices et reprenons notre récit.

Huit jours de marche nous séparaient du village de Kaiéié.

La route fut assez monotone.

Le costume du chef Muéni-Musenghi nous divertit cependant beaucoup : il se présenta à nous affublé d'un ancien jupon de femme venant d'Europe, confectionné en satin noir avec volant, d'un veston taillé dans des mouchoirs à ramages, et coiffé d'un chapeau en feutre mou garni de plumes de toutes nuances et de toutes dimensions. Enfin, derrière lui, un esclave portait un immense parasol rouge, surmonté d'une tête de femme sculptée! 
En un mot, il était si réussi que - j'en demande bien pardon au protocole - lorsqu'il m'apparut, je ne pus m'empêcher de partir d'un immense éclat de rire.

Il n'en fut d'ailleurs nullement offusqué : bien au contraire, il prit mon hilarité pour une amabilité et se montra tout heureux de l'effet produit.

La veille de mon arrivée à Kayéyé, je fus rejoint par vingt soldats de Luluabourg sous la conduite d'un caporal. Celui-ci me dit qu'il avait reçu de Legat la mission d'aller occuper le village de Kanda-Kanda, qui se plaignait d'être menacé par une forte bande de Kiokos.

Le caporal, ayant appris mon arrivée, était venu me rejoindre afin de prendre mes ordres.

Le 14 mai, nous arrivons au village de Kayéyé vers 9 heures.

Le chef, accompagné de tous ses guerriers, vient à notre rencontre en grande pompe et nous souhaite la bienvenue. Il a fait construire, à notre intention, un grand et bel abri, qui nous servira de salle à manger, ainsi qu'un grand nombre de cases pour nos soldats; ceux-ci n'ont donc qu'à s'installer.

Dans l'après-midi, il vient me payer un magnifique tribut. Je lui fais dire alors que je le recevrai à nouveau le lendemain matin, afin de m'entretenir avec lui des tristes événements dont son village a été le théâtre lors de la révolte. Voici comment il me conte la chose : Pelzer avait fait placer deux blancs en poste chez 
Kayéyé. Quand la révolte des soldats éclata à Luluabourg, ceux-ci, après avoir pillé et brûlé la mission de Kalala-Kafumba, se sont portés sur Kayéyé, qu'ils ont détruit de fond en comble.

Un des blancs est parvenu à se sauver; le second, le sergent Dehase, ayant appris par les indigènes l'arrivée des soldats révoltés, s'est résolument porté à leur' rencontre avec les soldats de son poste, mais, en route, son caporal lui a traîtreusement tiré dans le dos $\mathrm{mn}$ coup de feu qui l'a traversé de part en part. Dehase a encore fait quelques pas dans les herbes, puis est tombé mort.

Plus tard, les gens de Kayéyé, ayant retrouvé son cadarre, l'ont entouré de nattes et l'ont enterré à la place mème où il était tombé.

Je résolus de donner à notre pauvre ami une sépulture digne de lui.

Le lendemain matin, j'envoyai donc Lapière avec un peloton, afin qu'il pùt, sous la conduite du chef, retrouver les restes du paurre garçon, les envelopper dans de riches élofies et les ensevelir.

Quand Lapière m'eut fait prévenir que tout était prêt, j'envoyai un autre pelolon avec un drapeau aux confins du village, afin de faire escorte au cortège; puis je fis ranger tous mes soldats et tous mes porteurs sur la route qu'il devait suivre.

Aussitòt que le convoi apparaît, mes clairons sonnent 
aux champs, nos tambours battent et toute la troupe présente les armes, pendant que le cortège défile lentement.

Arrivé au bord de la fosse que j’ai fait creuser en face du chimbeck principal du chef, on dépose le corps et je lui adresse un suprême et dernier adieu au nom de la famille, des amis et de la patrie absente.

On le descend ensuite dans la fosse; puis tous les soldats, tous les porteurs et tous les gens de Kayéyé, qui sont armés de fusils, viennent successivement, par groupes de dix, tirer une salve sur la tombe.

Pendant l'après-midi, je donne également des ordres pour que tous les hommes de mon détachement, ainsi que tous les hommes de Kayéyé, aillent chercher de grosses pierres; on forme ainsi un tumulus qui atteint bientòt des proportions énormes; je fais surmonter le tout d'une croix portant le nom du défunt ainsi que la date de sa mort.

Je crois qu'il y a peu de blancs au Congo qui ont une tombe pareille à celle-là.

Celte cérémonie, à laquelle j’ai donné le plus d'apparat possible, doit avoir produit une impression profonde et durable sur l'esprit des indigènes.

Partis le 17 mai de Kayéyé, nous arrivons le 22 à Kanda-Kanda.

Pendant la route, une aventure bien désagréable faillit arriver à Lapière. 
Nous campions sur un plateau où les indigènes avaient creusé par centaines des pièges à gibier. Ces pièges consistent en fosses ayant plus de trois mètres de profondeur et allant toujours en se rétrécissant; au fond se trouve un pieu dont la tête est effilée.

Ces pièges étaient si admirablement dissimulés que l'œil le plus exercé ne pouvait les apercevoir.

Lapière, en voulant se rendre dans ma tente, mit le pied en plein dans un de ces trous; si un de ses hommes ue l'eût sais.i vigoureusement par le bras, il eut certainement dégringolé dans le fond, où il risquait de se faire empaler !

En entrant chez moi, il était encore tout ému ; j’avoue qu'il y avait de quoi l'être....

Un peu plus tard, son chien, moins heureux que son maître, alla donner tête baissée dans un de ces traquenards. Les soldats essayèrent de retirer la pauvre bète en lui jetant des nouds coulants au risque de l'étrangler. N'y parvenant pas, un d'eux se laissa descendre dans le trou au moyen d'une longue perche et en retira le chien, l'air tout penaud de sa mésaventure.

Plus tard encore, c'est un Haoussa qui tombe dans un piège avec tout son fourniment ainsi que son chien. Heureusement pour notre homme, il n'y avait pas de piquet dans cette trappe. On dut travailler assez longtemps pour le retirer de sa position plus ridicule 
que critique, au milieu des rires et des moqueries de ses camarades.

Quand nous arrivâmes à Kanda-Kanda, le chef se présenta à nous en véritable gentleman.

Il était beaucoup mieux habillé que nous.

Il était vêtu d'un complet en cheviote gros bleu et d'un chapeau mou gris perle tout neuf !

Il nous reçut très bien ; lui aussi nous fit préparer un magnifique campement, dans lequel nous n'eûmes qu’à nous installer.

Je restai quatre jours à Kanda-Kanda, afin de donner à mes lıommes un repos bien gagné.

De chez lui, je me rendis chez notre ami KalalaKafumba, chez qui j’arrivai le 4 juin, au bout de dix nouveaux jours de marche.

Après avoir fèté ce chef qui s'était toujours montré parfait pour nous, je partis pour le village de Kichimbi, oì j'arrivai le 8 .

Ici finissait ma longue randonnée pacificue.

Après avoir récompensé a vec joie, a vec bonheur, tous les dévouements que j'avais rencontrés sur ma route, le devoir m'ordonnait de m'occuper maintenant de mon second rôle : celui de justicier.

Si, pendant uos désastres, beaucoup de chefs nous sont restés fidèles, d'autres, au contraire, en ont profité pour tuer nos courriers, piller nos caravanes et attaquer les missions ainsi que nos alliés. 
Parmi ceux-ci, les plus dangereux étaient : N'Gongo, grand chef Bachilange, et M'Pogna, chef de tous les Bakuas-Kassassus.

Tous deux, établis aux portes de Luluabourg, étaient en rérolte ouverte envers l'Etat depuis longtemps, mais, comme tons deux également possédaient des bomas formidables et plusieurs milliers de fusils, le poste de Luluabourg n'avait jamais eu les forces sullisantes pour les déloger de leurs repaires de bandits.

Ils se croyaient si sirs de l'impunilé que N'Gongo s'élait flatté qu'il clouerait toutes les tètes des blancs de Luluabourg à son màt de pavillon.

Il ètait donc nécessaire de faire un exemple éclatant.

Voulant me mettre en paix a vec ma conscience, je leur envoyai un homme de Kichimbi, leur demandant si, oui ou non, ils voulaient faire leur soumission à l'Etat et payer une amende pour leurs crimes passés.

Ils me firent répondre qu'ils ne me craignaient pas et que, si j'élais trop poltron pour aller les attaquer, ce seraient enx qui viendraient m'attaquer dans mon camp.

C'était tout à la fois trop de crimes et Irop d'insolence : quoique aimant la paix par dessus tout, j’allais encore une fois ètre obligé de faire couler le sang à flots.

Il faut croire que c'était ma destinée au Congo.

Dès le 12, nous arrivons à six heures de marche du grand village de N'Gongo. 
J'envoie une reconnaissance, qui revient peu de temps après me disant que tous les indigènes se trouvent cachés aux environs de la route et dans la forèt que nous devons traverser le lendemain pour nous rendre au boma de N'Gongo.

Craignant, si je restais en place, une attaque de nuit, et bien qu'il fùt près de midi,je donnai quelques instants de repos à mes hommes, je les fis manger, puis... en avant!

Le combat fut acharné, les indigènes se défendirent, de clairière en clairière, avec un courage inouï, et ce fut seulement vers le soir qu'ils laichèrent pied définitivement pour se retirer dans le grand boma de N'Gongo.

Mes paurres hommes étaient éreintés.

A 4 heures du matin, je les fais réveiller en silence. Au point dı jour, je lais attaquer le boma, qui était formidable, par trois còtés à la fois.

Les indigènes firent une défense des plus héroïque, mais leur chef, N'Gongo, ayant été tué, ils finirent par se débander et nous pùmes enfin nous emparer de la place.

Aussitòt le boma pris, je fis arborer le drapeau de l'Elat sur le màt de pavillon de N'Gongo, ce même mât sur lequel le chef s'était vanté de faire clouer les têtes des blanes de Luluabourg!

La mort de N'Gongo dut certainement produire,sur les gens de la contrée, une impression énorme, car celui-ci passait aux yeux des indigènes pour être invulnérable. 
Restait maintenant le chef M’Pogna.

Après avoir donné un jour de repos à mes hommes, je me mets en marche pour le dénicher.

Sur la route, nous ne rencontrons personne, ce chef ayant préféré garder tout son monde sous la main, afin de mieux défendre son boma.

Le 20, nous arrivons de bon matin, dans un petit village en face du boma.

Notre avant-garde y est attaquée assez vivement par environ un millier de fusils.

Je fais immédiatement partir deux colonnes afin de les contourner et je fais trainer le combat pour donner à mes gens le temps de se placer.

Le moment arrivé, je fais pousser vigoureusement en arant et quand les hommes de M'Pogna veulent se retirer dans leur boma, nos deux colonnes d'assaut les suivent de si près que l'ennemi n'a pas le temps d'en boucher la porte: nos hommes y entrent à la suite des fuyards.

Un combat acharné ne s'engage pas moins dans les rues du village; il est près de midi quand nous sommes définitivement maîtres de la position.

Dans la poursuite, nos hommes furent assez heureux pour s'emparer du grand chef N'Pogna ainsi que de plus de 800 prisonniers.

Je restai cinq jours dans le village pour bien affirmer ma victoire et, pendant ce temps, je reçus 
la visite d'un grand nombre de chefs des environs : tous venaient me faire des protestations d'amitié et de fidélité à l'Etat.

Notre double victoire eut une répercussion énorme dans toute la contrée.

Le $\mathcal{1}^{\text {er }}$ juillet, je rentre à Luluabourg, où j'espérais bien pouvoir me reposer un peu.

J'y étais à peine depuis quelques jours, quand, j’apprends que Kalamba a été rejoint par les débris des forces de N'Gongo el de N'Pogna, qu'il a de plus avec lui une nombreuse bande de Kiokos et de Bihénos, ainsi que les dix soldats Batétélas des Wisman-Falls; enfin qu'il se trouve à la Niauw, c'est-à-dire à cinq heures de marche des missions et à 7 heures de Luluabourg, a vec environ 8,000 fusils à pierre et 25 Albini.

Ce vieux lutteur veut done encore une fois sacrifier au dieu des batailles.

Le danger élant pressant, dès le lendemain matin me voilà de nouveau " sur le sentier de la guerre ", comme dirait Gustave Aimard.

Je crois que ce fut gràce à la rapidité de ma marche en avant quie les missions furent sauvées, car, ainsi que je l'ai su par la suite, Kalamba s'apprêtait justement à les piller lorsqu'il apprit mon départ de Luluabourg.

Contrairement à mes prévisions, nous ne sommes pas attaqués au passage de la Miauw et toute ma troupe peut la traverser sans ètre inquiétée, l'ennemi s'étant retiré sur la rive gauche du Lubilache. 


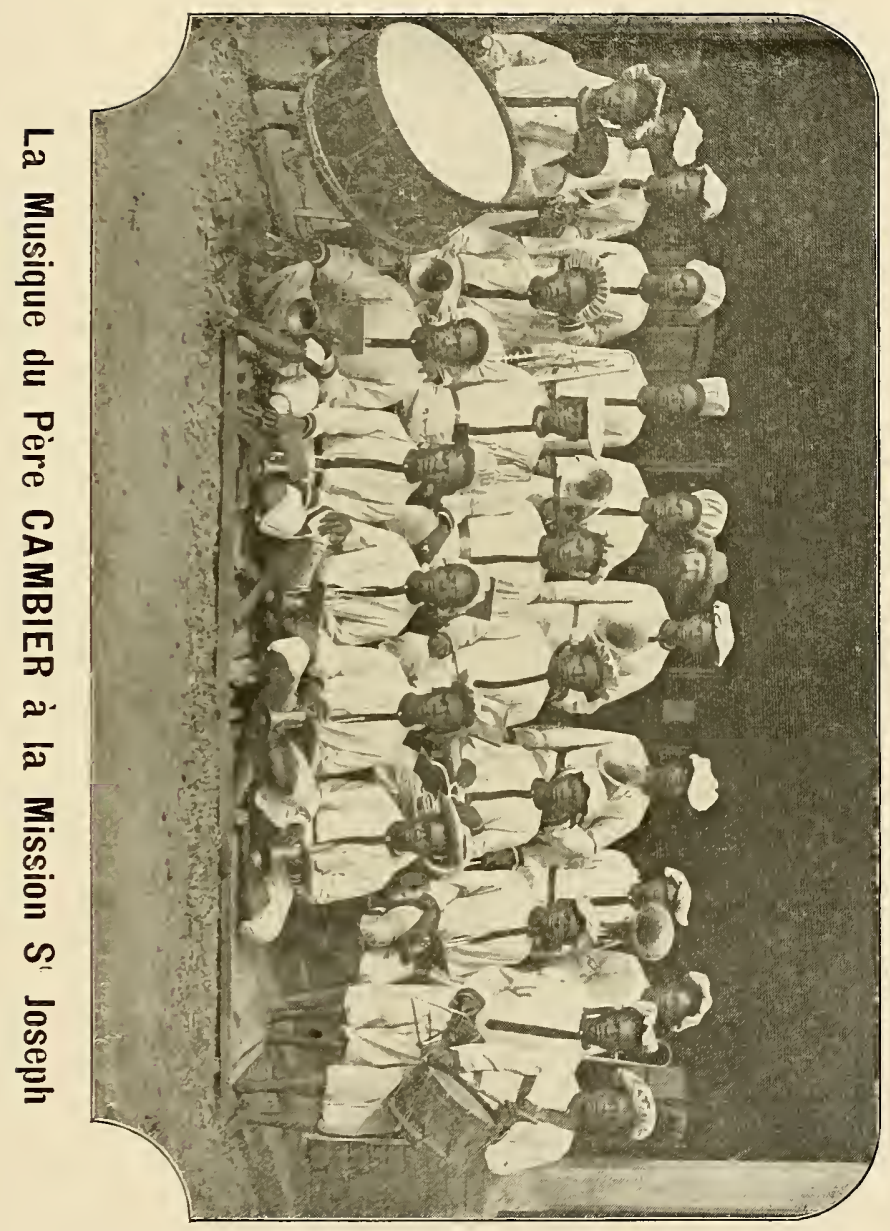




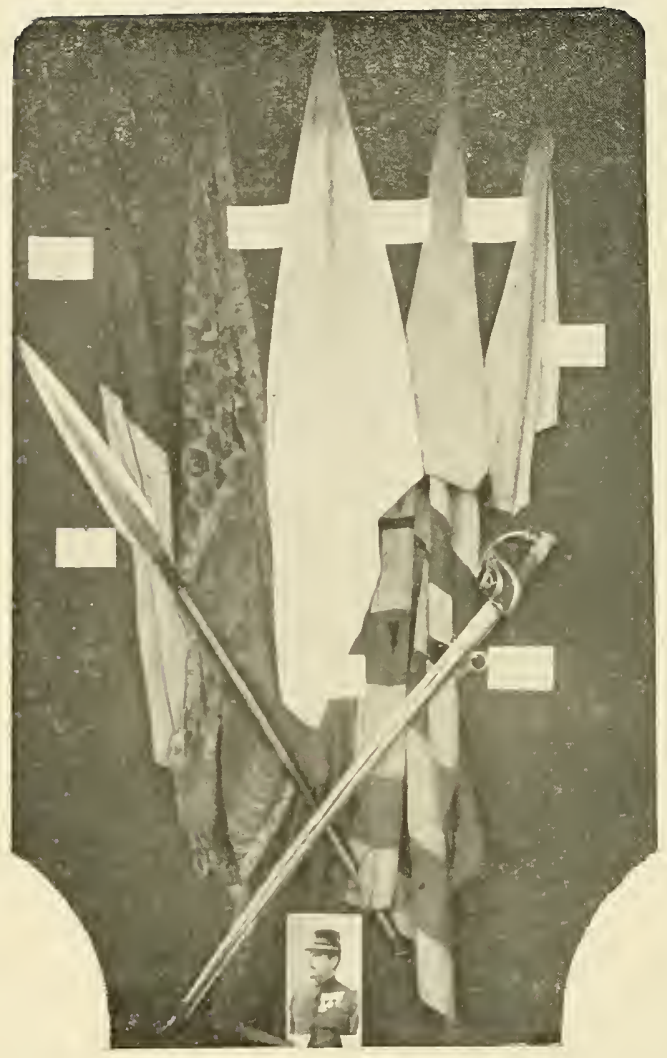

Trophée représentant les cinq drapeaux pris aux Arabes et aux Kiokos pendant les batailles des; 7 Février 1892, 23 Novembre 1892 et 3 Juillet 1896 


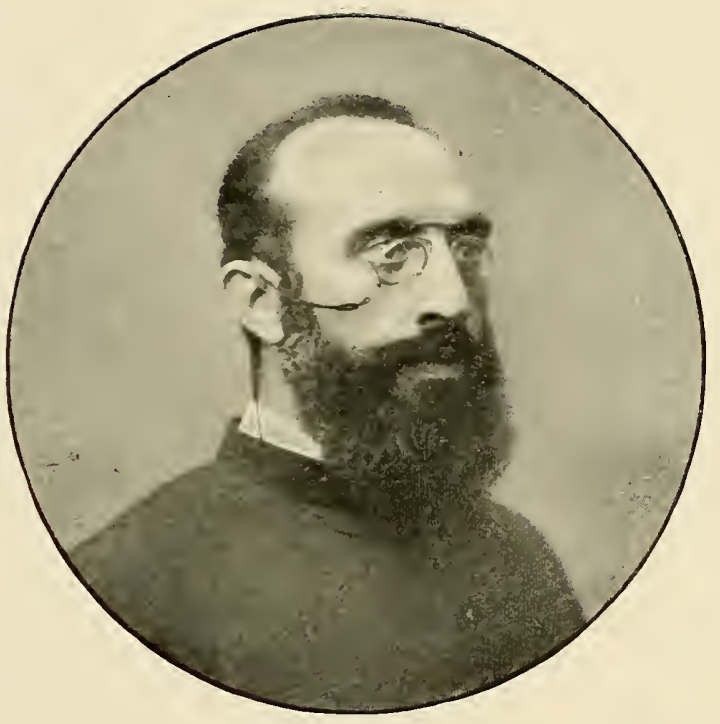

Un architecte... un briquetier... un maçon... un menuisier... un forgeron... un planteur... un soldat... un chef d'orchestre. . . . . . . le Père CAMBIER ! 


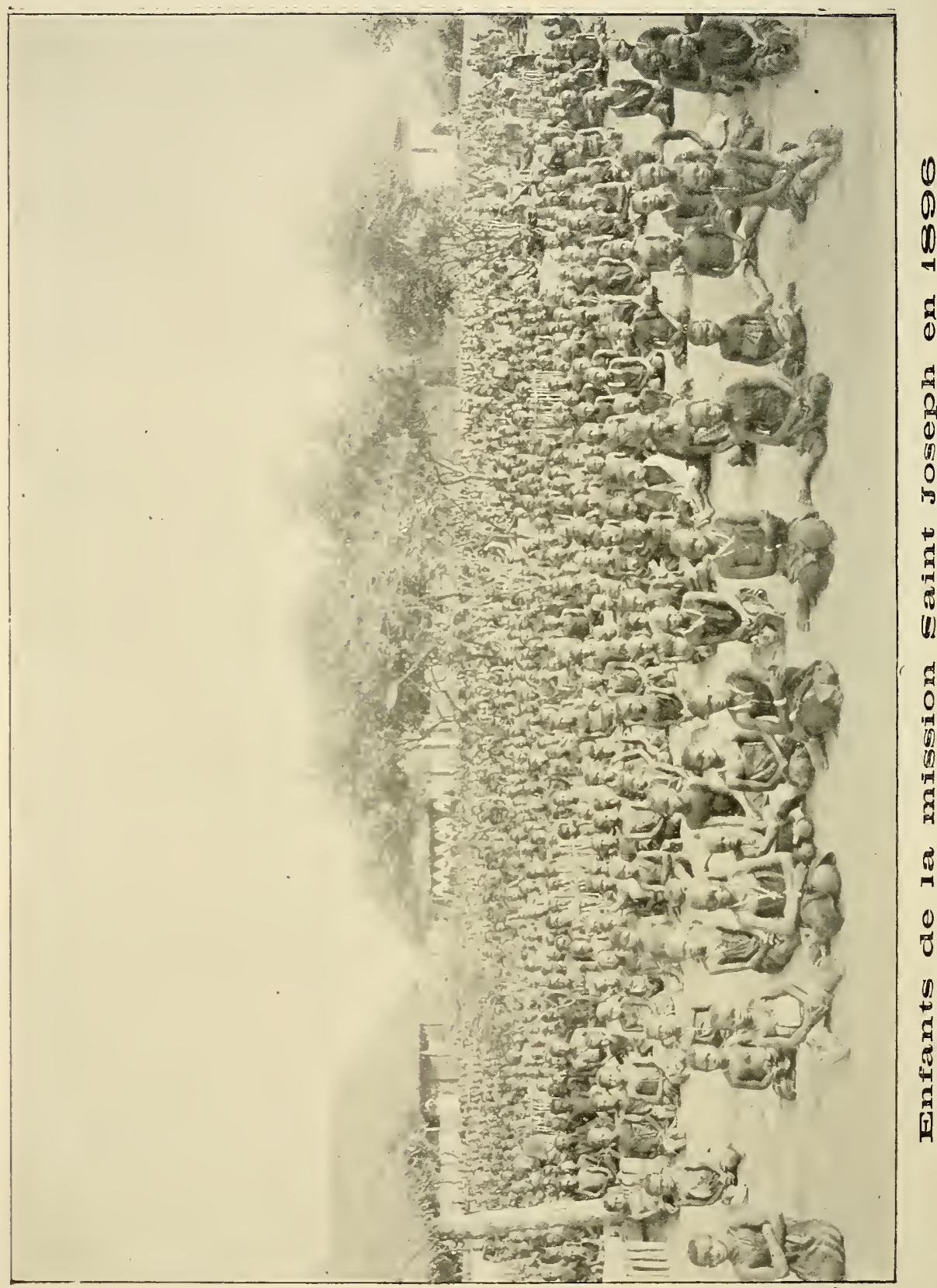


Une demi-heure après le passage de cette rivière, mon avant-garde,commandée par le $1^{\mathrm{er}}$ sergent Heurion, débouche dans une immense clairière. Heurion, tout fraìchement débarqué d'Europe, en était à sa première bataille.

Il se porte une centaine de mètres en avant; il était occupé à donner des ordres pour faire fouiller la lisière opposée, quand, tout à coup, une salve éclate et cinq de ses hommes roulent par terre.

Le paurre garçon est tellement saisi, tellement interloqué, qu'il reste debout au milieu du chemin, comme pétrifié, ne bougeant plus. Heureusement pour lui, j'arrive précisément avec le canon Nordenfeld, me suivant à quelques mètres.

- Eh bien Heurion! devenez-vous fou ? En tirailleurs, que diable ! et en avant !

Du coup, mon homme reprend ses esprits et exécute l'ordre donné ; je fais immédiatement mettre mon canon

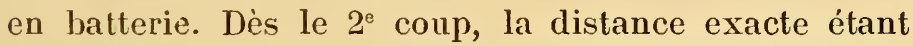
trouvée, il tire sans relàche, donnant ainsi de l'air à mes autres pelotons et leur permettant de déboucher à leur tour et de se porter sur la ligne des tirailleurs.

Heureusement, je n'ai avec moi que de vieux soldats très aguerris; en quelques minutes, chacun a gagné le poste assigné et nous pouvons faire partout face à l'ennemi, bien que celui-ci nous attaque de trois côtés à la fois. 
Les Bachilanges et leurs alliés se défendirent avec un courage que j’admirai malgré moi.

Ils jouaient leur dernier va-tout et ils se battirent comme des lions.

Quoique j'eusse avec moi 400 bons soldats et un canon, j'avoue que j'eus besoin de tout mon monde pour les forcer à la retraite.

Celle-ci fut quelque chose de démoniaque : lorsqu’ils lâchèrent pied, ils se précipitèrent presque tous sur la même ronte et comme ils se trouvaient là en masses profondes, je les fis poursuivre par des feux de salve et à coups de canon. Leurs pertes furent effrayantes et je crois bien que, maintenanl, Kalantba ne se risquera plus dans de nonvelles aventures.

Lor'sque les pelotons que j'avais lancés à la poursuite des fuyards furent rentrés, je rassemblai les blanes qui avaient pris part à la bataille et, comme j'avais eu la précaution d'emporter quelques bouteilles de champagne avec moi, je leur proposai de vider une coupe an Roi, ainsi cu’à la belle victoire que nous venions de remporter.

Tous ensemble, nous parlions des divers incidents de la bataille, quand je m’aperçus que Heurion restait à l'écart et paraissait plutòt triste, au milieu de l’allégresse générale.

— «Eh bien! Heurion, lui dis-je, qu’avez-vous done $)$ ? 
- "Commandant, me répond-il, me permettez-vous de rous demander quelque chose $n$ ?

- "Mais certainement. Que voulez-vous" ?

- "Arez-rous été content de moi, ce matin " ?

- "Très content; au début, vous avez été un peu interloqué, mais après, vous vous êtes montré très cràne. )

Sa réponse alors fut typique.

- "C'est que, me dit-il, j’avais terriblement peur d'avoir eu peur !"

La bataille finie, j’allai réinstaller mon ami Lapière à son ancien poste de Mukabua et, après l'avoir aidé dans le gros œuvre de reconstruction, je repris la route de Luluabourg.

Ainsi que je l'ai dit plus haut cette bataille fut l'une des plus sérieuses que je livrai au Congo.

Ce fut également dans cette bataille que je conquis mon deuxième drapeau sur les Kiokos, mon cinquième en comptant les trois drapeaux arabes que j'avais pris à ceux-ci à la bataille de Chigé sur le Lomami.

Comme je n'ai malheureusement pas d'enfant à qui je puisse les léguer,j’ai remis ces cinq drapeaux à Monsieur le Ministre de la Guerre, afin cu'il les fît déposer au Musée de l'Armée.

C'est arec fierté que je donne la copie de la lettre que je reçus à cette occasion : 


\section{Monsieur le Commandant,}

Je tiens à yous remercier bien vivement, de l'hommage que vous avez bien voulu faire au Gouvernement, des drapeaux que oous avez conquis sur l'ennemi au cours de la campagne arabe. Ce n'est pas sans émotion que je les ai recus de vos mains, car ils sont les précienx témoignages de la plus glorieuse des expéditions coloniales où nos officiers ont montré de quels éléments était composée l'Armée belge.

Je les ferai déposer au Musée de l'Armée, où ils rappelleront toujours le souvenir de ceux qui ont, à une heure critique, répondu à l'appel de Léopold II et honor'é leur pays, par la grande ouvre libératrice à laquelle ils consäcrèrent leur épée.

Je snis heureux qu'il me soit donné de recevoir ce précieux dépôt des mains d'un sétéran qui a vécu au Congo, ce que nos enfants appelleront plus tard l'époqne héroüque, et je vous prie de recesoir, Monsieur le Commandant, avec l'expression réitérée de ma reconnaissance, l'assurance de mon affectueux dévouement.

Le Ministre de la Guerre, (Signé) BROQUEVILLE.

Bruxelles, 19 Mars 1913.

Mais revenons à Kalamba et aux Bachilanges.

La tribu des Bachilanges est une des plus peuplées de tout le territoire du Congo et il n'y a pas de doute que dans le passé elle ait été une des plus florissantes et une de celles qui se rapprochait le plus de la civilisation.

Malheureusement son chef Kalamba a profité de l'autorité absolue dont il jouissait pour instituer la religion du chanvre dont il s'est proclamé lui et sa sœur grand prêtre et grande prêtresse ; il a de cette façon complètement abruti la plus grande partie de ses sujets. 
Chaque fois que Kalamba voulait donner une fête (et il en donnait souvent) il convoquait tous ses grands vassaux.

Il s'asseyait alors ayant sa sœur Mama Sambi à ses còtés et tous ses chefs réunis en demi-cercle autour de lui, chacun à la place que lui octroyait le protocole Congolais.

Sur un signe de Kalamba toutes les jeunes filles du village venaient danser devant leur auguste maître au son des madimbas. Cette danse d'abord lente se précipitait peu à peu pour finir dans une sarabande effrénée ; pendant ce temps l'une des jeunes filles de Kalamba apportait l'immense calebasse officielle et après s'être agenouillée la déposait sur le giron paternel. Cette calebasse était immense et recouverte de centaines peut-être de milliers de clous dorés.

Le frère de Kalamba remplissait alors de chanvre, un fourneau en terre cuite qu'il adaptait ensuite dans une ouverture ad hoc de la calebasse, tandis qu'une de ses filles y versait de l'eau. Mama Sambi au moyen d'une petite pince en fer saisissait alors une braise et allumait la pipe de son auguste frère.

Kalamba aspirait alors quelques longues bouffées de chanvre puis les yeux désorbités et injectés de sang, se mettait à tousser furieusement comme s'il avait avalé de travers.

Il passait alors la calebasse à celui de ses vassaux 
à qui il voulait faire le plus d'honneur et celle-ci passait alors de bouche en bouche jusqu'à ce que le fourneau fût vide.

La même cérémonie se renouvelait alors et ainsi de suite jusqu'à ce que Kalamba et tous ses invités fussent complètement abrutis.

Mais si Kalamba voulait que ses sujets s'enivrassent au moyen du chanvre, d'un autre còté il leur défendait sous peine de mort de boire du malafu (vin de palme). Pour ètre sùr d'ètre obéi il avait fait couper tous les palmiers de son immense contrée, privant par le fait même ses sujets non seulement de malafu, mais encore d'huile de palme, cependant si précieuse pour toute la race nègre.

En plus de la religion du chanvre qui fut introduite par Kalamba, les Bachilanges croient aussi aux fétiches ainsi qu’à la métempsycose.

Chacun d'eux a son fétiche particulier ainsi qu'une foule d'amulettes qui doivent les unes lui donner la fortune, les autres le rendre invulnérable etc.....

Lorsqu'un vol a été commis, ils forcent celui qui est soupçonné de tremper sa main dans de l'eau bouillante. Si celui-ci est brùlé, il est considéré comme coupable; s'il ne l'est pas, il est reconnu innocent et celui qui l'a accusé doit lui payer une indemnité.

D'autres fois, celui qui accuse prépare une drogue (la caze) et la fait boire à l'accusé. Si celui-ci en meurt 
il est déclaré eoupable; s’il en échappe, l'accusateur doit lui payer une forte amende.

Mais le plus curieux, c'est que janais aucun ne refuse de se soumettre à ce curieux jugement et que bien souvent ils retirent leur main de l'eau bouillante sans la moindre trace de brìlure.

Ainsi que je l’ai dit, ils croient aussi à la métempsycose et ils affirment sans sourciller que lorsque l'un d'eux en a assez de demeurer parmi les hommes, il se change à son gré soit en léopard, soil en éléphant, en lion, etc......

Albert Lapière m'a conté à cet efiet l'histoire suivante: L'n éléphant étant venu se promener dans les plantations du poste de Mukabua, les soldats du poste l'avaient abaltu à coups de fusil.

Les indigènes des environs accourus aussitôt au poste affirmèrent à mon ami avec un sérieux parfait que le pachyderme n'était autre cqu'un certain chef des environs qui avait disparu depuis quelque temps et qui, fatigué d'ètre homme, avait déclaré qu'il allail se faire éléphant.

Ceci dit, je continue mon récit.

Comme je devais me rendre à proximité de la mission S'-Joseplı, le Père Cambier envoya un de ses missionnaires à ma rencontre, me demandant avec insistance de bien rouloir passer avec mes troupes par la mission, car il avait amassé de nombreux vivres à notre in tention 
et désirait fêter un peu nos soldats, qui l'avaient si bien défendu pendant les moments critiques.

Je ne crus pas devoir refuser cette petite satisfaction à mes braves soldats.

Nous fûmes reçus on ne peut mieux; pendant les deux jours que nous restâmes à la mission, tous mes hommes furent réellement " dorlotés " par les Pères et par les sept Sours qui se trouvaient là.

Le lendemain de notre arrivée étant un dimanche, je résolus de faire une surprise que je savais devoir être agréable à ces pauvres femmes qui venaient de passer pendant des mois par toutes les angoisses qu'il est possible d'imaginer.

Dès sept heures sous prétexte d'inspection, je fis rassembler mes soldats en armes.

Tous sous leurs glorieux haillons (il y avait huit mois qu'ils étaient en campagne) avaient tout à la fois l'air fier et hardi ; l'intrépidité était peinte sur leur bonne et loyale figure et à la façon dont leurs yeux s'hypnotisaient dans les miens, je sentais leur désir ardent de n'avoir d'autre volonté que la mienne et aucune parole n'était nécessaire pour que nous sentions réciproquement que nos cœurs battaient à l'unisson.

Tout au plaisir de les inspecter, de les aimer et de me sentir aimé d'eux, j'oubliais le but qui me les avait fait rassembler, lorsqu'un bruit argentin vint traverser l'espace et me rappela à la réalité du moment. Ding !...... 
ding !..... ding !..... ding !..... C'est la cloche de la mission qui à toute volée, de ses notes claires et vibrantes invite les nouveaux prosélytes à assister au divin sacrifice.

Quelques instants après, par la porte de l'Eglise large ouverte, j'aperçois le Père Cambier qui vient de monter à l'autel; tous ses néophytes ainsi que les religieuses sont à leur banc habituel. C'est le moment.

En arant.... Marche, et prenant la tète de la colonne j'entre suivi du drapeau, des clairons, des tambours ainsi que d'une compagnie; les autres compagnies se massent à la porte de l'Eglise, celle-ci étant trop petite pour les contenir toutes. Aussitòt entré, je me place dans le chœur. Les soldats sont formés sur deux rangs.

Je regarde alors autour de moi : Le Père Cambier me paraît un peu nerveux; les sœurs sont émues et l'une après l'autre, essuient une larme furtive; les enfants des missions regardent curieusement et paraissent oublier leur chapelet, qu'ils tiennent distraitement à la main ; les soldats ont l'air interloqué et l'on se rend parfaitement compte que leur imagination est fortement frappée par ce mystère qui leur paraît d'autant plus formidable qu'ils n'y comprennent rien.

Le Père qui joue de l'harmonium a, sans le savoir, scandé sa mesure en accompagnant les Psaumes, il semble vouloir jouer une marche militaire. 
Mais bientòt je suis arraché à mes réflexions par la sonnette du petit nègre qui fait l'offiee d'enfant de chœur.

C'est le moment où le saerifiee d'amour vient de s'aceomplip et où le Pontife dans un geste de bénédiction, élève l'hostie et l'offre à l'adoration des fidèles.

A mon commandement toute la troupe présente les armes et notre beau drapeau pour la première fois s'incline, tandis que mes clairons sonnent et que mes lambours battent aux champs.

En ce moment l'Eglise tremble, e'est notre eanon qui placé juste en face du ehøur, vient lui aussi d'envoyer sou impressionnant salut. L'effet fut indicible sur ces pauvres femmes; toutes pleuraient; à la sortie de la messe, elles vinrent me remercier avec effusion; l'une m’assura mème que je lui avais proeuré la plus douee émotion qu'elle eùt ressentie dans son existenee.

Je sais que mon geste ne fut pas protoeolaire, que quelques esprits chagrins me reproeheront peut-être d'aroir fait assister mes soldats noirs à la messe, alors que je n'en avais pas le droit.

Je sais eela très bien, mais ee que je sais aussi, c'est qu’il m’a été donné de proeurer quelques instants de bonheur à sept paurres femmes belges qui, pendant plus d'un an, araient véeu un horrible eauehemar et avaient passé par toutes les tortures morales, des vierges menacées dans leur honneur... Ceux ehez qui 
la tète guide toujours tous les mouvements me condamneront certainement, mais je suis certain aussi que j'aurai les suffrages de ceux qui croient que, même en service, on peut parfois écouter la voix du cœur.

Je passai quelques jours seulement à Luluabourg, tout heureux de pouvoir me reposer, après plus de deux ans de royages et de combats continuels; je pris ensuite la route de Lusambo, où j'arrivai le $1^{\text {er }}$ aoùt.

Ici encore, une terrible déception m'attendait.

Un steamer, arrivé depuis quelques jours, m'apportait l'ordre de réunir tout ce qui restait de soldats Batétélas ou Balubas à Lusambo et de partir de suite pour aller coopérer avec Dhanis à la guerre qui se préparait contre les Mahdistes.

J'eus un véritable moment de découragement et de colère; je fus sur le point d'envoyer ma démission et de rentrer en Europe.

Mais je me ressaisis et je me dis que, puisque j'étais soldat et que moi le premier j'exigeais l'obéissance absolue de mes sous-ordres, je n'avais qu'une chose à faire, donner l'exemple de la discipline, quoi qu'il m’en coùtàt. 



\section{CHAPITRE XVII.}

Départ de Lusambo et arrivée à Nyangwé. - Les révoltês rentrent en campagne. - Je prends la direction des opérations. - Le Gouverneur approuve ma conduite. - Composition de l'expédition. - Je dois sévir contre des voleurs. - Dispositif habituel de marche et de campement. - Sanglant combat de nuit à Kapwa. - Poursuite de l'ennemi. - La famine. - Imprudence et mort de Burke. - La bravoure, c'est bien l'obéissance c'est mieux.-Dislocation de l'expédition.-Mort d'Hambursin. - Adieux à mes vieux braves! - Retour en Europe. - La défense de notre Colonie.

Je restai encore environ un mois à Lusambo, afin de remettre le district à mon successeur, puis je pris la route de Nyangwé avec les 115 soldats qui se trouvaient de la catégorie désignée dans la dépèche du Gouvernement.

Arrivé à Nyangwé, je résolus de donner un peu de repos à mes hommes et comme le commandant Antoine m'arait logé dans une excellente maison, je jouissais avec bonheur du “dolce farniente ». Or, un jour Antoine vint brusquement me réveiller pendant la méridienne que je faisais consciencieusement.

- (c Michaux, me dit-il, j’apprends à l’instant que les anciens soldats révoltés unis aux gens de Kabongo, Dibué et Kolomoni, viennent de se porter en avant et se dirigent de nouveau sur N'Gandu.Que comptes-tu faire? 
- Mais, lui répondis-je, je n’en sais rien, laisse-moi au moins le temps de m'éveiller, et puis est-ee sérieux ou est-ee une farce que tu me contes là ?

- Je te donne ma parole, me dit-il, que c'est tout ce qu'il y a de plus sérieux. "

Vu la gravité des eirconstanees, il fut décidé que j'éerirais immédiatement à tous les chefs de postes, de zones ou de districts des environs, afin de les prévenir de la marehe en arant des réroltés et que, par le même eourrier, j'enverrais des réquisitions afin de rassembler le plus de troupes possible pour faire face au danger.

Linsi donc, parti de Lusambo pour me rendre dans le Nord du Congo, voilà que, arrivé à Nyangwé, je devais m’apprêter à mareher vers le Sud !

Lorsque j'avais pris toutes ees mesures, j'avoue que je n’étais pas très tranquille, car je ne savais pas si la ligne de conduite que j'avais adoptée serait approuvée par le Gonvernement; aussi lorsque, quelques jours plus tard, je reçus tune lettre de Dhanis me preserivant de prendre précisément les mesures que j’avais arrètées, je fus tout heureux.

En mème temps, je recevais également une lettre du Gouverneur Général Wahis, me disant qu'étant aux Falls, il se rendait à Nyangrwé, où il arriverait presque aussitôt que sa lettre.

En effet, quelques jours après, il débarquait et je remontais aree lui jusque Kassongo. 
Non seulement il approura tout ce que j'avais fait, mais encore il me félicita de mon initiative et me remit une commission, me domnant les pouroirs les plus étendus.

C'est encore arec plaisir que je donne la copie de cette commission :

\section{Etat Indépendant du Congo}

CABIXET DU GOUVERTEUR GÉxÉRAL

" Le capitaine-commandant Michaux est chargé de " conduire les opérations contre les Batétélas révoltés.

" Il aura le commandement de toutes les troupes, quelle ") que soit leur provenance, qui concourront à l'exécntion ") de ces opérations. Il est autorisé à prendre toutes les " mesures politiques qu’il jugera nécessaires à la bonne ") exécution de ses mouvements. Il rendra compte de " ces mesures aux commissaires de districts et chefs ") de zones sur le territoire desquels il se trouvera.

"Kassongo, le 26 octobre 1896.

"Le Gouverneur Général, " (S.) WVAHIS. "

La situation à la date du 26 octobre était donc celle-ci : Les anciens révoltés, avec environ 500 Albini et 4.000 à 5.000 auxiliaires, menaçaient la zone de N'Gandu.

Nous avions à leur opposer : M. Swenson, qui se trouvait à Kolomoni avec 100 soldats et 800 auxiliaires, 
puis M. Gervais, ayant avec lui MIM. Burke et Windey, ainsi que 130 hommes; il était parti de Nyangrvé et était en marche afin de faire sa jonction avec Swenson ; je quittais Kassongo avec 315 soldats, dont 115 venus avec moi de Lusambo et 200 sous les ordres de Bastien, Spilliart et Bollen, provenant du camp de Kassongo; enfin Lusambo envoyait 150 hommes sous la conduite de MII. de Bèche et De Cock.

La concentration derait se faire à Kolomoni, où j'arrivai le 5. Tous mes détachements s'y trouvaient réunis, sauf celui de Lusambo. J'arais donc, en ce moment, 7 blancs et environ 550 soldats à opposer anx révoltés.

Pendant ma marche sur Kolomoni, les Likwangulas, venus de Kassongo, me donnèrent assez de tablature.

Sur les 200 hommes provenant du camp de Kassongo, il y avait 150 Likwangulas; or, ceux-ci sont de très braves soldats, quand il s'agit de se battre, cela est certain, mais ce sont aussi les plus grands voleurs que je connaisse.

Le lendemain de mon départ de Kassongo, je fus obligé de faire désarmer et mettre à la chaîne une dizaine de ces mauvais bougres, qui avaient été surpris à piller un petit village situé près de celui où nous logions.

Le lendemain, à peine arrivés à l'étape, une autre bande va piller un village qui se trouvait à 3 ou 4 kilomètres de notre campement. Ápprenant la chose, je leur 


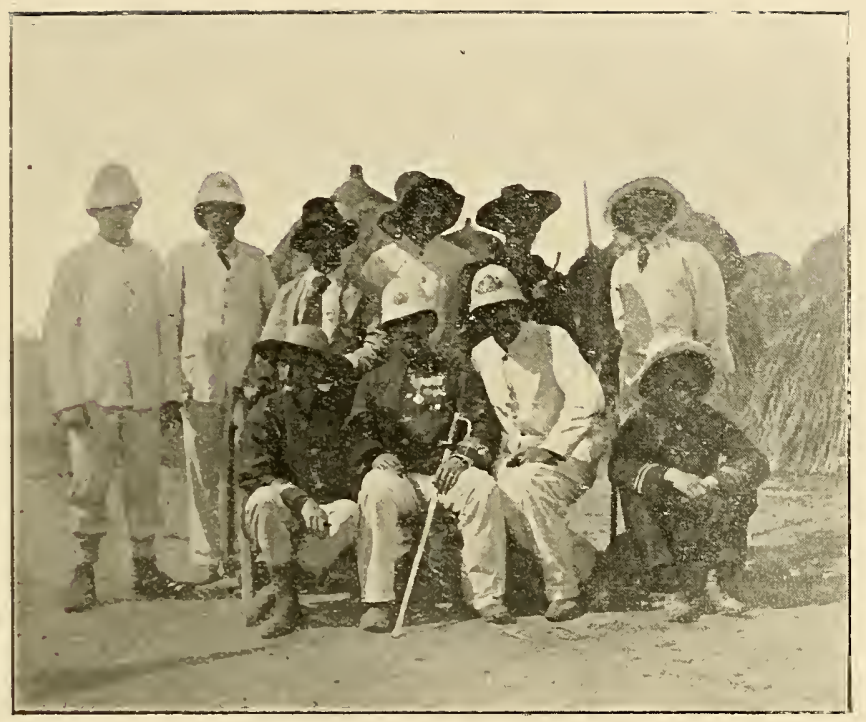

Officiers ayant pris part à la campagne contre les Batétélas révoltés. 1896-1897

ler plan de gauche à droite

SWENSON, MICHAUX, BASTIEN, de BESCHE

2e pian

DECOCK, BURKE, GERVAIS, BOLLEN

WINDEY, SPILLIAERT

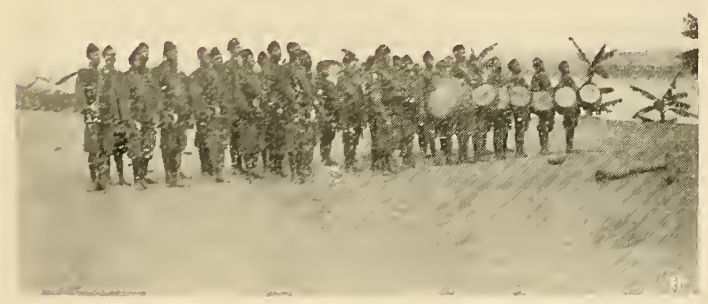

Une musique militaire au Congo 


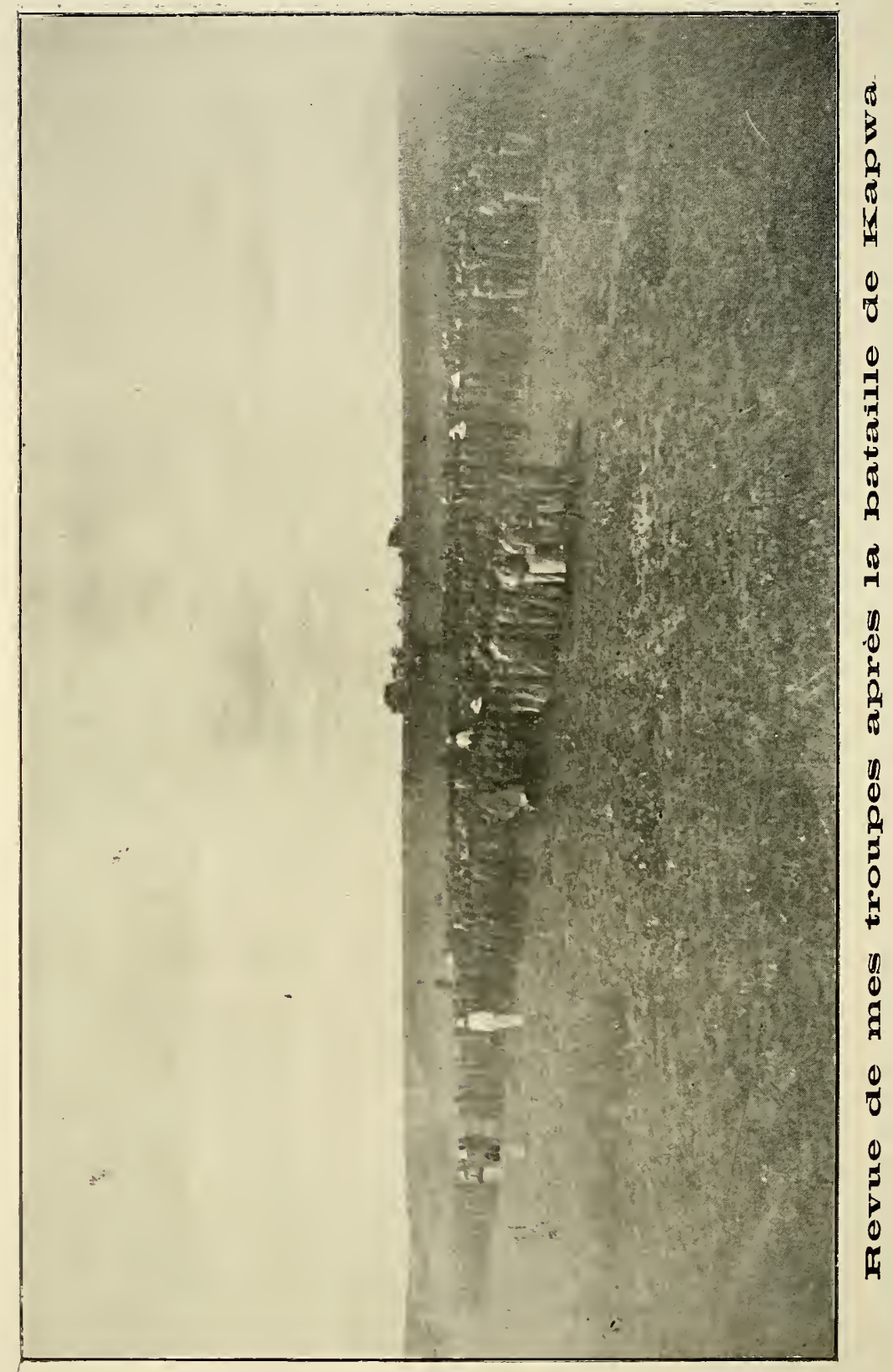


fais douner la chasse par mes vieux soldats, qui m'en ramènent 22 à la chaîne.

Cette fois, ma patience est à bout : il faut en finir sous peine de voir le pays pillé par ces malandrins noirs.

Je fais sonner le rassemblement ef, après avoir fait donner la chicote à mes 22 voleurs, je déclare qu'ils resteront à la chaine pendant le restant de l'expédition et que, dorénavant, tout soldat qui sera surpris à voler les armes à la main sera fusillé sćance tenante.

Ils ont enfin compris que je suis bien décidé à en tinir arec leurs rapines: je suis tranquille pour le restant de l'expédition.

Mais, encore une fois, quelle sale race et quelle diftérence avec mes bons vieux braves qui m'ont suivi partout et qui, eux, auraient pu servir de modèle, même à des soldats européens, tant par leur probité que par leur dérouement sans limite.

Aussitôt arrivé à liolomoni, j'envoyai deux de nos auxiliaires, Albert et Mohamedi, aux nouvelles, avec ordre d'occuper lialamba et de se rabattre ensuite sur Bena Kapwa.

Dès le 8 au soir, je recerais la nouvelle que nos auxiliaires se trouvaient en contact avec les avantpostes ennemis.

Bien que le détachement de Lusambo ne nous eùt pas encore rejoints, je décidai de me porter en avant dès le lendemain_matin. 
Je crois qu'il sera peut-être intéressant pour certains de nos lecteurs de savoir comment se faisaient une marche et un campement au Congo; c'est pourquoi je donne ici mon dispositif habituel de marche et de campement.

Le voici : mes troupes étaient divisées en six compagnies à trois pelotons. Chaque compagnie était numérotée de 1 à 5 ; la $6^{\text {e }}$, directement sous mes ordres et composée d'anciens soldats qui avaient fait leurs preuves, formait en quelque sorte ma réserve générale.

Lorsque nous étions en marche, j'avais toujours avec moi 100 à 150 auxiliaires indigènes, armés de fusils à piston et qui, commandés par quelques chefs jeunes et ambitieux, ne demandaient pas mieux que d'avoir l'occasion de se distinguer.

Sauf la solde qu'ils ne recevaient évidemment pas, ils étaient, au point de vue des vivres, traités sur le même pied que nos soldats. Ils me servaient en quelque sorte de cavalerie d'exploration et, tous les jours, ils étaient envoyés en avant de la colonne et devaient battre l'estrade en avant et sur les flanes.

Venait ensuite la compagnie qui était chargée de l'a vant-garde.

Cette compagnie se trouvait toujours de 500 à 1.000 mètres en avant du gros, suivant la nature du terrain.

La compagnie qui avait été à l'avant-garde aujourd'hui passait à l'arrière-garde demain, et ainsi de suite, 
chacune d'elles arrivant donc tous les cinq jours à être d'a vant-garde.

La compagnie qui se trouvait à l'arrière-garde avait un peloton en tète des bagages et un peloton en queue.

Les hommes du $3^{\text {e }}$ peloton étant intercalés parmi les porteurs, chacun arait à surveiller, aider ou défendre deux ou trois de ceux-ci, dont ils étaient responsables.

Je marchais en tète du gros avec la compagnie que j'appellerai de vétérans et qui, elle, ne me quittait jamais.

Le petit canon 3, 7 marchait immédiatement derrière cette compagnie.

En cas d'attaque, je me trourais à mème ainsi de transmettre mes ordres rapidement à toute la colonne.

Deux autres précautions avaient aussi été prises.

Chaque fois que l'on se mettait en marche, les hommes étaient comptés par " quatre ".

Les bois, dans ces pays-là, étant immenses, il est impossible de les fouiller complètement. Aussi, en temps de guerre, leur passage est-il toujours dangereux : une surprise est toujours à craindre.

Dans ce cas et sans commandement, les numéros 1 et 3 devaient faire un à droite et les numéros 2 et 4 un à gauche; de celte façon, aucun secteur n'était privé de feu.

En cas de surprise, le commandant de l'arrière-garde devenait en quelque sorte indépendant, 
Il avait l'ordre de choisir rapidement l'endroit qui lui paraissait le plus propre à la défense, et les porteurs, pressés par les soldats, devaient venir le plus vite possible se former en cercle autour de lui; les caisses et les ballots étaient, au fur et à mesure de l'arrivée des porteurs, mis en cercle et l'un au-dessus de l'autre, de façon à former un abri, derrière lequel les soldats de l'escorte prenaient position, tandis que tous les porteurs recevaient l'ordre de se coucher, afin d'empêcher tout désordre.

En arrivant à l'endroit que j’avais désigné pour le camp, mon $1^{\text {er }}$ sergent aidé de 4 caporaux, toujours les mêmes, plantait rapidement 4 drapeaux formant les 4 coins du camp.

Chaque compagnie, en arrivant, savait alors exactement l'endroit qu'elle devait occuper.

La compagnie qui avait formé l'avant-garde était à cheval sur la route; la compagnie qui la suivait et qui, par conséquent, devait prendre la garde, se mettait immédiatement derrière elle; le numéro 3 faisait face à droite; le numéro 4, face à gauche; le numéro 5 , face en arrière; la compagnie des vétérans se formait en cercle autour die ma tente et des bagages et fournissait tous les jours la garde qui devait veiller sur ceux-ci. Ils étaient en plus chargés de couper du bois pour mettre en dessous des bagages, afin que ceux-ci ne reposassent pas sur la terre, de les recouvrip d'herbes 
mouillées afin de les préserver du feu, de les arranger toujours dans le mème ordre au fur et à mesure qu'ils arriveraient, enfin de dresser ma tente et de faire le kilombe, où les blancs prenaient leurs repas.En revanche, ils étaient exempts de garde à l'extérieur du camp.

La garde de celui-ci était confiée à la compagnie qui se trouvait au deuxième rang et à cheval sur la route et qui, par conséquent, le lendemain matin, devait faire l'avant-garde.

Un peloton était affecté à cet effet. Les deux autres pelotons étaient considérés comme étant de piquet; des hommes armés devaient, lorsqu'on se trouvait dans une zone dangereuse en pays ennemi, accompagner les femmes ou les porteurs, qui se rendaient soit à l'eau, soit aux champs de manioc ou de patates.

Aussitòt que les cases des hommes étaient construites et qu'ils araient eu le temps de prendre un peu de repos, le camp était mis en état de défense.

Chaque compagnie, excepté bien entendu le numéro 2, devait, au moyen de ses machettes, déblayer un champ de tir d'environ 100 mètres. Tous les branchages abattus étaient amenés à environ 10 mètres de la lisière du camp, puis enchevêtrés le gros bout des branches du còté du camp, le petit bout du côté de l'ennemi. Cela fait, les hommes, au moyen de la pioche indigène dont chacun était muni, creusaient une tranchée-abri, rejetant les terres, sur le gros bout des branches. 
Une seule entrée étail laisséc au camp, el celle-ci étail défendue en avant par un redent, où se tenait un piquet.

Tout étranger, avant d'c̀tre introduit au camp, devait ĉtre interrogé par le chcf dc piquet.

En cas d'attaque pendant la nuit, la compagnie attaquée se défcndait derrière ses retranchcments avec son effectif au complet et étail bientôt renforcée du peloton de piquct qui n’était pas de garde à la porte d'entrće.

Les trois autres compagnies envoyaient leurs pelotons un et deux dans leurs tranchécs-abris respectifs, tandis quc lcur peloton numéro 3 venait rapidement sc former auprès de ma tente.

En comptant les trois autres pelotons de vétérans, il sc faisait donc que, mon camp parfaitement gardé, j'avais encorc six pelotons susceptibles d'êtrc dirigés successivement ou simultanćment sur l'endroit qui me semblait le plus menacć.

Quant au peloton qui se trouvait de garde aux avantpostes,il se repliait aussitôt que l'attaque s'était dessinée comme séricuse.

Celle-ci terminée, chaque sentinelle, qui ćtail toujours double, devait rejoindre son poste.

Cclles-ci étaient placćes la première fois par un officier accompagnć du sergent de garde. Tous deux devaient faire une ou plusieurs rondes pendant la nuit.

Les sentinelles étaieut toujours cachées, soit derrière des buissons, soit derrière un arbre. 
Tout homme surpris endormi pendant sa faction était impitoyablement dégradé le lendemain matin de son rang de soldat et devait servir, le restant de la campagne, comme porteur.

Une couple d'exemples suffirent ; plus jamais dans la suite aucune sentinelle ne fut prise en défaut.

Ceci dit, royons la suite des érènements.

Au reçu des renseignements fournis par mes auxiliaires, je m'étais porté en arant et j'avais établi mon campement, le 11, à Bena Kaprra, dans une position magnifique au point de vue de la défense.

Je ine trouvais, en effet, dans un terrain entièrement découvert et dont l'herbe rase empêchait toute surprise de la part de l'ennemi.

Ayant appris alors d'une façon certaine l'endroit où se trouvaient les forces des révoltés, j'envoyai l'ordre à Albert et à Mohamédi de se replier en arrière, même pendant la nuit, s'il le fallait.

Cet ordre fut exécuté d'une façon très intelligente; mes deux auxiliaires vinrent établir leur campement vers minuit dans un petit village à environ 1,500 mètres sur la droite de notre camp.

Le combat étant imminent, j'avais passé la journée à placer moi-mème les sentinelles et à donner à chacun ses instructions en cas d'alerte.

L'endroit par lequel nous serions presque certainement attaqués étant connu, je modifiai quelque peu mon dispositif habituel. 
C'est ainsi que je plaçai à cheval sur la route probable par où viendrait l'ennemi et à environ 500 mètres du corps principal, un détachement commandé par Swenson ayant sous ses ordres les sous-lieutenants Gervais et Burke.

Ce détachement était lui-même gardé par de petits postes et des sentinelles avancées.

L.e corps principal, qui se trouvait directement sous mes ordres, ètail formé en carré.

Le capilaine Bastien commandait l'aile droite, IVindey l'aile gauche. Bollen était à l'avant, Spilliart à l'arrière, mes " anciens " formant réserve générale au centre.

Albert et Mohamédi se trouvaient, comme je l'ai dit plus hanl, un pen en avant et à 1,500 mètres sur ma droite.

La nuit élait venue, noire, opaque, sans lune et presque sans éloiles : une véritable nuit à surprises.

Un silence lourd, qui avait quelque chose de morne, s'était appesanti sur le camp; il s'était comme recueilli sous l'altente d'un événement mystérieux et formidable. Seul le rire strident des hyènes et l'aboiement des chacals troublaient lugubrement le silence de la nuit.

Il était près de 3 heures du matin et nous pouvions espérer que la nuit se passerait sans alerte, quand, tout à coup, un coup de fusil éclate, puis deux, puis trois. Un court silence, puis une salve de peloton... 
Quelques rumeurs s'étant fait entendre dans le camp, "Silence! criai-je, éteignez les feux et chacun à vos postes! ”

Aussitòt, mes trois ordres furent exécutés; cinq minutes après, je pus constater que chacun occupait le poste qui lui arait été assigné pendant la journée et que tous s'apprètaient à faire vaillamment leur devoir.

Après la salve exécutée par le petit poste, les révoltés se déployèrent en un vaste demi-cercle, afin d'essayer de nous envelopper.

Cette manœuvre leur ayant demandé quelques minutes, ce court laps de temps avait suffi à chacun des nòtres pour occuper son poste de combat.

Les instructions que j'avais domnées dans la journée furent ponctuellement suivies.

Swenson s'étant porté en avant pour soutenir son petit poste, Gervais gagna au pas gymnastique son flanc gauche, tandis que Burke prolongeait son flane droit tout aussi rapidement.

Ces deux officiers, bien qu'assistant à leur premier combat, furent tous deux admirables de sang-froid et d'entrain.

Les Batétélas, ayant achevé leur mouvement, nous attaquent avec rage, avec folie; on sent qu'ils jouent leur va-tout et qu'ils se sont juré de vaincre ou de mourir.

Mais si l'attaque est énergique, la défense ne l'est pas moins et pour ceux qui, forcément, sont au repos, c'est 
une chose d'un tragique sans nom, que ce combat dans la nuit, où l'on n'a pour se guider que le feu des fusils de l'adversaire.

Nous sommes, nous, rivés à notre camp, lui peut manœuvrer : sa présence ne nous est révélée que par les coups qu'il nous envoie !

La fusillade se continue ainsi, pendant une heure, l'ageuse, désespérée ; mais alors l'ennemi semble faiblir et Swenson porte en avant son héroïque petite troupe. Or, ce que nous avions pris pour une reculade de l'ennemi n'était qu'une adroite manœuvre de sa part; il avait profité de la marche en avant de Swenson, pour faire avancer, derrière lui, un corps considérable dans l'espoir de piller le camp, qu'il escomptait peut-être sans défense, et prendre ensuite nos troupes entre deux feux.

Cette manœuvre fut déjouée. Aussitôt que les révoltés se présentèrent en face de Bollen, celui-ci, bien qu'assistant également à sa première bataille, les reçut par une succession de feux de salve, faits avec la même correction qu'à la manœuvre.

C'était magnifirque,et volontiers j’aurais crié « Bravo! »

Mais bientôt Swenson s'est aperçu de la manœuvre de l'ennemi : comme un vieux sanglier acculé par la meute, il fait un brusque demi-tour et se rue à nouveau sur l'ennemi qui, pris dans son propre piége, se trouve lui-mème entre deux feux et est enfin obligé de songer à la retraite. 
En se retirant, les révoltés vont butter contre le camp d'Albert Frees et de Mohamédi, qu'ils ne connaissaient pas, puisque ces derniers étaient arrivés pendant la nuit. Ils se croient alors tombés à leur tour dans une embuscade : la panique se met dans leurs rangs, qui, jusqu’alors, étaient restés unis; ils se débandent et prennent la fuite dans toutes les directions.

Il était álors exactement 5 heures 10 ; le jour commençait à poindre.

Je fis rassembler la réserve, ainsi que les troupes restées inaclives, et je les lançai, sous les ordres du capitaine Bastien, de MMI. Spilliart et IVindey, derrière les fuyards que Mohamédi et Albert poursuivaient déjà.

La poursuite dura toute la journée du 12.

Nos pertes furent assez sensibles; nous avions six soldats tués et dix-sept gravement blessés.

Quant aux pertes de l'ennemi, elles furent énormes. Leurs deux chefs principaux, Yamba-Yamba ainsi que Ulédi, furent tués et, ce qui peut donner une idée de l'acharnement de la lutte, plus de nonante cadavres furent trouvés sur un espace d'un peu moins d'un hectare.

Tous, dans ce combat, officiers et soldats, sé sont montrés admirables d'énergie et de sang-froid.

Je ne sais, en effet, ce que l'on doit le plus admirer dans ce combat de nuit. Est-ce l'héroïsme, la fougue, l'élan irrésistible de Swenson, de Burke et de Gervais, 
qui se battirent en lions, ou l'à-propos de Bollen, qui sut entrer en action si bien à point, ou enfin le calme, le courage raisonné dı capitaine Bastien, de Spilliart et de Windey, qui, rivés au poste que je leur avais ordonné d'occuper, assistaient impassibles à la lutte et l'arme au pied, plaisantaient avec leurs hommes sur la grêle de balles qui venaient s'abattre autour d'eux, et savaient, par leur calme, empècher ceux-ci de s'énerver et de gaspiller inutilement leurs munitions.

Deux faits aussi prouveront quel était le moral de nos soldats.

Un Mongo nommé Manguelli rentrant de courrier, pendant le combat, alla, quoique n'ayant que cinq cartouches, prendre sa place près de son chef de peloton. Mendiant une cartouche à chacun de ses voisiụs, il put faire le coup de feu jusqu'à la fin de la bataille. Un autre, nommé Abuganga, s'empara à lui seul de quatre fusils et fut promu caporal sur le champ de bataille.

Honneur soit donc rendu à tous ces braves : je salue en eux une troupe de héros!

Cette belle bataille, malheureusement, ne devait pas avoir de lendemain; toute cette expédition ayant dû être improvisée au plus vite, nous n'avions aucune espèce de vivres avec nous et nos marchandises étaient dérisoires. Enfin, pour comble de malheur, le pays que nous avions à parcourir à la suite de l'ennemi avait été complètement pillé et ruiné par celui-ci. 
Le lendemain de la bataille, De Bèche et De Cock, arrivaient arec 150 hommes de Lusambo, mais à eux non plus on n'avait pu presque rien donner, ni comme ravitaillement, ni comme marchandises.

Partis de Kapwa le 16 novembre, nous étions arrivés à Kabongo le 18 février sans incident remarquable, si ce n'est que blancs et noirs, tout le monde avait faim.

Il y arait trois mois que nous étions en route et nos paurres soldats étaient obligés de se nourrir la plupart du temps de manioc non fermenté, quand encore ils en trouvaient, car, sans l'aroir vue, il est impossible de se faire une idée de la misère du pays.

A en juger par ses vestiges, il avait cependant dù être très florissant; mais, au moment de notre passage, il n'y avait plus que des ruines et des plantations dèvastées.

Pas un être vivant; à peine de loin en loin, quelques plantes de manioc, au milieu des hautes herbes. Les blancs, d'ailleurs, étaient à peu près aussi mal lotis que les noirs; on en jugera par le fait suivant :

Un jour, une oie magnifique venant de l'arrière volait au-dessus de la colonne.

Aussitôt qu'il l'aperçoit, Bollen me crie : “ Commandant, commandant! une oie !.... "

Celle-ci était justement au-dessus de ma tête; sans prendre le temps de descendre de ma monture, je lui envoie un coup de fusil, l'oie décrit une courbe 
majestueuse et repasse une seconde fois au-dessus de moi. Je luị envoie un deuxième coup de fusil, mais sans plus de résultat que la première fois.

Alors De Cock se retourne furieux et, s'adressant à Bollen, lui dit : “ Eh bien! que le commandant vienne encore se vanter de ses chasses !... je sais bien ce que je lui répondrai.

" Voilà maintenant notre dîner qui f... le camp. "

Dans des conditions semblables, la maladie avait beau jeu. Le 14 décembre, j'avais fait partir Bastien et Gervais, chacun avec un détachement de malades ou d'hommes affaiblis.

Le 20 décembre, Swenson nous quitta avec la dysenterie, et je fus obligé de fạire partir De Bèche le 13 janvier, car il avait contracté la même maladie.

Le 15 janvier, je campai à Kabongo, dans le village de l'allié principal des révoltés. Ayant perdu toute trace de l'ennemi, j'avais envoyé De Cock et Bollen qui remontèrent l'un la rive gauche et l'autre la rive droite du Lomami, afin d'aller aux renseignements.

Ils rentrèrent le 16 au soir sans nouvelles.

Le 17, ce fut le tour de Burke et de TVindey.

Chacun d'eux avait 120 hommes sous ses ordres et devait reconnaître le pays, le $1^{\text {er }}$ au S. E. et le $2^{e}$ au N. E. Le 18, au matin, je reçus de Burke le billẹt suivant : 
Mon Commandant,

J'ai le plaisir de rous informer que je suis sur la trace des réroltés.

Une reconnaissance, que j’ai envoyée avec Kapopa, a rencontré une patrouille de Batétélas et l'a mise en fuite, après lui aroir tué deux hommes et en avoir blessé six.

On leur a pris aussi un Albini, un ceinturon et des cartouches que je vous enroie par quatre hommes de Mohamédi.

J'avancerai doucement demain et camperai sur la route

Ayez l'obligeance de nous envoyer vos instructions, ainsi que les femmes des soldats avec des vivres, car il n'y a rien à manger ici.

Les soldats sont en bon esprit et ne demandent pas mieux que de se battre.

Il y a sept heures de marche pour la caravane.

J'espère avoir de bonnes nouvelles à vous envoyer bientôt.

(S.) Intendant BURkE.

Un peu plus tard, je reçus un second billet me disant:

Mon Comnandant,

Je vous envoie deux guides; dans le cas où vous en auriez besoin, ils pourront vous montrer le chemin le plus court pour me rejoindre

(S.) BURKE.

Je lui répondis aussitôt :

Félicitations très sincères! je suis très content: N'attaquez pas sans moi. Je me mets en route a l'instant, mais je ne pourrai vous rejoindre que demain, car je dois prévenir Wınd€y et le faire rejoindre.

(S.) O. MICHAUX.

Je pris de suite toutes mes mesures: Après avoir envoyé un courrier rapide à IVindey, afin de le faire rentrer le plus vite possible, j’allai établir mon nouveau campement à trois heures de marçhe de l'ancien, 
Windey me rejoignit en effet dans la soirée; tous nous étions bien heureux puisque nous avions enfin l'espoir d'en finir en livrant une bonne bataille quand, vers 7 heures du soir, un fugitif de la troupe de Burke vint nous annoncer sa mort.

Que s'était-il passé ?

Je pus le reconstituer dans la suite.

Le 18 au matin (au lieu d'attendre mes ordres, ainsi qu'il me l'écrivait le 17 au soir), Burke s'était décidé brusquement à se porter en avant; énivré sans doute de son petit succès de la veille, croyant peut-ètre aussi pouvoir en finir à lui seul avec les révoltés, qu'il savait peu nombreux (il ne tenait aucun compte des bandes énormes de Kabongo), il avait résolu d'attaquer seul.

A partir de ce moment, il accumulait faute sur faute. Alors qu'il savait n'avoir avec lui que des hommes affaiblis par la faim et les privations sans nombre, il leur faisait faire ce jour une marche de neuf heures; en effet, parti le matin à 6 heures, il ne rencontra l'ennemi qu'à 3 heures de l'après-midi. Non content de cela, comme si la fatalité le poussait, il marchait en tête de ses soldats, sans avant-garde et sans s'inquiéter de savoir s'il était suivi!

Aussi, lorsqu'il alla donner tête baissée dans l'embuscade que l'ennemi lui ạvait tendıe, n'y eut-il pas de combat. 


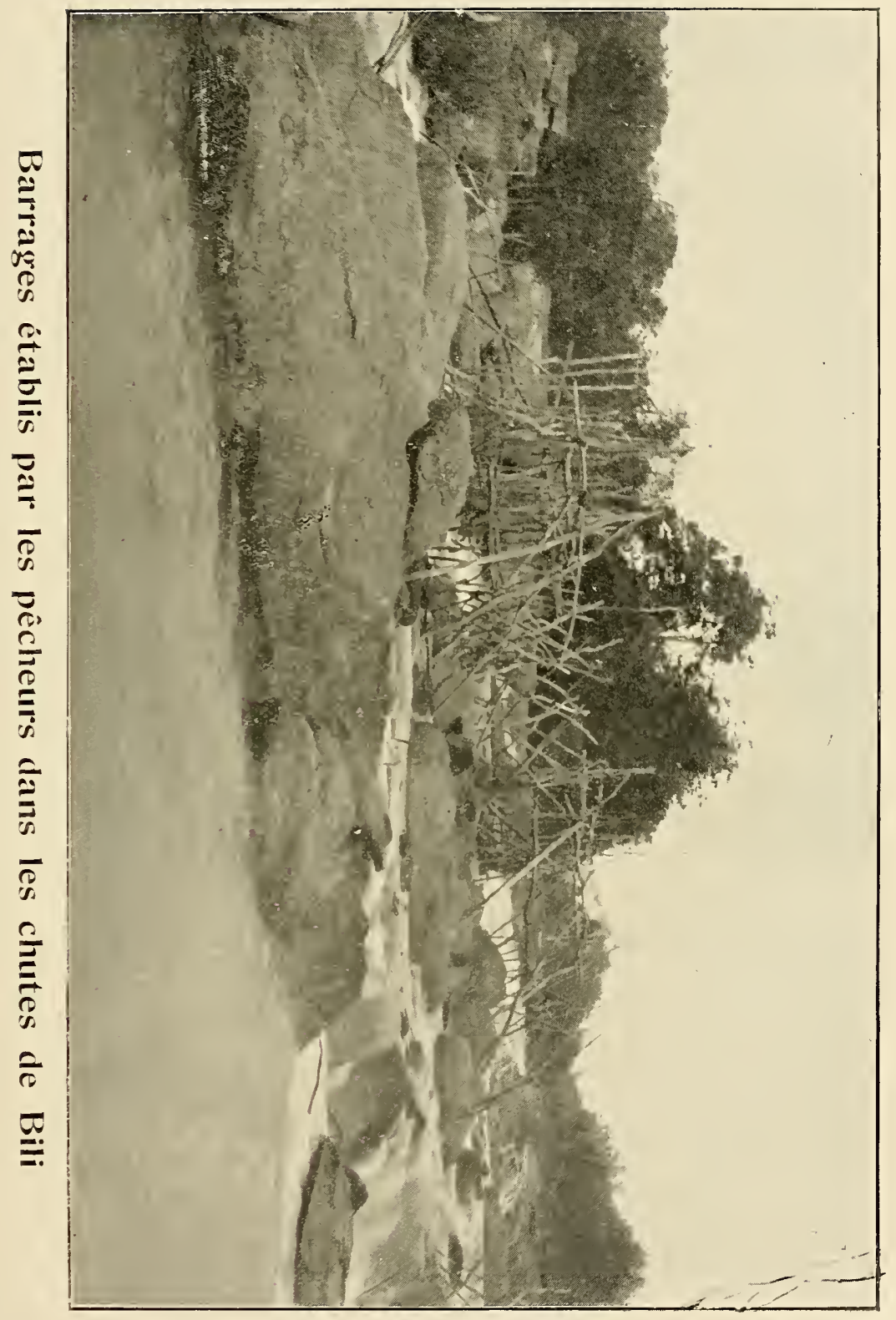




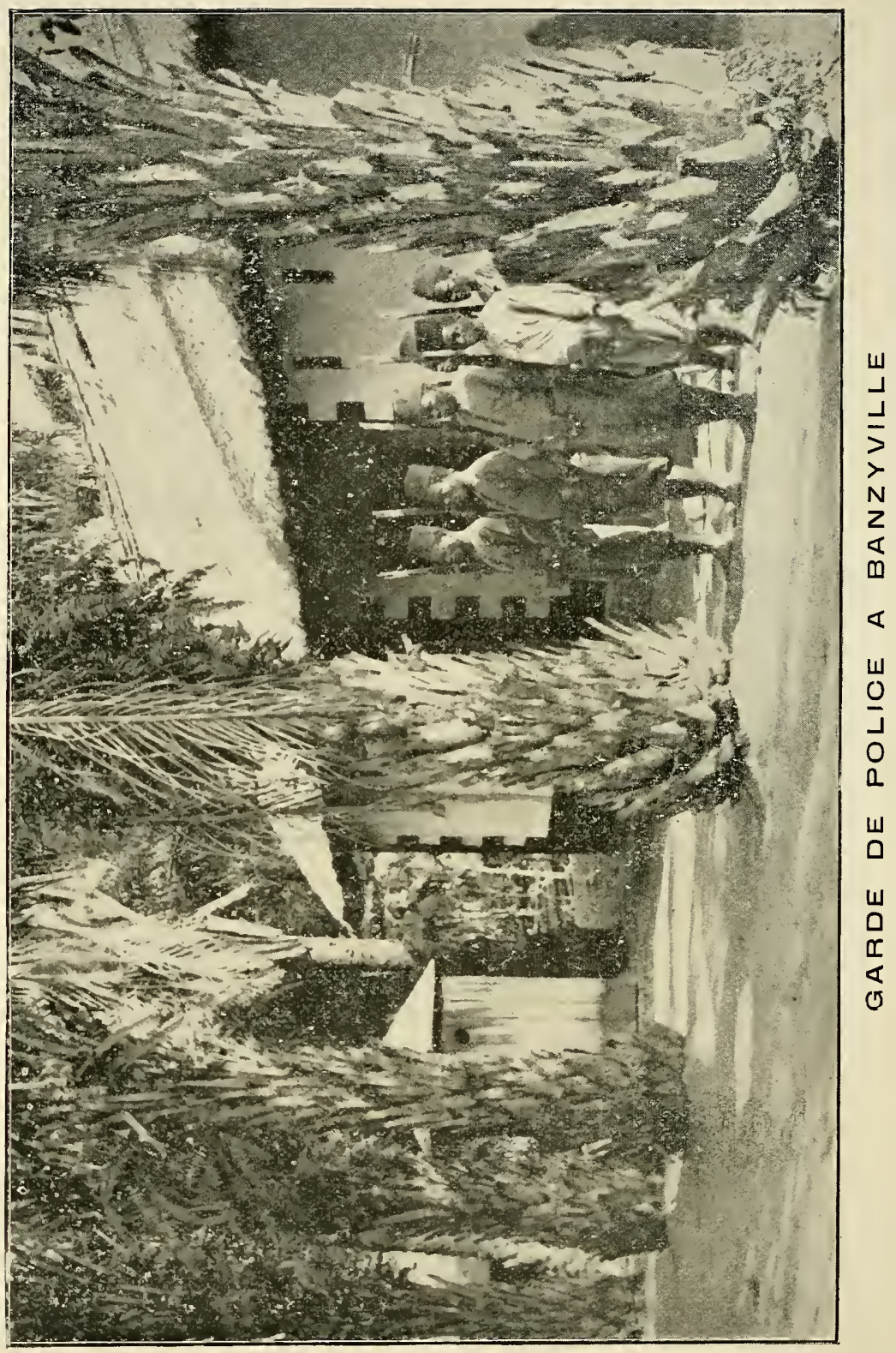


Frappé le premier, il n'eut même pas le temps de faire déployer les quelques hommes qui se trouvaient le plus près de lui.

Ceux-si, le voyant tomber, prirent la fuite, entrainant les autres arec eux.

Ce fut la débandade générale, sans le moindre combat. Aussi, deux jours après, lorsque j’arrivai à cet endroit, je pus compter 27 cadavres sur la route et pas un, sauf celui de Burke,à la place où le combat avait dù avoir lieu.

Cette panique fut quelque chose de si insensé, que je dus attendre pendant deux jours pour rallier tous les fuyards, ceux-ci rentrant tous isolément.

Comme ils s'étaient cachés dans les bois envirounants, je fis pendant deux jours faire des sonneries dans toutes les directions. Je pus, de cette façon, les rassembler presque tous : huit seulement manquèrent à l'appel.

Ainsi donc la folle équipée de Burke coûtait à l'Etat un blanc et trente-cinq soldats noirs.

Burke était certes un brave, il l'a prouvé ; mais sa mort mème nous est un bel et triste exemple de ce que l'héroïsme seul ne suffit pas : à la guerre, l'obéissance est la plus précieuse des qualités d'un chef.

S'il avait exécuté mes ordres à la lettre, nul doute que j'aurais eu l'occasion d'écraser définitivement les révoltés dans un dernier combat,tandis que, par son acte de bravoure inconsidérée, il nous fit perdre une bonne partie des fruits d'une campagne longue et difficile. 
Après avoir fait fouiller tous les bois, je me portai en avant, espérant bien que, énivrés de leur dernier succès, les révoltés consentiraient à me livrer une seconde bataille.

Mon espoir fut décu : le 23, j'arrivais à leur nouveau campement, mais là, comme partont où ils avaient passé, je ne trouvai que la dévastation et la ruine.

Pendant un mois encore, je les poursuivis ; mais alors je n'avais plus que des squelettes pour soldats; sous peine de les voir tous mourir de faim, je fus bien obligé de reprendre la route du retour.

Elle se fit sans incident; je licenciai successivement les différents détachements formant mes troupes, ne conservant avec moi que les 115 vieux soldats avec lesquels j’étais partis de Lusambo.

A Nyangwé, des ordres formels du Gouvernement m’ordonnaient de les désarmer avant de m'embarquer pour l'Europe, car, moi parti, comme ils étaient de race Ba tétéla et Wabudja, on n'avait plus de confiance en eux.

Ce fut donc sans armes que j'arrivai avec eux aux Falls.

Parmi les blancs qui se trouraient dans celle station, il y avait 111 pays et un camarade.

Le brave Hambursin, l'artilleur intrépide qui,quelques mois auparavant, pointait tranquillement son canon à 100 mètres des homas arabes, s'y trouvait cloué sur son lit de douleur. 
Le héros, aux hauts faits duquel nous arions tous applaudi, était vaincu par la terrible hématurie.

Il mourut dans mes bras; plus heureux en cela que tant d'autres, il eut au moins la consolation suprème d'exhaler son dernier soupir sur le sein d'un ami.

Quelques jours après mon arrivée aux Falls, où j'avais rencontré Dhanis, un steamer devait descendre à Léopoldville. Comme mon terme de service était expiré depuis longtemps, je résolus de prendre ce steamer, car je me sentais très fatigué.

Le jour du départ, une trentaine de blancs qui se trouvaient aux Falls s'étaient rangés sur la rive, afin de me faire leurs adieux.

Je me dirigeais vers eux quand, tout à coup, je rois une longue file noire d'hommes, marchant deux par deux et semblant se diriger vers nous.

Intrigué, je m'arrète un instant ; bientòt je reconnais mes anciens soldats qui, eux aussi, ont tenu à assister à mon départ.

Ils sont conduits par Mussongo.

Arrivée près de moi, toute la troupe fail front et salue militairement. Mussollgo s'avance alors vers moi :

" Chibalanga, me dit-il, nous n'avons plus de fusils pour te rendre les honneurs, mais nous avons tenu quand mème à venir te saluer avant lon départ pour I'Puttu, te souhaiter un bon voyage et te dire que tu emportes nos coeurs avec toi. " 
- « Mes enfants, répondis-je, je vous remercie beaucoup. Restez toujours......... »

En ce moment, un sanglot m'étouffa et, ne pouvant plus continuer, j'étreignis Mussongo dans mes bras; je serrai les quelques mains les plus proches et je me précipitai en pleurant dans ma cabine.

Quant aux blancs qui étaient réunis pour me saluer, je ne les vis mème pas et je passai devant eux en courant.

Après mon départ, tous mes anciens soldats ont fondé un village près des Falls et lui ont donné mon nom.

Voici ce que l'Almanach du Congo, édité en 1900 par les prètres de la mission Saint-Gabriel, à Stanley-Falls, publie à la page 16 :

" Un coup de fusil avertit nos voisins et bons ouvriers de Chibalanga, qui accoururent avec leurs mousquets. (Chibalanga est le nom du commandant Michaux.)

» Ses anciens soldats ont grardé affectueusement son sourenir.

"Comme les vieux légionnaires de la Rome antique, après avoir essuyé le feu des batailles, ils cultivent leur's champs et goùtent les loisirs de la paix. "

En quittant les Falls, je regagnai Boma, puis la Belgique, je ne vous parlerai pas de mon voyage du retour.

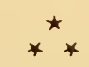

J'ai cependant encore un mot à vous adresser avant de finir mon récit. 
Des camarades m'ont souvent demandé si je crois qu'en cas de conflit arec une grande puissance quelconque, l'Etat du Congo, livré à ses seules ressources, pourrait faire une résistance honorable.

Comment donc! Tellement honorable mème que, le cas échéant, il stupéfierait le monde!

N'oublions pas que la plupart de nos officiers en Afrique sont aguerris, ainsi que les troupes qu'ils commandent; les uns comme les autres ont fait leurs preuves.

Seulement, à mon humble avis, et mon opinion est tout à fait personnelle, si un jour des forbans nous attaquent, nous ne devons pas livrer de grandes batailles. La tactique à suivre serait celle-ci :

Ne défendre que deux points; les passes de Boma ainsi qu'un endroit central, soigneusement choisi et puissamment fortifié; où l'on aurait accumulé toutes espèces de vivres et de munitions.

En cas de guerre tous les bateaux du fleuve iraient se mettre en sùreté sous les canons de la place.

Quant aux troupes de l'Etat, elles seraient réparties en quarante à cinquante guerillas, d'une force de quatre à cinq cents hommes chacune, sous les ordres de deux blancs. Le commandant et son second.

Chaque guerilla opérerait pour son propre compte et aurait ordre de ne jamais accepter le combat, elle devrait tendre partout des embuscades, dans lesquelles elle 
tirerait de 3 à 5 cartouches ; puis au moment où l'ennemi voudrait riposter, elle s'éparpillerait pour se reconstituer à quelque distance et recommencer sur un autre point.

Chaque groupe aurait un numéro d'ordre : de 1 à X. En cas de nécessité, lorsque plusieurs de ceux-ci concouraient à une même action, le commandant de la guerilla qui aurait le numéro le moins élevé, aurait momentanément la direction de l'opération; celle-ci terminée, les autres redeviendraient immédiatement indépendantes.

Nos troupes devraient également être très mobiles, nos ofliciers n'ayant avec eux que le strict nécessaire, réduit à quelques demi-charges.

Quant à nos officiers, on devrait les choisir parmi les plus intelligents et les plus énergiques et surtout les plus sympathiques.

Ce qu'il faut avant tout, c'est un caractère ferme qui, leur permeltant de regarder le danger en face, leur laisse toute leur liberté d'esprit et leur donne l'immense avantage d'ètre en possession de la plénitude de leurs moyens, afin de pouvoir prendre immédiatement une résolution et de l'exécuter avec vigueur.

Les qualités du cour leur seront aussi de toute nécessité. Il faut qu'ils connaissent bien leurs hommes, qu'ils sentent leurs besoins et comprennent leurs aspirations, qu'ils compatissent à leurs peines, partagent leurs fatigues et sachent subir les mêmes privations qu'eux. 
Connaissant bien leurs hommes, ils s'en feront aimer et posséderont leur confiance; au jour du danger, ce ne sera pas alors une masse inconsciente et purement passive qu'ils lanceront sur l'ennemi. Ce seront des hommes qui les aiment, qui les comprennent, qu'ils auront fait leurs; leur force individuelle sera centuplée par cent rolontés qui, se joignant à la leur, formeront un tout formidable,.... invincible.

Quant aux troupes, dès maintenant on devrait les exercer journellement au tir, leur donner une haute paie lorsqu'elles entrent en campagne et les habituer à ne toucher cette paie que lorsque la campagne est terminée.

Si nos troupes étaient conduites dans ces conditions, je ne doute nullement que le prix et les sacrifices qu'une puissance devrait s'imposer pour conquérir le Congo ne devinssent si fabuleux qu'aucune ne voudrait en courir les risques.

Mais ce sont là les moyens extrêmes, auxquels, j'espère bien, nous ne derrons jamais recourir.

C'est la simple serrure de sûreté que chacun de nous met à sa porte.

Encore faut-il que nous n'oubliions pas de pousser le verrou.

Ne trouverions-nous pas insensés ceux qui, sachant que des gens mal intentionnés ambitionnent leurs richesses, veulent les dévaliser, rôdent déjà autour de 
leurs maisons, ne prendraient cependant aucune mesure pour sauvegarder leur bien?

Je vous en supplie, ne soyons pas ceux-là !

Quelle que soit notre opinion politique, n'oublions pas que nous sommes Belges avant tout, que nous avons un riche patrimoine à conserver à nos enfants, un nom glorieux à leur transmettre.

Et lorsque nous entendons des marchands rapaces, toujour's les mèmes, qui, se couvrant hypocritement d'un masque faussement humanitaire, médisent de notre belle colonie, disons bien haut qu'ils ont menti! Si quelques faits délictueux ont été commis, ils ont été réprimés aussitôt connus!

Quelques-uns, peut-être,auront échappé au châtiment, mais ne faut-il pas être d'une mauvaise foi insigne pour en rendre le Gouvernement responsable? N'y a-t-il pas dans tous les pays des voleurs et des assassins?

Il ne faut pas conclure d'une rare exception à une règle générale!

C'est cependant ce que l'on veut faire pour le Congo. Ne négligeons donc aucune oćcasion de démasquer la cupidité et la mauvaise foi de ceux qui nous calomnient,

N'oublions pas que leur cœur vénal ne s'émeut que pour des populations sur les territoires desquelles il se trouve beaucoup d'or, de cuivre ou de caoutchouc. 
Que l'exemple de certains petits peuples qui ont tant d'affinité avec nous et qui, enx aussi, ont été diffamés et vilipendés, nous serve de leçon!

Et chaque fois que nous entendrons les bons apôtres s'apitoyer sur le sort de pauvres nègres qui sont infiniment mieux traités chez nous que dans la plupart de leurs colonies, disons-nous que le danger est peut-être proche, que des malfaiteurs veulent nous dévaliser...

A leurs yeux, nous avons deux grands torts: le premier c'est de n'avoir pas de cuirassés, le second c'est de posséder une belle colonie qui, jusqu'ici, a échappé à leur domination.

Ne cherchez pas autre chose.

Faisons tout ce que nous voulons, soyons aussi parfaits que possible; ils n'en continueront pas moins à crier à l'abomination; leur siège est fait.

Ne nous endormons donc pas dans une fausse quiétude, le danger est plus réel peut-être qu'on ne le croit, puisque des voraces ont faim. 



\section{EIPOGUE}

Nos glorieux morts. - Heureux avènement. - Magnifiques résultats obtenus. - Quelques vœux pour l'avenir. - Clairons sonnez aux champs !...... au drapeau ! !

La première édition de cet ouvrage a paru il y a six ans à peine et cependant que d'évènements se sont accomplis depuis cette époque!

Notre grand Roi, le Créateur de l'œuvre africaine est mort !......

Celui dont le règne fut pour son peuple une splendide leçon d'énergie, d'audace et de ténacité, n'est plus !

Lorsque le Congo était encore représenté sur la Carte d'Afrique par une tache blanche, il a su deviner les richesses de ce Continent mystérieux, et malgré l'inertie, l'indifférence et mème l'incrédulité de la plupart des Belges, après trente années d'efforts continus, par la seule force de sa volonté, il a doté son pays d'une splendide colonie 80 fois plus grande que la Mère Patrie.

Presque seul, avec l'aide de quelques hommes d'élite, tels que Banning, Lambermont, Strauch, Bernaert et Thys, il a accompli une tâche peut être plus grande encore, puisqu'il a su tirer ses compatriotes d'une torpeur légendaire.

Après les avoir animés de son initiative hardie et de sa clairvoyance extraordinaire, il en a fait un peuple entreprenant et colonisateur. 
Mais à tous ces bienfaits d'un ordre matériel, il en a ajouté d'autres d'un ordre moral supérieur.

Il y a trente ans, cette terre d'Afrique, était une terre d'épouvante et d'horreur, tout entière au pouvoir d'Arabes esclavagistes ou de féroces anthropophages.

Aujourd'hui tout le Congo est pacifié. L'Arabe a été vaincu, chassé du territoire, et le cannibalisme s'est fait honteux, se cache et n'existera bientôt plus qu'à l'état de légende.

Or, si de nos jours toutes ces populations peuvent vivre en paix, prospérer et se développer librement, c'est à Lui qu'elles le doivent, à Lui notre grand Roi LÉOPOLD II. (*)

(*) Voici en quels termes le Cardinal Lavigerie dans sa lettre du 8 Norembre 1889 et Paul Leroy-Beaulieu dans son ouvrage " De la Colonisation des peuples modernes, t. I, p. 26t, rendent hommage à l'ouvre de LÉOPOLD II :

“ La postérité placera parmi nous le nom de LÉOPOLD II à la tête dc ceux des bienfaiteurs les plus insignes de l'humanité pour l'initiative souveraine, la persévérance, les sacrifices mis par lui au service d'une telle cause ».

(Cardinal Lavigerie).

“ Ce sera l'éternel honneur du Roi LÉOPOLD d'avoir deviné l'avenir de cette partie du monde, de l'avoir préparé par d'immenses sacrifices, de ne s'être laissé envahir ni par la fatigue ni par le doute qu'eussent pu susciter chez un esprit moins ferme les lenteurs et les mécomptes du début. Il mérite par là d'être compté au rang des plus grands souverains de ce temps comme créateur d'empire ».

(P. Leroy-Beadlieu). 


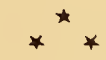

Morts aussi, mes deux anciens chefs, ces deux héros de l'épopée congolaise, Dhanis et Paul Le Marinel.

Mort également, Albert Lapière, ce brave entre les braves, celui de tous mes officiers qui le plus longtemps a servi directement sous mes ordres, celui auquel j’élais resté le plus attaché.

Morts encore Roget, Popelin, Van den Heuvel, Van de Velde, Burdo, Crespel, Hanssens, IIanolet, Hambursin, Ramackers, de Wouters, de Heuscl, Van Kerchove, Cambier, Milz, Becker, Ponthier, Dubois, Legat, Tobbac, Doorme, Dufour, Droeven, Swenson, Antoine, Duchène, Prégaldien, les Pères De Decken et Huberland, le Professeur Laurent et d'autres, hélas dont le nom n'évoque déjà plus qu'un lointain souvenir.

Et cependant, tous dans leur domaine ont été des héros.

En soldat, je les salue du sabre et je leur dis :

"Vous qui avez si grandement et si noblement rempli toute votre tâche :

"Vous, qui sans compter, par devoir, par dévouement, avez consacré les pluś belles années de votre vie à l'œuvre féconde de la colonisation :

"Vous, qui par votre travail, votre courage et votre abnégation avez soustrait tout un peuple à la barbarie et avez contribué si largement à la prospérité de notre 
Pays, dormez et reposez en paix dans le grand sommeil éternel :

"Vous avez bien mérité de la Patrie."

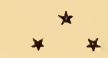

Bien que datant de quatre années à peine, l'a vènement du Roi ALBERT a déjà eu de profonds et féconds résultats tant au Congo qu'en Belgique.

Succédant à un Souverain comme LÉOPOLI II, sa tâche était certes difficile.

Aujourd'hui, grâce à ses qualités de cœur et d'esprit gràce à un travail de tous les instants, nul Souverain, nulle Famille régnante, n'est plus populaire, plus aimée ni plus respectée que la nôtre.

Voilà pour la Belgique.

Quant au rôle qu’ll était appelé à jouer dans nos affaires coloniales, Il s'y est préparé dès son enfance.

Il s'est occupé toujours avec passion de tout ce qui concerne les questions maritimes et coloniales.

Dès qu'Il l'a pu, Il s'est embarqué pour le Congo. Le récit des explorateurs avait tout à la fois amusé son enfance et éveillé toutes les curiosités de son adolescence.

Cette colonie, Il n'a pas voulu la parcourir simplement en curieux. Conscient de son rôle de Prince et des responsabilités qu'il aurait un jour à assumer, il a voulu voir le pays, tel qu'il est et s'assurer par lui-même de ses richesses et de ses besoins. 
Aussi, à peine sur le tròne, Il a déjà rendu d'immenses services aux colons, aux indigènes, aux agents et aux anciens agents.

C'est à Iui que nous devons :

$1^{\circ}$ ) Un secours aux veuves et parents besognenx d'agents décédés de l'ancienne administration coloniale.

$2^{n}$ ) Une indemnité de voyage aux femmes légitimes de magistrats, fonctionnaires, militaires ou agents du Gouvernement colonial, accompagnant leurs maris au Congo.

$\left.3^{\circ}\right)$ Une indemnité de voyage aux religieuses, missionnaires au Congo, rentrant en congé en Europe.

4) Un subside aux missions du Congo Belge, spécialement aux missions enseignantes.

5) Un subside au service d'hygiène du Congo Belge (maladie du sommeil, lazarets, missions scientifiques, indemnités de voyage et de séjour résultant de la fréquentation du Cours de l'Ecole de médecine tropicale). Achal d'instruments de précision.

6) La création d'un sanatorium sur les bords de la Méditerranée et indemnités de séjour pour les agents malades de l'administration coloniale.

$\left.7^{\circ}\right)$ Un subside pour le balisage du fleuve Congo.

8) L'envoi d'une mission ethnographique.

$\left.9^{n}\right)$ Traitements et salaires relatifs à la construction de l'Ecole coloniale de Tervueren et des cultures maraîchères et fruitières de Laeken et de Tervueren. 
$\left.10^{\circ}\right)$ La construction d'hôpitaux pour noirs.

$11^{\circ}$ ) Fonds pour favoriser le mariage des femmes indigènes unies à des monogames.

$\left.12^{\circ}\right)$ Expérience et installation de télégraphie sans fil.

$\left.13^{\circ}\right)$ Don d'un bateau rapide pour le service des postes.

14) Enfin il a accordé une pension civique aux anciens africains, aux pionniers de la première heure.

Rompant avec une habitude bien nationale, Il a voulu montrer à tous que, s'il convenait d'honorer toujours les morts, il était parfois seyant de savoir récompenser les vivants.

Son geste généreux aura certes jeté la consternation dans certains milieux qui se seront demandé avec stupéfaction, si le monde était changé !! !......

On leur a vait toujours enseigné que pour honorer ou récompenser un Belge, il convenait d'attendre qu'il fùt inort!.....

En récompensant les vieux, Il aura par le fait même stimulé l'ardeur des jeunes.

Au nom de tous les Congolais, qu'il me permette de Lui crier respectueusement :

MERCI SIRE! ET VIVE LE ROI!

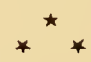

Depuis que grâce à la volonté du Roi LÉOPOLD II et aux efforts de ses principaux collaborateurs, mil. Schollaert, Renkin, de Lantsheere, Neujean, 


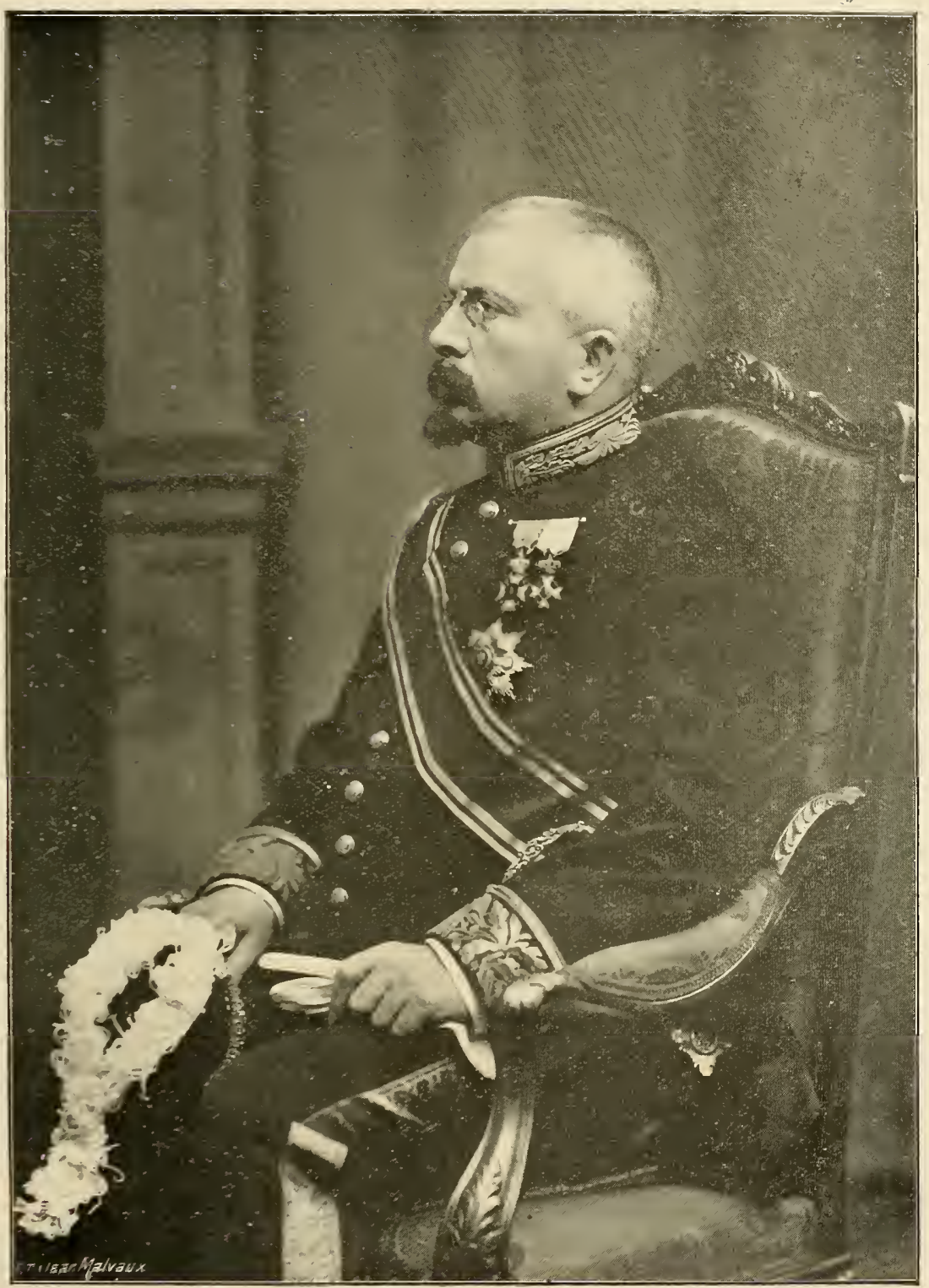

\section{Monsieur J. RENKIN}

NOTRE PREMIER MINISTRE DES COLONIES 


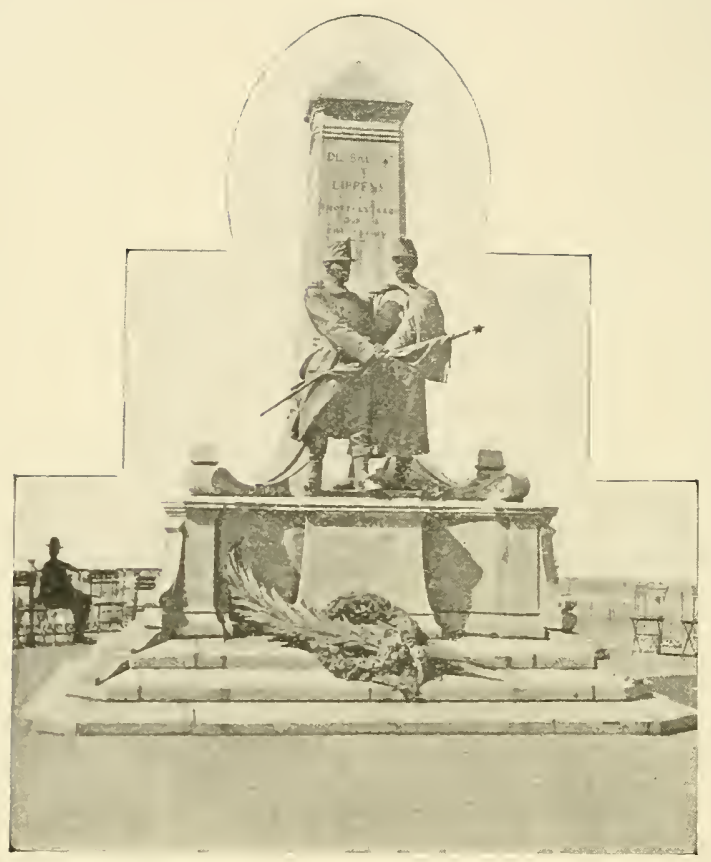

Monument DE BRUYNE et LIPPENS à Blankenberghe 
Helleputte, Hymaxs et Huysuans, le Congo, d'Etat indépendant est devenu Coloniẹ Belge, de grands progrès ont été accomplis dans toutes les branches de la colonisation.

J'estime que c'est pour moi un devoir et un très grand plaisir d'en signaler les principaux.

$\left.1^{\circ}\right)$ Introduction du commerce libre s'appuyant sur le travail libre.

$\left.2^{\circ}\right)$ Introduction de la monnaie et perception de l'impòt en argent.

$3^{\circ}$ ) La lutte contre la maladie du sommeil.

$4^{\circ}$ ) Décentralisation et initiative plus large laissée au gouvernement d'Afrique.

$\left.5^{n}\right)$ Les travaux publics et les moyens de transport ont été considérablement améliorés (Chemins de fer, porls, navigation fluviale).

$\left.6^{\circ}\right)$ Des tribunaux ont été installés dans tous les centres principaux.

$7^{\circ}$ ) La force publique a été réorganisée et considérablement augmentée.

8 ) L'instruction publique a été organisée et l'hygiène a fait de grands progrès. Des écoles professionnelles ont été créées dans les centres principaux.

$\left.9^{\circ}\right)$ Des postes de télégraphie sans fil ont été établis.

$\left.10^{\circ}\right)$ Le régime fiscal a été considérablement amélioré et simplifié. 
$11^{\circ}$ ) De très utiles ouvres scientifiques, telles que, le Musée de Tervueren, l'Ecole coloniale et l'Ecole de médecine tropicale, ont été créées.

$12^{\circ}$ ) Des pêcheries modèles, où les indigènes peuvent venir s'instruire, ont été établies.

Enfin l'industrie et le commerce ont fait des progrès énormes.

Ces progrès, nous les devons principalement à M. Renkin, Ministre des Colonies, ainsi qu'aux travaux des membres du Conseil Colonial.

Mais à côté d'eux, il y a eu d'autres travailleurs, dont il serait profondément injuste de laisser tomber les noms dans l'oubli.

J'ai déjà cité les noms de quelques-uns de nos glorieux morts; aussi je ne citerai maintenant que les noms de ceux que j’aime à croire encore en vie.

Dans le service administratif nous avons les Van Eetvelde, les Janssen, les Wahis, les Droogmans, les Liebrechts, les de Cuvelier, les Arnold, les Fuchs, les Van Gèle,les Wangermée,les Malfeyt,les Lantonnois, les Mahieu, les De Keyser, les Baerts, les Leplae, les Le Marinel, les Lombard, etc.....

Parmi les soldats je citerai :

de Nacar, Lothaire, Jacques, Descamps, Chaltin, Gillain, Henry, Daenen, Cassart, Renier, Bastien, Dubreucq, Gervais, Bollen, Sillye, Van Riel, Rue, De Grez, Sauvage, etc..... 
Parmi les missionnaires MM. Sims, Grenfeld, Bentley, le Père Cambier, Monseigneur Roelandts, Monseigneur Van Ronslé, le Père Liagre, le Père Gheluy, etc.....

Les industriels et les commerçants qui ont tout à la fois créé la richesse de notre colonie et aidé puissamment au développement de la Belgique, s’appellent :

Alexandre, Delcommune, Thys, Bolle, Lacourt, Hallet, Baron Goffinet, Baron Empain, Baron Lambert, Comte d'Ursel, etc.....

Les ingénieurs et les savants :

Charmanne, Goffin, Paulissen, Adam, Cito, Cornet, $D^{r}$ Etienne, Dr Broden, Dr Dupont, Dr Dryepondt, Dr Carré, Dr Van Campenhout, les Professeurs Laurent et Ambroise, le Lieutenant-Colonel Cabra, le Lieutenant Hutereau, etc.....

Tous ces noms sont connus du public. On ne saurait trop les répéter el tous devraient ètre gravés sur l'airain.

Nous devrions aussi nous faire un devoir de les apprendre à nos enfants, puisqu'ils représentent les vertus qui nous sont les plus chères.

Si les uns sont synonymes de courage, d'audace et de bravoure, les autres signifient travail, énergie, ténacité, progrès, science, organisation, perspicacité, justice, abnégation et charité. 


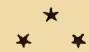

Je viens de donner une rapide énumération des grands progrès réalisés au Congo.

Est-ee à dire que tout soit parfait dans notre belle Colonie?

Certes non, puisque toute ouvre humaine est perfectible.

Je suis d'autant plus à l'aise pour écrire ees lignes que S. M. le Roi et le Ministre des Colonies sont les premiers à proelamer eette vérité.

Parmi les réformes qu'il nous reste à aeeomplir, il y en a une demi-douzaine qui sont eapitales.

Sans avoir la prétention de vouloir résoudre ees questions (ee livre ne comportant pas un pareil travail) je demanderai eependant à mes lecteurs, la permission d'attirer leur attention sur quelques points et, m'enhardissant de leur bienveillance,je pousserai même l'audaee jusqu’à émettre des vœux.

\section{VOIES DE COMMUNICATION}

Ce qui fait la valeur intrinsèque d'une colonie, ce sont les riehesses de son sol et de son sous-sol, ainsi que ses voies naturelles de communieation. 
Ce qui en fait sa valeur réelle, c'est la façon dont la Mère Patrie sait exploiter ces richesses.

Or, un pays ne peut donner son maximum de rendement qu'à la condition d'avoir un système parfait de voies de communication, autrement dit : une politique de roies de communication.

Au Congo, d'immenses progrès ont été réalisés. Ils sont dus surtout aux travaux et aux études des ingénieurs Goffin, Adam, Paulissen, Denil, du commandant Moulaert, des capitaines Bultinck et Gorovson et du lieutenant du génie danois Jensen.

Le cours du fleuve et de ses affluents a été presque partout étudié et amélioré.

Le chemin de fer de Matadi à Léopoldville et le chemin de fer dit des Grands Lacs sont terminés.

Les lignes du Mayumbe, d'Elisabethville à Kambove, de Kabala au Tanganika sont en voie d'achèvement.

Enfin différentes lignes, dont les trois plus importantes sont celles devant relier Kambove à Dilolo, celle partant de Kambove pour arriver à Lusambo et celle qui, partant de Dolo, traverse le Kwango, le Kasaï et ira aboutir à Bukama, sont à l'étude et seront probablement construites sous peu.

Mais toutes ces lignes, ainsi que je l'ai démontré dans "La mise en valeur de notre Colonie ", seront toujours plus longues et plus onéreuses que la ligne qui part de Lobito-Bay pour aboutir à Kambove en passant par Dilolo. 
Au point de vue de la rapidité du voyage, il n'y a rien à faire, mais au point de vue du fret, nous pourrions peut-être avoir une voie belge moins onéreuse, ainsi que je l'ai démontré. Pour cela il faudrait créer un passage à travers les chutes WVolff ou plutôt les rapides de Wolfi, car ce ne sont pas des chutes, mais bien des rapides.

Ce travail peut, je crois, se faire assez facilement.

En tout cas, la réussite de ce travail est d'une importance si capitale pour le développement de notre belle colonie en général et du Katanga en particulier que je crois pouvoir émettre à nouveau le vou que ce problème soit étudié sans retard par nos ingénieurs.

\section{LA JUSTICE}

Lorsque, il y a trois ans, j’ai publié l'ouvrage intitulé "Pourquoi et comment nous devons coloniser ", j’ai consacré un chapitre à l'organisation des chefferies indigènes et à la justice aux colonies.

Depuis lors, des travaux très importants ont été publiés sur ce sujet par des savants d'une renommée mondiale, tels que MM. Edmond Janssens, Galoppin, Victor Augagneur, $D^{r}$ Gustave Le Bon, H. Rolin, Harmand, C. Jonnart, A. Girault, Flandin et F. de Lamnoy, etc. 
Tous sont unanimes à demander deux codes bien différents, l'un pour les blancs et l'autre pour les noirs.

Le code applicable aux noirs doit respecter les us et coutumes de chaque race, tout en s'adaptant aux exigences de la civilisation.

Nous avons en ce moment 80 juges au Congo. C'est beaucoup au point de vue des finances de la Colonie et cependant c'est bien peu, si on se place au point de vue de l'étendue du territoire, puisque le Congo représente une superficie de plus de 80 fois la Belgique.

Si nous voulons que la justice puisse se rendre d'une façon eflicace sur tout cet immense territoire, nous devons forcément :

$\left.1^{\circ}\right)$ Eduquer convenablement les chefs et les fils de chefs, leur faire subir un petit examen sur les cas qu'ils auront le plus souvent à résoudre, ainsi que sur les sanctions que ces cas comportent.

Le pouvoir judiciaire des chefs ne pourrait s'étendre qu'aux membres de leur tribu et encore pour les seules fautes n'entraînant qu'une peine minime. Ils seraient les juges de paix, les juges de simple police de leur pays.

$2^{\text {v) }}$ Créer dans chaque circonscription territoriale une juridiction composée d'un agent du gouvernement et de deux assesseurs, l'un blanc et l'autre noir, ainsi que le préconise M.F. de Lannoy dans le remarquable travail qu'il a publié dans le Bulletin de juillet-août 1913 de la Société belge d'Etudes coloniales. 
$3^{\circ}$ ) Exiger d'une façon absolue que les magistrats ou les fonctionnaires qui seront appelés à rendre la justice au Congo, connaissent la langue indigèné de la contrće où ils sont appelés à siéger.

$4^{\circ}$ ) En plus de l'obtention d'un certificat spécial d'aptitude aux fonctions judiciaires coloniales, tout juge devrait faire un slage d'au moins un an en qualité d'altaché au service judiciaire auprès d'une Cour d'appel coloniale, avant de pouvoir être appelé à rendre des jugements.

5") Enfin, avec le Dr Maxwell, je suis partisan dans une certaine mesure des peines corporelles pour certaines calégories de noirs.

"Pour obtenir un résultat, dit le D" Maxwell, il faut que la peine soit vraiment pénible; dans le cas contraire, elle favorise la production du crime au lieu de l'empècher " .

Je suis absolument de cet avis.

Or, puisque pour la plupart des nègres la prison n'est pas considérée comme étant une peine, ou du moins puisqu'ils la considèrent comme une peine très légère, j'estime que dans certain cas, on doit continuer à appliquer la peine du fouet.

Je sais que cette appréciation fera tressauter quelques personnes d'une sensibilité excessive. Avant d'avoir été au Congo, j’aurais probablement pensé comme elles, car, moi aussi, j’ai toujours aimé et défendı les nègres. 
Malheureusement mon expérience de vieil Africain m'a démontré qu'avec certaines natures rebelles, le fouet seul pent parfois obtenir certain résultat.

\section{LA MAIN=D'CEUVRE}

Une des questions les plus intéressantes qu'il nous reste à résoudre au Congo, et particulièrement au Katanga, est certes celle de la main-d'œuvre.

Cette question est pour nous d'intérêt primordial, car le manque de bras se fait déjà grandement sentir et ce besoin ira en s'accentuant au fur et à mesure que l'activité industrielle se développera dans le pays noir.

L'étude de ce problème a déjà tenté beaucoup de spécialistes des plus capables.

Je citerai entre autres Camille Janssen, René Vauthier, le Dr Cureau, Emile Zimmerman, E. Walterthum, le capitaine commandant René Dubreucq, Henri Anet, Jacques Hassan, Georges Paquot, E. Francqui etc....

Les uns sont partisans d'employer la main-d'œuvre jaune, puisque la main-d'œuvre indigène fait défaut.

Les autres, après avoir fait le procès des jaunes et avoir expliqué tous les motifs (et ils sont nombreux!) qui militent en faveur de.leur exclusion de la colonie, réclament la continuation de la main-d'œuvre indigène.

Je me range énergiquement parmi ces derniers. 
Les expériences qui ont été tentées avec des jaunes sont nombreuses : partout elles ont donné des résultats peu encourageants.

Les essais fails dans les mines du Rand et au chemin de fer de Matadi à Léo sont concluants et, à moins d'y être absolument forcé, je demande que l'on éloigne d'une façon absolue cet élément dissolvant de notre belle Colonie.

Alors, me dira-t-on, où nous procurer la main-d'œuvre qui nous est indispensable?

Mais au Congo!

La plus grande partie du chemin de fer de Léo à Matadi et la presque totalité du chemin de fer dit des Grands Lacs ont été construits par des ourriers indigènes.

Quant aux mines de Kilo, on peut affirmer qu'elles sont presque exclusivement exploitées par des ouvriers indigènes et que maintenant tous les chemins de fer du Congo emploient des mécaniciens dı pays.

J'estime que ce qu'ils ont fait aux chemins de fer et aux mines de Kilo, ils peuvent le faire au Katanga.

A nous de les éduquer et de les amener à aller travailler au Katanga.

Ce sont deux conditions qui ne peuvent être obtenues sans l'aide la plus large du Gouvernement.

C'est à lui en effet qu'incombe le devoir d'éduquer les noirs et de les préparer au rôlequ’ils sont appelés à jouer dans le développement de la Colonie. 
Il faut aussi à tout prix et quels que soient les sacrifices qui seront reconnus nécessaires, que le gouvernement multiplie sur tous les points du territoire des écoles professionnelles et qu'il prenne des mesures énergiques pour que les cours soient suivis régulièrement. De cette façon, nous aurons des ouvriers.

Voici d'ailleurs ce que disait le Roi ALBERT, dans son beau discours, lors de l'inauguration de la Section Coloniale à l'Exposition de Gand.

"N'oublions surtout jamais que les populations du " Congo nous apporteront la plus précieuse et la plus ") indispensable des collaborations. En élevant les indi") gènes à une conception plus large de la vie, en ") accroissant leur bien-être, en développant chez eux le " goût des travaux qui répondent à leurs conditions 1) d'existence, nous trouverons en eux des artisans du ") progrès de la colonie. "

Oui, diront des camarades, c'est parfait en théorie, mais comme ces ouvriers sont nés paresseux et que pour eux, le besoin de travailler ne se fera jamais sentir, ils ne travailleront pas.

Peut-être!...

Ils ne travailleront pas, si le besoin de travailler ne se fait pas sentir, c'est très vrai. Mais c'est précisément ce besoin qu'il faut faire naître et même imposer.

Le moyen me paraît assez simple. 
Maintenant que l'impôt se perçoit en argent, il faut que le gouvernement exige son paiement d'une façon régulière.

Au besoin le Gouvernement peut augmenter quelque peu l'impòt.

Mais là ne doit pas se borner l'œuvre du Gouvernement. Il ne suffit pas qu'il oblige les indigènes à travailler, il faut aussi qu'il surveille de très près la façon dont on les fait travailler.

Lorsque l'on aura amené les indigènes à aller travailler au Katanga, il faudra, à mon avis, pour les retenir sur les travaux, observer les conditions suivantes :

$\left.1^{\circ}\right)$ Exiger que les contrats soient faits d'après un modèle fourni par le Gouveruement et le rendre strictement obligatoire pour les deux parties.

$\left.2^{\circ}\right)$ Exiger que les travailleurs soient traités avec justice et bonté.par les employeurs.

$\left.3^{\circ}\right)$ Obliger les compagnies à loger convenablement leurs ouvriers et, afin d'amener le plus possible de ménag'es, exiger que chacun d'eux ait une maisonnette convenable à sa disposition.

$\left.4^{\circ}\right)$ Leur distribuer des vêtements et des couvertures.

$\left.5^{\circ}\right)$ Leur procurer des divertissements, les uns gratuits, les autres à très bon compte.

$\left.6^{\circ}\right)$ Veiller à ce qu'ils aient des vivres frais en abondance et de bonne qualité. 
Pour obtenir ce dernier résultat, le gouvernement pourrait exonérer de l'impòt les indigènes qui se trouvent dans certaines zones et qui justifieraient qu'ils possèdent des plantations vivrières d'une contenance à déterminer.

La vente de leurs produits à un taux suffisamment rénumérateur devrait également leur ètre assurée.

$7^{\circ}$ ) Afin d'éviter autant que possible, les désertions parmi les travailleurs, une partic de leur paie, par exemple les $2 / 3$, serait payée hebdomadairement et le $3^{\text {me }}$ tiers leur serait payé à l'expiration de leur contrat.

De cette façon, non seulement on retiendrait davantage les nègres sur les travaux, mais encore ceux-ci, ayant un joli pécule à toucher à la fin de leur terme, iraient faire montre de leurs richesses dans leur village où ils feraient naître la con voitise.

Le nègre étant très vaniteux, il n'y a pas de doute que son besoin de paraìtre créerait bientòt un courant qui s'orienterait vers les mines.

Le problème de la main-d'œuvre serait done en grande partie résolu.

\section{LA COLONISATION AGRICOLE DU KIVU.}

Dans denx Jrochures : "Nos Paysans au Congo " et " La mise en valeur de notre Colonie ", j'ai demandé avec insistance que l'on créât une colonie agricole dans le Kivu. 
Les essais que nous avons faits au Katanga sont concluants. Pour le moment du moins, nous ne pouvons espérer installer des colons agricoles dans cette province du Congo.

Tout ce que nous pouvons faire, c'est d'y installer des maraîchers.

Au Kivu, au contraire, des hommes qui font autorité dans la matière, tels que le Gouverneur Général Baron Wahis et les vétérinaires Willaert et Carlier, déclarent qu'il fait aussi sain dans certaines parties du territoire, telles que Kalembé-Lembé, Bobandana, N’Goma, etc., qu'en Belgique.

Ils sont également unanimes à déclarer que l'élève du gros bétail peut s'y faire dans des conditions exceptionnelles et qu'il est déjà pratiqué sur une vaste échelle par les indigènes.

Enfin des essais ont été faits et il s'y trouve des terres d'une fertilité extraordinaire, telles par exemple, la région de Luvingi à Rutshuru, ainsi que la région du Bubaie.

Là, les pommes de terre, le blé, le tabac, etc., viennent très bien et sont à même de donner un excellent rendement.

J'ai expliqué ailleurs la façon dont je comprends la colonisation de cette contrée, ainsi que les moyens d'écouler les produits obtenus.

Je n’insisterai donc pas sur ce point. 
Mais, pour la troisième fois, j'émets le vœu de voir entreprendre le plus tòt possible la colonisation agricole de ce beau pays.

Ce rœu est d'autant plus ardent qu'il y a peu d'aléas, que la réussite en est certaine, ou à peu près.

\section{MARINE MARCHANDE. - MARINE DE GUERRE.}

Ceux qui en Belgique font autorité au point de vue commercial, sont unanimes à déplorer que notre marine marchande ne prenne pas plus d'extension.

Pour s'en convaincre, il suffit de lire les discours du Roi LÉOPOLD II à Anvers, le 12 Juin 1909, du Roi ALBERT au Sénat, lorsqu'il était encore Prince Royal, des Ministres Helleputte, de Lantsheere, Seegers, de MIM. Léon Hennebicq, Franck, Smeester, Hervy-Cousin, de Ryckère, Georges Lecointe, etc...

Ils vous diront que le commerce suit toujours le pavillon.

C'est à dire que la prospérité du pays est intimement liée au développement de notre marine marchande.

Tous, vous diront aussi que la stagnation de notre marine marchande provient de la difficulté que rencontrent nos armateurs pour se procurer de bons officiers de nationalité belge.

Pourquoi avons-nous peu de hons officiers de marinc en Belgique? 
Uniquement parce que nous ne possédons pas de marine de guerre et que c'est dans celle-ci que tous les pays maritimes recrutent leurs meilleurs officiers de marine marchande.

Cette objection suffirait à elle seule pour nous faire désirer avoir une petite marine de guerre.

Il y a d'autres motifs plus impérieux qui militent en sa faveur.

L’année dernière (en 1912), aux journées coloniales qui tenaient leurs assises à Bruxelles, M. René Vauthier, dans un beau et savant discours, nous a démontré d'une façon irréfutable que nous avons le droit d'avoir des colonies.

Il m'a paru qu'à ce beau discours une conclusion s'imposait.

J'ai donc demandé la parole et la conclusion que j'ai tirée était celle-ci :

"Nous arons le droit pour nous, c'est très bien, mais à quoi sert le droit, s’il ne s'appuie sur la force?

" De nos jours, on ne parle que de droit, et lorsque nous observons ce qui se passe autour de nous, nous voyons partout la force primer le droit!

"Nous sommes une nation de près de huit millions d'habitants et, au point de vue du commerce, nous sommes la quatrième nation du Globe. Cependant les grandes puissances nous traitent en quantité négligeable, alors que quatre petits peuples qui, tous 
ensemble, ont à peine notre population et qui sont loin d'ètre aussi prospères que nous, ticment toute l'Europe en émoi.

"Pourquoi cette différence?

" Uniquement parce que les Bulgares, les Serbes, les Grees et les Monténégrins ont une armée vraiment nationale, qui leur permet de parler fier et haut, tandis que notre armée n'est en rapport ni avec notre population, ni avec la prospérité du pays. »

En terminant, je disais :

"Le meilleur moyen de défendre notre Congo, c'est encore d'avoir une bonne armée en Belgique, car en politique, on aime où l'on fait semblant d'aimer ceux qui sont forts.

" Ayons donc une bonne armée; on nous aimera et l'on nous respectera. ")

Depuis lors, la résurrection de notre esprit national s'est affirmée et grâce aux efforts de notre Ministre de la Guerre, le Baron de Broqueville, et de patriotes de tous les partis, tels que : MM. Hymans, de Landsheere, Pirnez, Louis Ifuysman, Théodor, Monville, Léon Henuebicq, le Licutenant Général Baron de Heusch, Ludovic Thiriaux, Alban Bertrand, Knudsen, elc., nous allons enfin aroir une armée digne de nous et de notre glorieux passé!

Les preux qui furent nos ancêtres auront tressailli dans leur tombe, le jour où la loi du salut a été votée. 
Elle leur aura prouvé que leurs fils n'ont pas dégénéré et que le sang gaulois coule toujours pur dans leurs veines.

Certes, l'effort que nous avons fait est beau et lous les patriotes doivent une reconnaissance éternelle à tous ceux qui ont aidé à la rénovation de notre armée.

N'oublions pas cependant que l'orage gronde toujours et que, si le dauger semble s'ètre déplacé, il ne reste pas moins réel.

Des brochures, des journaux sont publiés et l'on y parle du partage ou de l'annexion de notre colonie, absolument comme si la succession était déjà otiverte.

Des mots!... des phrases !... me dira-t-on.

Oui, mais cela commence toujours par des mots on par des phrases, juscu'au jour où l'on se trouve devaut la terrible réalité.

Les peuples ont un besoin pressant d'expansion, cela est certain.

Notre colonie est vaste, riche et prospère. Donc, tentante!...

si nous roulons la conserver, sachons vouloir la défendre envers et contre tous ceux qui voudraient nous la voler.

M. E. de Renty, dans son bel ouvrage "L'Europe Voire "), dit à la page 139 :

" La neutralité du Congo semble aussi précaire cn Afrique que celle de la Belgique en Europe. Si l'une est entaméc, l'autre ne survivra pas longtemps. " 
On ne peut pas mieux dire. C'est la logique mème.

En défendant le Congo, c'est la Belgique que nous défendons, et en armant en Belgique, c'est le Congo que nous protégeons.

Mais, de toute éternité, comment défend-on une colonie?

C'est je pense au moyen d'une marine de gutere.

Je sais qu'après l'effort considérable que le pays vient de faire pour réorganiser son armée, ma demande va. faire pousser des cris d'effroi ou de colère à bien des gens.

Les uns diront : ces militaires ne sont jamais conlents, donnez-leur un doigt, ils prendront toute la main.

D'autres diront également : c'est un maladroit! Le moment est mal choisi pour demauder de noureaux sacrifices au pays; je sais cela très bien.

Mais ce que je sais aussi, c'est que le danger est peutètre plus proche que nous ne le croyons.

Quand je vois des peuples, tels que les Hollandais, qui n'hésitent pas à voler la construction de cinc dreadnoughts pour défendre leurs colonies, je pense que je serais criminel, si, puisque c'est ma conviction, je ne disais a mes compatriotes :

"Si vous voulez que des peuples amis nous aident à conserver notre beau Congo, il faut que nous le défendions nous-mèmes et qu'à côté de leurs puissantes escadres, notre pavillon soit au moins représenté par 4 ou jonnes unités de combat. 
"Songez qu'il y va non seulement du salut de notre colonie, mais peut-être aussi de l'indépendance de notre Patrie. L'appétit vient en mangeant et lorsqu'on commence à prendre, il n'y a pas de motif́s pour s'arrêter en route. Le proverbe dit : Aide-toi et le Ciel t'aidera.

En politique, cela veut dire : Arme-toi et l'on te respectera!n

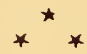

CLAIRONS! SONNEZ AUX CHAMPS....

\section{...AU DRAPEAU!}

Chez nous, un drapean, c'est bien peu de chose, trois morceaux d'élofíe de couleurs difrérentes, cousus ensemble el que l'on arbore les jours de fête. C'est à peine si on le regarde et l'on passe indifférent devant lui.

Au Congo, au contraire, dans chaque poste, dans chaque station, dans chaque camp, il u'y a qu'un drapeau. Toujours il est placé sur la perche la plus haute et lorsque, le soir, sa journée terminée on se trouve seul, assis sur sa chaise longue et qu'on rêve au pays natal, instiuctivement les yeux se portent vers lui.

Dans le grand silence d'une de ces belles soirées tropicales, lorsque l'on n'entend plus que le coassement monotone des grenouilles et le grincement éternel des grillous, on roit le soleil disparaitre lentement à I'horizon. Une sonnerie de clairons retentit. Les soldats 
sortent précipitamment de leurs cases et présentent les armes; les blanes se lèvent et se découvrent respectueusement.

Pourcuoi?

C'est qu’à ce moment on amène le drapeau.

Oh! non, à cet instant, ce drapeau n'est pas une loque, un chiffon. C'est l'àme mème de la Patrie absente! c'est notre guide, c'est notre conscience.

C'est lui (qui, au nom du progrès, nous dit : Marche, va de l'avant!

C'est lui aussi qui, an nom de la civilisation, nous dit encore : Sois juste el boll. Apprends à ces malheureux, à ces paurres déshérités que le droit du plus fort n'est pas toujours le plus juste, ni le meilleur. Apprends-leur ce que signifient ces denx grands mots qui sont à la base de toutes les civilisations : Justice et Charité.

Eufin, c'est encore lui qui nous réconforte dans les moments difficiles et, lorspue nous nous sentions las, découragés, prèts à faiblir peut-ètre, e'est encore lui qui nous crie : "Debout et haut les coeurs !"

\section{Fais ce que dois!} Advienne que pourra!....

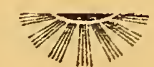





\section{TABLE DES MATIÈRES}

\section{PROLOGUE}

A mes anciens camarades d'Afrique.

\section{CHAPITRE I.}

Le départ d'Anvers. - Mes compagnons de route. - Ou sont mes malles? - L'lle de Wight. - Du cliampagne en chantant, une douche en dormant. - On ferme toutes les écoutilles: C'est la tempète!!.... - Las-Palnias : Les beautés de l'lle, ses produits . . . . . . . . . . .

\section{CHAPITRE II.}

Ln ex-cisailleur de haies improrisé coiffeur. - Entente peu cordiale entre les mules achetées à las-Palmas et leurs conducteurs anglais. - Une bande de marsouins fait escorte au navire. - Coups de feu dans la nuit. - Sierra-Léone à l'heure du marché. - Une distribution des prix chez les petites négresses. - ( Est-ce bon, Goffin? ) - Mort tragique de Smitlı. - A la lueur des éclairs . . . . . . . . ..

\section{CHAPITPE III.}

En rue de Banane. - Triste impression. - Le brave Docteur Etienne. - Le genievre au Congo, c'est la mort...... des microbes. - Petit « Boma » deviendra grand. - Merci, Meuleman! - De ci, do là, cahin-calıa. - Mort du Docteur Petit. - a Vous devez être fort en artillerie! - La $1^{*}$ batterie congolaise. - Chasses aux antilopes à coups de canon. - Mon dernier fait d'armes remarquable comme commandant d'artillerie. . . . . . . . . . . . . 


\section{GHAPITRE IV.}

Première chasse à l'hippopotame. - Je jone avec la fièrre, elle me terrasse. - Avocat d'office : acquittement de inon royal client. - Départ pour le Haut-Congo. - Matadi - Le chemin de fer, curre de Titans. - Sur la route des caravanes. - Rencontre avec le Gouverneur général à Lukongu. - Une mule anti-protocolaire. Les boys n'en font jamais d'autres. - Prédiction fatale. Je reçois ma destination définitive pour Lusambo . . . .

\section{CHAPITRE $V$,}

Arrivée a Léopoldville. - Mort tragique de Vial. - En route pour Lusambo. - Impossible de franchir la barre. Ilospitalité clıarmante des Pères de Bergh S'-llarie. Mon ami le Père « $U$ ). - Plus fort que le diable! - Les distractions du Pére Ferdinand. - Le Congo et le Kassaï. - Nons servons de festin aus monstiques. - « Baron, oit est la line »? . . . . . . . . . . . . . . . . . .

\section{CHAPITRE VI.}

1 Lusambo. - Fermier, bouliquier et cuisinier. - Cris de guerre! - Gongo Lutété et Descamps. - Ma première balaille. - Ai-je eu peur? - La critiqne est si facile! Retour de Le Marinel et de Gillain. - Le noir habille tres bien. - Pauvres cochons! - Lecon de modestie donnée par une tornade. - Qui a eu le plus peur : l'éléphant ou $110 \mathrm{i}$ ? - J’ai la variole : échaude d'abord.... Je suis pelé ensuite. - Six mois sans nonvelles !.... Sélóo !...... ! Sélòo! - En expedition. - « Si vous en monrez, c'est yous qui l'aurez roulı! ).... - Je le vise avec soin et.... je le manque . . . . . . . . . . . . . . .

\section{CIIAPITRE VII.}

Départ de Le Marinel pour le Katanga. - Une Suisse préhistorique. - La belle Tumba. - " Je te servirai, comme si tu étais mon père. ) - Nouvelle révolte des Bakuas Endus. - Je suis consacré féticheur! - Cinquante contre plus de deux mille. - Toréador's malgré nous. - Foudroyées ! .... - Chirurgien et mème dentiste . . . . . . . . . . . 


\section{CHAPITRE VIII.}

Retour de l'expédition du Katanga. - La danse chez les Bakuas N'Gombés. - Le vertige. - Encore Gongo Lutété. - Chez Kichimbi. - La bète était domptée, elle avait trouves ion inaitre. - Kentrant à Lu.sanlo, j'y trouve l'expédition Bia. - Tempète sur le Sankuru. - Pauvres diables! - Grand combat contre les Kiokos. - «Clairons, sonnez la charge! »-Mise à l'ordı'e du jour. - Départ de Le Marinel et Gillain pour l'Europe. - Arrivée de Dhanis.

\section{CHAPITRE IX.}

Vingt mille kgs de gibier. - Un bain forcé. - Attaques pendant la nuit. - Bèlè! Bèlè! Bèlè! - Au-dessus de l'abìme. - A cache-cache avec Fuamba. - Nouvelle expédition pour le Katanga. - Gongo Lutété demande la paix. - Les Arabes entrent en ligne. - Une tribu de Nains. - Chez Gongo. - Sanglante et tragique bataille du Lomami, à Chigé. - Le sergent Debruyn. - Répugnant festin. - Cadavres dans la mare. - Revolver à la main. -

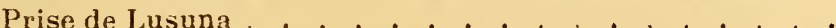

\section{CIHAPITRE $\mathrm{X}$.}

Réunion avec Dhanis à Lusuna. - Nevue des troupes de nos alliés. - La ménagerie Michaux. - Combat dans un marais. - Un réveillon le revolver à la ceinture. - Le fétiche de Dhanis. - Le brave Cassart! - Mort de Mohara. - Mes cheveux se dressèrent sur la tête.... - Attaque inopportune

\section{CHAPITRE XI.}

Le Lualaba. - Nyangwé ! - On nous prend pour des Arabes. - Affut et contre affut. - Invasion de femmes. Retour offensil des Arabes. - All right, sir! - Héprise qui eût pu être fatale. - Deux lettres disant : l'une oui et l'autre non. - Une flottille de canots à l'assaut . . . . . . . . 


\section{CHAPITRE XII.}

Cassart et moi quittons Nyangwé pour rentrer en Europe. - Une chasse à l'hippo en compagnie dụ Père De Decken. - Une situation difficile à décrire .... - Dibué, prend dans ses griffes une des jambes du juge Desagher. - Quelqu'un qui essaie de nous épater! - Brackman mystificateur !.... - Brackman mystifié ! - Le salıt de Pétillon. - Arrivée de ua ménagerie à Anvers. - Dibué, après a voir été offert au Roi, devient pensionnaire du Jarlin zoologique d'Anvers.

\section{CHAPITRE XIII.}

Second clépart pour le Congo. - L'lle de San Thomé : ses xites enchanteurs, ses roças sompluenses. - En ront pour Lusambo. - leux chasses des plus accidentées. - En route pour Luluabourg. - Lapière et le poste de Mukabua. Campagne contre Kalauba et les Kiokos. - Combats acharnés. - Une chefesse prisonnière fait appel à son peuple daus la nuit. - Douze heures de combat sous bois. Grande fîte précédant la plus terrible des catastrophes. .

\section{CHAPITRE XIY.}

L. révolle des soldats Batétilas. - I'n billet de Lassaux. - Triste cetom à Lusambo. - Les canses principales de la rivolte. - A la poursuite des révoltés. - Je perds un temps précieux à Luluabourg. - Le récit des événements par Cassart et Lapière. - Désastres de Kaiéié et de N'Gandu. - Lne page douloureuse à écrire. - J'opère Lapière malgré lui. - Combats du 18 octolse et du 6 novemble

\section{CHAPITRE XV.}

Rentrée ì Iasambo. - Départ de Gillain pour l'Europe. - Cirande expédition vers le Sud. - Réception émourante à Kabinda. - Le tribut rolontaire de Lupongu. - Chez Kaiéié. - Trop de gibier. - Singuliers effets de la foudre. - Ln éléphant monstrueux. - Les chutes et les grottes de 
Bena-Kaya. - Un marclie original. - Invasion de fourmis. - La mort de John. - Arrivée à Iluséa. - Départ de Ia cararane du Katanga. - Un Haoussa de Delcommune. Mon cuisinier met le feu au canıpement. - Le dévouement du soldat congolais. - Beaux spécimens de la race dans les deux sexe; : Ln soldat. - Un boy. - Mademoiselle Coco.

\section{CHAPITRE XVI.}

Chez Motombo Mukulu. - Coutumes bizarres. - Le grand chef Mata Yamro. - Conduite héroïqne d'Alliert Lapière. - Les Filles d'un grand chef !.... - Chez Kaiéié. - Éne cérémonie púnible et impressionnante. - Un loomme pris au piège. - Succession de combats acharnés. - Mort de N'Gongo. - Capture de MPogna. - Fuito de Kalanıba. - Prise d'un drapeau Kioko. - Mcurs et eroyances Bachilanges. - Réception du Père Cambier. Une messe militaire. - Retour à Lusambo. - Cruelle cléception

\section{CHAPITRE XVII.}

Départ de Lusambo et arrivée à Nyangwé. - Les révoltés reutrent en campagne. - Je prends la direction des opérations. - Le Gouverneur approuve ma conduite. Composition de l'expédition. - Je dois sévil contre des voleurs. - Dispositil habituel de marche et de campement. - Sanglant combat de nuit à Kapwa. - Poursuite de l'ennemi. - La famine. - Imprudence et mort de Burck. La bravoure c'est bien, l'obéissance c'est mienx. - 1)islocation de l'expédition. - Mort d'Hambursin. - Adieux a mes vieux braves! - Letour en Europe. - La défense de untre Colonie . . . . . . . . . . . . . . . . .

\section{EPILOGUL}

Ins glorieux morts. - Heureux arenement. - Magnifirues résultats olstenus. - Quelrues voux pour lavenir. Clairons sonnez aux champs !...... au drapenu ! . . . . 



\section{$\mathrm{JlO}$ \\ illes itinéraires suivis}

Imp. DUPAGNE-COUNET \& Fiss, èditeurs, Namur.

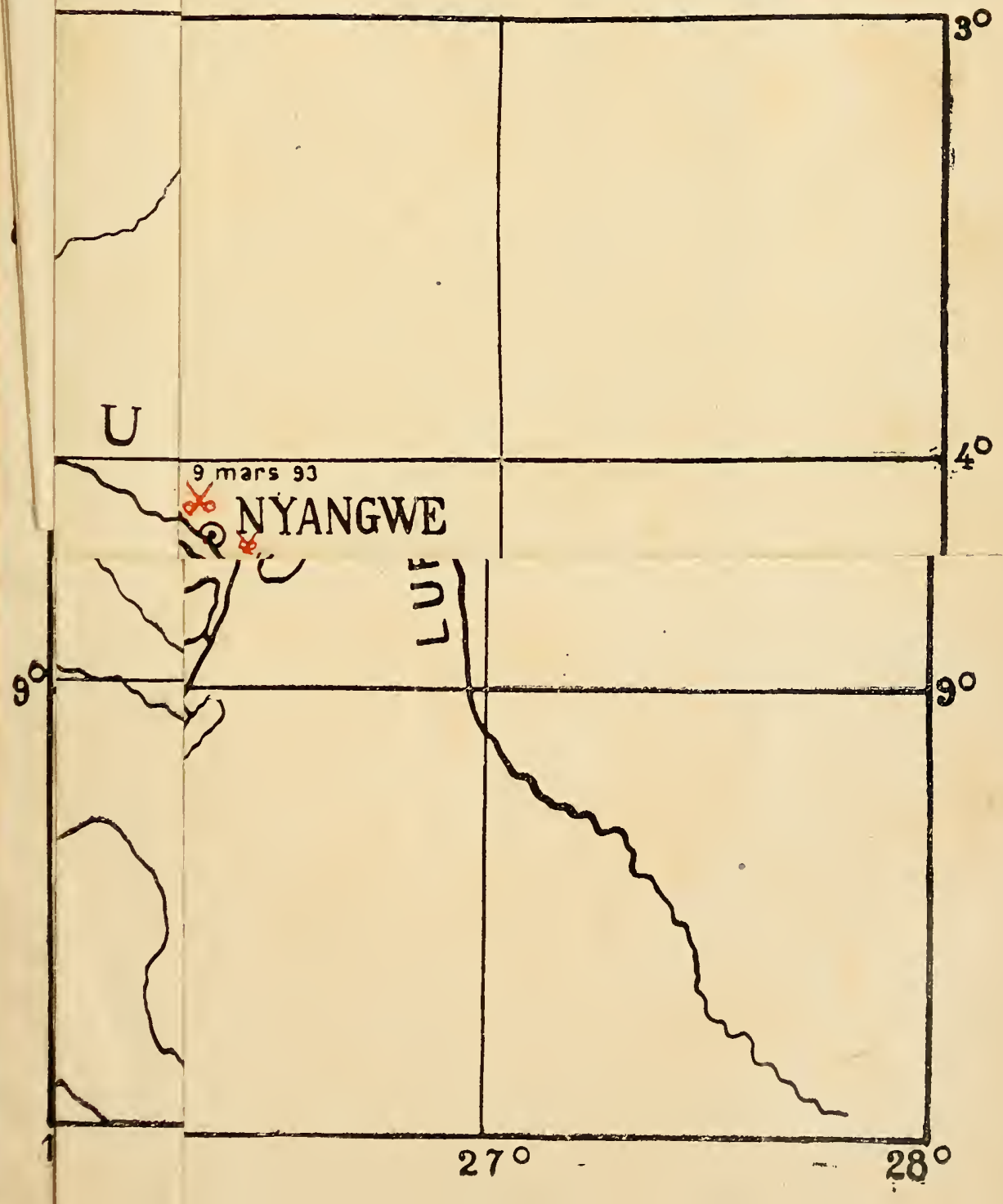





\section{CARTE DU SUD DU CONGO}

renseignant les emplacements des principales batailles que jai livrées ainsi que les itinéraires suivis

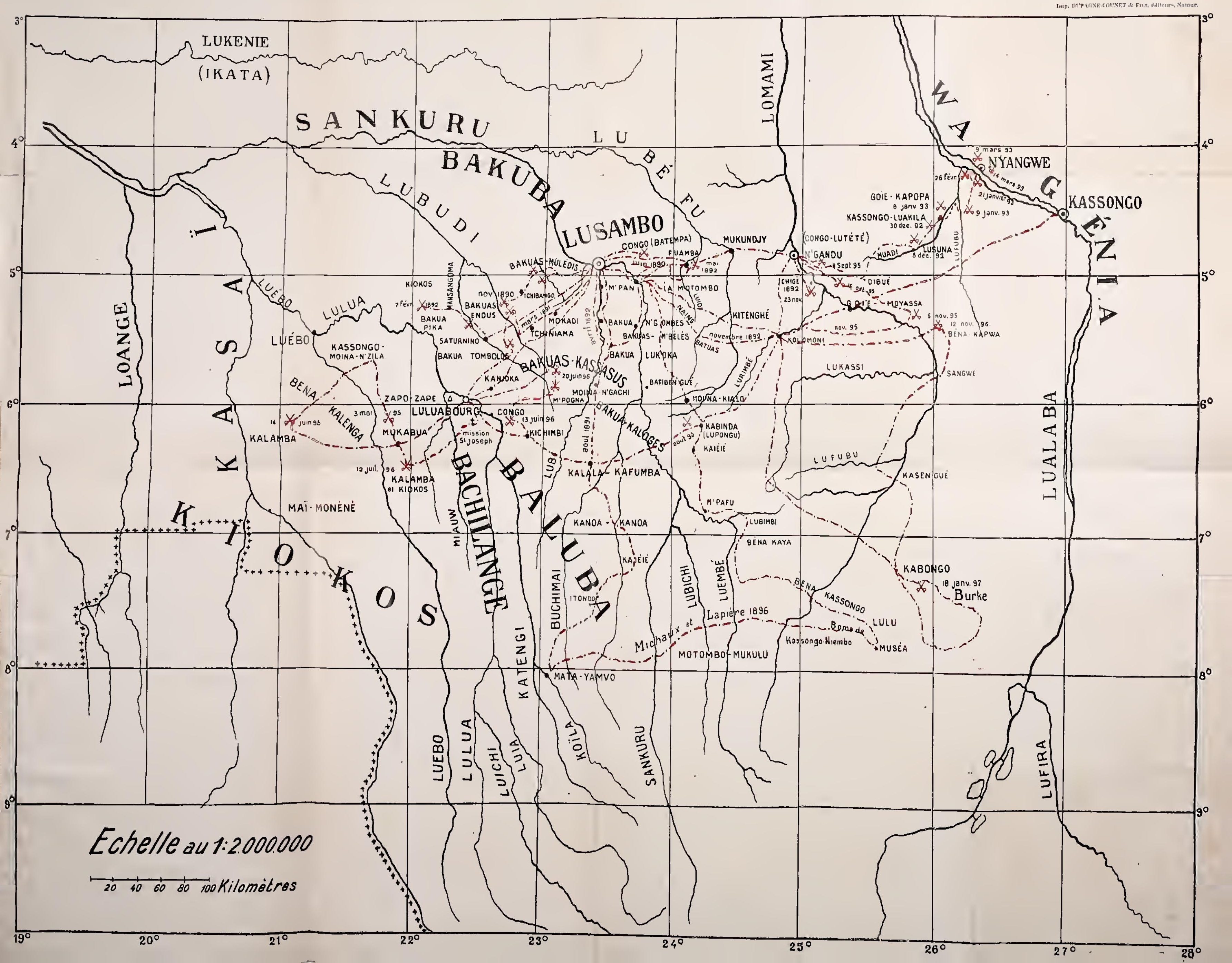







$$
8206
$$

$B z$ 
